\title{
Isolation of New Secondary Metabolites from \\ New Zealand Marine \\ Invertebrates
}

\author{
by \\ Joanna M. Wojnar
}

\begin{abstract}
A thesis
submitted to the Victoria University of Wellington in fulfilment of the requirements for the degree of Doctor of Philosophy in Chemistry
\end{abstract}




\section{Abstract}

This study describes the isolation and structure elucidation of several known and 13 new compounds from New Zealand marine organisms. Furthermore, it describes the development of a digital mask program for the analysis of HSQC spectra of crude sponge extracts. This was used as a screening tool to identify secondary metabolite producers that warranted further analysis.

As reports of metabolites from New Zealand nudibranchs are poorly represented in the literature, a study of five New Zealand nudibranch species was undertaken. These coloured and seemingly undefended nudibranchs are known to concentrate or sequester toxic metabolites from their prey, facilitating rapid isolation and structure elucidation of these metabolites. This study resulted in the isolation of a variety of metabolite classes; two new compounds, $13 \alpha$ acetoxypukalide diol (30) and lopholide diol (31) from the nudibranch Tritonia incerta, are described.

Examination of the sponge Raspailia agminata resulted in the isolation of a novel family of partially acetylated glycolipids which contain up to six glucose residues. The chromatographic separation of these compounds was a challenge due to the similarity of the congeners and their lack of a chromophore. MSguided isolation eventually led to the purification of agminosides A-E (145149).

An unidentified sponge of the order Dictyoceratida was found to contain a new isomer (186) of the known sesterterpene variabilin. As variabilin-type compounds are predominantly found from sponges of the family Irciniidae, the unidentified sponge is most likely an irciniid. In addition, the sponge contained two prenylated quinones, one of which, 189, is a new isomer of a known sponge metabolite.

The sponge Darwinella oxeata contained four new nitrogenous diterpenes of the aplysulphurane (rearranged spongian) skeleton, oxeatamide A (214), isooxeatamide A (215), oxeatamide A 23-methyl ester (216) and oxeatamide B (217). 


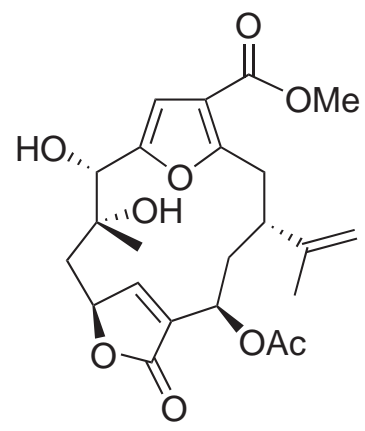

30

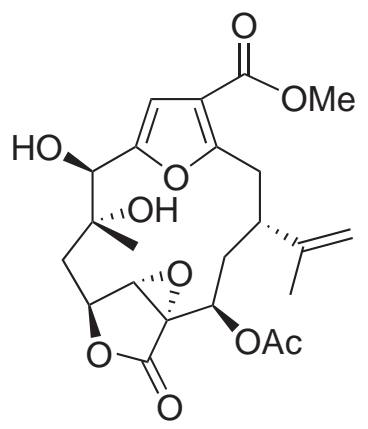

31

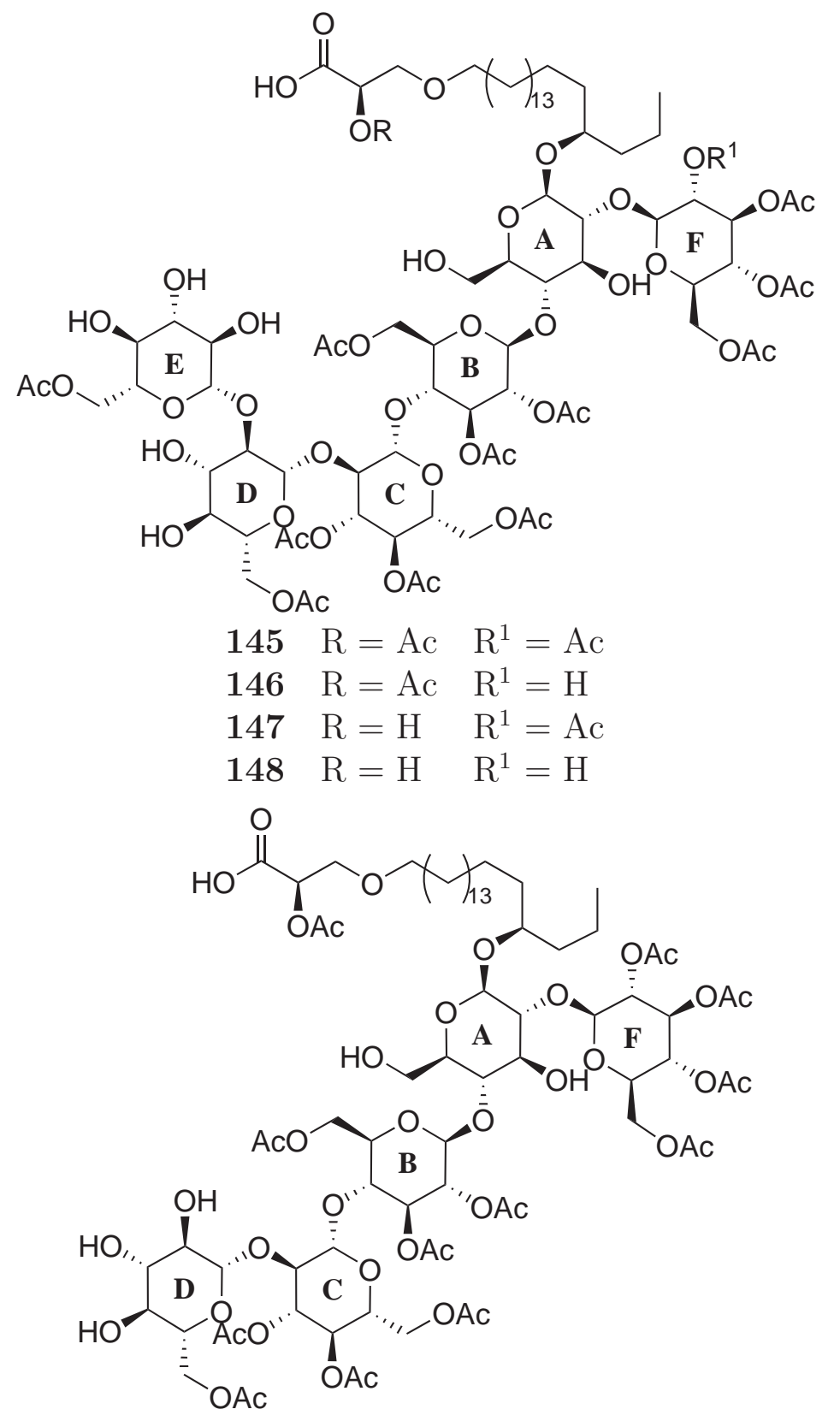


<smiles>CC(=CC1OC(=O)C(C)=C1O)CCC=C(C)CCCC(C)=CCCc1ccoc1</smiles><smiles>COC1=CC(=O)C=C(C/C=C(/C)CCC=C(C)CCC=C(C)C)C1=O</smiles><smiles>[R]OC(=O)CN1Cc2c(ccc([C@]3(C)CCCC(C)(C)C3)c2[C@H](C)C(=O)O)C1=O</smiles>

$214 \mathrm{R}=\mathrm{H}$

$216 \mathrm{R}=\mathrm{Me}$<smiles>C[C@H](C(=O)O)c1c([C@]2(C)CCCC(C)(C)C2)ccc2c1CN(CCc1cnc[nH]1)C2=O</smiles>

217 


\section{Ta my grandfather, \\ Prof. Or. kaliel. Eng. Tadeusz Senkara, wha wauld have been proud.}




\section{Acknowledgments}

It's been an interesting few years, with the usual ups and downs of research, the frustrations and the excitements, the trials and triumphs, the brick walls and the eureka! moments. I would not have kept my sanity were it not for the great atmosphere and camraderie of the lab. Katie's comment, when describing one of her first days in our group, epitomizes that spirit best: "I laughed till my face hurt!"

I will start by thanking my supervisor, Peter Northcote, for his enthusiasm, excellent suggestions and encyclopedic knowledge of NMR and natural products that always amazed me (how can you tell it's a linear furano-terpene from that dirty, crude proton?!). It has been a pleasure working for you.

Secondly, I will mention my "other head": Wendy Popplewell. I know we were called the two-headed monster, but it always amazed me how many people managed to get us confused. You have been a great friend and I have enjoyed our trips together (conferences and dive trips alike). Thank you for being my sounding-board, thank you for your suggestions, thank you for helping me untangle some of my sentences.

Thank you to Greta Moraes, the Silica Queen, for taking me under your wing and teaching me how to run a "proper" column. I learned a lot from you, and enjoyed sharing a lab bench with you.

Thank you to John Ryan, NMR Guy Extraordinaire. Where would we all be without your NMR skills and knowledge? Thank you for all your help throughout the years, for teaching me about NMR, and for your meticulous editing of my writing (even if I didn't agree with you about Oxford commas).

I must thank the other members of our group: Katie ("I'm sorry") Dowle for useful discussions on the oxeatamides and good suggestions. Jonathan Singh, our token male in the last few years, for always being a gentleman. Mike Page for R. agminata identification and underwater photo. Catherine Gray and Jenn Hadfield for spending that summer screening sponges for us. Helen Woolner 
for doing sponge spicule mounts and working on our sample database. Izabela Pomer for always being ready to help and bringing us cake. Arab Spice (aka Mina Razzak) for venturing into the mammoth building of the Cambridge University library to get me papers. Stephen Mackey for the early work on $R$. agminata and the soft coral.

To all the members of the lab, short or long term: you have been great friends and colleagues, making the lab a fun place to work in.

There are of course lots of other people whose help and support has been invaluable. So thank you to Joanne Harvey for various synthetic chemistry discussions and for careful editing of my writing. Thank you to her synthetic chemistry group for letting me "borrow" reagents. Thank you to Brian Halton for setting a high standard. Thank you especially to Rob Keyzers for editing and lots of helpful questions and suggestions.

To Almas Zayya: thank you for being my friend.

A big thank you to the general staff of the school: Darren, Teresa, Gordon, Jackie, Sally, Lisa, Rhys, Alan, Manu, Scotty. Sometimes you may be unappreciated, but without you working in the background, research would be impossible. Thank you to Kate McGrath and Celia Simpson for dealing with the administrative side of the degree.

I would like to thank the National Institute of Water and Atmospheric Research (NIWA) for the prosaically named MNP1002 sponge, which turned out to be so interesting. I must also thank all the other divers who collected the samples I worked on. They are Peter and Wendy of course, but also Toby Pugno, for making us laugh, and Kel Nairn, for being an all round excellent diver and boat companion. I must thank Kel as well for the underwater photo of D. oxeata. I also need to mention a diver I have never met: thank you to Ian Skipworth (http://www.ianskipworth.com/) for letting me use his beautiful nudibranch photos in this thesis.

The School of Biological Sciences has kindly run a range of bioassays on my compounds: thank you to James Matthews, David Bellows, Ariane Chan, and Christopher Miller especially. A special thanks to James as well for helping me with the MALDI.

Of course I must gratefully acknowledge my sources of funding: the Cancer Society Training Scholarship, the Curtis-Gordon Scholarship, the Marine Natural Products Scholarship and the VUW Completion Scholarship.

I would like to thank my brother Maciek, firstly for writing the digital mask program. It has been an interesting exercise in communication between two 
people speaking completely different languages: chemistry and computer science. It taught me a lot. I would also like to thank him for always coming to the lab to ask for a ride home, for always being ready with an argument, for always asking why, for being a great brother. But most of all thank you for introducing me to Linux and $\mathrm{LT}_{\mathrm{EX}}$ - it has been a steep learning curve (sometimes seemingly vertical!) but without it Microsoft would have driven me mad during this writeup.

Finally, thank you to the rest of my family. Words seem not enough, but I will try. Thank you for all the sacrifices you have made. Thank you for your unwavering support, thank you for your confidence in me, thank you for listening. Thank you for all those little things that mean so much: thank you for sending me home with food, buying me chocolate, fixing my leaky taps.

I know I can always rely on you. 


\section{Contents}

Abstract

Dedication $\quad$ v

Acknowledgments vi

Contents ix

List of Figures $\quad$ xiii

List of Tables $\quad$ xvii

List of Schemes $\quad$ xix

1 Introduction $\quad 1$

1.1 Natural products as pharmaceutical leads . . . . . . . . . . . . 1

Identifying lead compounds . . . . . . . . . . . . . 3

1.2 Marine environment . . . . . . . . . . . . . . . 5

The New Zealand marine ecoregion . . . . . . . . . . . . . . . . . 6

Marine natural products . . . . . . . . . . . . . . . 6

Chemical defense in the marine environment . . . . . . . . . 7

Marine natural products in clinical trials . . . . . . . . . . 9

1.3 Sponges . . . . . . . . . . . . . . . . . . . . 10

Microbial symbiosis in marine sponges . . . . . . . . . . . . . 10

1.4 Nudibranchs . . . . . . . . . . . . . . . . . . . . . . 12

Nudibranch defense . . . . . . . . . . . . . . . . . . . . . 12

1.5 Research aims . . . . . . . . . . . . . . . . . . . . . 14

1.6 Concluding remarks . . . . . . . . . . . . . . . . . . 14

2 Chemical Analysis of New Zealand Nudibranchs 15

2.1 Natural products from nudibranchs . . . . . . . . . . . . 15 


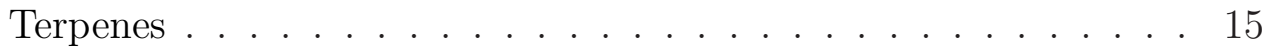

Macrolides . . . . . . . . . . . . . . . . . . 17

Peptides . . . . . . . . . . . . . . . . . . . . . 19

2.2 New Zealand nudibranchs . . . . . . . . . . . . . . . . 20

2.3 Tritonia incerta . . . . . . . . . . . . . . . . . . . . . . . . . 21

Metabolites isolated from T. incerta . . . . . . . . . . . . 22

Cembranoid diterpenes from octocorals . . . . . . . . . . . . 29

Concluding remarks . . . . . . . . . . . . . . . . 30

2.4 Dendrodoris denisoni . . . . . . . . . . . . . . . . . . 31

Metabolites isolated from D. denisoni . . . . . . . . . . . . . 32

Drimane sesquiterpenes . . . . . . . . . . . . . . . . . 32

Concluding remarks . . . . . . . . . . . . . . . . . 33

2.5 Aphelodoris luctuosa . . . . . . . . . . . . . . . . . . 35

Metabolite isolated from A. luctuosa . . . . . . . . . . . 36

Polymeric alkyl-pyridinium salts . . . . . . . . . . . . . . 38

Concluding remarks . . . . . . . . . . . . . . . . . . 40

2.6 Tambja morosa . . . . . . . . . . . . . . . . . . 41

Metabolite isolated from T. morosa . . . . . . . . . . . . . 42

The tambjamine alkaloids . . . . . . . . . . . . . . . 45

Concluding remarks . . . . . . . . . . . . . . 46

2.7 Ceratosoma amoenum . . . . . . . . . . . . . . . 48

Metabolites isolated from C. amoenum . . . . . . . . . . . 49

The dysin sesquiterpenes . . . . . . . . . . . . . . 50

$\mathrm{C}_{21}$ linear furanoterpenes . . . . . . . . . . . . . 50

Concluding remarks . . . . . . . . . . . . . . . 51

3 The Agminosides: Novel Glycolipids from Raspailia agminata 53

3.1 Secondary metabolites reported from the genus Raspailia . . . . . 53

3.2 The agminosides . . . . . . . . . . . . . . . . 58

Isolation of the agminosides . . . . . . . . . . . . . . 61

Structure elucidation of agminoside A . . . . . . . . . . . 62

Structure elucidation of agminosides B-E . . . . . . . . . . 84

3.3 Biological activity . . . . . . . . . . . . . . . . . . . 9 96

3.4 Glycolipids from sponges . . . . . . . . . . . . . . . . . 96

3.5 Concluding remarks . . . . . . . . . . . . . . . . 103 
4 NMR Screening 105

4.1 Screening with NMR . . . . . . . . . . . . . . . 105

4.2 NMR screening of sponges by the VUW Marine Natural Products Group . . . . . . . . . . . . . . . . . 107

History . . . . . . . . . . . . . . . . . . 107

Development of the digital mask . . . . . . . . . . . . . . 109

Applying the HSQC Mask . . . . . . . . . . . . . . . . . . 112

4.3 Future directions . . . . . . . . . . . . . . . . . 115

5 New Metabolites from a Sponge of the order Dictyoceratida 117

5.1 Order Dictyoceratida . . . . . . . . . . . . . . . . . 117

5.2 Terpenes from a dictyoceratid sponge . . . . . . . . . . . . 118

Isolation of new metabolites . . . . . . . . . . . . . . . 118

Structure elucidation of $\Delta_{18,20}$-isovariabilin . . . . . . . . . . . . . 119

Structure elucidation of two merosesquiterpene quinones . . . . . 120

5.3 Variabilins . . . . . . . . . . . . . . . . . . . . . . . 124

Variabilin as a chemotaxonomic marker for the family Irciniidae . 125

5.4 Quinones . . . . . . . . . . . . . . . . . . . 126

5.5 Concluding remarks . . . . . . . . . . . . . . . . . . . . . . . 128

6 The Oxeatamides: New Nitrogenous Diterpenes from Darwinella oxeata 130

6.1 Secondary metabolites reported from the genus Darwinella . . . . 130

6.2 The oxeatamides . . . . . . . . . . . . . . . . . . . . . 131

Isolation of the oxeatamides . . . . . . . . . . . . . . . 132

Structure elucidation of oxeatamide A . . . . . . . . . . . . 133

Structure elucidation of iso-oxeatamide A . . . . . . . . . . . . . 146

Structure elucidation of oxeatamide A 23-methyl ester . . . . . . . 149

Structure elucidation of oxeatamide B . . . . . . . . . . . . . . 151

6.3 Biological activity . . . . . . . . . . . . . . . . . . . 155

6.4 The aplysulphuranes . . . . . . . . . . . . . . . 156

6.5 Nitrogenous terpenes . . . . . . . . . . . . . . . . . . 159

Amino acid derived nitrogenous terpenoids . . . . . . . . . . . . 159

6.6 Biogenesis and proposed absolute configuration of the oxeatamides 161

6.7 Concluding remarks . . . . . . . . . . . . . . 166

$\begin{array}{llr}7 & \text { Conclusion } & 167\end{array}$ 
8.1 General experimental . . . . . . . . . . . . . . . . 169

8.2 Isolation of cembranoid diterpenes from the nudibranch $T$. incerta and the soft coral A. aurantiacum . . . . . . . . . . . . . . . 170

8.3 Isolation of two drimane sesquiterpenes from the nudibranch $D$. denisoni . . . . . . . . . . . . . . . . . . . 172

8.4 Isolation of a polymeric alkyl-pyridinium salt from the nudibranch A. luctuosa . . . . . . . . . . . . . . . . . . 173

8.5 Isolation of a pyrrole alkaloid from the nudibranch T. morosa . . 174

8.6 Isolation of three terpenes from the nudibranch C. amoenum . . . 175

8.7 Isolation of five glycolipids from the sponge $R$. agminata . . . . 176

8.8 Screening protocol . . . . . . . . . . . . . . . . . . . . . 179

8.9 Bulk extraction of sponge MNP998 . . . . . . . . . . . . . 180

8.10 Isolation of terpenes from a dictyoceratid sponge . . . . . . . . 180

8.11 Isolation of four aplysulphurane diterpenes from the sponge $D$. oxeata . . . . . . . . . . . . . . . . . . 182

$\begin{array}{lr}\text { A Cyclic Loading and Backloading } & 186\end{array}$

$\begin{array}{lr}\text { B NMR Spectra } & 189\end{array}$

$\begin{array}{ll}\text { Glossary } & 264\end{array}$

$\begin{array}{lr}\text { References } & 267\end{array}$ 


\section{List of Figures}

1.1 New Zealand Exclusive Economic Zone. . . . . . . . . . . . . . . . 6

1.2 Taxonomic classification of sponges. . . . . . . . . . . . . 11

1.3 Taxonomic classification of nudibranchs. . . . . . . . . . 13

2.1 Taxonomic classification of T. incerta. . . . . . . . . . . 21

2.2 Underwater photo of T. incerta. . . . . . . . . . . . 21

2.3 TLC plates (visualized by dipping in $5 \% \mathrm{H}_{2} \mathrm{SO}_{4}$ and heating) of (a) a silica gel column on the mixture and (b) the mixture (left) and the two more polar compounds (right). . . . . . . . . . 22

2.4 Key COSY and HMBC correlations establishing the connectivity of $13 \alpha$-acetoxypukalide. . . . . . . . . . . . . . . . . 23

2.5 Key NOE enhancements of $13 \alpha$-acetoxypukalide diol suggesting the relative configuration of the diol. . . . . . . . . . . . 25

2.6 Key NOE enhancements of lopholide diol suggesting the relative configuration of the diol. . . . . . . . . . . . . . 27

2.7 Taxonomic classification of D. denisoni. . . . . . . . . . . . . . . 31

2.8 Underwater photo of D. denisoni. . . . . . . . . . . . . . . . . 31

2.9 Key COSY and HMBC correlations establishing the connectivity of cinnamolide. . . . . . . . . . . . . . . . . 32

2.10 Taxonomic classification of A. luctuosa. . . . . . . . . . . 35

2.11 Underwater photo of A. luctuosa. . . . . . . . . . . . 35

2.12 Two different colour morphs of A. luctuosa. . . . . . . . . . 36

2.13 Taxonomic classification of T. morosa. . . . . . . . . . . . . . 41

2.14 Underwater photo of T. morosa. . . . . . . . . . . . . . . 41

2.15 NOE enhancements establishing the structure of tambjamine A. . 42

2.16 Fully coupled ${ }^{1} \mathrm{H}^{-15} \mathrm{~N}$ HSQC of tambjamine A. . . . . . . . . . . . 43

$2.17{ }^{1} \mathrm{H}^{-15} \mathrm{~N}$ HMBC correlations of tambjamine A. . . . . . . . . . . . 43

2.18 Taxonomic classification of $C$. amoenum. . . . . . . . . . 48

2.19 Underwater photo of C. amoenum. . . . . . . . . . . . . . . 48 
2.20 Key COSY and HMBC correlations establishing the C5-C17 segment of tetradehydrofurospongin-1. . . . . . . . . . . . . . 49

3.1 Taxonomic classification of $R$. agminata. . . . . . . . . . . . . . 59

3.2 Underwater photo of $R$. agminata. . . . . . . . . . . . 60

3.3 SEM image of $R$. agminata spicules. . . . . . . . . . . . . 60

$3.4{ }^{1} \mathrm{H}$ NMR spectrum $\left(600 \mathrm{MHz}, \mathrm{CD}_{3} \mathrm{OD}\right)$ of the $60 \% \mathrm{Me}_{2} \mathrm{CO}$ in $\mathrm{H}_{2} \mathrm{O}$ fraction. . . . . . . . . . . . . . . 61

3.5 ${ }^{1} \mathrm{H}$ NMR spectra $\left(600 \mathrm{MHz}, \mathrm{CD}_{3} \mathrm{OD}\right)$ of a fraction that looked pure by TLC (bottom) and purified agminoside A (top). . . . . . 62

3.6 A graph of the ion count intensity of glycolipid pseudomolecular ion signals, plotted vs. MPLC fraction number. . . . . . . . . . 63

3.7 Close-up of the COSY and HSQC-DEPT spectra $\left(\mathrm{CD}_{3} \mathrm{OD}, 600\right.$ $\mathrm{MHz}$ ) of agminoside A. . . . . . . . . . . . . . . . . . . 64

3.8 Close-up of the HSQC-TOCSY spectrum ( $\left.\mathrm{CD}_{3} \mathrm{OD}, 600 \mathrm{MHz}\right)$ of agminoside A, identifying the sugar F spin system through HSQC and TOCSY correlations. . . . . . . . . . . . . . 65

3.9 Key COSY, HMBC and ROESY correlations used to establish the structure of sugar F. . . . . . . . . . . . . . . . . 66

3.10 Key COSY, HMBC and ROESY correlations used to establish the structure of sugar B.

3.11 Key COSY, HMBC and ROESY correlations used to establish the structure of sugar C . . . . . . . . . . . . . . . . 68

3.12 Key COSY, HMBC and ROESY correlations used to establish the structure of sugar D. . . . . . . . . . . . . . . . . . 69

3.13 Key COSY, HMBC and ROESY correlations used to establish the structure of sugar E. . . . . . . . . . . . . . . . . 70

3.14 Key COSY, HMBC and ROESY correlations used to establish the structure of sugar A. . . . . . . . . . . . . . . . . . . 71

3.15 Key HMBC and ROESY correlations establishing the linkages between the sugars. . . . . . . . . . . . . . . . 73

3.16 Key correlations establishing the aglycon substructure. . . . . . . 74

3.17 Key COSY and HMBC correlations establishing the structure of the aglycon methyl ester. . . . . . . . . . . . . . . 76

3.18 Close-up of the carbonyl region in the HMBC spectra $(600 \mathrm{MHz}$, $\mathrm{CD}_{3} \mathrm{OD}$ ) of the glycolipids and the methylated glycolipids. . . . . 77

3.19 MS analysis of the acetylation reactions. . . . . . . . . . . . 85 
4.1 The final mask, comprising of 206 sponge screens. . . . . . . . . 110

4.2 Example of an uninteresting and a promising sponge screen. . . . 111

4.3 The mask applied to screen CAG1_33H. . . . . . . . . . . . . . 112

4.4 Round-bottom flask containing the backloading eluent of the $80 \%$ $\mathrm{Me}_{2} \mathrm{CO}$ in $\mathrm{H}_{2} \mathrm{O}$ fraction. . . . . . . . . . . . . . . . 113

4.5 ${ }^{1} \mathrm{H}$ NMR spectra (600 MHz, DMSO- $\mathrm{d}_{6}$ ) of the 20, 40, and $60 \%$ $\mathrm{Me}_{2} \mathrm{CO}$ in $\mathrm{H}_{2} \mathrm{O}$ fractions. . . . . . . . . . . . . . . . . . . 114

4.6 The mask applied to screen JMH1_17F. . . . . . . . . . . . . . . . 115

4.7 The mask applied to screen CAG1_36A. . . . . . . . . . . . . . 115

5.1 Taxonomic classification of the order Dictyoceratida. . . . . . . 117

5.2 Surface photo of the dictyoceratid sponge. . . . . . . . . . 118

5.3 Key COSY and HMBC correlations establishing the furan moiety

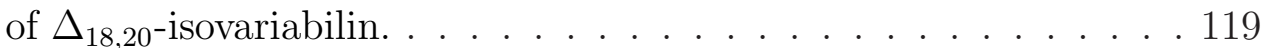

5.4 Key COSY and HMBC correlations establishing the tetronic acid moiety of $\Delta_{18,20}$-isovariabilin. . . . . . . . . . . . . 120

5.5 Key COSY and HMBC correlations establishing the isoprene portion of 6-((2E,6E)-3,7,11-trimethyl-2,6,10-dodecatrienyl)-2-methoxy-p-quinone. . . . . . . . . . . . . . . . . . 122

5.6 Key COSY and HMBC correlations and NOE enhancements establishing the $p$-quinone moiety of 6 -((2E,6E)-3,7,11-trimethyl2,6,10-dodecatrienyl)-2-methoxy-p-quinone. . . . . . . . . . . 123

5.7 Key COSY and HMBC correlations and NOE enhancements establishing the $p$-quinone moiety and the $Z$ configuration of the $\Delta_{2,3}$ double bond of 6-((2Z,6E)-3,7,11-trimethyl-2,6,10-dodecatrienyl)-2-methoxy- $p$-quinone.

6.1 Taxonomic classification of D. oxeata. . . . . . . . . . . . . . 131

6.2 Underwater photo of D. oxeata. . . . . . . . . . . . . . . 132

6.3 Key COSY and HMBC correlations establishing the structure of the cyclohexane ring of oxeatamide A. . . . . . . . . . . . . 134

6.4 Key COSY and HMBC correlations extending the substructure of oxeatamide A. . . . . . . . . . . . . . . . . . . 134

6.5 Key HMBC correlations further extending the partial structure of oxeatamide A. . . . . . . . . . . . . . . . . . . 135

6.6 Key HMBC correlations establishing the lactam moiety of oxeatamide A . . . . . . . . . . . . . . . . . . 136 
$6.7{ }^{1} \mathrm{H}$ NMR spectrum $\left(600 \mathrm{MHz}, \mathrm{CDCl}_{3}\right)$ of oxeatamide A dimethyl ester. . . . . . . . . . . . . . . . . 136

6.8 2D-NOESY spectrum $\left(600 \mathrm{MHz}, \mathrm{CDCl}_{3}\right)$ of oxeatamide A. . . . . 137

6.9 Key NOE enhancements of oxeatamide A dimethyl ester establishing the relative configuration. . . . . . . . . . . . . . . 139

$6.10{ }^{1} \mathrm{H}$ NMR spectrum (600 $\mathrm{MHz}, \mathrm{CDCl}_{3}$ ) of oxeatamide A 6-methyl ester, 23-TMSmethyl ester . . . . . . . . . . . . . . . . . 143

$6.11{ }^{1} \mathrm{H}$ NMR spectrum $\left(600 \mathrm{MHz}, \mathrm{CDCl}_{3}\right)$ of oxeatamide A 6-TMSmethyl ester, 23-methyl ester. . . . . . . . . . . . . . . . . . 143

$6.12{ }^{1} \mathrm{H}$ NMR spectrum $\left(600 \mathrm{MHz}, \mathrm{CDCl}_{3}\right)$ of oxeatamide A 6,23diTMSmethyl ester. . . . . . . . . . . . . . . . . . . . . . . . 144

6.13 Key HMBC correlations and NOE enhancements establishing the lactam orientation of iso-oxeatamide A. . . . . . . . . . . . . 147

6.14 Key HMBC correlations establishing the orientation of the lactam moiety and the methyl ester of oxeatamide A 23-methyl ester. . . 150

6.15 Diode array trace from the HPLC separation of the oxeatamides. 151

$6.16{ }^{1} \mathrm{H}$ NMR spectrum (600 MHz) of oxeatamide $\mathrm{B}$ in $\mathrm{CDCl}_{3}$. . . . . 152

$6.17{ }^{1} \mathrm{H}$ NMR spectrum $(600 \mathrm{MHz})$ of oxeatamide B in DMSO- $\mathrm{d}_{6}$. . . 152

6.18 Selected COSY and HMBC correlations establishing the diterpene fragment of oxeatamide B. . . . . . . . . . . . . . . 153

6.19 Key COSY and HMBC correlations establishing the histamine moiety of oxeatamide B. . . . . . . . . . . . . . . . . 154

A.1 Cyclic loading diagram. . . . . . . . . . . . . . . . . . 187 


\section{List of Tables}

2.1 NMR data (600 MHz, $\mathrm{CDCl}_{3}$ ) for $13 \alpha$-acetoxypukalide diol. . . . 26

$2.2 \mathrm{NMR}$ data $\left(600 \mathrm{MHz}, \mathrm{CDCl}_{3}\right)$ for lopholide diol. . . . . . . . . . . 28

2.3 NMR data (600 MHz, $\mathrm{d}_{6}$-DMSO) for tambjamine A. . . . . . . 44

3.1 NMR data $\left(600 \mathrm{MHz}, \mathrm{CD}_{3} \mathrm{OD}\right)$ for glucose F. . . . . . . . . . 66

3.2 NMR data $\left(600 \mathrm{MHz}, \mathrm{CD}_{3} \mathrm{OD}\right)$ for glucose B. . . . . . . . . . 67

3.3 NMR data $\left(600 \mathrm{MHz}, \mathrm{CD}_{3} \mathrm{OD}\right)$ for glucose $\mathrm{C}$. . . . . . . . . . 68

3.4 NMR data $\left(600 \mathrm{MHz}, \mathrm{CD}_{3} \mathrm{OD}\right)$ for glucose D. . . . . . . . . . . . 69

3.5 NMR data $\left(600 \mathrm{MHz}, \mathrm{CD}_{3} \mathrm{OD}\right)$ for glucose E. . . . . . . . . . . 70

3.6 NMR data $\left(600 \mathrm{MHz}, \mathrm{CD}_{3} \mathrm{OD}\right)$ for glucose A. . . . . . . . . . 71

3.7 NMR data $\left(600 \mathrm{MHz}, \mathrm{CDCl}_{3}\right)$ with the $\Delta \delta$ values for the two Mosher's derivatives of the aglycon methyl ester. . . . . . . . . 79

3.8 NMR data $\left(600 \mathrm{MHz}, \mathrm{CDCl}_{3}\right)$ for aglycon methyl ester. . . . . . . 80

3.9 NMR data $\left(600 \mathrm{MHz}, \mathrm{CD}_{3} \mathrm{OD}\right)$ for agminoside A. . . . . . . . . . 81

3.10 Array of significant glycolipid pseudomolecular ions observed in the MS, indicating sugar and acetate composition. . . . . . . . . 84

3.11 Comparison of proton chemical shifts $\left(\delta_{\mathrm{H}}\right)$ for the agminosides A-E. 87

$3.12 \mathrm{NMR}$ data $\left(600 \mathrm{MHz}, \mathrm{CD}_{3} \mathrm{OD}\right)$ for agminoside B. . . . . . . . . . 88

$3.13 \mathrm{NMR}$ data $\left(600 \mathrm{MHz}, \mathrm{CD}_{3} \mathrm{OD}\right)$ for agminoside $\mathrm{C}$. . . . . . . . . 90

$3.14 \mathrm{NMR}$ data $\left(600 \mathrm{MHz}, \mathrm{CD}_{3} \mathrm{OD}\right)$ for agminoside D. . . . . . . . . . 92

3.15 NMR data $\left(600 \mathrm{MHz}, \mathrm{CD}_{3} \mathrm{OD}\right)$ for agminoside E. . . . . . . . . . 94

3.16 Lipid categories. . . . . . . . . . . . . . . . 96

5.1 NMR data $\left(600 \mathrm{MHz}, \mathrm{CDCl}_{3}\right)$ for $\Delta_{18,20}$-isovariabilin. . . . . . . . 121

5.2 NMR data $\left(600 \mathrm{MHz}, \mathrm{CDCl}_{3}\right)$ for 6-((2E,6E)-3,7,11-trimethyl2,6,10-dodecatrienyl)-2-methoxy-p-quinone. . . . . . . . . . 123

5.3 NMR data $\left(600 \mathrm{MHz}, \mathrm{CDCl}_{3}\right)$ for 6-((2Z,6E)-3,7,11-trimethyl2,6,10-dodecatrienyl)-2-methoxy-p-quinone. . . . . . . . . 125

6.1 NMR data $\left(600 \mathrm{MHz}, \mathrm{CDCl}_{3}\right)$ for oxeatamide A. . . . . . . . . 140

6.2 NMR data (600 MHz, $\mathrm{CDCl}_{3}$ ) for oxeatamide A dimethyl ester. . 141 
$6.3 \mathrm{NMR}$ data $\left(600 \mathrm{MHz}, \mathrm{CDCl}_{3}\right)$ for iso-oxeatamide A. . . . . . . . . 148

6.4 NMR data $\left(600 \mathrm{MHz}, \mathrm{CDCl}_{3}\right)$ for oxeatamide A 23-methyl ester. . 150

6.5 NMR data (600 MHz, $\mathrm{d}_{6}$-DMSO) for oxeatamide B. . . . . . . . 155

8.1 NMR data $\left(600 \mathrm{MHz}, \mathrm{CD}_{3} \mathrm{OD}\right)$ for the polymeric 3-alkyl pyridinium salt. . . . . . . . . . . . . . . . . 174 


\section{List of Schemes}

2.1 Interconversion between tambjamine A and its protonated form. . 44

6.1 Mechanism of carboxylic acid methylation with diazomethane. . . 144

6.2 Mechanism of carboxylic acid methylation with $\mathrm{TMSCHN}_{2}$, with or without a protic solvent present. . . . . . . . . . . . 145

6.3 Ionic and tautomeric forms of the imidazole moiety. . . . . . . . . 154

6.4 Proposed biogenesis of the aplysulphurane skeleton. . . . . . . . 156

6.5 Proposed mechanism for the formation of the lactam moiety. . . . 165

6.6 Alternative biogenetic pathway for the formation of the lactam moiety. . . . . . . . . . . . . . . . . . 165

6.7 Proposed biogenetic mechanism for the formation of the lactam of the oxeatamides. . . . . . . . . . . . . . . . 166 


\section{Chapter 1}

\section{Introduction}

This thesis gives an account of my research into natural products chemistry. Specifically, it details the investigation of several New Zealand species of marine invertebrates (nudibranchs and sponges) for novel, biologically active, secondary metabolites. The use of NMR spectroscopy as a vital screening tool is discussed.

\subsection{Natural products as pharmaceutical leads}

Natural products chemistry deals with the isolation, identification, structure elucidation, and study of the characteristics of chemical substances produced by living organisms. The fascination with molecules found in nature gave birth to the field of organic chemistry as a whole (so named for its original definition as the chemistry of living things). ${ }^{1}$ Since as far back as $2600 \mathrm{BC}$ in ancient Mesopotamia, when records show the cultivation of the poppy (Papaver somniferum) for opium extraction began, natural products have played a pivotal role in human history, and particularly in medicine. ${ }^{2}$ Their vital role in the process of drug discovery has meant that, in the last century alone, drugs that trace their origin to natural products "have more than doubled the average lifespan of human beings." 1

The influence of natural products on medicine remains substantial. Close to two-thirds of the new drugs approved by the U.S. Food and Drug Administration (FDA) in the years 1981-2006 were either natural products, natural product derived, or synthetic compounds mimicking the action and/or pharmacophore of a natural product. ${ }^{3}$ The fraction is closer to three-quarters when considering only the areas of cancer and infectious diseases. ${ }^{3}$ This raises the questions: why do natural products have biological effects on humans? Why does a polyketide from a fungus lower cholesterol? Why does a peptide from a snail alleviate pain? 
These drugs are actually secondary metabolites produced by living organisms. Secondary metabolites are defined as those naturally produced substances (often specific to a particular species or a family) not involved in normal growth, development or reproduction of an organism, and therefore not essential to life. ${ }^{4}$ As their production involves enormous biochemical expense, however, they would not make evolutionary sense unless they had advantageous function. ${ }^{5}$ The compounds are in fact used for interactions with other organisms, often for defense. Organisms lacking an immune system are prolific producers of secondary metabolites (which are thought to act as an alternative defense mechanism), hence the wide variety of antifungal, antibacterial and cytotoxic natural products being isolated.

Natural products have been fine-tuned by nature through evolutionary selection to be precise, well-defined, three-dimensional structures for interaction with specific biological targets. These biological targets (such as protein binding sites) are "often well conserved among proteins of markedly different genetic sequences." 6 The 100,000 to 450,000 human proteins fall into only 600-8000 topologically distinct "folds" (three dimensional architectures). ${ }^{7}$

Furthermore, these so-called protein "folds" may serve different functional roles in different organisms. ${ }^{8}$ Secondary metabolites evolved for a particular purpose may therefore exert a different, but equally potent, effect in another organism. Simply put, while natural products may not have co-evolved with human proteins, they have evolved to interact with biomolecules in general. ${ }^{5}$

Unfortunately, many of the most promising natural product lead compounds* are available in only small amounts, and often have complex structures which are difficult to synthesize. This supply problem has discouraged many pharmaceutical companies from developing these compounds as potential drugs. Instead, the industry has embraced combinatorial chemistry and diversity oriented synthesis as a means of generating large compound libraries in a short time. ${ }^{6}$ Yet, despite the early promises of both combinatorial synthesis and high throughput screening, no real increase in the number of lead compounds has been observed. ${ }^{3,6-8,10,11}$ Only one compound generated from this method of chemical discovery has been approved for drug use anywhere: the antitumour drug sorafenib ${ }^{\dagger}(\mathbf{1}) .^{3}$

A study by Feher and Schmidt compared a range of natural products, drugs on the market and combinatorial synthetic molecules, and proposed that the failure of combinatorial synthesis lies in the "significant deficiencies in the types

\footnotetext{
*A lead compound is the pharmacologically active molecule from which synthetic analogues are developed in an effort to find safer and more effective alternatives. ${ }^{9}$

${ }^{\dagger}$ Nexavar (Bayer)
} 


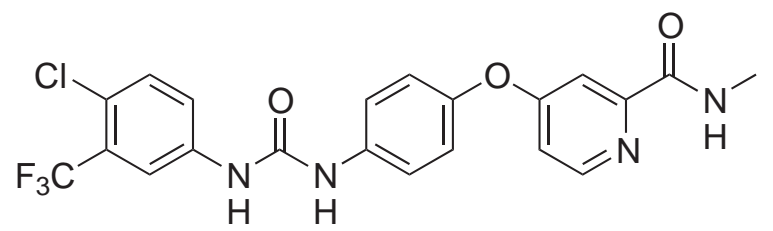

1

of chemical structures generated using combinatorial approaches." ${ }^{10}$ On average, natural products tend to be of higher molecular weight, have more chiral centres and more polar functional groups that can act as hydrogen bond acceptors. Combinatorial compounds, on the other hand, are decidedly more hydrophobic, incorporate more nitrogen, sulfur and halogen atoms, and have more unsaturation (usually aromatic rings). They tend to be more rigid, and have less emphasis on chirality. As a result, they often show less specific binding characteristics, leading to more undesirable side effects. ${ }^{6}$ Compared in the same way, the properties of pharmaceuticals usually fall somewhere in between the two groups, reflecting the mixed origins of these compounds from natural and synthetic sources. Clearly, "natural product structures have the characteristics of high chemical diversity, biochemical specificity and other molecular properties that make them favourable as lead structures for drug discovery." 8

\section{Identifying lead compounds}

Several criteria are used for selection of animal, plant or microbial material for screening. Commonly, a random sampling of species will be undertaken, although this method is often laborious and time-consuming. Some plants or animals are chosen because of their use in traditional medicines, or because they are closely related to organisms previously shown to contain active secondary metabolites. More recently, the emerging field of genomics has provided a powerful tool for predicting the secondary metabolite composition of an unknown organism. $^{12}$

Once the species to screen are chosen, "in the vast majority of industrial natural product discovery programs, compounds with desirable characteristics (hits) are identified by bioactivity assays." 13 This well-established method is the testing of crude or partially fractionated extracts in cell-based or biochemical assays. ${ }^{12}$ Cell-based biological activity assays are generally preferred, because activity can be assessed within the context of a living cell. Unfortunately, cell-based assays may be more variable, less sensitive and more resource intensive. ${ }^{13}$ Biochemical assays (for example with cloned receptors or enzymes) are the alternative, pro- 
viding particular, target-specific activity information. Regrettably, such in vitro assays do not always predict accurately the in vivo activity of molecules. ${ }^{12}$

The process then calls for the isolation of the active constituent(s) through the use of chromatographic separation, often requiring numerous cycles of fractionation in order to obtain sufficient quantities of the pure molecule. ${ }^{13}$ At each step, the fractions have to be submitted to bioassay to track the biological activity to the pure compound. Bioassay directed isolation can be a long and tedious process, financially costly and requiring significant manpower, even though more recently it is becoming increasingly automated. ${ }^{12,14}$

As natural product extracts are complex mixtures of many compounds, bioassay-guided fractionation may be complicated by false positives from nonspecific interferences, fluorescent compounds and insoluble components. ${ }^{15}$ The presence of interesting, but low-level, constituents may be masked by the mild activity of compounds at high concentrations. As the number of described natural products increases, so does the probability of rediscovery of known compounds (the so-called dereplication* problem). ${ }^{14}$ In addition, at times the activity being tracked does not increase during the separation, but spreads among many fractions. This is often attributed to synergistic effects of compounds in the mixture, but may also be due to loss of active ingredients through degradation or simply through irreversible adsorption to the solid phase during the separation process. ${ }^{16}$

One way to avoid the problem of crude extract screening is to test pure compound libraries (collections of individually isolated chemical compounds). Building up such a library can be time consuming and labour intensive, but avoids some of the above mentioned problems. The first systematic approach in this direction is the German Natural Product Pool. ${ }^{17}$ Spearheaded by the HansKnöll-Institut (Jena, Germany), the Pool now contains about 9,000 compounds ${ }^{18}$ obtained from more than 70 commercial and academic laboratories, being used by several pharmaceutical and agrochemical companies. ${ }^{17}$

Such an approach involves activity-independent isolation and characterization of compounds. The idea of ignoring the desired biological activity of metabolites during screening and isolation was first postulated by Umezawa in the 1970s and later developed by Zähner and co-workers. ${ }^{19}$ They used TLC and colourization with a staining reagent for the discovery and isolation of new secondary metabolites in a strategy later named "chemical screening."

*Dereplication is the process of identifying previously isolated compounds as early as possible to eliminate wasted effort and resources. 
A logical extension of this method is the use of physico-chemical screening, with selection criteria based on chromatographic behaviour as well as spectroscopic characteristics. A typical example is the screening for secondary metabolites by HPLC in combination with multi-wavelength $\mathrm{UV} /$ vis (diode-array) detection (HPLC-DAD). Unfortunately, the dependence of this method on a $\mathrm{UV} /$ vis detectable chromophore limits its applicability, and alternate detection methods like mass spectrometry and NMR spectroscopy have been applied. ${ }^{19}$

\subsection{Marine environment}

The origins of natural product chemistry can be traced back to the study of plants, which led to the isolation of such medically important compounds as morphine (from the opium poppy), aspirin (willow tree), digitoxin (foxglove) and quinine (the chinchona tree). ${ }^{20}$ The true blossoming of natural product chemistry occured after the success of penicillin during World War II, when pharmaceutical companies shifted their focus to drug discovery from microorganisms. ${ }^{13}$ Since then, between 30,000 and 50,000 compounds have been discovered from microorganisms, many of them biologically active, but the rate of discovery is decreasing. ${ }^{21}$ More recently, therefore, researchers have turned to alternate, more exotic sources such as the marine environment, which is considered a largely untapped store of chemical diversity. ${ }^{14}$

The vast oceans cover about $70 \%$ of the earth's surface, and current estimates suggest the majority of all species on this planet actually live in the oceans. ${ }^{22}$ Of the 38 animal phyla described, 26 are exclusively aquatic, and of those, 19 are marine. In contrast, only one living animal phylum (Onchyophoria, or velvet worms) is exclusively terrestrial. ${ }^{22}$

While marine life has been found down to the deepest abyss, the majority of marine species diversity occurs at the ocean fringe. This land-sea interface with its high biodiversity constitutes one of "the most species rich and biologically productive regions of the world." 23 In certain marine ecosystems, such as coral reefs, the biological diversity is estimated as higher than in the tropical rainforest. ${ }^{22}$ 


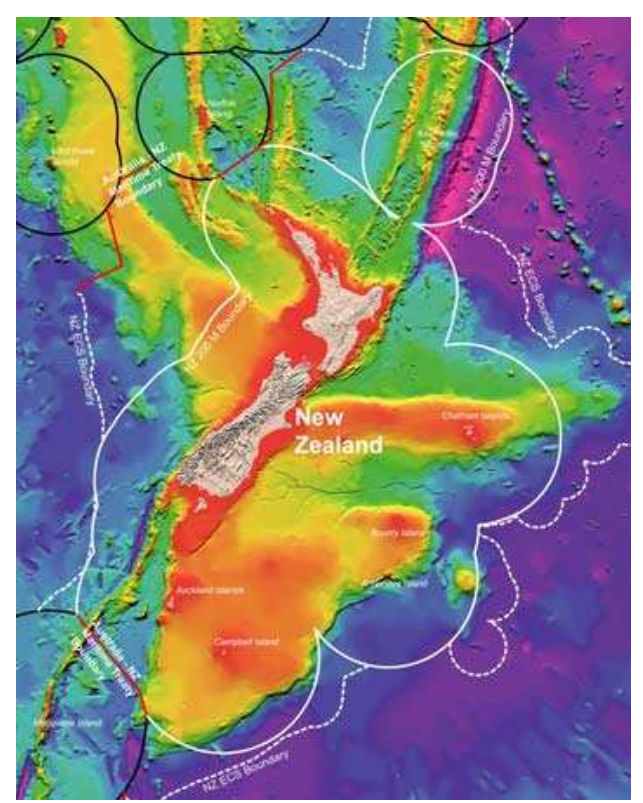

Figure 1.1. New Zealand Exclusive Economic Zone. Image courtesy of the National Institute of Water and Atmospheric research (NIWA).

\section{The New Zealand marine ecoregion}

New Zealand is a relatively long and narrow archipelago, forming the western boundary to the South Pacific ocean south of $34^{\circ}$ S. Its Territorial Sea and Exclusive Economic Zone comprises more than 4.2 million $\mathrm{km}^{2}$, and spans over 30 degrees of latitude (Figure 1.1). The New Zealand marine environment extends from subtropical waters to the subantarctic, and from the shallows to the deep sea. This range and complexity of habitats, coupled with the number of major ocean currents and New Zealand's geographical isolation, has created diverse marine communities, home to an estimated 23,000 species including approx. 16,000 marine invertebrates. ${ }^{24}$

\section{Marine natural products}

Scientific investigation of marine organisms was initially limited to easily accessible and readily collectable specimens, for example macro-algae collected by hand at low tide or using a snorkel. ${ }^{25}$ Marine natural products emerged as a fully fledged discipline only in the 1970s, after the introduction and widespread use of SCUBA. Initially, the field was dominated by the study of toxins such as saxitoxin (2) (isolated from a dinoflagellate), and tetrodotoxin (3) (isolated from a pufferfish*). ${ }^{23,26}$ More recently, complex polyether toxins such as maito-

\footnotetext{
${ }^{*}$ The true origin of $\mathbf{3}$ is now believed to be microbial. ${ }^{21}$
} 


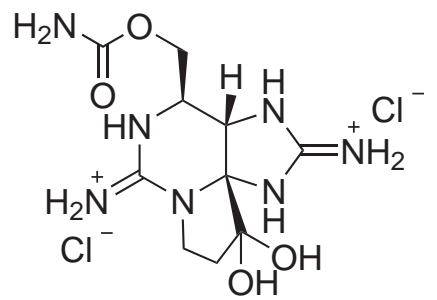

2

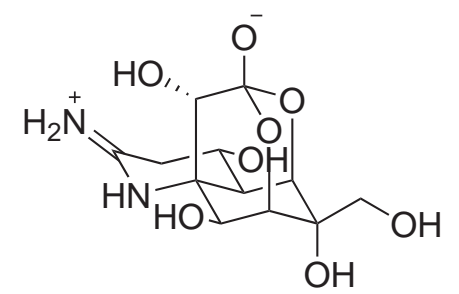

3

toxin (4), the largest and most lethal non-proteinaceous toxin known, has been isolated from the dinoflagellate Gambierdiscus toxicus. The structure elucidation of this highly complex molecule was a feat that required a combination of both spectroscopy and synthesis to achieve. Due to the increasing frequency of algal blooms and associated shellfish contamination, these marine toxins with a "ladder-like" polyether skeleton remain of great interest to researchers. ${ }^{27}$
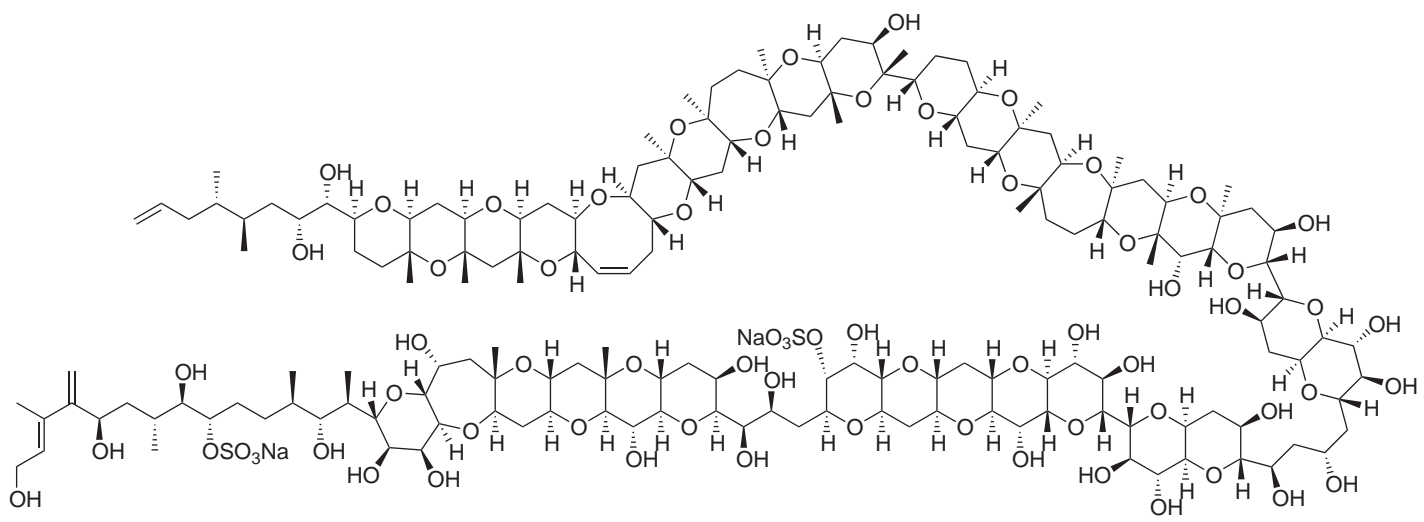

4

Parallel to the study of toxins was the search for marine biomedicinals, although early efforts "prioritized description of unique structural chemistry rather than discovering drugs or drug leads." 23 More recently, the emphasis has shifted to a more interdisciplinary approach. Chemists and pharmacologists together utilize these metabolites as molecular probes that provide key insights into complex cellular events. ${ }^{26}$ The additional integration of the study of marine chemical ecology with chemistry and pharmacology has resulted in what is now known collectively as marine natural products chemistry. ${ }^{27}$

\section{Chemical defense in the marine environment}

The majority of marine bioactive secondary metabolites are produced by invertebrates. Most of them are slow-moving or completely sessile, and often lack physical means of defense. Instead, many species have evolved chemical means of repelling or deterring predators, through accumulation of toxic or distasteful 
<smiles>CC(C)=CCC[C@]1(C)CC(=C(Cl)CN=C(Cl)Cl)C[C@@H](O)[C@@H]1Cl</smiles>

5

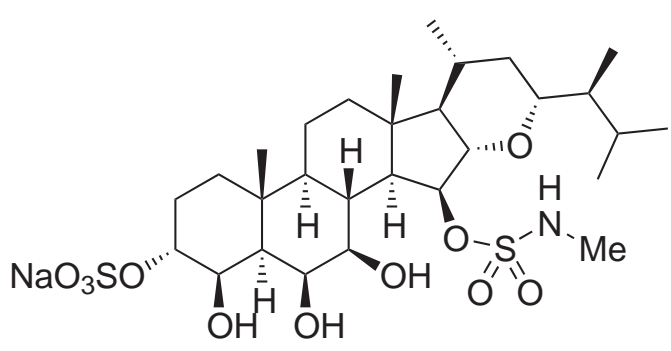

6<smiles>C[C@](Cl)(/C=C/Br)C(Cl)/C=C/Br</smiles>

7

secondary metabolites. ${ }^{23,27-29}$

While protection against predation is very important for sessile organisms such as sponges, equally important is defense against the overgrowth of competitors. Sponges are filter-feeding organisms that cannot tolerate settlement of other organisms such as barnacles or bryozoans on their surface. To protect their water-pumping capacity, some sponges produce a level of cytotoxic compounds that is high enough to create a bare zone around them. ${ }^{30}$ Compounds (for example pheromones) are also produced for communication between organisms. In addition, secondary metabolites can protect against bacterial, fungal and parasitic infections. ${ }^{29,30}$ Finally, some species of invertebrates-like the Conus snails - are able to use highly potent toxins for immobilizing prey. These fierce predators are able to overpower their physically much stronger prey by launching a specialized radular tooth (a kind of harpoon), which delivers a paralyzing peptide. $^{22}$

Not surprisingly, this marine chemical arsenal has proven to be a rich source of interesting and bioactive secondary metabolites. ${ }^{31}$ Many new carbon skeletons have been described, most being unique to the marine environment. ${ }^{27,32}$ Several functional groups, such as the dichloroimine functionality of $\mathbf{5}$ and the sulfamate group of haplosamate A (6), are either uniquely or predominantly marine as well. ${ }^{33}$ Another feature of marine natural products is the high incorporation of covalently bound bromine and chlorine (presumably due to their availability in seawater), ${ }^{23}$ giving rise to such highly halogenated molecules as $7 .{ }^{27}$

Marine secondary metabolites need to be highly potent as they may be released into the water and rapidly diluted. ${ }^{25}$ This, coupled with immense biological (and therefore chemical) diversity, means the oceans provide a huge number 
of novel and potently bioactive chemical entities that can be useful in the search for new drugs for the treatment of many human diseases. ${ }^{22}$

\section{Marine natural products in clinical trials}

One of the earliest forays into the realm of marine natural products by Bergman and Feeney in the $1950 \mathrm{~s}^{34,35}$ yielded the arabinosyl nucleosides spongothymidine (8) and spongouridine (9). Isolated from the sponge Cryptotethia crypta, these unusual nucleosides spurred researchers to synthesize analogues, which resulted in the antiviral drug Ara-A (10) and the anticancer agent Ara-C (11), still in use today. ${ }^{30}$

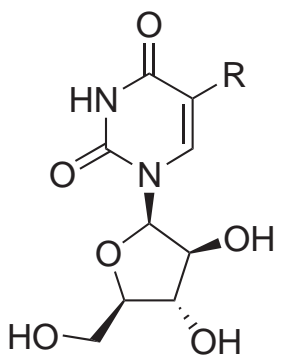

$8 \mathrm{R}=\mathrm{Me}$

$9 \mathrm{R}=\mathrm{H}$

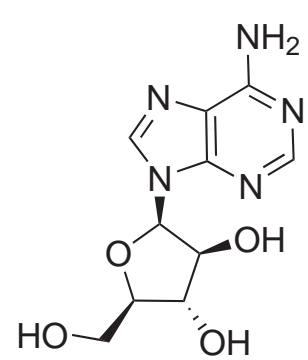

10<smiles>Nc1ccn([C@@H]2O[C@H](CO)[C@@H](O)[C@H]2O)c(=O)n1</smiles>

11

Mayer et al. reviewed ${ }^{36,37}$ the most recent marine natural products in preclinical and clinical trials; 150 are antitumour and cytotoxic compounds; 67 show a range of activities such as antibacterial, anticoagulant, antimalarial or antiviral; 45 are being tested for effects on the cardiovascular, immune and nervous systems; and 54 compounds are reported to act on a variety of cellular targets. A significant number of marine-derived molecules are in, or approaching, Phase II/III clinical trials in cancer, allergy and cognitive diseases, and may see regulatory approval in the near future. ${ }^{25}$

The latest success story, and in fact the first true marine natural product to be approved by the FDA, is ziconotide, ${ }^{*}$ the synthetic equivalent of $\omega$-conotoxin MVIIA. The 25 amino acid peptide 12 was isolated from the piscivorous "magician's snail" Conus magus, a marine mollusc which uses numerous toxic peptides to subdue its fish prey. ${ }^{38}$ Ziconotide is a non-opioid analgesic; it is a highly selective, very potent blocker of mammalian neuronal N-type voltage-sensitive calcium channels which usually transmit the pain signal. ${ }^{39}$ Ziconotide was approved as an intrathecal infusion for severe, chronic pain by the FDA on Decem-

*Prialt (Elan Pharmaceuticals) 


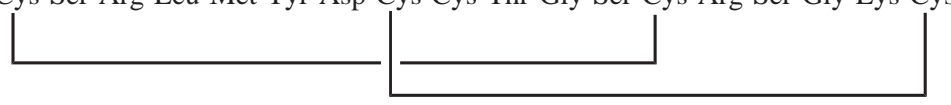

12

ber 28, 2004, and by the EU on February 22, 2005. It is the first new intrathecal analgesic approved in two decades. ${ }^{40}$

\subsection{Sponges}

Sponges are sedentary, filter-feeding organisms. They are invertebrates and the most primitive phylum of multicellular animals. They have neither true organized tissues nor organs, and their cells show extensive independence from each other. ${ }^{41}$ They have indeterminate growth, much like a terrestrial plant, and a variable body plan. Sponges show considerable plasticity in response to environmental variables - such as available space, current, habitat - which can drastically affect their morphology. This variability has made classification of sponges a difficult task, with debate at the class level still appearing in the literature. ${ }^{42,43}$ The most recent classification by Hooper and van Soest $^{43}$ (Figure 1.2) recognizes three classes within the phylum Porifera: Calcarea (calcareous sponges), Hexactinellida (glass sponges) and Demospongiae (spongin sponges), based on the type of spicule (skeletal element) they possess. Calcarea have a skeleton of calcium carbonate, while the spicules of Hexactinellida are siliceous, arranged in a hexactine (six-rayed) structure. The Demospongiae, which are the largest group of sponges accounting for over $90 \%$ of sponge species, are characterized by mono- and tetractine spicules, and/or by an organic skeleton of the collagen protein spongin. ${ }^{42}$

Since the first discovery of the arabinosyl nucleosides $\mathbf{8}$ and $\mathbf{9}$, sponges have become a rich source of interesting and biomedically important metabolites. Well over 5,000 new compounds have been isolated from sponges to date, ${ }^{44}$ with anti-inflammatory, antitumour, immunosuppresive, antiviral, antimalarial and antibiotic activities represented.

\section{Microbial symbiosis in marine sponges}

Interestingly, many sponge derived natural products closely resemble those characteristic of microbes. ${ }^{45}$ Microbial symbionts can constitute up to $60 \%$ of the 


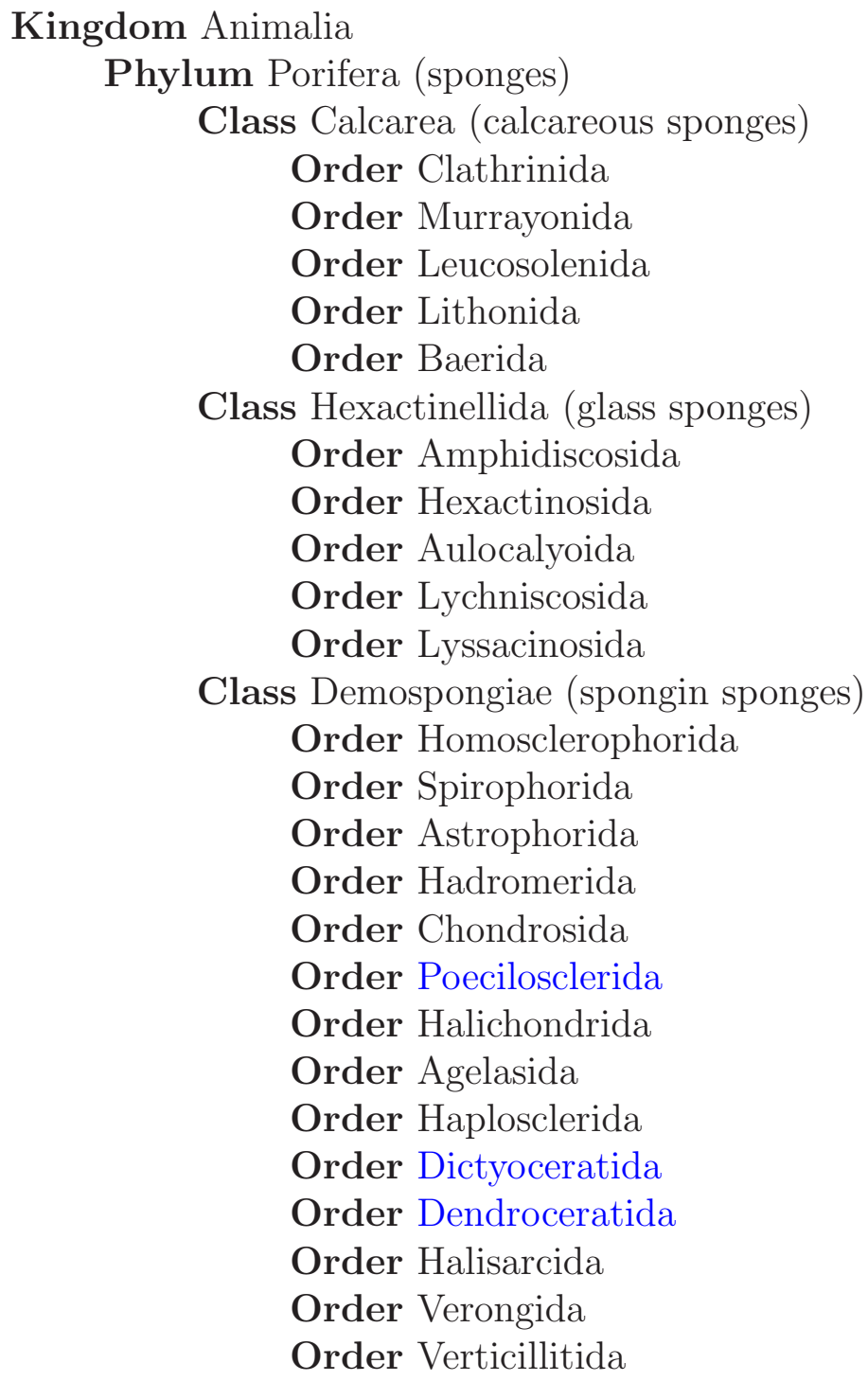

Figure 1.2. Taxonomic classification of sponges, after Hooper and van Soest. ${ }^{43}$. Orders examined in this study are printed in blue.

biomass of some sponges and are often suspected to be the true producers of the secondary metabolites. Unfortunately, most of these symbionts are presently unculturable, ${ }^{46}$ so the microbial origin of some natural products is assumed from indirect evidence, such as: one sponge species containing different classes of metabolites; taxonomically different organisms containing the same metabolite; free-living microorganisms producing similar or identical compounds; or extremely low metabolite concentration. ${ }^{47}$ Nevertheless, as collection or cultivation of large amounts of sponge for drug production is often a problem, cultivation of symbionts or the transfer of symbiont biosynthetic genes into culturable bacteria remains an intriguing and lucrative proposition. ${ }^{46}$ 


\subsection{Nudibranchs}

The phylum Mollusca (for taxonomy, see Figure 1.3), encompasses all types of mollusks, including squid and octopus (class Cephalopoda), bivalves (class Pelecypoda) and snails (class Gastropoda). Slugs are snails that have lost their shell (or only have a very rudimentary one), and include both land (Pulmonata) and sea (Opisthobranchia) species. The sea-slugs that lack a shell are called "nudibranchs", a term that comes from the Latin nudus meaning "naked" and Greek brankhia meaning "gills", as they have "naked gills" in full view on their back. The order Nudibranchia is usually divided into four suborders: Doridina (dorids), Dendronotina (dendronotids), Arminina (arminaceans) and Æolidina (aeloids). The dorids usually have gills situated towards the rear, grouped in a circle or semi-circle. The majority can withdraw them into pockets beneath the mantle surface. The aeolids, dendronotids and arminaceans have gills formed by various outgrowths from the body, and are never retractile into pockets. All nudibranchs are hermaphrodites (they have both sets of sex organs) and their heads always have a pair of rhinophores (sensory tentacles). Most common nudibranchs grow from one to five centimetres in size. ${ }^{48}$

Nudibranchs are found in most habitat types throughout the world's oceans, occuring at all depths and latitudes, including beneath the Antarctic ice. The greatest diversity, however, is found in the tropical seas such as the Indo-Pacific region, where 800 of the approximately 3,000 world-wide species of nudibranch can be found. ${ }^{48}$

\section{Nudibranch defense}

Due to their lack of a shell, nudibranchs should be vulnerable to predation. Few nudibranch predators are in fact known, as the sea-slugs have developed numerous defense strategies. ${ }^{48}$ Some are behavioural adaptations: for instance many nudibranchs are mainly active at night. Some, like Discodoris lilacina (often called D. fragilis) are capable of autotomy (casting off of one's body parts when threatened). Camouflage is also a widely employed defense tactic, with some nudibranchs not only taking on the colour but also the texture of their common food or habitat. Others show countershading (dark dorsal and light or silver ventral surface) like that of many fish, or are outright mimics of toxic or poisonous species. ${ }^{48,49}$

The aeolids have perhaps the most unusual method of defense. They feed on hydroids or corals that possess nematocysts (stinging cells), but are not affected 


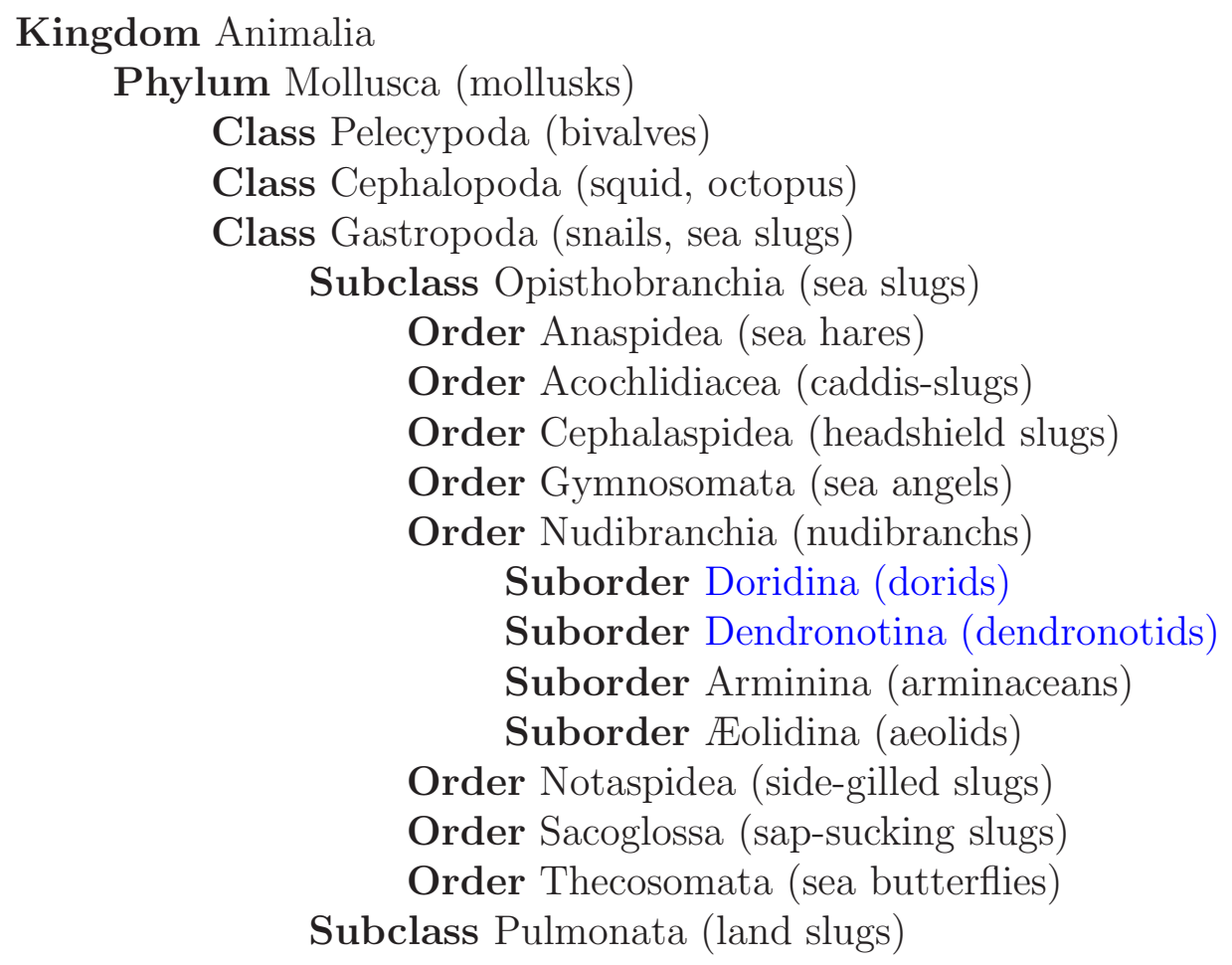

Figure 1.3. Taxonomic classification of nudibranchs, after Rudman. ${ }^{49}$ Suborders examined in this study are printed in blue.

by their poison. Instead, the nudibranchs separate and transport these cells to their extremities, where they use them for their own protection. ${ }^{48}$

Of particular interest to the natural product chemist are the chemical methods of defense employed by some nudibranchs. Certain species are known to contain distasteful and sometimes toxic chemicals in their skin. ${ }^{48}$ Many of these species show aposematic (warning) colouration, resulting in an array of beautiful, bright colour patterns that have earned nudibranchs the nickname "butterflies of the sea."

Examination of nudibranchs and their food sources has revealed that many sea-slugs obtain defensive chemicals from their food. ${ }^{50,51}$ The presence in nudibranchs of secondary metabolites identical to those isolated from their sponge (or other organism) food source cannot be just incidental; the defensive metabolites are sequestered (selectively accumulated), often localized in the mantle or in special glands where they can be most effective at deterring predators. The acquisition of a chemical mode of defense appears to predate the loss of the shell. The mechanical protection of the shell became obsolete as the nudibranchs switched from a physical to a chemical mode of protection. ${ }^{50}$ 
Unfortunately, this leaves the nudibranch dependent on its food as the source of defensive metabolites. Clearly the ability to synthesize its own feeding deterrents would be quite advantageous, and indeed, Cimino et al. demonstratedthrough feeding experiments with carbon-14 labelled mevalonic acid - that the nudibranch Dendrodoris limbata synthesizes the defensive sesquiterpene polygodial. ${ }^{52}$ Since then, de novo biosynthesis has been shown in many nudibranch species. ${ }^{51,53}$

\subsection{Research aims}

This research aims to discover new, bioactive, secondary metabolites from marine invertebrate sources. Several dive trips will be undertaken to collect New Zealand species of sponge and nudibranch. These will be screened according to the protocol developed by the Marine Natural Products Group at Victoria University. Crude extract fractions will be evaluated by 1D and 2D NMR spectroscopy, and the mask used to screen the spectra will be updated and developed further. Interesting species will be examined in detail, leading to the isolation of pure compounds whose structure will be elucidated using a range of spectroscopic techniques. Compounds isolated will be subjected to biological activity testing.

\subsection{Concluding remarks}

With its coastline spanning a range of latitudes and its varied marine environment with high biodiversity, New Zealand is an excellent place to study marine natural products. Many marine invertebrates, such as sponges and nudibranchs, do not have physical means of defense and so have developed a rich chemical arsenal that can be exploited in the search for new pharmaceutical leads. Although the pharmaceutical industry focuses on activity screening and bioassay-guided isolation for their lead structure discovery, activity-independent screening can lead to the isolation of novel compounds (with interesting biological activity) that would otherwise have been missed. 


\section{Chapter 2}

\section{Chemical Analysis of New Zealand Nudibranchs}

\subsection{Natural products from nudibranchs}

When faced with a plethora of seemingly similar invertebrates, the diver's eye is often attracted to the brightly coloured nudibranchs. The seemingly undefended sea-slugs are excellent candidates for natural products research because they often concentrate the most biologically-active defensive metabolites derived from their diet. These molluscs are able to direct the researcher towards the most interesting chemistry, and the high concentration of these metabolites (sometimes four orders of magnitude higher than that present in the food source ${ }^{25}$ ) facilitates isolation and structure elucidation. Unsurprisingly, a number of important marine metabolites were first isolated from nudibranchs.

As most nudibranch metabolites are sequestered from their diet, the variety of compound classes isolated from sea-slugs reflects the wide range of metabolites present in sponges and other species on which nudibranchs prey. Selected examples will be discussed.

\section{Terpenes}

A multitude of regular, rearranged, and degraded sesquiterpenes, diterpenes, sesterterpenes, and triterpenes have been isolated from nudibranchs. Interesting instances are presented below.

The nudibranch Phyllidia varicosa has long been known to secrete a strong and unusual-smelling, heat-stable, volatile substance that is lethal to fish. In 1975, Scheuer et al. reported the isolation of the sesquiterpene metabolite 9- 
isocyanopupukeanane (13) from 20 P. varicosa individuals, which they "milked" through gentle squeezing and repeated rinsing to obtain enough exudate for further purification. Compound $\mathbf{1 3}$ was later isolated from the prey sponge Hymeniacidon sp., collected from Pupukea, Hawaii. ${ }^{54}$ The structure of $\mathbf{1 3}$ was solved by X-ray diffraction and was the first member of the unusual isotwistane (tricyclo[4.3.1.0 $\left.0^{3,7}\right]$ decane) carbon framework. ${ }^{55}$ It is one of the early examples of an isocyanide reported from the marine environment.

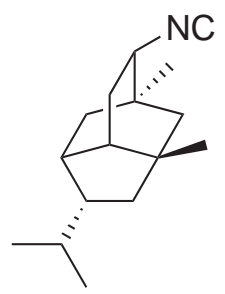

13

A variety of diterpenes, often related to the spongian skeleton, have been isolated from nudibranchs. A rearranged spongian metabolite norrisolide (14) was isolated from the dorid nudibranch Chromodoris norrisi in $1983 .{ }^{56}$ It has an unusual structure with a perhydroindane core bridged via a one carbon bridge to an acetylated $\gamma$-lactol- $\gamma$-lactone ring system. Norrisolide has attracted recent interest due to its unusual biological activity: it is the only known compound to induce irreversible vesiculation of the Golgi apparatus in intact cells by binding to the Golgi membranes. ${ }^{57}$ Experiments with several norrisolide-based fluorescent probes have shown that the unfunctionalized perhydroindane moiety is essential for this activity. ${ }^{57}$

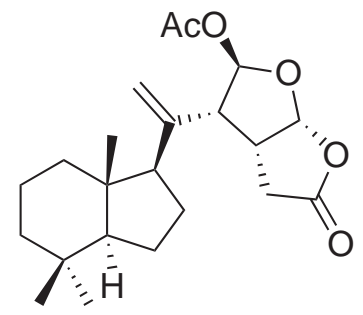

14

Several bioactive sesterterpenoids have been isolated from nudibranchs, most of them scalarane-type, or linear furanoterpenes. The Japanese nudibranch Chromodoris inornata, however, was found to contain inorolides A and B (15, 16) two cytotoxic sesterterpenes with a novel carbon skeleton containing an unusual seven-membered ring. ${ }^{58}$ 


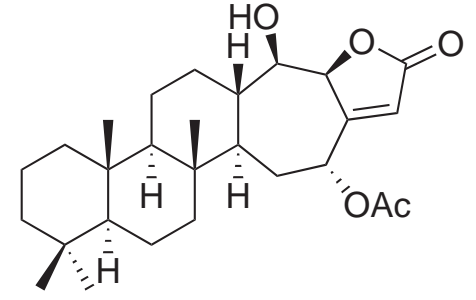

15

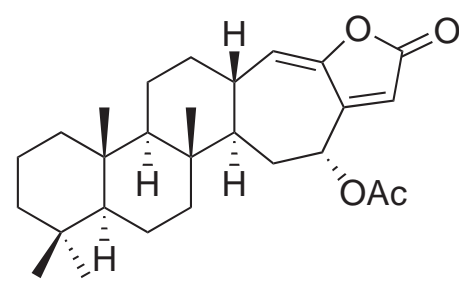

16

The first example of a triterpenoid metabolite isolated from a nudibranch is the degraded triterpene lovenone (17), isolated from the North Sea nudibranch Adalaria loveni in 1995. This compound possesses a steroidal carbon skeleton with an unusual degraded ring $\mathrm{A}$, which appears to be without precedent. ${ }^{59}$

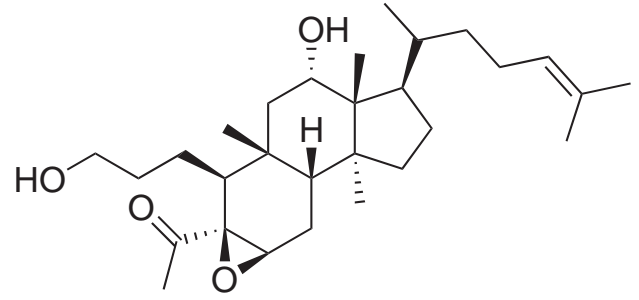

17

\section{Macrolides}

Ulapualide A and B $(\mathbf{1 8}, \mathbf{1 9})$ and kabiramide C $(\mathbf{2 0})$ were the first isolated members of an extraordinary family of macrolides, characterized by three contiguous oxazole rings. ${ }^{60,61}$ The ulapualides were isolated from the egg masses of the brilliantly coloured nudibranch Hexabranchus sanguineus collected from Pupukea, Hawaii, ${ }^{60}$ while kabiramide $\mathrm{C}$ was isolated from the egg mass of an unidentified nudibranch species, ${ }^{*}$ collected from Kabira Bay, Ishagaki-jima Island, Japan. ${ }^{61}$ These were subsequently followed by the halichondramides, mycalolides and jaspisamides, exemplified by halichondramide $(\mathbf{2 1}),{ }^{63}$ mycalolide A $(\mathbf{2 2})^{64}$ and jaspisamide A (23) ${ }^{65}$ from sponges of the genus Halichondria, Mycale and Jaspis respectively. To date, approximately 35 congeners have been reported. ${ }^{62}$

These compounds are all based on a 25-membered macrolide with a trisoxazole unit; a lipid-like side chain is attached to the macrolide core, terminating in a formyl enamide residue. The differences between the molecules are mostly in the oxygenation patterns and alkyl group substitution of the aliphatic chain portion of the structures. Their complex configuration has been established

\footnotetext{
*later identified as a Hexabranchus sp. ${ }^{62}$
} 


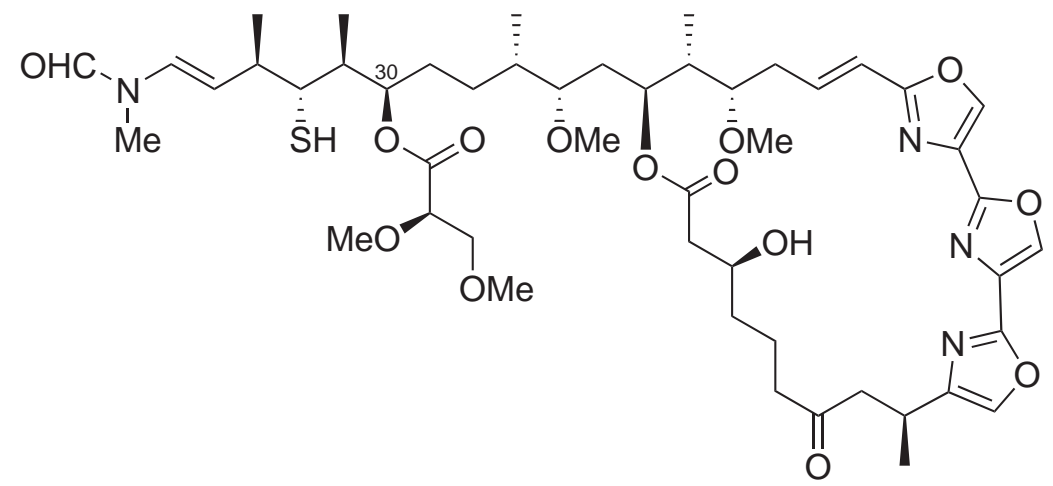

18

$19 \mathrm{C} 30=$ ketone

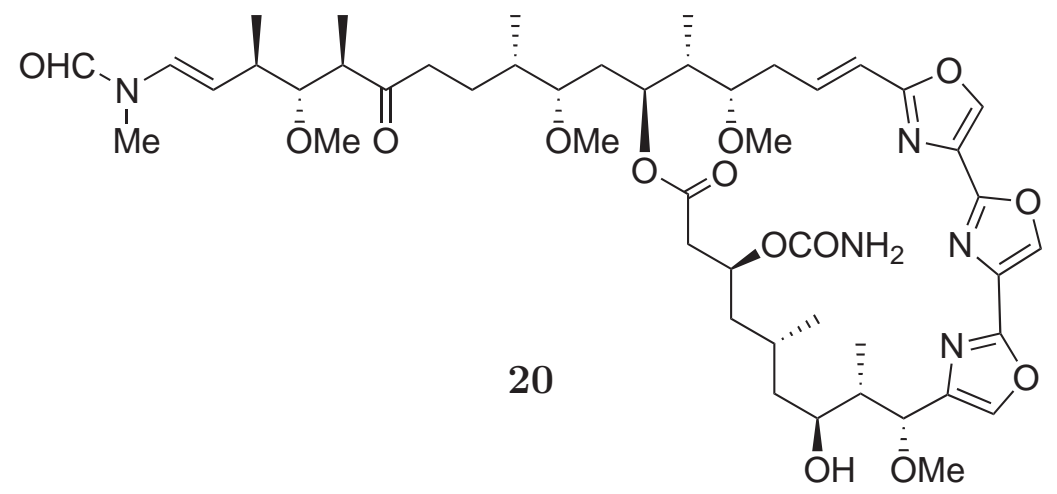

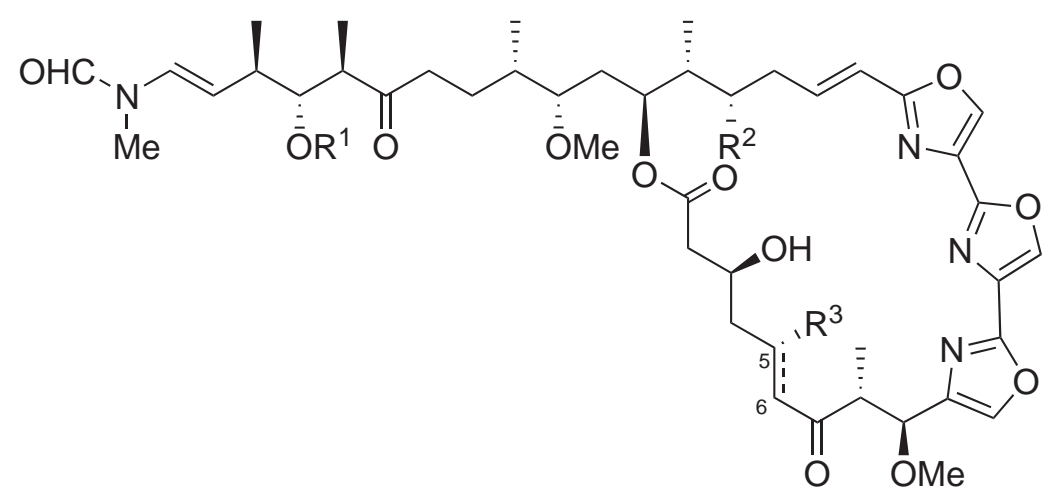

$21 \quad \mathrm{R}^{1}=\mathrm{Me} \quad \mathrm{R}^{2}=\mathrm{H} \quad \mathrm{R}^{3}=\mathrm{H} \quad \Delta_{5,6}$

$22 \mathrm{R}^{1}=\mathrm{Ac} \quad \mathrm{R}^{2}=\mathrm{OMe} \quad \mathrm{R}^{3}=\mathrm{H} \quad \Delta_{5,6}$

$23 \mathrm{R}^{1}=\mathrm{Me} \quad \mathrm{R}^{2}=\mathrm{H} \quad \mathrm{R}^{3}=\mathrm{OH}$ 
through a combination of X-ray diffraction, chemical degradation and NMR spectroscopy. ${ }^{62,66,67}$

Members of this family of macrolides have shown a range of interesting biological activities, including ichthyotoxic and ichthyodeterrent properties. All show pronounced antifungal activity and cytotoxicity, but no antibacterial activity, suggesting they act on eukaryote-specific cellular components. A range of experiments has shown that the trisoxazole macrolides depolymerize F-actin, and form a 1:1 complex with G-actin. ${ }^{62}$ As they interfere with actin filament dynamics, these compounds may be useful as cellular probes for actin-mediated cell functions. ${ }^{66}$

\section{Peptides}

While the opistobranch sea hare Dolabella auricularia is not strictly a nudibranch as it posesses the remanants of a shell and belongs to the order Anaspidea, it nevertheless deserves mention because of the remarkably potent antineoplastic peptides it contains. The anticancer properties of $D$. auricularia extracts have been known since the 1970s, but due to the extremely small quantities ( $\sim 1.0 \mathrm{mg} / 100 \mathrm{~kg}$ of collected organism) of the active compound, dolastatin 10 (24), the structure was not elucidated until $1987 .{ }^{68}$

Several other members of this peptide family have been isolated since this report, including those from the Symploca marine cyanobacterium (on which the sea hare grazes), indicating an exogenous, dietary origin of the peptides in $D$. auricularia. ${ }^{23}$ Investigation of the potent biological activity of the dolostatins has shown they strongly affect microtubule assembly. ${ }^{36}$

Dolastatin 10 (24) progressed to Phase II clinical trials, but unfortunately was withdrawn as it did not demonstrate significant in vivo antitumour activity in humans. ${ }^{25}$ Other members of the dolostatin family (including synthetic analogues), however, are currently being evaluated in clinical trials. ${ }^{25}$

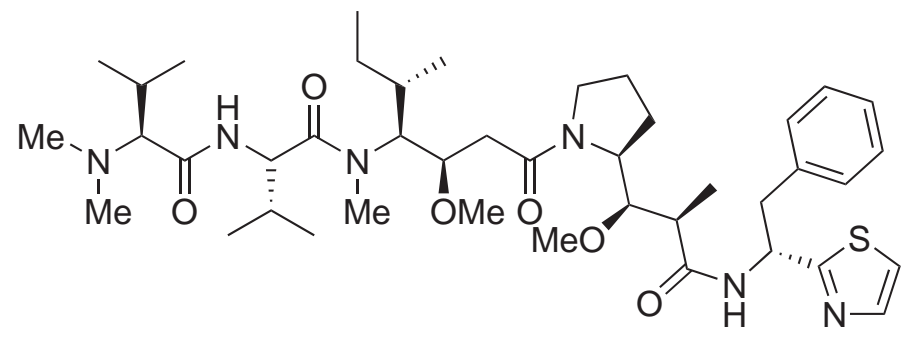

24 


\section{$2.2 \quad$ New Zealand nudibranchs}

New Zealand is home to over 150 species of nudibranch, mostly found in the warmer northern region, particularly on the eastern coast of the northern tip of the North Island. Although diversity in New Zealand waters is low in comparison to the tropical Pacific, most nudibranch families are represented by at least one species. $^{48,69}$

When this study began, no metabolites had been reported in the literature from New Zealand nudibranchs. A subsequent review of the published chemistry of Australian and New Zealand molluscs, by Garson in 2006, revealed a lack of studies on natural products from New Zealand nudibranchs, concluding that there continues to be much scope for further research. ${ }^{70}$ More recently, Grkovic et al. reported several known compounds from some common New Zealand opisthobranch molluscs, including some of those species covered below. ${ }^{71}$ 


\subsection{Tritonia incerta}

The nudibranch Tritonia incerta (see Figure 2.1 for taxonomy) is an apricotorange to vermilion-pink coloured nudibranch, such as that shown in Figure 2.2, that can grow up to $130 \mathrm{~mm}$ in size. It has non-retractile gills in tufts on a lateral ridge, and its oral veil is a fringed border of finger-like tentacles. T. incerta is found in the sea around the northern half of the North Island of New Zealand, extending from subtidal to beyond $200 \mathrm{~m}$ depths at the edge of the continental shelf. It is usually found in open, rocky situations, often clustered on the soft coral Alcyonium aurantiacum which is its food source. ${ }^{48,69}$

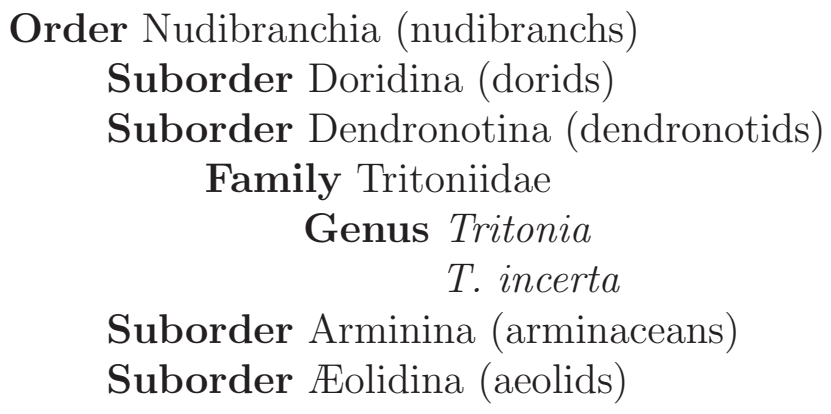

Figure 2.1. Taxonomic classification of T. incerta, after Rudman. ${ }^{49}$

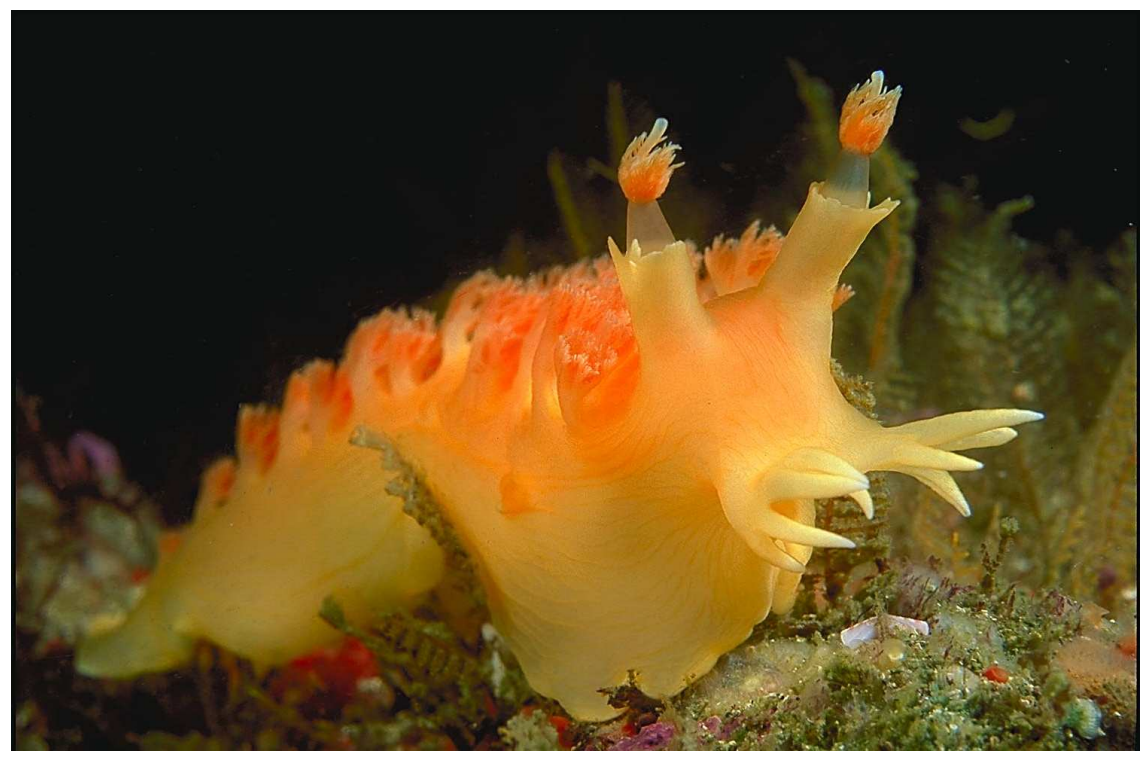

Figure 2.2. Underwater photo of $T$. incerta (courtesy of Ian Skipworth). 


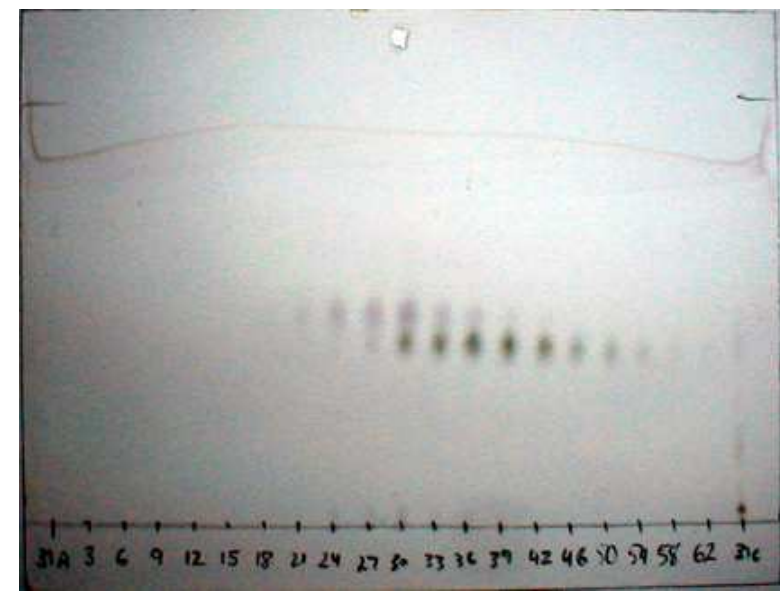

(a) $10 \% \mathrm{EtOAc} / \mathrm{CH}_{2} \mathrm{Cl}_{2}$

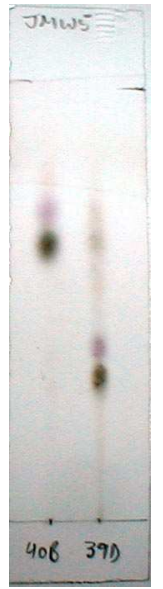

(b) $50 \% \mathrm{EtOAc} / \mathrm{CH}_{2} \mathrm{Cl}_{2}$

Figure 2.3. TLC plates (visualized by dipping in $5 \% \mathrm{H}_{2} \mathrm{SO}_{4}$ and heating) of (a) a silica gel column on the mixture and (b) the mixture (left) and the two more polar compounds (right).

\section{Metabolites isolated from T. incerta}

Nineteen T. incerta individuals were collected from Rauhomaumau Island, Tutukaka, New Zealand, in December 2003. They were extracted in $\mathrm{MeOH}$, and cyclic loaded onto reversed-phase HP20 beads, which were eluted with increasing concentrations of $\mathrm{Me}_{2} \mathrm{CO}$ in $\mathrm{H}_{2} \mathrm{O}$. The $75 \% \mathrm{Me}_{2} \mathrm{CO}$ in $\mathrm{H}_{2} \mathrm{O}$ fraction showed interesting features in the NMR spectra, and was purified further on a normal phase (DIOL) column eluted with $\mathrm{CH}_{2} \mathrm{Cl}_{2}$ in pet. ether. The pet. ether fractions yielded the cembranoid diterpene (-)-epi-thunbergol (25).

Fractions eluting with $30 \% \mathrm{CH}_{2} \mathrm{Cl}_{2}$ contained a mixture of two compounds with a similar $\mathrm{R}_{f}$ on TLC (0.55 and 0.51 in $10 \% \mathrm{EtOAc} / \mathrm{CH}_{2} \mathrm{Cl}_{2}$ ) but distinct pink and green chars when visualized by dipping in $5 \%$ methanolic $\mathrm{H}_{2} \mathrm{SO}_{4}$ and heating. The two compounds were purified on a silica gel column (eluted with EtOAc/ $\mathrm{CH}_{2} \mathrm{Cl}_{2}$ mixtures); unfortunately only differential enrichment of the compounds was achieved (see Figure 2.3(a)). The fractions were combined on the basis of TLC into three parts: early eluting (pink charring), the mixture, and late eluting (green charring). The column was repeated multiple times on the mixture to eventually afford $13 \alpha$-acetoxypukalide (26) and lopholide (27), each in about $90-95 \%$ purity.

The less polar fractions of the DIOL column eluting with $20 \% \mathrm{CH}_{2} \mathrm{Cl}_{2}$ showed a mixture of two minor compounds by TLC. Further purification of these fractions on a DIOL column $\left(\mathrm{CH}_{2} \mathrm{Cl}_{2}\right.$ in pet. ether) resulted in the isolation of pukalide (28) and 11 $\beta, 12 \beta$-epoxypukalide (29). 
The final "wash" elutions from the multiple silica columns showed a mixture of two compounds, which charred pink and green like 27 and 26, but were significantly more polar (see Figure 2.3(b)). The two compounds were separated on an analytical DIOL HPLC column (eluted with 20\% IPA in hexane) to afford $13 \alpha$-acetoxypukalide diol (30) and lopholide diol (31).

The soft coral Alcyonium aurantiacum is preyed upon by T. incerta. Previous examination of the soft coral in our lab has led to the isolation of lopholide (27). ${ }^{72}$ Examination of another collection of the soft coral also resulted in the isolation of (-)-epi-thunbergol (25).

The major compound isolated from T. incerta was $13 \alpha$-acetoxypukalide (26), and its structure was elucidated first. The connectivity of $\mathbf{2 6}$ was established through a series of COSY and HMBC correlations as depicted in Figure 2.4. It contained an epoxide bridging positions 7 and 8 , indicated by the unusual chemical shifts and large ${ }^{1} J_{\mathrm{CH}}$ recorded $\left(\mathrm{CH}-7: \delta_{\mathrm{C}} 54.9, \delta_{\mathrm{H}} 4.09,{ }^{1} J_{\mathrm{CH}} 183 \mathrm{~Hz}\right.$; C-8: $\left.\delta_{\mathrm{C}} 56.7\right)$. A review of the literature revealed 26 was first isolated from the Australian soft coral Sinularia polydactyla in $1989 .{ }^{73}$ Comparison of NMR data confirmed they were identical.

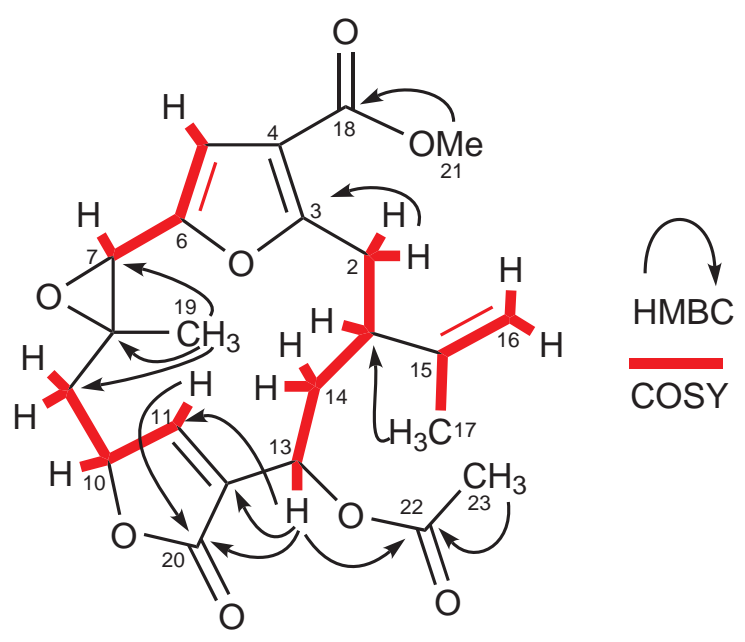

Figure 2.4. Key COSY and HMBC correlations establishing the connectivity of $13 \alpha$-acetoxypukalide (26).

With the structure of $\mathbf{2 6}$ in hand, the structures of four of the other, related metabolites were quickly identified by comparison of NMR data to those reported in the literature. Lopholide (13 $\alpha$-acetoxy-11 $\beta, 12 \beta$-epoxypukalide) (27) had also been isolated from $S$. polydactyla concurrently with $\mathbf{2 6},{ }^{73}$ pukalide (28) was first isolated from Sinularia abrupta, ${ }^{74}$ while $11 \beta, 12 \beta$-epoxypukalide (29) was first reported from the gorgonian Leptogorgia setacea. ${ }^{75}$

(-)-epi-Thunbergol (25) is a very non-polar compound, much less function- 


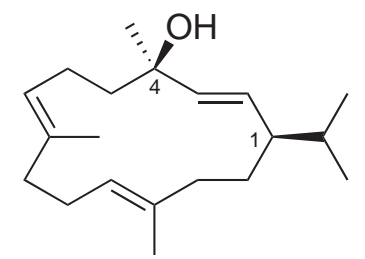

25

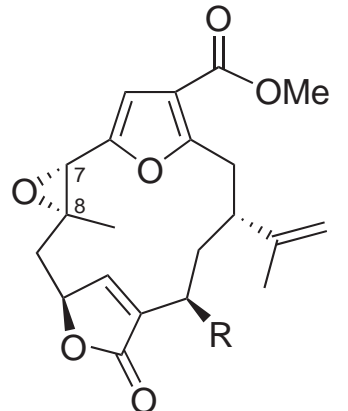

$26 \mathrm{R}=\mathrm{OAc}$

$28 \mathrm{R}=\mathrm{H}$

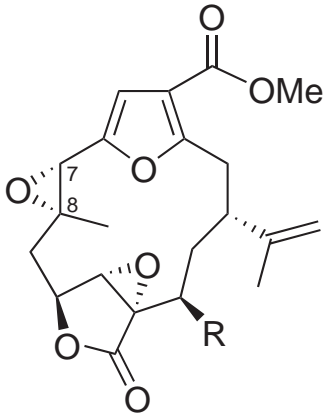

$27 \mathrm{R}=\mathrm{OAc}$

$29 \mathrm{R}=\mathrm{H}$

alized than the pukalide-type compounds, with only one allylic alcohol and two trisubstituted double bonds. It is a common soft coral metabolite, and was identified through comparison of NMR and optical rotation data with literature values. ${ }^{73,76}$

\section{Structure elucidation of two minor diterpenes}

Positive ion mode HRESIMS analysis of the two minor, polar, metabolites $\mathbf{3 0}$ and 31 indicated they had molecular formulae of $\mathrm{C}_{23} \mathrm{H}_{28} \mathrm{O}_{9}\left(471.1631[\mathrm{M}+\mathrm{Na}]^{+}\right.$, $\Delta 1.7 \mathrm{ppm})$ and $\mathrm{C}_{23} \mathrm{H}_{28} \mathrm{O}_{10}\left(487.1579[\mathrm{M}+\mathrm{Na}]^{+}, \Delta 0.2 \mathrm{ppm}\right)$ respectively. The formulae indicated the presence of an extra oxygen and two hydrogens, as compared to $13 \alpha$-acetoxypukalide (26) lopholide (27). Both formulae required 10 double bond equivalents, one less than $\mathbf{2 6}$ and $\mathbf{2 7}$. Compounds $\mathbf{3 0}$ and $\mathbf{3 1}$ had

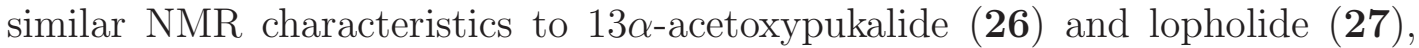
but conspicuously absent for both were the unusual methine and quaternary carbon signals of the 7,8-epoxide. A "regular" oxymethine and an oxygenated, quaternary carbon were present instead. These data suggested that $\mathbf{3 0}$ and $\mathbf{3 1}$ were the 7,8-dihydroxy-desepoxy analogues of $\mathbf{2 6}$ and $\mathbf{2 7}$.

A more detailed analysis of the NMR spectra confirmed this assignment. The majority of the NMR resonances of diol 30 compared favourably to $13 \alpha$ acetoxypukalide (26), allowing the construction of the same carbon skeleton. The methyl $\mathrm{H}_{3}-19$ showed HMBC correlations to an oxymethine carbon $\left(\delta_{\mathrm{C}} 76.1\right)$ and an oxygenated, quaternary carbon $\left(\delta_{\mathrm{C}} 73.7\right)$, assigned as $\mathrm{CH}-7$ and $\mathrm{C}-8$ re- 


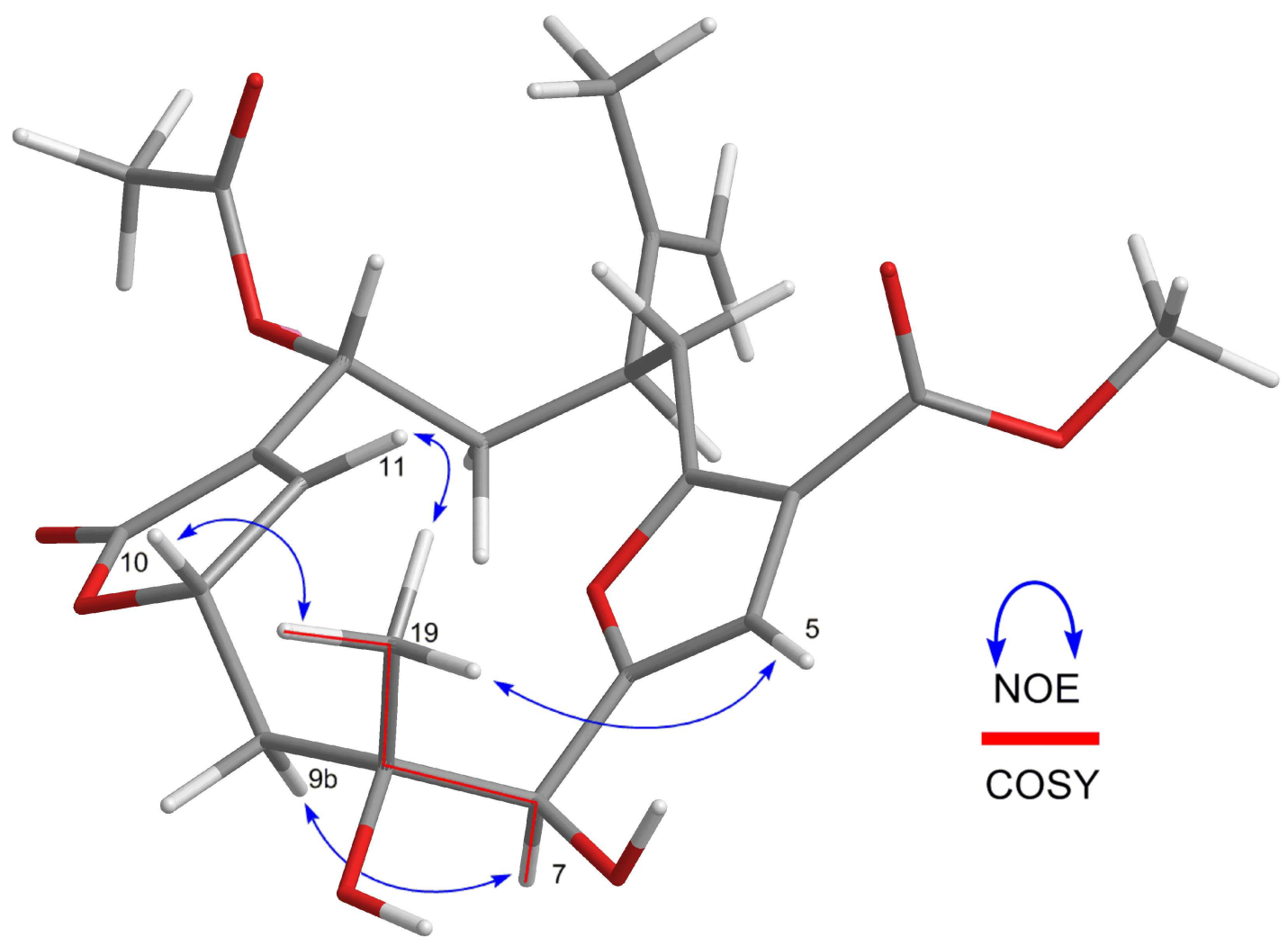

Figure 2.5. Key NOE enhancements of $13 \alpha$-acetoxypukalide diol (30) suggesting the relative configuration of the diol. W-coupling is shown in red.

spectively. The one-bond proton-carbon coupling of $\mathrm{CH}-7$ was $146 \mathrm{~Hz}$, consistent with an oxymethine not in a strained ring, supporting the presence of a 7,8-diol moiety.

The configuration of the diol was assigned through the use of NOE enhancements and coupling constant considerations. Observed NOE enhancements from $\mathrm{H}_{3}-19$ to $\mathrm{H}-11, \mathrm{H}-10$ and $\mathrm{H}-5$ placed them all in close proximity on the same face of the molecule. H-9b was assigned anti to H-10 because of the large coupling $(11.4 \mathrm{~Hz})$ between them, and was therefore placed on the opposite face of the molecule. An NOE enhancement between H-7 and H-9b therefore positioned H-7 on the opposite face as well, anti to $\mathrm{CH}_{3}-19$. This assignment was supported by the observation of W-coupling in the COSY spectrum between $\mathrm{H}_{3}-19$ and $\mathrm{H}-7$, as depicted in Figure 2.5.

As a result, the configuration of the diol was tentatively assigned as $7 S$ and $8 R$. Although a conformation with a $7 R$ configuration is also consistent with the NOE data, it appears more contrived. A simple examination of a model suggests this is a higher energy conformer and consequently appears unlikely. The structure of $13 \alpha$-acetoxypukalide diol is therefore proposed as $(7 S, 8 R)$-dihydroxydesepoxy-13 $\alpha$-acetoxypukalide (30). Full NMR data are presented in Table 2.1. 
Table 2.1. NMR data (600 MHz, $\mathrm{CDCl}_{3}$ ) for $13 \alpha$-acetoxypukalide diol (30).

\begin{tabular}{|c|c|c|c|c|c|c|c|c|}
\hline pos. & $\begin{array}{c}\delta_{\mathrm{C}} \\
(\mathrm{ppm})\end{array}$ & mult & $J_{\mathrm{CH}}$ & $\begin{array}{c}\delta_{\mathrm{H}} \\
(\mathrm{ppm})\end{array}$ & $\begin{array}{l}\text { mult, } \\
J(\mathrm{~Hz})\end{array}$ & $\mathrm{COSY}$ & $\mathrm{HMBC}$ & NOE \\
\hline 1 & 41.4 & $\mathrm{CH}$ & 128 & 2.31 & $\operatorname{td}(10.8,2.0)$ & $2 \mathrm{a}, 2 \mathrm{~b}, 14 \mathrm{a}, 14 \mathrm{~b}$ & $(15,16)$ & $2 \mathrm{~b}, 2 \mathrm{~b}, 16,17,14 \mathrm{~b}$ \\
\hline $2 \mathrm{a}$ & & & 132 & 3.60 & dd $(15.3,10.8)$ & $1,2 \mathrm{~b}$ & $1,(3), 14$ & \\
\hline $2 \mathrm{~b}$ & 32.1 & $\mathrm{CH}_{2}$ & 128 & 2.75 & $\mathrm{~d}(15.3)$ & $1,2 \mathrm{a},(14 \mathrm{~b})$ & $1,3,4,14,15$ & $1,2 \mathrm{a}, 14 \mathrm{~b}, 16,17$ \\
\hline 3 & 160.6 & $\mathrm{C}$ & - & - & - & - & - & - \\
\hline 4 & 115.7 & C & - & - & - & - & - & - \\
\hline 5 & 108.9 & $\mathrm{CH}$ & 181 & 6.76 & $\mathrm{~s}$ & 7 & $3,4,6$ & 11,19 \\
\hline 6 & 152.3 & $\mathrm{C}$ & - & - & - & - & - & - \\
\hline 7 & 76.0 & $\mathrm{CH}$ & 146 & 4.54 & $\mathrm{~s}$ & 5,19 & $5,6,8,9 \mathrm{a}, 19$ & $9 \mathrm{~b}, 19$ \\
\hline 8 & 73.7 & $\mathrm{C}$ & - & - & - & - & - & - \\
\hline $9 a$ & & & 132 & 2.62 & dd $(14.8,5.6)$ & $9 \mathrm{~b}, 10$ & $7,8,10,11$ & \\
\hline $9 \mathrm{~b}$ & 42.7 & $\mathrm{CH}_{2}$ & 130 & 1.82 & $\mathrm{dd}(14.4,11.4)$ & 91,10 & $7,8,10,(19)$ & \\
\hline 10 & 77.9 & $\mathrm{CH}$ & 151 & 4.95 & $\mathrm{dd}(11.2,5.5)$ & $91,9 b, 11$ & $9,11,12$ & $9 \mathrm{~b}, 11,19$ \\
\hline 11 & 154.5 & $\mathrm{CH}$ & 174 & 6.09 & $\mathrm{~s}$ & 10 & $10,(12), 13,20$ & $5,10,13,19$ \\
\hline 12 & 129.8 & $\mathrm{C}$ & - & - & - & - & - & - \\
\hline 13 & 66.8 & $\mathrm{CH}$ & 150 & 5.51 & $\mathrm{dd}(11.2,5.0)$ & $1,13,14 b$ & $11,12,14,20$ & $1,2 \mathrm{~b}, 11,14 \mathrm{a}, 14 \mathrm{~b}$ \\
\hline $14 \mathrm{a}$ & 362 & & 126 & 1.91 & ddd $(13.1,11.2,5.1)$ & $1,13,14 b$ & $1,2,12,13$ & $2 \mathrm{~b}, 13,14 \mathrm{~b}, 16$ \\
\hline $14 \mathrm{~b}$ & 30.2 & $\mathrm{CH}_{2}$ & 130 & 2.63 & $\operatorname{td}(12.2,3)$ & $1,(2 \mathrm{~b}), 13,14 \mathrm{a}$ & & \\
\hline 15 & 148.7 & $\mathrm{C}$ & - & - & - & - & - & - \\
\hline $16 \mathrm{a}$ & 1107 & & 154 & 4.82 & $\mathrm{~s}$ & & $2,(15), 23$ & \\
\hline $16 \mathrm{~b}$ & 110.7 & $\mathrm{CH}_{2}$ & 154 & 4.81 & br s & & $2,(15), 23$ & \\
\hline 17 & 20.9 & $\mathrm{CH}_{3}$ & 124 & 1.81 & br s & & $1,15,16$ & \\
\hline 18 & 163.8 & $\mathrm{C}$ & - & - & - & - & - & - \\
\hline 19 & 18.8 & $\mathrm{CH}_{3}$ & 126 & 1.42 & $\mathrm{~s}$ & 7 & $7,8,9,(10)$ & $5,10,11$ \\
\hline 20 & 170.0 & $\mathrm{C}^{\circ}$ & - & - & - & - & - & - \\
\hline 21 & 52.0 & $\mathrm{CH}_{3}$ & 148 & 3.88 & $\mathrm{~s}$ & & 18 & \\
\hline 22 & 170.4 & $\mathrm{C}$ & - & - & - & - & - & - \\
\hline 23 & 21.2 & $\mathrm{CH}_{3}$ & 129 & 1.98 & br s & & 22 & \\
\hline
\end{tabular}

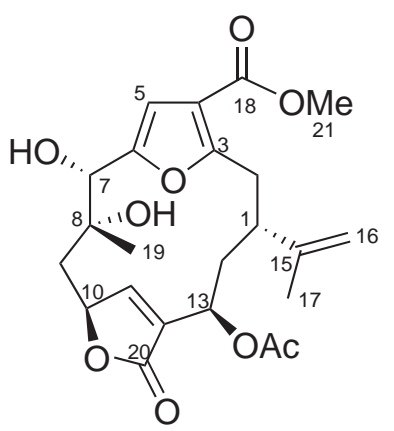

In a similar fashion, the NMR data of diol 31 closely matched those of lopholide (27), with the exception of positions 7 and 8 . Their signals were now found at $\delta_{\mathrm{C}} 73.7, \delta_{\mathrm{H}} 5.21\left({ }^{1} J_{\mathrm{CH}} 148 \mathrm{~Hz}\right)$, and $\delta_{\mathrm{C}} 74.2$ respectively, based on HMBC correlations from $\mathrm{H}_{3}-19$ to $\mathrm{C}-7$ and $\mathrm{C}-8$, once again indicating a diol.

Interestingly, NOE enhancements for 31 suggested a different configuration at position 7 . Figure 2.6 shows the NOE enhancements around the stereocentres in question. Once again, $\mathrm{H}_{3}-19$ showed enhancements to $\mathrm{H}-5$ and $\mathrm{H}-10$, placing those protons on the same face of the molecule. The observation of enhancements between $\mathrm{H}-7$ and $\mathrm{H}-5$ and between $\mathrm{H}-7$ and $\mathrm{H}_{3}-19$ indicated $\mathrm{H}-7$ is pseudo-equatorial (as shown in Figure 2.6), implying an $R$ configuration. No W-coupling between $\mathrm{H}_{3}-19$ and $\mathrm{H}-7$ was observed in the COSY to refute this 


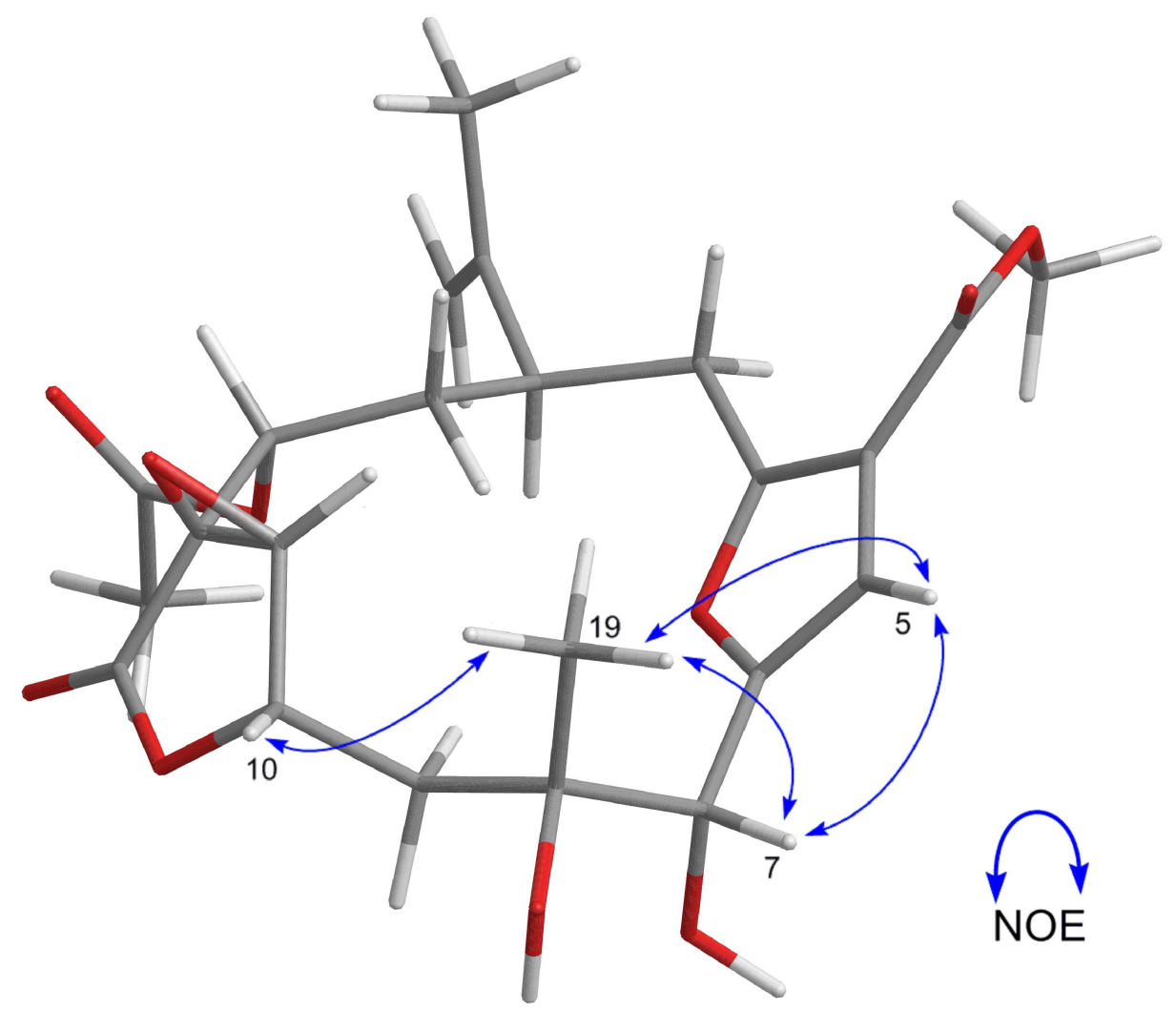

Figure 2.6. Key NOE enhancements of lopholide diol (31) suggesting the relative configuration of the diol.

assignment.

Again, the compound with the opposite (that is $S$ ) configuration at position 7 may satisfy the observed NOE enhancements, but its model appears more forced and it would be expected to exist in a conformation inconsistent with the observed data. Lopholide diol is therefore tentatively assigned as $(7 R, 8 R)$ dihydroxy-desepoxy-lopholide (31); NMR data are shown in Table 2.2.

The similarity of $13 \alpha$-acetoxypukalide (26) and lopholide (27), the major compounds isolated, to the minor new compounds $\mathbf{3 0}$ and $\mathbf{3 1}$ is quite striking. The only difference is the opening of the 7,8-epoxide, a highly strained and reactive functional group. Compounds 26 and 27 were separated from each other on silica gel with the new diol compounds eluting off the column in the more polar fractions. The separation was repeated multiple times on mixtures of 26 and 27, and each time more of the new diol compounds was obtained. As the mixture had already been purified on silica gel, it should not have had any more polar compounds; the presence of the diols $\mathbf{3 0}$ and $\mathbf{3 1}$ suggests they are being generated in situ on the column.

Silica gel has long been known to catalyze a variety of functional group 
Table 2.2. NMR data (600 $\left.\mathrm{MHz}, \mathrm{CDCl}_{3}\right)$ for lopholide diol (31).

\begin{tabular}{|c|c|c|c|c|c|c|c|c|}
\hline pos. & $\begin{array}{c}\delta_{\mathrm{C}} \\
(\mathrm{ppm}) \\
\end{array}$ & mult & $J_{\mathrm{CH}}$ & $\begin{array}{c}\delta_{\mathrm{H}} \\
(\mathrm{ppm})\end{array}$ & $\begin{array}{l}\text { mult, } \\
J(\mathrm{~Hz})\end{array}$ & COSY & $\overline{\mathrm{HMBC}}$ & $\mathrm{NOE}$ \\
\hline 1 & 37.3 & $\mathrm{CH}$ & 127 & 3.31 & br s & $2 \mathrm{a},(2 \mathrm{~b})$ & & 16,17 \\
\hline $2 a$ & 331 & & 130 & 3.07 & $\mathrm{dd}(17,1.8)$ & $1,2 \mathrm{~b}$ & $1,3,4,14,15$ & 16 \\
\hline $2 \mathrm{~b}$ & 33.1 & $\mathrm{H}_{2}$ & 130 & 3.02 & dd $(17,10.8)$ & $(1), 2 \mathrm{a}$ & $(1), 3,(4), 14$ & 16,17 \\
\hline 3 & 160.0 & $\mathrm{C}$ & - & - & - & - & - & - \\
\hline 4 & 115.2 & $\mathrm{C}$ & - & - & - & - & - & - \\
\hline 5 & 109.0 & $\mathrm{CH}$ & 182 & 6.65 & $\mathrm{~s}$ & (7) & $3,4,5,7,18$ & 19 \\
\hline 6 & 152.7 & $\mathrm{C}$ & - & - & - & - & - & - \\
\hline 7 & 73.7 & $\mathrm{CH}$ & 148 & 5.21 & br s & (5) & $(7,8)$ & $9 \mathrm{~b}, 19$ \\
\hline 8 & 74.2 & $\mathrm{C}$ & - & - & - & - & - & - \\
\hline $9 a$ & 410 & & 123 & 1.74 & dd $(14.4,5.9)$ & $9 \mathrm{~b}, 10$ & $7,8,19$ & 10 \\
\hline $9 \mathrm{~b}$ & 41.0 & $\mathrm{H}_{2}$ & 122 & 1.60 & $\mathrm{~m}$ & $9 \mathrm{a}, 10$ & & 7 \\
\hline 10 & 74.6 & $\mathrm{CH}$ & 161 & 4.82 & $\mathrm{dd}(9.2,6.4)$ & $9 \mathrm{a}, 9 \mathrm{~b}$ & $11,12,20$ & $9 \mathrm{a}, 19$ \\
\hline 11 & 63.4 & $\mathrm{CH}$ & & 4.12 & br s & & & \\
\hline 12 & 59.2 & $\mathrm{C}$ & - & - & - & - & - & - \\
\hline 13 & 69.5 & $\mathrm{CH}$ & 148 & 4.96 & dd $(6.4,1.3)$ & $14 \mathrm{a}, 14 \mathrm{~b}$ & $1,12,20,22$ & $14 \mathrm{a}$ \\
\hline $14 \mathrm{a}$ & & & 124 & 2.42 & $\mathrm{~m}$ & $13,14 b$ & & $14 \mathrm{~b}, 16$ \\
\hline $14 \mathrm{~b}$ & 33.2 & $\mathrm{CH}_{2}$ & 122 & 1.73 & $\mathrm{~m}$ & $13,14 \mathrm{a}$ & & $14 \mathrm{a}, 19$ \\
\hline 15 & 147.6 & $\mathrm{C}$ & - & - & - & - & - & - \\
\hline 16 & 111.1 & $\mathrm{CH}_{2}$ & 157 & 4.84 & $\mathrm{~s}$ & 17 & $1,15,17$ & $1,2 \mathrm{a}, 2 \mathrm{~b}, 17$ \\
\hline 17 & 20.9 & $\mathrm{CH}_{3}$ & 126 & 1.83 & $\mathrm{~s}$ & 16 & $1,15,16$ & $1,2 \mathrm{~b}, 14 \mathrm{a}, 16 \mathrm{a}$ \\
\hline 18 & 163.9 & $\mathrm{C}$ & - & - & - & - & - & - \\
\hline 19 & 22.7 & $\mathrm{CH}_{3}$ & 127 & 1.39 & $\mathrm{~s}$ & & $7,8,9$ & $5,7,10,14 \mathrm{~b}$ \\
\hline 20 & 168.8 & $\mathrm{C}$ & - & - & - & - & - & - \\
\hline 21 & 51.7 & $\mathrm{CH}_{3}$ & 148 & 3.80 & $\mathrm{~s}$ & & 4,18 & \\
\hline 22 & 170.6 & $\mathrm{C}$ & - & - & - & - & - & - \\
\hline 23 & 20.8 & $\mathrm{CH}_{3}$ & 129 & 2.07 & $\mathrm{~s}$ & - & - & - \\
\hline
\end{tabular}

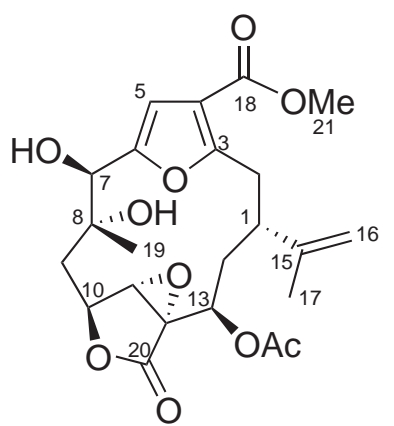

31

transformations, most likely due to water, present in the form of silicic acid, acting as a Brønsted acid catalyst. ${ }^{77}$ It has also been shown to catalyze the opening of epoxide rings, for example in the synthesis of 2 -amino alcohols ${ }^{78}$ and $\beta$-halohydrins. ${ }^{79}$ It therefore may have catalyzed the opening of the 7,8 -epoxide of $13 \alpha$-acetoxypukalide (26) and lopholide (27) during their chromatographic separation, to form the diols $\mathbf{3 0}$ and $\mathbf{3 1 .}$

An $R$ configuration at position 7 for diol 31 represents an inversion of configuration from the parent compound lopholide (27). This is consistent with an $\mathrm{S}_{\mathrm{N}}$ 2-like epoxide opening through nucleophilic attack on the less substituted carbon, lending credence to the assignment. On the other hand, the proposal of a $7 S, 8 R$ configuration for compound $\mathbf{3 0}$ is more difficult to explain mechanisti- 
cally. Position 7 is next to the aromatic furan ring, and may therefore be more susceptible to epimerization, equilibrating to the more stable $S$ configuration for 7,8-dihydroxy-desepoxy-13 $\alpha$-acetoxypukalide (30).

Alternatively, the assigned configurations for positions 7 and 8 may be incorrect, although models of the two compounds $\mathbf{3 0}$ and $\mathbf{3 1}$ seem to fit the NOE data better than any alternatives. The other possibilities are much more contrived; congeners with other configurations and conformations which may fit the observed NOE data appear energetically unfavourable.

\section{Cembranoid diterpenes from octocorals}

Octocorals (phylum Cnidaria, class Anthozoa, subclass Alcyonaria), so called for their eight-fold radial symmetry, are colonial invertebrates which do not have calcium carbonate skeletons and are therefore often termed soft-corals. ${ }^{80}$ They produce a vast range of terpenoid metabolites, the majority of which are macrocyclic diterpenes. Of these, cembranoid diterpenes (based on the cembrane skeleton 32 which is characterized by a 14 -membered ring) are most common. ${ }^{80}$ A significant number have the furanocembranoid skeleton 33, featuring a furan at C-3 to C-6, and often a butenolide moiety at C-10 to C-12. Their chemistry and biology are reviewed by Roethle and Trauner. ${ }^{81}$

Cembranoid diterpenes have also been isolated from plants; a case in point is thunbergol, isolated both from Douglas fir and soft corals. ${ }^{73,76,80,82,83}$ Both diastereomeric pairs have been reported, although $1 S, 4 R$-thunbergol is exclusively terrestrial. ${ }^{83}$

Cembranoid diterpenes have been implicated in a range of biological roles. Experiments have shown that (-)-epi-thunbergol (25) acts as a sperm attractant for the soft coral Lobophytum crassum. ${ }^{83}$ Pukalide (28) and $11 \beta, 12 \beta$-epoxypukalide (29) have been isolated from the eggs of five Sinularia soft corals. ${ }^{84}$ No trace of the compounds was detected in the tissue of the coral itself, suggesting the compounds were synthesized for a specific role in the eggs, such as a chemical release factor for ovulation, or as a defensive toxin. The latter is more likely, as

pukalide was later shown to induce vomiting in fish. ${ }^{85}$

Other furanocembranoids are potent neurotoxins which selectively and irreversibly bind to nicotinic acetylcholine receptors through a covalent interaction with Tyr $^{190}$ in the $\alpha$-subunit. ${ }^{86}$ The first example reported was lophotoxin (34), isolated from sea whips of the genus Lophogorgia by Fenical et al. in $1981 .{ }^{87}$ Since then, structure/activity and molecular modelling studies by Abramson et al. have established a possible pharmacophore: the section from the 7,8-epoxide 


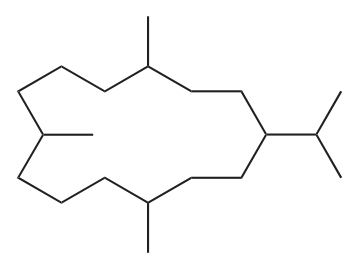

32

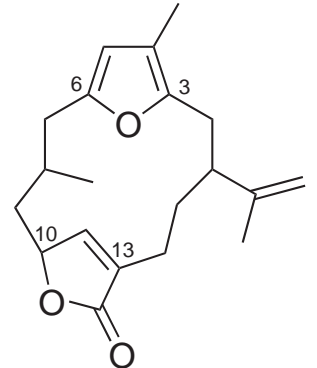

33

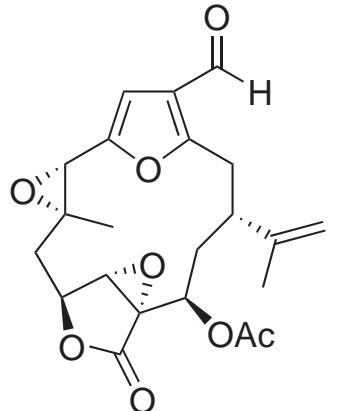

34

to the lactone carbonyl at C-20. The 7,8-epoxide can conceivably provide a site for nucleophilic attack by Tyr ${ }^{190}$. The lophotoxins have aroused interest as they may provide new insights into the mechanism of irreversible inhibition involving $\mathrm{Tyr}^{190}$ and lead to the design of novel irreversible nicotinic acetylcholine receptor antagonists. $^{86}$

\section{Concluding remarks}

The isolation of known octocoral metabolites from the nudibranch T. incerta and the isolation of two of those metabolites from the soft coral Alcyonium aurantiacum is good evidence that the nudibranch sequesters the secondary metabolites of the soft coral. The pukalide-type or lophotoxin family of furanocembranoids are known to be ichthyotoxic or ichthyodeterrent; they most likely serve a similar purpose for T. incerta.

A tentative assignment of the configuration of the 7,8-diols has been made for the two new compounds diol 30 and diol 31, based on observed NOE enhancements. Unfortunately, the flexiblility of such macrocycles can make establishment of configuration unreliable and therefore other diastereomers cannot be unequivocally excluded. 


\subsection{Dendrodoris denisoni}

Dendrodoris denisoni (see Figure 2.7 for taxonomy) is a distinctive nudibranch with a highly convoluted, creamy-brown mantle with raised pustules and smooth, oval-shaped, peacock-blue areas between the folds, as can be seen in Figure 2.8. It has large, very finely branched brown gills and brown rhinophores, and grows up to a maximum size of $70 \mathrm{~mm}$. D. denisoni is found throughout the tropical and warm temperate Indo-West Pacific. In New Zealand (where it is often called D. gemmacea), its range is limited to the northern part of the North Island. Predominantly intertidal, D. denisoni is usually found on semi-sheltered coasts. Little is known about its feeding habits, but for defense it is known to secrete a compound with a distinctive sharp and peppery taste from its mantle. ${ }^{48,69}$

Order Nudibranchia (nudibranchs)

Suborder Doridina (dorids)

Family Chromodorididae

Family Dendrodorididae

Genus Dendrodoris

D. denisoni

Family Dorididae

Family Polyceridae

Suborder Dendronotina (dendronotids)

Suborder Arminina (arminaceans)

Suborder Æolidina (aeolids)

Figure 2.7. Taxonomic classification of D. denisoni, after Rudman. ${ }^{49}$

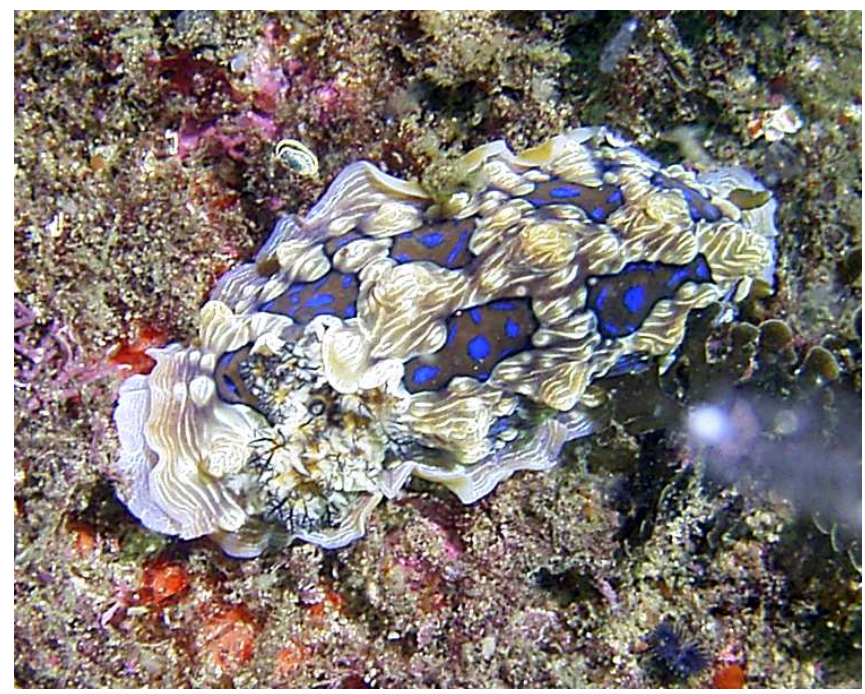

Figure 2.8. Underwater photo of $D$. denisoni (courtesy of Peter Northcote). 


\section{Metabolites isolated from $D$. denisoni}

Two D. denisoni nudibranchs were collected from Rauhomaumau Island, Tutukaka, New Zealand in December 2003. The MeOH extracts were cyclic loaded onto a reversed-phase HP20 column, and eluted with increasing concentrations of $\mathrm{Me}_{2} \mathrm{CO}$ in $\mathrm{H}_{2} \mathrm{O}$. NMR analysis of the resulting fractions revealed that the $70 \%$ $\mathrm{Me}_{2} \mathrm{CO} / \mathrm{H}_{2} \mathrm{O}$ fraction contained predominantly one compound. Subsequent normal phase chromatography on DIOL and silica gel resulted in the isolation of two compounds, the major cinnamolide (35) and the minor dendocarbin A (36).

Examination of the NMR spectra of compound 35 revealed the presence of 15 carbons and 22 protons. The key features were three methyl singlets, a trisubstituted double bond, and an oxymethylene pair of protons appearing as sharp triplets. A series of COSY and HMBC correlations, depicted in Figure 2.9, allowed construction of the structure of the known sesquiterpene cinnamolide (35). Comparison of the NMR data with literature values ${ }^{88,89}$ confirmed the assignment.

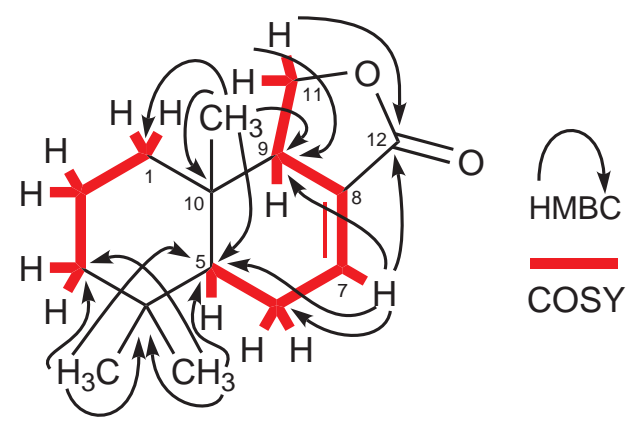

Figure 2.9. Key COSY and HMBC correlations establishing the connectivity of cinnamolide $(\mathbf{3 5})$.

The more polar, minor compound $\mathbf{3 6}$ had very similar NMR characteristics to cinnamolide (35). The main difference was the absence of the two triplets belonging to the oxymethylene at position 11. A new broadened resonance at $\delta_{\mathrm{H}} 5.65$ with a relative integration of one proton was apparent instead, implying a substitution at C-11. A search of the literature and comparison of the NMR data revealed 36 was dendocarbin A. ${ }^{90}$

\section{Drimane sesquiterpenes}

Both 35 and 36 possess the drimane sesquiterpene skeleton, so named after drimenol (37), the first drimane discovered, which was isolated from the bark of Drimys winteri in $1956 .{ }^{91}$ Many drimanes have been isolated from vascular 
plants, ${ }^{91,92}$ and indeed, cinnamolide was first reported from the bark of the Madagascan tree Cinnamosma fragrans. ${ }^{88}$ One rich source of drimanes is the plant Polygonum hydropiper, often known as marsh pepper because of the hot, peppery taste experienced when chewing its leaves. ${ }^{91}$ The peppery qualities of this plant (used in Japanese cuisine and as a pepper substitute in other regions) have been traced to several drimanic aldehydes such as polygodial (38). Their role in the plant is thought to be antifeedant and insect repellant. ${ }^{91,92}$

Drimanes are also common metabolites of sponges of the genus Dysidea, and have been isolated from several dorid nudibranch species. ${ }^{92}$ For example, the Japanese dorid Dendrodoris carbunculosa was found to contain a series of drimane metabolites: isodrimeninol (39), first isolated from the seeds of P. hydropiper, and the new dendocarbins $\mathrm{A}-\mathrm{N}(\mathbf{3 6}, \mathbf{4 0}-\mathbf{5 2}) .{ }^{90}$

D. carbunculosa is described as having a "bitter and sharp peppery taste," and Sakio et al. report that 39, the major sesquiterpene isolated from the nudibranch, also has a sharp peppery taste. ${ }^{90}$ The reports of a peppery taste of the nudibranch $D$. denisoni is therefore most likely due to its major drimane constituent, cinnamolide (35). This hypothesis, however, was not tested in our laboratory.

Drimanes are typical sponge metabolites suggesting a dietary origin of these compounds in the nudibranchs. ${ }^{92}$ Biosynthetic experiments on several dorid species, however, have unambiguously demonstrated that they are capable of de novo biosynthesis of drimanes. The first such experiments, by Cimino et al. in 1982, involved the nudibranch Dendrodoris limbata, injected with carbon-14 labelled mevalonic acid. Subsequent extraction of D. limbata led to the isolation of radiolabelled polygodial (38), proving the nudibranch elaborates its own chemical defense. ${ }^{52}$

\section{Concluding remarks}

Many reports have implicated drimane sesquiterpenes as a chemical marker present in all Dendrodoris species. ${ }^{53}$ Researchers have also demonstrated de novo biosynthesis of a number of drimanes found in Dendrodoris nudibranchs. This may mean that all drimanes produced by Dendrodoris nudibranchs, including cinnamolide (35) and dendocarbin A (36), are biosynthesised rather than sequestered from their diet.

The ability to synthesize their own metabolites rather than relying on dietary sources is an evolutionary adaptation observed in multiple nudibranch species. ${ }^{51}$ It is not limited to drimanes but includes the de novo biosynthe- 
<smiles>[R]C1OC(=O)C2=CC[C@H]3[C@@H](C)CCC[C@]3(C)[C@@H]21</smiles>

$35 \mathrm{R}=\mathrm{H}$

$36 \mathrm{R}=\mathrm{OH}$<smiles>CC1(C)CCC[C@]2(C)[C@H]3C(=CC[C@@H]12)CO[C@H]3O</smiles>

39<smiles>C[C@H]1CCC[C@]2(C)C3[C@H](O)OC(=O)[C@@]3(O)CC[C@@H]12</smiles>

42<smiles>[R6]C1OC(=O)C2=C1[C@]1(C)CCC[C@H](C)[C@H]1C[C@H]2O</smiles>

$48 \mathrm{R}=\mathrm{Et}$

$50 \mathrm{R}=\mathrm{H}$<smiles>CC1=CC[C@H]2[C@@H](C)CCC[C@]2(C)[C@H]1CO</smiles>

37<smiles>CC1(C)C[C@@H](O)C[C@]2(C)C3C(=O)OCC3=CC[C@H]12</smiles>

40

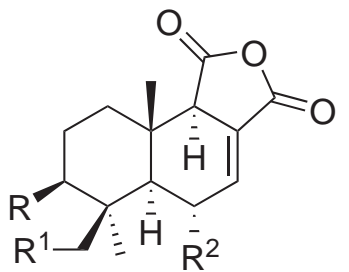<smiles>CCO[C@@H]1OC(=O)C2=C1[C@@H](O)C[C@H]1[C@@H](C)CCC[C@@]21C</smiles>

$43 \mathrm{R}=\mathrm{OH} \quad \mathrm{R}^{1}=\mathrm{R}^{2}=\mathrm{H}$

$44 \mathrm{R}=\mathrm{R}^{2}=\mathrm{H} \quad \mathrm{R}^{1}=\mathrm{OH}$

$45 \mathrm{R}=\mathrm{R}^{1}=\mathrm{H} \quad \mathrm{R}^{2}=\mathrm{OH}$

$46 \mathrm{R}=\mathrm{R}^{1}=\mathrm{R}^{2}=\mathrm{H}$

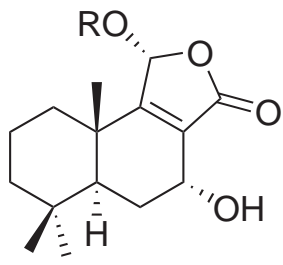

$49 \mathrm{R}=\mathrm{Et}$

$51 \mathrm{R}=\mathrm{H}$<smiles>C[C@H]1CCC[C@@]2(C)[C@H]1[C@@H](O)C[C@@]1(O)CO[C@@H](O)[C@@H]12</smiles><smiles>C[C@H]1CCC[C@]2(C)[C@@H](C=O)C(C=O)=CC[C@H]12</smiles>

38

$\mathrm{HO}$,<smiles>C[C@H]1CCC[C@@]2(C)C3COCC3=C[C@H](O)[C@@H]12</smiles>

41

52

sis of unusual lactones of prostaglandins, various terpenoid skeletons and some polyketide metabolites. ${ }^{53}$ This "emancipation" from their food source allows nudibranchs with biosynthetic capability to exploit other, chemically undefended, prey. ${ }^{51}$ However, "the advantage of not being dependent on specific food sources for defensive metabolites is balanced against the need to maintain a complex biosynthetic mechanism." 93 


\subsection{Aphelodoris luctuosa}

A narrow and elongated nudibranch, Aphelodoris luctuosa (see Figure 2.10 for taxonomy) is ornamented with chocolate-brown radial bands, streaked concentrically with irregular black lines. Its gills and rhinophores are brown and edged with yellow, as can be seen in Figure 2.11. A. luctuosa is found throughout New Zealand, and is probably the most common subtidal dorid found around Northland's east coast. Usually seen in open and semi-sheltered rocky environments, the nudibranch can be found as far down as $40 \mathrm{~m}$, unusually deep for a dorid. Growing up to $75 \mathrm{~mm}$ in size, it can show considerable colour variation, including a cream and white form from Stewart Island. ${ }^{48,69}$

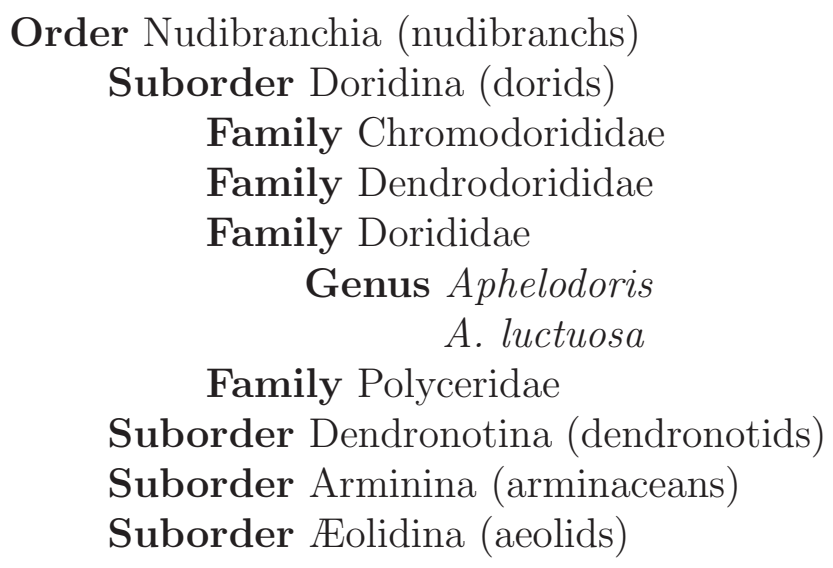

Figure 2.10. Taxonomic classification of A. luctuosa, after Rudman. ${ }^{49}$

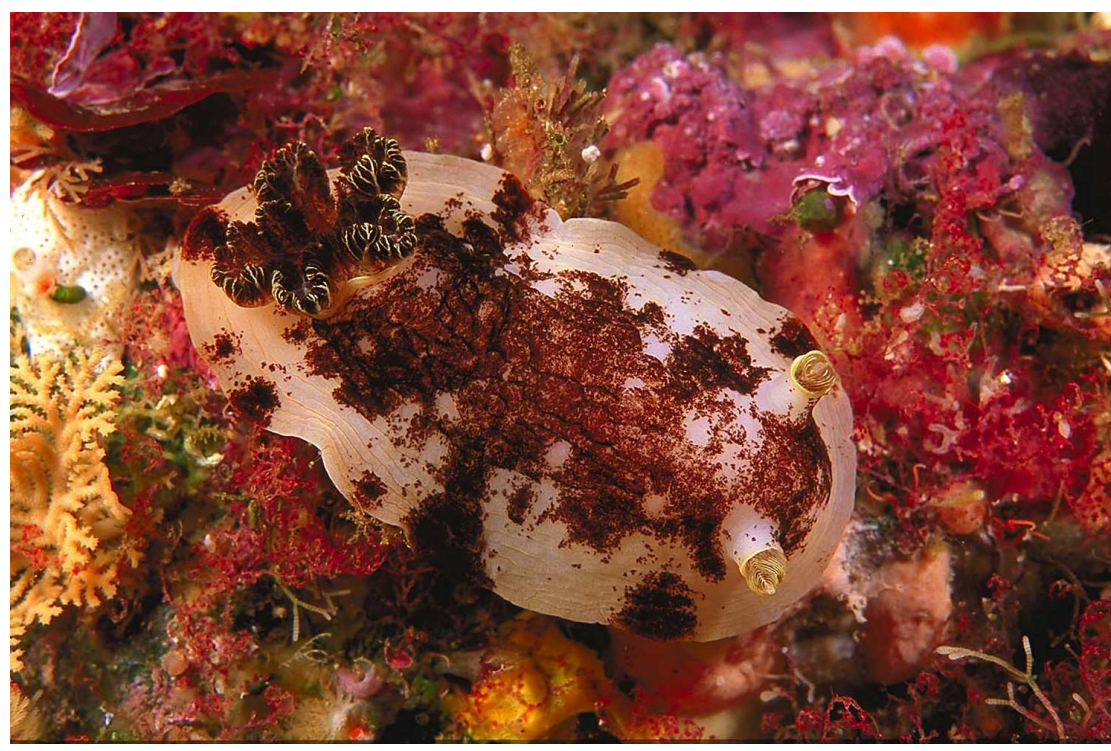

Figure 2.11. Underwater photo of A. luctuosa (courtesy of Ian Skipworth). 

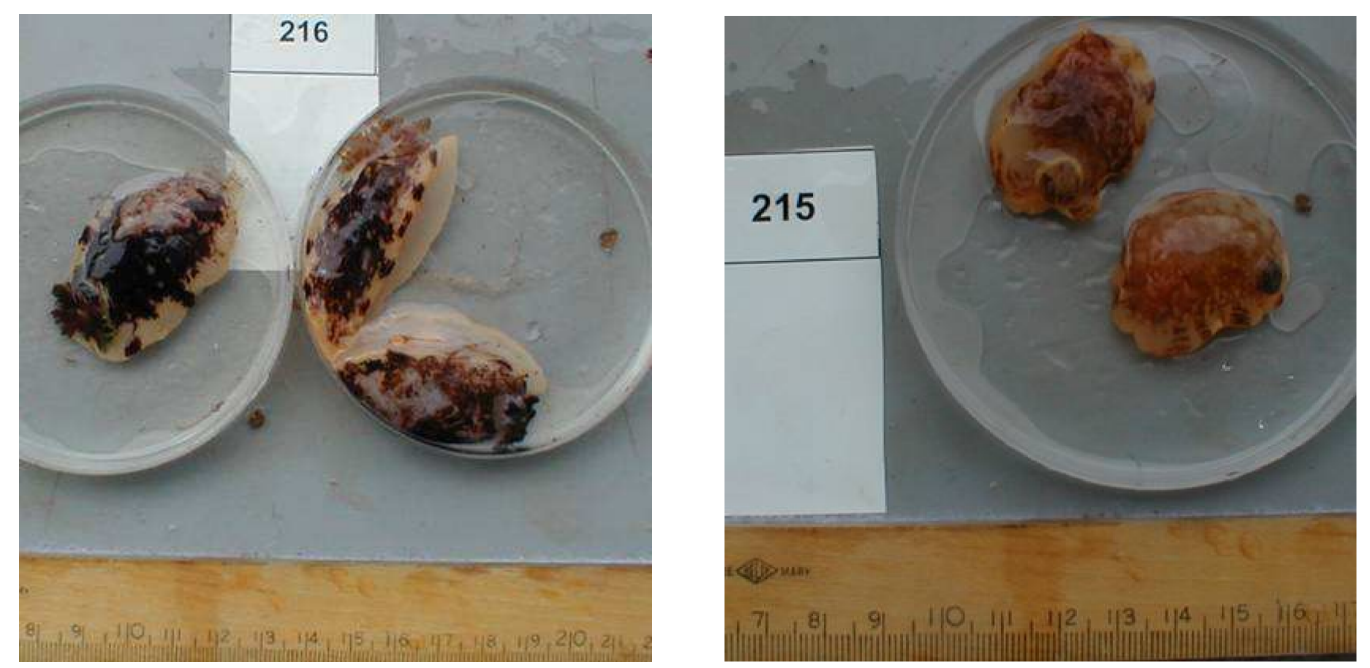

Figure 2.12. Two different colour morphs of A. luctuosa. Photos courtesy of Peter Northcote.

\section{Metabolite isolated from A. luctuosa}

Six nudibranchs identified as A. luctuosa were collected off the northern coast of the North Island of New Zealand in December, 2003. Five similar but lightercoloured individuals were also collected at the same time. The two collections of nudibranchs (shown in Figure 2.12), initially thought to be different species, were extracted separately in $\mathrm{MeOH}$, and the extracts cyclic loaded onto reversedphase HP20. The columns were eluted with increasing concentrations of $\mathrm{Me}_{2} \mathrm{CO}$ in $\mathrm{H}_{2} \mathrm{O}$. The $30 \% \mathrm{Me}_{2} \mathrm{CO} / \mathrm{H}_{2} \mathrm{O}$ fractions showed some unusual characteristics: half of the mass eluted from the column was contained in these fractions (5-25\% is more usual) and the fractions were water soluble, whereas usually the $30 \%$ fraction is a mixture of compounds that do not dissolve fully in any solvent.

The NMR spectra of the $30 \%$ fractions was identical for both the dark and light coloured nudibranchs, confirming that they were colour morphs of the same species. ${ }^{1} \mathrm{H}$ NMR revealed the presence of one major compound, with four signals in the aromatic/heteroaromatic region $\left(\delta_{\mathrm{H}} 8.00-9.00\right)$, some in the alkyl region, as well as a " $\mathrm{CH}_{2}$ envelope" at $\delta_{\mathrm{H}} 1.29$. The major signals were all broadened, perhaps indicating poor solubility in $\mathrm{CD}_{3} \mathrm{OD}$.

Attempts were made to find suitable silica-gel TLC conditions, but in all cases the compound did not move off the origin. In order to avoid irreversible binding to normal phase packing material, the sample was purified on an LH-20 sizeexclusion column, with $10 \% \mathrm{H}_{2} \mathrm{O} / \mathrm{MeOH}$ as the mobile phase. The compound of interest (53) eluted with the solvent front, indicating it was fully excluded from the pores of the resin and was therefore larger than 4000-5000 Da. 


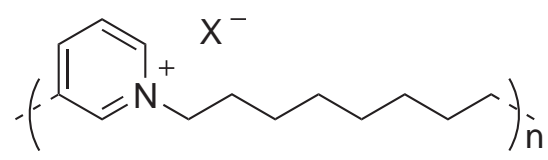

53

Examination of the NMR spectra revealed the presence five aromatic carbons: three methines and one non-protonated carbon. One aromatic methine was a singlet, two were doublets, and one was a triplet; the data were consistent with a 3-substituted pyridine ring, although the ${ }^{1} \mathrm{H}$ and ${ }^{13} \mathrm{C}$ chemical shifts were downfield from normal pyridine. A methylene $\left(\delta_{\mathrm{C}} 33.5, \delta_{\mathrm{H}} 2.88\right)$ showed an HMBC correlation to the non-protonated aromatic carbon, and was therefore placed adjacent to it. A second methylene $\left(\delta_{\mathrm{C}} 62.9, \delta_{\mathrm{H}} 4.63,{ }^{1} J_{\mathrm{CH}} 144 \mathrm{~Hz}\right)$ also showed several HMBC correlations into the aromatic ring. Based on these correlations, its unusual chemical shifts, and high ${ }^{1} J_{\mathrm{CH}}$ coupling constant, the methylene was placed next to the nitrogen establishing a 3-alkyl substituted pyridinium moiety.

A review of the literature (see below) revealed that several 3-alkyl pyridinium salts have been reported from marine sponges, all with long alkyl chains. Indeed, COSY and HMBC correlations from the methylenes attached to the pyridinium ring allowed the construction of a saturated alkyl chain, with both ends showing correlations into the $\mathrm{CH}_{2}$ envelope. As the chromatographic behaviour of $\mathbf{5 3}$ suggested a polymer, the structure was proposed to be 3 -alkyl pyridinium salts linked head to tail with an alkyl chain consisting of eight methylene units (as estimated from the ${ }^{1} \mathrm{H}$ integration ratio).

What appeared to be a minor compound in the sample showed similar NMR characteristics, with five aromatic carbons and several methylenes. The aromatic resonances were shifted upfield from those of the major compound, being in good agreement with a 3-alkyl substituted pyridine rather than a pyridinium salt. This suggested that rather than a separate, minor compound, the 3-alkyl pyridine moiety may in fact be a terminating unit of the polymer. Comparison of the ${ }^{1} \mathrm{H}$ signal integrations suggests a ratio of 17:1 "internal" to "terminal" units, implying an average polymer size of approx. $3200 \mathrm{Da}$, in agreement with the early elution with the solvent front from the LH-20 column.

In addition, several features in the NMR spectra (initally attributed to the "minor" component) suggested the presence of alternate alkyl linking chains, including some with oxygenation (e.g. a methine $\delta_{\mathrm{C}} 80.2, \delta_{\mathrm{H}} 4.62$ ). As no further purification was undertaken, these resonances may still be due to a minor impurity that co-eluted off the LH-20 column. 


\section{Polymeric alkyl-pyridinium salts}

Sponges belonging to the order Haplosclerida are known to contain pyridinium alkaloids, often with potent biological activities. They are all characterized by 3-alkyl pyridinium units, connected via long alkyl chains. Sometimes the alkyl chains show unsaturation, as in the niphatoxins $\mathrm{A}$ and $\mathrm{B}(\mathbf{5 4}, \mathbf{5 5})$, isolated from the sponge Niphates sp. ${ }^{94}$ Cyclic versions have also been isolated, such as the dimeric cyclostellettamines A-F (56-61) reported $^{95}$ from the sponge Stelletta maxima $^{*}$ and the trimeric version of 58, viscosamine (62) ${ }^{97}$ from the Arctic sponge Haliclona viscosa. Most recently, the alkyl pyridinium alkaloid viscosaline (63), with the unusual $\beta$-alanine covalently bonded to one alkyl chain, was also isolated from $H$. viscosa. ${ }^{98}$

Interestingly, the 3-alkyl pyridinium alkaloids are also found as oligomers or polymers, with the 3-alkyl chain bound head to tail to the adjacent pyridinium subunit. The first example isolated was halitoxin (64) from three different $\mathrm{Ha}$ liclona species of sponge. ${ }^{99}$ Halitoxin is proposed to be a complex mixture of molecules of varying sizes, with random variations in the length and structure of the alkyl chains. Membrane ultrafiltration of aqueous solutions was used to purify the toxin and separate it into molecular weight range fractions, from 500 to greater than 25,000 Da. All the different molecular weight fractions exhibited the same cytotoxicity against $\mathrm{KB}$ cancer cells $\left(\mathrm{ED}_{50}=5-7 \mu \mathrm{g} / \mathrm{mL}\right) .{ }^{99}$ The crude sponge extracts also showed toxicity to mice $\left(\mathrm{LD}_{50}=5 \mathrm{mg} / \mathrm{kg}\right)$ and caused haemolysis at a threshold concentration of $1 \mu \mathrm{g} / \mathrm{mL} .{ }^{99}$

Re-examination of one of the Haliclona species by a different research group led to the identification of amphitoxin (65), containing randomly distributed 3-alkyl and 3-alkenyl pyridinium units in an approximate ratio of 1:1. ${ }^{100}$ The compound deterred feeding by the bluehead wrasse, a common predatory fish, strongly suggesting amphitoxin plays a defensive role. ${ }^{100}$

A similar polymer or oligomer (66) (with unbranched alkyl chains) was isolated from the sponge Callyspongia fibrosa through bioassay-guided fractionation on LH-20, followed by centrifugal countercurrent chromatography. ${ }^{101}$ The structure of $\mathbf{6 6}$ was initially proposed to be a cyclic, dimeric, structure on the basis of ion-spray MS and the absence of any terminal groups in the NMR spectra. Subsequent synthesis of the dimer refuted that proposal, and the structure of 66 was reassigned as a polymer or oligomer containing at least eight subunits. ${ }^{101}$

\footnotetext{
*Although S. maxima belongs to the order Astrophorida, subsequent examination of the voucher sample found it to be encrusted by a Haliclona, raising the question of the true origin of the cyclostellettamines. ${ }^{96}$
} 
<smiles>ClCCCCCCCC=CCC=CCc1cccnc1</smiles>

$54 \mathrm{n}=2$

$55 \mathrm{n}=3$

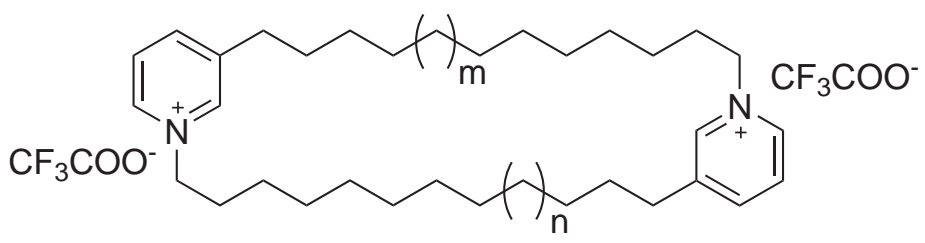

$$
\begin{array}{lll}
\mathbf{5 6} & \mathrm{m}=1 & \mathrm{n}=1 \\
\mathbf{5 7} & \mathrm{m}=1 & \mathrm{n}=2 \\
\mathbf{5 8} & \mathrm{m}=2 & \mathrm{n}=2 \\
\mathbf{5 9} & \mathrm{m}=1 & \mathrm{n}=3 \\
\mathbf{6 0} & \mathrm{m}=2 & \mathrm{n}=3 \\
\mathbf{6 1} & \mathrm{m}=3 & \mathrm{n}=3
\end{array}
$$<smiles></smiles>

62<smiles>[X][n+]1cccc(CCCCCCCCCCCCCNCCC(=O)O)c1</smiles>

63

Compound 66 was a potent $\left(\mathrm{IC}_{50}=2 \mu \mathrm{g} / \mathrm{mL}\right)$ inhibitor of the epidermal growth factor (EGF). As EGF is often overexpressed in carcinomas, EGF inhibitors may therefore be useful as antitumour agents. ${ }^{101}$

More recent research on sponges of the genera Amphimedon* and Reniera* have led to the isolation of $\mathbf{6 4}$ and 66 but with differing molecular weight distributions and different biological activity profiles. ${ }^{96,102}$ As some of the biological activity of the polymeric complexes was found to vary with molecular weight ${ }^{96}$,

${ }^{*}=$ Haliclona 


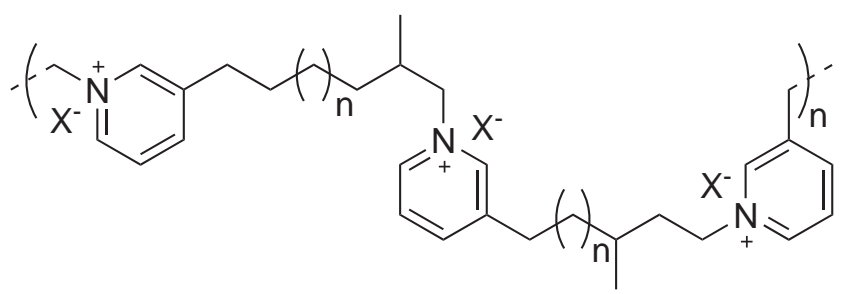

$64 \mathrm{n}=2,3,4,5$<smiles>[X]c1c(CC=CCCCCCC)ccc[n+]1CCCCCCCc1ccc[n+](C)c1</smiles>

65<smiles>CC(C)(C)CCCc1ccc[n+](CCCC(C)(C)C)c1</smiles>

66

researchers believe different extraction procedures result in the isolation of compounds of differing molecular weight and therefore different biological activity. ${ }^{102}$

\section{Concluding remarks}

To the best of our knowledge, this is the first time a polymeric 3-alkyl pyridinium salt has been isolated from a nudibranch species. It has the same basic structure as the polymeric pyridinium alkaloid 66 isolated from the sponge C. fibrosa, ${ }^{101}$ although some subunits may show oxygenation. As these types of compounds are found exclusively from sponges of the order Haplosclerida, the origin of the compound in the nudibranch is most likely dietary. On a subsequent dive trip to the north of the North Island, a search was undertaken for a possible food-source sponge of $A$. luctuosa, unfortunately without success. 


\subsection{Tambja morosa}

Tambja morosa (see Figure 2.13 for taxonomy) is a very dark, usually black, nudibranch that can be found throughout the tropical Western Pacific. The oral veil, foot margin and gill bases are highlighted with royal blue lines, while the highly branched gills are pure black. In the cooler waters of Australia and northern New Zealand, dark green specimens are observed, as shown in Figure 2.14. T. morosa occurs towards the bases of coral reef slopes (at depths of 9-21 m), where it feeds on arborescent bryozoans. ${ }^{48,49}$

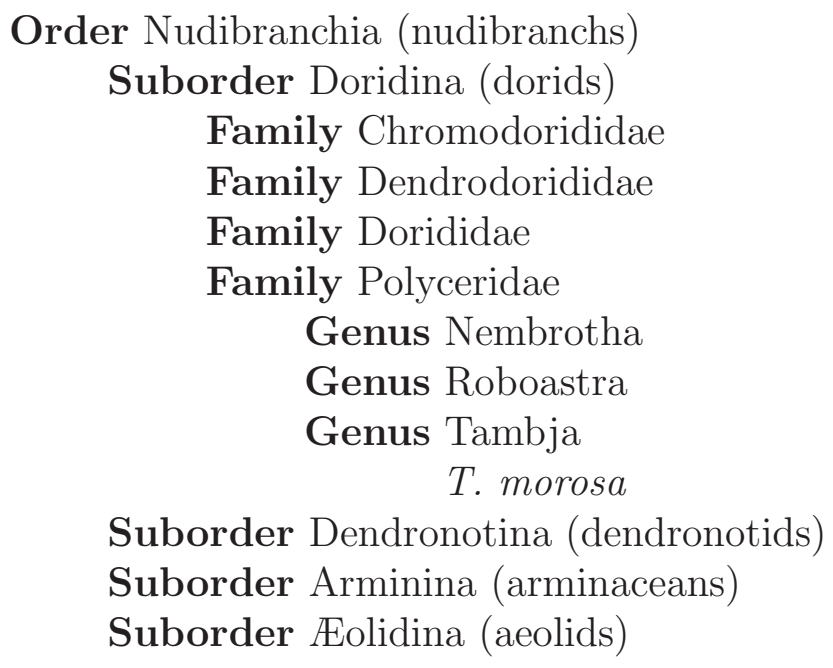

Figure 2.13. Taxonomic classification of T. morosa, after Rudman. ${ }^{49}$

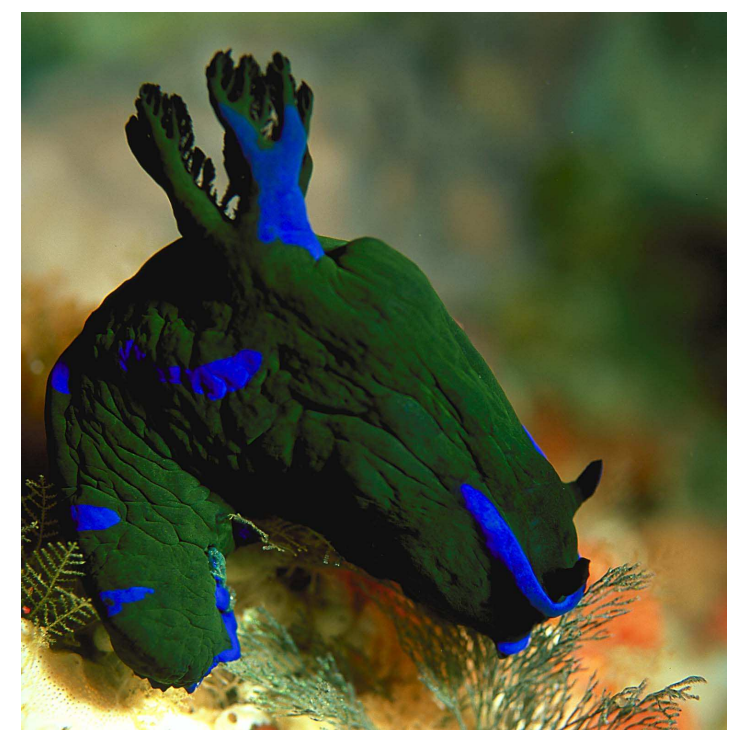

Figure 2.14. Underwater photo of T. morosa (courtesy of Ian Skipworth). 


\section{Metabolite isolated from T. morosa}

Three T. morosa individuals were collected from Rauhomaumau Island, Tutukaka, New Zealand in December 2003. They were extracted in $\mathrm{MeOH}$, and the extract cyclic loaded onto a reversed-phase HP20 column, which was then eluted with increasing concentrations of $\mathrm{Me}_{2} \mathrm{CO}$ in $\mathrm{H}_{2} \mathrm{O}$. The $30 \% \mathrm{Me}_{2} \mathrm{CO} / \mathrm{H}_{2} \mathrm{O}$ fraction, coloured dark green, showed interesting signals in the ${ }^{1} \mathrm{H}$ NMR spectrum and was selected for further analysis.

In preparation for a reversed-phase MPLC column, the sample (approx. $40 \mathrm{mg}$ ) was cyclic loaded onto a small column of HP20SS. While the majority of colour adsorbed onto the column, the eluent remained a bright yellow. It was concentrated under reduced pressure to yield $12 \mathrm{mg}$ of material, a significant portion of the original sample. This suggested that either the column was overloaded, or the material was so polar it preferred the mobile phase over adsorption onto the packing material. Examination of the sample by NMR spectroscopy revealed it was one compound in $>90 \%$ purity. Preliminary analysis of spectra run in $\mathrm{CD}_{3} \mathrm{OD}$ suggested the presence of exchangeable protons; upon changing the solvent to DMSO- $\mathrm{d}_{6}$ four new ${ }^{1} \mathrm{H}$ resonances at $\delta_{\mathrm{H}}>9.5$ became apparent. In addition, five olefinic or aromatic methines and four non-protonated aromatic carbons were present, some with unsual chemical shifts (e.g. $\left.\delta_{\mathrm{C}} 92.2\right)$ indicating highly polarized double bonds.

Clearly, the molecule had an aromatic or heteroaromatic structure. This meant that COSY and HMBC spectra - the most common experiments used for structure elucidation - were of limited utility, as all the ${ }^{1} \mathrm{H}$ resonances showed numerous correlations via long range coupling. Fortunately, as most aromatic systems are planar and quite rigid, NOE enhancements (depicted in Figure 2.15) were instrumental in the elucidation of the structure, proposed to be the bipyrrole alkaloid 67 a.

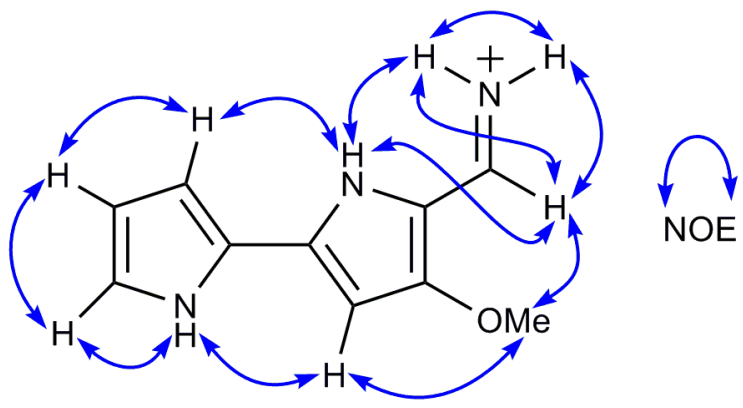

Figure 2.15. NOE enhancements establishing the structure of tambjamine A (67a). 


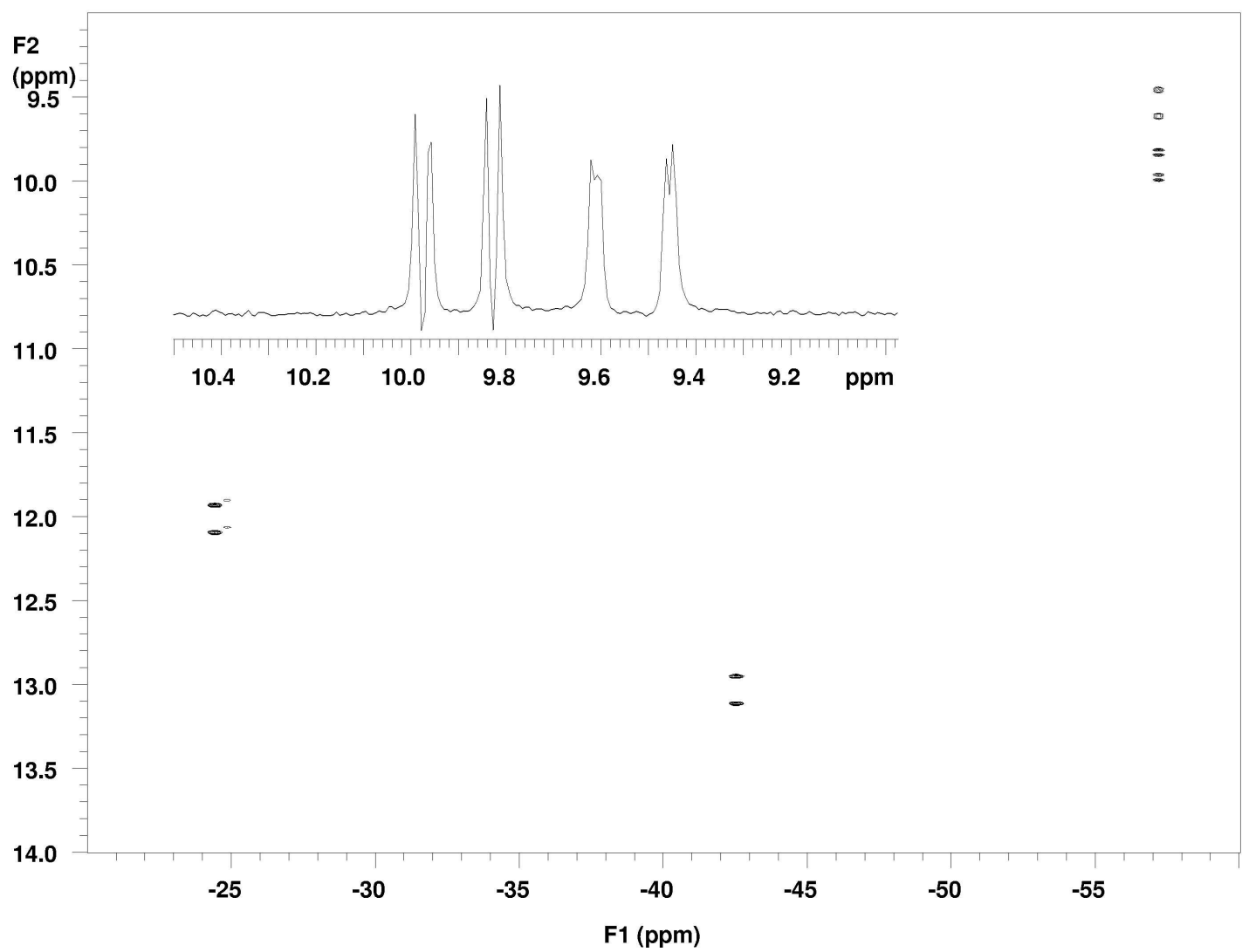

Figure 2.16. Fully coupled ${ }^{1} \mathrm{H}^{-15} \mathrm{~N}$ HSQC of tambjamine A (67a), including a trace through $\mathrm{NH}_{2}-12\left(\delta_{\mathrm{N}}-57.2\right)$ (inset) showing the ${ }^{1} J_{\mathrm{NH}}$ of $\mathrm{H}-12 \mathrm{a}$ and $\mathrm{H}-12 \mathrm{~b}$. Also visible is the cis (small) and trans (large) coupling to H-11.

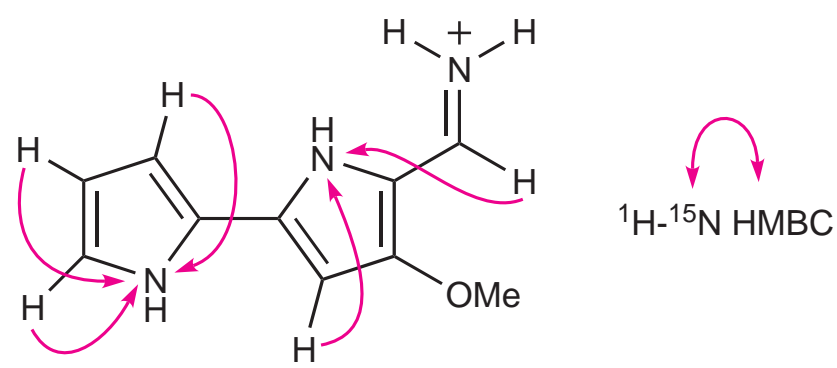

Figure 2.17. ${ }^{1} \mathrm{H}-{ }^{15} \mathrm{~N}$ HMBC correlations of tambjamine A (67a).

In order to unequivocally prove the presence of nitrogens, indirectly detected ${ }^{15} \mathrm{~N}$ NMR experiments (HSQC and HMBC) were run on the sample. ${ }^{1} \mathrm{H}-{ }^{15} \mathrm{~N}$ HSQC experiments (the fully coupled HSQC can be seen in Figure 2.16) proved the presence of at least three nitrogens. A ${ }^{1} \mathrm{H}-{ }^{15} \mathrm{~N}$ HMBC experiment confirmed the placement of the pyrrole nitrogens, through correlations depicted in Figure 2.17.

The proposed structure of $\mathbf{6 7 a}$ (see Table 2.3 for full NMR data) is a charged form of the known compound tambjamine A (67). ${ }^{103}$ Carté and Faulkner report 
that tambjamine $\mathrm{A}$ exists as the more stable enamine tautomer; isolation of 67a suggests that when charged, the imine form is preferred. Clearly, this is an equilibrium process (depicted in Scheme 2.1) that will be $\mathrm{pH}$ dependent. The isolation of the charged form $67 \mathbf{a}$ is most likely due to different extraction and purification protocols.<smiles></smiles>

67<smiles>COc1cc(-c2ccc[nH]2)[nH]c1/C=[NH+]\[NH2+]</smiles>

$67 \mathrm{a}$

Scheme 2.1. Interconversion between tambjamine A (67) and its protonated form $(67 \mathbf{a})$.

Table 2.3. NMR data (600 MHz, $\mathrm{d}_{6}$-DMSO) for tambjamine A (67a).

\begin{tabular}{|c|c|c|c|c|c|c|c|c|}
\hline pos. & $\begin{array}{l}\delta_{\mathrm{C}} / \delta_{\mathrm{N}} \\
(\mathrm{ppm})\end{array}$ & mult & ${ }^{1} J_{\mathrm{XH}}$ & $\begin{array}{c}\delta_{\mathrm{H}} \\
(\mathrm{ppm})\end{array}$ & $\begin{array}{l}\text { mult, } \\
J(\mathrm{~Hz})\end{array}$ & COSY & HMBC & $\mathrm{NOE}$ \\
\hline 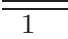 & -24.5 & $\overline{\mathrm{NH}}$ & $\overline{95}$ & $\overline{12.03}$ & $\overline{\text { br s }}$ & $2,3,4$ & & $\overline{22,7}$ \\
\hline 2 & 123.9 & $\mathrm{CH}$ & 191 & 7.08 & $\operatorname{td}(2.6,1.4)$ & 1,3 & 1 & 1,3 \\
\hline 3 & 110.7 & $\mathrm{CH}$ & 174 & 6.24 & $\mathrm{dt}(4.6,2.3)$ & $1,2,4$ & 1 & 2,4 \\
\hline 4 & 111.7 & $\mathrm{CH}$ & 173 & 7.11 & ddd $(3.7,2.5,1.4)$ & 1,3 & $1,4,3,5$ & 3,10 \\
\hline 5 & 122.4 & $\mathrm{qC}$ & - & - & - & - & - & - \\
\hline 6 & 142.2 & $\mathrm{qC}$ & - & - & - & - & - & - \\
\hline 7 & 92.2 & $\mathrm{CH}$ & 182 & 6.58 & $\mathrm{~d}(2.0)$ & 10 & 9,10 & 1,13 \\
\hline 8 & 164.4 & $\mathrm{qC}$ & - & - & - & - & - & - \\
\hline 9 & 111.2 & $\mathrm{qC}$ & - & - & - & - & - & - \\
\hline 10 & -42.6 & NH & 99 & 13.05 & br s & 7 & $7,8,9,11$ & $4,11,12 \mathrm{a}$ \\
\hline 11 & 141.9 & $\mathrm{CH}$ & 192 & 7.78 & dd $(15.8,8.2)$ & $12 \mathrm{a}, 12 \mathrm{~b}$ & $8,9,10$ & $10,12 \mathrm{a}, 12 \mathrm{~b}, 13$ \\
\hline $12 \mathrm{a}$ & & & 90 & 9.92 & $\mathrm{~d}(16.2)$ & $11,12 \mathrm{~b}$ & 9 & $10,11,12 \mathrm{~b}$ \\
\hline $12 \mathrm{~b}$ & -57.2 & $\mathrm{NH}_{2}$ & 96 & 9.55 & $\mathrm{~d}(8.0)$ & $11,12 \mathrm{a}$ & 9 & $11,12 \mathrm{a}$ \\
\hline 13 & 58.9 & $\mathrm{CH}_{3}$ & 149 & 3.89 & $\mathrm{~s}$ & - & - & 7,11 \\
\hline
\end{tabular}<smiles>COc1cc(-c2ccc[nH]2)[nH]c1C=[N+](C)C</smiles>

$67 a$ 


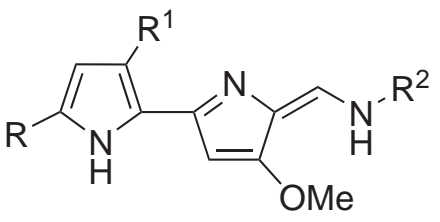

$$
\begin{array}{llll}
\mathbf{6 7} & \mathrm{R}=\mathrm{H} & \mathrm{R}^{1}=\mathrm{H} & \mathrm{R}^{2}=\mathrm{H} \\
\mathbf{6 8} & \mathrm{R}=\mathrm{Br} & \mathrm{R}^{1}=\mathrm{H} & \mathrm{R}^{2}=\mathrm{H} \\
\mathbf{6 9} & \mathrm{R}=\mathrm{H} & \mathrm{R}^{1}=\mathrm{H} & \mathrm{R}^{2}=\mathrm{CH}_{2} \mathrm{CH}\left(\mathrm{CH}_{3}\right)_{2} \\
\mathbf{7 0} & \mathrm{R}=\mathrm{H} & \mathrm{R}^{1}=\mathrm{Br} & \mathrm{R}^{2}=\mathrm{CH}_{2} \mathrm{CH}\left(\mathrm{CH}_{3}\right)_{2} \\
\mathbf{7 2} & \mathrm{R}=\mathrm{H} & \mathrm{R}^{1}=\mathrm{Br} & \mathrm{R}^{2}=\mathrm{CH}_{2} \mathrm{CH}_{3} \\
\mathbf{7 3} & \mathrm{R}=\mathrm{H} & \mathrm{R}^{1}=\mathrm{H} & \mathrm{R}^{2}=\mathrm{CH}_{2} \mathrm{CH}_{2} \mathrm{Ph} \\
\mathbf{7 4} & \mathrm{R}=\mathrm{Br} & \mathrm{R}^{1}=\mathrm{H} & \mathrm{R}^{2}=\mathrm{CH}_{2} \mathrm{CH}_{3} \\
\mathbf{7 5} & \mathrm{R}=\mathrm{Br} & \mathrm{R}^{1}=\mathrm{H} & \mathrm{R}^{2}=\mathrm{CH}_{2} \mathrm{CH}_{2} \mathrm{CH}_{3} \\
\mathbf{7 6} & \mathrm{R}=\mathrm{Br} & \mathrm{R}^{1}=\mathrm{H} & \mathrm{R}^{2}=\mathrm{CH}_{2} \mathrm{CH}\left(\mathrm{CH}_{3}\right)_{2} \\
77 & \mathrm{R}=\mathrm{Br} & \mathrm{R}^{1}=\mathrm{H} & \mathrm{R}^{2}=\mathrm{CH}_{2} \mathrm{CH}\left(\mathrm{CH}_{3}\right) \mathrm{CH}_{2} \mathrm{CH}_{3}
\end{array}
$$

\section{The tambjamine alkaloids}

Tambjamine-type bipyrrole alkaloid pigments have been isolated from bryozoans, ${ }^{103,104}$ nudibranchs, ${ }^{103,105}$ and ascidians. ${ }^{105}$ Tambjamines A-D (67-70) were first isolated from three nudibranch species, Tambja abdere, T. eliora and their predator, Roboastra tigris. ${ }^{103}$ As with most nudibranch compounds, the tambjamines have been traced to a dietary origin: the bryozoan Sessibugula translucens. Tambjamines $\mathrm{C}$ and $\mathrm{D}(\mathbf{6 9}, \mathbf{7 1})$ were isolated from the marine ascidian Atapozoa sp. and its associated nudibranch predators (genus: Nebrotha), together with 67 and 69. ${ }^{105}$ Finally, the marine bryozoan Bugula dentata was found to contain tambjamines E-J (72-77).

The tambjamines are all bipyrroles containing a methoxy group (initially suspected to be an artifact of isolation, but subsequently proven otherwise). They also contain an imine group, enolized to produce an enamine. ${ }^{103}$ Tambjamines C-J (69-77) are $N$-alkyl derivatives, with isobutyl, ethyl, 2-phenylethyl, propyl and 2-methylbutyl residues on the enamine nitrogen. ${ }^{103-105}$

The closest relatives of the tambjamines are the prodigiosin (78) family of alkaloids, tripyrrole metabolites of the bacterium Serratia marcescens. ${ }^{106}$ They bear the same "prodiginine" core, with different alkyl substituents, such as $\mathbf{7 9}$. Also isolated from a mutant strain of $S$. marcenscens was the tetrapyrrole $\mathbf{8 0}$, subsequently found in the bryozoan $B$. dentata and two ascidians. ${ }^{105,107,108}$ The finding of compounds so similar to the tambjamines in bacterial strains suggests a microbial origin for these metabolites. This is further supported by the isolation of two tambjamine-like analogues $\mathbf{8 1}$ (from a marine bacterium) ${ }^{109}$ and $\mathbf{8 2}$ (from 


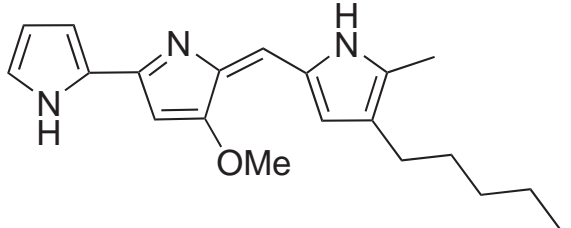

78

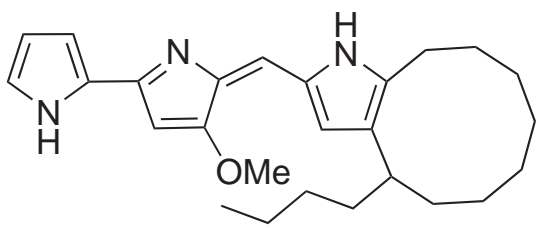

79<smiles>COC1=CC(c2ccc[nH]2)=[NH+]/C1=C/c1[nH]c(-c2ccc[nH]2)cc1OC</smiles>

80<smiles>CCCCCCCCCCCCN/C=C1/N=C(c2ccc[nH]2)C=C1OC</smiles>

81<smiles>CCCCCCCC/C=C/CCN/C=C1/N=C(c2ccc[nH]2)C=C1OC</smiles>

82

a streptomycete), ${ }^{110}$ both with long alkyl chain enamine substituents.

The role of the tambjamines is thought to be a chemical defense mechanism against predators. When threatened, the nudibranch T. abdere exudes a mucous containing high quantities of the tambjamines. This slime is distasteful enough to deter most predators, although the specialist predator $R$. tigris can often breach this defense mechanism, even using the slime trail to track its preferred prey. ${ }^{103,111}$

The prodigiosins show a broad range of biological activity, including the ability to cleave DNA under oxidative conditions. ${ }^{106}$ While the tambjamines are less potent, they still show appreciable cytotoxicity, ${ }^{104}$ antimicrobial ${ }^{103}$ and antitumour activity. ${ }^{110}$

\section{Concluding remarks}

The tambjamine class of pyrrole alkaloids has been found in ascidians, bryozoa, nudibranchs that feed on them, and Roboastra tigris that in turn preys on the nudibranchs. The isolation of similar compounds from bacteria suggests the ultimate source of the tambjamines may in fact be microbial. 
As with other members of the genus, T. morosa was found to contain tambjamine A (67), although isolated as the charged imine tautomer. NOE enhancements and ${ }^{15} \mathrm{~N}$ NMR spectroscopy were crucial to the identification of the structure.

Nitrogen is an important element in natural products chemistry, appearing in alkaloids, peptides and other nitrogenous molecules. Unfortunately the low natural abundance $(0.37 \%)$ and low gyromagnetic ratio of ${ }^{15} \mathrm{~N}$ make it an insensitive nuclide to employ as a structural probe. ${ }^{112}$ Inverse-detected methods that use the ${ }^{1} \mathrm{H}$ nucleus for the excitation and detection of the NMR signal can overcome this difficulty. ${ }^{113}$ The ability to probe another nuclide can be very useful, especially in heteroaromatic systems where long range ${ }^{1} \mathrm{H}-{ }^{1} \mathrm{H}$ and ${ }^{1} \mathrm{H}-{ }^{13} \mathrm{C}$ coupling can make structure elucidation difficult. 


\subsection{Ceratosoma amoenum}

Ceratosoma amoenum (see Figure 2.18 for taxonomy) is a nudibranch of distinctly gaudy colouration: a pale mantle with vivid orange and vermilion spots, with the gills and rhinophores highlighted in magenta. The colour patterns are unique and can be used to identify individuals. The vermilion spots tend to be absent and the orange ones larger in New Zealand individuals (see Figure 2.19). The nudibranch is found only in open, rocky situations, as it is intolerant of silt. Its range extends from the northern half of New Zealand to temperate southern and south-eastern Australia, at depths of 0-40 m. C. amoenum can grow up to $60 \mathrm{~mm}$ in size, but $25-30 \mathrm{~mm}$ is more usual. ${ }^{48,49,69}$

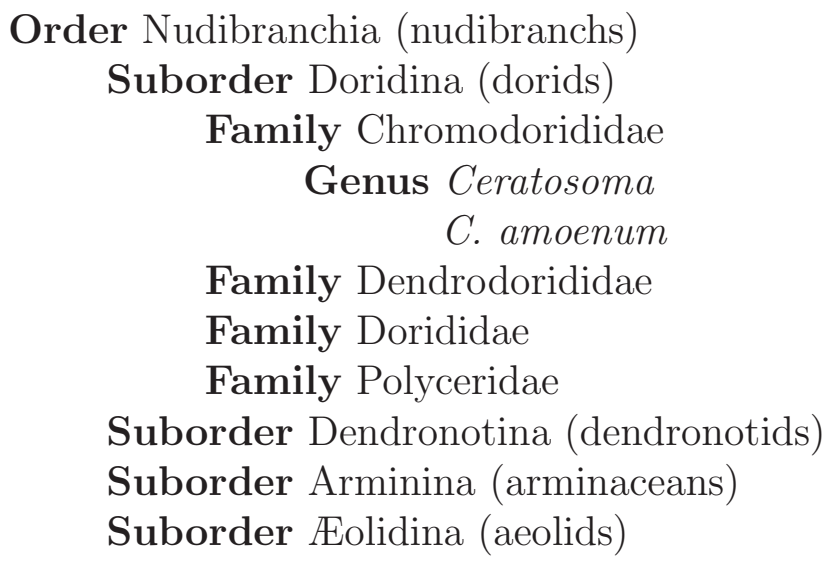

Figure 2.18. Taxonomic classification of C. amoenum, after Rudman. ${ }^{49}$

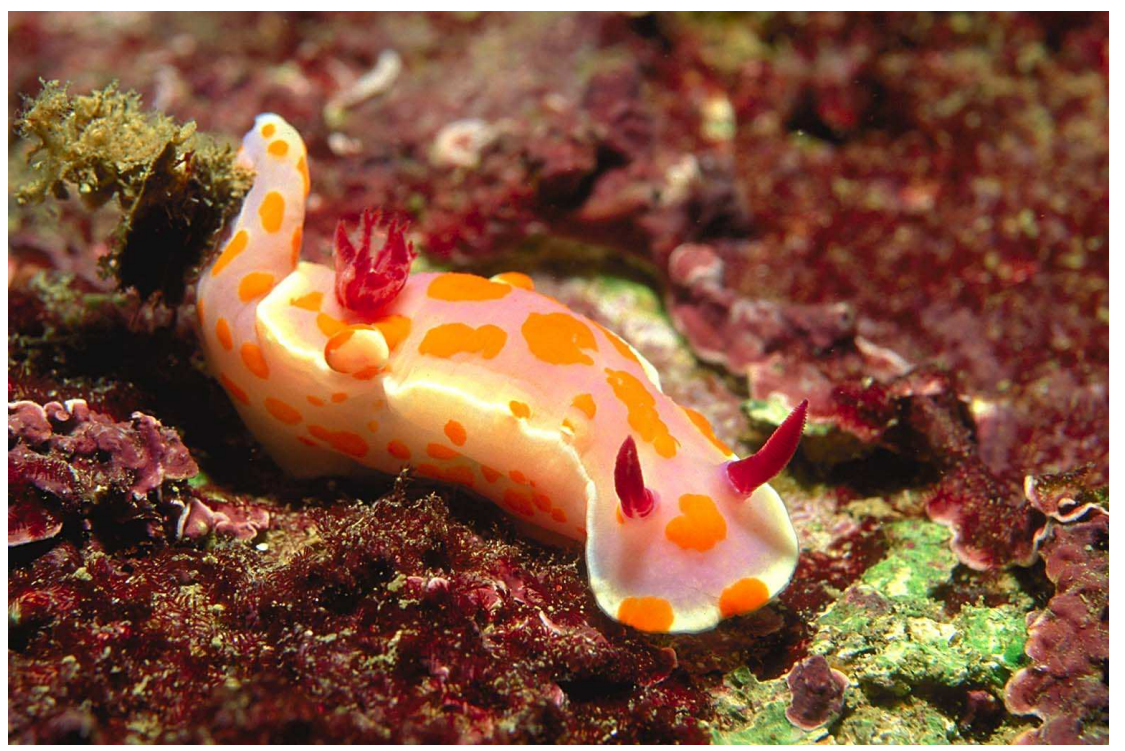

Figure 2.19. Underwater photo of $C$. amoenum (courtesy of Ian Skipworth). 


\section{Metabolites isolated from C. amoenum}

C. amoenum specimens (28 individuals) were collected off the coast of Northland, New Zealand. They were extracted in $\mathrm{MeOH}$, their extracts cyclic loaded onto reversed-phase $\mathrm{HP} 20$ and eluted with increasing concentrations of $\mathrm{Me}_{2} \mathrm{CO} / \mathrm{H}_{2} \mathrm{O}$.

The $100 \% \mathrm{Me}_{2} \mathrm{CO}$ fraction showed the presence of one major compound by NMR spectroscopy and was further purified on normal phase silica gel, yielding furodysinin (83). The $75 \%$ fraction was also subjected to normal phase chromatography (both silica gel and DIOL), resulting in the isolation of $O$-methylfurodysinin lactone (84) and tetradehydrofurospongin-1 (85). Both 83 and 84 have been previously isolated in our lab from a Dysidea sponge, ${ }^{114}$ and were readily identifiable from comparison of NMR data. The compound $\mathbf{8 5}$, however, required de novo structure elucidation.

The key features in the NMR spectra of $\mathbf{8 5}$ were the presence of signals consistent with two 3 -substituted furan rings: four $\alpha$-methine signals $\left(\delta_{\mathrm{C}} 138-140\right.$, $\left.\delta_{\mathrm{H}} 7.2-7.4\right)$ and two $\beta$-methine signals $\left(\delta_{\mathrm{C}} 107-111, \delta_{\mathrm{H}} 6.3-6.5\right)$. Furthermore, two trisubstitued double bonds, one disubstituted double bond, two olefinic methyls, four methylenes and one oxymethine were also apparent.

The COSY spectrum was interpreted cautiously, as many protons exhibited allylic and homoallylic coupling. The HMBC correlations from the two methyls allowed the construction of the two trisubstituted double bonds. They were connected together via the oxymethine and one methylene through COSY correlations from $\mathrm{H}-10$ to $\mathrm{H}-11$, and from $\mathrm{H}-11$ to $\mathrm{H}_{2}-12$. Other COSY correlations placed two methylenes next to $\mathrm{CH}-15$, and the disubstituted double bond next to $\mathrm{CH}_{2}-7$, as depicted in Figure 2.20. These assignments were confirmed by HMBC correlations (not shown).

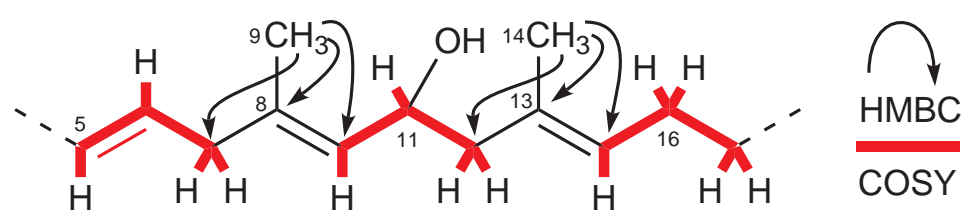

Figure 2.20. Key COSY and HMBC correlations establishing the C5-C17 segment of tetradehydrofurospongin-1 (85).

Using this fragment and the suspected presence of two furan rings, a search of the literature suggested this compound may be (-)-tetradehydrofurospongin-1 (85), first reported from a Hippospongia sp. sponge in 1989 as untenospongin $\mathrm{B},{ }^{115}$ and later renamed. ${ }^{116}$ This was confirmed by comparison of NMR and optical rotation data. 


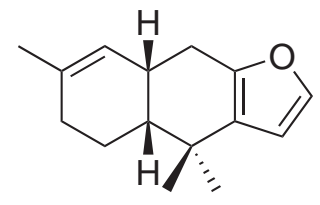

83

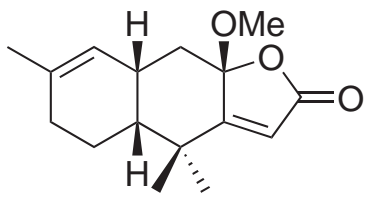

84

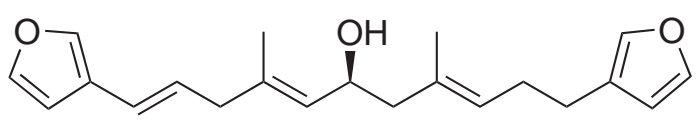

85

\section{The dysin sesquiterpenes}

A series of related compounds belonging to the so-called "dysin" family of sesquiterpenes has been isolated from Dysidea species (family Dysideidae, order Dictyoceratida) and predatory dorid nudibranchs. They are typified by furodysin (86), and the rearranged furodysinin (83), ${ }^{117}$ which was isolated in this study. Interestingly, in addition to various oxygenated derivatives, several sulfur-containing dysin sesquiterpenes have been isolated, such as thiofurodysin acetate (87), thiofurodysinin acetate (88), methylthiofurodysinin (89) and thiofurodysinin (90) from sponges of the genus Dysidea and the nudibranch Ceratosoma brevicaudatum. ${ }^{117-119}$ C. brevicaudatum also contained the unusual dimer dithiofurodysinin disulfide (91), possibly an artifact arising from the oxidative coupling of the free thiol 90 as thiols readily dimerize in air. ${ }^{118}$

Notable variants are the butenolide versions furodysin lactone (92) and furodysinin lactone (93), once again isolated from Dysidea sponges. ${ }^{120,121}$ The $O$ methyl version (84) isolated during this research has also been reported from the nudibranch Chromodoris funerea. ${ }^{122}$ In addition, Carté et al. report that both $\mathbf{9 3}$ and $\mathbf{8 4}$ can be prepared by singlet oxygen oxidation of furodysinin (83). ${ }^{122}$

\section{$\mathrm{C}_{21}$ linear furanoterpenes}

Many sponges of the family Spongiidae (order Dictyoceratida) are characterized by $\mathrm{C}_{21}$ linear furanoterpenes, which have two 3-substituted furan moieties connected by a linear isoprenyl portion. ${ }^{116}$ This is exemplified by the simplest variant anhydrofurospongin (94). ${ }^{123}$ These furanoterpenes usually only show variation in oxygenation or saturation along the linear isoprenyl section. ${ }^{114}$ As terpenes are biosynthesized by the sequential addition of five-carbon isoprenoid units, $\mathrm{C}_{21}$ terpenes are quite unusual; they are most likely derived from degradation of higher terpenoids. ${ }^{116}$ 
<smiles>[R]CC1=C[C@H]2Cc3ccoc3C(C)(C)[C@H]2CC1</smiles>

$86 \mathrm{R}=\mathrm{H}$

$87 \mathrm{R}=\mathrm{SAc}$<smiles>[R]CC1=C[C@H]2Cc3occc3[C@@H](C)[C@]2(C)CC1</smiles>

$83 \mathrm{R}=\mathrm{H}$

$88 \mathrm{R}=\mathrm{SAc}$

$89 \mathrm{R}=\mathrm{SMe}$

$90 \mathrm{R}=\mathrm{SH}$<smiles>C[C@H]1c2ccoc2CC2C=C(CSSCC3=C[C@H]4Cc5occc5C(C)(C)[C@]4(C)CC3)CC[C@H]21</smiles>

91<smiles>CC1=C[C@H]2CC3=CC(=O)O[C@@]3(O)C(C)(C)[C@@H]2CC1</smiles>

92

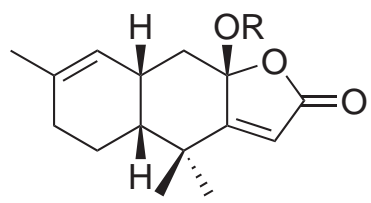

$93 \mathrm{R}=\mathrm{H}$

$84 \mathrm{R}=\mathrm{Me}$<smiles></smiles>

94<smiles>C/C(=C\C(O)CC(C)(O)CCCc1ccoc1)C/C=C/c1ccoc1</smiles>

95<smiles>C/C(=C\[C@H](O)C/C(C)=C/CCc1ccoc1)C/C=C/c1ccoc1</smiles>

96

(-)-Tetradehydrofurospongin-1 (85) was first isolated along with compound 95 from the marine sponge Hippospongia sp.; both were reported to exhibit potent coronary vasodilating activity. ${ }^{115}$ Fontana et al. later isolated the $11 R$ enantiomer of tetradehydrofurospongin-1 (96) from the sponge Spongia virgultosa, solving its absolute configuration using Mosher's method. ${ }^{116}$

\section{Concluding remarks}

Nudibranchs of the family Chromodorididae, as the name suggests, are some of the most colourful. Their gaudy colouring is thought to be a warning to predators of their highly distasteful secretions. ${ }^{69}$ Indeed, several of the dysin 
metabolites show ichthyodeterrent properties. ${ }^{120,122}$ The isolation of these metabolites from both Dysidea sponges and their predatory nudibranchs (and the consistent localization of the compounds in the nudibranch's gut contents ${ }^{124}$ ) imply a dietary origin.

During this study, two dysin metabolites and a linear furanoterpene were isolated from the nudibranch $C$. amoenum. The concurrent presence of a $\mathrm{C}_{21}$ linear furanoterpene (which are most often isolated from sponges of the family Spongiidae) and dysin metabolites (found in Dysidea sponges) in the same nudibranch suggests it may feed on several sponge species from different families. 


\section{Chapter 3}

\section{The Agminosides: Novel Glycolipids from Raspailia agminata}

\subsection{Secondary metabolites reported from the genus Raspailia}

The genus Raspailia, which is characterized by the absence of microsclere spicules, belongs to the family Raspailiidae (order Poecilosclerida). It contains more than one hundred described species, distributed world-wide mainly in shallow waters. ${ }^{43}$ Thirty-nine new compounds have been reported from Raspailia sponges belonging to four major classes: acetylenic glyceryl enol-ethers, cyclic hemi-ketals, adenine-diterpene asmarines, and clerodane diterpenes.

The first Raspailia compounds to be isolated were a series of long-chain glyceryl enol-ethers from two north-east Atlantic sponges, $R$. pumila and R. ramosa in 1986. ${ }^{125,126}$ The enol double bond is conjugated in sequence to both acetylenic and olefinic bonds. These raspailynes, as they are known, can be grouped based on the configuration of their double bonds. Those that have a $(1 Z, 5 Z)$ configuration are raspailynes $\mathrm{A}, \mathrm{A} 1, \mathrm{~B}, \mathrm{~B} 1, \mathrm{~B} 2$ (97-101), and isoraspailynes $\mathrm{A}, \mathrm{B}$ and $\mathrm{B} 1(\mathbf{1 0 2}-\mathbf{1 0 4})$. The $(1 Z, 5 E)$ configuration is present in isoraspailyne $\mathrm{Ba}(\mathbf{1 0 5})$ and B1a (106), while isoraspailyne B1b (107) is (1E,5Z). Compound 100 has also been isolated from the sponge $R$. agminata. ${ }^{127}$ While acetylenic and polyacetylenic metabolites are frequently isolated from sponges, acetylenic glyceryl enol-ethers are relatively rare. ${ }^{128}$

Next to be isolated from a Raspailia sponge were two cyclic hemi-ketals, 

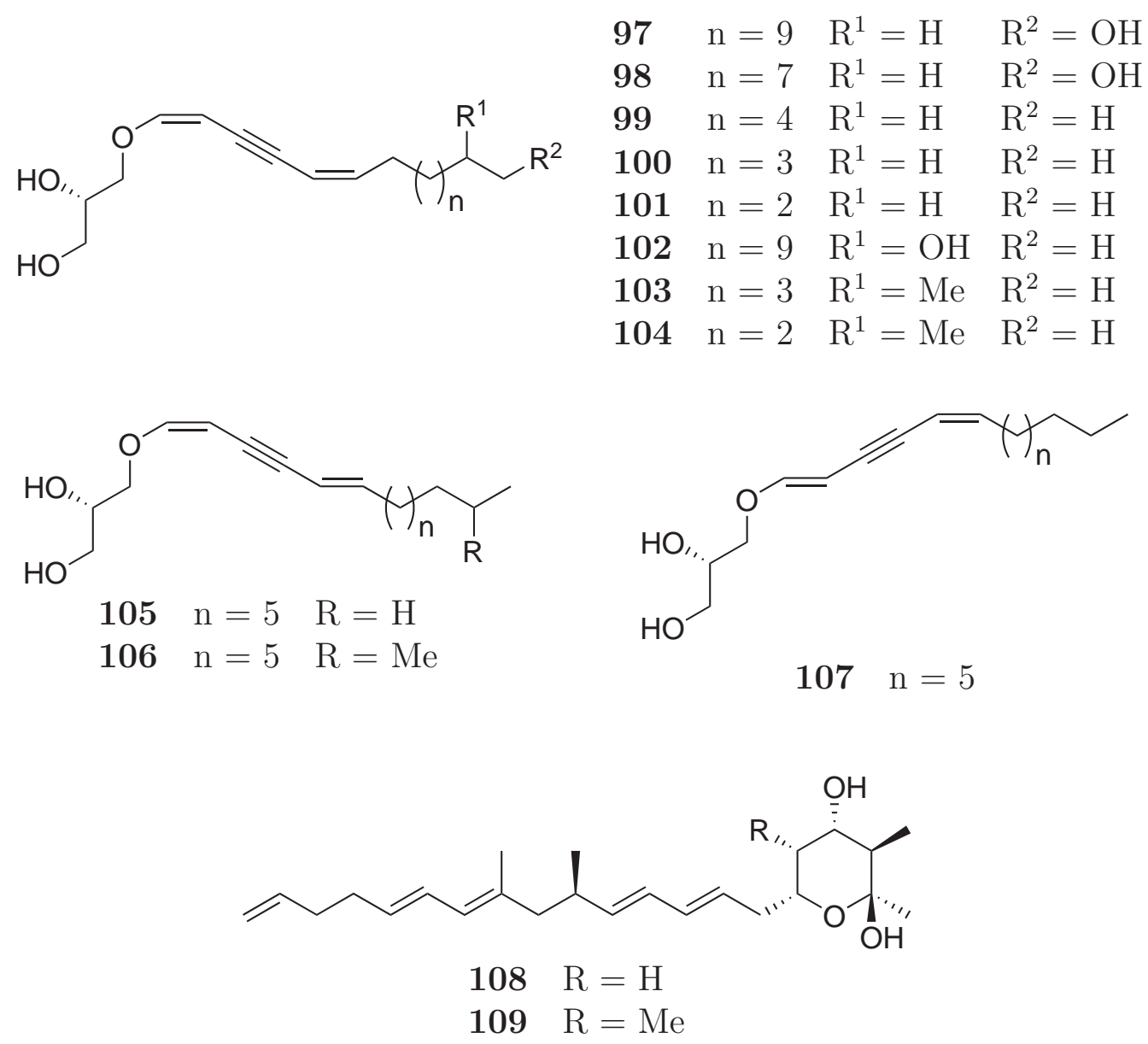

named raspailols A (108) and B (109) from a Palauan sponge of unidentified species. ${ }^{129}$ The absolute configuration of the ring portion was determined by Mosher's method, but the full stereochemical assignment was only accomplished by total synthesis. ${ }^{130}$ Although the crude sponge extract showed mild antibacterial activity, no activity has been reported for the pure compounds.

The asmarines A-K (110-120) are nitrogenous metabolites of mixed biogenesis: clerodane diterpene and adenine. They were isolated by Kashman and coworkers from an undescribed Raspailia species from Eritrea, ${ }^{131,132}$ Kenya ${ }^{133}$ and Madagascar ${ }^{134}$. Two new diterpenes, barekol (121) ${ }^{133}$ and nosyberkol (122) ${ }^{134}$ were also isolated, along with the three known diterpenes chelodane (123), barekoxide (124) and zaatirin (125), previously reported from the sponge Chelonaplysilla erecta, ${ }^{135}$ and a $5 \beta$-cholanic acid derivative, methyl 3-oxo-cholan-24oate (126). ${ }^{132,133}$ Of note is that $\mathbf{1 2 3}$ is the biogenetically appropriate diterpene precursor to form asmarines 110, 113, 114 and 116-119. Two asmarines, 110 and 111, show cytotoxic activity against a number of cell cultures at the micromolar level; while the other asmarines are also active, they are less potent. ${ }^{131,133,134}$ 

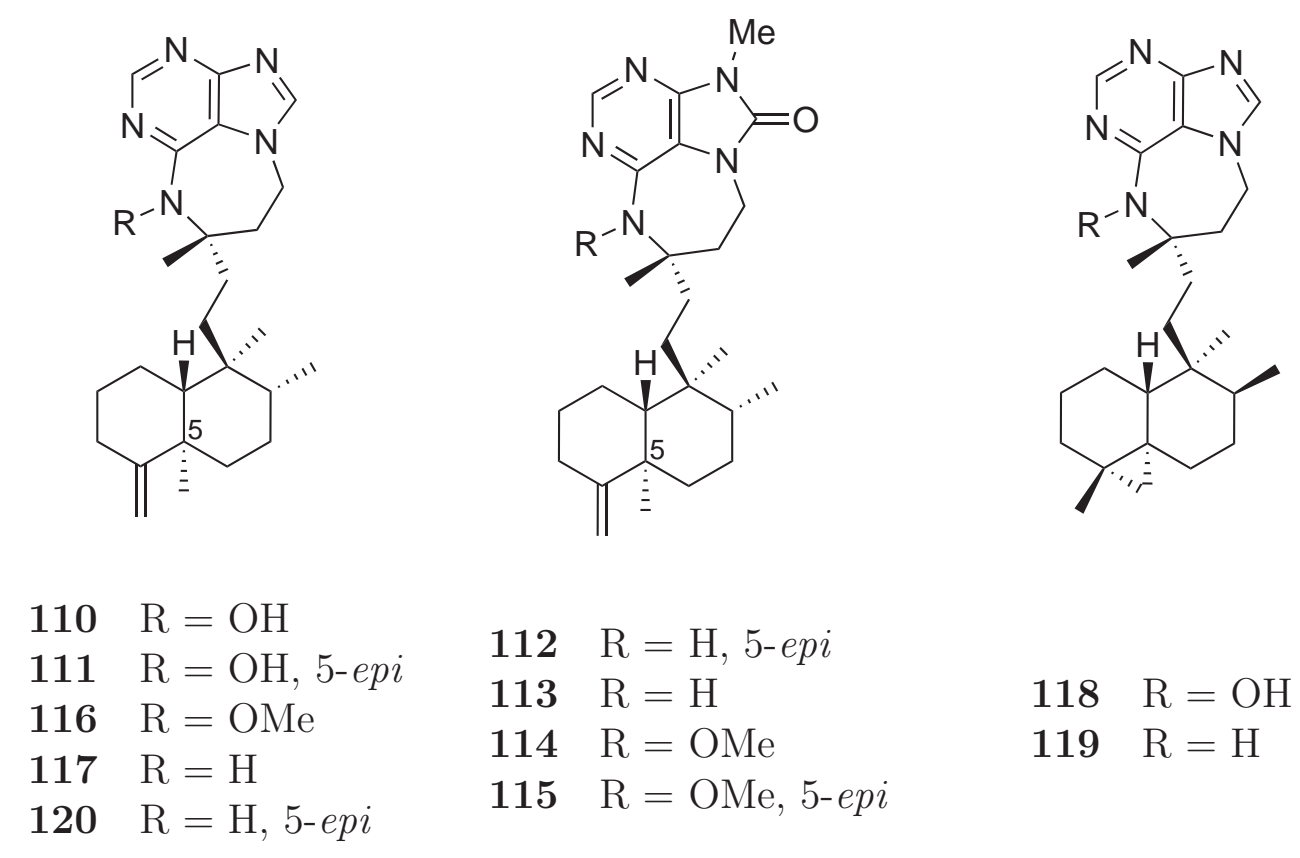

$112 \mathrm{R}=\mathrm{H}$, 5-epi

$113 \mathrm{R}=\mathrm{H}$

$118 \mathrm{R}=\mathrm{OH}$

$114 \mathrm{R}=\mathrm{OMe}$

$115 \mathrm{R}=\mathrm{OMe}, 5-e p i$

$119 \mathrm{R}=\mathrm{H}$

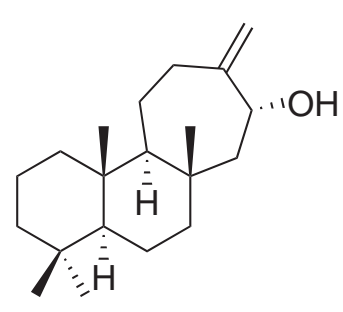

121

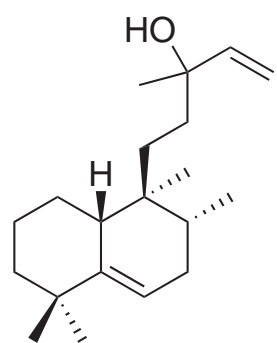

122

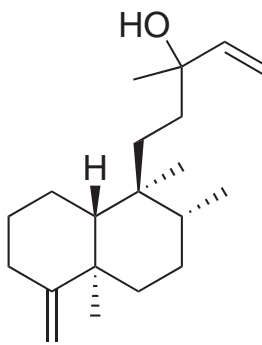

123

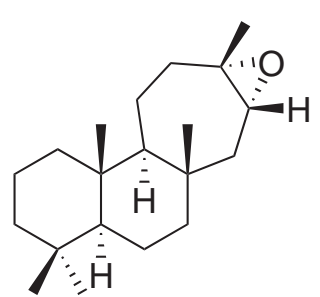

124<smiles>C=C[C@H]1CCC[C@@H](CCC2C(=C)CCCC2(C)C)O1</smiles><smiles>COC(=O)CCC(C)C1CCC2C3CC[C@H]4CC(=O)CC[C@]4(C)C3CC[C@]12C</smiles> 
The New Zealand marine sponge $R$. topsenti is a rich source of secondary metabolites, with 13 clerodane diterpenes isolated to date. ${ }^{127,136-139}$ The first reported were raspailol (127) and raspailenone (128) by West et al. in 1998. ${ }^{136}$ Since then, raspailenone B (129), ${ }^{137}$ raspailodanes A-G $(\mathbf{1 3 0}-\mathbf{1 3 6})^{127,138}$ and topsentanes A (137) and B (138) ${ }^{137}$ have been isolated by our research group. Most recently, another member of this family has been isolated in this lab: a butenolide version of $\mathbf{1 2 7}$, compound 139. ${ }^{139}$ Due to the paucity of material, the configuration of $\mathbf{1 3 9}$ has not been assigned, but is most likely analogous to 127. R. topsenti clearly has more interesting, as yet unidentified metabolites, ${ }^{139}$ although some are proposed to be degradation products. ${ }^{137}$

The majority of clerodanes are isolated from terrestrial plants, ${ }^{140}$ and the few clerodanes of marine origin (for example the asmarines) often have little or no oxygenation, and are of mixed biogenesis. In contrast, the metabolites of $R$. topsenti are highly unusual. They often have high levels of oxygenation, often have the uncommon cis ring fusion (compounds 127-131 and 135), and represent the first 19-norclerodanes (compounds 132-134, 136-138) from the marine environment. Subsequent to their isolation, raspailol (127) and topsentanes A and B $(\mathbf{1 3 7}, \mathbf{1 3 8})$ have been shown to possess anti-inflammatory activity in vitro. ${ }^{127,137}$ The other metabolites were inactive in the same assay.

Capon et al. isolated esmodil (140), an acetylcholine mimic, from a Raspailia sp. sponge. ${ }^{141}$ Esmodil is a known synthetic drug investigated in the early 20th century; the ecological role it plays in the sponge remains unresolved. Also present in the sponge were the known antifungal and cytostatic macrolides phorboxazoles A and B $(\mathbf{1 4 1}, \mathbf{1 4 2})$, previously reported from the marine sponge Phorbas sp. ${ }^{142,143}$ Most recently, during a search for $\alpha$-glucosidase inhibitors (which may be useful for the development of AIDS and diabetes treatments), Saludes et al. report the small molecule inhibitor 1,4-dideoxy-1,4-imino-D-arabinitol (143) from Raspailia sp. and Haliclona sp. ${ }^{144}$

One final compound has been isolated from a Raspailia sponge: okadaic acid (144) from the New Zealand sponge $R$. agminata. ${ }^{145}$ As okadaic acid was also isolated from two other sponge orders from around New Zealand, and is a known dinoflagellate toxin, it is presumably being taken up by filter-feeding sponges exposed to algal blooms, as opposed to being a sponge metabolite. ${ }^{145}$ 


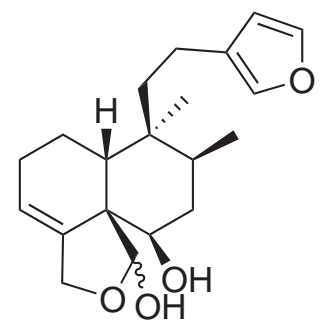

127

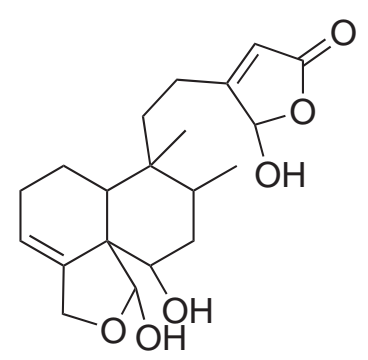

139

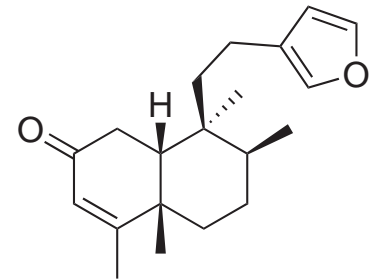

128

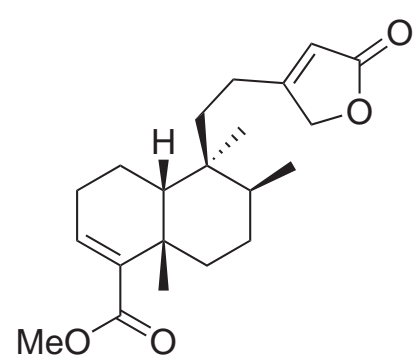

131

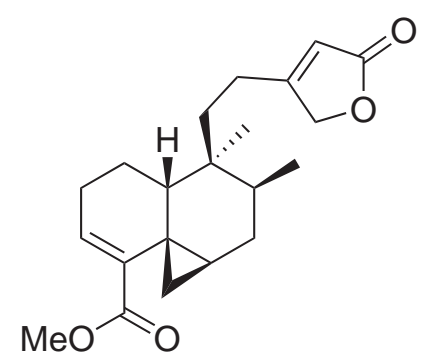

135

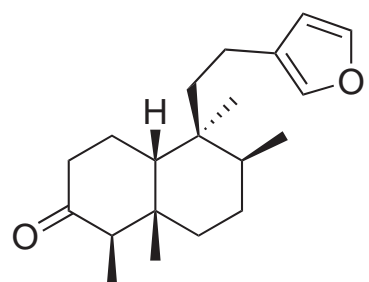

129

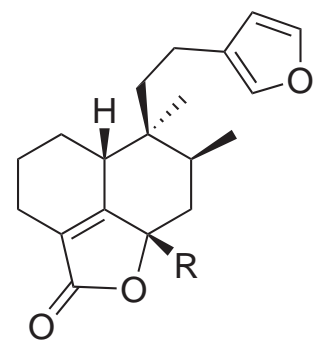

$132 \mathrm{R}=\mathrm{OMe}$

$133 \mathrm{R}=\mathrm{H}$

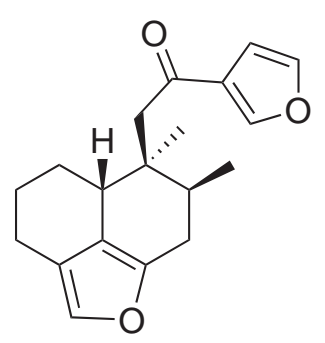

137

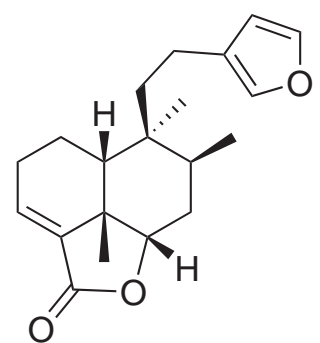

130

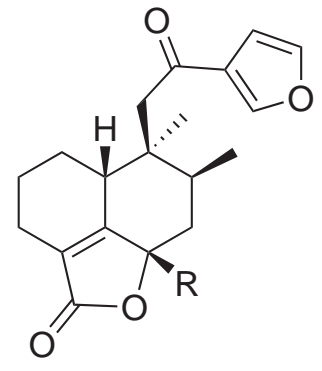

$134 \mathrm{R}=\mathrm{H}$

$136 \mathrm{R}=\mathrm{OMe}$

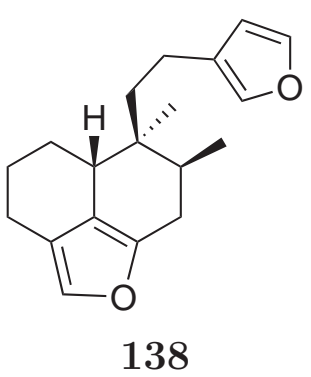


<smiles>[R7]C(=O)O</smiles><smiles></smiles>

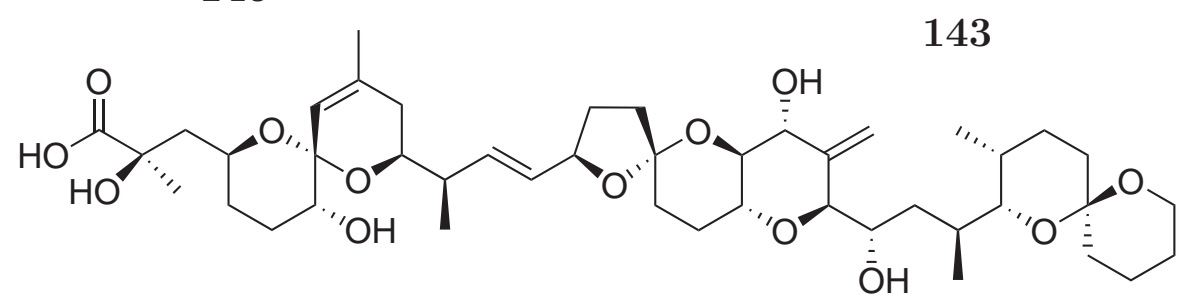

144

\subsection{The agminosides}

Raspailia agminata (see Figure 3.1 for taxonomy) is usually a massive, somewhat conical sponge with several finger-like projections, a thick mat with cone-like projections, or a thick encrustation. It is found throughout New Zealand, usually under rock ledges, low tidal boulders, or on wharf piles, but never exposed to direct sunlight. ${ }^{41}$ Under water it is dark brown with oscules $1.0-2.5 \mathrm{~mm}$ in diameter often situated on the apex of the conical projections ${ }^{41,146}$ as can be seen in Figure 3.2. Its skeleton is composed of megascleres only, with styles and subtylostyles measuring from 500-2500 microns, slender, curved oxeas of 200500 microns and strongly spined acanthostyles 80-190 microns long and up to 12 microns thick. ${ }^{146}$ These can be seen in Figure 3.3.

Apart from the isolation of okadaic acid (144) ${ }^{145}$ and raspailyne B1 (100), ${ }^{127}$ no other metabolites from $R$. agminata have been reported in the literature. The sponge has, however, been successfully grown in an aquaculture trial. ${ }^{147}$

R. agminata had been briefly examined in our lab previously. ${ }^{72}$ As the NMR spectra showed many interesting signals in the oxymethine and acetate region, the sponge was re-examined in an effort to isolate these interesting metabolites. 
Order Poecilosclerida

Suborder Microcionina

Family Microcionidae

Family Acarnidae

Family Raspailiidae

Subamily Raspailiinae

Genus Acanthostylotella

Genus Aulospongus

Genus Ectyoplasia

Genus Endectyon

Genus Eurypon

Genus Hymeraphia

Genus Raspaciona

Genus Raspailia

$R$. typica (type sp.)

$R$. agminata

Genus Raspailopsis

Genus Rhabdeurypon

Genus Trachostylea

Subfamily Thrinacophorinae

Subamily Plocamioninae

Subamily Echinodictyinae

Subamily Cyamoninae

Family Rhabdermiidae

Suborder Myxillina

Suborder Mycalina

Suborder Latrunculina

Figure 3.1. Taxonomic classification of $R$. agminata, after Hooper and van Soest. ${ }^{43}$ 


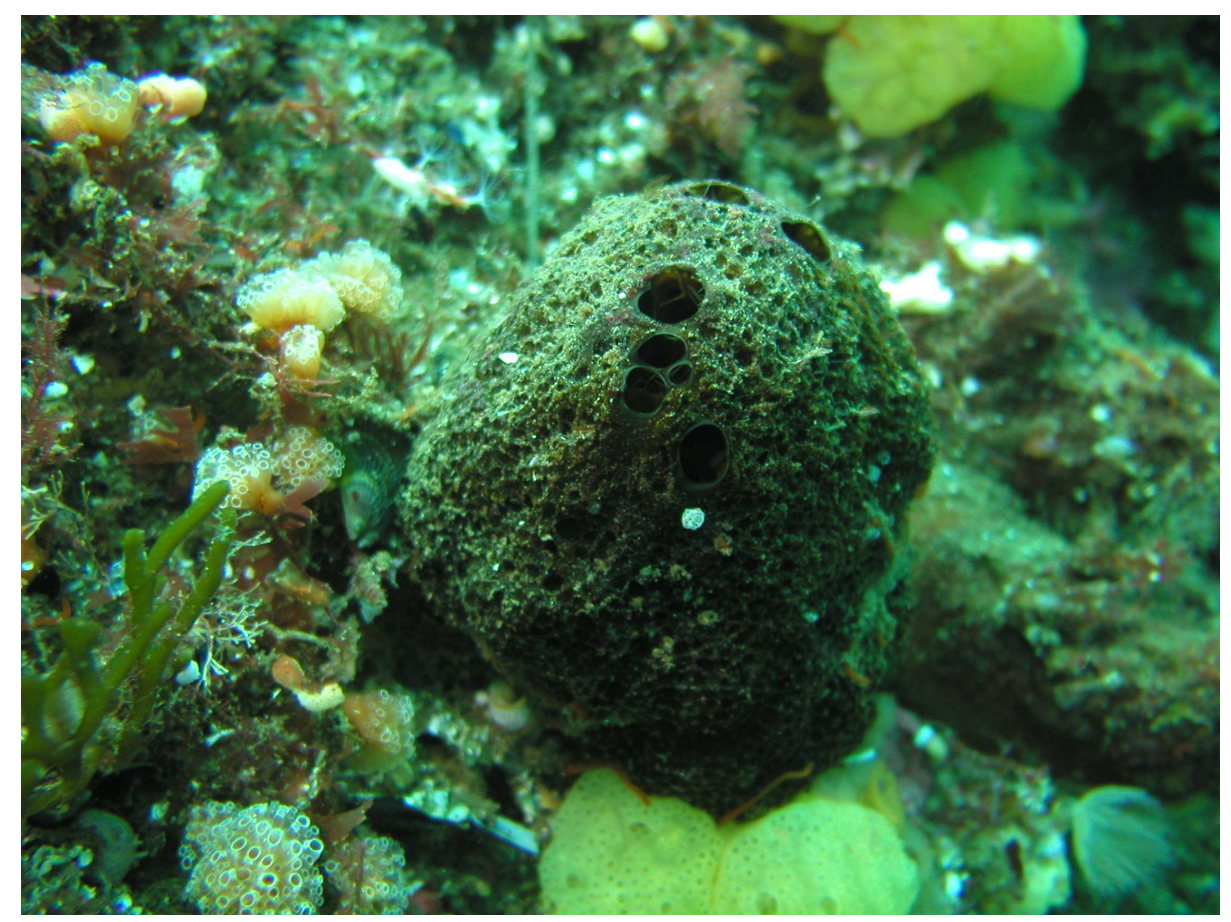

Figure 3.2. Underwater photo of $R$. agminata (courtesy of Mike Page).

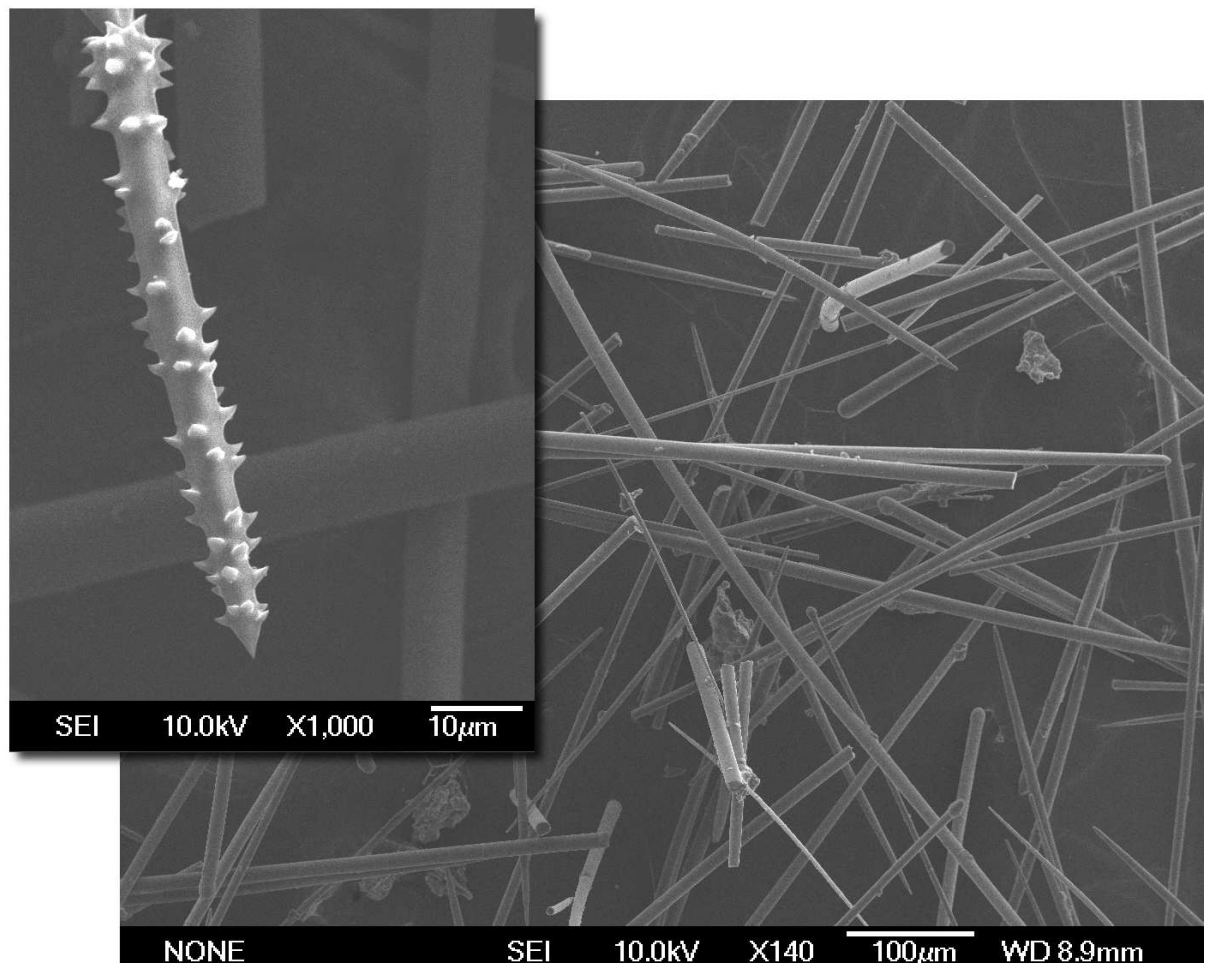

Figure 3.3. SEM image of $R$. agminata spicules. 


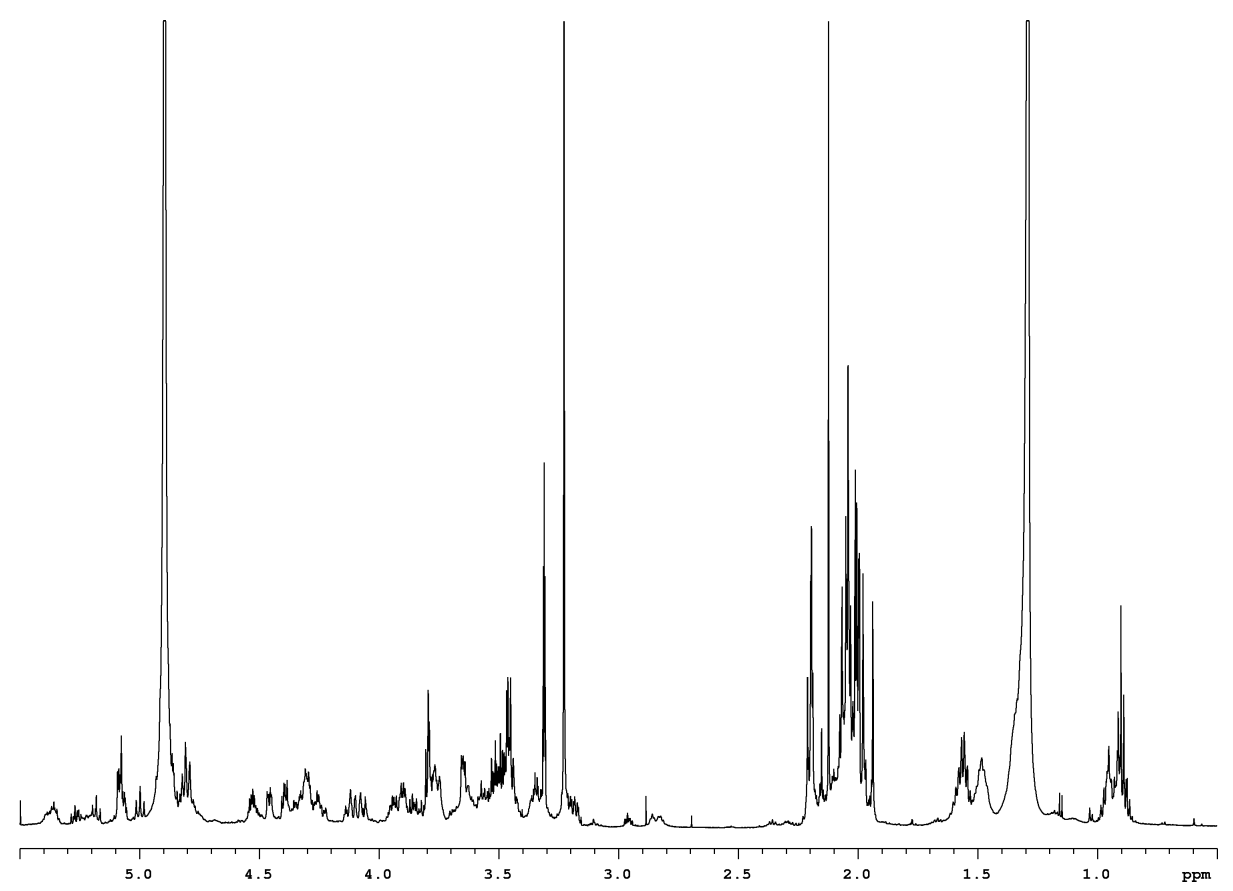

Figure 3.4. ${ }^{1} \mathrm{H}$ NMR spectrum $\left(600 \mathrm{MHz}, \mathrm{CD}_{3} \mathrm{OD}\right)$ of the $60 \% \mathrm{Me}_{2} \mathrm{CO}$ in $\mathrm{H}_{2} \mathrm{O}$ fraction.

\section{Isolation of the agminosides}

R. agminata was collected from Taheke Reef, Cavalli Islands, New Zealand in December 2003. The sponge was extracted with $\mathrm{MeOH}$ and the extracts were cyclic loaded onto reversed-phase HP20 beads. The column was eluted with increasing concentrations of $\mathrm{Me}_{2} \mathrm{CO}$ in $\mathrm{H}_{2} \mathrm{O}$. NMR examination of the resulting fractions showed that the interesting signals were confined to the $60 \% \mathrm{Me}_{2} \mathrm{CO}$ in $\mathrm{H}_{2} \mathrm{O}$ fraction (Figure 3.4). Previous work ${ }^{72}$ suggested that the molecules of interest were quite large, and hence the next step of purification was a size exclusion column.

Early eluting fractions off the LH20 column were combined based on TLC, ${ }^{*}$ affording a mixture of compounds that was free of structurally unrelated impurities. This was further separated on silica gel columns, using $\mathrm{CH}_{2} \mathrm{Cl}_{2}: \mathrm{MeOH}: \mathrm{H}_{2} \mathrm{O}$ mixtures, the only solvent system that gave good chromatographic results. This observation suggested amphiphilic molecules, and as the NMR spectra showed multiple oxymethines (including acetal-type signals) and a $\mathrm{CH}_{2}$ envelope at $\delta_{\mathrm{H}} 1.29$, they were probably glycolipids.

Initially, the fractions from the normal phase silica gel columns were combined based on TLC char, but NMR analysis quickly revealed they were not as pure as the TLC would suggest, as shown in Figure 3.5. They were, in fact, still

*100:20:3 $\mathrm{CH}_{2} \mathrm{Cl}_{2}: \mathrm{MeOH}: \mathrm{H}_{2} \mathrm{O}$, visualised by dipping into $5 \% \mathrm{H}_{2} \mathrm{SO}_{4} / \mathrm{MeOH}$ and heating. 


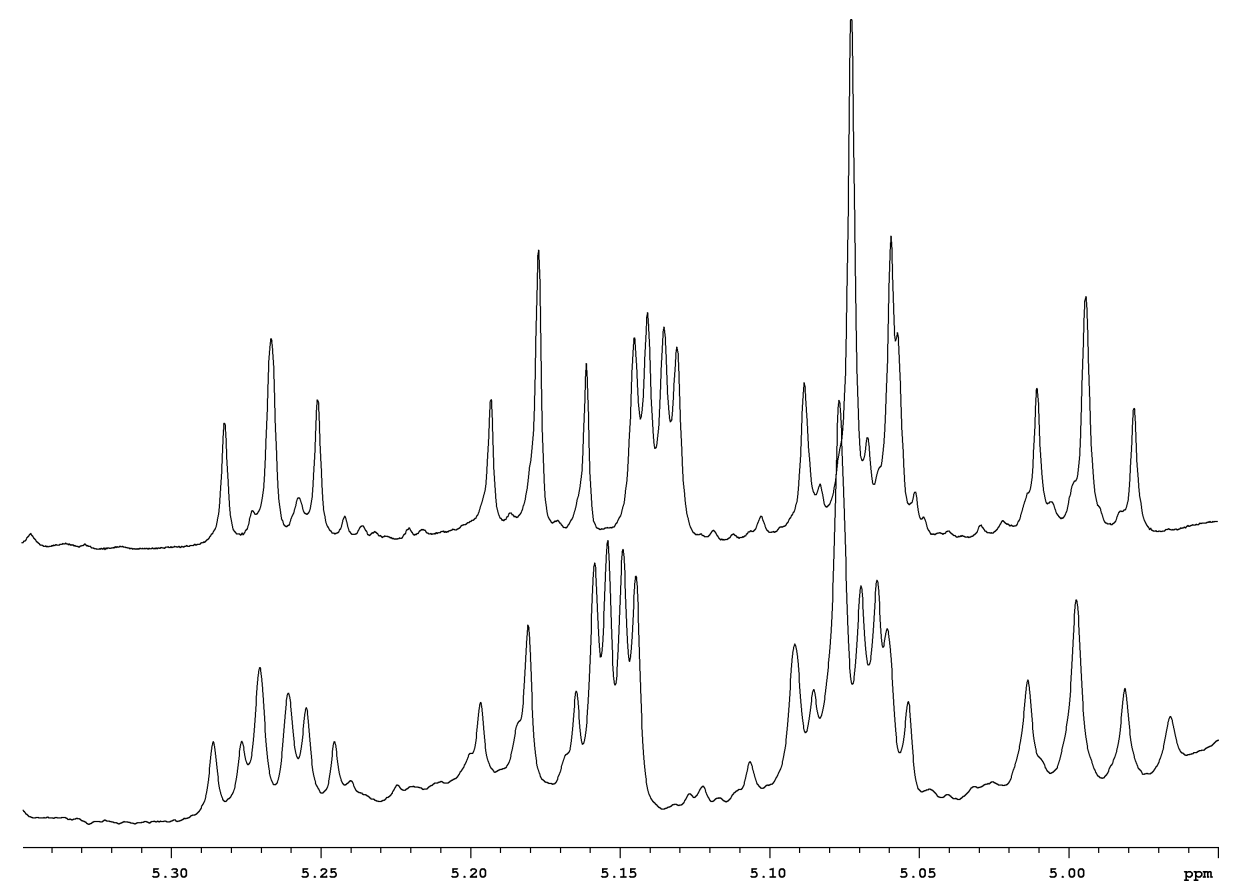

Figure 3.5. ${ }^{1} \mathrm{H}$ NMR spectra $\left(600 \mathrm{MHz}, \mathrm{CD}_{3} \mathrm{OD}\right)$ of a fraction that looked pure by TLC (bottom) and purified agminoside A (top).

mixtures of closely related glycolipids with almost identical retention factors. The glycolipids had no appreciable chromophore, which meant chromatographic monitoring became a problem. Fortunately, the compounds ionised well in negative ion mode of an ESI mass spectrometer, which allowed the rest of the purification to be guided by MS. Even though it is a destructive technique, the sensitivity of MS meant only a small percentage of the sample was consumed.

Multiple silica gel MPLC and semi-preparative HPLC steps were performed in an effort to purify the main glycolipid. Each time, the fractions were subsampled and individually subjected to mass spectrometry. As the compounds were so similar, their rate of ionization in the MS was assumed to be proportional to their relative concentrations. By plotting the maximum ion count for each pseudomolecular ion against fraction number, as can be seen in Figure 3.6, a qualitative measure of the separation achieved can be obtained. Based on this, enriched fractions were combined, and the process repeated, eventually resulting in the isolation of agminosides $\mathrm{A}-\mathrm{E}(\mathbf{1 4 5}-\mathbf{1 4 9})$.

\section{Structure elucidation of agminoside A}

The main component of the glycolipid mixture, agminoside A (145) had a low resolution mass of 1919 Da in negative ion mode. Due to the large size of the molecule, 145 was subjected to MALDI-TOF analysis, which gave rise to a 


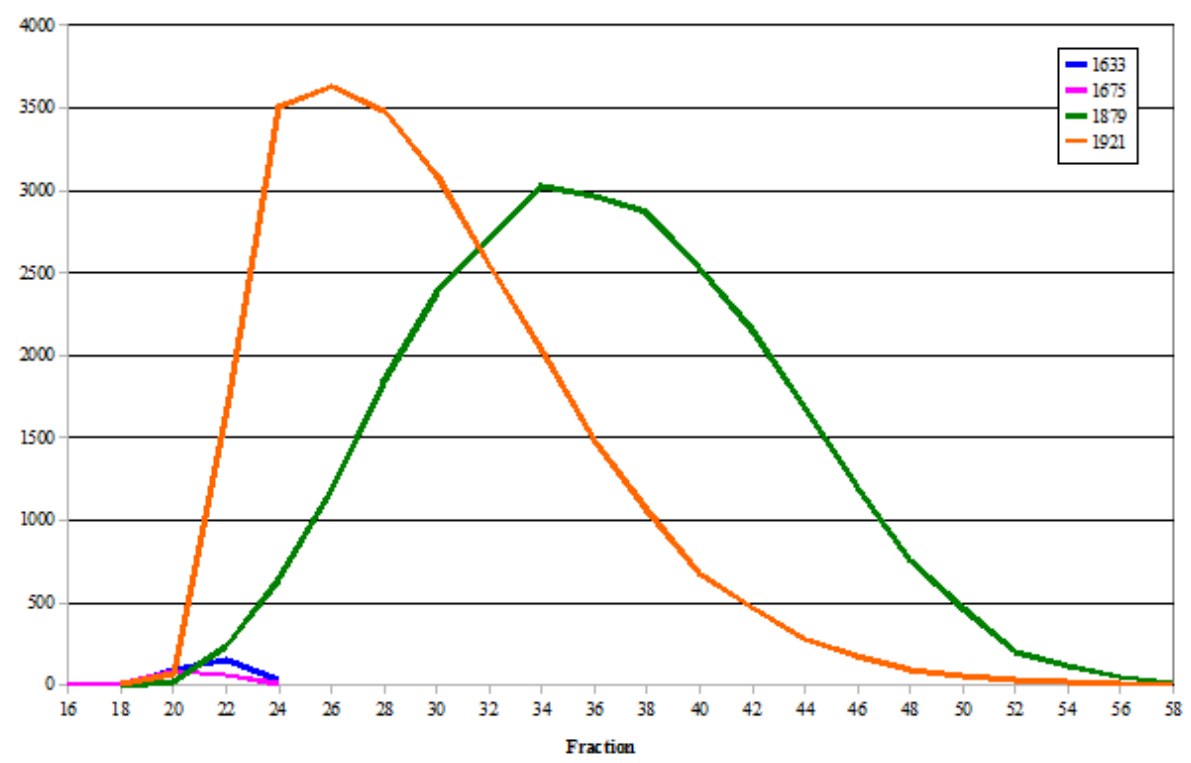

Figure 3.6. A graph of the ion count intensity of glycolipid pseudomolecular ion signals, plotted vs. MPLC fraction number.

pseudomolecular ion of 1943.7707, consistent with a formula of $\mathrm{C}_{85} \mathrm{H}_{132} \mathrm{O}_{48} \mathrm{Na}$ $(\Delta 3.8 \mathrm{ppm})$. Unfortunately a series of other formulae could also have been valid. The majority could be discounted based on the minimum/maximum number of carbons visible in the ${ }^{13} \mathrm{C}$ spectrum (82-90), but there were still at least six formulae to consider. Detailed NMR analysis was required to unequivocally determine the right molecular formula.

\section{The oligosaccharide}

Analysis of the ${ }^{1} \mathrm{H},{ }^{13} \mathrm{C}$ and HSQC-DEPT spectra revealed the presence of six anomeric (acetal) methines, as well as 26 oxymethines and eight oxymethylenes, sufficient for six pyranohexanose sugar moieties. Usually, COSY and HSQC spectra are sufficient for the assignment of sugar residues, but due to the size and complexity of agminoside A (150), both spectra were quite complicated (as shown in Figure 3.7) with a lot of overlapping resonances. When following a series of COSY correlations, a high degree of overlap can lead to unintentional crossing over from one spin system to another.

The HSQC-TOCSY was instrumental in the unambiguous identification of sugar spin systems, as it dispersed any overlapping proton signals in the carbon dimension. From the proton of each of the anomeric centres four oxymethines and an oxymethylene were identified for each of the six sugar spin systems (an example for sugar $\mathrm{F}$ is shown in Figure 3.8). 


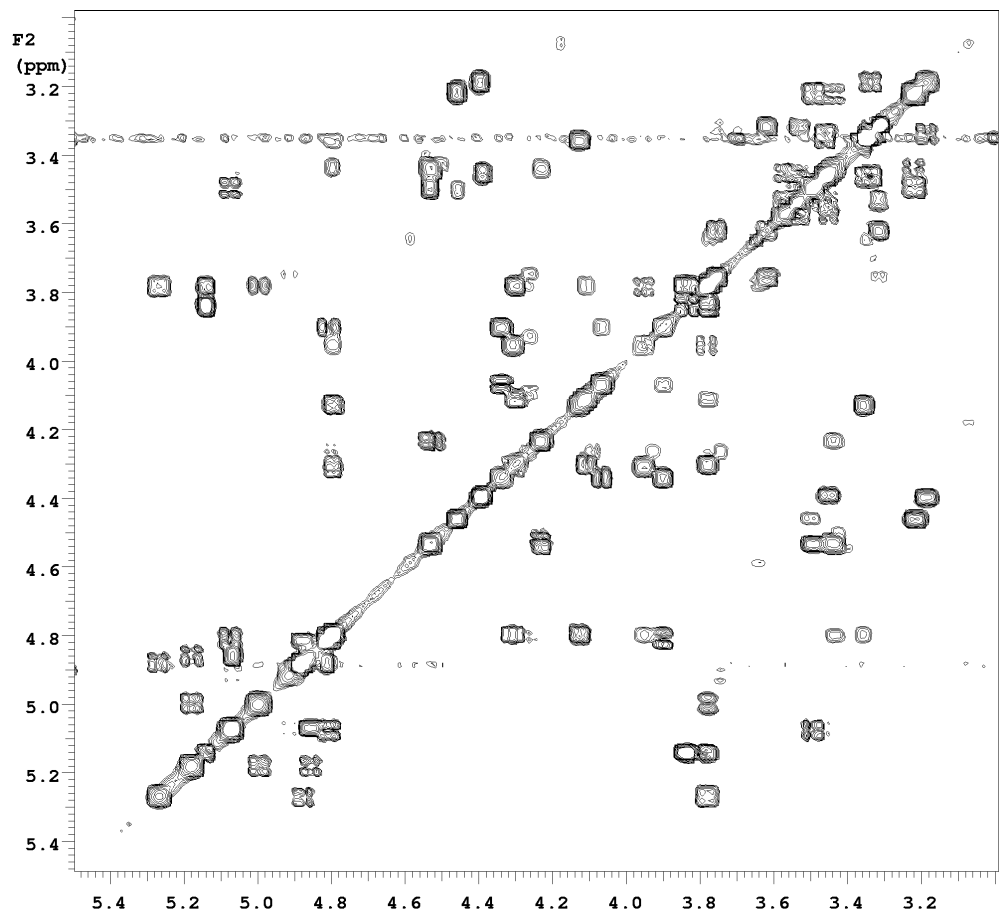

$\mathrm{F} 1(\mathrm{ppm})$

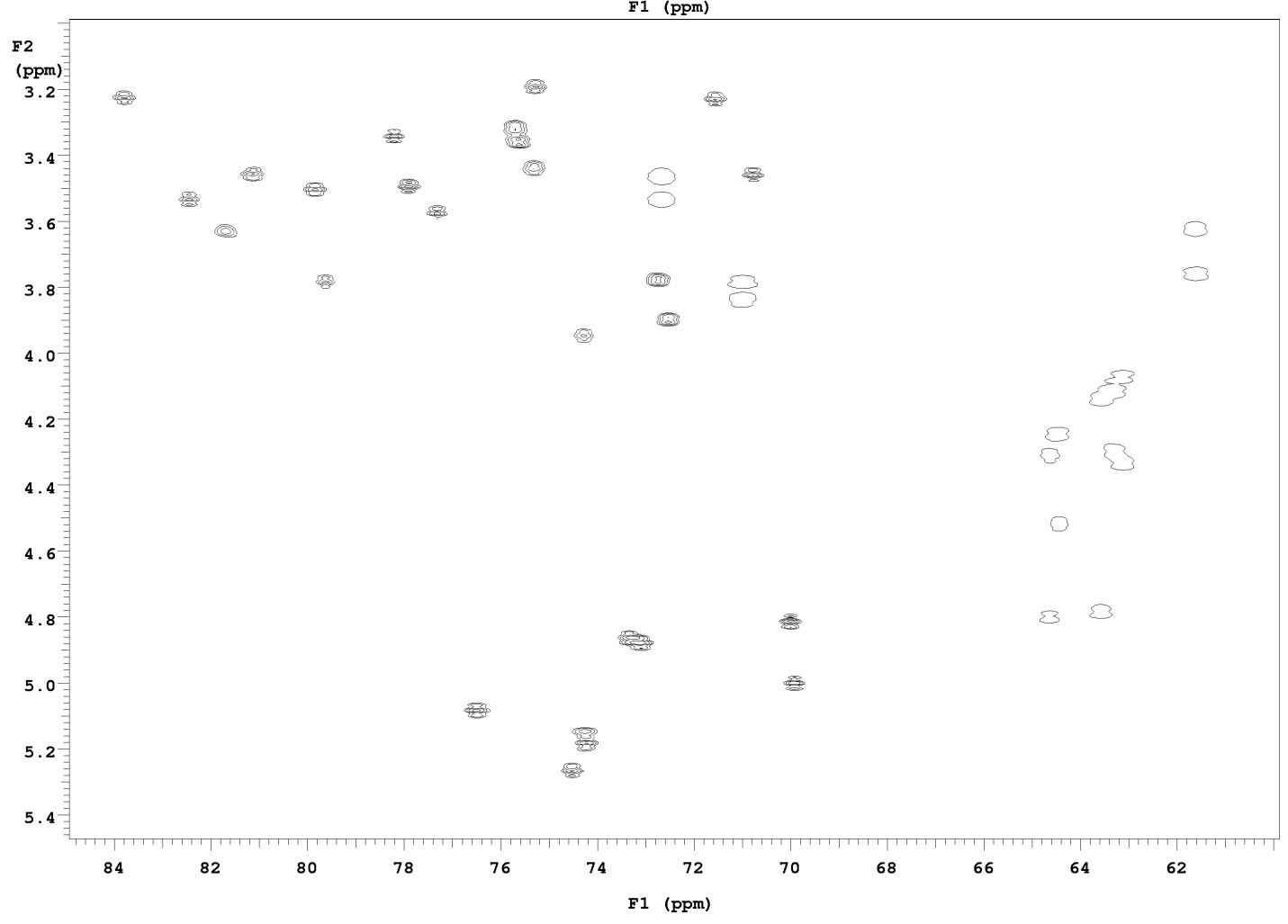

Figure 3.7. Close-up of the COSY and HSQC-DEPT spectra $\left(\mathrm{CD}_{3} \mathrm{OD}, 600\right.$ $\mathrm{MHz}$ ) of agminoside A. 


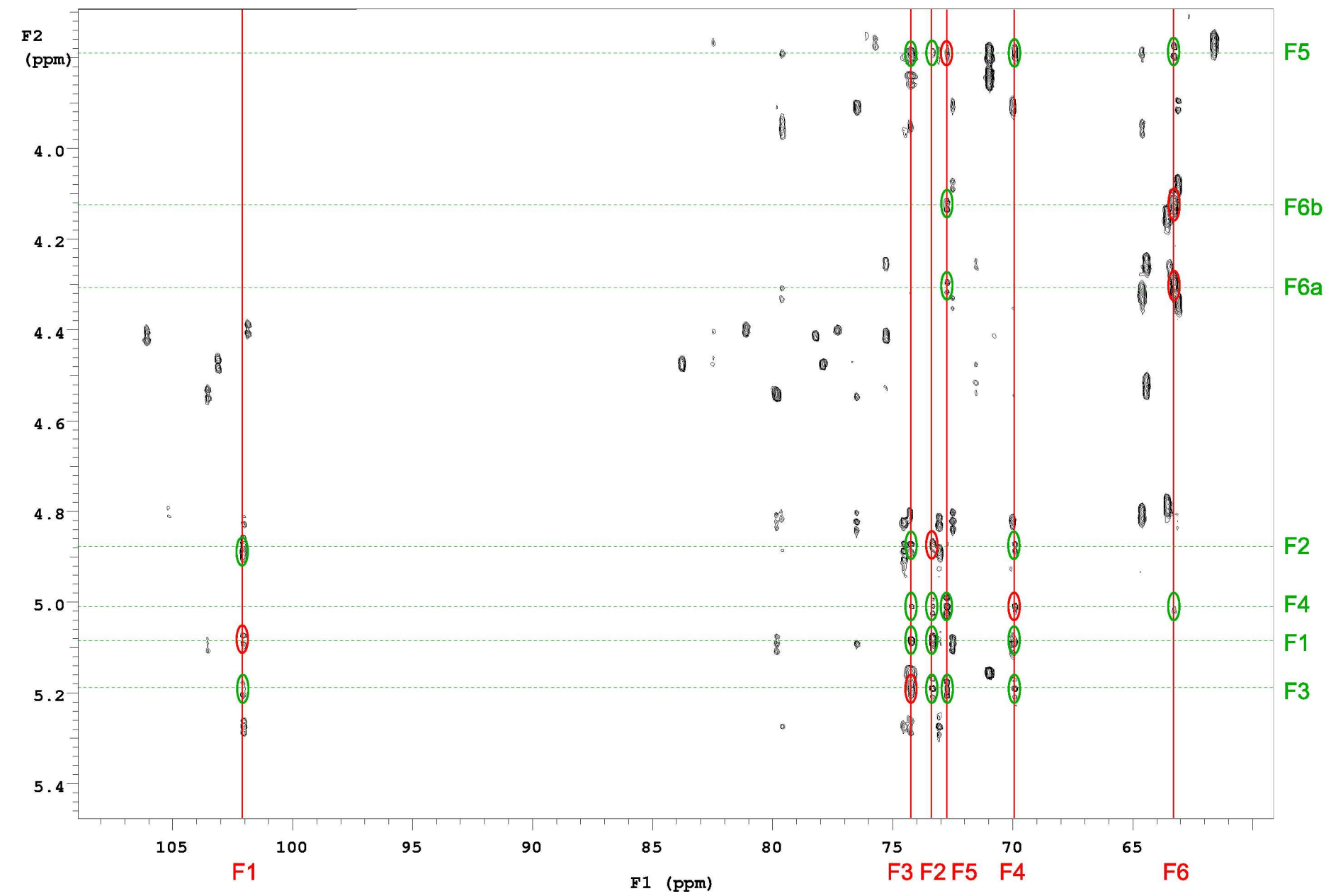

Figure 3.8. Close-up of the HSQC-TOCSY spectrum $\left(\mathrm{CD}_{3} \mathrm{OD}, 600 \mathrm{MHz}\right)$ of agminoside A, identifying the sugar F spin system through HSQC (red) and TOCSY (green) correlations. 
Starting with sugar F, which was most distinctive and was therefore elucidated first, the spin system (see Table 3.1) was identified through HSQC-TOCSY correlations to contain the anomeric oxymethine $\mathrm{CH}-\mathrm{F} 1\left(\delta_{\mathrm{C}} 102.1, \delta_{\mathrm{H}} 5.07\right)$, four oxymethines CH-F2 $\left(\delta_{\mathrm{C}} 73.3, \delta_{\mathrm{H}} 4.86\right), \mathrm{CH}-\mathrm{F} 3\left(\delta_{\mathrm{C}} 74.2, \delta_{\mathrm{H}} 5.18\right), \mathrm{CH}-\mathrm{F} 4\left(\delta_{\mathrm{C}} 69.8\right.$, $\left.\delta_{\mathrm{H}} 5.00\right)$ and $\mathrm{CH}-\mathrm{F} 5\left(\delta_{\mathrm{C}} 72.7, \delta_{\mathrm{H}} 3.78\right)$ as well as an oxymethylene $\mathrm{CH}_{2}-\mathrm{F} 6$ $\left(\delta_{\mathrm{C}} 63.5, \delta_{\mathrm{Ha}} 4.78, \delta_{\mathrm{Hb}} 4.14\right)$. In the COSY spectrum, correlations were observed between H-F1/H-F2, H-F2/H-F3, H-F3/H-F4, H-F4/H-F5, and H-F5/H-F6a,b, establishing the sequence of positions in the sugar. HMBC correlations from $\mathrm{H}-$ F2 to C-F1 and C-F3, from H-F3 to C-F2 and C-F4, from H-F4 to C-F3, C-F5 and C-F6, from H-F5 to C-F4 (weakly), and from H-F6b to C-F4 and C-F5, confirmed this sequence.
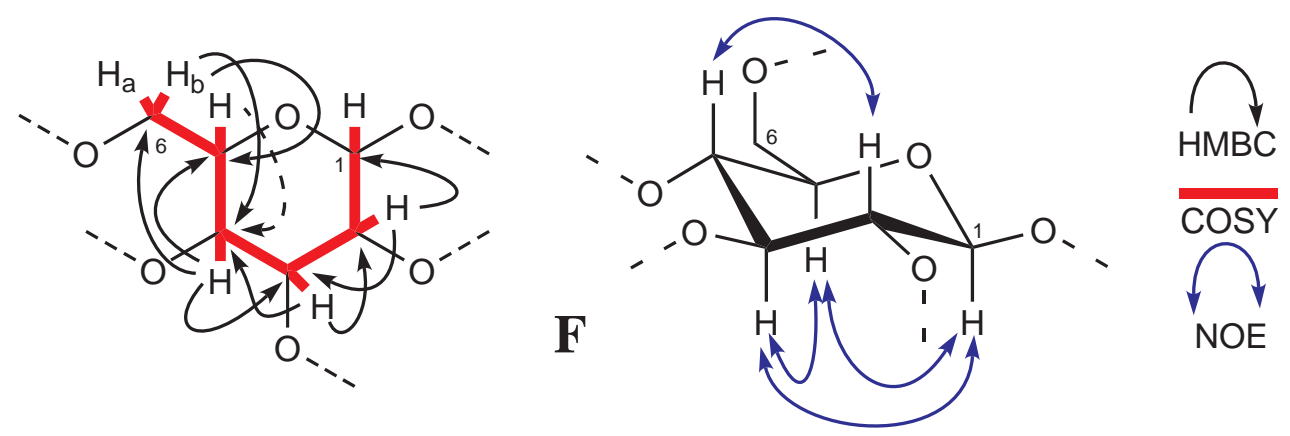

Figure 3.9. Key COSY, HMBC and ROESY correlations used to establish the structure of sugar F.

The coupling constants observed between the oxymethines were all large $(\mathrm{H}-$ F1/H-F2 $J=7.9 \mathrm{~Hz}, \mathrm{H}-\mathrm{F} 2 / \mathrm{H}-\mathrm{F} 3 J=9.8 \mathrm{~Hz}, \mathrm{H}-\mathrm{F} 3 / \mathrm{H}-\mathrm{F} 4 J=9.4 \mathrm{~Hz}, \mathrm{H}-\mathrm{F} 4 / \mathrm{H}-$ F5 $J=9.7 \mathrm{~Hz}$ ), indicating a 1,2-trans relationship between the oxymethine protons. This is consistent with a $\beta$-glucopyranoside, and an NOE enhancement between H-F1 and H-F5 observed in the ROESY spectrum confirmed the presence of the pyran ring. The 1,3-diaxial relationship between all the protons was proven by correlations in the ROESY spectrum $(\mathrm{H}-\mathrm{F} 1 / \mathrm{H}-\mathrm{F} 3 / \mathrm{H}-\mathrm{F} 5$ and $\mathrm{H}-\mathrm{F} 2 / \mathrm{H}-\mathrm{F} 4)$.

Table 3.1. NMR data $\left(600 \mathrm{MHz}, \mathrm{CD}_{3} \mathrm{OD}\right)$ for glucose $\mathrm{F} .^{a}$

\begin{tabular}{|c|c|c|c|c|c|c|c|c|}
\hline pos. & $\begin{array}{c}\delta_{\mathrm{C}} \\
(\mathrm{ppm})\end{array}$ & mult & $\begin{array}{c}\delta_{\mathrm{H}} \\
(\mathrm{ppm}) \\
\end{array}$ & $\begin{array}{l}\text { mult, } \\
J(\mathrm{~Hz})\end{array}$ & COSY & HMBC & TOCSY & ROESY \\
\hline$\overline{F 1}$ & 102.1 & $\mathrm{CH}$ & 5.07 & $\mathrm{~d}(7.9)$ & F2 & & $\mathrm{F} 2, \mathrm{~F} 3$ & F2,F3,F5 \\
\hline $\mathrm{F} 2$ & 73.3 & $\mathrm{CH}$ & 4.86 & dd $(9.8,7.9)$ & F1,F3 & F1,F3 & $\mathrm{F} 1, \mathrm{~F} 3, \mathrm{~F} 4, \mathrm{~F} 5$ & $\mathrm{~F} 1, \mathrm{~F} 4$ \\
\hline F3 & 74.2 & $\mathrm{CH}$ & 5.18 & $\mathrm{t}(9.4)$ & $\mathrm{F} 2, \mathrm{~F} 4$ & $\mathrm{~F} 2, \mathrm{~F} 4$ & $\mathrm{~F} 1, \mathrm{~F} 2, \mathrm{~F} 4, \mathrm{~F} 5$ & $\mathrm{~F} 1, \mathrm{~F} 2, \mathrm{~F} 4,(\mathrm{~F} 5)$ \\
\hline $\mathrm{F} 4$ & 69.8 & $\mathrm{CH}$ & 5.00 & $\mathrm{t}(9.7)$ & F3,F5 & $\mathrm{F} 3, \mathrm{~F} 5, \mathrm{~F} 6$ & $\mathrm{~F} 1, \mathrm{~F} 2, \mathrm{~F} 3, \mathrm{~F} 5$ & $\mathrm{~F} 2, \mathrm{~F} 3, \mathrm{~F} 5$ \\
\hline F5 & 72.7 & $\mathrm{CH}$ & 3.78 & ddd $(9.6,4.1,2.7)$ & $\mathrm{F} 4, \mathrm{~F} 6 \mathrm{a}, \mathrm{F} 6 \mathrm{~b}$ & $(\mathrm{~F} 4)$ & $\mathrm{F} 3, \mathrm{~F} 4, \mathrm{~F} 6 \mathrm{a}, \mathrm{F} 6 \mathrm{~b}$ & $\mathrm{~F} 1, \mathrm{~F} 3, \mathrm{~F} 6 \mathrm{a}, \mathrm{F} 6 \mathrm{~b}$ \\
\hline F6a & 632 & & 4.30 & $\mathrm{~m}$ & F5 & & & F5,F6b \\
\hline F6b & 03.2 & $\mathrm{H}_{2}$ & 4.11 & $\mathrm{~m}$ & F5 & $\mathrm{F} 4, \mathrm{~F} 5$ & $\mathrm{~F} 4, \mathrm{FJ}$ & F5, F6a \\
\hline
\end{tabular}

\footnotetext{
${ }^{a}$ Only correlations within the sugar spin system are listed.
} 
In a similar fashion, the HSQC-TOCSY identified the spin system of sugar B (see Table 3.2) as consisting of the anomeric oxymethine CH-B1 $\left(\delta_{\mathrm{C}} 102.0\right.$, $\left.\delta_{\mathrm{H}} 4.81\right)$, four oxymethines CH-B2 $\left(\delta_{\mathrm{C}} 73.0, \delta_{\mathrm{H}} 4.88\right)$, CH-B3 $\left(\delta_{\mathrm{C}} 74.5, \delta_{\mathrm{H}} 5.27\right)$, $\mathrm{CH}-\mathrm{B} 4\left(\delta_{\mathrm{C}} 79.6, \delta_{\mathrm{H}} 3.78\right)$ and $\mathrm{CH}-\mathrm{B} 5\left(\delta_{\mathrm{C}} 74.2, \delta_{\mathrm{H}} 3.94\right)$, and the oxymethylene $\mathrm{CH}_{2}-\mathrm{B} 6\left(\delta_{\mathrm{C}} 64.6, \delta_{\mathrm{Ha}} 4.31, \delta_{\mathrm{Hb}} 4.80\right)$. Correlations in the COSY spectrum were observed between H-B1/H-B2, H-B2/H-B3, H-B3/H-B4, H-B4/H-B5, and HB5/H-B6a,b. Together with HMBC correlations from H-B2 to C-B1 and C-B3, from H-B3 to C-B2 and C-B4, from H-B4 to C-B3, C-B5, and C-B6 and from $\mathrm{H}-\mathrm{B} 5$ to C-B4 (weakly) they established the sequence of carbons in the sugar.
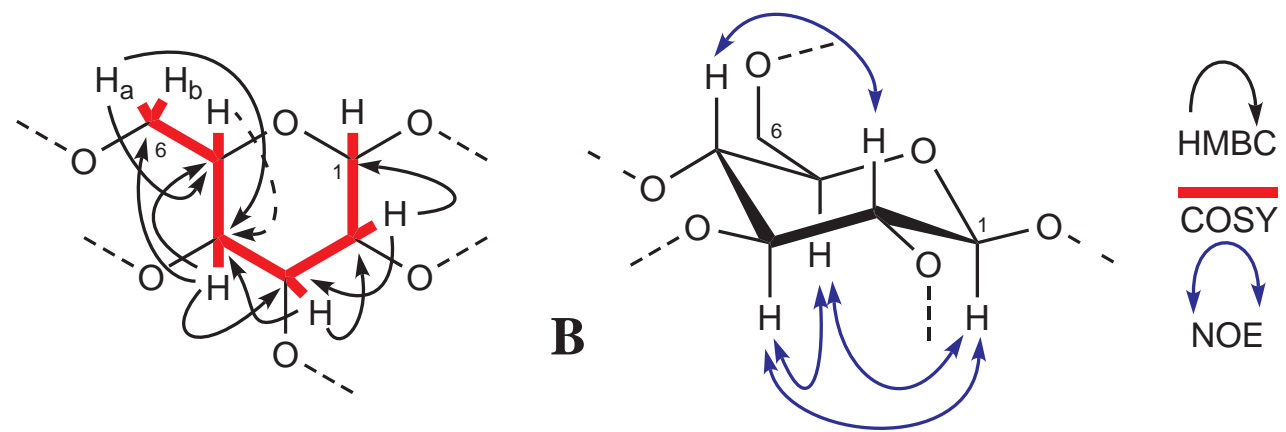

Figure 3.10. Key COSY, HMBC and ROESY correlations used to establish the structure of sugar B.

Large coupling constants between the oxymethines (H-B1/H-B2 $J=8.2 \mathrm{~Hz}$, H-B2/H-B3 $J=8.2 \mathrm{~Hz}, \mathrm{H}-\mathrm{B} 3 / \mathrm{H}-\mathrm{B} 4 J=9.4 \mathrm{~Hz}, \mathrm{H}-\mathrm{B} 4 / \mathrm{H}-\mathrm{B} 5 J=9.4 \mathrm{~Hz}$ ) showed all the ring protons were in the axial orientation, and so suggested another $\beta$ glucopyranoside. The presence of the pyran ring was established through NOE enhancements observed between $\mathrm{H}-\mathrm{B} 1$ and H-B5. The axial positioning of the protons was confirmed through correlations observed in the ROESY spectrum between H-B1, H-B3, and H-B5 and between H-B2 and H-B4.

Table 3.2. NMR data $\left(600 \mathrm{MHz}, \mathrm{CD}_{3} \mathrm{OD}\right)$ for glucose $\mathrm{B}^{a}$

\begin{tabular}{|c|c|c|c|c|c|c|c|c|}
\hline pos. & $\begin{array}{c}\delta_{\mathrm{C}} \\
(\mathrm{ppm})\end{array}$ & mult & $\begin{array}{c}\delta_{\mathrm{H}} \\
(\mathrm{ppm})\end{array}$ & $\begin{array}{l}\text { mult, } \\
J(\mathrm{~Hz})\end{array}$ & COSY & HMBC & TOCSY & ROESY \\
\hline$\overline{\mathrm{B} 1}$ & 102.0 & $\mathrm{CH}$ & 4.81 & $\mathrm{~d}(8.2)$ & $\overline{\mathrm{B} 2}$ & & B2,B3 & B3,B5 \\
\hline B2 & 73.0 & $\mathrm{CH}$ & 4.88 & $\mathrm{t}(8.2)$ & B1,B3 & B1,B3 & B1,B3,B4 & B4 \\
\hline B3 & 74.5 & $\mathrm{CH}$ & 5.27 & $\mathrm{t}(9.4)$ & $\mathrm{B} 2, \mathrm{~B} 4$ & $\mathrm{~B} 2, \mathrm{~B} 4$ & $\mathrm{~B} 1, \mathrm{~B} 2,(\mathrm{~B} 4, \mathrm{~B} 5)$ & $\mathrm{B} 1, \mathrm{~B} 2, \mathrm{~B} 4, \mathrm{~B} 5$ \\
\hline B4 & 79.6 & $\mathrm{CH}$ & 3.78 & $\mathrm{t}(9.4)$ & B3,B5 & $\mathrm{B} 3, \mathrm{~B} 5, \mathrm{~B} 6$ & $\mathrm{~B} 2, \mathrm{~B} 3, \mathrm{~B} 5, \mathrm{~B} 6 \mathrm{~b}$ & $\mathrm{~B} 2, \mathrm{~B} 3, \mathrm{~B} 6 \mathrm{~b}$ \\
\hline B5 & 74.2 & $\mathrm{CH}$ & 3.94 & ddd $(9.6,7.2,1.8)$ & $\mathrm{B} 4, \mathrm{~B} 6 \mathrm{a}, \mathrm{B} 6 \mathrm{~b}$ & (B4) & $\mathrm{B} 2, \mathrm{~B} 3, \mathrm{~B} 4, \mathrm{~B} 6 \mathrm{a}$ & $\mathrm{B} 1, \mathrm{~B} 3,(\mathrm{~B} 4), \mathrm{B} 6 \mathrm{a}$ \\
\hline $\mathrm{B} 6 \mathrm{a}$ & 646 & $\mathrm{CH}$ & 4.80 & $\mathrm{~m}$ & $\mathrm{~B} 6 \mathrm{~b}, \mathrm{~B} 5$ & B5 & $\mathrm{B} 4 \mathrm{~B} 5$ & B4 \\
\hline $\mathrm{B} 6 \mathrm{~b}$ & & $\Pi_{2}$ & 4.31 & $\mathrm{~m}$ & B6a,B5 & & & B5 \\
\hline
\end{tabular}

\footnotetext{
${ }^{a}$ Only correlations within the sugar spin system are listed.
} 
The spin system of sugar $\mathrm{C}$ (see Table 3.3) (CH-C1: $\delta_{\mathrm{C}} 103.6, \delta_{\mathrm{H}} 4.53$; $\mathrm{CH}-\mathrm{C} 2: \delta_{\mathrm{C}} 79.8, \delta_{\mathrm{H}} 3.50 ; \mathrm{CH}-\mathrm{C} 3 \delta_{\mathrm{C}} 76.5, \delta_{\mathrm{H}} 5.08 ; \mathrm{CH}-\mathrm{C} 4: \delta_{\mathrm{C}} 69.9, \delta_{\mathrm{H}} 4.81$; $\left.\mathrm{CH}-\mathrm{C} 5 \delta_{\mathrm{C}} 72.5, \delta_{\mathrm{H}} 3.90 ; \mathrm{CH}_{2}-6: \delta_{\mathrm{C}} 64.4, \delta_{\mathrm{Ha}} 4.33, \delta_{\mathrm{Hb}} 4.07\right)$ was once again identified through the use of the HSQC-TOCSY experiment. COSY correlations between H-C1/H-C2, H-C2/H-C3, H-C3/H-C4, H-C4/H-C5 and H-C5/H-C6a,b established the order of positions in the sugar, and were corroborated by HMBC correlations from $\mathrm{H}-\mathrm{C} 2$ to $\mathrm{C}-\mathrm{C} 1$ and $\mathrm{C}-\mathrm{C} 3$, from $\mathrm{H}-\mathrm{C} 3$ to $\mathrm{C}-\mathrm{C} 2$ and $\mathrm{C}-\mathrm{C} 4$, from $\mathrm{H}-\mathrm{C} 4$ to $\mathrm{C}-\mathrm{C} 3, \mathrm{C}-\mathrm{C} 5$ and $\mathrm{C}-\mathrm{C} 6$, from H-C5 to C-C4 (weakly) and from H-C6b to $\mathrm{C}-\mathrm{C} 4$ and $\mathrm{C}-\mathrm{C} 5$.
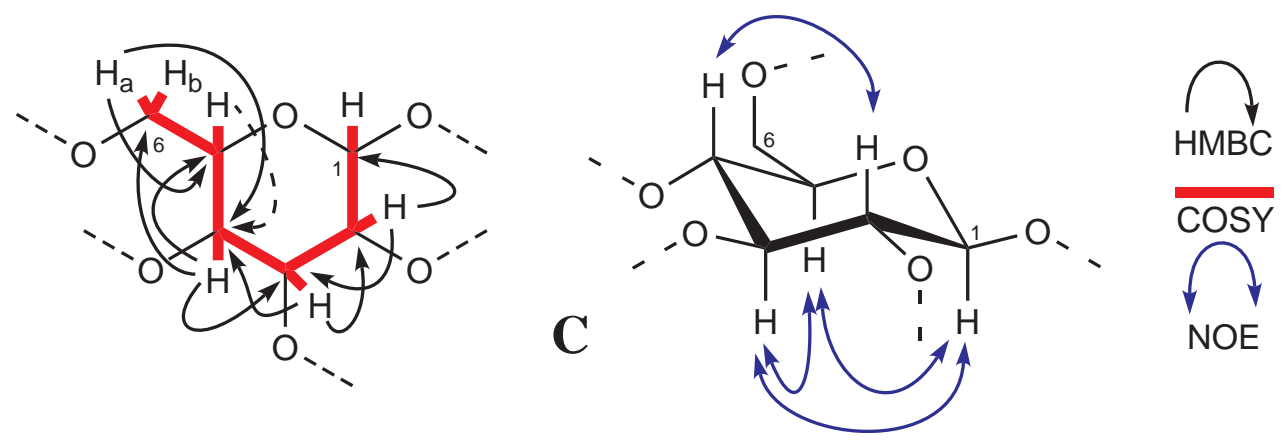

Figure 3.11. Key COSY, HMBC and ROESY correlations used to establish the structure of sugar C.

The protons of sugar $\mathrm{C}$ also exhibited all large coupling constants $(\mathrm{H}-\mathrm{C} 1 / \mathrm{H}-$ $\mathrm{C} 2 J=7.8 \mathrm{~Hz}, \mathrm{H}-\mathrm{C} 2 / \mathrm{H}-\mathrm{C} 3 J=8.4 \mathrm{~Hz}, \mathrm{H}-\mathrm{C} 3 / \mathrm{H}-\mathrm{C} 4 J=9.5 \mathrm{~Hz}, \mathrm{H}-\mathrm{C} 4 / \mathrm{H}-\mathrm{C} 5 J$ $=10.0 \mathrm{~Hz}$ ), indicative of a $\beta$-glucopyranoside. This stereochemical assignment was once again confirmed through ROESY correlations between $\mathrm{H}-\mathrm{C} 1, \mathrm{H}-\mathrm{C} 3$ and $\mathrm{H}-\mathrm{C} 5$ and between $\mathrm{H}-\mathrm{C} 2$ and $\mathrm{H}-\mathrm{C} 4$, indicating 1,3-diaxial relationships. The observation of NOE enhancements between $\mathrm{H}-\mathrm{C} 1$ and $\mathrm{H}-\mathrm{C} 5$ supported the assignment of a pyran ring.

Table 3.3. NMR data $\left(600 \mathrm{MHz}, \mathrm{CD}_{3} \mathrm{OD}\right)$ for glucose C. ${ }^{a}$

\begin{tabular}{|c|c|c|c|c|c|c|c|c|}
\hline pos. & $\begin{array}{c}\delta_{\mathrm{C}} \\
(\mathrm{ppm})\end{array}$ & mult & $\begin{array}{c}\delta_{\mathrm{H}} \\
(\mathrm{ppm})\end{array}$ & $\begin{array}{l}\text { mult, } \\
J(\mathrm{~Hz})\end{array}$ & COSY & HMBC & TOCSY & ROESY \\
\hline$\overline{\mathrm{C} 1}$ & 103.6 & $\overline{\mathrm{CH}}$ & $\overline{4.53}$ & $\mathrm{~d}(7.8)$ & $\overline{\mathrm{C} 2}$ & & $\overline{\mathrm{C} 2, \mathrm{C} 3}$ & C3,C5 \\
\hline $\mathrm{C} 2$ & 79.8 & $\mathrm{CH}$ & 3.50 & $\mathrm{t}(8.4)$ & $\mathrm{C} 1, \mathrm{C} 3$ & $\mathrm{C} 1, \mathrm{C} 3$ & $\mathrm{C} 1, \mathrm{C} 3, \mathrm{C} 4$ & $\mathrm{C} 4$ \\
\hline C3 & 76.5 & $\mathrm{CH}$ & 5.08 & $\mathrm{t}(9.5)$ & $\mathrm{C} 2, \mathrm{C} 4$ & $\mathrm{C} 2, \mathrm{C} 4$ & $\mathrm{C} 1, \mathrm{C} 2, \mathrm{C} 4, \mathrm{C} 5$ & $\mathrm{C} 1, \mathrm{C} 2, \mathrm{C} 4, \mathrm{C} 5$ \\
\hline $\mathrm{C} 4$ & 69.9 & $\mathrm{CH}$ & 4.81 & $\mathrm{t}(10.0)$ & $\mathrm{C} 3, \mathrm{C} 5$ & $\mathrm{C} 3, \mathrm{C} 5, \mathrm{C} 6$ & $(\mathrm{C} 1), \mathrm{C} 2, \mathrm{C} 3, \mathrm{C} 5, \mathrm{C} 6 \mathrm{a}$ & $\mathrm{C} 2$ \\
\hline C5 & 72.5 & $\mathrm{CH}$ & 3.90 & ddd $(10.0,3.6,2.3)$ & $\mathrm{C} 4, \mathrm{C} 6 \mathrm{a}, \mathrm{C} 6 \mathrm{~b}$ & $(\mathrm{C} 4)$ & $\mathrm{C} 3, \mathrm{C} 4, \mathrm{C} 6 \mathrm{a}, \mathrm{C} 6 \mathrm{~b}$ & $\mathrm{C} 1, \mathrm{C} 3, \mathrm{C} 6 \mathrm{a}, \mathrm{C} 6 \mathrm{~b}$ \\
\hline $\mathrm{C} 6 \mathrm{a}$ & 63 & & 4.33 & $\mathrm{dd}(12.6,4.2)$ & $\mathrm{C} 6 \mathrm{~b}, \mathrm{C} 5$ & & & $\mathrm{C} 5, \mathrm{C} 6 \mathrm{~b}$ \\
\hline $\mathrm{C} 6 \mathrm{~b}$ & 03.1 & $\mathrm{H}_{2}$ & 4.07 & $\mathrm{~d}(12.0)$ & $\mathrm{C} 6 \mathrm{a}, \mathrm{C} 5$ & $\mathrm{C} 4, \mathrm{C} 5$ & $(\cup 4), \cup 5$ & $\mathrm{C} 5, \mathrm{C} 6 \mathrm{a}$ \\
\hline
\end{tabular}

\footnotetext{
${ }^{a}$ Only correlations within the sugar spin system are listed.
} 
The HSQC-TOCSY correlations identified the spin system of sugar D (see Table 3.12) as containing the anomeric position CH-D1 $\left(\delta_{\mathrm{C}} 103.1, \delta_{\mathrm{H}} 4.46\right)$, four oxymethines CH-D2 $\left(\delta_{\mathrm{C}} 83.8, \delta_{\mathrm{H}} 3.22\right)$, CH-D3 $\left(\delta_{\mathrm{C}} 77.9, \delta_{\mathrm{H}} 3.49\right)$, CH-D4 $\left(\delta_{\mathrm{C}} 71.5, \delta_{\mathrm{H}} 3.23\right)$ and CH-D5 $\left(\delta_{\mathrm{C}} 75.3, \delta_{\mathrm{H}} 3.44\right)$, and an oxymethylene $\mathrm{CH}_{2}$-D6 $\left(\delta_{\mathrm{C}} 64.4, \delta_{\mathrm{Ha}} 4.51, \delta_{\mathrm{Hb}} 4.24\right)$. Unfortunately this sugar has two protons that are severely overlapping $\left(\delta_{\mathrm{H}} 3.22\right.$ and 3.23$)$. This made the interpretation of the COSY more difficult, as H-D1, H-D3 and H-D5 all showed correlations to $\delta_{\mathrm{H}} \sim 3.22$. In the HMBC spectrum, however, the more upfield proton $\left(\delta_{\mathrm{H}} 3.22\right)$ correlated to C-D1, and was therefore assigned as H-D2. The more downfield proton $\left(\delta_{\mathrm{H}} 3.23\right)$ showed HMBC correlations to C-D5 and C-D6, and was assigned as H-D4. $\delta_{\mathrm{H}} 3.49$ showed HMBC correlations to both C-D2 and C-D4, and was assigned as H-D3, completing the sequence of the sugar.
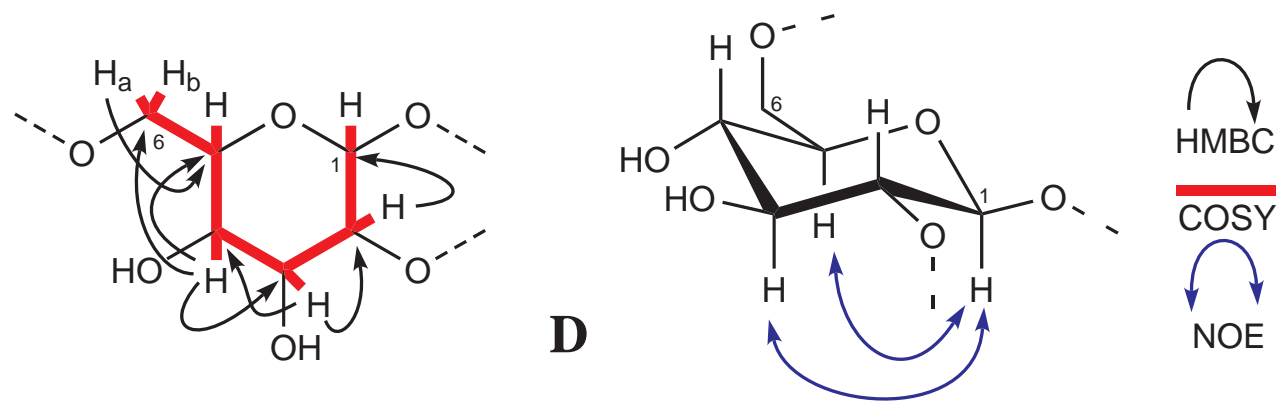

Figure 3.12. Key COSY, HMBC and ROESY correlations used to establish the structure of sugar D.

The overlap of H-D2 and H-D4 also made the interpretation of their coupling constants more difficult. Fortunately, the coupling of H-D1 (d, $J=7.8 \mathrm{~Hz}$ ) H-D3 (t, $J=7.9 \mathrm{~Hz}$ ) and H-D5 (ddd, $J=9.4,7.0,1.5 \mathrm{~Hz}$ ) could be resolved, and once again pointed to a 1,2-trans relationship of the neighbouring oxymethine protons, and therefore to another $\beta$-glucopyranoside. ROESY correlations between $\mathrm{H}$ D1 and H-D5 (indicating the pyran ring), and H-D1 and H-D3 supported this assignment.

Table 3.4. NMR data $\left(600 \mathrm{MHz}, \mathrm{CD}_{3} \mathrm{OD}\right)$ for glucose $\mathrm{D}^{a}$

\begin{tabular}{|c|c|c|c|c|c|c|c|c|}
\hline pos. & $\begin{array}{c}\delta_{\mathrm{C}} \\
(\mathrm{ppm})\end{array}$ & mult & $\begin{array}{c}\delta_{\mathrm{H}} \\
(\mathrm{ppm})\end{array}$ & $\begin{array}{l}\text { mult, } \\
J(\mathrm{~Hz})\end{array}$ & COSY & HMBC & TOCSY & ROESY \\
\hline D1 & 103.1 & $\mathrm{CH}$ & 4.46 & $\mathrm{~d}(7.8)$ & D2 & $\mathrm{C} 2$ & D2,D3 & D3,D5 \\
\hline D2 & 83.8 & $\mathrm{CH}$ & 3.22 & $\mathrm{~m}$ & D1, D3 & D1 & D1,D3,D4,D5 & \\
\hline D3 & 77.9 & $\mathrm{CH}$ & 3.49 & $\mathrm{t}(7.9)$ & $\mathrm{D} 2, \mathrm{D} 4$ & $\mathrm{D} 2, \mathrm{D} 4$ & D1,D2,D4,D5 & D1 \\
\hline D4 & 71.5 & $\mathrm{CH}$ & 3.23 & $\mathrm{~m}$ & D3,D5 & D3,D5,D6 & D3,D5,D6a,D6b & \\
\hline D5 & 75.3 & $\mathrm{CH}$ & 3.44 & ddd $(9.4,7.0,1.5)$ & D4,D6a,D6b & & D3,D4,D6a,D6b & D1,D6a,D6b \\
\hline D6a & 64.4 & & 4.51 & dd $(11.0,7.5)$ & D6b,D5 & D5 & & D5,D6b \\
\hline D6b & 04.4 & $\mathrm{H}_{2}$ & 4.24 & dd $(10.3,1.6)$ & D6a,D5 & & D4,DU & D5,D6a \\
\hline
\end{tabular}

\footnotetext{
${ }^{a}$ Only correlations within the sugar spin system are listed.
} 
The fifth sugar, sugar E (see Table 3.13), consisted of the anomeric oxymethine CH-E1 $\left(\delta_{\mathrm{C}} 106.1, \delta_{\mathrm{H}} 4.40\right)$, four oxymethines CH-E2 $\left(\delta_{\mathrm{C}} 75.2, \delta_{\mathrm{H}} 3.19\right)$, $\mathrm{CH}-\mathrm{E} 3\left(\delta_{\mathrm{C}} 78.2, \delta_{\mathrm{H}} 3.34\right)$, CH-E4 $\left(\delta_{\mathrm{C}} 70.7, \delta_{\mathrm{H}} 3.46\right)$ and $\mathrm{CH}-\mathrm{E} 5\left(\delta_{\mathrm{C}} 75.6, \delta_{\mathrm{H}} 3.36\right)$, and an oxymethylene $\mathrm{CH}_{2}$-E6 $\left(\delta_{\mathrm{C}} 63.5, \delta_{\mathrm{Ha}} 4.78, \delta_{\mathrm{Hb}} 4.14\right)$, as identified from the HSQC-TOCSY. Correlations were observed in the COSY spectrum between H-E1/H-E2, H-E2/H-E3, H-E3/H-E4, H-E4/H-E5 and H-E5/H-E6b, allowing the assignment of the sequence of positions. This order was further supported by HMBC correlations from H-E2 to C-E1 and C-E3, from H-E3 to C-E2 and C-E4, from H-E4 to C-E5 and C-E6, and from H-E6a to C-E4 and C-E5.
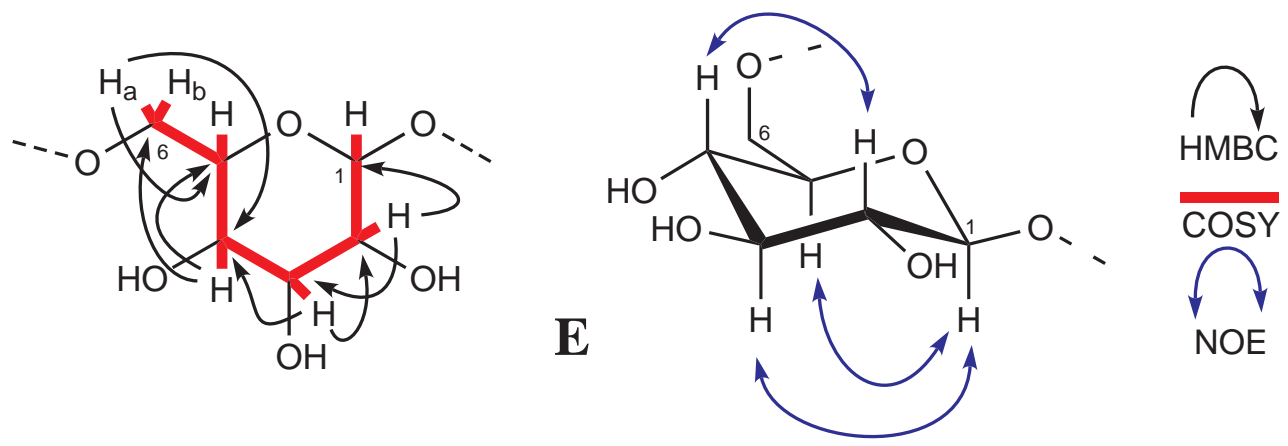

Figure 3.13. Key COSY, HMBC and ROESY correlations used to establish the structure of sugar E.

Protons H-E1-H-E4 had large coupling constants (H-E1 $J=7.9 \mathrm{~Hz}$; H-E2 $J=8.1 \mathrm{~Hz}$; H-E3 8.6 Hz; H-E4 9.7 Hz), once again suggesting a $\beta$-glucopyranoside. The pyran ring was established through observation of NOE enhancements between H-E1 and H-E5. 1,3-Diaxial interactions were also observed in the ROESY spectrum, which showed correlations between H-E1 and both H-E3 and $\mathrm{H}-\mathrm{E} 5$, and between H-E2 and H-E4, supporting the stereochemical assignment of the sugar as $\beta$-glucopyranoside.

Table 3.5. NMR data $\left(600 \mathrm{MHz}, \mathrm{CD}_{3} \mathrm{OD}\right)$ for glucose E. ${ }^{a}$

\begin{tabular}{|c|c|c|c|c|c|c|c|c|}
\hline pos. & $\begin{array}{c}\delta_{\mathrm{C}} \\
(\mathrm{ppm})\end{array}$ & mult & $\begin{array}{c}\delta_{\mathrm{H}} \\
(\mathrm{ppm})\end{array}$ & $\begin{array}{l}\text { mult, } \\
J(\mathrm{~Hz})\end{array}$ & COSY & HMBC & TOCSY & ROESY \\
\hline$\overline{\mathrm{E} 1}$ & 106.1 & $\mathrm{CH}$ & 4.40 & $\mathrm{~d}(7.9)$ & $\mathrm{E} 2$ & & $\mathrm{E} 2, \mathrm{E} 3$ & $\mathrm{E} 3, \mathrm{E} 5$ \\
\hline $\mathrm{E} 2$ & 75.2 & $\mathrm{CH}$ & 3.19 & $\mathrm{t}(8.1)$ & $\mathrm{E} 1, \mathrm{E} 3$ & $\mathrm{E} 1, \mathrm{E} 3$ & $\mathrm{E} 1, \mathrm{E} 3, \mathrm{E} 4, \mathrm{E} 5$ & $\mathrm{E} 1, \mathrm{E} 3, \mathrm{E} 4$ \\
\hline E3 & 78.2 & $\mathrm{CH}$ & 3.34 & $\mathrm{t}(8.6)$ & $\mathrm{E} 2, \mathrm{E} 4$ & $\mathrm{E} 2, \mathrm{E} 4$ & $\mathrm{E} 1, \mathrm{E} 2, \mathrm{E} 4, \mathrm{E} 5$ & $\mathrm{E} 1, \mathrm{E} 2, \mathrm{E} 4$ \\
\hline $\mathrm{E} 4$ & 70.7 & $\mathrm{CH}$ & 3.46 & $\mathrm{t}(9.7)$ & E3,E5 & E5,E6 & $\mathrm{E} 1, \mathrm{E} 2, \mathrm{E} 3, \mathrm{E} 5$ & $\mathrm{E} 2, \mathrm{E} 3, \mathrm{E} 5$ \\
\hline E5 & 75.6 & $\mathrm{CH}$ & 3.36 & $\mathrm{~m}$ & $\mathrm{E} 4, \mathrm{E} 6 \mathrm{~b}$ & & $\mathrm{E} 2, \mathrm{E} 3, \mathrm{E} 4$ & $\mathrm{E} 1, \mathrm{E} 6 \mathrm{a}, \mathrm{E} 6 \mathrm{~b}$ \\
\hline E6a & 63 & $\mathrm{CH}_{\mathrm{H}}$ & 4.78 & $\mathrm{~m}$ & E6b & $\mathrm{E} 5, \mathrm{E} 4$ & F5 & E5,E6b \\
\hline E6b & 00.0 & $\mathrm{H}_{2}$ & 4.14 & $\mathrm{~m}$ & E6a,E4 & & Lu & $\mathrm{E} 5, \mathrm{E} 6 \mathrm{a}$ \\
\hline
\end{tabular}

${ }^{a}$ Only correlations within the sugar spin system are listed. 
Finally, the spin system of sugar A (see Table 3.6) was revealed by the HSQC-TOCSY to consist of the anomeric position CH-A1 $\left(\delta_{\mathrm{C}} 101.9, \delta_{\mathrm{H}} 4.39\right)$, four oxymethines $\mathrm{CH}-\mathrm{A} 2\left(\delta_{\mathrm{C}} 81.1, \delta_{\mathrm{H}} 3.46\right)$, CH-A3 $\left(\delta_{\mathrm{C}} 77.3, \delta_{\mathrm{H}} 3.58\right)$, CH-A4 $\left(\delta_{\mathrm{C}} 82.4, \delta_{\mathrm{H}} 3.53\right)$ and $\mathrm{CH}-\mathrm{A} 5\left(\delta_{\mathrm{C}} 75.7, \delta_{\mathrm{H}} 3.32\right)$, and the oxymethylene $\mathrm{CH}_{2}-$ A6 $\left(\delta_{\mathrm{C}} 61.6, \delta_{\mathrm{Ha}} 3.76, \delta_{\mathrm{Hb}} 3.62\right)$. The sequence of positions in the sugar was established through COSY correlations between H-A1/H-A2, H-A2/H-A3, HA3/H-A4, H-A4/H-A5, H-A5/H-A6a (weakly) and H-A5/H-A6b. They were further supported by observed HMBC correlations from $\mathrm{H}-\mathrm{A} 2$ to $\mathrm{C}-\mathrm{A} 1$ and $\mathrm{C}$ A3, from H-A3 to C-A2 and C-A4, from H-A4 to C-A3, C-A5, and C-A6, and from H-A6a to C-A4 and C-A5.
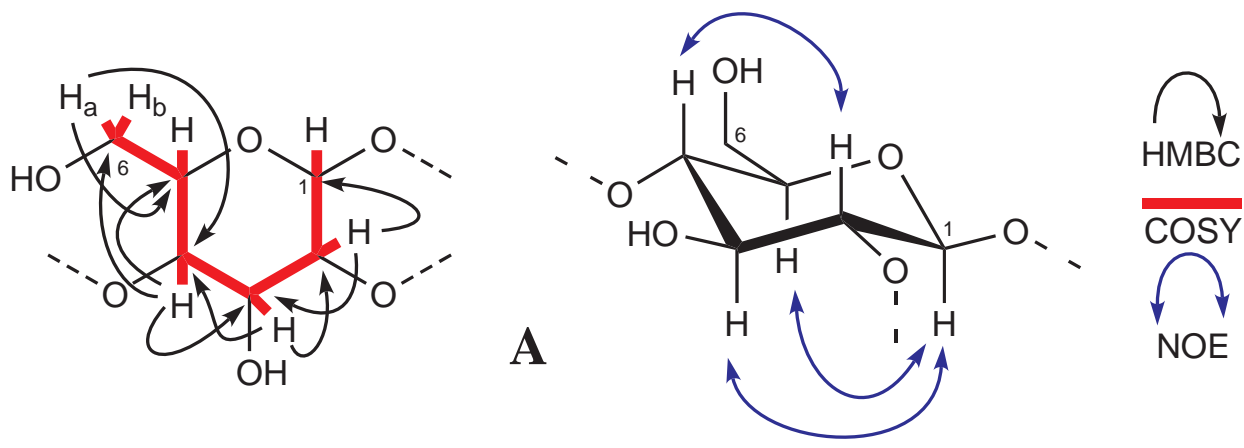

Figure 3.14. Key COSY, HMBC and ROESY correlations used to establish the structure of sugar A.

Due to overlap of multiple signals of this sugar, only the coupling constants of H-A1 (d, $J=7.8 \mathrm{~Hz})$ and $\mathrm{H}-\mathrm{A} 2(\mathrm{t}, J=8.3 \mathrm{~Hz})$ were determined. These suggest that the protons of the oxymethines $\mathrm{CH}-\mathrm{A} 1-\mathrm{CH}-\mathrm{A} 3$ exist in a 1,2-trans relationship. An NOE enhancement between $\mathrm{H}-\mathrm{A} 1$ and $\mathrm{H}-\mathrm{A} 5$ as well as 1,3diaxial interactions observed in the ROESY (correlations between $\mathrm{H}-\mathrm{A} 1 / \mathrm{H}-\mathrm{A} 3$, $\mathrm{H}-\mathrm{A} 1 / \mathrm{H}-\mathrm{A} 5$ and between $\mathrm{H}-\mathrm{A} 2 / \mathrm{H}-\mathrm{A} 4)$ together with the observed coupling constants imply the final sugar is also a $\beta$-glucopyranoside.

Table 3.6. NMR data $\left(600 \mathrm{MHz}, \mathrm{CD}_{3} \mathrm{OD}\right)$ for glucose A. ${ }^{a}$

\begin{tabular}{|c|c|c|c|c|c|c|c|c|}
\hline pos. & $\begin{array}{c}\delta_{\mathrm{C}} \\
(\mathrm{ppm})\end{array}$ & mult & $\begin{array}{c}\delta_{\mathrm{H}} \\
(\mathrm{ppm})\end{array}$ & $\begin{array}{l}\text { mult, } \\
J(\mathrm{~Hz})\end{array}$ & COSY & $\mathrm{HMBC}$ & TOCSY & ROESY \\
\hline$\overline{\mathrm{A} 1}$ & $\overline{101.9}$ & $\overline{\mathrm{CH}}$ & 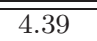 & $\overline{\mathrm{d}(7.8)}$ & $\overline{\mathrm{A} 2}$ & $\overline{17}$ & $\overline{\mathrm{A} 2, \mathrm{~A} 3,(\mathrm{~A} 4)}$ & $\overline{\mathrm{A} 3, \mathrm{~A} 5}$ \\
\hline $\mathrm{A} 2$ & 81.1 & $\mathrm{CH}$ & 3.46 & $\mathrm{t}(8.3)$ & $\mathrm{A} 1, \mathrm{~A} 3$ & $\mathrm{~A} 1, \mathrm{~A} 3$ & $\mathrm{~A} 1, \mathrm{~A} 3, \mathrm{~A} 4, \mathrm{~A} 5$ & $\mathrm{~A} 4$ \\
\hline A3 & 77.3 & $\mathrm{CH}$ & 3.58 & $\mathrm{~m}$ & $\mathrm{~A} 2, \mathrm{~A} 4$ & $\mathrm{~A} 2, \mathrm{~A} 4$ & $\mathrm{~A} 1, \mathrm{~A} 2, \mathrm{~A} 4, \mathrm{~A} 5$ & $\mathrm{~A} 1$ \\
\hline A4 & 82.4 & $\mathrm{CH}$ & 3.53 & $\mathrm{~m}$ & $\mathrm{~A} 3, \mathrm{~A} 5$ & $\mathrm{~A} 3, \mathrm{~A} 5, \mathrm{~A} 6$ & $\mathrm{~A} 1, \mathrm{~A} 2, \mathrm{~A} 3, \mathrm{~A} 5, \mathrm{~A} 6 \mathrm{a}, \mathrm{A} 6 \mathrm{~b}$ & A2 \\
\hline A5 & 75.7 & $\mathrm{CH}$ & 3.32 & $\mathrm{~m}$ & $\mathrm{~A} 4,(\mathrm{~A} 6 \mathrm{a}), \mathrm{A} 6 \mathrm{~b}$ & & $\mathrm{~A} 3, \mathrm{~A} 4, \mathrm{~A} 6$ & $\mathrm{~A} 1, \mathrm{~A} 6 \mathrm{a}$ \\
\hline A6a & 61.6 & $\mathrm{CH}_{2}$ & $\begin{array}{l}3.76 \\
3.62\end{array}$ & $\mathrm{~d}(11.9)$ & $\mathrm{A} 6 \mathrm{~b},(\mathrm{~A} 5)$ & $\mathrm{A} 4, \mathrm{~A} 5$ & $\mathrm{~A} 4, \mathrm{~A} 5$ & $\mathrm{~A} 5, \mathrm{~A} 6 \mathrm{~b}$ \\
\hline
\end{tabular}

\footnotetext{
${ }^{a}$ Only correlations within the sugar spin system are listed.
} 
$\mathrm{H}-\mathrm{A} 1$ also showed an HMBC correlation to an oxymethine $\left(\delta_{\mathrm{C}} 81.7, \delta_{\mathrm{H}} 3.63\right)$ which did not belong to any sugar spin system. It was therefore identified as the connection point to the aglycon.

Seven of the oxymethines, H-B2 $\left(\delta_{\mathrm{H}} 4.88\right), \mathrm{H}-\mathrm{B} 3\left(\delta_{\mathrm{H}} 5.27\right), \mathrm{H}-\mathrm{C} 3\left(\delta_{\mathrm{H}} 5.08\right)$, $\mathrm{H}-\mathrm{C} 4\left(\delta_{\mathrm{H}} 4.81\right), \mathrm{H}-\mathrm{F} 2\left(\delta_{\mathrm{H}} 4.86\right), \mathrm{H}-\mathrm{F} 3\left(\delta_{\mathrm{H}} 5.18\right)$ and H-F4 $\left(\delta_{\mathrm{H}} 5.00\right)$, and five of the oxymethylenes, $\mathrm{H}_{2}-\mathrm{B} 6\left(\delta_{\mathrm{Ha}} 4.81, \delta_{\mathrm{Hb}} 4.31\right), \mathrm{H}_{2}-\mathrm{C} 6\left(\delta_{\mathrm{Ha}} 4.33, \delta_{\mathrm{Hb}} 4.07\right), \mathrm{H}_{2}-\mathrm{D} 6$ $\left(\delta_{\mathrm{Ha}} 4.51, \delta_{\mathrm{Hb}} 4.24\right), \mathrm{H}_{2}-\mathrm{E} 6\left(\delta_{\mathrm{Ha}} 4.78, \delta_{\mathrm{Hb}} 4.14\right)$ and $\mathrm{H}_{2}-\mathrm{F} 6\left(\delta_{\mathrm{Ha}} 4.30, \delta_{\mathrm{Hb}} 4.11\right)$ had proton chemical shifts 1-2 ppm downfield from normal. These data, together with the presence of acetate methyls and ester carbonyls in the proton and carbon spectra indicated acetylation at those positions. HMBC correlations from each of the oxymethylene and oxymethine protons to the acetate carbonyls confirmed this assignment (for all acetate assignments see the full NMR data, Table 3.9).

In summary, the six sugar substructures were established through a combination of HSQC-TOCSY, COSY and HMBC experiments. All sugars were assigned as $\beta$-glucopyranoside based on large (7.8-10.0 Hz) coupling constants between the oxymethines, and 1,3-diaxial interactions observed in the ROESY spectrum.

Five of the sugar oxymethines showed lower field carbon chemical shifts (C$\left.\mathrm{A} 2 \delta_{\mathrm{C}} 81.1, \mathrm{C}-\mathrm{A} 4 \delta_{\mathrm{C}} 82.4, \mathrm{C}-\mathrm{B} 4 \delta_{\mathrm{C}} 79.6, \mathrm{C}-\mathrm{C} 2 \delta_{\mathrm{C}} 79.8, \mathrm{C}-\mathrm{D} 2 \delta_{\mathrm{C}} 83.8\right)$ characteristic of glycosidic linking carbons. The sugar linkages were established through key HMBC and ROESY correlations, shown in Figure 3.15. Reciprocal HMBC correlations were observed between positions A2 and F1 (H-A2 to C-F1 and $\mathrm{H}-\mathrm{F} 1$ to $\mathrm{C}-\mathrm{A} 2), \mathrm{A} 4$ and B1, B4 and $\mathrm{C} 1, \mathrm{C} 2$ and D1 and D2 and E1. The interglycosidic linkages were further confirmed by NOE cross-peaks between H-A2 and H-F1, H-A4 and H-B1, H-B4 and H-C1, and H-D2 and H-E1 observed in the ROESY spectrum. As detailed above, the anomeric proton doublets all had large coupling constants $(7.8-8.2 \mathrm{~Hz})$ suggesting $\beta$-glycosidic linkages. ${ }^{1} J_{\mathrm{CH}} \mathrm{cou}-$ pling constants of about $160 \mathrm{~Hz}$ further supported the axial positioning of the anomeric proton. ${ }^{148}$ The oligosaccharide can therefore be described as: Glc $\beta 1$ 2 Glc $\beta 1-2$ Glc $\beta 1-4$ Glc $\beta 1-4($ Glc $\beta 1-2)$ Glc $\beta 1$-aglycon. 


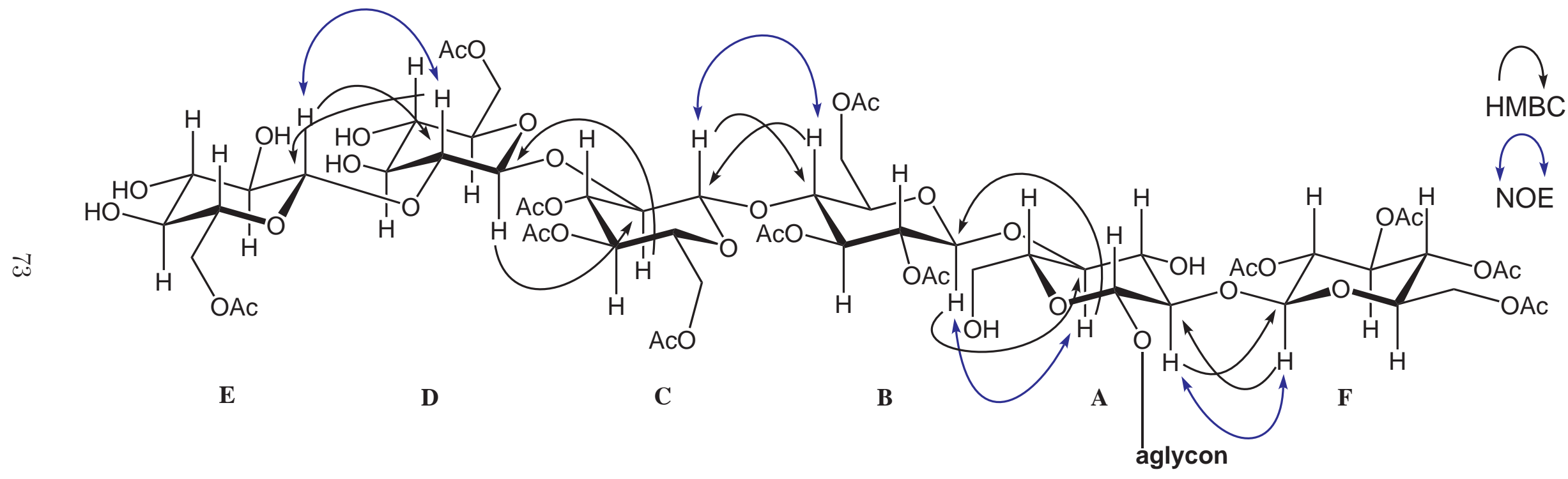

Figure 3.15. Key HMBC and ROESY correlations establishing the linkages between the sugars. 


\section{The aglycon}

The oligosaccharide portion accounted for the majority of the NMR signals. The remaining two oxymethylenes, two oxymethines, one acetate, a methyl triplet, six methylenes and the $\mathrm{CH}_{2}$ envelope were attributed to the aglycon. Based on COSY and HSQC-TOCSY correlations, they were assigned to three separate spin systems.

Starting from the methyl triplet, COSY and HSQC-TOCSY correlations allowed the construction of the first substructure, consisting of the methyl triplet $\left(\mathrm{CH}_{3}-20: \delta_{\mathrm{C}} 14.8, \delta_{\mathrm{H}} 0.92\right)$ attached to two methylenes $\left(\mathrm{CH}_{2}-19: \delta_{\mathrm{C}} 18.9, \delta_{\mathrm{H}} 1.48\right.$; $\left.\mathrm{CH}_{2}-18: \delta_{\mathrm{C}} 37.2, \delta_{\mathrm{H}} 1.48\right)$, next to the oxymethine $\mathrm{CH}-17\left(\delta_{\mathrm{C}} 81.7, \delta_{\mathrm{H}} 3.63\right)$ followed by the methylene $\mathrm{CH}_{2}-16\left(\delta_{\mathrm{C}} 35.9, \delta_{\mathrm{Ha}} 1.57, \delta_{\mathrm{Hb}} 1.49\right)$ and $\mathrm{CH}_{2}-15\left(\delta_{\mathrm{C}} 26.2\right.$, $\left.\delta_{\mathrm{H}} 1.37\right) . \mathrm{H}_{2}-15$ showed correlations to the $\mathrm{CH}_{2}$ envelope $\left(\delta_{\mathrm{C}} 30.7, \delta_{\mathrm{H}} 1.29\right)$.

The second substructure consisted of the oxymethylene $\mathrm{CH}_{2}-1\left(\delta_{\mathrm{C}} 72.8\right.$, $\left.\delta_{\mathrm{Ha}} 3.54, \delta_{\mathrm{Hb}} 3.47\right)$ which showed COSY correlations to the proton resonances of methylene $\mathrm{CH}_{2}-2\left(\delta_{\mathrm{C}} 30.7, \delta_{\mathrm{H}} 1.56\right)$, which in turn showed both COSY and TOCSY cross-peaks to the methylene $\mathrm{CH}_{2}-3\left(\delta_{\mathrm{C}} 27.2, \delta_{\mathrm{H}} 1.34\right) . \mathrm{H}_{2}-3$ also correlated to the $\mathrm{CH}_{2}$ envelope, ending the substructure.

The remaining oxymethine $\mathrm{CH}-2^{\prime}\left(\delta_{\mathrm{C}} 74.3, \delta_{\mathrm{H}} 5.14\right)$ showed a correlation to the last oxymethylene $\mathrm{CH}_{2}-3^{\prime}\left(\delta_{\mathrm{C}} 70.9, \delta_{\mathrm{Ha}} 3.83, \delta_{\mathrm{Hb}} 3.78\right)$ in the COSY spectrum. The ${ }^{1} \mathrm{H}$ chemical shift of $\mathrm{H}-2^{\prime}$ was indicative once again of acetylation, and indeed, a correlation from $\mathrm{H}-2^{\prime}$ to the acetate carbonyl $\delta_{\mathrm{C}} 172.4$ was observed in the HMBC spectrum, and from the acetate methyl $\left(\delta_{\mathrm{C}} 20.8, \delta_{\mathrm{H}} 2.13\right)$ to the same carbonyl.

The three substructures accounted for all the remaining visible signals in the NMR spectra. The first two substructures were clearly connected through a long $\mathrm{CH}_{2}$ chain of unknown length (the integration of the $\mathrm{CH}_{2}$ envelope suggested a further 11-12 methylenes). The final substructure was connected to the rest through observations of reciprocal HMBC correlations from $\mathrm{H}-3^{\prime}$ a and $\mathrm{H}-3^{\prime} \mathrm{b}$ to $\mathrm{C}-1$, and from $\mathrm{H}-1 \mathrm{a}$ and $\mathrm{H}-1 \mathrm{~b}$ to $\mathrm{C}-3^{\prime}$, establishing an ether linkage between the two parts. The final aglycon substructure is depicted in Figure 3.16.

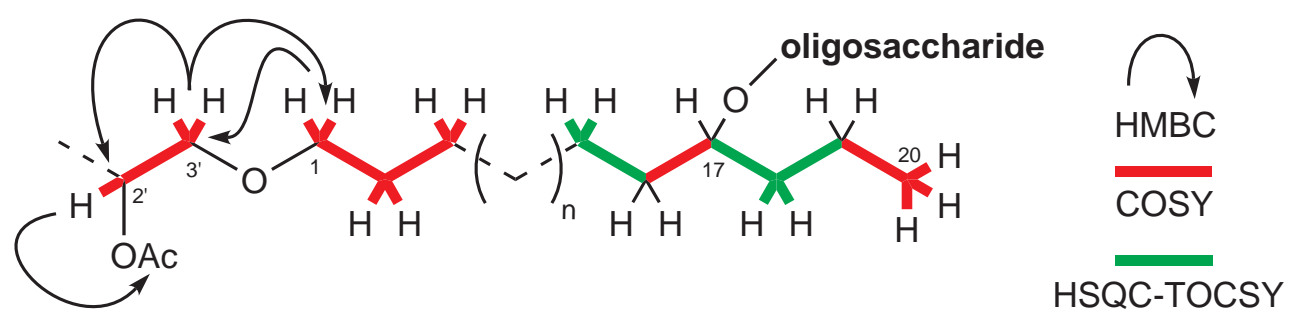

Figure 3.16. Key correlations establishing the aglycon substructure. 
The connectivity between the aglycon and the oligosaccharide was established through observation of a correlation in the HMBC spectrum from H-A1 to C-17, as previously mentioned, which indicated the anomeric position of sugar A was connected to position 17 of the aliphatic chain of the aglycon. This assigment was confirmed by an NOE enhancement between H-17 and H-A1 observed in a ROESY experiment.

At this point, the observed NMR signals suggested a minimum molecular formula of $\mathrm{C}_{84} \mathrm{H}_{131} \mathrm{O}_{46}$, and at least 19 double bond equivalents (six sugars and 13 acetate carbonyls). These data narrowed down the possible molecular formulae to one: $\mathrm{C}_{85} \mathrm{H}_{132} \mathrm{O}_{48} \mathrm{Na}$. This is consistent with a $[\mathrm{M}+\mathrm{Na}]^{+}$pseudomolecular ion, with the negative ion mode ESIMS showing a $[\mathrm{M}-\mathrm{H}]^{-}$pseudomolecular ion at 1919. With the molecular formula established, one further carbon, two oxygens, a hydrogen and a double bond equivalent remained unaccounted for, and were not apparent in the NMR spectra.

\section{Chemical derivatization reactions}

In order to fully assign the structure of the aglycon, a methanolysis of the glycolipid was performed to remove the attached sugars. Agminoside A (145) (1 mg) was heated in methanolic $\mathrm{HCl}$ for $48 \mathrm{~h}$, and the reaction was worked up by cyclic loading onto HP20SS. The resulting free aglycon (151) had a $[\mathrm{M}+\mathrm{Na}]^{+}$ pseudomolecular ion of 439.3381 in positive ion mode HRESIMS, indicating a formula of $\mathrm{C}_{24} \mathrm{H}_{48} \mathrm{O}_{5}(\Delta 3.0 \mathrm{ppm})$. Due to the paucity of material, a similar methanolysis was performed on a mixture of glycolipids to obtain $11 \mathrm{mg}$ of the aglycon, which had identical ${ }^{1} \mathrm{H}$ NMR and the same pseudomolecular ion by MS.

Analysis of the ${ }^{1} \mathrm{H}$ and ${ }^{13} \mathrm{C}$ NMR spectra revealed the presence of a carbonyl carbon (which accounted for the one double bond equivalent indicated by the molecular formula), two oxymethines, two oxymethylenes, a series of methylenes, a methyl triplet, and a new $O$-methyl resonance that was not apparent in the original ${ }^{1} \mathrm{H}$ spectrum of 145 (see Figure B.23). The COSY spectrum indicated the presence of three spin systems, as were found in the aglycon of agminoside A (145). From methyl $\mathrm{CH}_{3}-20\left(\delta_{\mathrm{C}} 14.3, \delta_{\mathrm{H}} 0.92\right)$, COSY and HMBC correlations allowed the assignment of two contiguous methylenes $\mathrm{CH}_{2}-19$ and $\mathrm{CH}_{2}-18$ $\left(\delta_{\mathrm{C}} 19.0, \delta_{\mathrm{H}} 1.44 ; \delta_{\mathrm{C}} 39.8, \delta_{\mathrm{H}} 1.41\right)$ followed by the oxymethine $\mathrm{CH}-17\left(\delta_{\mathrm{C}} 71.9\right.$, $\left.\delta_{\mathrm{H}} 3.59\right)$, which correlated to methylene $\mathrm{CH}_{2}-16\left(\delta_{\mathrm{C}} 37.6, \delta_{\mathrm{H}} 1.41\right)$ and methylene $\mathrm{CH}_{2}-15\left(\delta_{\mathrm{C}} 25.8, \delta_{\mathrm{H}} 1.40\right)$. From the other side of the aglycon, COSY and HMBC correlations established that oxymethylene $\mathrm{CH}_{2}-1\left(\delta_{\mathrm{C}} 72.0, \delta_{\mathrm{Ha}} 3.49, \delta_{\mathrm{Hb}} 3.42\right)$ was attached to methylene $\mathrm{CH}_{2}-2\left(\delta_{\mathrm{C}} 29.5, \delta_{\mathrm{H}} 1.54\right)$ followed by methylene $\mathrm{CH}_{2}$ - 


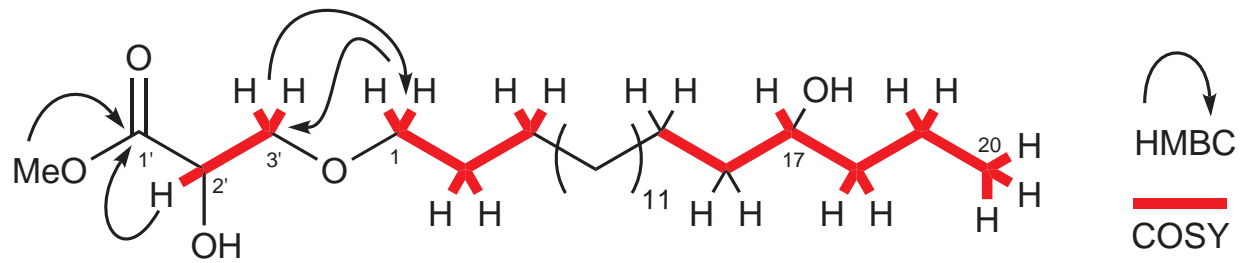

Figure 3.17. Key COSY and HMBC correlations establishing the structure of the aglycon methyl ester (151).

$3\left(\delta_{\mathrm{C}} 26.1, \delta_{\mathrm{H}} 1.26\right)$. Both methylene $\mathrm{CH}_{2}-3$ and $\mathrm{CH}_{2}-15$ showed correlations to the $\mathrm{CH}_{2}$ envelope at $\delta_{\mathrm{C}} 29.7$ and $\delta_{\mathrm{H}} 1.24$, indicating they were connected via a long chain of $\mathrm{CH}_{2}$ units. The integration in the ${ }^{1} \mathrm{H}$ spectrum indicated a further 11 methylenes, a number that matched exactly with the molecular formula.

The remaining oxymethylene, oxymethine, carbonyl carbon and oxymethyl resonances constituted the final substructure. Oxymethylene $\mathrm{CH}_{2}-3^{\prime}\left(\delta_{\mathrm{C}} 72.1\right.$, $\left.\delta_{\mathrm{H}} 3.70\right)$ and oxymethine $\mathrm{CH}-2^{\prime}\left(\delta_{\mathrm{C}} 71.0, \delta_{\mathrm{H}} 4.30\right)$ were placed next to each other, based on a correlation between their respective protons observed in the COSY spectrum. The carbonyl resonance $\mathrm{C}-1^{\prime}$ was assigned as an ester, based on a strong HMBC correlation from the OMe $\left(\delta_{\mathrm{C}} 52.7, \delta_{\mathrm{H}} 3.79\right)$ to $\delta_{\mathrm{C}} 173.3$. HMBC correlations from $\mathrm{H}_{2}-3^{\prime}$ and $\mathrm{H}-2^{\prime}$ to the carbonyl, and from the OMe to $\mathrm{C}-2^{\prime}$ and C-3' established the final substructure as the methyl ester derivative of glyceric acid (2,3-dihydroxypropanoic acid).

Observation of HMBC correlations from $\mathrm{H}_{2}-3^{\prime}$ to $\mathrm{C}-1$ and from $\mathrm{H}_{2}-1$ to C-3' linked the substructures together through an ether, as can be seen in Figure 3.17. As the OMe resonance was not observed in the original NMR spectra of the natural product, it is most likely a product of the methanolysis, indicating the original functional group present in the aglycon was actually a carboxylic acid. A carboxylic acid carbon resonance was not apparent in the NMR spectra of 145, possibly due to one or more of the following: overlap (with one of the 13 carbonyl resonances of the acetates), slow relaxation (resulting in a weak signal indistinguishable from the baseline noise) and long range deuterium-carbon coupling (which would reduce the signal intensity due to coupling). Interestingly though, the HMBC spectrum of the glycolipid mixture (which is mainly 145) did show a correlation from $\delta_{\mathrm{H}} 5.11$ (oxymethine $\mathrm{CH}-2^{\prime}$ ) to $\delta_{\mathrm{C}} 173.2$ (carbonyl C-1') (as marked in Figure 3.18(a)).

In order to unequivocally prove the presence of a free carboxylic acid moiety in the aglycon, a methylation was performed on a mixture of the glycolipids. Diazomethane is a common reagent for methylations; since the conditions are mild and the reaction is high yielding, it is very useful for methylation of natural 


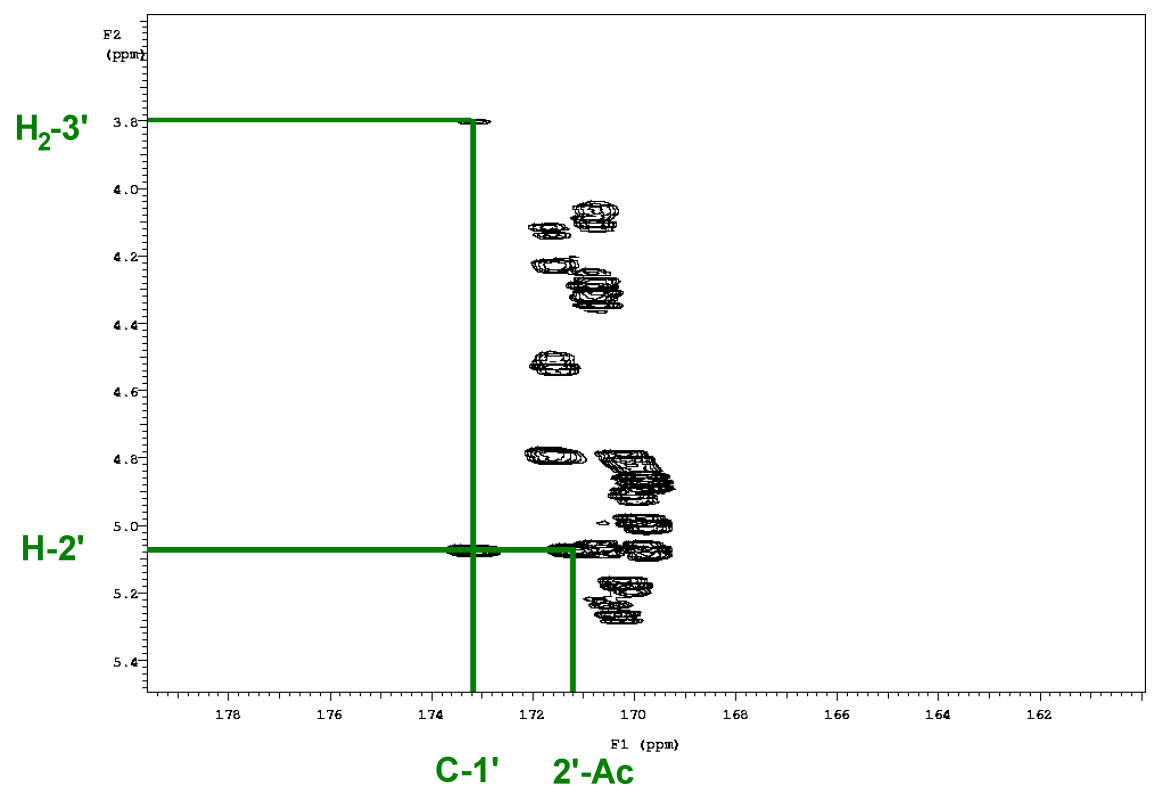

(a) A section of the HMBC of the glycolipid mixture.

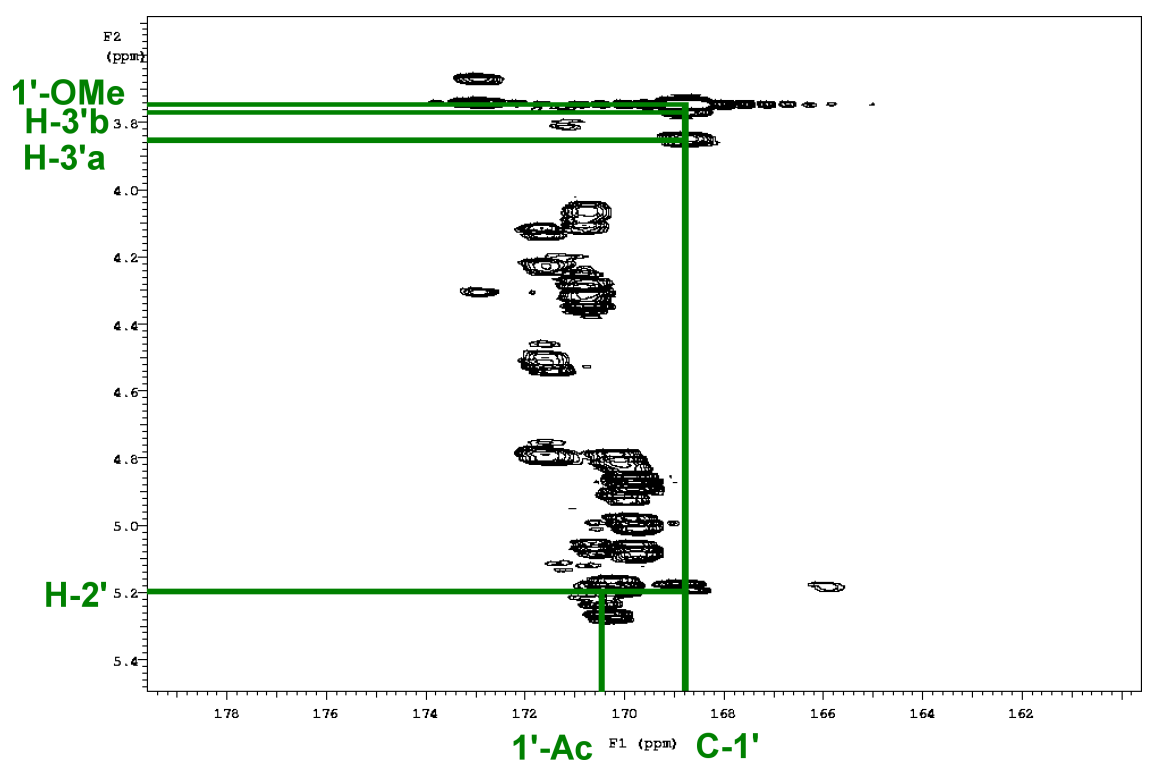

(b) A section of the HMBC of the methylated glycolipid mixture.

Figure 3.18. Close-up of the carbonyl region in the HMBC spectra (600 MHz, $\mathrm{CD}_{3} \mathrm{OD}$ ) of the glycolipids and the methylated glycolipids.

products (which are often temperature sensitive and scarce). ${ }^{149}$ Unfortunately, diazomethane is highly toxic, thermally labile and explosive. Trimethylsilyldiazomethane $\left(\mathrm{TMSCHN}_{2}\right)$ has been developed as a safer, more stable alternative for the methylation of carboxylic acids and alcohols. ${ }^{150}$

The mixture of glycolipids was therefore subjected to $\mathrm{TMSCHN}_{2}$. Analysis of the NMR spectra of the resulting product mixture revealed the presence of a new signal at $\delta_{\mathrm{C}} 51.6$ and $\delta_{\mathrm{H}}$ 3.74. A correlation from $\delta_{\mathrm{H}} 3.74$ to $\delta_{\mathrm{C}} 170.3$ was 
observed in the HMBC spectrum (see Figure 3.18(b)), indicating the successful formation of a methyl ester. Correlations from $\delta_{\mathrm{H}} 3.86,3.76$ and 5.18 to the same carbonyl resonance were attributed to $\mathrm{H}-3^{\prime} \mathrm{a}, \mathrm{H}-3^{\prime} \mathrm{b}$ and $\mathrm{H}-2^{\prime}$ respectively.

The remaining question to be answered was that of the configuration of the two chiral centres of the aglycon; as they were both secondary alcohol derivatives, Mosher's method was ideal for this purpose. ${ }^{151}$ Two portions of 151 were subjected to esterification with $(R)$ - and $(S)$-MTPA chloride $((R)$ - or $(S)$ - $\alpha$ methoxy- $\alpha$-trifluoromethylphenylacetic acid chloride) according to standard procedure. ${ }^{152}$ The reaction was incomplete, and the products consisted of a mixture that probably included unreacted starting material, the 17-MTPA ester, the 2'MTPA ester and the di-ester derivatives. As the two chiral centres are quite remote, however, they should have no effect on each other; the mixture could be treated simply as containing either the starting material, or the ester product. They were assigned fully by NMR spectroscopy without further purification.

The difference between the chemical shift (the $\Delta \delta$ ) of the $(S)$ - and the $(R)$ MTPA derivative was calculated (see Table 3.7). For the most part, the results were consistent, showing positive (blue) and negative (red) $\Delta \delta$ values at either side of the chiral centre. Two anomalous values (of the two carbons on either side of the ether bridge) were excluded from the analysis. Assuming the ester exists predominantly in one conformation (as first proposed by Mosher ${ }^{153,154}$ and later confirmed by X-ray ${ }^{155}$ ), the data suggest the absolute configuration of the aglycon is $17 R$ and $2^{\prime} R$.

As final confirmation of the stereochemical assigment, ${ }^{19} \mathrm{~F}$ NMR was run on the two MTPA derivatives. For both centres, an upfield shift of $\delta_{\mathrm{F}}$ was observed supporting the assignment of positions 17 and $2^{\prime}$ as $R$. Fluorine NMR is the original NMR experiment proposed by Mosher for determination of configuration, as it showed larger chemical shift differences than for the proton signals and was best suited for the low field NMR available at the time. ${ }^{154}$ The advent of high field NMR spectroscopy and the use of sophisticated 2D experiments now allow the resolution and full assignment of all proton and carbon resonances. The advantage of using proton and carbon resonances for the stereochemical assignment is that the shielding effect can be observed on multiple centres, rather than relying on a single measurement. Nevertheless, ${ }^{19} \mathrm{~F}$ NMR spectroscopy can be a useful tool as the fluorine spectrum is simple and easy to interpret, even if its accuracy is sometimes called into question. ${ }^{154}$

The assignment of the centre $2^{\prime}$ as $R$ is credible, as this is the configuration for the natural (D) glyceric acid. Therefore, the final structure of the aglycon 
Table 3.7. NMR data $\left(600 \mathrm{MHz}, \mathrm{CDCl}_{3}\right)$ with the $\Delta \delta$ values for the two Mosher's derivatives of the aglycon methyl ester.

\begin{tabular}{|c|c|c|c|c|c|c|c|c|}
\hline \multicolumn{4}{|c|}{$(S)$-MPTA derivative } & \multicolumn{3}{|c|}{$(R)$-MPTA derivative } & \multicolumn{2}{|c|}{$\Delta \delta$} \\
\hline$\delta_{\mathrm{C}}$ & mult & $\delta_{\mathrm{H}}$ & & $\delta_{\mathrm{C}}$ & mult & $\delta_{\mathrm{H}}$ & $\overline{\delta S}$ & $-\delta R$ \\
\hline$(\mathrm{ppm})$ & & $(\mathrm{ppm})$ & position & $(\mathrm{ppm})$ & & $(\mathrm{ppm})$ & $\Delta \delta_{\mathrm{C}}$ & $\Delta \delta_{\mathrm{H}}$ \\
\hline & & 3.492 & $1 \mathrm{a}$ & & & 3.402 & & 0.090 \\
\hline 11.92 & $\mathrm{CH}_{2}$ & 3.423 & $1 b$ & 82.04 & $\mathrm{CH}_{2}$ & 3.308 & -0.12 & 0.115 \\
\hline 29.65 & $\mathrm{CH}_{2}$ & 1.517 & 2 & 29.56 & $\mathrm{CH}_{2}$ & 1.431 & 0.09 & 0.086 \\
\hline 26.07 & $\mathrm{CH}_{2}^{2}$ & 1.266 & 3 & 25.98 & $\mathrm{CH}_{2}^{2}$ & 1.212 & 0.09 & 0.054 \\
\hline 29.7 & $\mathrm{CH}_{2}$ & 1.26 & $4-14$ & 29.7 & $\mathrm{CH}_{2}$ & 1.26 & 0 & 0 \\
\hline 24.97 & $\mathrm{CH}_{2}^{2}$ & 1.157 & 15 & 25.36 & $\mathrm{CH}_{2}^{2}$ & 1.286 & -0.39 & -0.129 \\
\hline 33.60 & $\mathrm{CH}_{2}$ & 1.540 & $16 \mathrm{a}$ & 33.86 & $\mathrm{CH}_{2}$ & 1.580 & -0.26 & $\begin{aligned}-0.040 & -040\end{aligned}$ \\
\hline 77.54 & $\mathrm{CH}$ & & $\begin{array}{l}16 \mathrm{~b} \\
17\end{array}$ & 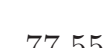 & $\mathrm{CH}$ & $\begin{array}{l}1.638 \\
5.099\end{array}$ & & -0.098 \\
\hline 11.04 & Un & 0.090 & 18 & 11.05 & $\mathrm{CH}$ & $\begin{array}{l}5.099 \\
1568\end{array}$ & & \\
\hline 36.00 & $\mathrm{CH}_{2}$ & $\begin{array}{l}1.042 \\
1.556\end{array}$ & $\begin{array}{l}18 \mathrm{a} \\
18 \mathrm{~b}\end{array}$ & 35.68 & $\mathrm{CH}_{2}$ & $\begin{array}{l}1.568 \\
1.509\end{array}$ & 0.32 & $\begin{array}{l}0.074 \\
0.047\end{array}$ \\
\hline 1868 & & 1333 & $19 a$ & 825 & & 1.245 & 0.43 & 0.088 \\
\hline 10.00 & $\mathrm{H}_{2}$ & 1.500 & $19 \mathrm{~b}$ & 10.20 & ${ }^{1}$ & 1.176 & 0.40 & 0.157 \\
\hline 14.06 & $\mathrm{CH}_{3}$ & 0.910 & 20 & 13.96 & $\mathrm{CH}_{3}$ & 0.844 & 0.10 & 0.066 \\
\hline 69.10 & $\mathrm{CH}_{2}$ & 3.879 & $3^{\prime}$ a & 69.17 & $\mathrm{CH}_{2}$ & 3.859 & -0.07 & 0.020 \\
\hline & 2 & 3.853 & $3^{\prime} \mathrm{b}$ & & & 3.762 & & 0.091 \\
\hline 73.64 & $\mathrm{CH}$ & 5.495 & $2^{\prime}$ & 73.99 & $\mathrm{CH}$ & 5.427 & & \\
\hline 167.46 & C & - & $1^{\prime}$ & 167.74 & C & - & -0.28 & - \\
\hline 52.79 & $\mathrm{CH}_{3}$ & 3.751 & $1^{\prime}-\mathrm{OMe}$ & 52.85 & $\mathrm{CH}_{3}$ & 3.800 & -0.06 & -0.049 \\
\hline
\end{tabular}

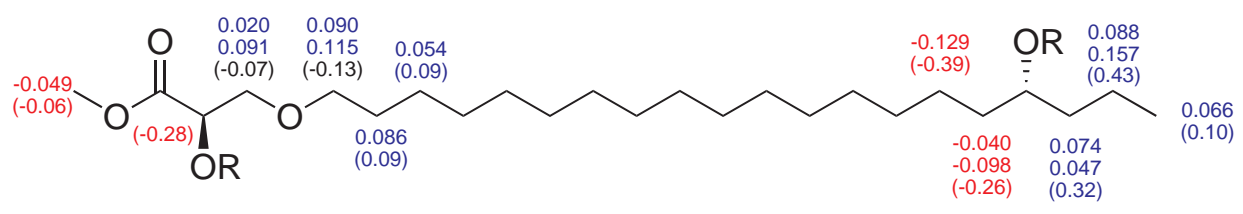

methyl ester is assigned as 151; NMR data are presented in Table 3.8.

The methanolysis of the glycolipids to obtain the aglycon also resulted in the methanolysis of the oligosaccharide portion. Only one methyl glucoside was obtained (41:9 $\alpha$ to $\beta$ anomer) and assigned as 1- $O$-methyl-glucose, consistent with the assignment of all the sugars as glucose in agminoside A (145). The measured optical rotation of these sugars in $\mathrm{H}_{2} \mathrm{O}$ was +209 . This is comparable (in sign if not in magnitude) to the literature value of $[\alpha]_{\mathrm{D}}^{20}=+158.9$ for 1 $O$-methyl- $\alpha$-D-glucose. ${ }^{156}$ While this suggested that the glucose sugars were Dglucose, further evidence was obtained through chiral derivatization and GC analysis.

A mixture of the glycolipids was subjected to acid catalyzed hydrolysis. The aglycon was extracted with $\mathrm{CH}_{2} \mathrm{Cl}_{2}$ and the aqueous residue was evaporated to dryness under reduced pressure. A portion of these hydrolysed sugars was subjected to reductive amination with $(S)$-1-amino-2-propanol and peracetylated, 
Table 3.8. NMR data (600 MHz, $\mathrm{CDCl}_{3}$ ) for aglycon methyl ester (151).

\begin{tabular}{|c|c|c|c|c|c|c|}
\hline position & $\begin{array}{c}\delta_{\mathrm{C}} \\
(\mathrm{ppm})\end{array}$ & mult & $\begin{array}{c}\delta_{\mathrm{H}} \\
(\mathrm{ppm})\end{array}$ & $\begin{array}{l}\text { mult, } \\
J(\mathrm{~Hz})\end{array}$ & COSY & HMBC \\
\hline $1 \mathrm{a}$ & & $\mathrm{CH}_{2}$ & 3.49 & $\overline{\mathrm{dtt}(9.4,6.6)}$ & $1 \mathrm{1b}, 2$ & $\overline{3^{\prime}}$ \\
\hline $1 b$ & 12.0 & $\mathrm{CH} 2$ & 3.42 & $\mathrm{dt}(9.4,6.6)$ & $1 \mathrm{a}, 2$ & $3^{\prime}$ \\
\hline 2 & 29.5 & $\mathrm{CH}_{2}$ & 1.54 & quin (6.7) & $1 \mathrm{a}, 1 \mathrm{~b}, 3$ & 3,4 \\
\hline 3 & 26.1 & $\mathrm{CH}_{2}$ & 1.26 & $\mathrm{~m}$ & 2,4 & \\
\hline $4-14$ & 29.7 & $\mathrm{CH}_{2}$ & 1.24 & $\mathrm{~m}$ & & \\
\hline 15 & 25.8 & $\mathrm{CH}_{2}$ & 1.40 & $\mathrm{~m}$ & & \\
\hline 16 & 37.6 & $\mathrm{CH}_{2}$ & 1.41 & $\mathrm{~m}$ & 17 & \\
\hline 17 & 71.9 & $\mathrm{CH}$ & 3.59 & $\mathrm{~m}$ & 16,18 & $15,(16,18), 19$ \\
\hline 18 & 39.8 & $\mathrm{CH}_{2}$ & 1.41 & $\mathrm{~m}$ & 17,19 & \\
\hline 19 & 19.0 & $\mathrm{CH}_{2}$ & 1.44 & $\mathrm{~m}$ & 18,20 & \\
\hline 20 & 14.3 & $\mathrm{CH}_{3}^{2}$ & 0.92 & $\mathrm{t}(6.9)$ & 19 & 18,19 \\
\hline $3^{\prime}$ & 72.1 & $\mathrm{CH}_{2}$ & 3.70 & $\mathrm{~d}(3.5)$ & $2^{\prime}$ & $1,1^{\prime}, 2^{\prime}$ \\
\hline $2^{\prime}$ & 71.0 & $\mathrm{CH}$ & 4.30 & $\mathrm{t}(3.5)$ & $3^{\prime}$ & $1^{\prime}, 3^{\prime}$ \\
\hline $1^{\prime}$ & 173.3 & $\mathrm{C}$ & - & - & - & - \\
\hline $1^{\prime}$-OMe & 52.7 & $\mathrm{CH}_{3}$ & 3.79 & $\mathrm{~s}$ & & $1^{\prime}\left(2^{\prime}, 3^{\prime}\right)$ \\
\hline
\end{tabular}<smiles>CCC[C@H](O)CCCCCCCCCCCCCCCCOC[C@H](O)C(=O)OC</smiles>

151

as previously described. ${ }^{157}$ The resulting product was subjected to GC analysis and compared to a D-glucose standard derivatized in a similar fashion. The product and the standard had the same retention time, and in fact co-eluted when co-injected, proving conclusively that the sugars were indeed D-glucose.

The complete structure of agminoside $\mathrm{A}$ is therefore assigned as $\mathbf{1 4 5}$, with NMR data presented in Table 3.9.

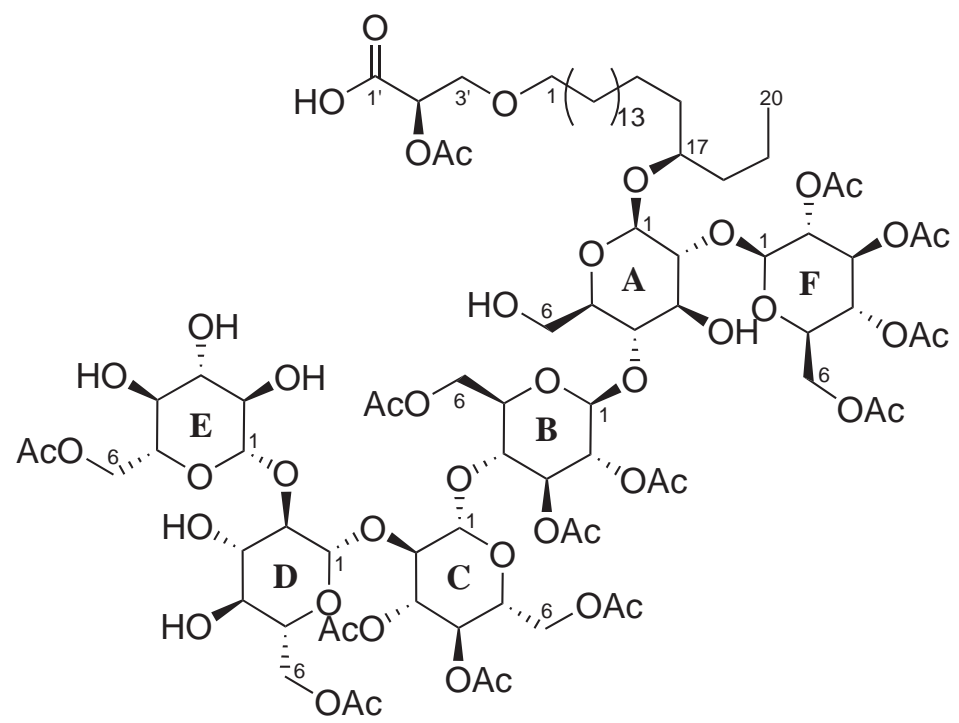

145 
Table 3.9. NMR data (600 MHz, $\left.\mathrm{CD}_{3} \mathrm{OD}\right)$ for agminoside A (145).

\begin{tabular}{|c|c|c|c|c|c|c|c|c|c|}
\hline pos. & $\begin{array}{c}\delta_{\mathrm{C}} \\
(\mathrm{ppm})\end{array}$ & mult & ${ }^{1} J_{\mathrm{CH}}$ & $\begin{array}{c}\delta_{\mathrm{H}} \\
(\mathrm{ppm})\end{array}$ & $\begin{array}{l}\text { mult, } \\
J(\mathrm{~Hz})\end{array}$ & COSY & HMBC & TOCSY & ROESY \\
\hline & \multirow{2}{*}{\multicolumn{9}{|c|}{ Aglycon }} \\
\hline $1 \mathrm{a}$ & & & & & & & & & \\
\hline $1 \mathrm{~b}$ & 72.8 & $\mathrm{CH}_{2}$ & 141 & 3.47 & $\mathrm{~m}$ & 1a, 2 & $3^{\prime}$ & 2,3 & 2 \\
\hline 2 & 30.7 & $\mathrm{CH}_{2}$ & 125 & 1.56 & $\mathrm{~m}$ & $1 \mathrm{a}, 1 \mathrm{~b}, 3$ & 1,3 & 1,3 & $1 b, 3$ \\
\hline 3 & 27.2 & $\mathrm{CH}_{2}^{2}$ & 124 & 1.34 & $\mathrm{~m}$ & 2,4 & 2 & 1,4 & 2 \\
\hline $4-14$ & 30.7 & $\mathrm{CH}_{2}$ & 120 & 1.29 & $\mathrm{~m}$ & 3 & & & \\
\hline 15 & 26.2 & $\mathrm{CH}_{2}^{2}$ & 124 & 1.37 & $\mathrm{~m}$ & & & 16 & \\
\hline $16 \mathrm{a}$ & \multirow{2}{*}{35.9} & \multirow{2}{*}{$\mathrm{CH}_{2}$} & 119 & 1.57 & $\mathrm{~m}$ & $16 \mathrm{~b}$ & & & \multirow[t]{2}{*}{15} \\
\hline $16 \mathrm{~b}$ & & & 124 & 1.49 & $\mathrm{~m}$ & $16 \mathrm{a}$ & & & \\
\hline 17 & 81.7 & $\mathrm{CH}$ & 141 & 3.63 & $\mathrm{~m}$ & $16 \mathrm{a}, 16 \mathrm{~b}$ & 19 & 16,18 & $18, \mathrm{~A} 1$ \\
\hline 18 & 37.2 & $\mathrm{CH}_{2}$ & 120 & 1.48 & $\mathrm{~m}$ & & & & \\
\hline 19 & 18.9 & $\mathrm{CH}_{2}^{2}$ & 120 & 1.48 & $\mathrm{~m}$ & & 18,20 & 18,20 & \\
\hline 20 & 14.8 & $\mathrm{CH}_{3}^{2}$ & 124 & 0.92 & $\mathrm{t}(6.9)$ & 19 & 18,19 & 18,19 & 19 \\
\hline $3^{\prime} \mathrm{a}$ & & & 144 & 3.83 & dd $(11.2,5.6)$ & $3^{\prime} \mathrm{b}$ & $1,2^{\prime}$ & $2^{\prime}$ & $2^{\prime}$ \\
\hline $3^{\prime} \mathrm{b}$ & 70.9 & $\mathrm{CH}_{2}$ & 144 & 3.78 & $\mathrm{~m}$ & $3^{\prime} \mathrm{a}$ & $1,2^{\prime}$ & $2^{\prime}$ & \\
\hline $2^{\prime}$ & 74.3 & $\mathrm{CH}$ & 151 & 5.14 & dd $(5.9,2.6)$ & $3^{\prime} \mathrm{a}, 3^{\prime} \mathrm{b}$ & $2^{\prime}-\mathrm{Ac}, 3^{\prime}$ & $3^{\prime}$ & $3^{\prime} \mathrm{a}, 3^{\prime} \mathrm{b}$ \\
\hline $1^{\prime}$ & a & $\mathrm{C}$ & - & - & - & - & - & - & \\
\hline \multirow{2}{*}{$2^{\prime}-\mathrm{Ac}$} & 172.4 & $\mathrm{C}$ & - & - & - & - & - & - & - \\
\hline & $20.8^{\mathrm{b}}$ & $\mathrm{CH}_{3}$ & - & 2.13 & $\mathrm{~s}$ & - & $2^{\prime}-\mathrm{Ac}$ & - & \\
\hline & \multicolumn{9}{|c|}{ Glucose A } \\
\hline A1 & 101.9 & $\mathrm{CH}$ & 158 & 4.39 & $\mathrm{~d}(7.8)$ & A2 & 17 & $\mathrm{~A} 2, \mathrm{~A} 3,(\mathrm{~A} 4)$ & $17, \mathrm{~A} 3, \mathrm{~A} 5$ \\
\hline $\mathrm{A} 2$ & 81.1 & $\mathrm{CH}$ & 146 & 3.46 & $\mathrm{t}(8.3)$ & $\mathrm{A} 1, \mathrm{~A} 3$ & $\mathrm{~A} 1, \mathrm{~A} 3, \mathrm{~F} 1$ & $\mathrm{~A} 1, \mathrm{~A} 3, \mathrm{~A} 4, \mathrm{~A} 5$ & $\mathrm{~A} 4, \mathrm{~F} 1$ \\
\hline A3 & 77.3 & $\mathrm{CH}$ & 145 & 3.58 & $\mathrm{~m}$ & $\mathrm{~A} 2, \mathrm{~A} 4$ & $\mathrm{~A} 2, \mathrm{~A} 4$ & $\mathrm{~A} 1, \mathrm{~A} 2, \mathrm{~A} 4, \mathrm{~A} 5$ & A1 \\
\hline A4 & 82.4 & $\mathrm{CH}$ & 147 & 3.53 & $\mathrm{~m}$ & $\mathrm{~A} 3, \mathrm{~A} 5$ & $\mathrm{~A} 3, \mathrm{~A} 5, \mathrm{~A} 6, \mathrm{~B} 1$ & $\mathrm{~A} 1, \mathrm{~A} 2, \mathrm{~A} 3, \mathrm{~A} 5, \mathrm{~A} 6 \mathrm{a}, \mathrm{A} 6 \mathrm{~b}$ & $\mathrm{~A} 2, \mathrm{~B} 1$ \\
\hline A5 & 75.7 & $\mathrm{CH}$ & 140 & 3.32 & $\mathrm{~m}$ & $\mathrm{~A} 4,(\mathrm{~A} 6 \mathrm{a}), \mathrm{A} 6 \mathrm{~b}$ & & $\mathrm{~A} 3, \mathrm{~A} 4, \mathrm{~A} 6$ & A1, A6a \\
\hline A6a & \multirow{2}{*}{61.6} & \multirow[b]{2}{*}{$\mathrm{CH}_{2}$} & 144 & 3.76 & $\mathrm{~d}(11.9)$ & $\mathrm{A} 6 \mathrm{~b},(\mathrm{~A} 5)$ & $\mathrm{A} 4, \mathrm{~A} 5$ & & $\mathrm{~A} 5, \mathrm{~A} 6 \mathrm{~b}$ \\
\hline A6b & & & 142 & 3.62 & dd $(11.9,3.8)$ & A6a, A5 & & $\mathrm{A} 4, \mathrm{~A} 5$ & A6a \\
\hline & \multicolumn{9}{|c|}{ Glucose B } \\
\hline B1 & 102.0 & $\mathrm{CH}$ & 166 & 4.81 & $\mathrm{~d}(8.2)$ & B2 & $\mathrm{A} 4$ & $\mathrm{~B} 2, \mathrm{~B} 3$ & $\mathrm{~A} 4, \mathrm{~B} 3, \mathrm{~B} 5$ \\
\hline $\mathrm{B} 2$ & 73.0 & $\mathrm{CH}$ & 153 & 4.88 & $\mathrm{t}(8.2)$ & B1, B3 & $\mathrm{B} 1, \mathrm{~B} 3, \mathrm{~B} 2-\mathrm{Ac}$ & $\mathrm{B} 1, \mathrm{~B} 3, \mathrm{~B} 4$ & $\mathrm{~B} 4$ \\
\hline B3 & 74.5 & $\mathrm{CH}$ & 151 & 5.27 & $\mathrm{t}(9.4)$ & $\mathrm{B} 2, \mathrm{~B} 4$ & $\mathrm{~B} 2, \mathrm{~B} 4, \mathrm{~B} 3-\mathrm{Ac}$ & $\mathrm{B} 1, \mathrm{~B} 2,(\mathrm{~B} 4, \mathrm{~B} 5)$ & $\mathrm{B} 1, \mathrm{~B} 2, \mathrm{~B} 4, \mathrm{~B} 5$ \\
\hline B4 & 79.6 & $\mathrm{CH}$ & 148 & 3.78 & $\mathrm{t}(9.4)$ & B3, B5 & $\mathrm{B} 3, \mathrm{~B} 5, \mathrm{~B} 6, \mathrm{C} 1$ & $\mathrm{~B} 2, \mathrm{~B} 3, \mathrm{~B} 5, \mathrm{~B} 6 \mathrm{~b}$ & $\mathrm{C} 1, \mathrm{~B} 2, \mathrm{~B} 3, \mathrm{~B} 6 \mathrm{~b}$ \\
\hline B5 & 74.2 & $\mathrm{CH}$ & $\begin{array}{l}140 \\
147\end{array}$ & $\begin{array}{l}0.10 \\
3.94\end{array}$ & ddd $(9.6,7.2,1.8)$ & $\mathrm{B} 4, \mathrm{~B} 6 \mathrm{a}, \mathrm{B} 6 \mathrm{~b}$ & (B4) & $\mathrm{B} 2, \mathrm{~B} 3, \mathrm{~B} 4, \mathrm{~B} 6 \mathrm{a}$ & $\mathrm{B} 1, \mathrm{~B} 3,(\mathrm{~B} 4), \mathrm{B} 6 \mathrm{a}$ \\
\hline
\end{tabular}

${ }^{a}$ not observed

$\mathrm{b}, \mathrm{c}, \mathrm{d}, \mathrm{e}, \mathrm{f}$ can be interchanged 
Table 3.9. - continued from previous page

\begin{tabular}{|c|c|c|c|c|c|c|c|c|c|}
\hline pos. & $\begin{array}{c}\delta_{\mathrm{C}} \\
(\mathrm{ppm})\end{array}$ & mult & ${ }^{1} J_{\mathrm{CH}}$ & $\begin{array}{c}\delta_{\mathrm{H}} \\
(\mathrm{ppm})\end{array}$ & $\begin{array}{l}\text { mult, } \\
J(\mathrm{~Hz})\end{array}$ & COSY & HMBC & TOCSY & ROESY \\
\hline B6a & & & 150 & 4.80 & $\mathrm{~m}$ & $\mathrm{~B} 6 \mathrm{~b}, \mathrm{~B} 5$ & $\mathrm{~B} 5, \mathrm{~B} 6-\mathrm{Ac}$ & B4 B5 & $\mathrm{B} 4$ \\
\hline B6b & 04.6 & $\mathrm{CH}_{2}$ & 148 & 4.31 & $\mathrm{~m}$ & B6a, B5 & $\mathrm{B} 6-\mathrm{Ac}$ & B4, B5 & B5 \\
\hline \multirow{2}{*}{$\mathrm{B} 2-\mathrm{Ac}$} & $171.2^{\mathrm{c}}$ & $\mathrm{C}$ & - & - & - & - & - & - & - \\
\hline & 20.7 & $\mathrm{CH}_{3}$ & - & 2.06 & s & - & B2-Ac & - & \\
\hline \multirow{2}{*}{ B3-Ac } & 171.7 & $\mathrm{C}^{\circ}$ & - & - & - & - & - & - & - \\
\hline & $20.8^{\mathrm{b}}$ & $\mathrm{CH}_{3}$ & - & $2.01^{\mathrm{d}}$ & $\mathrm{s}$ & - & B3-Ac & - & \\
\hline \multirow{2}{*}{ B6-Ac } & 172.5 & $\mathrm{C}^{\circ}$ & - & - & - & - & - & - & - \\
\hline & 21.2 & $\mathrm{CH}_{3}$ & - & 2.21 & $\mathrm{~s}$ & - & $\mathrm{B} 6-\mathrm{Ac}$ & - & \\
\hline & \multicolumn{9}{|c|}{ Glucose C } \\
\hline $\mathrm{C} 1$ & 103.6 & $\mathrm{CH}$ & 160 & 4.53 & $\mathrm{~d}(7.8)$ & $\mathrm{C} 2$ & B4 & $\mathrm{C} 2, \mathrm{C} 3$ & $\mathrm{~B} 4, \mathrm{C} 3, \mathrm{C} 5$ \\
\hline $\mathrm{C} 2$ & 79.8 & $\mathrm{CH}$ & 148 & 3.50 & $\mathrm{t}(8.4)$ & $\mathrm{C} 1, \mathrm{C} 3$ & $\mathrm{C} 1, \mathrm{C} 3, \mathrm{D} 1$ & $\mathrm{C} 1, \mathrm{C} 3, \mathrm{C} 4$ & $\mathrm{C} 4$ \\
\hline C3 & 76.5 & $\mathrm{CH}$ & 152 & 5.08 & $\mathrm{t}(9.5)$ & $\mathrm{C} 2, \mathrm{C} 4$ & $\mathrm{C} 2, \mathrm{C} 4, \mathrm{C} 2-\mathrm{Ac}$ & $\mathrm{C} 1, \mathrm{C} 2, \mathrm{C} 4, \mathrm{C} 5$ & $\mathrm{C} 1, \mathrm{C} 2, \mathrm{C} 4, \mathrm{C} 5$ \\
\hline $\mathrm{C} 4$ & 69.9 & $\mathrm{CH}$ & 152 & 4.81 & $\mathrm{t}(10.0)$ & $\mathrm{C} 3, \mathrm{C} 5$ & $\mathrm{C} 3, \mathrm{C} 5, \mathrm{C} 6, \mathrm{C} 4-\mathrm{Ac}$ & (C1), C2, C3, C5, C6a & $\mathrm{C} 2$ \\
\hline C5 & 72.5 & $\mathrm{CH}$ & 143 & 3.90 & ddd $(10.0,3.6,2.3)$ & $\mathrm{C} 4, \mathrm{C} 6 \mathrm{a}, \mathrm{C} 6 \mathrm{~b}$ & (C4) & $\mathrm{C} 3, \mathrm{C} 4, \mathrm{C} 6 \mathrm{a}, \mathrm{C} 6 \mathrm{~b}$ & $\mathrm{C} 1, \mathrm{C} 3, \mathrm{C} 6 \mathrm{a}, \mathrm{C} 6 \mathrm{~b}$ \\
\hline $\mathrm{C} 6 \mathrm{a}$ & & & 145 & 4.33 & $\mathrm{dd}(12.6,4.2)$ & $\mathrm{C} 6 \mathrm{~b}, \mathrm{C} 5$ & $\mathrm{C} 6-\mathrm{Ac}$ & (C4) $\mathrm{C}_{5}$ & $\mathrm{C} 5, \mathrm{C} 6 \mathrm{~b}$ \\
\hline $\mathrm{C} 6 \mathrm{~b}$ & 63.1 & $\mathrm{CH}_{2}$ & 148 & 4.07 & $\mathrm{~d}(12.0)$ & $\mathrm{C} 6 \mathrm{a}, \mathrm{C} 5$ & $\mathrm{C} 4, \mathrm{C} 5, \mathrm{C} 6-\mathrm{Ac}$ & $(\mathrm{C} 4), \mathrm{C} 5$ & $\mathrm{C} 5, \mathrm{C} 6 \mathrm{a}$ \\
\hline \multirow{2}{*}{$\mathrm{C} 3-\mathrm{Ac}$} & $171.2^{\mathrm{c}}$ & $\mathrm{C}$ & - & - & - & - & - & - & - \\
\hline & 21.3 & $\mathrm{CH} 3$ & - & 1.99 & $\mathrm{~s}$ & - & $\mathrm{C} 3-\mathrm{Ac}$ & - & \\
\hline \multirow{2}{*}{$\mathrm{C} 4-\mathrm{Ac}$} & 171.5 & C & - & - & - & - & - & - & - \\
\hline & $20.8^{\mathrm{b}}$ & $\mathrm{CH}_{3}$ & - & 1.93 & $\mathrm{~s}$ & - & $\mathrm{C} 4-\mathrm{Ac}$ & - & \\
\hline \multirow{2}{*}{ C6-Ac } & $172.2^{\mathrm{e}}$ & $\mathrm{C}^{0}$ & - & - & - & - & - & - & - \\
\hline & 20.6 & $\mathrm{CH}_{3}$ & - & 2.04 & $\mathrm{~s}$ & - & $\mathrm{C} 6-\mathrm{Ac}$ & - & \\
\hline & \multicolumn{9}{|c|}{ Glucose D } \\
\hline D1 & 103.1 & $\mathrm{CH}$ & 163 & 4.46 & $\mathrm{~d}(7.8)$ & D2 & $\mathrm{C} 2$ & D2, D3 & D3, D5 \\
\hline D2 & 83.8 & $\mathrm{CH}$ & 145 & 3.22 & $\mathrm{~m}$ & D1, D3 & D1, E1 & D1, D3, D4, D5 & $\mathrm{E} 1$ \\
\hline D3 & 77.9 & $\mathrm{CH}$ & 144 & 3.49 & $\mathrm{t}(7.9)$ & $\mathrm{D} 2, \mathrm{D} 4$ & $\mathrm{D} 2, \mathrm{D} 4$ & $\mathrm{D} 1, \mathrm{D} 2, \mathrm{D} 4, \mathrm{D} 5$ & D1 \\
\hline D4 & 71.5 & $\mathrm{CH}$ & 143 & 3.23 & $\mathrm{~m}$ & D3, D5 & D3, D5, D6 & D3, D5, D6a, D6b & \\
\hline D5 & 75.3 & $\mathrm{CH}$ & 140 & 3.44 & ddd $(9.4,7.0,1.5)$ & $\mathrm{D} 4, \mathrm{D} 6 \mathrm{a}, \mathrm{D} 6 \mathrm{~b}$ & & $\mathrm{D} 3, \mathrm{D} 4, \mathrm{D} 6 \mathrm{a}, \mathrm{D} 6 \mathrm{~b}$ & D1, D6a, D6b \\
\hline D6a & & & 144 & 4.51 & $\mathrm{dd}(11.0,7.5)$ & D6b, D5 & D5, D6-Ac & & D5, D6b \\
\hline $\mathrm{D} 6 \mathrm{~b}$ & 64.4 & $\mathrm{CH}_{2}$ & 148 & 4.24 & $\mathrm{dd}(10.3,1.6)$ & D6a, D5 & D6-Ac & D4, D5 & D5, D6a \\
\hline \multirow{2}{*}{ D6-Ac } & 173.0 & C & - & - & - & - & - & - & - \\
\hline & 21.4 & $\mathrm{CH}_{3}$ & - & $2.19^{\mathrm{f}}$ & $\mathrm{s}$ & - & D6-Ac & - & \\
\hline & \multicolumn{9}{|c|}{ Glucose E } \\
\hline E1 & 106.1 & $\mathrm{CH}$ & 161 & 4.40 & $\mathrm{~d}(7.9)$ & $\mathrm{E} 2$ & D2 & $\mathrm{E} 2, \mathrm{E} 3$ & $\mathrm{D} 2, \mathrm{E} 3, \mathrm{E} 5$ \\
\hline $\mathrm{E} 2$ & 75.2 & $\mathrm{CH}$ & 146 & 3.19 & $\mathrm{t}(8.1)$ & E1, E3 & E1, E3 & E1, E3, E4, E5 & $\mathrm{E} 1, \mathrm{E} 3, \mathrm{E} 4$ \\
\hline E3 & 78.2 & $\mathrm{CH}$ & 143 & 3.34 & $\mathrm{t}(8.6)$ & $\mathrm{E} 2, \mathrm{E} 4$ & $\mathrm{E} 2, \mathrm{E} 4$ & $\mathrm{E} 1, \mathrm{E} 2, \mathrm{E} 4, \mathrm{E} 5$ & $\mathrm{E} 1, \mathrm{E} 2, \mathrm{E} 4$ \\
\hline E4 & 70.7 & $\mathrm{CH}$ & 148 & 3.46 & t (9.7) & $\mathrm{E} 3, \mathrm{E} 5$ & $\mathrm{E} 5, \mathrm{E} 6$ & $\mathrm{E} 1, \mathrm{E} 2, \mathrm{E} 3, \mathrm{E} 5$ & $\mathrm{E} 2, \mathrm{E} 3, \mathrm{E} 5$ \\
\hline E5 & 75.6 & $\mathrm{CH}$ & 137 & 3.36 & $\mathrm{~m}$ & E4, E6b & & $\mathrm{E} 2, \mathrm{E} 3, \mathrm{E} 4$ & E1, E6a, E6b \\
\hline
\end{tabular}


Table 3.9. - continued from previous page

\begin{tabular}{|c|c|c|c|c|c|c|c|c|c|}
\hline pos. & $\begin{array}{c}\delta_{\mathrm{C}} \\
(\mathrm{ppm})\end{array}$ & mult & ${ }^{1} J_{\mathrm{CH}}$ & $\begin{array}{c}\delta_{\mathrm{H}} \\
(\mathrm{ppm})\end{array}$ & $\begin{array}{l}\text { mult, } \\
J(\mathrm{~Hz})\end{array}$ & COSY & HMBC & TOCSY & ROESY \\
\hline $\begin{array}{l}\text { E6a } \\
\text { E6b }\end{array}$ & 63.5 & $\mathrm{CH}_{2}$ & $\begin{array}{l}151 \\
156\end{array}$ & $\begin{array}{l}4.78 \\
4.14\end{array}$ & $\begin{array}{l}\mathrm{m} \\
\mathrm{m}\end{array}$ & $\begin{array}{l}\text { E6b } \\
\text { E6a, E4 }\end{array}$ & $\begin{array}{l}\text { E5, E4, E6-Ac } \\
\text { E6-Ac }\end{array}$ & E5 & $\begin{array}{l}\text { E5, E6b } \\
\text { E5, E6a }\end{array}$ \\
\hline E6-Ac & $\begin{array}{r}173.1 \\
21.6\end{array}$ & $\mathrm{C}$ & - & $2 . \overline{1} 9^{f}$ & - & - & $-\bar{E} 6-\mathrm{Ac}$ & - & - \\
\hline & \multicolumn{9}{|c|}{ Glucose F } \\
\hline F1 & 102.1 & $\mathrm{CH}$ & 165 & 5.07 & $\mathrm{~d}(7.9)$ & $\mathrm{F} 2$ & A2 & $\mathrm{F} 2, \mathrm{~F} 3$ & $\mathrm{~A} 2, \mathrm{~F} 2, \mathrm{~F} 3, \mathrm{~F} 5$ \\
\hline $\mathrm{F} 2$ & 73.3 & $\mathrm{CH}$ & 152 & 4.86 & $\mathrm{dd}(9.8,7.9)$ & F1, F3 & $\mathrm{F} 1, \mathrm{~F} 3, \mathrm{~F} 2-\mathrm{Ac}$ & $\mathrm{F} 1, \mathrm{~F} 3, \mathrm{~F} 4, \mathrm{~F} 5$ & $\mathrm{~F} 1, \mathrm{~F} 4$ \\
\hline F3 & 74.2 & $\mathrm{CH}$ & 150 & 5.18 & $\mathrm{t}(9.4)$ & $\mathrm{F} 2, \mathrm{~F} 4$ & $\mathrm{~F} 2, \mathrm{~F} 4, \mathrm{~F} 3-\mathrm{Ac}$ & $\mathrm{F} 1, \mathrm{~F} 2, \mathrm{~F} 4, \mathrm{~F} 5$ & $\mathrm{~F} 1, \mathrm{~F} 2, \mathrm{~F} 4,(\mathrm{~F} 5)$ \\
\hline F4 & 69.8 & $\mathrm{CH}$ & 152 & 5.00 & $\mathrm{t}(9.7)$ & F3, F5 & $\mathrm{F} 3, \mathrm{~F} 5, \mathrm{~F} 6, \mathrm{~F} 4-\mathrm{Ac}$ & $\mathrm{F} 1, \mathrm{~F} 2, \mathrm{~F} 3, \mathrm{~F} 5$ & $\mathrm{~F} 2, \mathrm{~F} 3, \mathrm{~F} 5$ \\
\hline F5 & 72.7 & $\mathrm{CH}$ & 141 & 3.78 & ddd $(9.6,4.1,2.7)$ & $\mathrm{F} 4, \mathrm{~F} 6 \mathrm{a}, \mathrm{F} 6 \mathrm{~b}$ & (F4) & F3, F4, F6a. F6b & F1, F3, F6a, F6b \\
\hline F6a & & & 146 & 4.30 & $\mathrm{~m}$ & F5 & F6-Ac & & F5, F6b \\
\hline F $6 \mathrm{~b}$ & 63.2 & $\mathrm{CH}_{2}$ & 149 & 4.11 & $\mathrm{~m}$ & F5 & F4, F5, F6-Ac & $\mathrm{F} 4, \mathrm{~F} 5$ & F5, F6a \\
\hline \multirow{2}{*}{$\mathrm{F} 2-\mathrm{Ac}$} & 171.3 & $\mathrm{C}$ & - & - & - & - & - & - & - \\
\hline & 20.6 & $\mathrm{CH}_{3}$ & - & 2.00 & $\mathrm{~s}$ & - & $\mathrm{F} 2-\mathrm{Ac}$ & - & \\
\hline \multirow{2}{*}{ F3-Ac } & 171.6 & $\mathrm{C}^{3}$ & - & - & - & - & - & - & - \\
\hline & 20.5 & $\mathrm{CH}_{3}$ & - & 1.98 & $\mathrm{~s}$ & - & F3-Ac & - & \\
\hline \multirow{2}{*}{ F4-Ac } & $171.2^{\mathrm{c}}$ & $\mathrm{C}$ & - & - & - & - & - & - & - \\
\hline & 20.9 & $\mathrm{CH}_{3}$ & - & $2.01^{\mathrm{d}}$ & $\mathrm{s}$ & - & F4-Ac & - & \\
\hline \multirow{2}{*}{ F6-Ac } & $172.2^{\mathrm{e}}$ & $\mathrm{C}$ & - & - & - & - & - & - & - \\
\hline & $20.8^{\mathrm{b}}$ & $\mathrm{CH}_{3}$ & - & 2.05 & $\mathrm{~s}$ & - & F6-Ac & - & \\
\hline
\end{tabular}


Table 3.10. Array of significant glycolipid pseudomolecular ions observed in the MS, indicating sugar and acetate composition.

\begin{tabular}{|c|c|c|c|c|c|}
\hline & \multicolumn{4}{|c|}{ no. of sugars } \\
\hline & & 6 & 5 & 4 & 3 \\
\hline & 14 & 1962 & & & \\
\hline & 13 & 1920 & 1758 & & \\
\hline$\stackrel{0}{0}$ & 12 & 1878 & 1716 & 1554 & \\
\hline to & 11 & 1836 & 1674 & 1512 & \\
\hline ש & 10 & 1794 & 1632 & 1470 & \\
\hline "艹 & 9 & & 1590 & 1428 & 1266 \\
\hline$\stackrel{\varrho}{g}$ & 8 & & 1548 & 1386 & 1224 \\
\hline & 7 & & & & 1182 \\
\hline & 6 & & & & 1140 \\
\hline
\end{tabular}

\section{Structure elucidation of agminosides B-E}

While agminoside A (145) was the main glycolipid in the mixture, a multitude of other signals was apparent in the MS, indicating many related congeners. A single aglycon and only D-glucose sugars were obtained from either the methanolysis or hydrolysis of the glycolipid mixture, meaning the congeners had the same aglycon and were comprised of the same sugar. The only difference could be in the position and number of acetates, the sugar number, and perhaps the sugar connectivity. A closer look at the masses apparent in the MS of various fractions supported this idea: they were all related to each other either via a combination of 42 (an acetyl) or 162 (a sugar) mass units, as illustrated by Table 3.10.

In order to confirm the close structural relationship of the glycolipids, the mixture as well as agminoside A was peracetylated and analysed by MS. Negative ion mode ESIMS analysis of peracetylated agminoside A showed two major peaks, at 2214.8 (full acetylation, 20 acetates) and 2172.8 (19 acetates) as can be seen in Figure 3.19(a). MS analysis of the peracetylated glycolipid mix (Figure 3.19(b)) showed a pattern of peaks 288 units apart, which correspond to peracetylated glycolipids with $3,4,5$, and 6 sugars. Peaks corresponding to glycolipids with one less acetate were also apparent by the fully acetylated glycolipid masses, just as was seen for peracetylated 145. These data indicate that one hydroxy group may be difficult to acetylate and only the glycolipid with three sugars shows full acetylation. Alternatively, this may simply be a MS artifact.

The four agminoside congeners isolated were assigned in a similar fashion to 145. Starting from the anomeric positions, spin systems were identified through a combination of COSY, HSQC-TOCSY and HMBC correlations. Sugar linkages were confirmed through key HMBC correlations. 


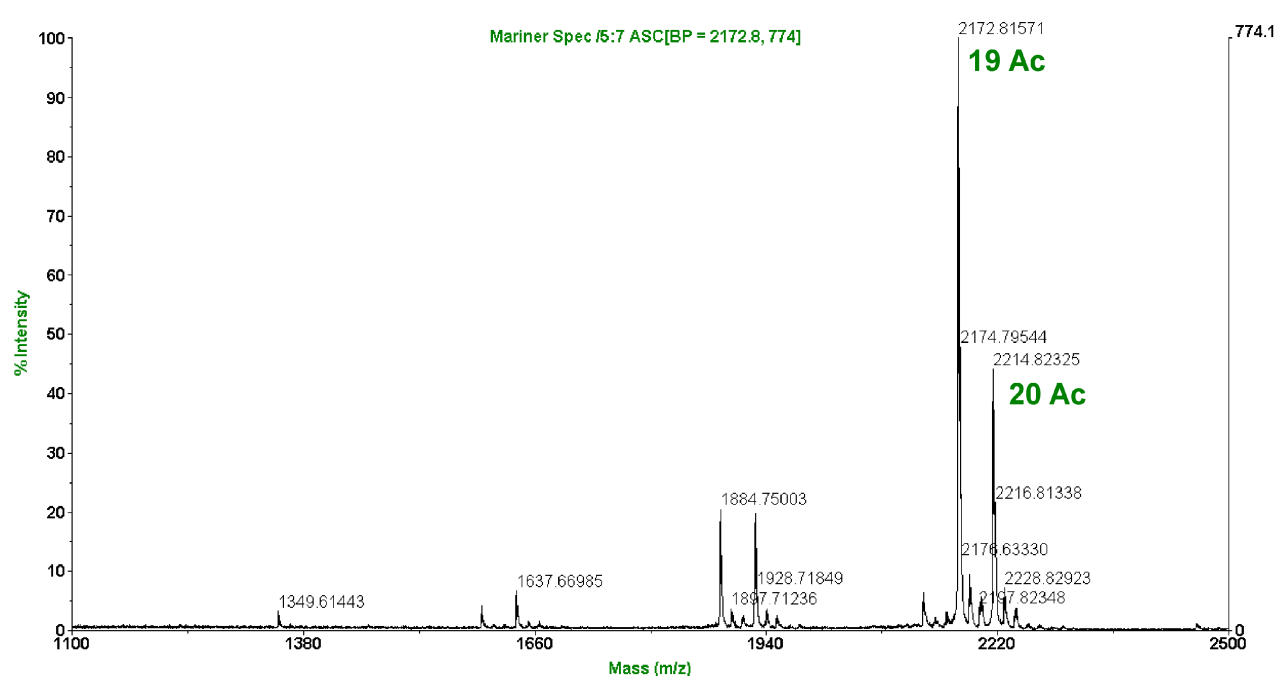

(a) MS plot of peracetylated agminoside A (145).

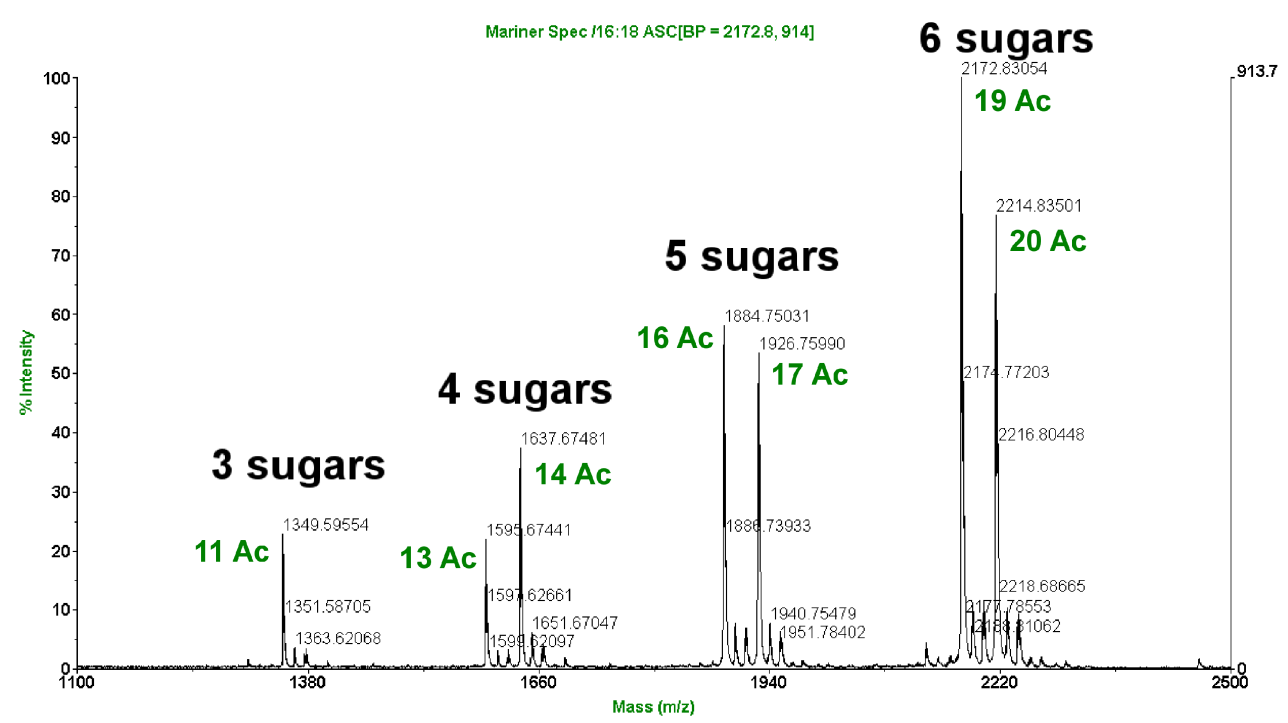

(b) MS plot of the peracetylated glycolipid mix.

Figure 3.19. MS analysis of the acetylation reactions.

\section{Agminoside B}

Negative ion mode HRESIMS analysis of agminoside B (146) indicated a molecular formula of $\mathrm{C}_{83} \mathrm{H}_{130} \mathrm{O}_{47}\left(1877.7734[\mathrm{M}-\mathrm{H}]^{-}, \Delta 1.6 \mathrm{ppm}\right)$ implying a loss of one acetate with respect to agminoside A. Indeed, only 12 acetate signals were observed in the ${ }^{1} \mathrm{H}$ and ${ }^{13} \mathrm{C}$ NMR spectra. The chemical shifts of the aglycon and most of the sugar positions were within $0.02 \mathrm{ppm}$ of those for agminoside A. Significant differences were observed for sugar $\mathrm{F}$, the biggest change being at $\mathrm{H}-\mathrm{F} 2$ $\left(\delta_{\mathrm{H}} 3.43\right.$ vs. $\delta_{\mathrm{H}} 4.86$ in $\left.\mathbf{1 4 5}\right)$. This indicated the loss of the acetate at that position, and explained the changes in chemical shift for that sugar. The structure of agminoside B is given as 146, with NMR data presented in Table 3.12. 


\section{Agminoside C}

Agminoside C (147) also had a molecular formula of $\mathrm{C}_{83} \mathrm{H}_{130} \mathrm{O}_{47}$ (1877.7721 $\left.[\mathrm{M}-\mathrm{H}]^{-}, \Delta 0.9 \mathrm{ppm}\right)$ and only 12 acetate signals in the NMR spectra. However, it had a different retention time on the HPLC, implying it was an isomer of agminoside B (146). Close examination of the NMR data revealed that the sugar portion of $\mathbf{1 4 7}$ was identical (within $0.02 \mathrm{ppm}$ ) to that of agminoside A (145). The major difference was the absence of the signals characteristic of the acetylated oxymethine $\mathrm{CH}-2^{\prime}$ and the $2^{\prime}$-Ac. A resonance at $\delta_{\mathrm{H}} 4.34$ was present instead, suggesting the acetate was absent from the $2^{\prime}$ position. Agminoside $\mathrm{C}$ is therefore assigned as $\mathbf{1 4 7}$, with NMR data given in Table 3.13.

\section{Agminoside D}

A pseudomolecular ion peak observed in negative ion mode HRESIMS for agminoside D (148) indicated a molecular formula of $\mathrm{C}_{81} \mathrm{H}_{128} \mathrm{O}_{46}\left(1835.7599[\mathrm{M}-\mathrm{H}]^{-}\right.$ $\Delta 0.4 \mathrm{ppm})$, suggesting a loss of two acetates compared to agminoside A. Only 11 acetate signals were observed in the ${ }^{1} \mathrm{H}$ and ${ }^{13} \mathrm{C}$ spectra, supporting this assumption. Changes in chemical shift of sugar $\mathrm{F}$ resonances analogous to that in 146 indicated a loss of the F2-acetate. Once again, the $\delta_{\mathrm{H}}$ of $\mathrm{CH}-2^{\prime}$ was shifted higher upfield to $4.11 \mathrm{ppm}$ and the signals characteristic of the $2^{\prime}$-Ac were absent as well, suggesting this position was no longer acetylated. The remainder of the ${ }^{1} \mathrm{H}$ and ${ }^{13} \mathrm{C}$ signals were very similar to agminoside $\mathrm{A}$. The structure of agminoside D is therefore assigned as 148, with NMR data detailed in Table 3.14.

\section{Agminoside E}

The final glycolipid isolated was agminoside E (149). A pseudomolecular ion peak of 1715.7176 observed in negative ion mode HRESIMS indicated a formula of $\mathrm{C}_{77} \mathrm{H}_{119} \mathrm{O}_{42}\left([\mathrm{M}-\mathrm{H}]^{-}, \Delta 1.2 \mathrm{ppm}\right)$, consistent with a loss of a whole sugar and one acetate. Observation of only five anomeric signals and 12 acetates in the NMR spectra supported this assumption. Again, the majority of signals remained similar to that of agminoside A, although signals characteristic for sugar E were totally absent and some differences were apparent for sugar D. The most distinct change was in the chemical shift of C-D2. In agminoside A (145) C-D2 is at $\delta_{\mathrm{C}} 83.8$, being a glycosidic linking carbon. In 149 it is at $\delta_{\mathrm{C}} 74.7$, consistent with the loss of sugar E. The absence of sugar E also accounts for the loss of one acetate (E6-Ac); the remaining acetylation is identical to agminoside A. Agminoside E is assigned as 149, NMR data are listed in Table 3.15. 
Table 3.11. Comparison of proton chemical shifts $\left(\delta_{\mathrm{H}}\right)$ for the agminosides $\mathrm{A}-\mathrm{E}$ (145-149). Significant chemical shift differences from agminoside A (145) are highlighted in yellow.

\begin{tabular}{|c|c|c|c|c|c|}
\hline \multirow[b]{2}{*}{ position } & \multicolumn{5}{|c|}{ compound } \\
\hline & 145 & 146 & 147 & 148 & 149 \\
\hline $1 \mathrm{a}$ & 3.54 & 3.52 & 3.48 & 3.52 & 3.51 \\
\hline $1 b$ & 3.47 & 3.45 & 3.45 & 3.45 & 3.45 \\
\hline 2 & 1.56 & 1.55 & 1.57 & 1.57 & 1.55 \\
\hline 3 & 1.34 & 1.34 & 1.34 & 1.34 & 1.34 \\
\hline $4-14$ & 1.29 & 1.29 & 1.29 & 1.29 & 1.29 \\
\hline 15 & 1.37 & 1.37 & 1.37 & 1.37 & 1.36 \\
\hline $16 \mathrm{a}$ & 1.57 & 1.58 & 1.58 & 1.59 & 1.57 \\
\hline $16 \mathrm{~b}$ & 1.49 & 1.49 & 1.49 & 1.49 & 1.48 \\
\hline 17 & 3.63 & 3.65 & 3.66 & 3.66 & 3.62 \\
\hline 18 & 1.48 & 1.48 & 1.53 & 1.53 & 1.48 \\
\hline 19 & 1.48 & 1.48 & 1.47 & 1.47 & 1.47 \\
\hline 20 & 0.92 & 0.92 & 0.92 & 0.92 & 0.95 \\
\hline $3^{\prime} \mathrm{a}$ & 3.83 & & 3.69 & & \\
\hline $3^{\prime} \mathrm{b}$ & 3.78 & 3.79 & 3.62 & 3.78 & 3.78 \\
\hline $2^{\prime}$ & 5.14 & 5.11 & 4.34 & 4.11 & 5.08 \\
\hline A1 & 4.39 & 4.46 & 4.39 & 4.45 & 4.38 \\
\hline A2 & 3.46 & 3.50 & 3.44 & 3.50 & 3.45 \\
\hline A3 & 3.58 & 3.76 & 3.57 & 3.76 & 3.55 \\
\hline A 4 & 3.53 & 3.58 & 3.52 & 3.58 & 3.53 \\
\hline A5 & 3.32 & 3.35 & 3.31 & 3.35 & 3.30 \\
\hline A $6 a$ & 3.76 & 3.77 & 3.75 & 3.77 & 3.75 \\
\hline A6b & 3.62 & 3.64 & 3.62 & 3.63 & 3.61 \\
\hline B1 & 4.81 & 4.83 & 4.81 & 4.82 & 4.78 \\
\hline B2 & 4.88 & 4.88 & 4.87 & 4.88 & 4.86 \\
\hline B3 & 5.27 & 5.26 & 5.27 & 5.26 & 5.23 \\
\hline B4 & 3.78 & 3.78 & 3.78 & 3.78 & 3.78 \\
\hline B5 & 3.94 & 3.93 & 3.95 & 3.93 & 3.92 \\
\hline B6a & 4.80 & 4.80 & 4.79 & 4.80 & 4.75 \\
\hline B6b & 4.31 & 4.26 & 4.31 & 4.26 & 4.30 \\
\hline
\end{tabular}

\begin{tabular}{|c|c|c|c|c|c|}
\hline \multirow[b]{2}{*}{ position } & \multicolumn{5}{|c|}{ compound } \\
\hline & 145 & 146 & 147 & 148 & 149 \\
\hline C1 & 4.53 & 4.53 & 4.53 & 4.52 & 4.52 \\
\hline $\mathrm{C} 2$ & 3.50 & 3.49 & 3.50 & 3.49 & 3.56 \\
\hline C3 & 5.08 & 5.07 & 5.07 & 5.07 & 5.22 \\
\hline $\mathrm{C} 4$ & 4.81 & 4.81 & 4.80 & 4.80 & 4.87 \\
\hline C5 & 3.90 & 3.90 & 3.90 & 3.90 & 3.81 \\
\hline C6a & 4.33 & 4.34 & 4.34 & 4.34 & 4.35 \\
\hline $\mathrm{C} 6 \mathrm{~b}$ & 4.07 & 4.07 & 4.06 & 4.07 & 4.03 \\
\hline D1 & 4.46 & 4.45 & 4.46 & 4.45 & 4.31 \\
\hline D2 & 3.22 & 3.21 & 3.22 & 3.21 & 3.09 \\
\hline D3 & 3.49 & 3.48 & 3.48 & 3.48 & 3.29 \\
\hline D4 & 3.23 & 3.21 & 3.22 & 3.22 & 3.19 \\
\hline D5 & 3.44 & 3.43 & 3.43 & 3.43 & 3.44 \\
\hline D6a & 4.51 & 4.52 & 4.53 & 4.51 & 4.46 \\
\hline D6b & 4.24 & 4.24 & 4.23 & 4.24 & 4.29 \\
\hline E1 & 4.40 & 4.39 & 4.40 & 4.39 & \\
\hline E2 & 3.19 & 3.18 & 3.18 & 3.18 & \\
\hline E3 & 3.34 & 3.33 & 3.33 & 3.33 & \\
\hline E4 & 3.46 & 3.45 & 3.46 & 3.45 & \\
\hline E5 & 3.36 & 3.35 & 3.35 & 3.36 & \\
\hline E6a & 4.78 & 4.79 & 4.80 & 4.78 & \\
\hline E6b & 4.14 & 4.13 & 4.12 & 4.13 & \\
\hline F1 & 5.07 & 4.80 & 5.07 & 4.80 & 5.07 \\
\hline $\mathrm{F} 2$ & 4.86 & 3.43 & 4.85 & 3.43 & 4.85 \\
\hline F3 & 5.18 & 5.07 & 5.18 & 5.07 & 5.17 \\
\hline F4 & 5.00 & 4.91 & 4.99 & 4.91 & 4.99 \\
\hline F5 & 3.78 & 3.74 & 3.77 & 3.75 & 3.78 \\
\hline F6a & 4.30 & 4.27 & 4.30 & 4.26 & 4.29 \\
\hline F $6 b$ & 4.11 & 4.09 & 4.11 & 4.10 & 4.10 \\
\hline
\end{tabular}

Agminosides B-E (146-149) showed the same reciprocal HMBC correlations (detailed in Tables 3.12-3.15) between the anomeric positions and their attachments as for agminoside A (145), indicating the sugar connectivity is identical for all congeners isolated. The majority of chemical shifts were very similar to 145, with changes appearing at and near points of difference. The proton chemical shifts of the five compounds are compared in Table 3.11, with the significant differences highlighted.

The agminoside glycolipids all have the same aglycon, the same sugars (glucose), and even the same sugar connectivity. The differences were only in the number and placement of acetylation, and a loss of one sugar moiety. Analysis of other fractions by MS indicated the presence of further glycolipid congeners with four or even three sugars, but as they were present in very low quantities, they were not isolated. The agminosides constituted the majority of the sponge extract; what biological role they play for the sponge is an interesting, and as yet unanswered, question. 
Table 3.12. NMR data (600 MHz, $\left.\mathrm{CD}_{3} \mathrm{OD}\right)$ for agminoside $\mathrm{B}$ (146).

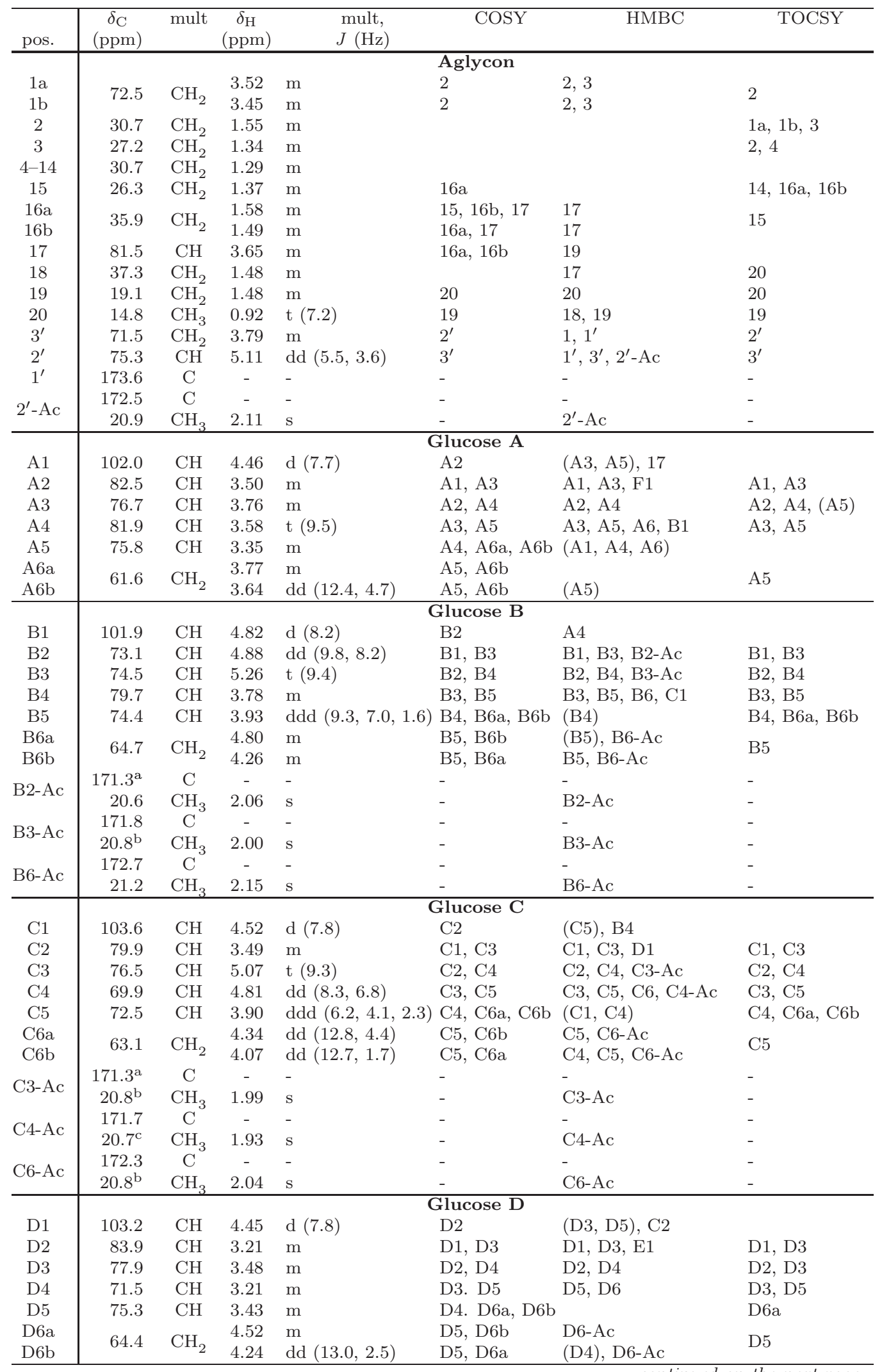

a,b,c,d can be interchanged 
Table 3.12. - continued from previous page

\begin{tabular}{|c|c|c|c|c|c|c|c|}
\hline pos. & $\begin{array}{c}\delta_{\mathrm{C}} \\
(\mathrm{ppm})\end{array}$ & mult & $\begin{array}{c}\delta_{\mathrm{H}} \\
(\mathrm{ppm})\end{array}$ & $\begin{array}{l}\text { mult, } \\
J(\mathrm{~Hz})\end{array}$ & COSY & HMBC & TOCSY \\
\hline \multirow{2}{*}{ D6-Ac } & 173.0 & $\mathrm{C}$ & - & - & - & - & - \\
\hline & 21.4 & $\mathrm{CH}_{3}$ & 2.18 & $\mathrm{~s}$ & - & D6-Ac & - \\
\hline E1 & 106.2 & $\mathrm{CH}$ & 4.39 & $\mathrm{~d}(8.3)$ & $\begin{array}{l}\text { Glucose } \mathbf{E} \\
\text { E2 }\end{array}$ & $(\mathrm{E} 5), \mathrm{D} 2$ & \\
\hline $\mathrm{E} 2$ & 75.3 & $\mathrm{CH}$ & 3.18 & dd $(8.9,7.9)$ & E1, E3 & E1, E3 & $\mathrm{E} 1, \mathrm{E} 4$ \\
\hline E3 & 78.2 & $\mathrm{CH}$ & 3.33 & $\mathrm{~m}$ & $\mathrm{E} 2, \mathrm{E} 4$ & (E1), E2, E4 & $\mathrm{E} 2, \mathrm{E} 4$ \\
\hline E4 & 70.8 & $\mathrm{CH}$ & 3.45 & $\mathrm{~m}$ & E3, E5 & $\mathrm{E} 3, \mathrm{E} 5, \mathrm{E} 6$ & E5 \\
\hline E5 & 75.6 & $\mathrm{CH}$ & 3.35 & $\mathrm{~m}$ & $\mathrm{E} 4, \mathrm{E} 6 \mathrm{a}, \mathrm{E} 6 \mathrm{~b}$ & (E1) & E4 \\
\hline E6a & \multirow{2}{*}{63.6} & \multirow[b]{2}{*}{$\mathrm{CH}_{2}$} & 4.79 & dd $(12.0,3.7)$ & $\mathrm{E} 5, \mathrm{E} 6 \mathrm{~b}$ & $\mathrm{E} 4, \mathrm{E} 5, \mathrm{E} 6-\mathrm{Ac}$ & \\
\hline $\mathrm{E} 6 \mathrm{~b}$ & & & 4.13 & $\mathrm{~m}$ & E5, E6a & $\mathrm{E} 6-\mathrm{Ac}$ & \\
\hline \multirow{2}{*}{ E6-Ac } & 173.2 & $\mathrm{C}$ & - & - & - & - & - \\
\hline & 21.4 & $\mathrm{CH}_{3}$ & 2.19 & $\mathrm{~s}$ & - & E-6Ac & - \\
\hline & \multicolumn{7}{|c|}{ Glucose F } \\
\hline F1 & 105.2 & $\mathrm{CH}$ & 4.80 & $\mathrm{~m}$ & $\mathrm{~F} 2$ & $\mathrm{~A} 2$ & \\
\hline $\mathrm{F} 2$ & 74.3 & $\mathrm{CH}$ & 3.43 & $\mathrm{~m}$ & F1, F3 & F1, F3 & F1, F3 \\
\hline F3 & 76.1 & $\mathrm{CH}$ & 5.07 & $\mathrm{t}(9.3)$ & $\mathrm{F} 2, \mathrm{~F} 4$ & $(\mathrm{~F} 1), \mathrm{F} 2,(\mathrm{~F} 5), \mathrm{F} 3-\mathrm{Ac}$ & $\mathrm{F} 2, \mathrm{~F} 4$ \\
\hline F4 & 70.0 & $\mathrm{CH}$ & 4.91 & $\mathrm{t}(9.9)$ & F3, F5 & $\mathrm{F} 3, \mathrm{~F} 5, \mathrm{~F} 6, \mathrm{~F} 4-\mathrm{Ac}$ & F3, F5 \\
\hline F5 & 73.1 & $\mathrm{CH}$ & 3.74 & $\mathrm{~m}$ & $\mathrm{~F} 4, \mathrm{~F} 6 \mathrm{a}, \mathrm{F} 6 \mathrm{~b}$ & $(\mathrm{~F} 1, \mathrm{~F} 4)$ & $\mathrm{F} 4, \mathrm{~F} 6 \mathrm{a}$ \\
\hline F6a & 634 & & 4.27 & $\mathrm{~m}$ & $\mathrm{~F} 5, \mathrm{~F} 6 \mathrm{~b}$ & $\mathrm{~F} 4, \mathrm{~F} 5, \mathrm{~F} 6-\mathrm{Ac}$ & $\mathrm{F}_{5}$ \\
\hline F6b & 03.4 & $\mathrm{CH}_{2}$ & 4.09 & dd $(12.1,2.2)$ & $\mathrm{F} 5, \mathrm{~F} 6 \mathrm{a}$ & $\mathrm{F} 4, \mathrm{~F} 5, \mathrm{~F} 6-\mathrm{Ac}$ & F5 \\
\hline \multirow{2}{*}{ F3-Ac } & 172.1 & $\mathrm{C}$ & - & - & - & - & - \\
\hline & $20.7^{\mathrm{c}}$ & $\mathrm{CH}_{3}$ & $2.03^{\mathrm{d}}$ & $\mathrm{s}$ & - & F3-Ac & - \\
\hline \multirow{2}{*}{ F4-Ac } & 172.1 & $\mathrm{C}^{\circ}$ & - & - & - & - & - \\
\hline & $20.8^{\mathrm{b}}$ & $\mathrm{CH}_{3}$ & 2.02 & $\mathrm{~s}$ & - & $\mathrm{F} 4-\mathrm{Ac}$ & - \\
\hline \multirow{2}{*}{ F6-Ac } & 172.3 & $\mathrm{C}$ & - & - & - & - & - \\
\hline & 20.7 & $\mathrm{CH}_{3}$ & $2.03^{\mathrm{d}}$ & $\mathrm{s}$ & - & F6-Ac & - \\
\hline
\end{tabular}

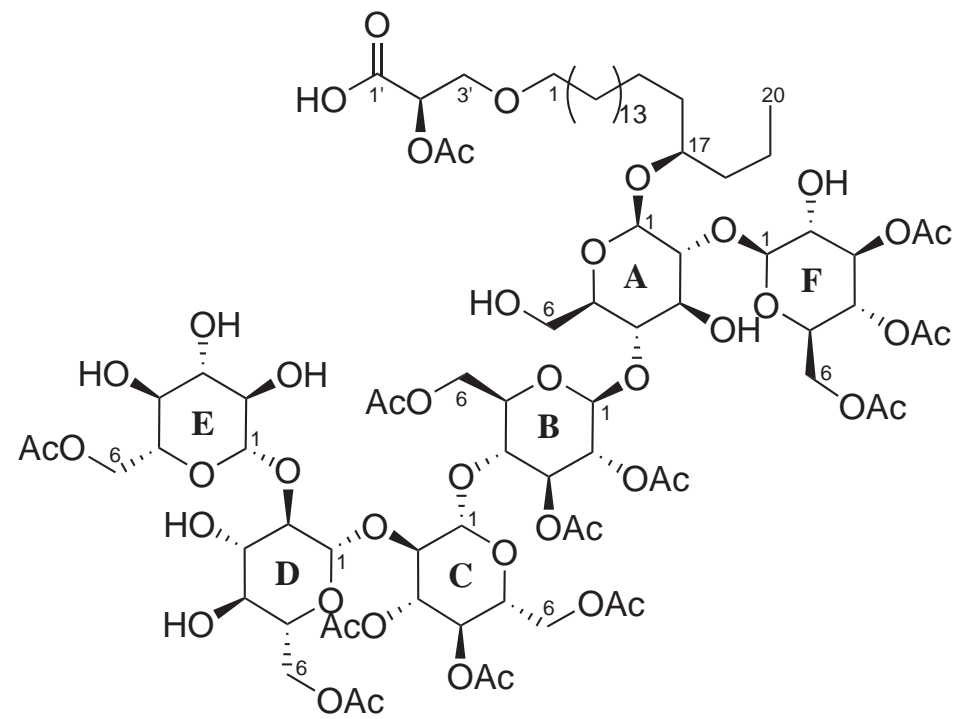

146 
Table 3.13. NMR data (600 MHz, $\left.\mathrm{CD}_{3} \mathrm{OD}\right)$ for agminoside $\mathrm{C}(\mathbf{1 4 7})$.

\begin{tabular}{|c|c|c|c|c|c|c|}
\hline pos. & $\begin{array}{c}\delta_{\mathrm{C}} \\
(\mathrm{ppm})\end{array}$ & mult & $\begin{array}{c}\delta_{\mathrm{H}} \\
(\mathrm{ppm})\end{array}$ & $\begin{array}{l}\text { mult, } \\
J(\mathrm{~Hz})\end{array}$ & COSY & HMBC \\
\hline & \multicolumn{6}{|c|}{ Aglycon } \\
\hline $1 \mathrm{a}$ & \multirow[b]{2}{*}{72.4} & \multirow[b]{2}{*}{$\mathrm{CH}_{2}$} & 3.51 & $\mathrm{~m}$ & $1 b, 2$ & $2,3,3^{\prime}$ \\
\hline $1 b$ & & & 3.45 & $\mathrm{~m}$ & $1 \mathrm{a}, 2$ & $2,3,3^{\prime}$ \\
\hline 2 & 30.8 & $\mathrm{CH}_{2}$ & 1.56 & $\mathrm{~m}$ & $1 \mathrm{a}, 1 \mathrm{~b}, 3$ & 3 \\
\hline 3 & 27.2 & $\mathrm{CH}_{2}^{2}$ & 1.34 & $\mathrm{~m}$ & 2 & 4 \\
\hline $4-14$ & 30.8 & $\mathrm{CH}_{2}^{2}$ & 1.28 & $\mathrm{~m}$ & & \\
\hline 15 & 26.3 & $\mathrm{CH}_{2}^{2}$ & 1.37 & $\mathrm{~m}$ & & 16 \\
\hline $16 \mathrm{a}$ & \multirow{2}{*}{35.8} & \multirow{2}{*}{$\mathrm{CH}_{2}$} & 1.55 & $\mathrm{~m}$ & $16 \mathrm{~b}, 17$ & \\
\hline $16 \mathrm{~b}$ & & & 1.48 & $\mathrm{~m}$ & $16 \mathrm{a}$ & $(15)$ \\
\hline 17 & 81.7 & $\mathrm{CH}$ & 3.63 & $\mathrm{~m}$ & $16 \mathrm{a}, 18$ & 19 \\
\hline 18 & 37.2 & $\mathrm{CH}_{2}$ & 1.47 & $\mathrm{~m}$ & & \\
\hline 19 & 18.8 & $\mathrm{CH}_{2}$ & 1.48 & $\mathrm{~m}$ & 20 & 18,20 \\
\hline 20 & 14.8 & $\mathrm{CH}_{3}$ & 0.95 & $\mathrm{~m}$ & 19 & 18,19 \\
\hline $3^{\prime} \mathrm{a}$ & \multirow{2}{*}{71.4} & \multirow{2}{*}{$\mathrm{CH}_{2}$} & 3.69 & dd $(10.2,2.6)$ & $2^{\prime}$ & \\
\hline $3^{\prime} \mathrm{b}$ & & & 3.62 & $\mathrm{dd}(10.9,5.5)$ & $2^{\prime}$ & \\
\hline $2^{\prime}$ & a & $\mathrm{CH}$ & 4.34 & $\mathrm{~m}$ & $3^{\prime} \mathrm{a}, 3^{\prime} \mathrm{b}$ & \\
\hline \multirow[t]{2}{*}{$1^{\prime}$} & a & $\mathrm{C}$ & - & - & - & - \\
\hline & \multicolumn{6}{|c|}{ Glucose A } \\
\hline A1 & 102.0 & $\mathrm{CH}$ & 4.39 & $\mathrm{~d}(7.6)$ & A2 & 17 \\
\hline A2 & 81.1 & $\mathrm{CH}$ & 3.44 & $\mathrm{~m}$ & $\mathrm{~A} 1, \mathrm{~A} 3$ & $\mathrm{~A} 1, \mathrm{~A} 3, \mathrm{~F} 1$ \\
\hline A3 & 77.4 & $\mathrm{CH}$ & 3.57 & $\mathrm{~m}$ & $\mathrm{~A} 2, \mathrm{~A} 4$ & \\
\hline A4 & 82.4 & $\mathrm{CH}$ & 3.52 & $\mathrm{~m}$ & $\mathrm{~A} 3, \mathrm{~A} 5$ & $\mathrm{~A} 3, \mathrm{~A} 5, \mathrm{~A} 6, \mathrm{~B} 1$ \\
\hline A5 & 75.7 & $\mathrm{CH}$ & 3.31 & $\mathrm{~m}$ & \multirow{3}{*}{\multicolumn{2}{|c|}{$\begin{array}{l}\mathrm{A} 4,(\mathrm{~A} 6 \mathrm{a}), \mathrm{A} 6 \mathrm{~b} \\
(\mathrm{~A} 5), \mathrm{A} 6 \mathrm{~b} \\
\mathrm{~A} 5, \mathrm{~A} 6 \mathrm{a}\end{array}$}} \\
\hline A6a & \multirow{2}{*}{61.7} & \multirow{2}{*}{$\mathrm{CH}_{2}$} & 3.75 & $\mathrm{~m}$ & & \\
\hline \multirow[t]{2}{*}{$\mathrm{A} 6 \mathrm{~b}$} & & & 3.62 & $\mathrm{~m}$ & & \\
\hline & \multicolumn{6}{|c|}{ Glucose B } \\
\hline B1 & 102.0 & $\mathrm{CH}$ & 4.81 & $\mathrm{~d}(8.3)$ & B2 & A4 \\
\hline B2 & 73.0 & $\mathrm{CH}$ & 4.87 & $\mathrm{~m}$ & B1, B3 & $\mathrm{B} 3, \mathrm{~B} 2-\mathrm{Ac}$ \\
\hline B3 & 74.5 & $\mathrm{CH}$ & 5.27 & $\mathrm{t}(9.4)$ & $\mathrm{B} 2, \mathrm{~B} 4$ & $\mathrm{~B} 2, \mathrm{~B} 4, \mathrm{~B} 3-\mathrm{Ac}$ \\
\hline B4 & 79.7 & $\mathrm{CH}$ & 3.78 & $\mathrm{~m}$ & B3 & $\mathrm{B} 3, \mathrm{~B} 5, \mathrm{~B} 6, \mathrm{C} 1$ \\
\hline B5 & 74.3 & $\mathrm{CH}$ & 3.95 & ddd $(9.5,7.1,1.9)$ & $(\mathrm{B} 6 \mathrm{a}), \mathrm{B} 6 \mathrm{~b}$ & \\
\hline B6a & & & 4.79 & $\mathrm{~m}$ & (B5), B6b & $\mathrm{B} 6-\mathrm{Ac}$ \\
\hline $\mathrm{B} 6 \mathrm{~b}$ & 64.5 & $\mathrm{CH}_{2}$ & 4.31 & $\mathrm{~m}$ & $\mathrm{~B} 5, \mathrm{~B} 6 \mathrm{a}$ & $\mathrm{B} 5, \mathrm{~B} 6-\mathrm{Ac}$ \\
\hline \multirow{2}{*}{$\mathrm{B} 2-\mathrm{Ac}$} & 171.3 & $\mathrm{C}$ & - & - & - & - \\
\hline & $20.8^{\mathrm{b}}$ & $\mathrm{CH}_{3}$ & 2.06 & $\mathrm{~s}$ & - & $\mathrm{B} 2-\mathrm{Ac}$ \\
\hline P. 4 & 171.7 & $\mathrm{C}^{\circ}$ & - & - & - & - \\
\hline $\mathrm{D} J-\mathrm{AC}$ & 21.4 & $\mathrm{CH}_{3}$ & 2.01 & $\mathrm{~s}$ & - & B3-Ac \\
\hline $\mathrm{P} 6 \mathrm{~A}$ & 172.1 & $\mathrm{C}^{\circ}$ & - & - & - & - \\
\hline $\mathrm{BO}-\mathrm{AC}$ & 21.4 & $\mathrm{CH}_{3}$ & 2.20 & $\mathrm{~s}$ & - & $\mathrm{B} 6-\mathrm{Ac}$ \\
\hline & & & & Glucose & $\mathrm{C}$ & \\
\hline $\mathrm{C} 1$ & 103.4 & $\mathrm{CH}$ & 4.53 & $\mathrm{~d}(7.4)$ & $\mathrm{C} 2$ & B4 \\
\hline $\mathrm{C} 2$ & 79.8 & $\mathrm{CH}$ & 3.50 & $\mathrm{~m}$ & $\mathrm{C} 1, \mathrm{C} 3$ & $\mathrm{C} 1, \mathrm{D} 1$ \\
\hline $\mathrm{C} 3$ & 76.5 & $\mathrm{CH}$ & 5.08 & $\mathrm{t}(9.4)$ & $\mathrm{C} 2, \mathrm{C} 4$ & $\mathrm{C} 2, \mathrm{C} 4, \mathrm{C} 3-\mathrm{Ac}$ \\
\hline $\mathrm{C} 4$ & 69.9 & $\mathrm{CH}$ & 4.80 & $\mathrm{~m}$ & $\mathrm{C} 3, \mathrm{C} 5$ & $\mathrm{C} 3, \mathrm{C} 5, \mathrm{C} 6, \mathrm{C} 4-\mathrm{Ac}$ \\
\hline $\mathrm{C} 5$ & 72.5 & $\mathrm{CH}$ & 3.90 & ddd $(10.0,4.0,2.1)$ & $\mathrm{C} 4, \mathrm{C} 6 \mathrm{a}$ & \\
\hline C6a & & & 4.34 & & $\mathrm{C} 5, \mathrm{C} 6 \mathrm{~b}$ & C6-Ac \\
\hline $\mathrm{C} 6 \mathrm{~b}$ & 63.1 & $\mathrm{CH}_{2}$ & 4.06 & dd $(12.6,1.7)$ & $\mathrm{C} 6 \mathrm{a}$ & $\mathrm{C} 4, \mathrm{C} 5, \mathrm{C} 6-\mathrm{Ac}$ \\
\hline C3-Ac & 171.2 & $\mathrm{C}$ & - & - & - & - \\
\hline C3-Ac & 21.4 & $\mathrm{CH}_{3}$ & 1.99 & $\mathrm{~s}$ & - & $\mathrm{C} 3-\mathrm{Ac}$ \\
\hline$C 4$ & 171.6 & $\mathrm{C}^{\circ}$ & - & - & - & - \\
\hline C4-Ac & $20.8^{\mathrm{b}}$ & $\mathrm{CH}_{3}$ & 1.93 & $\mathrm{~s}$ & - & $\mathrm{C} 4-\mathrm{Ac}$ \\
\hline C6-As & $172.2^{\mathrm{C}}$ & $\mathrm{C}^{\mathrm{J}}$ & - & - & - & - \\
\hline Cb-Ac & $20.8^{\mathrm{b}}$ & $\mathrm{CH}_{3}$ & $2.04^{\mathrm{d}}$ & $\mathrm{s}$ & - & C6-Ac \\
\hline & & & & Glucose & $\mathbf{D}$ & \\
\hline D1 & 103.1 & $\mathrm{CH}$ & 4.46 & $\mathrm{~d}(7.9)$ & D2 & $\mathrm{C} 2$ \\
\hline D2 & 83.8 & $\mathrm{CH}$ & 3.22 & $\mathrm{~m}$ & D1 & D1 \\
\hline D3 & 77.9 & $\mathrm{CH}$ & 3.48 & $\mathrm{~m}$ & & $\mathrm{D} 4$ \\
\hline D4 & 71.6 & $\mathrm{CH}$ & 3.22 & $\mathrm{~m}$ & & D5 \\
\hline D5 & 75.3 & $\mathrm{CH}$ & 3.43 & $\mathrm{~m}$ & D6a & \\
\hline D6a & & & 4.53 & $\mathrm{dd}(11.8,5.0)$ & D5, D6b & D5 \\
\hline D6b & 64.5 & $\mathrm{CH}_{2}$ & 4.23 & dd $(11.7,1.8)$ & D6a & \\
\hline
\end{tabular}

${ }^{a}$ not observed

b,c,d,e,f can be interchanged 
Table 3.13. - continued from previous page

\begin{tabular}{|c|c|c|c|c|c|c|}
\hline pos. & $\begin{array}{c}\delta_{\mathrm{C}} \\
(\mathrm{ppm})\end{array}$ & mult & $\begin{array}{c}\delta_{\mathrm{H}} \\
(\mathrm{ppm})\end{array}$ & $\begin{array}{l}\text { mult, } \\
J(\mathrm{~Hz})\end{array}$ & COSY & HMBC \\
\hline \multirow{2}{*}{ D6-Ac } & 172.9 & $\mathrm{C}$ & - & - & - & - \\
\hline & 21.5 & $\mathrm{CH}_{3}$ & 2.19 & $\mathrm{~s}$ & - & D6-Ac \\
\hline & \multicolumn{6}{|c|}{ Glucose E } \\
\hline E1 & 106.1 & $\mathrm{CH}$ & 4.40 & $\mathrm{~d}(7.8)$ & $\mathrm{E} 2$ & D2 \\
\hline $\mathrm{E} 2$ & 75.3 & $\mathrm{CH}$ & 3.18 & $\mathrm{~m}$ & E1, E2 & E1, E3 \\
\hline E3 & 78.2 & $\mathrm{CH}$ & 3.33 & $\mathrm{~m}$ & $\mathrm{E} 2, \mathrm{E} 4$ & $\mathrm{E} 1, \mathrm{E} 2, \mathrm{E} 4$ \\
\hline $\mathrm{E} 4$ & 70.7 & $\mathrm{CH}$ & 3.46 & $\mathrm{~m}$ & E3, E5 & E5, E6 \\
\hline E5 & 75.6 & $\mathrm{CH}$ & 3.35 & $\mathrm{~m}$ & $\mathrm{E} 4,(\mathrm{E} 6 \mathrm{a}), \mathrm{E} 6 \mathrm{~b}$ & \\
\hline $\mathrm{E} 6 \mathrm{a}$ & \multirow{2}{*}{63.3} & \multirow{2}{*}{$\mathrm{CH}_{2}$} & 4.80 & $\mathrm{~m}$ & $(\mathrm{E} 5), \mathrm{E} 6 \mathrm{~b}$ & $\mathrm{E} 4, \mathrm{E} 5, \mathrm{E} 6-\mathrm{Ac}$ \\
\hline $\mathrm{E} 6 \mathrm{~b}$ & & & 4.12 & dd $(12.0,3.4)$ & $\mathrm{E} 5, \mathrm{E} 6 \mathrm{a}$ & E6-Ac \\
\hline \multirow{2}{*}{ E6-Ac } & 173.1 & $\mathrm{C}$ & - & - & - & - \\
\hline & 21.7 & $\mathrm{CH}_{3}$ & 2.19 & $\mathrm{~s}$ & - & E6-Ac \\
\hline & \multicolumn{6}{|c|}{ Glucose F } \\
\hline F1 & 102.1 & $\mathrm{CH}$ & 5.07 & $\mathrm{~d}(8.3)$ & $\mathrm{F} 2$ & $\mathrm{~A} 2$ \\
\hline $\mathrm{F} 2$ & 73.3 & $\mathrm{CH}$ & 4.85 & $\mathrm{~m}$ & F1, F3 & $\mathrm{F} 1, \mathrm{~F} 2-\mathrm{Ac}$ \\
\hline F3 & 74.2 & $\mathrm{CH}$ & 5.18 & $\mathrm{t}(9.5)$ & $\mathrm{F} 2, \mathrm{~F} 4$ & $\mathrm{~F} 2, \mathrm{~F} 4, \mathrm{~F} 3-\mathrm{Ac}$ \\
\hline $\mathrm{F} 4$ & 69.8 & $\mathrm{CH}$ & 4.99 & $\mathrm{t}(9.8)$ & F3, F5 & $\mathrm{F} 3, \mathrm{~F} 5, \mathrm{~F} 6, \mathrm{~F} 4-\mathrm{Ac}$ \\
\hline F5 & 72.7 & $\mathrm{CH}$ & 3.77 & $\mathrm{~m}$ & $\mathrm{~F} 4, \mathrm{~F} 6 \mathrm{a}$ & \\
\hline F6a & 620 & & 4.30 & $\mathrm{~m}$ & $\mathrm{~F} 5, \mathrm{~F} 6 \mathrm{~b}$ & F6-Ac \\
\hline F6b & 63.2 & $\mathrm{CH}_{2}$ & 4.11 & $\mathrm{dd}(12.4,2.0)$ & $\mathrm{F} 6 \mathrm{a}$ & $\mathrm{F} 4, \mathrm{~F} 5, \mathrm{~F} 6-\mathrm{Ac}$ \\
\hline \multirow{2}{*}{$\mathrm{F} 2-\mathrm{Ac}$} & $171.2^{\mathrm{e}}$ & $\mathrm{C}$ & - & - & - & - \\
\hline & 20.6 & $\mathrm{CH}_{3}$ & $2.00^{f}$ & s & - & F2-Ac \\
\hline \multirow{2}{*}{ F3-Ac } & 171.6 & $\mathrm{C}$ & - & - & - & - \\
\hline & 20.6 & $\mathrm{CH}_{3}$ & 1.97 & s & - & F3-Ac \\
\hline \multirow{2}{*}{ F4-Ac } & $171.2^{\mathrm{e}}$ & $\mathrm{C}^{3}$ & - & - & - & - \\
\hline & 21.1 & $\mathrm{CH}_{3}$ & $2.00^{f}$ & s & - & F4-Ac \\
\hline \multirow{2}{*}{ F6-Ac } & $172.2^{\mathrm{d}}$ & $\mathrm{C}^{3}$ & - & - & - & - \\
\hline & $20.8^{\mathrm{d}}$ & $\mathrm{CH}_{3}$ & $2.04^{\mathrm{d}}$ & $\mathrm{s}$ & - & F6-Ac \\
\hline
\end{tabular}

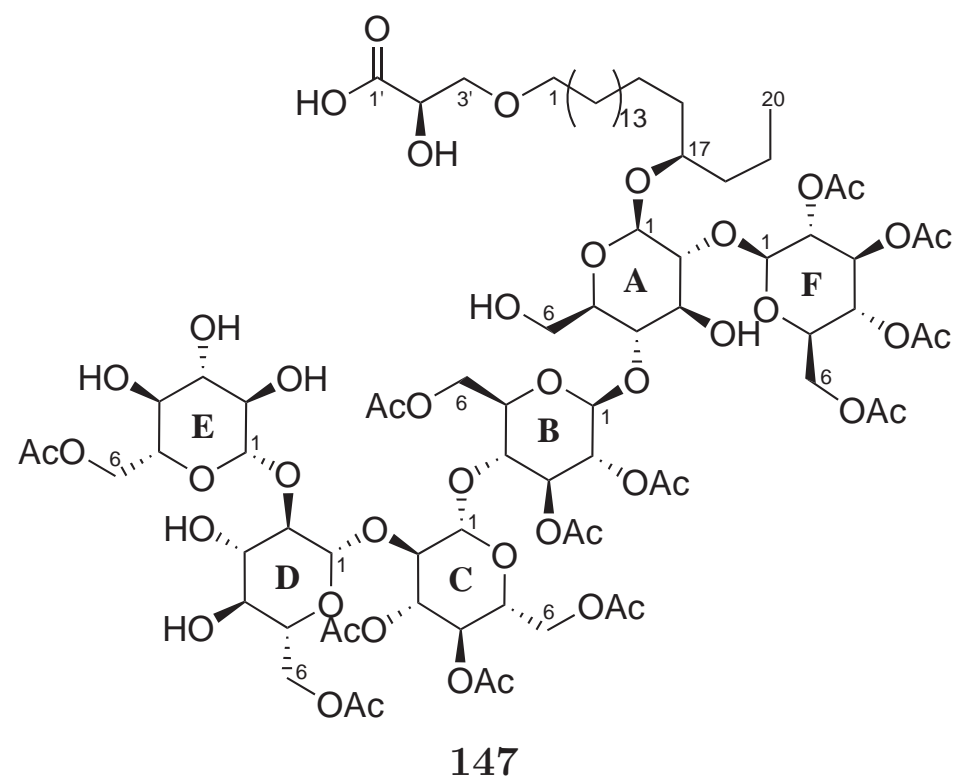


Table 3.14. NMR data (600 MHz, $\left.\mathrm{CD}_{3} \mathrm{OD}\right)$ for agminoside $\mathrm{D}$ (148).

\begin{tabular}{|c|c|c|c|c|c|c|c|}
\hline pos. & $\begin{array}{c}\delta_{\mathrm{C}} \\
(\mathrm{ppm})\end{array}$ & mult & $\begin{array}{c}\delta_{\mathrm{H}} \\
(\mathrm{ppm}) \\
\end{array}$ & $\begin{array}{l}\text { mult, } \\
J(\mathrm{~Hz})\end{array}$ & COSY & HMBC & TOCSY \\
\hline & \multicolumn{7}{|c|}{ Aglycon } \\
\hline $1 \mathrm{a}$ & 72.5 & $\mathrm{CH}_{2}$ & 3.52 & $\mathrm{~m}$ & 2 & 2,3 & 2,3 \\
\hline $1 \mathrm{~b}$ & 12.0 & $\mathrm{I}_{2}$ & 3.48 & $\mathrm{~m}$ & 1,3 & 2,3 & 2,0 \\
\hline 2 & 30.8 & $\mathrm{CH}_{2}$ & 1.57 & $\mathrm{~m}$ & 2 & 1,3 & $1 \mathrm{a}, 1 \mathrm{~b}$ \\
\hline 3 & 27.3 & $\mathrm{CH}_{2}$ & 1.34 & $\mathrm{~m}$ & & & \\
\hline $4-14$ & 30.7 & $\mathrm{CH}_{2}$ & 1.29 & $\mathrm{~m}$ & & & \\
\hline 15 & 26.7 & $\mathrm{CH}_{2}$ & 1.37 & $\mathrm{~m}$ & & 16 & \\
\hline $16 \mathrm{a}$ & 35.9 & $\mathrm{CH}_{2}$ & 1.59 & $\mathrm{~m}$ & & & 14,15 \\
\hline $\begin{array}{c}16 \mathrm{~b} \\
17\end{array}$ & 81.4 & $\mathrm{CH}$ & $\begin{array}{l}1.49 \\
3.66\end{array}$ & $\begin{array}{l}\mathrm{m} \\
\mathrm{m}\end{array}$ & 18 & $(15), 19$ & $16 \mathrm{~b}, 20$ \\
\hline 18 & 37.2 & $\mathrm{CH}_{2}$ & 1.53 & $\mathrm{~m}$ & 17 & 19 & $16 \mathrm{~b}, 19,20$ \\
\hline 19 & 19.1 & $\mathrm{CH}_{2}$ & 1.47 & $\mathrm{~m}$ & 20 & 20 & 20 \\
\hline 20 & 15.0 & $\mathrm{CH}_{3}$ & 0.92 & $\mathrm{t}(7.2)$ & 19 & 18,19 & 19 \\
\hline $3^{\prime}$ & 72.0 & $\mathrm{CH}_{2}$ & 3.78 & $\mathrm{~m}$ & $2^{\prime}$ & 1 & \\
\hline $2^{\prime}$ & 73.3 & $\mathrm{CH}$ & 4.11 & $\mathrm{~m}$ & $3^{\prime}$ & & \\
\hline $1^{\prime}$ & & $\mathrm{C}$ & - & - & - & - & - \\
\hline & \multicolumn{7}{|c|}{ Glucose A } \\
\hline A1 & 102.0 & $\mathrm{CH}$ & 4.45 & $\mathrm{~d}(7.9)$ & A2 & 17 & $\mathrm{~A} 2, \mathrm{~A} 3$ \\
\hline A2 & 82.4 & $\mathrm{CH}$ & 3.50 & $\mathrm{~m}$ & $\mathrm{~A} 1, \mathrm{~A} 3$ & $\mathrm{~F} 1, \mathrm{~A} 4$ & $\mathrm{~A} 1, \mathrm{~A} 3, \mathrm{~A} 4, \mathrm{~A} 5$ \\
\hline A3 & 76.7 & $\mathrm{CH}$ & 3.76 & $\mathrm{~m}$ & $\mathrm{~A} 2, \mathrm{~A} 4$ & $\mathrm{~A} 2, \mathrm{~A} 4$ & $\mathrm{~A} 1, \mathrm{~A} 2, \mathrm{~A} 4, \mathrm{~A} 5$ \\
\hline $\mathrm{A} 4$ & 81.9 & $\mathrm{CH}$ & 3.58 & $\mathrm{~m}$ & $\mathrm{~A} 3, \mathrm{~A} 5$ & B1 & (A1), A2, A4, A5 \\
\hline A5 & 75.5 & $\mathrm{CH}$ & 3.35 & $\mathrm{~m}$ & $\mathrm{~A} 4, \mathrm{~A} 6 \mathrm{a}, \mathrm{A} 6 \mathrm{~b}$ & & $\mathrm{~A} 4, \mathrm{~A} 6$ \\
\hline A6a & \multirow[b]{2}{*}{61.6} & \multirow[b]{2}{*}{$\mathrm{CH}_{2}$} & 3.77 & $\mathrm{~m}$ & \multirow{2}{*}{\multicolumn{2}{|c|}{$\begin{array}{l}\mathrm{A} 5, \mathrm{~A} 6 \mathrm{~b} \\
\mathrm{~A} 5, \mathrm{~A} 6 \mathrm{a}\end{array}$}} & \\
\hline $\mathrm{A} 6 \mathrm{~b}$ & & & 3.63 & $\mathrm{~m}$ & & & A5 \\
\hline & \multicolumn{7}{|c|}{ Glucose B } \\
\hline B1 & 102.0 & $\mathrm{CH}$ & 4.82 & $\mathrm{~m}$ & B2 & A4 & B2, B3 \\
\hline $\mathrm{B} 2$ & 73.0 & $\mathrm{CH}$ & 4.88 & $\mathrm{~m}$ & B1, B3 & $\mathrm{B} 1, \mathrm{~B} 3, \mathrm{~B} 2-\mathrm{Ac}$ & B1, B3 \\
\hline B3 & 74.5 & $\mathrm{CH}$ & 5.26 & $\mathrm{t}(9.7)$ & $\mathrm{B} 2, \mathrm{~B} 4$ & $\mathrm{~B} 2, \mathrm{~B} 4, \mathrm{~B} 3-\mathrm{Ac}$ & B1, B2 \\
\hline B4 & 79.7 & $\mathrm{CH}$ & 3.78 & $\mathrm{~m}$ & B3, B5 & $\mathrm{B} 3, \mathrm{~B} 6, \mathrm{C} 1$ & B3, B5, B6b \\
\hline B5 & 74.4 & $\mathrm{CH}$ & 3.93 & $\mathrm{~m}$ & $\mathrm{~B} 4, \mathrm{~B} 6 \mathrm{a}, \mathrm{B} 6 \mathrm{~b}$ & & $\mathrm{~B} 2, \mathrm{~B} 3, \mathrm{~B} 4, \mathrm{~B} 6 \mathrm{a}$ \\
\hline B6a & \multirow{2}{*}{64.7} & \multirow{2}{*}{$\mathrm{CH}_{2}$} & 4.80 & $\mathrm{~m}$ & $\mathrm{~B} 5, \mathrm{~B} 6 \mathrm{~b}$ & \multirow[t]{2}{*}{$\mathrm{B} 5, \mathrm{~B} 6-\mathrm{Ac}$} & \\
\hline B6b & & & 4.26 & $\mathrm{~m}$ & $\mathrm{~B} 5, \mathrm{~B} 6 \mathrm{a}$ & & В4, В5 \\
\hline \multirow{2}{*}{ B2-Ac } & 171.3 & $\mathrm{C}$ & - & - & - & - & - \\
\hline & 20.8 & $\mathrm{CH}_{3}$ & $2.01^{\mathrm{b}}$ & $\mathrm{s}$ & - & $\mathrm{B} 2-\mathrm{Ac}$ & - \\
\hline \multirow{2}{*}{ B3-Ac } & 171.8 & $\mathrm{C}$ & - & - & - & - & - \\
\hline & $20.7^{\mathrm{c}}$ & $\mathrm{CH}_{3}$ & 2.03 & $\mathrm{~s}$ & - & B3-Ac & - \\
\hline \multirow{2}{*}{$\mathrm{B} 6-\mathrm{Ac}$} & 172.4 & $\mathrm{C}$ & - & - & - & - & - \\
\hline & 21.1 & $\mathrm{CH}_{3}$ & $2.11^{\mathrm{d}}$ & $\mathrm{s}$ & - & $\mathrm{B} 6-\mathrm{Ac}$ & - \\
\hline & & & & & Glucose & & \\
\hline $\mathrm{C} 1$ & 103.6 & $\mathrm{CH}$ & 4.52 & $\mathrm{~d}(7.7)$ & $\mathrm{C} 2$ & B4 & $\mathrm{C} 2,(\mathrm{C} 3)$ \\
\hline $\mathrm{C} 2$ & 79.9 & $\mathrm{CH}$ & 3.49 & $\mathrm{~m}$ & $\mathrm{C} 1, \mathrm{C} 3$ & $\mathrm{C} 1, \mathrm{D} 1$ & $\mathrm{C} 1, \mathrm{C} 3, \mathrm{C} 4$ \\
\hline $\mathrm{C} 3$ & 76.5 & $\mathrm{CH}$ & 5.07 & $\mathrm{t}(8.9)$ & $\mathrm{C} 2, \mathrm{C} 4$ & $\mathrm{C} 2, \mathrm{C} 4, \mathrm{C} 3-\mathrm{Ac}$ & $\mathrm{C} 1, \mathrm{C} 2, \mathrm{C} 4, \mathrm{C} 5$ \\
\hline $\mathrm{C} 4$ & 69.9 & $\mathrm{CH}$ & 4.80 & $\mathrm{~m}$ & $\mathrm{C} 3, \mathrm{C} 5$ & $\mathrm{C} 5, \mathrm{C} 6, \mathrm{C} 4-\mathrm{Ac}$ & $(\mathrm{C} 1), \mathrm{C} 2, \mathrm{C} 3, \mathrm{C} 5$ \\
\hline C5 & 72.5 & $\mathrm{CH}$ & 3.90 & $\mathrm{~m}$ & $\mathrm{C} 4, \mathrm{C} 6 \mathrm{a}, \mathrm{C} 6 \mathrm{~b}$ & & $\mathrm{C} 3, \mathrm{C} 4, \mathrm{C} 6 \mathrm{a}, \mathrm{C} 6 \mathrm{~b}$ \\
\hline C6a & 630 & & 4.34 & $\mathrm{dd}(13.7,6.8)$ & $\mathrm{C} 5, \mathrm{C} 6 \mathrm{~b}$ & C6-Ac & \\
\hline $\mathrm{C} 6 \mathrm{~b}$ & 03.0 & $\mathrm{CH}_{2}$ & 4.07 & dd $(13.6,1.9)$ & $\mathrm{C} 5, \mathrm{C} 6 \mathrm{a}$ & C6-Ac & C5 \\
\hline $\mathrm{C} 3-\mathrm{Ac}$ & 171.2 & $\mathrm{C}$ & - & - & - & - & - \\
\hline & $20.7^{\mathrm{c}}$ & $\mathrm{CH}_{3}$ & 1.99 & $\mathrm{~s}$ & - & $\mathrm{C} 3-\mathrm{Ac}$ & - \\
\hline C4-Ac & 171.5 & $\mathrm{C}$ & - & - & - & - & - \\
\hline & $20.7^{\mathrm{c}}$ & $\mathrm{CH}_{3}$ & 1.93 & $\mathrm{~s}$ & - & $\mathrm{C} 4-\mathrm{Ac}$ & - \\
\hline C6-Ac & $172.2^{\mathrm{e}}$ & $\mathrm{C}$ & - & - & - & - & - \\
\hline CO-AC & $20.6^{\mathrm{d}}$ & $\mathrm{CH}_{3}$ & $2.04^{\mathrm{g}}$ & $\mathrm{s}$ & - & $\mathrm{C} 6-\mathrm{Ac}$ & - \\
\hline & & & & & Glucose & & \\
\hline D1 & 103.2 & $\mathrm{CH}$ & 4.45 & $\mathrm{~d}(7.9)$ & D2 & $\mathrm{C} 2$ & D2, D3 \\
\hline D2 & 83.8 & $\mathrm{CH}$ & 3.21 & $\mathrm{~m}$ & D1, D3 & D1, D3, E1 & D1, D3, D5 \\
\hline D3 & 77.9 & $\mathrm{CH}$ & 3.48 & $\mathrm{~m}$ & & & $\mathrm{D} 1, \mathrm{D} 2, \mathrm{D} 4$ \\
\hline D4 & 71.5 & $\mathrm{CH}$ & 3.22 & $\mathrm{~m}$ & & D3, D5, D6 & $(\mathrm{D} 1), \mathrm{D} 3, \mathrm{D} 5, \mathrm{D} 6 \mathrm{a}, \mathrm{D} 6 \mathrm{~b}$ \\
\hline D5 & 75.3 & $\mathrm{CH}$ & 3.43 & $\mathrm{~m}$ & & & D6b \\
\hline D6a & 64.3 & & 4.51 & $\mathrm{dd}(11.5,6.5)$ & D5, D6b & D5, D6-Ac & D4. D5 \\
\hline $\mathrm{D} 6 \mathrm{~b}$ & & $\mathrm{H}_{2}$ & 4.24 & $\mathrm{dd}(12.9,1.8)$ & D5, D6a & D6-Ac & D4, D5 \\
\hline
\end{tabular}

${ }^{a}$ not observed

b,c,d,e,f,g can be interchanged 
Table 3.14. - continued from previous page

\begin{tabular}{|c|c|c|c|c|c|c|c|}
\hline pos, & $\begin{array}{c}\delta_{\mathrm{C}} \\
(\mathrm{ppm})\end{array}$ & mult & $\begin{array}{c}\delta_{\mathrm{H}} \\
(\mathrm{ppm})\end{array}$ & $\begin{array}{l}\text { mult, } \\
J(\mathrm{~Hz})\end{array}$ & COSY & HMBC & TOCSY \\
\hline \multirow{2}{*}{ D6-Ac } & 173.0 & $\mathrm{C}$ & - & - & - & - & - \\
\hline & 21.5 & $\mathrm{CH}_{3}$ & 2.19 & $\mathrm{~s}$ & - & D6-Ac & - \\
\hline & \multicolumn{7}{|c|}{ Glucose E } \\
\hline E1 & 106.1 & $\mathrm{CH}$ & 4.39 & $\mathrm{~d}(7.9)$ & $\mathrm{E} 2$ & D2 & $\mathrm{E} 2, \mathrm{E} 3$ \\
\hline E2 & 75.3 & $\mathrm{CH}$ & 3.18 & $\mathrm{~m}$ & E1, E3 & E1, E3 & $\mathrm{E} 1, \mathrm{E} 3, \mathrm{E} 4$ \\
\hline E3 & 78.2 & $\mathrm{CH}$ & 3.33 & $\mathrm{~m}$ & $\mathrm{E} 2, \mathrm{E} 4$ & $\mathrm{E} 1, \mathrm{E} 2, \mathrm{E} 4$ & $\mathrm{E} 1, \mathrm{E} 2,(\mathrm{E} 4)$ \\
\hline $\mathrm{E} 4$ & 70.8 & $\mathrm{CH}$ & 3.45 & $\mathrm{~m}$ & E3, E5 & E5, E6 & $(\mathrm{E} 1), \mathrm{E} 2, \mathrm{E} 3, \mathrm{E} 5$ \\
\hline E5 & 75.7 & $\mathrm{CH}$ & 3.36 & $\mathrm{~m}$ & $\mathrm{E} 4, \mathrm{E} 6 \mathrm{a}, \mathrm{E} 6 \mathrm{~b}$ & & \\
\hline E6a & \multirow{2}{*}{63.5} & \multirow{2}{*}{$\mathrm{CH}_{2}$} & 4.78 & $\mathrm{~m}$ & $\mathrm{E} 5, \mathrm{E} 6 \mathrm{~b}$ & $\mathrm{E} 4, \mathrm{E} 5, \mathrm{E} 6-\mathrm{Ac}$ & \multirow{2}{*}{ E5 } \\
\hline E6b & & & 4.13 & $\mathrm{~m}$ & $\mathrm{E} 5, \mathrm{E} 6 \mathrm{a}$ & E6-Ac & \\
\hline \multirow{2}{*}{ E6-Ac } & 173.3 & $\mathrm{C}$ & - & - & - & - & - \\
\hline & 21.4 & $\mathrm{CH}_{3}$ & 2.19 & $\mathrm{~s}$ & - & E6-Ac & - \\
\hline & \multicolumn{7}{|c|}{ Glucose F } \\
\hline $\mathrm{F} 1$ & 105.2 & $\mathrm{CH}$ & 4.80 & $\mathrm{~m}$ & $\mathrm{~F} 2$ & A2 & $\mathrm{F} 2,(\mathrm{~F} 3)$ \\
\hline $\mathrm{F} 2$ & 74.3 & $\mathrm{CH}$ & 3.43 & $\mathrm{~m}$ & $\mathrm{~F} 1, \mathrm{~F} 3$ & $\mathrm{~F} 1, \mathrm{~F} 3$ & $\mathrm{~F} 1$ \\
\hline F3 & 76.1 & $\mathrm{CH}$ & 5.07 & $\mathrm{t}(8.9)$ & $\mathrm{F} 2, \mathrm{~F} 4$ & $\mathrm{~F} 2, \mathrm{~F} 3-\mathrm{Ac}$ & $\mathrm{F} 1, \mathrm{~F} 2, \mathrm{~F} 4, \mathrm{~F} 5$ \\
\hline $\mathrm{F} 4$ & 70.0 & $\mathrm{CH}$ & 4.91 & $\mathrm{~m}$ & F3, F5 & $\mathrm{F} 3, \mathrm{~F} 5, \mathrm{~F} 6, \mathrm{~F} 4-\mathrm{Ac}$ & $\mathrm{F} 1, \mathrm{~F} 2, \mathrm{~F} 3, \mathrm{~F} 5$ \\
\hline F5 & 73.0 & $\mathrm{CH}$ & 3.75 & $\mathrm{~m}$ & $\mathrm{~F} 4, \mathrm{~F} 6 \mathrm{a}, \mathrm{F} 6 \mathrm{~b}$ & $(\mathrm{~F} 4)$ & $\mathrm{F} 6 \mathrm{~F} 4, \mathrm{~F} 3, \mathrm{~F} 6 \mathrm{a}, \mathrm{F} 6 \mathrm{~b}$ \\
\hline F6a & \multirow{2}{*}{63.4} & \multirow{2}{*}{$\mathrm{CH}_{2}$} & 4.26 & $\mathrm{~m}$ & $\mathrm{~F} 5, \mathrm{~F} 6 \mathrm{~b}$ & F6-Ac & \multirow{2}{*}{ F5 } \\
\hline F6b & & & 4.10 & $\mathrm{~m}$ & $\mathrm{~F} 5, \mathrm{~F} 6 \mathrm{a}$ & $\mathrm{F} 5, \mathrm{~F} 6-\mathrm{Ac}$ & \\
\hline \multirow{2}{*}{ F3-Ac } & 172.0 & $\mathrm{C}$ & - & - & - & - & - \\
\hline & $20.7^{\mathrm{c}}$ & $\mathrm{CH}_{3}$ & $2.04^{\mathrm{g}}$ & $\mathrm{s}$ & - & F3-Ac & - \\
\hline \multirow{2}{*}{ F4-Ac } & 171.4 & $\mathrm{C}$ & - & - & - & - & - \\
\hline & 20.6 & $\mathrm{CH}_{3}$ & $2.01^{\mathrm{b}}$ & $\mathrm{s}$ & - & $\mathrm{F} 4-\mathrm{Ac}$ & - \\
\hline \multirow{2}{*}{ F6-Ac } & $172.2^{\mathrm{e}}$ & $\mathrm{C}$ & - & - & - & - & - \\
\hline & 21.2 & $\mathrm{CH}_{3}$ & $2.11^{\mathrm{c}}$ & $\mathrm{s}$ & - & F6-Ac & - \\
\hline
\end{tabular}

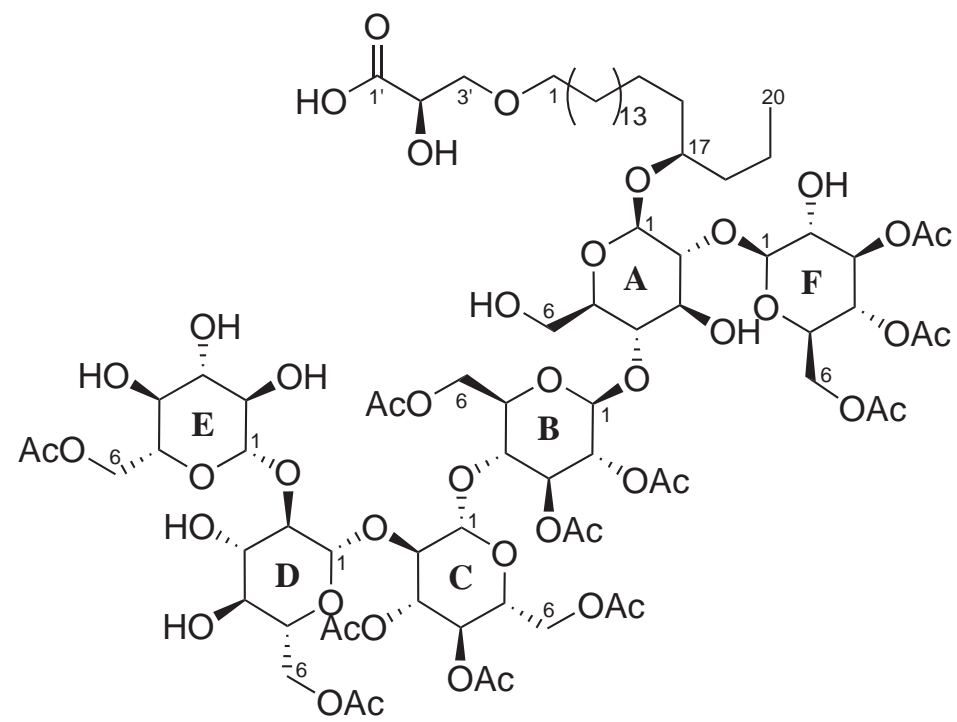

148 
Table 3.15. NMR data (600 MHz, $\left.\mathrm{CD}_{3} \mathrm{OD}\right)$ for agminoside $\mathrm{E}(\mathbf{1 4 9})$.

\begin{tabular}{|c|c|c|c|c|c|c|c|}
\hline pos. & $\begin{array}{c}\delta_{\mathrm{C}} \\
(\mathrm{ppm})\end{array}$ & mult & $\begin{array}{c}\delta_{\mathrm{H}} \\
(\mathrm{ppm})\end{array}$ & $\begin{array}{l}\text { mult, } \\
J(\mathrm{~Hz})\end{array}$ & COSY & HMBC & TOCSY \\
\hline & \multicolumn{7}{|c|}{ Aglycon } \\
\hline $1 \mathrm{a}$ & \multirow{2}{*}{72.4} & \multirow{2}{*}{$\mathrm{CH}_{2}$} & 3.51 & $\mathrm{~m}$ & 2 & 2,3 & \multirow{2}{*}{$2,3,4$} \\
\hline $1 b$ & & & 3.45 & $\mathrm{~m}$ & 2 & 2,3 & \\
\hline 2 & 30.67 & $\mathrm{CH}_{2}$ & 1.55 & $\mathrm{~m}$ & $1 \mathrm{a}, 1 \mathrm{~b}, 3$ & $1,3,4$ & \\
\hline 3 & 27.2 & $\mathrm{CH}_{2}^{2}$ & 1.34 & $\mathrm{~m}$ & 2 & & 4 \\
\hline $4-14$ & 30.8 & $\mathrm{CH}_{2}^{2}$ & 1.29 & $\mathrm{~m}$ & & & \\
\hline 15 & 26.4 & $\mathrm{CH}_{2}^{2}$ & 1.36 & $\mathrm{~m}$ & & & 14 \\
\hline $16 \mathrm{a}$ & \multirow{2}{*}{35.8} & \multirow{2}{*}{$\mathrm{CH}_{2}$} & 1.57 & $\mathrm{~m}$ & $16 b$ & & \multirow{2}{*}{14} \\
\hline $16 \mathrm{~b}$ & & & 1.48 & $\mathrm{~m}$ & $16 \mathrm{a}$ & & \\
\hline 17 & 81.7 & $\mathrm{CH}$ & 3.62 & $\mathrm{~m}$ & $16 \mathrm{a}, 16 \mathrm{~b}, 18$ & 19 & $14,16 \mathrm{~b}, 20$ \\
\hline 18 & 37.1 & $\mathrm{CH}_{2}$ & 1.48 & $\mathrm{~m}$ & & 20 & 20 \\
\hline 19 & 18.9 & $\mathrm{CH}_{2}^{2}$ & 1.47 & $\mathrm{~m}$ & 20 & 18,20 & \\
\hline 20 & 14.8 & $\mathrm{CH}_{3}^{2}$ & 0.95 & $\mathrm{t}(6.5)$ & 19 & 18,19 & \\
\hline $3^{\prime}$ & 71.7 & $\mathrm{CH}_{2}^{3}$ & 3.78 & $\mathrm{~m}$ & $2^{\prime}$ & 1 & $2^{\prime}$ \\
\hline $2^{\prime}$ & 76.0 & $\mathrm{CH}$ & 5.08 & $\mathrm{~m}$ & $1^{\prime}$ & $1^{\prime}, 2^{\prime}-\mathrm{Ac}$ & $3^{\prime}$ \\
\hline $1^{\prime}$ & $\mathrm{a}$ & $\mathrm{C}$ & - & - & - & - & \\
\hline \multirow{2}{*}{$2^{\prime}-\mathrm{Ac}$} & 172.6 & $\mathrm{C}$ & - & - & - & - & - \\
\hline & $21.1^{\mathrm{b}}$ & $\mathrm{CH}_{3}$ & 2.11 & $\mathrm{~s}$ & - & $2^{\prime}, 3^{\prime}-\mathrm{Ac}$ & \\
\hline & & & & & Glucose A & & \\
\hline A1 & 101.9 & $\mathrm{CH}$ & 4.38 & $\mathrm{~d}(7.5)$ & A2 & 17 & $\mathrm{~A} 2, \mathrm{~A} 3, \mathrm{~A} 4$ \\
\hline A2 & 81.1 & $\mathrm{CH}$ & 3.45 & $\mathrm{~m}$ & $\mathrm{~A} 1, \mathrm{~A} 3$ & $\mathrm{~A} 1, \mathrm{~A} 3, \mathrm{~F} 1$ & A1 \\
\hline A3 & 77.3 & $\mathrm{CH}$ & 3.55 & $\mathrm{~m}$ & $\mathrm{~A} 2, \mathrm{~A} 4$ & $\mathrm{~A} 2, \mathrm{~A} 4$ & \\
\hline $\mathrm{A} 4$ & 82.4 & $\mathrm{CH}$ & 3.53 & $\mathrm{~m}$ & $\mathrm{~A} 3, \mathrm{~A} 5$ & A5 & A1 \\
\hline A5 & 75.7 & $\mathrm{CH}$ & 3.30 & $\mathrm{~m}$ & $\mathrm{~A} 4, \mathrm{~A} 6 \mathrm{a}$ & & A1 \\
\hline A6a & \multirow{2}{*}{61.6} & \multirow{2}{*}{$\mathrm{CH}_{2}$} & 3.75 & $\mathrm{~m}$ & $\mathrm{~A} 6 \mathrm{~b}$ & \multirow[t]{2}{*}{$\mathrm{A} 4, \mathrm{~A} 5$} & \\
\hline $\mathrm{A} 6 \mathrm{~b}$ & & & 3.61 & $\mathrm{~m}$ & $\mathrm{~A} 5, \mathrm{~A} 6 \mathrm{a}$ & & \\
\hline & \multicolumn{7}{|c|}{ Glucose B } \\
\hline B1 & 102.1 & $\mathrm{CH}$ & 4.78 & $\mathrm{~m}$ & $\mathrm{~B} 2$ & $\mathrm{~A} 4$ & $\mathrm{~B} 2, \mathrm{~B} 4$ \\
\hline $\mathrm{B} 2$ & 73.0 & $\mathrm{CH}$ & 4.86 & $\mathrm{~m}$ & B1, B3 & $\mathrm{B} 1, \mathrm{~B} 3, \mathrm{~B} 2-\mathrm{Ac}$ & B1 \\
\hline B3 & 74.4 & $\mathrm{CH}$ & 5.23 & $\mathrm{~m}$ & $\mathrm{~B} 2, \mathrm{~B} 4$ & $\mathrm{~B} 2, \mathrm{~B} 4$ & $\mathrm{~B} 1, \mathrm{~B} 2, \mathrm{~B} 4$ \\
\hline B4 & 79.3 & $\mathrm{CH}$ & 3.78 & $\mathrm{~m}$ & B3 & $\mathrm{B} 5, \mathrm{~B} 6, \mathrm{C} 1$ & \\
\hline B5 & 74.2 & $\mathrm{CH}$ & 3.92 & $\mathrm{~m}$ & $\mathrm{~B} 6 \mathrm{a}$ & & \\
\hline $\mathrm{B} 6 \mathrm{a}$ & & & 4.75 & $\mathrm{~m}$ & $\mathrm{~B} 6 \mathrm{a}, \mathrm{B} 5, \mathrm{~B} 6-\mathrm{Ac}$ & & \\
\hline $\mathrm{B} 6 \mathrm{~b}$ & 64.3 & $\mathrm{CH}_{2}$ & 4.30 & $\mathrm{~m}$ & $\mathrm{~B} 6 \mathrm{~b}$ & B6-Ac & B5 \\
\hline \multirow{2}{*}{ B2-Ac } & 171.2 & $\mathrm{C}$ & - & - & - & - & - \\
\hline & $20.6^{\mathrm{c}}$ & $\mathrm{CH}_{3}$ & 2.06 & $\mathrm{~s}$ & - & $\mathrm{B} 2-\mathrm{Ac}$ & - \\
\hline \multirow{2}{*}{ B3-Ac } & 171.8 & $\mathrm{C}^{\mathrm{J}}$ & - & - & - & - & - \\
\hline & $20.6^{\mathrm{c}}$ & $\mathrm{CH}_{3}$ & $2.00^{\mathrm{d}}$ & $\mathrm{s}$ & - & $\mathrm{B} 3-\mathrm{Ac}$ & - \\
\hline \multirow{2}{*}{ B6-Ac } & 172.6 & $\mathrm{C}^{\mathrm{J}}$ & - & - & - & - & - \\
\hline & $21.1^{\mathrm{b}}$ & $\mathrm{CH}_{3}$ & 2.19 & $\mathrm{~s}$ & - & $\mathrm{B} 6-\mathrm{Ac}$ & - \\
\hline & & & & & Glucose C & & \\
\hline $\mathrm{C} 1$ & 103.6 & $\mathrm{CH}$ & 4.52 & $\mathrm{~d}(7.7)$ & $\mathrm{C} 2$ & & $\mathrm{C} 2, \mathrm{C} 5$ \\
\hline $\mathrm{C} 2$ & 80.9 & $\mathrm{CH}$ & 3.56 & $\mathrm{~m}$ & $\mathrm{C} 1, \mathrm{C} 3$ & $\mathrm{C} 1, \mathrm{D} 1$ & $\mathrm{C} 1, \mathrm{C} 4, \mathrm{C} 5$ \\
\hline C3 & 76.1 & $\mathrm{CH}$ & 5.22 & $\mathrm{~m}$ & $\mathrm{C} 2, \mathrm{C} 4$ & $\mathrm{C} 2, \mathrm{C} 4, \mathrm{C} 3-\mathrm{Ac}$ & $\mathrm{C} 1$ \\
\hline $\mathrm{C} 4$ & 69.7 & $\mathrm{CH}$ & 4.87 & $\mathrm{~m}$ & $\mathrm{C} 3, \mathrm{C} 5$ & $\mathrm{C} 3, \mathrm{C} 5, \mathrm{C} 6, \mathrm{C} 4-\mathrm{Ac}$ & \\
\hline C5 & 72.6 & $\mathrm{CH}$ & 3.81 & $\mathrm{~m}$ & $\mathrm{C} 4, \mathrm{C} 6 \mathrm{a}, \mathrm{C} 6 \mathrm{~b}$ & & $\mathrm{C} 1$ \\
\hline $\mathrm{C} 6 \mathrm{a}$ & 620 & & 4.35 & $\mathrm{dd}(12.5,3.9)$ & $\mathrm{C} 5, \mathrm{C} 6 \mathrm{~b}$ & C6-Ac & \\
\hline $\mathrm{C} 6 \mathrm{~b}$ & 63.0 & $\mathrm{CH}_{2}$ & 4.03 & $\mathrm{dd}(12.3,2.0)$ & $\mathrm{C} 5, \mathrm{C} 6 \mathrm{a}$ & $\mathrm{C} 4, \mathrm{C} 5, \mathrm{C} 6-\mathrm{Ac}$ & \\
\hline $\mathrm{C} 3-\mathrm{Ac}$ & 171.6 & $\mathrm{C}$ & - & - & - & - & - \\
\hline U-AC & 20.8 & $\mathrm{CH}_{3}$ & $2.02^{\mathrm{e}}$ & $\mathrm{s}$ & - & C3-Ac & - \\
\hline $\mathrm{C} 4-\mathrm{As}_{\mathrm{c}}$ & 171.4 & $\mathrm{C}^{\mathrm{J}}$ & - & - & - & - & - \\
\hline $\mathrm{C} 4-\mathrm{AC}$ & $20.6^{\mathrm{c}}$ & $\mathrm{CH}_{3}$ & 1.96 & $\mathrm{~s}$ & - & $\mathrm{C} 4-\mathrm{Ac}$ & - \\
\hline$C 6-A c$ & 172.2 & $\mathrm{C}^{3}$ & - & - & - & - & - \\
\hline & 20.8 & $\mathrm{CH}_{3}$ & 2.04 & $\mathrm{~s}$ & - & C6-Ac & - \\
\hline & & & & & Glucose D & & \\
\hline D1 & 106.0 & $\mathrm{CH}$ & 4.31 & $\mathrm{~d}(8.0)$ & D2 & $\mathrm{C} 2$ & $\mathrm{D} 2, \mathrm{D} 3, \mathrm{D} 4$ \\
\hline D2 & 74.7 & $\mathrm{CH}$ & 3.09 & $\mathrm{dd}(9.4,8.4)$ & D1, D3 & D1, D3 & D1, D3 \\
\hline D3 & 77.7 & $\mathrm{CH}$ & 3.29 & $\mathrm{~m}$ & $\mathrm{D} 2, \mathrm{D} 4$ & $\mathrm{D} 2, \mathrm{D} 4$ & D1 \\
\hline D4 & 71.6 & $\mathrm{CH}$ & 3.19 & $\mathrm{t}(9.4)$ & D3, D5 & D3, D5, D6 & D1 \\
\hline D5 & 75.4 & $\mathrm{CH}$ & 3.44 & $\mathrm{~m}$ & $\mathrm{D} 4, \mathrm{D} 6 \mathrm{a}, \mathrm{D} 6 \mathrm{~b}$ & $\mathrm{D} 4, \mathrm{D} 6$ & $\mathrm{D} 1, \mathrm{D} 4$ \\
\hline
\end{tabular}

${ }^{a}$ not observed

$\mathrm{b}, \mathrm{c}, \mathrm{d}, \mathrm{e}$ can be interchanged 
Table 3.15. - continued from previous page

\begin{tabular}{|c|c|c|c|c|c|c|c|}
\hline pos. & $\begin{array}{c}\delta_{\mathrm{C}} \\
(\mathrm{ppm})\end{array}$ & mult & $\begin{array}{c}\delta_{\mathrm{H}} \\
(\mathrm{ppm})\end{array}$ & $\begin{array}{l}\text { mult, } \\
J(\mathrm{~Hz})\end{array}$ & COSY & $\mathrm{HMBC}$ & $\overline{\text { TOCSY }}$ \\
\hline $\begin{array}{l}\text { D6a } \\
\text { D6b }\end{array}$ & 69.6 & $\mathrm{CH}_{2}$ & $\begin{array}{l}4.46 \\
4.29\end{array}$ & $\begin{array}{l}\mathrm{dd}(11.8,6.9) \\
\mathrm{m}\end{array}$ & $\begin{array}{l}\text { D5, D6b } \\
\text { D5, D6a }\end{array}$ & $\begin{array}{l}\text { D6-Ac } \\
\text { D6-Ac }\end{array}$ & \\
\hline D6-Ac & $\begin{array}{r}173.0 \\
21.4 \\
\end{array}$ & $\begin{array}{c}\mathrm{C} \\
\mathrm{CH}_{3}\end{array}$ & $\begin{array}{c}- \\
2.20\end{array}$ & s & - & D6-Ac & - \\
\hline & \multicolumn{7}{|c|}{ Glucose F } \\
\hline F1 & 102.1 & $\mathrm{CH}$ & 5.07 & $\mathrm{~d}(8.1)$ & $\mathrm{F} 2$ & $\mathrm{~A} 2$ & $\mathrm{~F} 2$ \\
\hline $\mathrm{F} 2$ & 73.3 & $\mathrm{CH}$ & 4.85 & $\mathrm{~m}$ & F1, F3 & F1, F3, F6-Ac & \\
\hline F3 & 74.2 & $\mathrm{CH}$ & 5.17 & $\mathrm{t}(9.6)$ & $\mathrm{F} 2, \mathrm{~F} 4$ & $\mathrm{~F} 2, \mathrm{~F} 4, \mathrm{~F} 3-\mathrm{Ac}$ & \\
\hline F4 & 69.8 & $\mathrm{CH}$ & 4.99 & $\mathrm{t}(9.6)$ & $\mathrm{F} 3, \mathrm{~F} 5$ & $\mathrm{~F} 3, \mathrm{~F} 6, \mathrm{~F} 4-\mathrm{Ac}$ & $\mathrm{F} 1, \mathrm{~F} 2$ \\
\hline F5 & 76.7 & $\mathrm{CH}$ & 3.78 & $\mathrm{~m}$ & $\mathrm{~F} 4, \mathrm{~F} 6 \mathrm{a}$ & & \\
\hline F6a & 632 & $\mathrm{CH}$ & 4.29 & $\mathrm{~m}$ & $\mathrm{~F} 5, \mathrm{~F} 6 \mathrm{~b}$ & $\mathrm{~F} 4, \mathrm{~F} 5, \mathrm{~F} 6-\mathrm{Ac}$ & F5 \\
\hline F6b & 63.2 & $\mathrm{CH}_{2}$ & 4.10 & $\mathrm{dd}(12.1,2.2)$ & F6a & F6-Ac & F5 \\
\hline \multirow{2}{*}{$\mathrm{F} 2-\mathrm{Ac}$} & 171.4 & $\mathrm{C}$ & - & - & - & - & - \\
\hline & 21.0 & $\mathrm{CH}_{3}$ & $2.02^{\mathrm{e}}$ & $\mathrm{s}$ & - & $\mathrm{F} 2-\mathrm{Ac}$ & - \\
\hline \multirow{2}{*}{ F3-Ac } & 171.6 & $\mathrm{C}^{3}$ & - & - & - & - & - \\
\hline & 20.5 & $\mathrm{CH}_{3}$ & 1.97 & $\mathrm{~s}$ & - & F3-Ac & - \\
\hline \multirow{2}{*}{$\mathrm{F} 4-\mathrm{Ac}$} & 171.3 & $\mathrm{C}^{3}$ & - & - & - & - & - \\
\hline & 20.9 & $\mathrm{CH}_{3}$ & $2.00^{\mathrm{d}}$ & $\mathrm{s}$ & - & $\mathrm{F} 4-\mathrm{Ac}$ & - \\
\hline \multirow{2}{*}{ F6-Ac } & 172.2 & $\mathrm{C}^{3}$ & - & - & - & - & - \\
\hline & 20.7 & $\mathrm{CH}_{3}$ & 2.03 & $\mathrm{~s}$ & - & F6-Ac & - \\
\hline
\end{tabular}

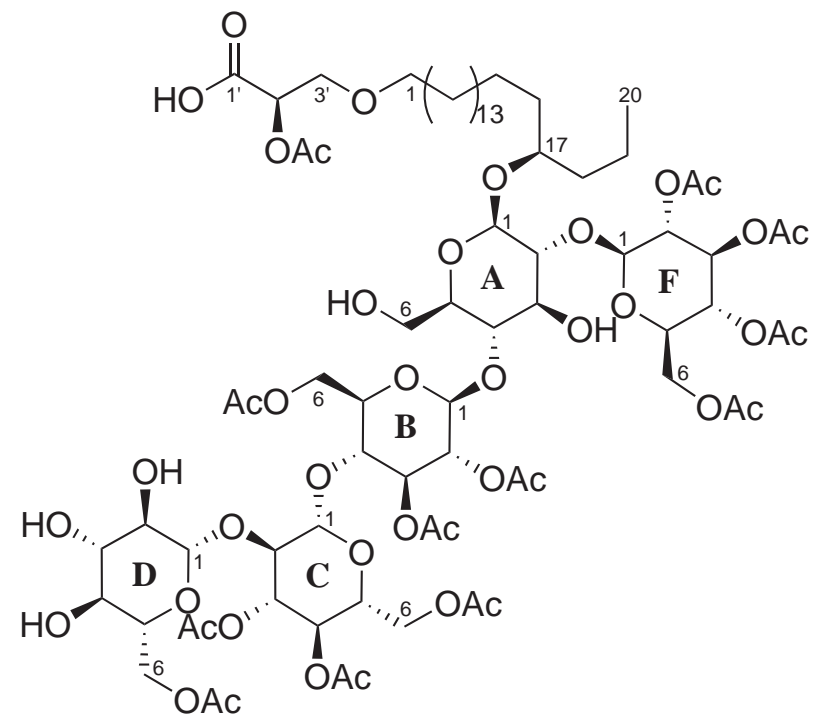




\subsection{Biological activity}

The biological activity of the agminoside glycolipids was investigated by researchers from the School of Biological Sciences, VUW. Agminoside A (145) was subjected to a $72 \mathrm{~h}$ MTT assay against HeLa (cervical cancer) cells. It showed weak growth inhibitory activity $\left(\mathrm{IC}_{50}=32 \mu \mathrm{M}\right)$ that may be due to non-specific lipid effects. ${ }^{158}$

The mixture of glycolipids (with 145 being the major constituent) was submitted to the chemical genetics programme at the School of Biological Sciences, VUW. The programme surveys genetic interactions in a Saccharomyces cerevisiae model system as a novel approach to drug discovery. Chemical genetics is based on the idea that a molecule that is a specific inhibitor of a protein will functionally act like a mutation of that gene, allowing the identification of potential new drugs and drug targets. ${ }^{159}$

The agminosides were tested against approx. 4800 individual haploid mutant yeast strains. ${ }^{160}$ Unfortunately they did not show any differential activity, perhaps due to their inability to enter cells because of their large size. ${ }^{161}$

\subsection{Glycolipids from sponges}

Lipid is a broad term encompassing biological substances that are generally hydrophobic, insoluble or immiscible with water but soluble in organic solvents. ${ }^{162}$ They can be classified into categories based on the identity of their core lipid: polyketides, acylglycerols, sphingolipids, prenols, and saccharolipids. In addition, for historical and bioinformatics reasons, fatty acyls are separated from other polyketides, glycerophospholipids from other glycerolipids, and sterols from other prenols, resulting in eight final categories (Table 3.16). ${ }^{162}$

Table 3.16. Lipid categories.

\begin{tabular}{|l|l|}
\hline Core lipid type & Lipid category \\
\hline \multirow{2}{*}{ polyketide } & fatty acyl lipids \\
\cline { 2 - 2 } & other polyketide lipids \\
\hline \multirow{2}{*}{ acylglycerol } & glycerolipids \\
\cline { 2 - 2 } & glycerophospholipids \\
\hline sphingoid & sphingolipids \\
\hline \multirow{2}{*}{ isoprenoid } & prenol lipids \\
\cline { 2 - 2 } $\begin{array}{l}\text { fatty acid linked directly } \\
\text { to sugar backbone }\end{array}$ & sterol lipids \\
\hline
\end{tabular}



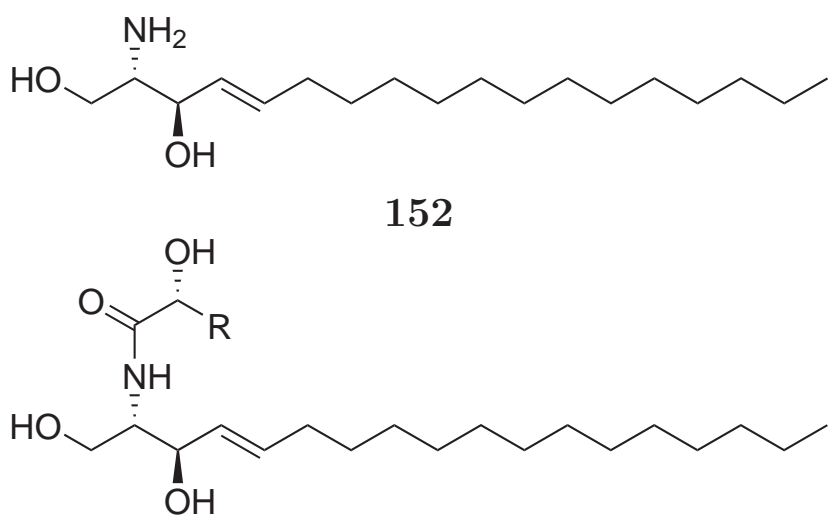

153

Any compound containing one or more monosaccharide residues bound by a glycosidic linkage to a lipid is termed a glycolipid. ${ }^{163}$ Glycolipids occur in all kingdoms of living organisms, as they are important membrane components, and are involved in cellular trafficking, signalling, external interactions, proliferation, differentiation and apoptosis. ${ }^{164,165}$

Usually, glycolipids fall into three categories depending on their lipid moiety: glycosphingolipids, glycoglycerolipids and isoprenoid glycosides. These have either a sphingoid (long chain aliphatic amino alcohol, such as sphingosine (152)) or a ceramide ( $N$-acylsphingoid e.g. 153), an acylated glycerol, or a terpene alcohol as their lipid moiety respectively. ${ }^{163}$ Other glycolipids exist that are not easily categorized. These often contain a glycosyl moiety (one or more saccharide units) linked through an ether bond to a fatty alcohol or a hydroxy fatty acid, or through an ester bond to the carboxyl of a fatty acid. ${ }^{164}$

Natural glycolipids are often complex mixtures of homologues differing only in the length and branching of their alkyl chains. ${ }^{166,167}$ Because of their similarity, they are notoriously difficult to separate, and are often reported as mixtures, the ratio of the various homologues having been determined through chemical degradation. For example, the diglycosylated glycosphingolipid vesparioside (154) (isolated from the sponge Speciospongia vesparia) is reported as a mixture. ${ }^{167}$ The sugar residues were assigned by NMR analysis, revealing the presence of a $\beta$-glucopyranoside and a $\beta$-arabinopyranoside, the first pentose sugar unit reported from a natural diglycosylceramide. Preliminary NMR analysis revealed that the alkyl chain mixture differed in length and position of branching; the exact composition was determined by microscale chemical degradation. ${ }^{167}$

Of the glycolipids isolated from sponges, the glycosphingolipids are the most numerous, and no attempt is made here to provide a comprehensive review. Many show both interesting chemistry and biological activity, such as the plako- 


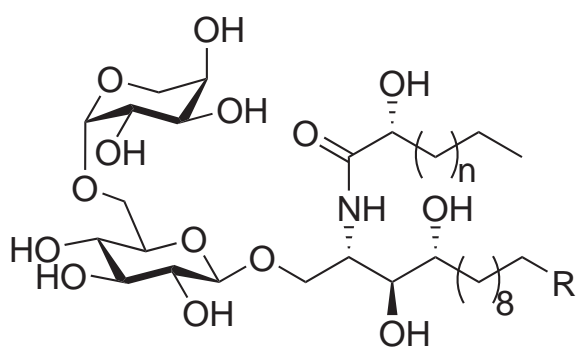

154

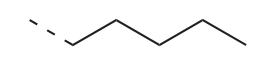

$60.4 \%$<smiles>CCCCC(C)C</smiles>

$25.5 \%$<smiles>CCCC(C)CC</smiles>

$9.4 \%$

$4.7 \%$

$\mathrm{n}=20$

$83.2 \%$

$\mathrm{n}=21$
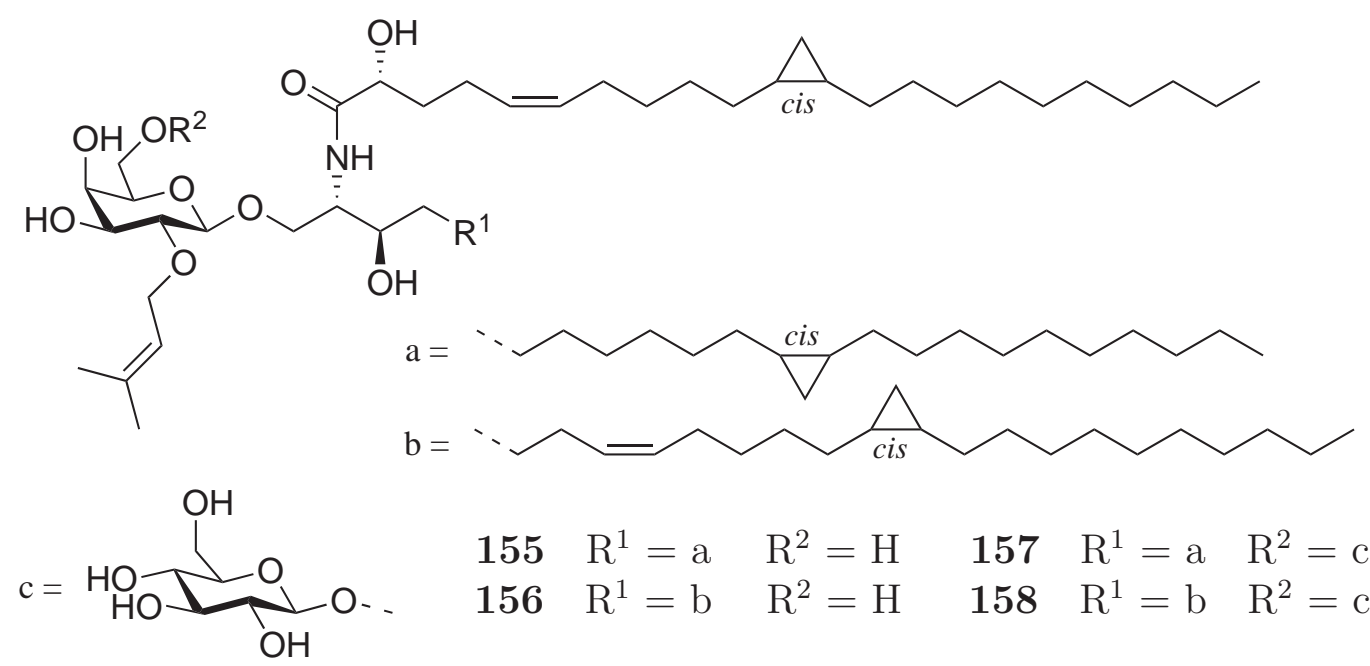

$155 \mathrm{R}^{1}=\mathrm{a} \quad \mathrm{R}^{2}=\mathrm{H}$

$157 \mathrm{R}^{1}=\mathrm{a} \quad \mathrm{R}^{2}=\mathrm{c}$

$156 \mathrm{R}^{1}=\mathrm{b} \quad \mathrm{R}^{2}=\mathrm{H}$

$158 \quad \mathrm{R}^{1}=\mathrm{b} \quad \mathrm{R}^{2}=\mathrm{c}$

sides A-D (155-158). ${ }^{168,169}$ They are the first examples of a natural glycosphingolipid with a prenylated sugar, and the first with a cyclopropane-containing ceramide. ${ }^{168}$ Compounds $\mathbf{1 5 5}$ and $\mathbf{1 5 6}$ were isolated from the sponge Plakortis simplex, while 157 and 158 were reported from Ectyoplasia ferox, raising doubts about the actual organism responsible for biosynthesis. ${ }^{169}$ Plakosides A and B show strong immunosuppressive activity in an activated $\mathrm{T}$ cell assay without any appreciable toxicity, meaning they or their analogues may be quite useful as therapeutic agents. ${ }^{168}$

The agelasphins (159-166) are a family of highly biologically active glycosphingolipids. ${ }^{170,171}$ Isolated from the Japanese sponge Agelas mauritianus, they were the first naturally occuring $\alpha$-galactosylceramides isolated. ${ }^{170}$ They have all shown antitumour activity, and several analogues have been synthesized using the most potent compound 162 as the lead structure. ${ }^{172}$ The culmination of this research, the agent KRN-7000 (167), is now in clinical trials for cancer immunotherapy. ${ }^{25}$ 


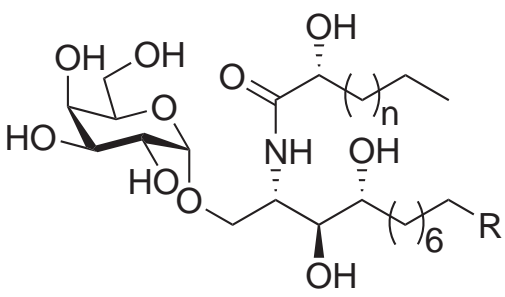

$159 \mathrm{n}=20 \quad \mathrm{R}=\mathrm{a}$

$160 \mathrm{n}=20 / 21 \quad \mathrm{R}=\mathrm{c} / \mathrm{d} / \mathrm{e} / \mathrm{f}$

$161 \mathrm{n}=20 \mathrm{R}=\mathrm{b}$ $\mathrm{a}=\leadsto$

$\mathrm{b}=\sim^{\mathrm{e}=}$

$\mathrm{c}=\mathrm{f}=$

$\mathrm{g}=$<smiles>CCCCCC(C)CC</smiles>

$162 \mathrm{n}=20 \quad \mathrm{R}=\mathrm{e}$

$164 \mathrm{n}=20 \mathrm{R}=\mathrm{g}$

$166 \mathrm{n}=21 \mathrm{R}=\mathrm{g}$

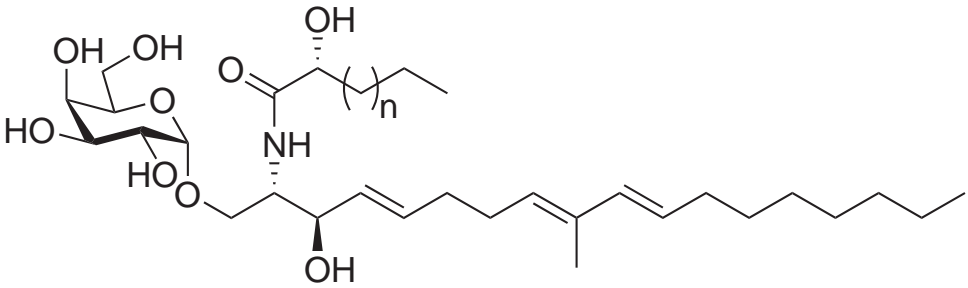

$163 \mathrm{n}=20$

$165 \mathrm{n}=21$

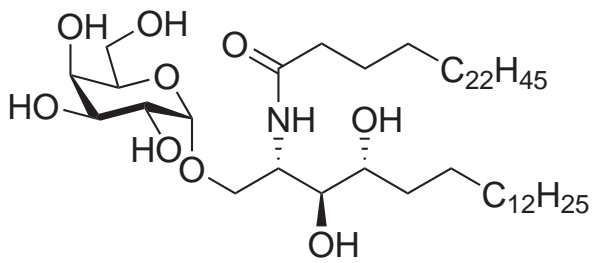

167

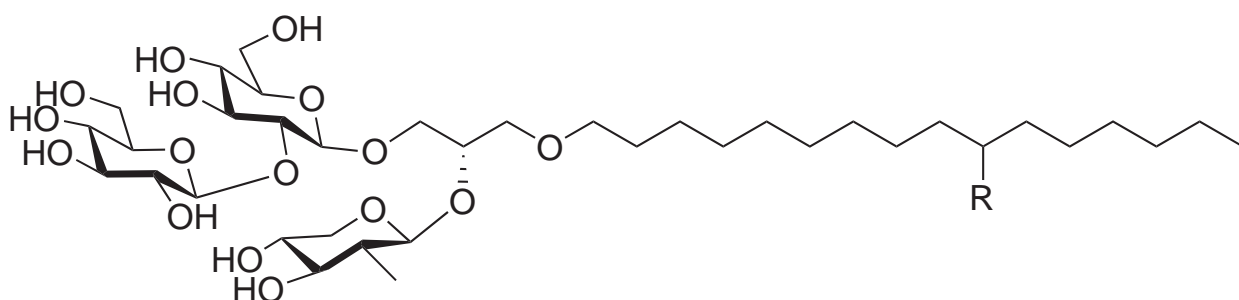

$168 \mathrm{R}=\mathrm{H}$

$169 \mathrm{R}=\mathrm{Me}$

The myrmekiosides A and B $(\mathbf{1 6 8}, \mathbf{1 6 9})$ are examples of sponge derived glycoglycerolipids. ${ }^{173}$ They were isolated from the Japanese marine sponge Myrmekioderma sp. and were found to reverse tumour cell morphology of ras-transformed cells at $5 \mu \mathrm{g} / \mathrm{mL} .{ }^{173}$ While the agminosides contain a glycerol-derived moiety, they are not true glycoglycerolipids, which are always glycosylated on the glycerol. ${ }^{162}$

A growing number of steroidal (triterpene) glycolipids (often termed glycosides or saponins) are being isolated from sponges, ${ }^{*}$ but being significantly

*for a recent example see Afiyatullov et al. ${ }^{174}$ 


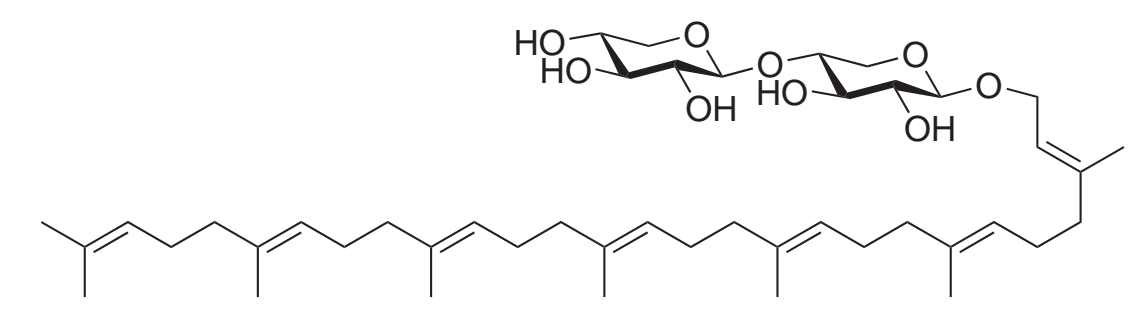

170

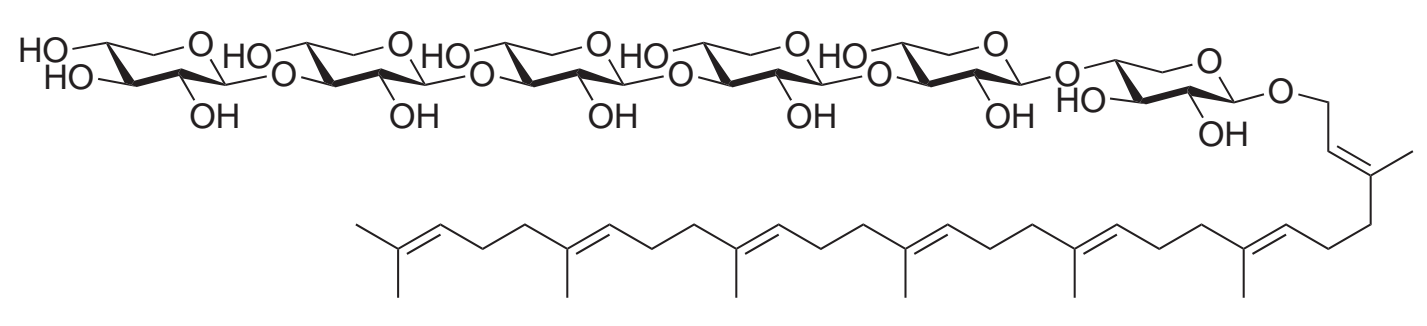

171

different to the agminosides, they will not be discussed here. The linear terpene glycolipids are represented by plakopolyprenoside (170) and plaxyloside (171) from the sponge $P$. simplex. ${ }^{175,176}$ They are composed of a $\mathrm{C}_{35}$ polyprenyl alcohol and two or six xylose sugar residues. As with many glycolipids, they were peracetylated in order to facilitate their isolation and subsequent structure elucidation. ${ }^{175}$ Peracetylation reduces the amphiphilic nature of the glycolipid, resulting in better chromatographic separation. In addition, acetylation of a hydroxy position moves the $\delta_{\mathrm{H}}$ approx. $1 \mathrm{ppm}$ downfield. This results in the spreading out of the ${ }^{1} \mathrm{H}$ signals, reducing overlap and easing structure elucidation. The major drawback of this procedure is that while the introduced acetates can be removed through mild hydrolysis, any naturally present acetates will be removed also, leading to uncertainty about the actual structure of the natural glycolipid. ${ }^{175}$ To overcome this, Costantino and co-workers take a small portion of the crude glycolipid, acetylate it with trideuteroacetic anhydride instead of acetic anhydride, and subject the sample to the same purification procedure as the normally peracetylated compound. Once pure, comparison of the the ${ }^{1} \mathrm{H}$ NMR spectra of the two peracetylated compounds will reveal any naturally present acetates, as they will be apparent in both spectra. ${ }^{175,176}$

Not very many sponge glycolipids are naturally acetylated. The erylusamines A-E (172-176) have been isolated by Fusetani and co-workers from the Japanese sponge Erylus placenta, and consist of a tetrasaccharide (L-arabinopyranose and D-xylopyranose sugars, partially acetylated) and a long chain fatty amide derivative, terminated with a $N, N$-dimethylpentanediamine unit. ${ }^{177,178}$ The position of the ketone and the two hydroxyls was deduced from positive FAB-MS data, the absolute configuration of the sugars was assigned through the use of chiral GC 

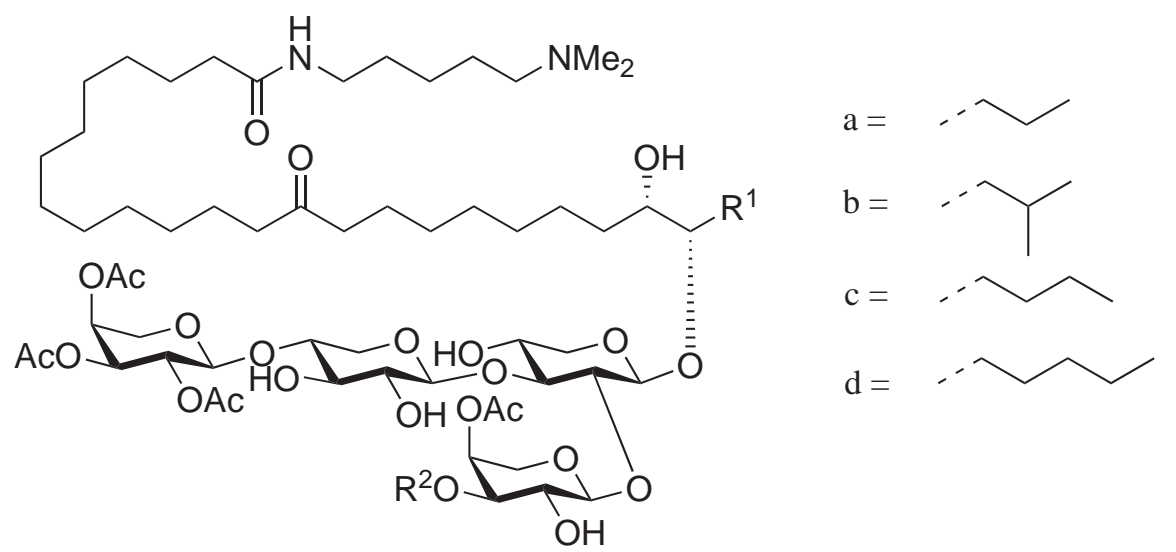

$172 \mathrm{R}^{1}=\mathrm{a} \quad \mathrm{R}^{2}=\mathrm{H}$

$173 \quad \mathrm{R}^{1}=\mathrm{b} \quad \mathrm{R}^{2}=\mathrm{H}$

$174 \quad \mathrm{R}^{1}=\mathrm{b} \quad \mathrm{R}^{2}=\mathrm{Ac}$

$175 \quad \mathrm{R}^{1}=\mathrm{c} \quad \mathrm{R}^{2}=\mathrm{Ac}$

$176 \mathrm{R}^{1}=\mathrm{d} \quad \mathrm{R}^{2}=\mathrm{Ac}$

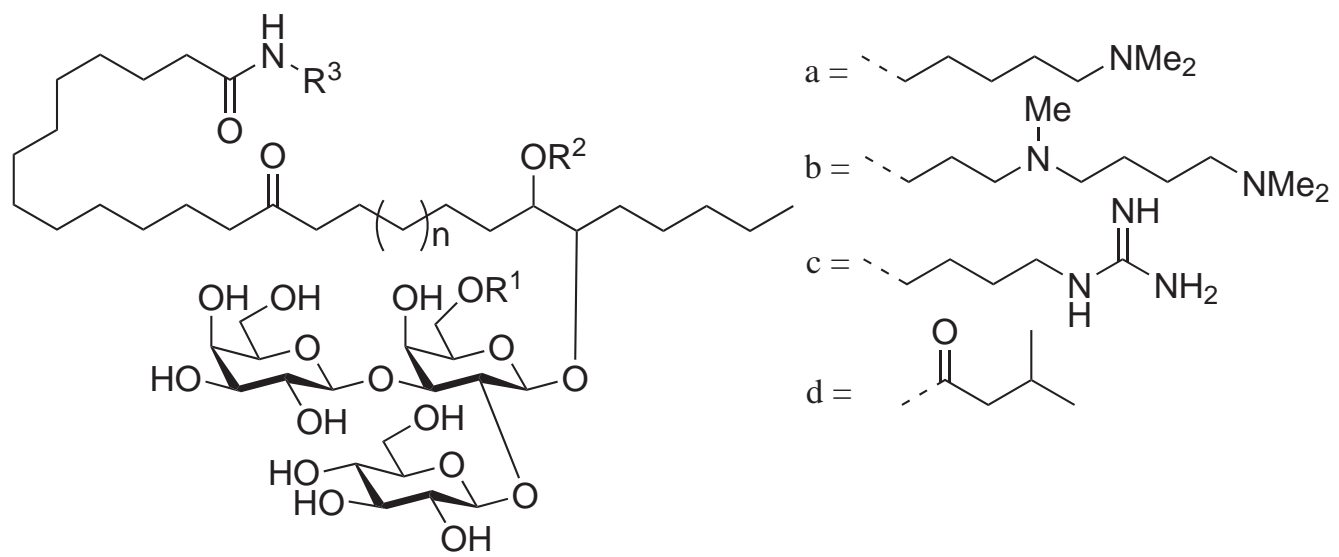

$$
\begin{array}{lllll}
\mathbf{1 7 7} & \mathrm{n}=2 & \mathrm{R}^{1}=\mathrm{Ac} & \mathrm{R}^{2}=\mathrm{H} & \mathrm{R}^{3}=\mathrm{a} \\
\mathbf{1 7 8} & \mathrm{n}=2 & \mathrm{R}^{1}=\mathrm{Ac} & \mathrm{R}^{2}=\mathrm{H} & \mathrm{R}^{3}=\mathrm{b} \\
\mathbf{1 7 9} & \mathrm{n}=3 & \mathrm{R}^{1}=\mathrm{H} & \mathrm{R}^{2}=\mathrm{d} & \mathrm{R}^{3}=\mathrm{c}
\end{array}
$$

analysis of the hydrolysate, and the configuration of the two hydroxyls was determined through the use of CD spectroscopy in the presence of $\mathrm{Eu}(\mathrm{fod})_{3} \cdot{ }^{178} \mathrm{Com}$ pounds 173-176 were found to be strong inhibitors of interleukin-6, a multifunctional cytokine involved in many biological functions and disease processes. ${ }^{177,178}$

Soon after, Kashman et al. isolated related glycolipids from Erylus cf. lendenfeldi collected from the Red Sea (Eritrea). ${ }^{179}$ They differ in their sugar portion, which is composed of two galactopyranoses and a glucopyranose sugar acetylated at one position at most. Erylusamine TA (177) possesses the same aglycon structure as 176, while erylusine (178) and erylusidine (179) have a $\omega$ - $N, N$-dimethylaminobutyl- $N$-methyl-1,3-propanediamine or a 4-(aminobutyl)guanidine (agmatine) unit respectively, terminating the fatty chain. ${ }^{179}$ 


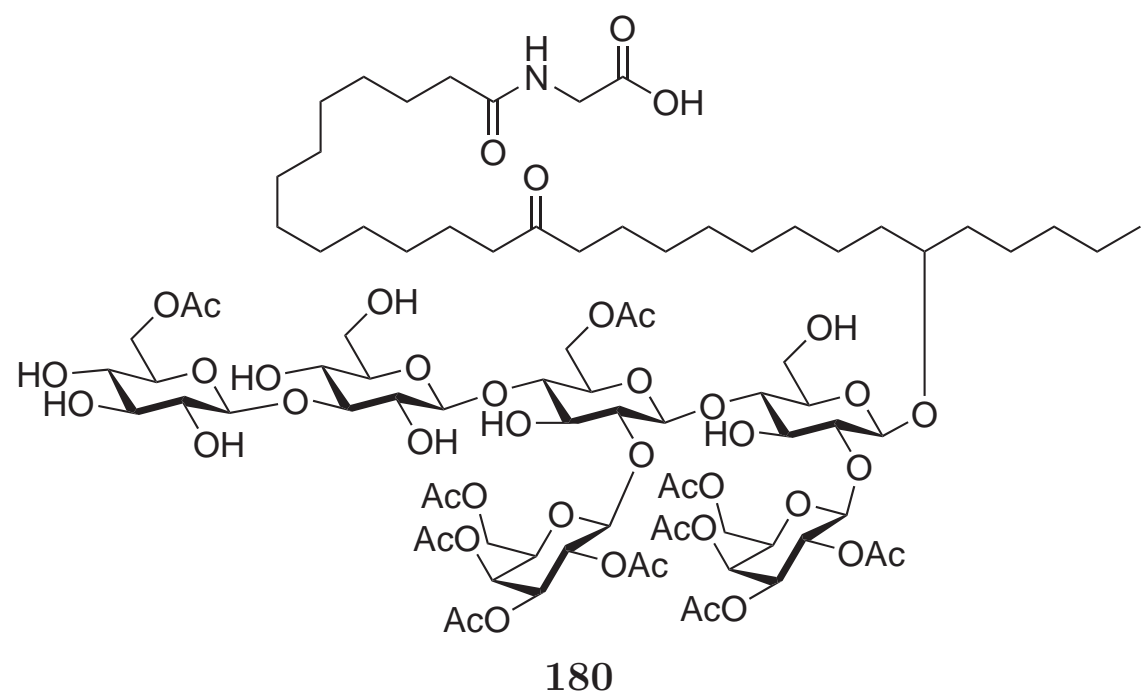

Pachymoside A (180) is one member of a family of related glycolipids found in the marine sponge Pachymatisma johnstonia. ${ }^{180}$ The pachymosides contain four glucose and two galactose residues, with varying levels and positions of acetylation. The aglycon is very similar to that of $\mathbf{1 7 6}$, except the amino component of the amide is acidic, not basic.

A final family of partially acetylated glycolipids is the caminoside family (181-184). They were isolated from the marine sponge Caminus sphaeroconia collected from the Toucari Caves in Dominica. Fractionation using a bioassay for the inhibition of the secretion of proteins by enteropathogenic Escherichia coli (which is the major cause of infantile diarrhoea) for guidance, yielded the active components $\mathbf{1 8 1}-\mathbf{1 8 4} .^{181,182}$ All four caminosides share the same four sugars (two glucoses, a quinovose, and the unusual 6-deoxytalose residue) and the same $\mathrm{C}_{19}$ linear chain with a methyl ketone terminus. They differ only in the number and position of acetates and butyrates attached to the sugar residues. ${ }^{181,182}$ The absolute configuration of the aglycon portion of the molecules proved a challenge to determine. Normally, configuration of secondary alcohols can be assigned through NMR analysis of their Mosher's esters. Unfortunately, the stereocentre in question was separated from the chain termini by at least seven $\mathrm{CH}_{2}$ groups. Assigning configuration at remote stereocentres in acyclic molecules is a well-known problem in natural product structure elucidation. In this case, the stereochemical assignment was achieved through the use of excitoncoupling circular dichroism, using liposomes to limit conformation averaging and obtain partial ordering of the lipid chain. ${ }^{183}$

Perhaps the most unusual glycolipid to be isolated from marine sponges is the highly sulfated lipopolysaccharide axinelloside A (185). It was isolated from the 


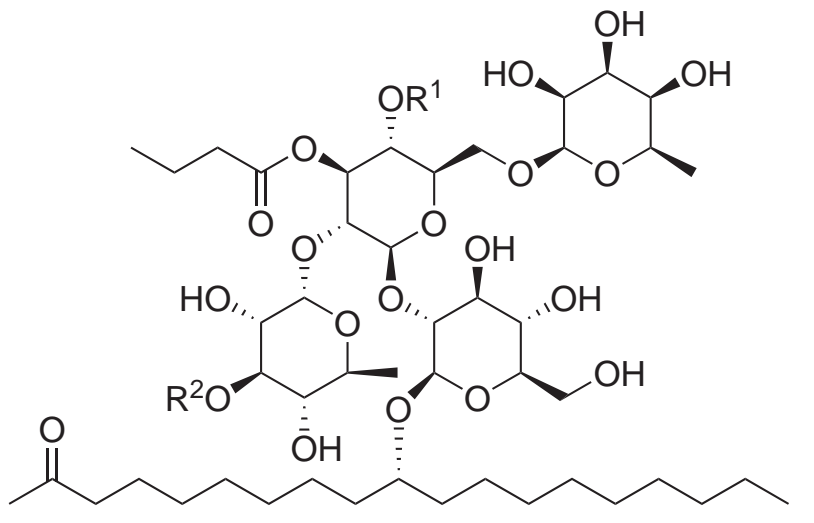

$$
\begin{array}{lll}
181 & \mathrm{R}^{1}=\text { Ac } & \mathrm{R}^{2}=\mathrm{H} \\
182 & \mathrm{R}^{1}=\mathrm{x} & \mathrm{R}^{2}=\mathrm{H} \\
183 & \mathrm{R}^{1}=\text { Ac } & \mathrm{R}^{2}=\mathrm{x} \\
184 & \mathrm{R}^{1}=\mathrm{x} & \mathrm{R}^{2}=\mathrm{x} \\
& \mathrm{x}=\text { butyrate }
\end{array}
$$

marine sponge Axinella infundibula through bioassay guided fractionation using a telomerase inibition assay. ${ }^{184}$ The structure of this very large glycolipid (molecular weight of 4780.4) was determined mainly through spectroscopic methods. Axinelloside A was found to consist of 12 sugars (including a scyllo-inositol, a polyol rarely found in natural products) with 19 sulfates and four fatty acids. ${ }^{184}$ As $(R)$-3-hydroxy fatty acids (such as that present in 185) are typically found in bacterial lipopolysaccharides, axinelloside A is likely the product of a symbiont bacterium. ${ }^{184}$ Its function in the sponge remains unknown.

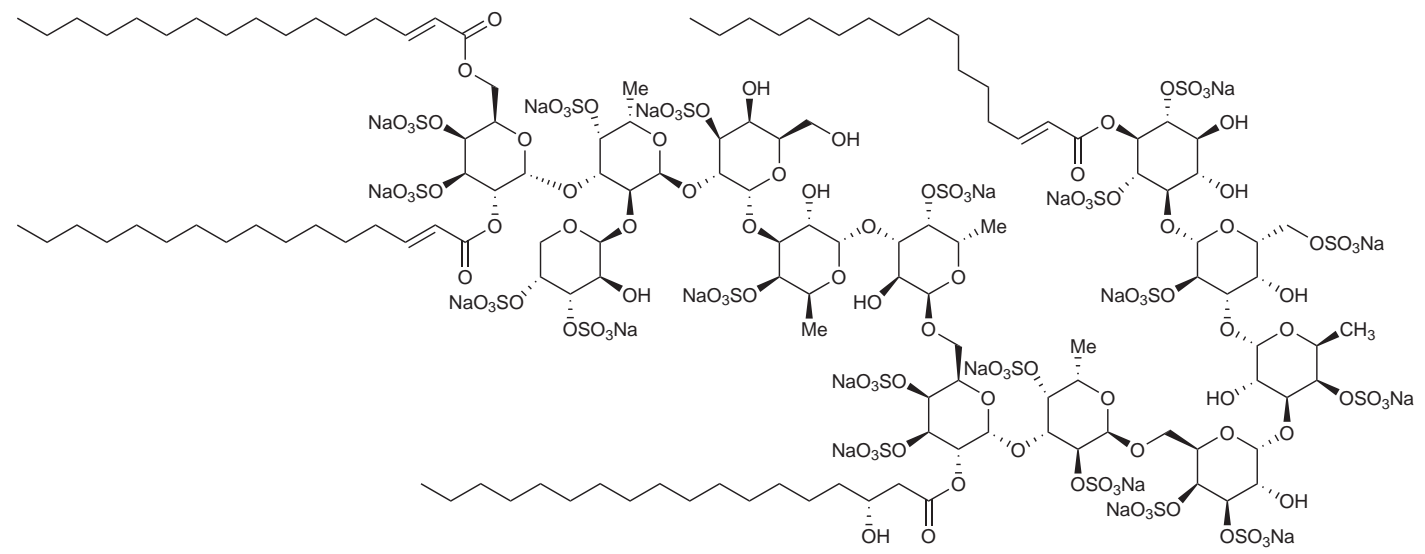

185

\subsection{Concluding remarks}

A varied range of secondary metabolites has been isolated from sponges of the genus Raspailia. These include such structural classes as acetylenic glyceryl enolethers, cyclic hemi-ketals, adenine-diterpenes, and clerodane diterpenes. The agminosides, partially acetylated glycolipids with up to six sugar residues, have been isolated from $R$. agminata, and are the first reported glycolipids from this 
genus. They were purified through multiple cycles of normal phase chromatography monitored by MS as the glycolipids did not possess a chromophore.

Although challenging, the chromatographic separation of the agminosides was successful, and Costantino's peracetylation method of glycolipid isolation ${ }^{175,176}$ was not required. All the acetates present in the agminosides are therefore of natural origin. The partial acetylation was useful as it dispersed the ${ }^{1} \mathrm{H}$ signals sufficiently for NMR assignment. Confirmation of the structure and the assignment of absolute configuration was achieved through semi-synthetic modifications.

Sponges (or perhaps their symbiotic micro-organisms) produce a variety of glycolipids, the majority of which are sphingolipids with one or two sugars, and are often inseparable mixtures of alkyl chain homologues. The agminosides are therefore highly unusual, as they contain up to six sugar residues and have a single aglycon, which is glycosylated on the alkyl chain even though the lipid contains a glycerol derivative. The agminosides show both 1-2 and 1-4 glycosidic linkages and also display partial acetylation, an unusual feature found in very few reported sponge glycolipids. 


\section{Chapter 4}

\section{NMR Screening}

Bioassay remains the most popular screening method employed in drug discovery programmes, but alternate chemical and physico-chemical screening techniques are being utilized as complementary methods to gain access to previously unexplored chemical diversity. The use of NMR spectroscopy as a mode of detection was considered "rare" nine years ago ${ }^{19}$, but since then it has become a vital screening tool because of its selective advantages.

\subsection{Screening with NMR}

In contrast to analysis by MS, NMR spectroscopy is a non-destructive technique that also provides more detailed structural information. This is of particular importance when searching for novel chemotypes, but can also be used for the tailoring of chromatographic separation conditions. ${ }^{185,186}$ In addition, NMR provides quantitative composition information that is not dependent on ease of ionization (MS) or chromophore intensity (DAD). ${ }^{186}$ NMR spectroscopy lacks the sensitivity of MS, but recent technological advances both in magnetic field strength and cryogenic techniques have greatly improved the limit of detection.

The combination of HPLC with NMR detection (LC-NMR) has proven to be a powerful tool in the analysis of complex mixtures, and it is commonly being used as a method of dereplication. On-flow and stopped-flow or loop-storage LC-NMR modes are used for the identification of major substances or detailed structural elucidation of major peaks, respectively. For low concetrations of analytes, solid-phase extraction (SPE) to concentrate the sample, and a cryogenic probe can increase sensitivity. For small sample amounts, capillary LC-NMR is the best solution. ${ }^{187}$

Another approach to NMR screening is the use of diffusion-edited NMR ex- 
periments, which utilize the variance in translational diffusion of organic molecules as a function of their molecular size. ${ }^{188}$ For example, diffusion-ordered NMR spectroscopy (DOSY) disperses a complicated and overlapping ${ }^{1} \mathrm{H}$ spectrum of a mixture along a second axis (representing the logarithm of the diffusion constant). ${ }^{188}$ In practical terms, the DOSY separates the signals of molecules of different sizes, and was successfully utilized for the analysis of a partially purified mixture of bromopyrrole alkaloids, resulting in the isolation of two new compounds. ${ }^{188}$

Schröder and co-workers approach NMR screening in a slightly different fashion. They argue that analytical methods involving a chromatographic step are likely to discriminate against some compound classes, while favouring others. ${ }^{189}$ In their experience, "structurally unique compounds will often not survive arbitrarily chosen chromatographic techniques, which is one reason they have remained undetected." 186 They therefore use NMR analysis of whole crude extracts for a more "impartial view" of the sample's contents. NMR spectra of the pure compounds are later compared with the spectra of the crude sample to determine whether the metabolites isolated are natural compounds, or degradation products. ${ }^{186}$

The complexity of NMR spectra typically obtained from crude extracts makes their analysis difficult. Dispersion of signals in a second dimension (as in the DOSY example above) somewhat mitigates the problem. To further simplify the spectra, Schröder at al. used differential analysis of arrays of 2D NMR spectra. ${ }^{185}$ They examined several unfractionated extracts of the fungus Tolypocladium cylindrosporum (cultured on four different media according to seven different protocols) by double quantum filtered correlation spectroscopy (DQFCOSY). The DQF-COSY spectra were examined graphically based on multiplicative stacking of their bitmaps, clearly distinguishing signals common to several spectra from signals present in only one. ${ }^{185}$

The graphical manipulation was accomplished using commonly available image editing software; by manipulating bitmaps derived from the on-screen display of the DQF-COSY spectra the problems of working with actual 2D NMR data were avoided. This simple method was able to distinguish compounds produced by the fungus under most culturing conditions from those produced under a specific one, allowing the rapid detection of two new natural products. ${ }^{185}$

This method compared extracts of one organism cultured under different conditions, looking for changes in metabolite production. A somewhat similar method using differential 2D NMR has been used by our group for a number 
of years, comparing extracts of different sponge species to identify secondary metabolite producers warranting further analysis.

\subsection{NMR screening of sponges by the VUW Marine Natural Products Group}

The Victoria University of Wellington Marine Natural Products Group has been using NMR spectroscopy as a tool for the screening of sponge extracts, or rather the screening of partially fractionated samples (after one chromatography step). While any chromatography will discriminate against some compound classes as argued by Schröder, ${ }^{189}$ this can be advantageous. Extracts are solutions of complex mixtures of many types of metabolites, from highly polar carbohydrates, salts and amino acids, to non-polar fats, steroids and triglycerides. Secondary metabolites, on the other hand, are often of intermediate polarity. They need both hydrophilic and hydrophobic character to be easily transportable across biological membranes (often a requirement for biological activity). This difference in polarity is exploited to achieve separation of the majority of primary from secondary metabolites at a very early stage of purification. Using the cyclic loading technique (discused in detail in Appendix A, page 186), an extract is loaded onto reversed-phase polymeric resin, and eluted stepwise with $30 \%, 75 \% \mathrm{Me}_{2} \mathrm{CO}$ in $\mathrm{H}_{2} \mathrm{O}$, and $100 \% \mathrm{Me}_{2} \mathrm{CO}$. ${ }^{*}$ The most polar salts, amino acids and sugars will be in the $30 \%$ fraction (or even in the eluent, not having adsorbed to the column in the first place), while the non-polar fats and triglycerides will be in the $100 \%$ fraction. Secondary metabolites of intermediate polarity will most often appear enriched in the $75 \%$ fraction. Removing a significant amount of the usually uninteresting primary metabolites from the mixture achieves two important goals. It makes the sample much more soluble for NMR (the solids from a crude extract are unlikely to dissolve in any solvent due the range in polarity of compounds in the mixture). In addition, it concentrates the secondary metabolites which helps with the relative insensitivity of NMR spectroscopy.

\section{History}

Screening of the $75 \%$ fractions by NMR spectroscopy began with a simple analysis of the $1 \mathrm{D}{ }^{1} \mathrm{H}$ spectra run in $\mathrm{CDCl}_{3} \cdot{ }^{127}$ This fraction still contained a large amount of fats, steroids and other metabolites, leading to significant overlap

\footnotetext{
*The current sponge screening procedure is detailed on page 179, Section 8.8.
} 
of signals between 0.5 and $5.5 \mathrm{ppm}$. Unsurprisingly, the first compounds isolated using this method all contained olefins, furans or aromatic rings, that is compounds with resonances that were readily observable in the clear portion of the ${ }^{1} \mathrm{H}$ spectrum at $>5.5 \mathrm{ppm} .{ }^{127}$ The screening protocol was therefore expanded to include 2D NMR experiments (COSY and HSQC), which dispersed the signals in a second dimension. ${ }^{190}$ In addition, early results showed that more interesting resonances were observed in samples dissolved in $\mathrm{CD}_{3} \mathrm{OD}$, as many interesting secondary metabolites were not soluble in $\mathrm{CDCl}_{3} \cdot \mathrm{CD}_{3} \mathrm{OD}$, although significantly more expensive, dissolved virtually all the metabolites even at high

concentrations and so became the solvent of choice for subsequent screens. ${ }^{190}$

\section{The problem}

Despite the chromatographic step that separates a significant amount of the primary metabolites from the compounds of intermediate polarity, the $75 \%$ fraction is still a complex mixture leading to highly complicated COSY and HSQC spectra. In order for the NMR screening to be effective, it must be able to distinguish between interesting secondary and uninteresting primary metabolites, and determine how much of the signal in the NMR screen corresponds to each.

In contrast to secondary metabolites, primary metabolites are common to all sponges. Signals appearing frequently at certain coordinates in sponge screens, therefore, are most likely to be due to primary metabolites. Conversely, correlations appearing only rarely at a certain coordinate, or observed only once, are most likely due to a secondary metabolite. The problem can therefore be reduced to how frequently a signal in an NMR screen has been observed at that particular coordinate before.

\section{The solution}

The solution to this problem has been a "mask", created from a series of sponge screen data sets. By overlaying multiple NMR spectral screens for a range of sponges and counting the number of times a given signal is observed, common correlations can be identified. The resulting mask of frequently appearing correlations can then be overlaid on a screen spectrum of a specific extract, and used to differentiate between common and rare signals. More generally, the mask can be used to determine how many of the signals in a screen are due to commonly seen primary metabolites, and how many are most likely due to secondary metabolites of interest. A decision can thereby be made whether to pursue a particular sponge extract further. 


\section{Development of the HSQC digital mask}

Initially, the mask was just a piece of paper with correlations identified as common simply drawn on it. It was placed over a printout of a spectrum to be analyzed (hence its name "mask"), and with the use of a light table interesting correlations (those present in the spectrum but not in the mask) could be identified. This method allowed the identification of crude sponge extracts with secondary metabolites that did not necessarily possess olefinic or aromatic resonances (which the $1 \mathrm{D}{ }^{1} \mathrm{H}$ spectra singled out), leading to the isolation of a range of new compounds and therefore "proof of principle." 190

Unfortunately this (fairly primitive) manual mask has some drawbacks. It has no gradation in the frequency of occurence of the peaks (if they are in the mask, they are "frequent"). Evaluation of correlations by eye is time-consuming, tedious and prone to error. In addition, areas with dense correlations are hard to analyze, and interesting signals may be missed. Screening out common correlations is, however, a job well suited for a computer.

In order to further develop this technique and maximize the sponge "hit" rate for this study, a computer programmer was employed to write a program to generate a digital mask, specifically for HSQC screen data. While COSY spectra are good at "fingerprinting" extracts, HSQC spectra can provide functional group information, giving an idea of chemical novelty.

The principle behind the program is exactly the same as the manual mask, except it is much more accurate. HSQC screens are added together to give a digital mask: a numerical representation of how frequently certain correlations appear in sponge screens (that is each coordinate of the mask matrix stores how many times that point has been a signal). The mask can then be applied to a particular screen, establishing whether correlations in the screen are interesting (appear only rarely), or whether they are common (appear frequently).

Over the course of the last seven years, 206 sponges were screened according to the standard protocol. A total of 141 were run on a $300 \mathrm{MHz}$ spectrometer, while 65 were run on the $600 \mathrm{MHz}$ instrument. Several were multiplicity edited HSQCs (HSQC-DEPTs), and therefore had positive and negative correlations. Some older HSQCs were run at varying proton and carbon ranges (before the NMR experiments were standardized). The HSQC mask program was therefore designed to deal with a range of resolutions and a range of ${ }^{1} \mathrm{H}$ and ${ }^{13} \mathrm{C}$ scales, as well as HSQC-DEPT experiments.

Figure 4.1 shows the mask generated from the addition of 206 sponge screens. The top figure shows common correlations (white) that appear in most, if not all, 


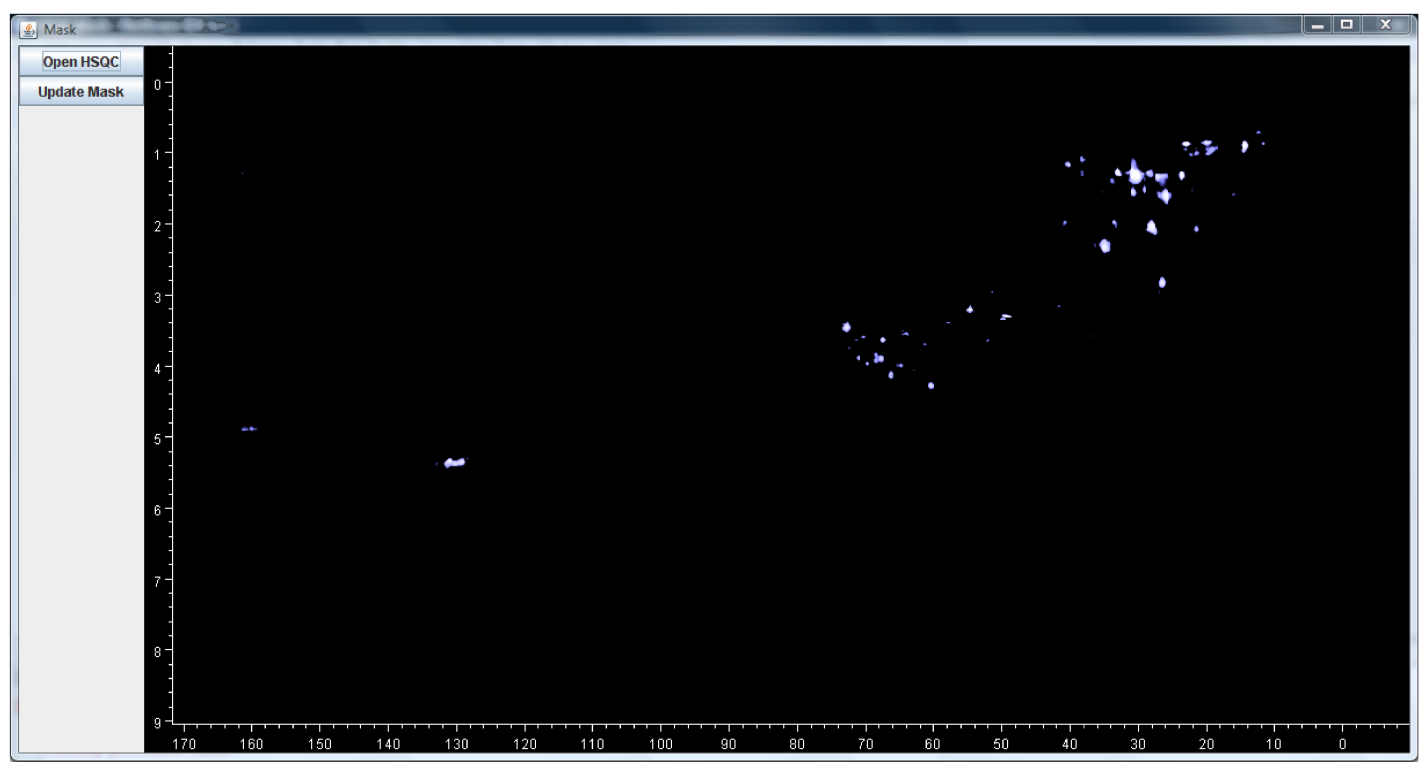

(a) The mask showing only the most common correlations.

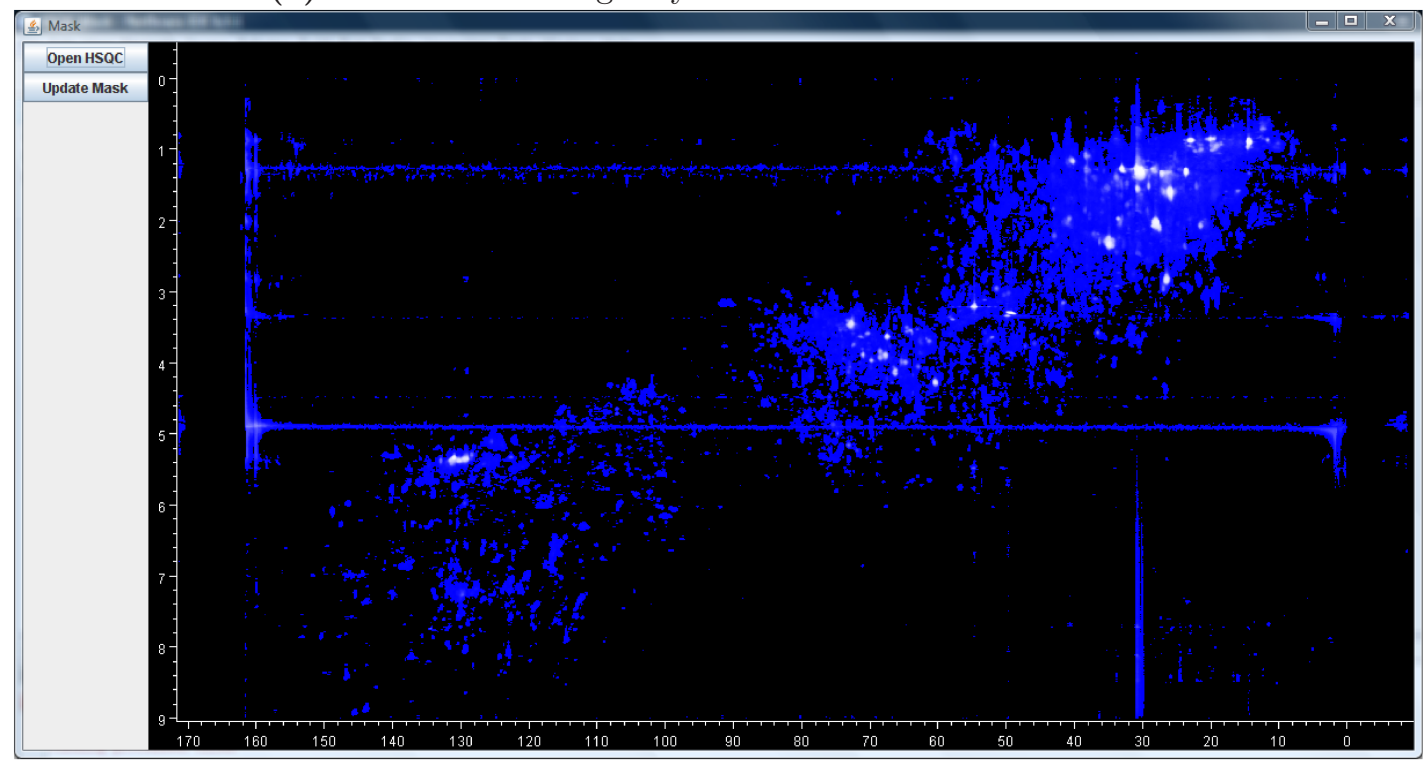

(b) The full mask, showing all correlations.

Figure 4.1. The final mask, comprising of 206 sponge screens.

of the screens. Several alkyl-type peaks, as well as some oxymethines and a few olefinic correlations are the most common HSQC signals of sponge screens. They are probably due to unsaturated triglyceride-type primary metabolites. The full mask, shown in the bottom figure, displays a wide variety of correlations. The majority of them, however, are rarely seen (coloured blue).

Some areas are clearly not real correlations but noise (for example the horizontal line through the middle of the spectrum). In some spectra certain noise (usually T1 noise) was so strong that to eliminate it by raising the threshold would have resulted in the loss of some real data points. 
The mask can be applied to a screen by overlaying the mask matrix with the screen. Comparing the two can give an idea of whether a signal in the screen is common, or rare. This is displayed graphically by colour-coding common correlations green, and rare correlations red, with an adjustable threshold between them. Two examples can be seen in Figure 4.2, with the common vs. rare threshold set at 3\%: correlations are coloured red if they appear in less then $3 \%$ (less than six) of the screens. The top image is of a sponge extract with mostly common correlations, probably containing few compounds of interest, while in contrast the bottom image shows a multitude of rare signals, making this a very interesting sponge screen.

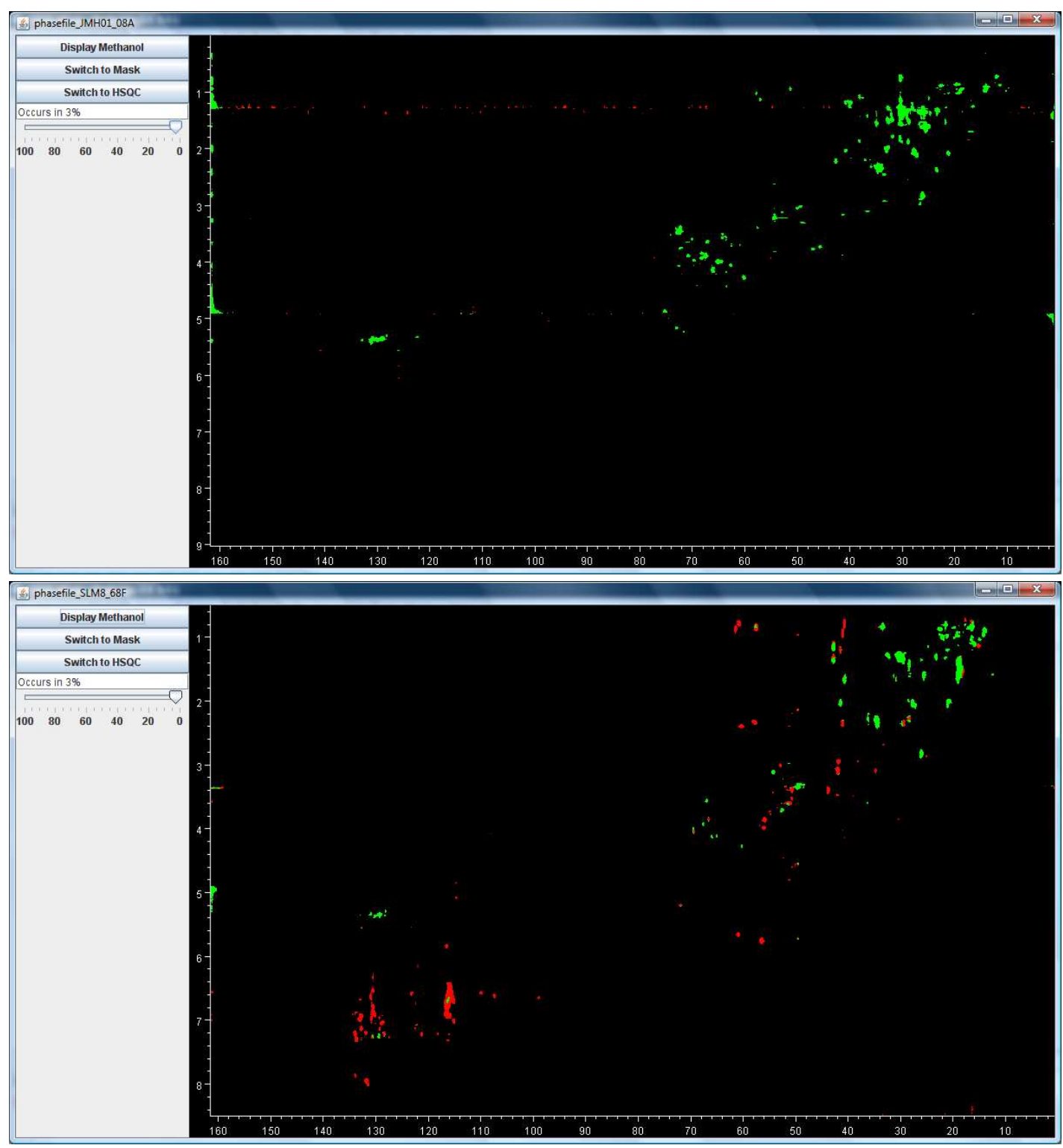

Figure 4.2. Example of an uninteresting (top) and a promising sponge screen (bottom). 


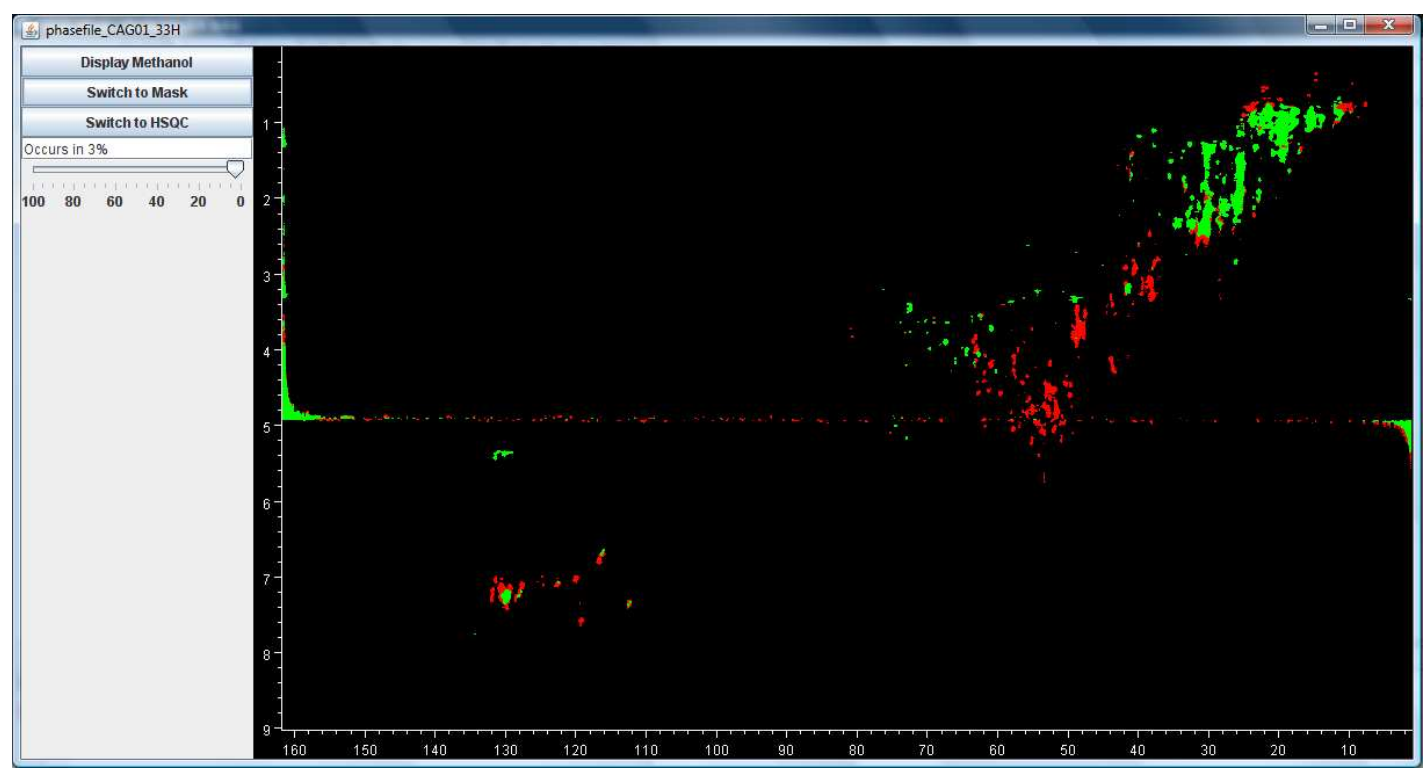

Figure 4.3. The mask applied to screen CAG1_33H.

\section{Applying the HSQC Mask program}

The mask was applied to a series of HSQC spectra from sponge screens that had not yet been examined. Below, in Figures 4.3, 4.6 and 4.7, are three screens that were chosen for further examination based on the high number of rare and interesting correlations, as revealed by application of the mask. Their "common" vs. "rare" threshold was set at $3 \%$.

\section{Screen CAG1_33H}

Figure 4.3 shows the mask applied to screen CAG1_33H. It shows some strong signals in the aromatic area, as well as a multitude of oxymethine-type signals. A range of interesting alkyl, as well as " $N$-methyl" type $\left(\delta_{\mathrm{C}} 40-50, \delta_{\mathrm{H}} 2.5-3.5\right)$ correlations were also apparent.

The sponge was extracted in bulk for a more detailed analysis. Approx. $500 \mathrm{~g}$ of sponge was extracted in $\mathrm{MeOH}$, and cyclic loaded onto reversed-phase HP20 beads. The column was then eluted with $20 \%, 40 \%, 60 \%, 80 \% \mathrm{Me}_{2} \mathrm{CO}$ in $\mathrm{H}_{2} \mathrm{O}$, and $100 \% \mathrm{Me}_{2} \mathrm{CO}$, and the individual fractions were backloaded onto HP20. During backloading, the sample is usually diluted once with $\mathrm{H}_{2} \mathrm{O}$ before loading onto the column. At times when a sample is very rich in metabolites, however, addition of the $\mathrm{H}_{2} \mathrm{O}$ causes the more non-polar components to precipitate. In such cases, the fraction is passed through the column without dilution first. The $\mathrm{H}_{2} \mathrm{O}$ is added to the eluent, before being passed through the column again.

Both the $60 \%$ and the $80 \%$ fractions showed this behaviour, and had to 


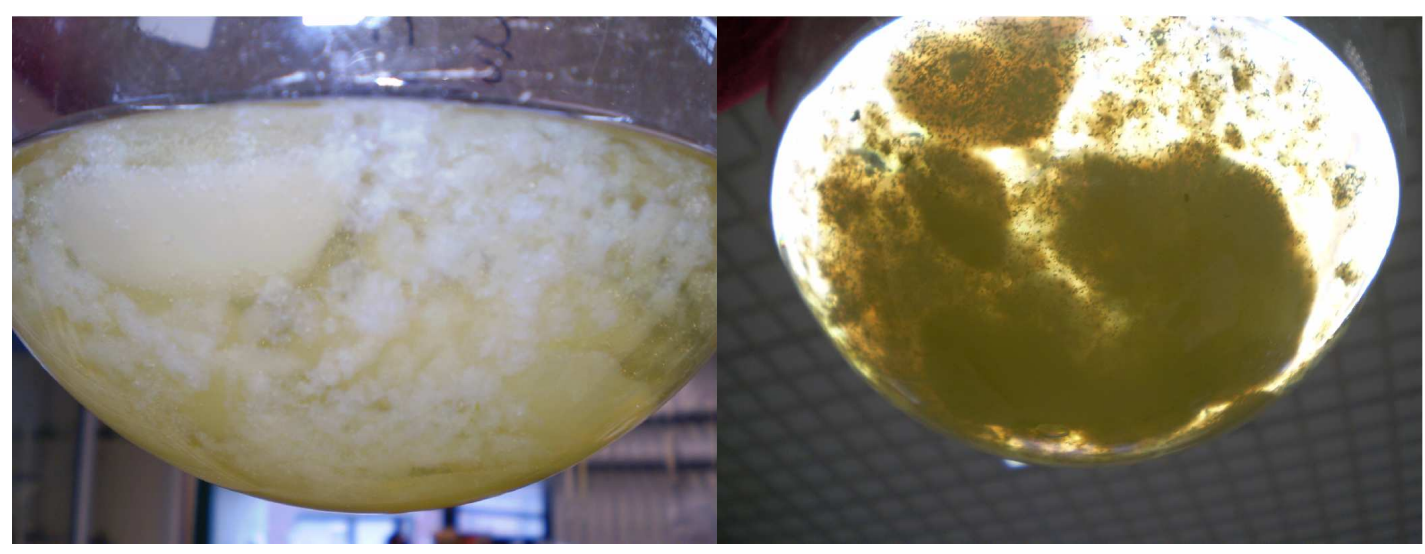

Figure 4.4. Round-bottom flask containing the backloading eluent of the $80 \%$ $\mathrm{Me}_{2} \mathrm{CO}$ in $\mathrm{H}_{2} \mathrm{O}$ fraction.

be passed through the column before dilution. In addition, the elution of the backloaded $60 \%$ was problematic. The backloading column is always washed with $\mathrm{H}_{2} \mathrm{O}$ before elution with an organic solvent. Additon of $100 \% \mathrm{Me}_{2} \mathrm{CO}$ to the washed beads generated a milky white precipitate that clogged the column. The sample was probably only partially soluble in acetone; upon mixing with the remnants of water still on the column, any compounds that had moved into the mobile phase precipitated. The solvent was switched to $\mathrm{MeOH}$, the precipitate redissolved, and the column eluted with an $\mathrm{Me}_{2} \mathrm{CO} / \mathrm{MeOH}$ mixture.

The $80 \%$ fraction also exhibited unusual behaviour during backloading. As there is always some $\mathrm{H}_{2} \mathrm{O}$ remaining on the column, the first few mililitres that elute have a high percentage of $\mathrm{H}_{2} \mathrm{O}$. Often, as compounds start eluting with the organic solvent front, they precipitate in the flask before redissolving once enough organic solvent passes through the column. The $80 \%$ fraction eluting from the backloading column initially turned milky white, reminiscent of the precipitate on the column of the $60 \%$ fraction backloading. As more $\mathrm{Me}_{2} \mathrm{CO}$ passed through, the eluent turned into an unusual, gelatinous precipitate, shown in Figure 4.4. The jelly-like substance eventually dissolved.

Problems with solubility became apparent almost immediately. Although soluble at high dilution, upon concentration the $60 \%$ and $80 \%$ fractions (and to a lesser degree the $20 \%$ and $40 \%$ fractions) were not fully soluble in any solvent tried. Figure 4.5 shows ${ }^{1} \mathrm{H}$ NMR spectra of the 20,40 , and $60 \%$ fractions run in DMSO- $\mathrm{d}_{6}$. Despite the broadening of the signals due to the solubility issues, the NMR spectra show a multitude of signals in the aromatic and heteroaromatic region, as well as the oxymethine area. Undoubtedly the sponge contains some very interesting secondary metabolites and warrants further investigation, but due to the solubility issues and the availability of two other, very promising, 


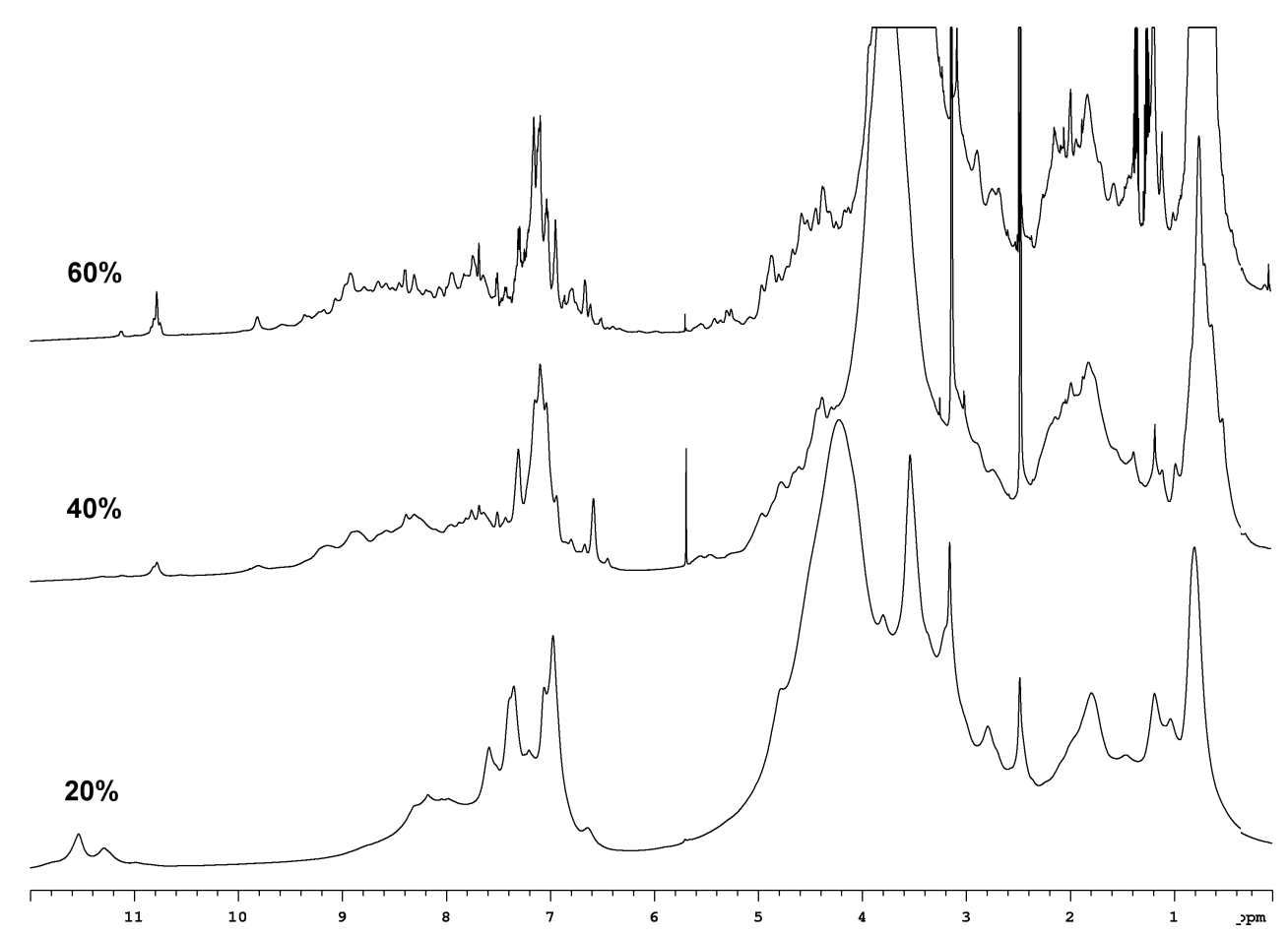

Figure 4.5. ${ }^{1} \mathrm{H}$ NMR spectra $\left(600 \mathrm{MHz}, \mathrm{DMSO}-\mathrm{d}_{6}\right)$ of the 20,40 , and $60 \%$ $\mathrm{Me}_{2} \mathrm{CO}$ in $\mathrm{H}_{2} \mathrm{O}$ fractions.

sponges, the decision was made to focus on the other screens instead.

\section{Screen JMH1_17F}

The mask applied to screen JMH1_17F (Figure 4.6) revealed a multitude of interesting correlations. A significant number of them were in the aromatic and olefinic region of the spectrum, showing widely varying ${ }^{1} \mathrm{H}$ and ${ }^{13} \mathrm{C}$ chemical shifts. In addition, a series of oxymethine and " $N$-methyl" type correlations were apparent, as well as unusual alkyl-like chemical shifts. This sponge was also chosen for bulk extraction and detailed examination. The analysis of this sponge is discussed in Chapter 5 (page 117).

\section{Screen CAG1_36A}

Figure 4.7 is of the mask applied to screen CAG1_36A. The screen displays several strong correlations indicative of one major compound. Particulaly interesting are the pairs of methylene protons, indicating chirality and/or restricted rotation. A series of methylene pairs at unusual chemical shifts $\left(\delta_{\mathrm{C}} 40-50\right)$, and several interesting aromatic and alkyl correlations make this a highly interesting screen. The sponge was therefore examined in detail; Chapter 6 (page 130) deals with the isolation of new secondary metabolites from this sponge. 


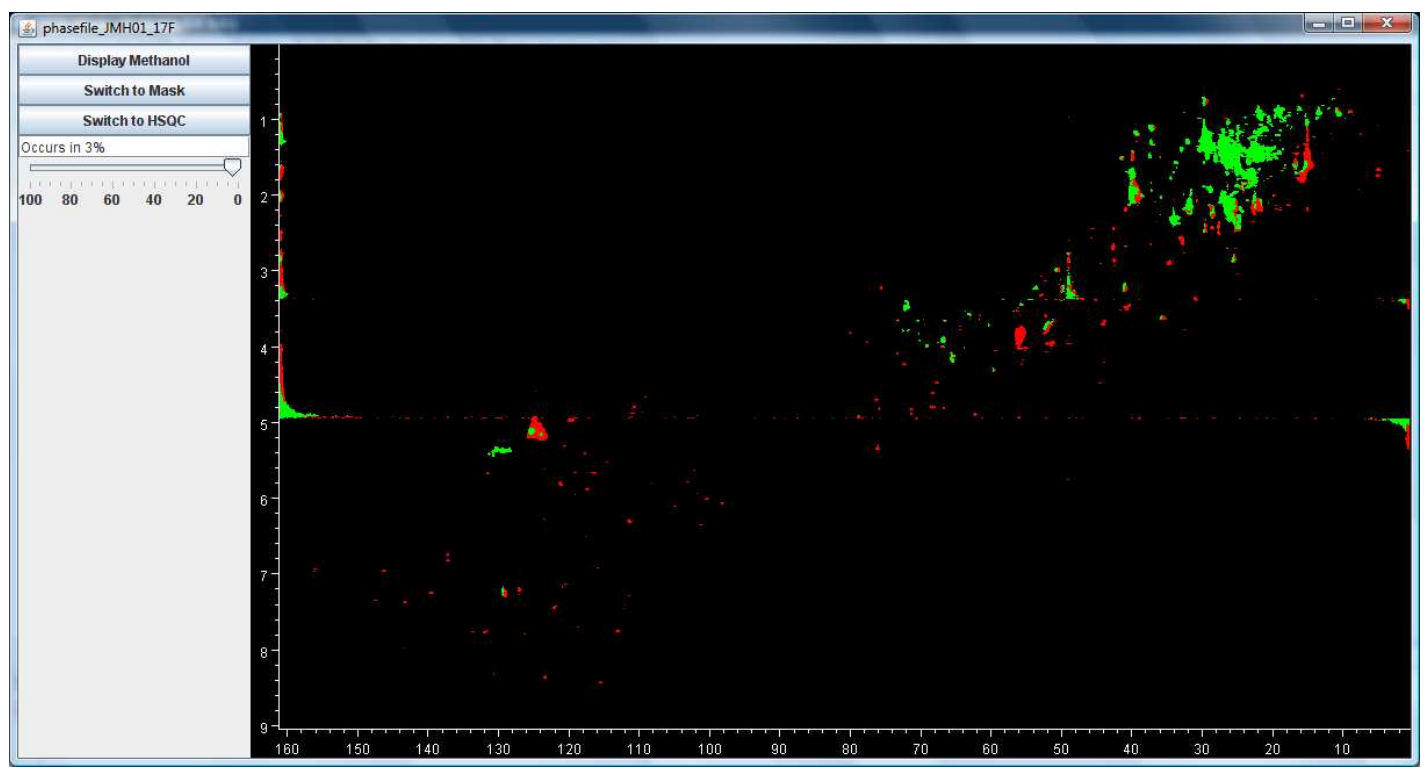

Figure 4.6. The mask applied to screen JMH1_17F.

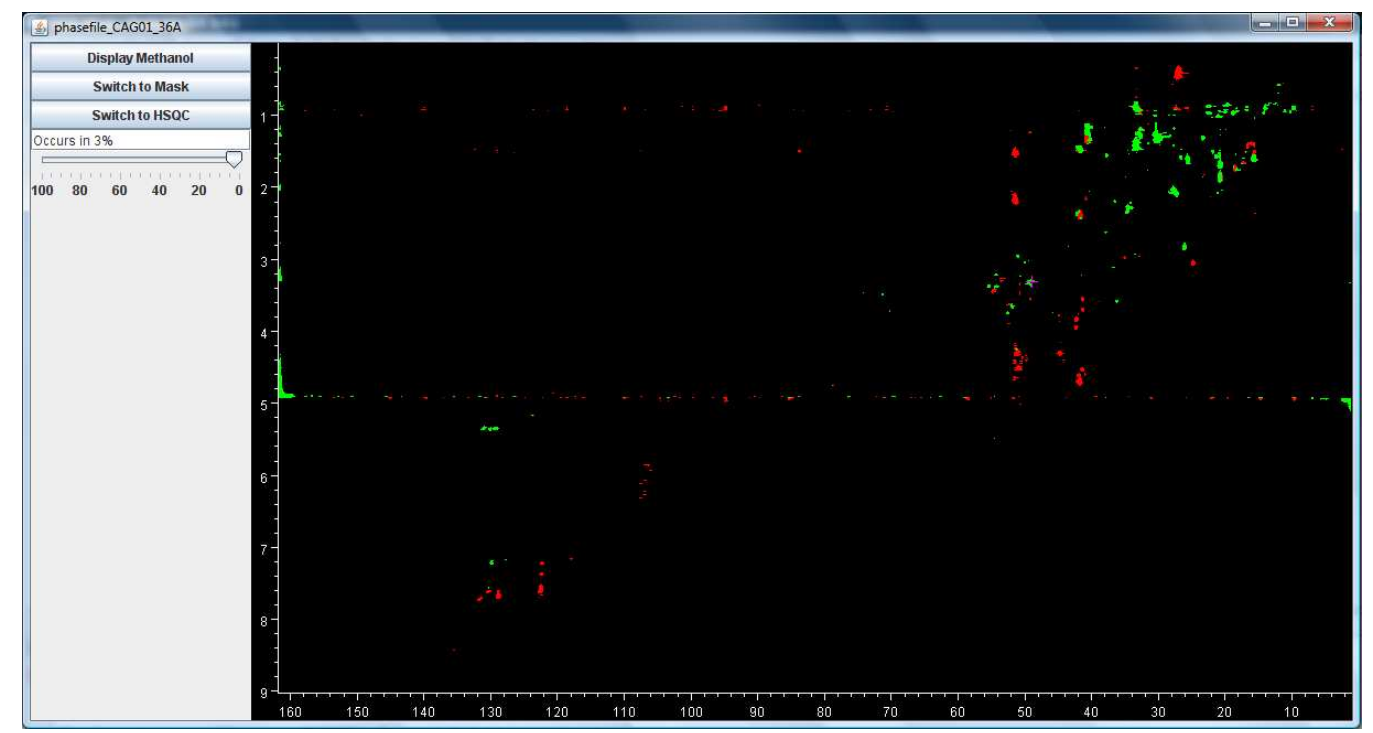

Figure 4.7. The mask applied to screen CAG1_36A.

\subsection{Future directions}

While the HSQC mask program has been very successful in this research, it can be expanded upon and improved further, for example by applying the same principles to a COSY mask. Screening by COSY has the major advantage of significantly shorter NMR acquisition times (COSY: 20 min vs. HSQC: 4 hrs). The COSY can also provide some connectivity information through the identification of spin systems, allowing the construction of substructures and aiding dereplication efforts early in the isolation.

Dereplication is a common problem in natural product discovery. ${ }^{14}$ While 
the HSQC mask program is very good at differentiating primary from secondary metabolites (common vs. rare correlations), it currently has no mechanism to identify previously examined (duplicate) screens or compounds already known from the literature. The program does offer large scope for further development in this area. For example, with advanced pattern recognition the program could compare screens, looking for patterns of correlations that would indicate duplicate screens, or related metabolite types. In theory, it could also identify known compounds from their unique HSQC correlation "fingerprint", without the need for any further purification. This would be an invaluable dereplication method. 


\section{Chapter 5}

\section{New Metabolites from a Sponge of the order Dictyoceratida}

\subsection{Order Dictyoceratida}

Dictyoceratida is an order that does not have any silicaceous spicules, making taxonomic identification of dictyoceratid sponges more difficult. The sponges are tough and flexible, typically with a conulose (marked by conules or cone-shaped elevations) surface. Often they will have a marked difference in external and internal pigmentation, with a dark exterior and the interior ranging from white, cream, through to pale brown or yellow. The order consists of four families: Dysideidae, Irciniidae, Spongiidae and Thorectidae, as shown in Figure 5.1. ${ }^{43}$

A variety of metabolites has been isolated from dictyoceratid sponges, ${ }^{44}$ and a full review is beyond the scope of this report. In addition, the taxonomy of the Dictyoceratida has been revised multiple times. ${ }^{43}$ The restructuring of the phylogeny has resulted in taxonomic inconsistencies within the literature, making a detailed review of dictyoceratid secondary metabolites problematic.

\section{Order Dictyoceratida \\ Family Dysideidae \\ Family Irciniidae \\ Family Spongiidae \\ Family Thorectidae}

Subfamily Phyllospongiinae

Subfamily Thorectinae

Figure 5.1. Taxonomic classification of the order Dictyoceratida, after Hooper and van Soest. ${ }^{43}$ 


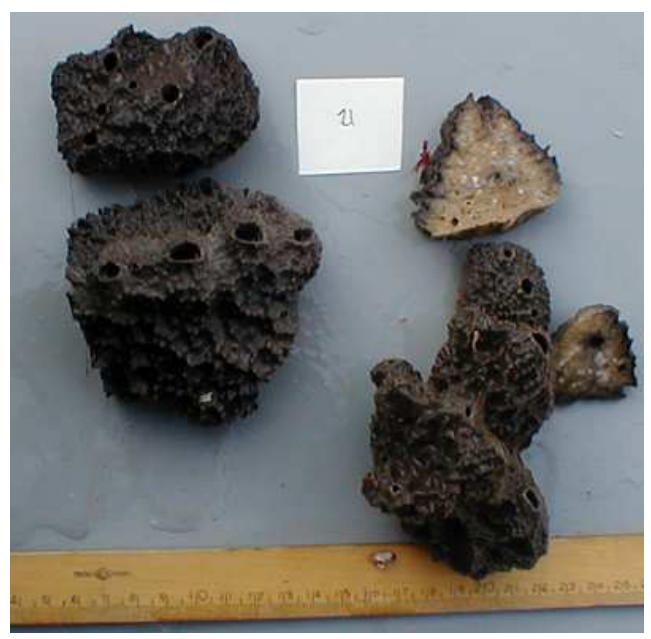

Figure 5.2. Surface photo of the dictyoceratid sponge (courtesy of Peter Northcote).

\subsection{Terpenes from a dictyoceratid sponge}

The sponge examined in this research (shown in Figure 5.2) was a soft, massive sponge with large oscules and tented surface. It was dark grey on the surface with a beige internal colour, somewhat slimy due to an exuded mucous. It contained no silicaceous spicules, and has tentatively been identified as belonging to the order Dictyoceratida.

\section{Isolation of new metabolites}

The sponge was collected from Dowd Rock, Tutukaka, New Zealand in December 2003. It was extracted in $\mathrm{MeOH}$ and cyclic loaded onto a reversed-phase HP20 column. The column was eluted with increasing concentrations of $\mathrm{Me}_{2} \mathrm{CO}$ in $\mathrm{H}_{2} \mathrm{O}$. The $60 \% \mathrm{Me}_{2} \mathrm{CO}$ in $\mathrm{H}_{2} \mathrm{O}$ fraction showed interesting NMR signals, indicating one major compound. The sample was purifed on a silica gel column eluted with $\mathrm{CH}_{2} \mathrm{Cl}_{2} / \mathrm{MeOH}$ mixtures to yield $\Delta_{18,20}$-isovariabilin (186) (structure shown on page 121).

NMR of the $100 \% \mathrm{Me}_{2} \mathrm{CO}$ fraction also indicated the presence of one major compound. A portion (400 mg) of this sample was subjected to chromatographic separation on silica gel. Eluting in $100 \%$ pet. ether was $100 \mathrm{mg}$ of the ubiquitous linear furanosesterterpene furospinosulin-1 (187), first isolated from the sponge Ircinia spinosula in 1972. ${ }^{191}$<smiles>CC(C)=CCC/C(C)=C/CC/C(C)=C/CC/C(C)=C/CCc1ccoc1</smiles> 
The $100 \% \mathrm{CH}_{2} \mathrm{Cl}_{2}$ fraction from the silica gel column was further purified on silica gel, and finally on reversed-phase $\mathrm{C}_{18} \mathrm{HPLC}$ eluted with $\mathrm{MeCN} / \mathrm{H}_{2} \mathrm{O}$ to yield two merosesquiterpene quinones 188 and 189 .

\section{Structure elucidation of $\Delta_{18,20}$-isovariabilin}

The observation of a pseudomolecular ion by positive mode HRESIMS indicated a molecular formula of $\mathrm{C}_{25} \mathrm{H}_{34} \mathrm{O}_{4}$ for $\Delta_{18,20}$-isovariabilin (186) (421.2354 $\left.[\mathrm{M}+\mathrm{Na}]^{+}, \Delta 0.2 \mathrm{ppm}\right)$, requiring nine double bond equivalents. Examination of the ${ }^{1} \mathrm{H}$ and ${ }^{13} \mathrm{C}$ spectra revealed the presence of 25 distinct carbons and 33 of the 34 protons. The salient features of the NMR spectra were four olefinic methyl singlets, three signals with chemical shifts consistent with a 3-substituted furan ring, three trisubstituted double bonds and one oxymethine.

Three methines CH-1 $\left(\delta_{\mathrm{C}} 142.6, \delta_{\mathrm{H}} 7.33\right), \mathrm{CH}-2\left(\delta_{\mathrm{C}} 111.2, \delta_{\mathrm{H}} 6.27\right)$, CH-4 $\left(\delta_{\mathrm{C}} 138.9, \delta_{\mathrm{H}} 7.20\right)$ and one non-protonated carbon $\mathrm{C}-3\left(\delta_{\mathrm{C}} 125.1\right)$ were characteristic of a 3-substituted furan ring and showed COSY and HMBC correlations supporting that assignment. Furthermore, coupling was observed between H4 and $\mathrm{H}_{2}-5$ in the COSY spectrum and between $\mathrm{H}_{2}-5$ and $\mathrm{H}_{2}-6$, allowing the construction of the first fragment of 186, depicted in Figure 5.3.

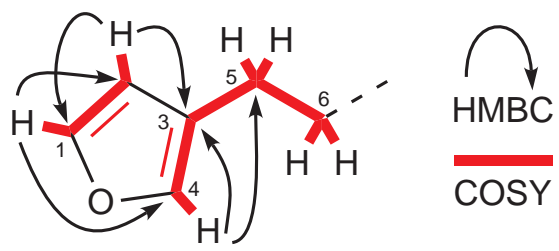

Figure 5.3. Key COSY and HMBC correlations establishing the furan moiety of $\Delta_{18,20}$-isovariabilin (186).

Two signals showed unusual chemical shifts: methyl $\mathrm{CH}_{3}-25\left(\delta_{\mathrm{C}} 6.2, \delta_{\mathrm{H}} 1.72\right)$ and the non-protonated carbon C-23 $\left(\delta_{\mathrm{C}} 97.0\right)$. Together with the carbons C-24 $\left(\delta_{\mathrm{C}} 177.3\right), \mathrm{C}-22\left(\delta_{\mathrm{C}} 174.7\right)$ and the oxymethine $\mathrm{CH}-21\left(\delta_{\mathrm{C}} 75.6, \delta_{\mathrm{H}} 5.37\right)$, the five signals were consistent with a 3 -methyl substituted tetronic acid. ${ }^{192} \mathrm{HMBC}$ correlations from $\mathrm{H}_{3}-25$ to C-22, C-23 and C-24, and from H-21 to C-22, C-23 and C-24 supported this assignment.

Further HMBC correlations from H-21 to the olefinic carbon C-18 $\left(\delta_{\mathrm{C}} 147.6\right)$, olefinic methine $\mathrm{CH}-20\left(\delta_{\mathrm{C}} 118.2, \delta_{\mathrm{H}} 4.97\right)$ and olefinic methyl $\mathrm{CH}_{3}-19\left(\delta_{\mathrm{C}} 23.8\right.$, $\delta_{\mathrm{H}}$ 1.78) placed a double bond adjacent to the tetronic acid moiety. The methyl placement on the double bond was established through HMBC correlations from $\mathrm{H}_{3}-19$ to $\mathrm{C}-20, \mathrm{C}-18$, and the carbon of $\mathrm{CH}_{2}-17\left(\delta_{\mathrm{C}} 32.2, \delta_{\mathrm{Ha}} 2.16, \delta_{\mathrm{Hb}} 2.10\right)$. 
Observation of a COSY correlation between $\mathrm{H}_{2}-17$ and the protons of $\mathrm{CH}_{2}-16$ $\left(\delta_{\mathrm{C}} 26.5, \delta_{\mathrm{H}} 1.55\right)$ extended the partial structure, shown in Figure 5.4.

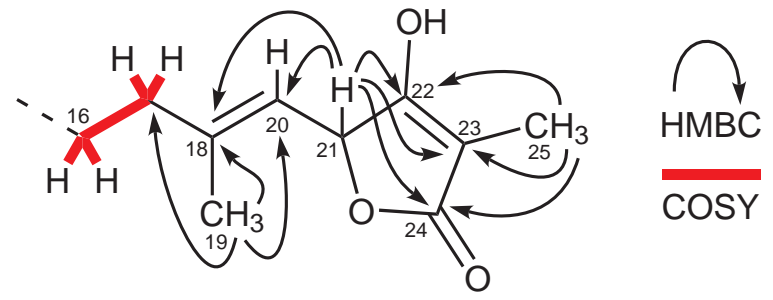

Figure 5.4. Key COSY and HMBC correlations establishing the tetronic acid moiety of $\Delta_{18,20}$-isovariabilin (186).

The remaining fragment of the structure was difficult to assign due to overlap of several resonances in both the ${ }^{1} \mathrm{H}$ and ${ }^{13} \mathrm{C}$ spectra. Two olefinic methyls were almost identical in chemical shift $\left(\delta_{\mathrm{C}} 16.1, \delta_{\mathrm{H}} 1.58\right.$ and $\left.\delta_{\mathrm{C}} 15.9, \delta_{\mathrm{H}} 1.58\right)$ as were two allylic methylenes $\left(\delta_{\mathrm{C}} 39.7, \delta_{\mathrm{H}} 1.98\right.$ and $\left.\delta_{\mathrm{C}} 39.5, \delta_{\mathrm{H}} 1.98\right)$. These, as well as two olefinic methines $\left(\delta_{\mathrm{C}} 123.8, \delta_{\mathrm{H}} 5.15\right.$ and $\left.\delta_{\mathrm{C}} 124.8, \delta_{\mathrm{H}} 5.10\right)$ are typical signals of an underivatized isoprene chain; together with the furan and tetronic acid moieties they suggested $\mathbf{1 8 6}$ was a linear furanosesterterpene of the variabilin class of compounds. The NMR data of the C-1 to C-16 fragment compared favourably to literature values of related compounds; ${ }^{193}$ the connectivity of $\mathbf{1 8 6}$ was confirmed by HMBC correlations detailed in Table 5.1.

Due to spectral overlap, NOE enhancements were of limited utility in determining the geometry of the double bonds. Fortunately, methyl groups on isolated trisubstituted double bonds of linear polyprene chains show characteristic NMR shifts: $\delta_{\mathrm{H}}<1.6$ and $\delta_{\mathrm{C}}<20$ for the $E$, and $\delta_{\mathrm{H}}>1.6$ and $\delta_{\mathrm{C}}>20$ for $Z$ geometry. ${ }^{194}$ Based on this, and the similarity of chemical shifts with related compounds, all double bonds were assigned as $E$. The final structure of $\Delta_{18,20}$-isovariabilin is given as $\mathbf{1 8 6 .}$

\section{Structure elucidation of two merosesquiterpene quinones}

Analysis of the quinone $\mathbf{1 8 8}$ by positive ion mode HRESIMS gave rise to three pseudomolecular ions: 365.2096, 397.2358 and 707.4269 indicating a molecular formula of $\mathrm{C}_{22} \mathrm{H}_{30} \mathrm{O}_{3}\left([\mathrm{M}+\mathrm{Na}]^{+}, \Delta 2.3 \mathrm{ppm} ;[\mathrm{M}+\mathrm{MeOH}+\mathrm{Na}]^{+}, \Delta 2.3 \mathrm{ppm}\right.$; $\left.[2 \mathrm{M}+\mathrm{Na}]^{+}, \Delta 1.9 \mathrm{ppm}\right)$, requiring eight double bond equivalents. Twenty-two distinct carbon resonances were observed in the ${ }^{13} \mathrm{C}$ spectrum and the ${ }^{1} \mathrm{H}$ spectrum accounted for all 30 protons required by the molecular formula. Analysis of the ${ }^{1} \mathrm{H},{ }^{13} \mathrm{C}$ and HSQC-DEPT spectra revealed the presence of four olefinic 
Table 5.1. NMR data $\left(600 \mathrm{MHz}, \mathrm{CDCl}_{3}\right)$ for $\Delta_{18,20}$-isovariabilin (186).

\begin{tabular}{|c|c|c|c|c|c|c|c|}
\hline pos. & $\begin{array}{c}\delta_{\mathrm{C}} \\
(\mathrm{ppm})\end{array}$ & mult & $\begin{array}{c}{ }^{1} J_{\mathrm{CH}} \\
(\mathrm{Hz})\end{array}$ & $\begin{array}{c}\delta_{\mathrm{H}} \\
(\mathrm{ppm})\end{array}$ & $\begin{array}{l}\text { mult, } \\
J(\mathrm{~Hz})\end{array}$ & COSY & HMBC \\
\hline 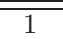 & $\bar{~} 142.6$ & $\overline{\overline{\mathrm{CH}}}$ & 203 & 7.33 & $\overline{\mathrm{t} \text { t (1.6) }}$ & 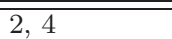 & $2,3,4$ \\
\hline 2 & 111.2 & $\mathrm{CH}$ & 174 & 6.27 & $\mathrm{~s}$ & 1,4 & $1,3,4,5$ \\
\hline 3 & 125.1 & $\mathrm{C}$ & - & - & - & - & - \\
\hline 4 & 138.9 & $\mathrm{CH}$ & 203 & 7.20 & $\mathrm{~s}$ & $1,2,5$ & $1,2,3,(5)$ \\
\hline 5 & 25.1 & $\mathrm{CH}_{2}$ & 127 & 2.43 & $\mathrm{t}(7.4)$ & 4,6 & $2,3,4,6,7$ \\
\hline 6 & 28.5 & $\mathrm{CH}_{2}$ & 125 & 2.23 & $\mathrm{q}(7.5)$ & $5,7,9,(10)$ & $3,5,7,8$ \\
\hline 7 & 123.8 & $\mathrm{CH}$ & 150 & 5.15 & $\mathrm{t}(7.3)$ & 6,9 & $5,6,9,10$ \\
\hline 8 & 135.8 & $\mathrm{C}$ & - & - & - & - & - \\
\hline 9 & 16.1 & $\mathrm{CH}_{3}$ & 122 & 1.58 & $\mathrm{~s}$ & 6,7 & 7,8 \\
\hline 10 & 39.7 & $\mathrm{CH}_{2}$ & 123 & 1.98 & $\mathrm{t}(7.5)$ & $(6), 11$ & $7,8,9,11$ \\
\hline 11 & 26.6 & $\mathrm{CH}_{2}^{2}$ & 116 & 2.07 & $\mathrm{q}(7.2)$ & $10,12,14$ & $8,10,12,13$ \\
\hline 12 & 124.8 & $\mathrm{CH}^{2}$ & 152 & 5.10 & $\mathrm{t}(6.9)$ & 11,14 & $14,15,16$ \\
\hline 13 & 134.5 & $\mathrm{C}$ & - & - & - & - & - \\
\hline 14 & 15.9 & $\mathrm{CH}_{3}$ & 122 & 1.58 & $\mathrm{~s}$ & 11,12 & 12,13 \\
\hline 15 & 39.5 & $\mathrm{CH}_{2}$ & 123 & 1.98 & $\mathrm{t}(7.5)$ & 16 & $12,13,14,16,17$ \\
\hline 16 & 26.5 & $\mathrm{CH}_{2}^{2}$ & 125 & 1.55 & quin $(8.2)$ & $15,17 \mathrm{a}, 17 \mathrm{~b}$ & $13,15,17,18$ \\
\hline $17 \mathrm{a}$ & & & 125 & 2.16 & $\mathrm{dt}(14.0,8.0)$ & $16,17 \mathrm{a}$ & $15,16,18,19,20$ \\
\hline $17 \mathrm{~b}$ & 32.2 & $\mathrm{CH}_{2}$ & 125 & 2.10 & $\mathrm{t}(7.8)$ & $16,17 \mathrm{~b}$ & $15,16,18,19,20$ \\
\hline 18 & 147.6 & $\mathrm{C}$ & - & - & - & - & - \\
\hline 19 & 23.8 & $\mathrm{CH}_{3}$ & 124 & 1.78 & $\mathrm{~s}$ & 20 & $(16), 17,18,20,(22)$ \\
\hline 20 & 118.2 & $\mathrm{CH}$ & 159 & 4.97 & $\mathrm{~d}(9.4)$ & 19,21 & $17,19,21,22$ \\
\hline 21 & 75.6 & $\mathrm{CH}$ & 150 & 5.37 & $\mathrm{~d}(9.4)$ & 20,25 & $18,(19), 20,22,23,24$ \\
\hline 22 & 174.7 & $\mathrm{C}$ & - & - & - & - & - \\
\hline 23 & 97.0 & $\mathrm{C}$ & - & - & - & - & - \\
\hline 24 & 177.3 & $\mathrm{C}$ & - & - & - & - & - \\
\hline 25 & 6.2 & $\mathrm{CH}_{3}$ & 126 & 1.72 & $\mathrm{~s}$ & 21 & $(20,21), 22,23,24$ \\
\hline
\end{tabular}<smiles>CC(=CCCc1ccoc1)CCC=C(C)CCCC(C)=CC1OC(=O)C(C)=C1O</smiles>

186

methyl singlets, five olefinic methines, an oxymethyl resonance and two carbonyltype resonances.

HMBC correlations from one of the methyl singlets $\left(\mathrm{CH}_{3}-12: \delta_{\mathrm{C}} 25.9, \delta_{\mathrm{H}} 1.67\right)$ to $\mathrm{C}-10\left(\delta_{\mathrm{C}} 124.5, \delta_{\mathrm{H}} 5.09\right), \mathrm{C}-11\left(\delta_{\mathrm{C}} 131.5\right)$ and the carbon of another methyl singlet $\left(\mathrm{CH}_{3}-13: \delta_{\mathrm{C}} 17.8, \delta_{\mathrm{H}} 1.59\right)$ implied the presence of geminal methyls on a trisubstituted double bond. Sequential COSY correlations from the olefinic proton $\mathrm{H}-10$ to $\mathrm{H}_{2}-9\left(\delta_{\mathrm{C}} 26.8, \delta_{\mathrm{H}} 2.05\right)$, and from $\mathrm{H}_{2}-9$ to $\mathrm{H}_{2}-8\left(\delta_{\mathrm{C}} 39.8, \delta_{\mathrm{H}} 1.98\right)$ positioned two contiguous methylenes next to the double bond. Correlations observed in the HMBC spectrum from the adjacent methylene $\mathrm{H}_{2}-9$ to $\mathrm{C}-10$ and $\mathrm{C}-11$ confirmed the placement of the two methyls $\mathrm{CH}_{3}-12$ and $\mathrm{CH}_{3}-13$ in a geminal position at the terminus of the molecule.

$\mathrm{CH}_{2}-8$ showed $\mathrm{HMBC}$ correlations to ${ }^{13} \mathrm{C}$ resonances attributed to another trisubstituted double bond: $\mathrm{C}-7\left(\delta_{\mathrm{C}} 135.6\right)$, the carbon of the olefinic methine $\mathrm{CH}-6\left(\delta_{\mathrm{C}} 123.9, \delta_{\mathrm{H}} 2.11\right)$ and the carbon of the methyl $\mathrm{CH}_{3}-14\left(\delta_{\mathrm{C}} 16.2, \delta_{\mathrm{H}} 1.59\right)$. The proton chemical shift of $\mathrm{CH}_{3}-14$ was identical to that of $\mathrm{CH}_{3}-13$, making 
interpretation of their HMBC correlations difficult. As the C-8 to C-13 fragment was already established through other means, any correlations observed from $\delta_{\mathrm{H}} 1.59$ to signals not consistent with that fragment were attributed to $\mathrm{CH}_{3}-14$. In that fashion, HMBC correlations to C-7, C-6 and C-8 allowed the placement of the double bond next to $\mathrm{CH}_{2}-8$.

Two further methylenes $\left(\mathrm{CH}_{2}-5: \delta_{\mathrm{C}} 26.5, \delta_{\mathrm{H}} 2.11 ; \mathrm{CH}_{2}-4: \delta_{\mathrm{C}} 39.8, \delta_{\mathrm{H}} 2.06\right)$ were placed next to the double bond based on COSY correlations observed from H-6 to $\mathrm{H}_{2}-5$ and from $\mathrm{H}_{2}-5$ to $\mathrm{H}_{2}-4$. The structure was unveiling itself again as an isoprene chain; unsurprisingly HMBC and COSY correlations established the presence of another trisubstituted double bond adjacent. The final isoprene substructure (which accounts for three double bond equivalents) with key COSY and HMBC correlations is presented in Figure 5.5.

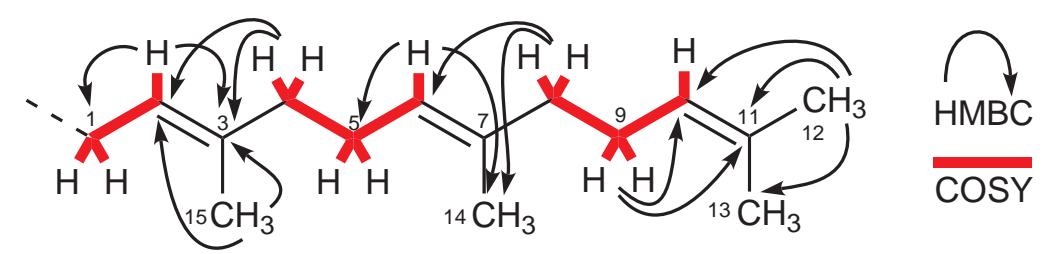

Figure 5.5. Key COSY and HMBC correlations establishing the isoprene portion of 6 -((2E,6E)-3,7,11-trimethyl-2,6,10-dodecatrienyl)-2-methoxy- $p$-quinone 188.

The remaining signals were two carbonyls C-1' $\left(\delta_{\mathrm{C}} 188.0\right), \mathrm{C}-4^{\prime}\left(\delta_{\mathrm{C}} 182.4\right)$, an oxymethyl $\mathrm{CH}_{3}-2^{\prime}-\mathrm{OMe}\left(\delta_{\mathrm{C}} 56.4, \delta_{\mathrm{H}} 3.81\right)$, a double bond $\left(\mathrm{CH}-5^{\prime}: \delta_{\mathrm{C}} 133.0\right.$, $\left.\delta_{\mathrm{H}} 6.45 ; \mathrm{C}-6^{\prime}: \delta_{\mathrm{C}} 146.6\right)$ and a polarized double bond $\left(\mathrm{C}-2^{\prime}: \delta_{\mathrm{C}} 159.0 ; \mathrm{CH}-3^{\prime}\right.$ : $\left.\delta_{\mathrm{C}} 107.3, \delta_{\mathrm{H}} 5.87\right)$, consistent with a 2,5 -substituted $p$-quinone, which accounts for the remaining five double bond equivalents required by the molecular formula. This assignment was further supported by meta coupling $(J=2.0 \mathrm{~Hz}$ ) observed between the two methines.

The oxymethyl showed HMBC correlations to the polarized double bond C- $2^{\prime}$ and $\mathrm{C}-3^{\prime}$, and was therefore placed as the $2^{\prime}$-substituent. NOE enhancements between it and $\mathrm{H}-3^{\prime}$ confirmed the placement. C- $6^{\prime}$ was established as the attachment point to the rest of the isoprene chain based on allylic coupling between $\mathrm{H}_{2}-1$ and $\mathrm{H}-5^{\prime}$ observed in the COSY spectrum. This was further confirmed by HMBC correlations from $\mathrm{H}-2$ to $\mathrm{C}-6^{\prime}$ and from $\mathrm{H}-5^{\prime}$ to $\mathrm{C}-1$ and observed NOE enhancements between $\mathrm{H}-5^{\prime}$ and $\mathrm{H}-1$ and $\mathrm{H}-2$. The quinone moiety is depicted in Figure 5.6, with more detailed COSY and HMBC correlations listed in Table 5.2.

The structure of $\mathbf{1 8 8}$ is therefore 6-((2E,6E)-3,7,11-trimethyl-2,6,10-dodecatrienyl)-2-methoxy-p-quinone. A review of the literature revealed that quinone 

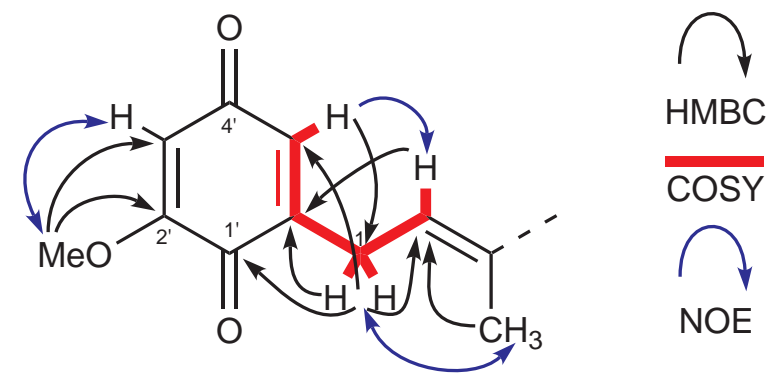

Figure 5.6. Key COSY and HMBC correlations and NOE enhancements establishing the $p$-quinone moiety of 6 - $((2 E, 6 E)-3,7,11$-trimethyl-2,6,10-dodecatrienyl)-2-methoxy-p-quinone 188.

188 was first reported from a southern Australian sponge identified as Thorecta choanides. ${ }^{195}$ Comparison of NMR data revealed them to be identical.

Table 5.2. NMR data $\left(600 \mathrm{MHz}, \mathrm{CDCl}_{3}\right)$ for 6-((2E,6E)-3,7,11-trimethyl2,6,10-dodecatrienyl)-2-methoxy-p-quinone 188.

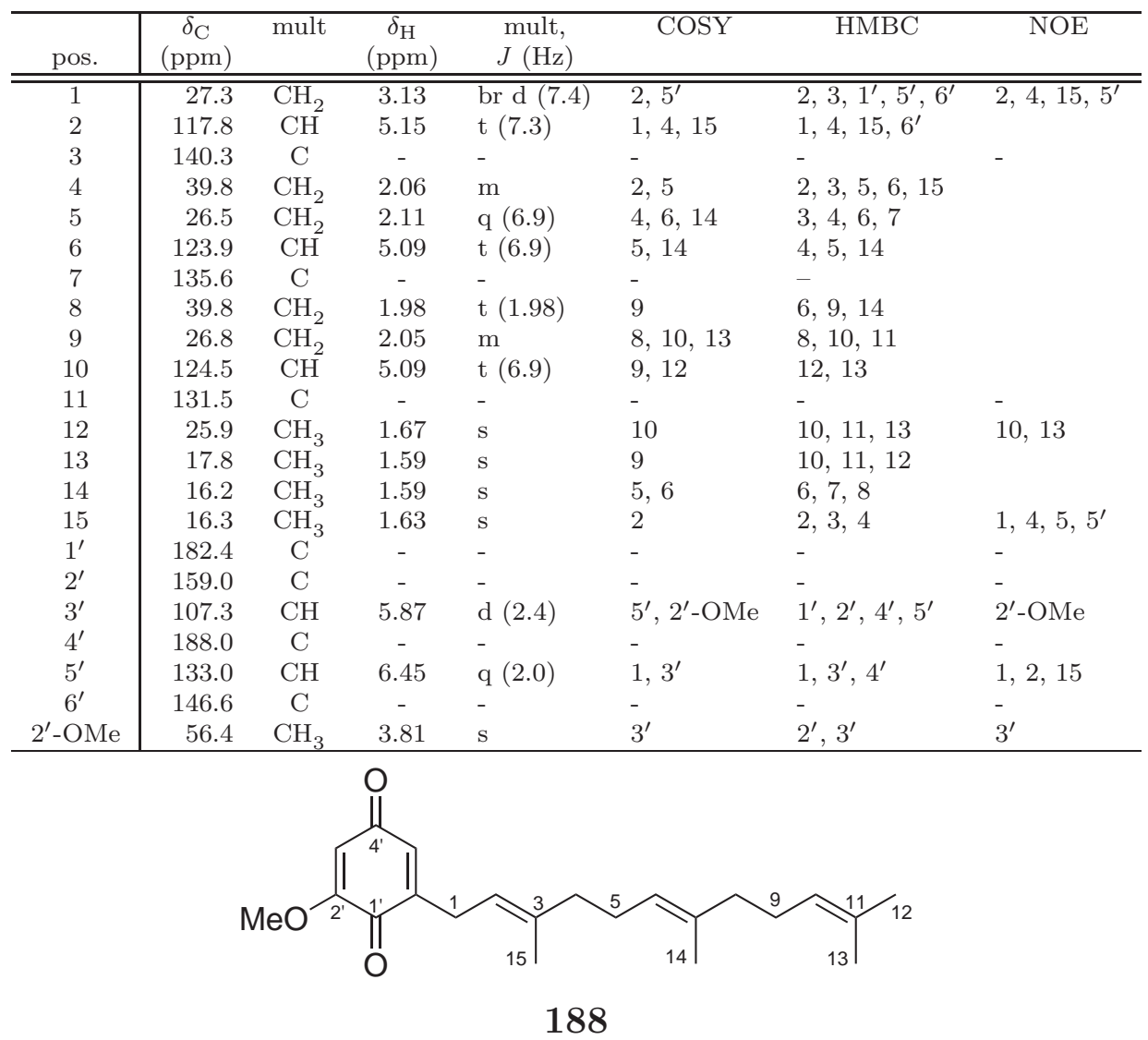

During the purification of $\mathbf{1 8 8}$, a minor compound 189 which showed similar NMR characteristics was also isolated. The pseudomolecuar ions observed in the HRESIMS $\left(365.2095[\mathrm{M}+\mathrm{Na}]^{+}, \Delta 0.5 \mathrm{ppm} ; 397.2341[\mathrm{M}+\mathrm{MeOH}+\mathrm{Na}]^{+}\right.$, $\Delta 3.5 \mathrm{ppm}$ ) suggested a molecular formula of $\mathrm{C}_{22} \mathrm{H}_{30} \mathrm{O}_{3}$, isomeric with quinone 
188. Examination of the ${ }^{1} \mathrm{H},{ }^{13} \mathrm{C}$ and HSQC-DEPT spectra revealed that the majority of signals were very similar if not identical to the major compound $\mathbf{1 8 8}$, allowing the construction of the same connectivity for the molecule. The main difference was the chemical shift change of $\mathrm{CH}_{3}-15$, now at the more deshielded chemical shift of $\delta_{\mathrm{C}} 23.8, \delta_{\mathrm{H}} 1.76$.

As previously mentioned, the methyl of a trisubstituted double bond with $Z$ geometry is more deshielded than one on an $E$ double bond. ${ }^{194-196}$ This implies that the minor quinone $\mathbf{1 8 9}$ is the $2 Z$-isomer of quinone $\mathbf{1 8 8}$. NOE enhancements observed from $\mathrm{H}_{3}-15$ to $\mathrm{H}-2$ (depicted in Figure 5.7) support the assignment of the double bond as $Z$. The structure of the new compound 189 is therefore 6-((2Z,6E)-3,7,11-trimethyl-2,6,10-dodecatrienyl)-2-methoxy- $p$ quinone, with full NMR data presented in Table 5.3.

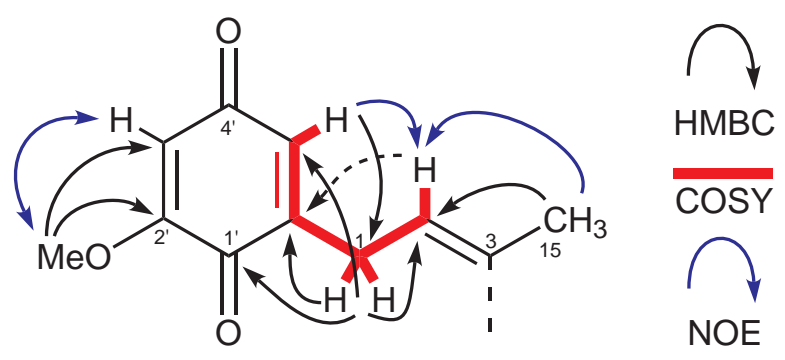

Figure 5.7. Key COSY and HMBC correlations and NOE enhancements establishing the $p$-quinone moiety and the $Z$ configuration of the $\Delta_{2,3}$ double bond of 6-((2Z,6E)-3,7,11-trimethyl-2,6,10-dodecatrienyl)-2-methoxy-p-quinone $\mathbf{1 8 9}$.

\subsection{Variabilins}

$\Delta_{18,20}$-Isovariabilin (186) is a double-bond positional isomer of the known compound variabilin (190), first reported by Faulkner in 1973 from the sponge Ircinia variabilis. ${ }^{197}$ Variabilin was the first member of a group of sesterterpene tetronic acids; since then, several geometric, stereo- and regioisomers have been reported, and are reviewed by Liu et al. ${ }^{198}$

Most of the marine sesterterpene tetronic acids have a $\Delta_{20,21}$ double bond, ${ }^{198}$ and both $E$ and $Z$ isomers have been reported as for 190 and 191. ${ }^{193}$ Some examples with the tetronic acid not further conjugated have been isolated, such as palinurin (192) isolated from I. variabilis collected from the Mediterranean ${ }^{199}$ and the tetronic acid 193, from the Australian marine sponge Spongia sp. ${ }^{200}$

$\Delta_{18,20}$-Isovariabilin (186) is unusual in that it possesses a $\Delta_{18,20}$ double bond. Only one other example of a variabilin compound with a double bond in that location has been reported: ircinic acid (194), isolated from a Fijian sponge of 
Table 5.3. NMR data $\left(600 \mathrm{MHz}, \mathrm{CDCl}_{3}\right)$ for 6-((2Z,6E)-3,7,11-trimethyl2,6,10-dodecatrienyl)-2-methoxy-p-quinone 189.

\begin{tabular}{|c|c|c|c|c|c|c|c|}
\hline pos. & $\begin{array}{c}\delta_{\mathrm{C}} \\
(\mathrm{ppm})\end{array}$ & mult & $\begin{array}{c}\delta_{\mathrm{H}} \\
(\mathrm{ppm})\end{array}$ & $\begin{array}{l}\text { mult, } \\
J(\mathrm{~Hz})\end{array}$ & COSY & HMBC & $\mathrm{NOE}$ \\
\hline 1 & 27.2 & $\overline{\mathrm{CH}_{2}}$ & $\overline{3.14}$ & $\overline{\text { br d (7.7) }}$ & $2,15,5^{\prime}$ & $2,3,1^{\prime},\left(4^{\prime}\right), 5^{\prime}, 6^{\prime}$ & $2,4,5^{\prime}$ \\
\hline 2 & 118.2 & $\mathrm{CH}$ & 5.14 & $\mathrm{t}(7.2)$ & 1,15 & $1,4,15,\left(6^{\prime}\right)$ & \\
\hline 3 & 140.4 & $\mathrm{C}$ & - & - & - & - & - \\
\hline 4 & 32.2 & $\mathrm{CH}_{2}$ & 2.04 & $\mathrm{~m}$ & 5 & $2,3,5$ & \\
\hline 5 & 26.7 & $\mathrm{CH}_{2}$ & 2.10 & $\mathrm{q}(7.0)$ & 4,6 & $3,6,7,8$ & \\
\hline 6 & 123.9 & $\mathrm{CH}$ & 5.09 & $\mathrm{t}(6.7)$ & 5,14 & $(4), 8$ & \\
\hline 7 & 135.6 & $\mathrm{C}$ & - & - & - & - & - \\
\hline 8 & 39.8 & $\mathrm{CH}_{2}$ & 1.97 & $\mathrm{~m}$ & 9 & $6,7,9,10,14$ & \\
\hline 9 & 26.8 & $\mathrm{CH}_{2}^{2}$ & 2.05 & $\mathrm{~m}$ & $8,10,12$ & 7,11 & \\
\hline 10 & 124.5 & $\mathrm{CH}$ & 5.08 & $\mathrm{t}(7.3)$ & 9,12 & 12,13 & \\
\hline 11 & 131.6 & $\mathrm{C}$ & - & - & - & - & - \\
\hline 12 & 25.9 & $\mathrm{CH}_{3}$ & 1.67 & $\mathrm{~s}$ & 10 & $10,11,13$ & \\
\hline 13 & 18.0 & $\mathrm{CH}_{3}$ & 1.59 & $\mathrm{~s}$ & & $10,11,14$ & \\
\hline 14 & 16.3 & $\mathrm{CH}_{3}$ & 1.59 & $\mathrm{~s}$ & 6 & $6,7,8$ & \\
\hline 15 & 23.8 & $\mathrm{CH}_{3}$ & 1.76 & $\mathrm{~s}$ & 1,2 & $2,3,4,5$ & 2,4 \\
\hline $1^{\prime}$ & 182.4 & $\mathrm{C}^{3}$ & - & - & - & - & - \\
\hline $2^{\prime}$ & 159.0 & $\mathrm{C}$ & - & - & - & - & - \\
\hline $3^{\prime}$ & 107.4 & $\mathrm{CH}$ & 5.87 & $\mathrm{~d}(2.3)$ & $5^{\prime}, 2^{\prime}-\mathrm{OMe}$ & $1^{\prime}, 2^{\prime}, 4^{\prime}, 5^{\prime}$ & $2^{\prime}-\mathrm{OMe}$ \\
\hline $4^{\prime}$ & 188.0 & $\mathrm{C}$ & - & - & - & - & - \\
\hline $5^{\prime}$ & 133.01 & $\mathrm{CH}$ & 6.47 & $q(1.9)$ & $1,5^{\prime}$ & $1,1^{\prime}, 3^{\prime}$ & 1,2 \\
\hline $6^{\prime}$ & 147.0 & $\mathrm{C}$ & - & - & - & - & - \\
\hline $2^{\prime}$-OMe & 56.5 & $\mathrm{CH}_{3}$ & 3.81 & $\mathrm{~s}$ & $5^{\prime}$ & $\left(1^{\prime}\right), 2^{\prime}, 3^{\prime}$ & $3^{\prime}$ \\
\hline
\end{tabular}

189

the genus Ircinia. ${ }^{192}$

Variabilin-type compounds exhibit a variety of biological activities, including antiviral, cytotoxic and antimicrobial activities. ${ }^{194,198}$ As with many spongederived compounds, they also show ichthyotoxic properties and therefore may act to deter predators. ${ }^{198}$

\section{Variabilin as a chemotaxonomic marker for the family Irciniidae}

Variabilin (190) and its various isomers are quite widespread, although the majority are reported from the genera Ircinia, Psammocinia and Sarcotragus (all belonging to the familiy Irciniidae). ${ }^{198}$ An examination of New Zealand sponges of the order Dictyoceratida revealed 190 to be the major component of 10 Ircinia, Psammocinia and Sarcotragus extracts. ${ }^{201}$ Sesterterpene tetronic acids were not detected in the other five dictyoceratid genera examined in that study. Based on 
<smiles>CC(=CCCc1ccoc1)CCCC(C)C=C1OC(=O)C(C)=C1O</smiles>

190<smiles>CC(=CCCC(C)C=C1OC(=O)C(C)=C1O)CCC=C(C)CCCc1ccoc1</smiles>

191<smiles>CC(=CC=C[C@@H](C)CCC=C(C)CC1OC(=O)C(C)=C1O)CCCc1ccoc1</smiles>

192<smiles>CC(=CCCC(C)=CCCc1ccoc1)CCC=C(C)C[C@@H]1OC(=O)C(C)=C1O</smiles>

193<smiles>CC1=C(O)C(/C=C(\C)CCC/C(C)=C/C=C/C(C)=C/CCc2ccoc2)OC1=O</smiles>

194

the prevalence of furanosesterterpenes (especially variabilin and its analogues) in irciniid sponges, Liu et al. propose variabilin and other variabilin-type compounds as a chemotaxonomic marker for the family Irciniidae. ${ }^{202}$

\subsection{Quinones}

Terpenoid quinones and hydroquinones are quite common sponge metabolites, with most examples possessing the drimane or 4,9-friedodrimane sesquiterpene skeletons. ${ }^{92,203}$ Avarol (195) and avarone (196), isolated from the sponge Dysidea avara in 1974, were the first examples of 4,9-friedo-rearranged drimanes. ${ }^{204}$ Since then, a myriad of related compounds has been isolated, most displaying pronounced biological activity. ${ }^{203}$

The linear polyprenyl benzoquinones (and their corresponding hydroquinones) that are thought to be the precursors of the more complex, cyclic quinone 


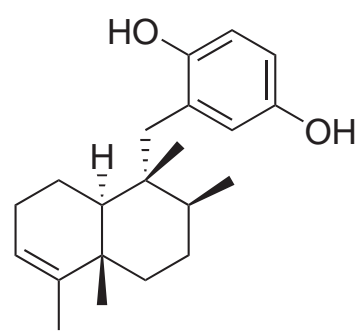

195

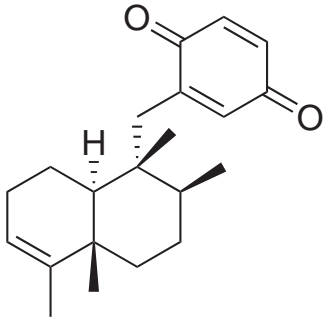

196

metabolites, have long been known from marine organisms. The most common sources are brown algae of the order Fucales and sponges of the order Dictyoceratida, but a few examples have also been isolated from soft coral and ascidians. ${ }^{196}$

The marine sponges Ircinia muscarum and Dysidea pallescens were found to contain the linear tetra- (197) and pentaprenylated (198) quinones respectively. ${ }^{205,206}$ The higher homologues 199-201 were isolated from I. spinosula together with furospinosulin-1 (187). ${ }^{191}$ Subsequently a New Caledonian sponge, Ircinia sp., yielded 197 and 198. ${ }^{207}$

The corresponding hydroquinones (quinols) (202-206) are almost always co-isolated with the benzoquinones. ${ }^{191,200,205}$ Bonny and Capon, who first isolated quinone 188, used silica gel for purification, co-isolating the corresponding hydroquinone (207). ${ }^{195}$ Pouchus et al. suggest that the quinones are actually artifacts of isolation, produced through oxidation of the hydroquinones on silica gel. ${ }^{208}$ They examined a Tunesian Hippospongia communis sponge and isolated the hepta- and octaprenyl hydroquinones 205 and 206 and the corresponding quinones 200 and 201 through purification on silica gel. They found that on re-injecting one of the hydroquinones onto a silica gel column, more of the corresponding quinone could be isolated. ${ }^{208}$

Two studies did not use silica gel for chromatography. Lumsdon et al. examined an extract of an Australian marine sponge of the genus Spongia using size-exclusion choromatography and reversed-phase HPLC. They report the presence of tetronic acid 193 and the pentaprenylated hydroquinone 203. ${ }^{200}$ West isolated the hexaprenylated hydroquinone 204 from a sponge identified as Sarcotragus sp., using only reversed-phase chromatography. ${ }^{127}$ The absence of the corresponding pentaprenylated and hexaprenylated quinones $(\mathbf{1 9 8}, \mathbf{1 9 9})$ in both studies is noteworthy.

The majority of the linear polyprenyl quinones and hydroquinones isolated have the more stable all $E$ configuration of their double bonds. One example with a $Z$ geometry is the diprenylquinone 208, isolated with its $E$ isomer 209 from an ascidian. ${ }^{196}$ 
<smiles>CCC(C)(C=C(C)C)C1=CC(=O)C=CC1=O</smiles>

$197 \mathrm{n}=4$

$198 \mathrm{n}=5$

$199 \mathrm{n}=6$

$200 \mathrm{n}=7$

$201 \mathrm{n}=8$<smiles>CCCC(C)(C)CCC(C)(C)c1cc(O)ccc1O</smiles>

$202 \mathrm{n}=4$

$203 \mathrm{n}=5$

$204 \mathrm{n}=6$

$205 \mathrm{n}=7$

$206 \mathrm{n}=8$<smiles>COC1=CC(=O)C=C(C/C=C(\C)CC/C=C(\C)CCC=C(C)C)C1=O</smiles>

188<smiles>COc1cc(O)cc(C/C=C(\C)CC/C=C(\C)CCC=C(C)C)c1O</smiles>

207<smiles>COC1=CC(=O)C=C(C/C=C(/C)CC/C=C/C(C)=O)C1=O</smiles><smiles>COC1=CC(=O)C=C(CC=C(C)CCC=C(C)C)C1=O</smiles>

209

\subsection{Concluding remarks}

Terpenoid quinones are widespread in nature and include such essential compounds as the vitamins $\mathrm{K}$ and the ubiquinones. ${ }^{191}$ They are utilized in photosynthesis and electron transport relays in biological systems because of the low oxidation/reduction potentials of the hydroquinone/quinone interconversion. ${ }^{209}$

Silica gel, already implicated as a possible catalyst, may catalyze the oxidation of hydroquinones during their purification. ${ }^{208}$ If that is true, many of the reported quinones, including compounds 188 and 189 isolated during this study, may be isolation artifacts. Pouchus et al. recommend less reactive stationary phases such as DIOL for the purification of hydroquinones. ${ }^{208}$

Furano and lactone terpenes have been implicated as taxonomic markers of 
the Dictyoceratid and Dendrocaratid sponges. ${ }^{210}$ In a subsequent review, however, Erpenbeck and van Soest do not believe they are a suitable marker, as such compounds have also been found from sponges of other orders. ${ }^{202}$ More recently, the presence of variabilin and its analogues has been proposed as a specific chemotaxonomic marker for the dictyoceratid family Irciniidae. ${ }^{211}$ While the vast majority of variabilin-type compounds have been found from Irciniidae sponges, a few examples have also been reported from the other three Dictyoceratid families. ${ }^{198}$

Chemotaxonomy is fraught with pitfalls, including a clear bias in the literature towards reporting only new compounds, the possible symbiont origins of metabolites, taxonomic misidentification, and sponge-sponge contamination (such as that seen with the cyclostelletamines). ${ }^{202}$ Unless the presence of variabilin-type compounds in the other three Dictyoceratid families is explained by misidentification or sponge-sponge contamination, it seriously weakens the reliability of the variabilins as a marker for the family Irciniidae. Nevertheless, the preponderance of variabilin-type metabolites isolated from the family Irciniidae suggests the sponge examined in this study may well be an irciniid. 


\section{Chapter 6}

\section{The Oxeatamides: New Nitrogenous Diterpenes from Darwinella oxeata}

\subsection{Secondary metabolites reported from the genus Darwinella}

The Dendroceratida are one of the three orders of Demospongiae which lack any siliceous spicules. The family Darwinellidae has a dendritic, fibrous spongin skeleton instead. Four genera, found throughout the world, belong to this family: Darwinella, Chelonaplysilla, Aplysilla and Dendrilla. Because of similar surface morphologies and ranges of pigmentation, Darwinella species (especially small specimens) are often confused with Aplysilla. ${ }^{43}$

Only seven new compounds have been reported from Darwinella sponges. Examination of a hexane extract of $D$. oxeata resulted in the isolation of the porphyrin 210. ${ }^{212}$ The structure of this chlorophyll A derivative was solved through $\mathrm{X}$-ray diffraction and is the first example of a porphyrin isolated from a sponge.

A sponge identified as $D$. australensis has yielded three new sulfated sesterterpenes, the halisulfates $8-10(\mathbf{2 1 1}-\mathbf{2 1 3}) .{ }^{213}$ Molecules of this class have previously been isolated from a taxonomically quite different halichondriidae sponge. They have shown antimicrobial and cytotoxic activities. ${ }^{214}$

Finally, four diterpenes with a rearranged spongian diterpene skeleton have been isolated from D. oxeata. They will be detailed in Section 6.4 together with other metabolites of this class. 


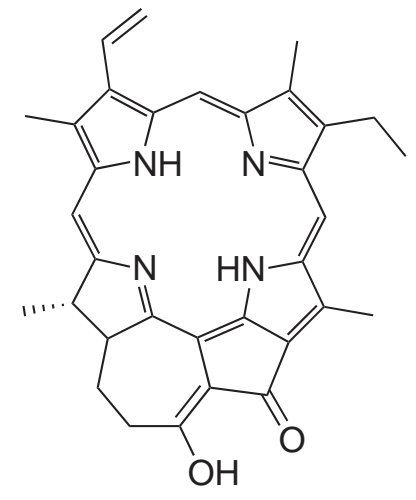

210

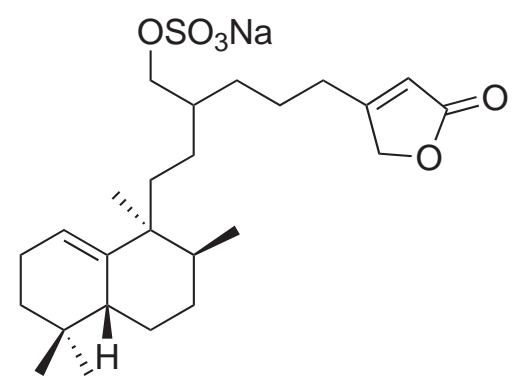

212

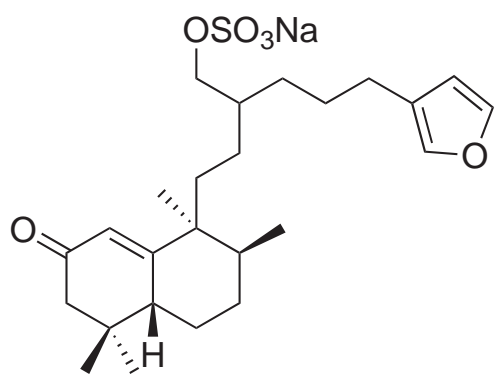

211<smiles>COC1C=C(CCCC(CCCC2C(=O)CCCC2C)COC(N)=O)C(C)CCC1C</smiles>

213

\subsection{The oxeatamides}

Darwinella oxeata (see Figure 6.1 for taxonomy) is found frequently around New Zealand rocky coasts. It is a bright yellow, encrusting sponge with a surface marked by conules as shown in Figure 6.2. The common, thin, encrusting form is often confused with Aplysilla sulphurea. D. oxeatea is soft, fleshy and slimy, exuding a mucous when damaged. When removed from the water it rapidly turns a dark red/brown to black colour, as do all sulfur-yellow dendroceratid and verongid sponges. ${ }^{215}$

Order Dendroceratida

Family Darwinellidae

Genus Aplysilla

Genus Chelonaplysilla

Genus Darwinella

D. aurea (type species)

D. oxeata

Genus Dendrilla

Family Dictyodendrillidae

Figure 6.1. Taxonomic classification of D. oxeata, after Hooper and van Soest. ${ }^{43}$ 


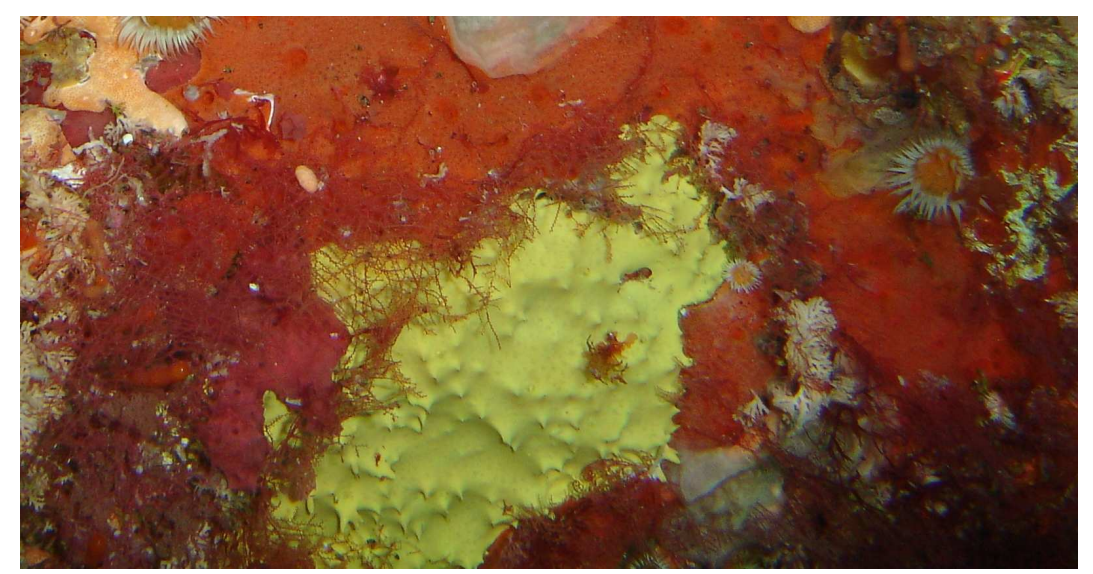

Figure 6.2. Underwater photo of D. oxeata (courtesy of Kel Nairn).

\section{Isolation of the oxeatamides}

The bright yellow D. oxeata was collected from Port Hardy, D'Urville Island, New Zealand in April 2000. It was extracted in $\mathrm{MeOH}$, and the extracts were cyclic loaded onto reversed-phase HP20 beads. The column was eluted with increasing concentrations of $\mathrm{Me}_{2} \mathrm{CO}$ in $\mathrm{H}_{2} \mathrm{O}$. Fraction $1\left(20 \% \mathrm{Me}_{2} \mathrm{CO}\right.$ in $\left.\mathrm{H}_{2} \mathrm{O}\right)$ showed the presence of one major compound by NMR spectroscopy and was further purified on a DIOL column (eluted with $\mathrm{MeOH} / \mathrm{CH}_{2} \mathrm{Cl}_{2}$ mixtures). The chromatographic separation was poor, with the major compound "streaking" accross several fractions, but the $10 \% \mathrm{MeOH}$ in $\mathrm{CH}_{2} \mathrm{Cl}_{2}$ fraction had the major compound in sufficient purity for preliminary structure elucidation. The poor chromatography and partial NMR data suggested the molecule contained one or more carboxylic acids. Final purification was therefore achieved through HPLC on a semi-preparative $\mathrm{C}_{18}$ reversed-phase column eluted with $70 \% \mathrm{MeOH} / 0.1 \mathrm{M}$ $\mathrm{HCOOH}$. Oxeatamide A (214) was the major compound, with a retention time of 21 minutes.

Fraction 2 from the cyclic loading $\left(40 \% \mathrm{Me}_{2} \mathrm{CO}\right.$ in $\mathrm{H}_{2} \mathrm{O}$ ) had NMR signals characteristic of $\mathbf{2 1 4}$ together with related compounds, and was fractionated on a DIOL column in a similar fashion. The $10 \% \mathrm{MeOH}$ in $\mathrm{CH}_{2} \mathrm{Cl}_{2}$ fraction was subjected to HPLC using identical conditions as described above. Three fractions were collected, corresponding to oxeatamide B (217), oxeatamide A (214), and iso-oxeatamide A (215) with retention times of 5-8, 21.0 and 25.1 minutes respectively.

Fractions that eluted after $\mathbf{2 1 4}$ from the HPLC injections (and showed further interesting ${ }^{1} \mathrm{H}$ NMR signals) were combinded, concentrated, and re-injected onto the HPLC under the same conditions. This resulted in the isolation of oxeatamide A 23-methyl ester (216) which had a retention time of $27.4 \mathrm{~min}$. 


\section{Structure elucidation of oxeatamide A}

The observation of pseudomolecular ions by positive ion mode HRESIMS indicated a molecular formula of $\mathrm{C}_{22} \mathrm{H}_{29} \mathrm{NO}_{5}$ for oxeatamide $\mathrm{A}$ (214) (388.2115 $\left.[\mathrm{M}+\mathrm{H}]^{+}, \Delta 2.3 \mathrm{ppm} ; 410.1940[\mathrm{M}+\mathrm{Na}]^{+}, \Delta 0.9 \mathrm{ppm}\right)$, requiring nine double bond equivalents. Analysis of the ${ }^{13} \mathrm{C}$ NMR spectrum revealed the presence of 22 distinct carbons, and the ${ }^{1} \mathrm{H}$ spectrum accounted for 27 of the 29 protons. The salient features of the ${ }^{1} \mathrm{H},{ }^{13} \mathrm{C}$ and HSQC-DEPT spectra were the presence of three methyl singlets (one of which ahd an unusual, highly shielded proton signal), six aromatic carbons, three carbonyls, and six methylenes. Most of the methylenes had protons with significantly unequal chemical shifts (with differences of up to $0.87 \mathrm{ppm}$ ) indicating chirality and/or restricted rotation.

The first spin system, a chain of three methylenes $\mathrm{CH}_{2}-1\left(\delta_{\mathrm{C}} 41.0, \delta_{\mathrm{Ha}} 2.31\right.$, $\left.\delta_{\mathrm{Hb}} 1.44\right), \mathrm{CH}_{2}-2\left(\delta_{\mathrm{C}} 20.1, \delta_{\mathrm{Ha}} 1.80, \delta_{\mathrm{Hb}} 1.44\right)$, and $\mathrm{CH}_{2}-3\left(\delta_{\mathrm{C}} 39.8, \delta_{\mathrm{Ha}} 1.32\right.$, $\delta_{\mathrm{Hb}}$ 1.27), was identified through COSY correlations between their respective protons. A further (long range) COSY correlation was observed between $\mathrm{H}_{2}-3$ and the methyl $\mathrm{H}_{3}-18\left(\delta_{\mathrm{C}} 27.4, \delta_{\mathrm{H}} 0.40\right)$

HMBC correlations observed from two of the methyl singlets $\mathrm{H}_{3}-18$ and $\mathrm{H}_{3}-19$ $\left(\delta_{\mathrm{C}} 33.1, \delta_{\mathrm{H}} 0.91\right)$ to the same three carbons $\left(\delta_{\mathrm{C}} 39.8,31.9,50.9\right)$ as well as to each other's carbons clearly established them as gem-dimethyls. Two carbons had a chemical shift of $39.8 \mathrm{ppm}$ (the methylene $\mathrm{CH}_{2}-3$ and the quaternary carbon C-10), making assignment difficult. Observation of HMBC correlations from H3a, H-3b to the gem-dimethyls, as well as to $\delta_{\mathrm{C}} 31.9(\mathrm{C}-4)$ and $\delta_{\mathrm{C}} 50.9(\mathrm{C}-5)$, however, clearly placed $\mathrm{CH}_{2}-3$ next to the gem-dimethyl moiety and established the $\mathrm{C}-3 / \mathrm{C}-4$ bond.

Observation of a correlation in the HMBC spectrum between the third methyl singlet $\mathrm{H}_{3}-20\left(\delta_{\mathrm{C}} 32.9, \delta_{\mathrm{H}} 1.40\right)$ and $\mathrm{C}-5$ extended the fragment further. $\mathrm{H}_{3}-20$ also showed a correlation to an aromatic carbon and $\delta_{\mathrm{C}} 39.8$, but this now could not be the methylene $\mathrm{CH}_{2}-3$, as it was too far away. This correlation was attributed to $\mathrm{C}-10$, which had to be the attachment point of $\mathrm{CH}_{3}-20$. Finally, an $\mathrm{HMBC}$ correlation from $\mathrm{H}_{3}-20$ to $\mathrm{C}-1$ completed a cyclohexane ring, depicted in Figure 6.3.

The presence of six $s p^{2}$ carbons C-8 ( $\left.\delta_{\mathrm{C}} 135.2\right)$, C-9 $\left(\delta_{\mathrm{C}} 151.5\right), \mathrm{CH}-11$ $\left(\delta_{\mathrm{C}} 127.8, \delta_{\mathrm{H}} 7.58\right), \mathrm{CH}-12\left(\delta_{\mathrm{C}} 122.7, \delta_{\mathrm{H}} 7.63\right), \mathrm{C}-13\left(\delta_{\mathrm{C}} 130.2\right), \mathrm{C}-14\left(\delta_{\mathrm{C}} 142.0\right)$ suggested an aromatic ring, and the large (ortho) coupling constant of the two aromatic methines ( $\mathrm{H}-11$ and $\mathrm{H}-12: J=8.1 \mathrm{~Hz}$ ) indicated a 1,2,3,4-tetrasubstituted benzene moiety. $\mathrm{H}-11$, but not $\mathrm{H}-12$, showed an HMBC cross peak to $\delta_{\mathrm{C}} 39.8$ (which had to be $\mathrm{C}-10$ ), establishing the C-9/C-10 bond and placing the 


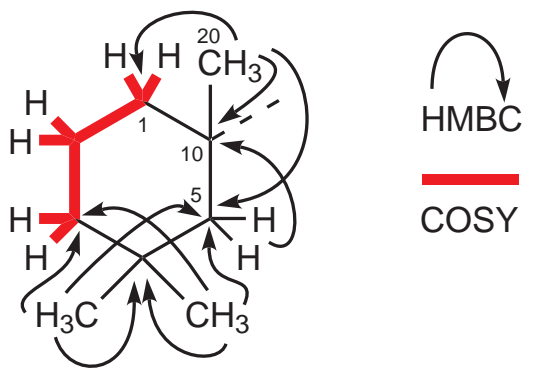

Figure 6.3. Key COSY and HMBC correlations establishing the structure of the cyclohexane ring of oxeatamide A (214).

cyclohexane ring ortho to $\mathrm{CH}-11$. HMBC correlations from $\mathrm{H}_{3}-20$ and $\mathrm{H}-5 \mathrm{~b}$ to the aromatic carbon C-9 established the attachment of C-10 of the cyclohexane ring to $\mathrm{C}-9$ of the aromatic ring.

The fourth methyl $\mathrm{CH}_{3}-17\left(\delta_{\mathrm{C}} 15.5, \delta_{\mathrm{H}} 1.58\right)$ was a doublet, showing a COSY correlation to the methine $\mathrm{CH}-7\left(\delta_{\mathrm{C}} 40.9, \delta_{\mathrm{H}} 4.71\right)$. HMBC correlations from $\mathrm{H}_{3}-17$ to $\mathrm{C}-7$ and from $\mathrm{H}-7$ to $\mathrm{C}-17$ confirmed their attachment. Both proton resonances also showed HMBC cross peaks to one of the ester/acid carbonyl resonances $\mathrm{C}-6\left(\delta_{\mathrm{C}} 179.2\right)$, establishing the $\mathrm{C}-6 / \mathrm{C}-7$ bond. The HMBC spectrum showed correlations from H-7 to the three aromatic carbons C-8, C-9 and C-14, and from $\mathrm{H}_{3}-17$ to $\mathrm{C}-8$, establishing the connection between $\mathrm{C}-7$ and $\mathrm{C}-8$ and placing this substructure next to the cyclohexane ring on the aromatic ring as shown in Figure 6.4.

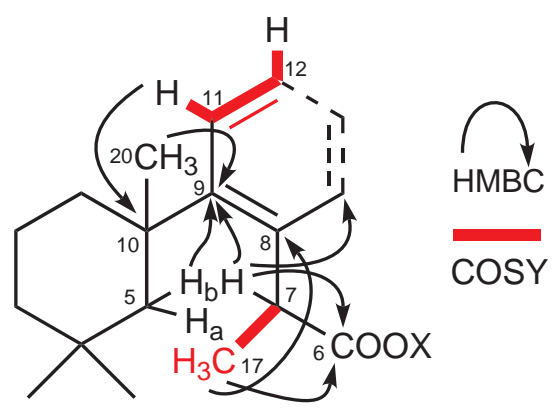

Figure 6.4. Key COSY and HMBC correlations extending the substructure of oxeatamide A (214).

HMBC correlations from $\mathrm{H}-11$ and $\mathrm{H}-12$ allowed the assignment of the remaining aromatic positions. Although both protons showed correlations to all four remaining non-protonated aromatic carbons, the strength of the correlations was used as an indication of whether a carbon was two or three bonds away. For HMBC experiments which are optimized for $8 \mathrm{~Hz}$ (the usual case), aromatic systems show stronger three-bond than two-bond correlations, as their 
${ }^{3} J_{\mathrm{CH}}$ is about $7-8 \mathrm{~Hz}$ while ${ }^{2} J_{\mathrm{CH}}$ is only $1.0 \mathrm{~Hz} .{ }^{216} \mathrm{H}-11$ had strong (three bond) correlations to C-8 and C-13, placing them meta to CH-11. Strong (three bond) HMBC correlations from H-12 to C-9 and C-14 confirmed their assignments as meta to $\mathrm{CH}-12$. Both $\mathrm{H}-11$ and $\mathrm{H}-12$ showed HMBC correlations to carbonyl C$16\left(\delta_{\mathrm{C}} 169.4\right)$, placing it ortho to $\mathrm{CH}-12$, while $\mathrm{H}_{2}-15\left(\delta_{\mathrm{C}} 50.2, \delta_{\mathrm{Ha}} 4.40, \delta_{\mathrm{Hb}} 4.31\right)$ showed correlations to C-8 and C-9, establishing its connection to the aromatic position C-14 (see Figure 6.5).

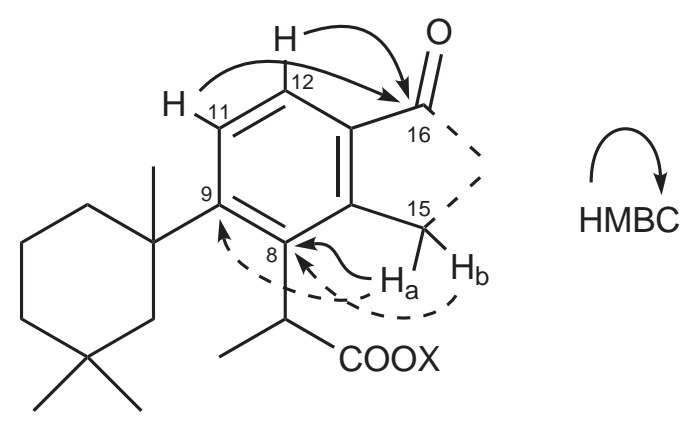

Figure 6.5. Key HMBC correlations further extending the partial structure of oxeatamide A (214).

A review of the literature at this point revealed that the proposed partial diterpenoid skeleton has precedence in the literature. The chemical shifts of the closely related membranolides ${ }^{217,218}$ (discussed further in Section 6.4) compared favourably with the structure of oxeatamide A (214) constructed so far. None of the known compounds contained a nitrogen, however.

A methylene, the nitrogen, a carbonyl, two oxygens and a proton remained unaccounted for, as well as one degree of unsaturation. Methylene $\mathrm{H}_{2}-22\left(\delta_{\mathrm{C}} 43.8\right.$, $\left.\delta_{\mathrm{Ha}} 4.77, \delta_{\mathrm{Hb}} 3.97\right)$ showed a strong HMBC correlation to the remaining carbonyl carbon $\mathrm{C}-23\left(\delta_{\mathrm{C}} 173.9\right)$, which was most likely an acid. Both methylene $\mathrm{CH}_{2}{ }^{-}$ 22 and $\mathrm{CH}_{2}-15$ had unusually large ${ }^{1} J_{\mathrm{CH}}$ coupling constants $(140-142 \mathrm{~Hz}$, as compared to $120-127 \mathrm{~Hz}$ for a standard methylene), suggesting attachment to a heteroatom, most likely a nitrogen as the ${ }^{1} \mathrm{H}$ and ${ }^{13} \mathrm{C}$ chemical shifts were too shielded for an adjacent oxygen. Both methylenes also showed correlations to C-16 $\left(\delta_{\mathrm{C}} 169.4\right)$, which suggested a tertiary amide in a five-membered ring. The ring satisfied the final degree of unsaturation, and the nitrogen evidenced by the molecular formula was confirmed through the observation of correlations from $\mathrm{H}-15 \mathrm{a}, \mathrm{H}-15 \mathrm{~b}$ to $\mathrm{N}-21$ in a ${ }^{1} \mathrm{H}-{ }^{15} \mathrm{~N}$ HMBC experiment (see Figure 6.6). The chemical shift of the nitrogen $\left(\delta_{\mathrm{N}}-264.5^{*}\right)$ was consistent with an amide. ${ }^{113}$

With the entire molecular formula except two protons, and all degrees of

\footnotetext{
${ }^{* 15} \mathrm{~N}$ chemical shift referenced to nitromethane $\left(\mathrm{CH}_{3} \mathrm{NO}_{2}\right)$.
} 


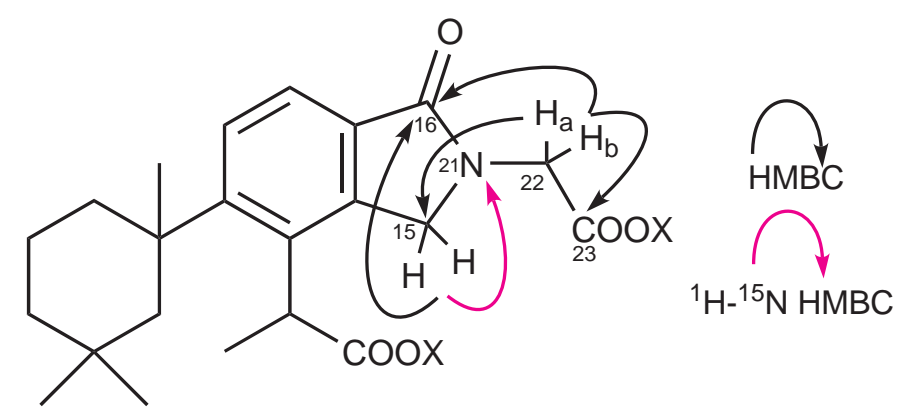

Figure 6.6. Key HMBC correlations establishing the lactam moiety of oxeatamide A (214).

unsaturation accounted for, the final structure was proposed to be a di-acid. To unequivocally confirm the presence of two acidic functionalities, a methylation of $\mathbf{2 1 4}$ was undertaken. A portion of $\mathbf{2 1 4}$ was subjected to $\mathrm{TMSCHN}_{2}$, yielding the expected dimethyl ester derivative of oxeatamide A (218). The ${ }^{1} \mathrm{H}$ NMR spectrum (Figure 6.7) showed the appearance of two new $O$-methyl signals as expected, and HRESIMS confirmed $\mathrm{C}_{24} \mathrm{H}_{33} \mathrm{NO}_{5}$ as the new molecular formula $\left(416.2434[\mathrm{M}+\mathrm{H}]^{+}, \Delta 0.6 \mathrm{ppm} ; 438.2254[\mathrm{M}+\mathrm{Na}]^{+}, \Delta 0.7 \mathrm{ppm}\right)$, confirming the presence of the two carboxylic acids in 214. For the full NMR assignment of oxeatamide A dimethyl ester (218) see Table 6.2.

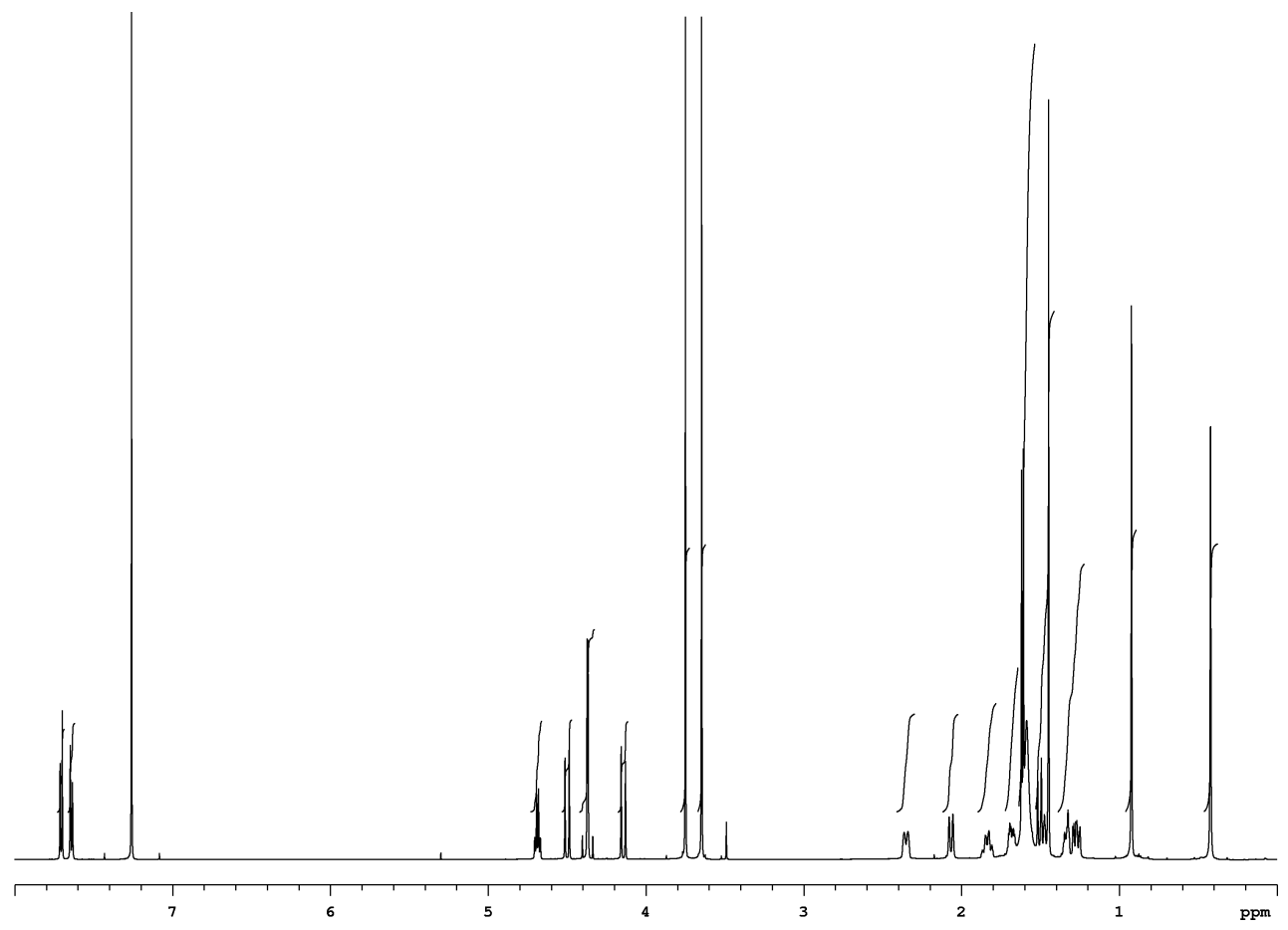

Figure 6.7. ${ }^{1} \mathrm{H}$ NMR spectrum $\left(600 \mathrm{MHz}, \mathrm{CDCl}_{3}\right)$ of oxeatamide A dimethyl ester (218). 


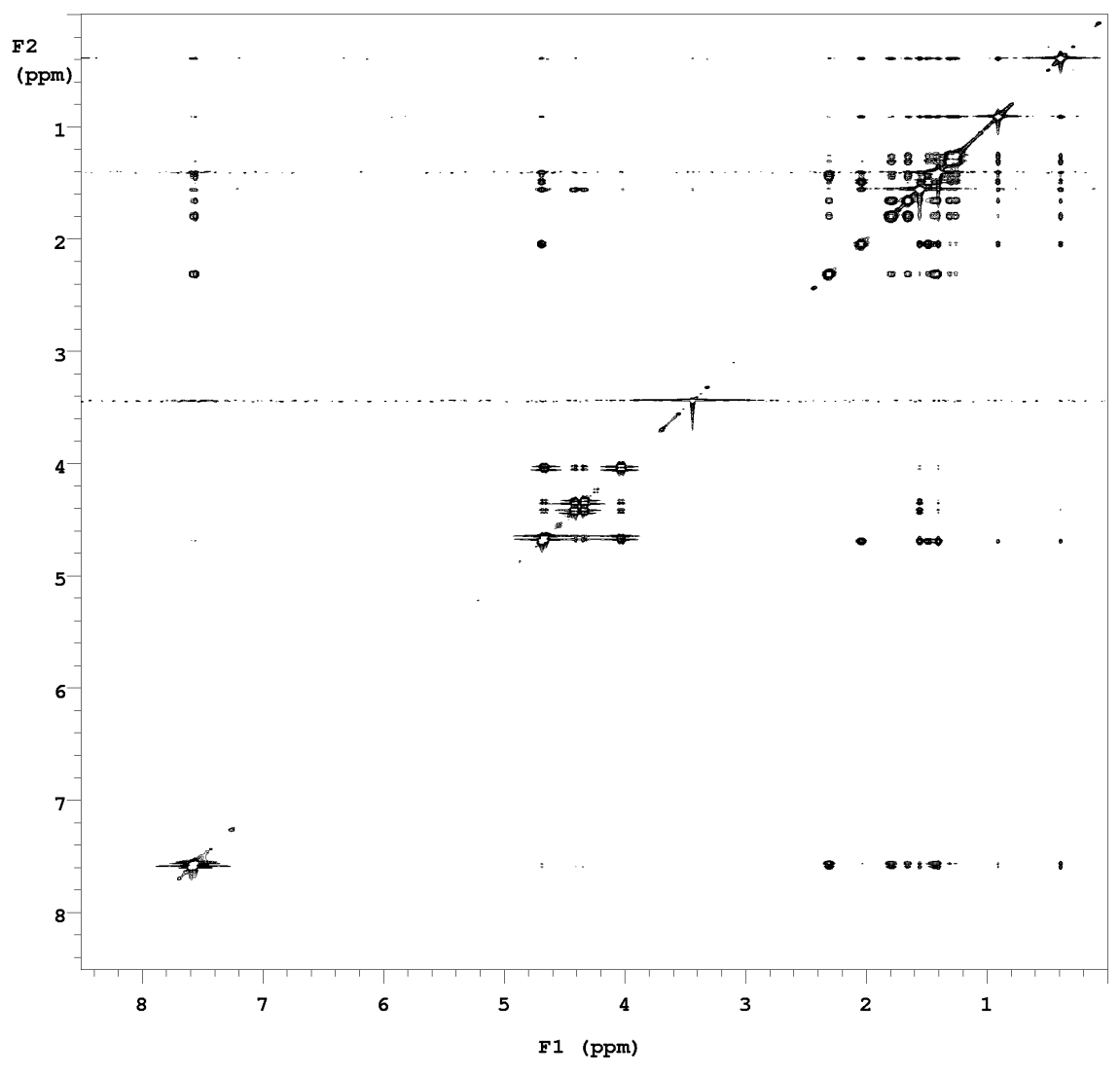

Figure 6.8. 2D-NOESY spectrum (600 $\left.\mathrm{MHz}, \mathrm{CDCl}_{3}\right)$ of oxeatamide $\mathrm{A}(\mathbf{2 1 4})$.

With the connectivity of $\mathbf{2 1 4}$ established, the question remained of the configuration of $\mathrm{CH}-7$ and C-10. To answer this, a 2D-NOESY experiment was run on the compound, but surprisingly, all the enhancements were negative. The sign and magnitude of an NOE is dependent on molecular tumbling rates, which are affected by size and shape of the molecule, the solution conditions (viscosity, temperature, $\mathrm{pH}$ etc.) and spectrometer strength. ${ }^{219}$ Generally, though, negative NOEs are only observed for larger (more slowly tumbling) molecules. The observation of negative enhancements for oxeatamide A (established to have a molecular weight of only 387) is therefore most unusual. Furthermore, closer examination of the 2D-NOESY spectrum (Figure 6.8) revealed a plethora of correlations, many of which (e.g. H-22a and H-22b showing multiple cross-peaks to the cyclohexane ring protons) were at odds with the proposed structure.

Carboxylic acids exist largely as dimers in solution, due to the formation of two strong hydrogen bonds in the dimeric form. ${ }^{220}$ As oxeatamide A (214) has 
two carboxylic acid functionalities and therefore has two sites for hydrogen bond formation, it can quite feasibly form an extensive network. Such an oligomer would explain the anomalous NOE enhancements observed: they are negative because the hydrogen-bonded netwok is very large, and some correlations are in fact inter-molecular enhancements.

To avoid this problem, a 2D-NOESY experiment was run on the dimethyl ester derivative 218. Its NOE enhancements were all positive, as expected for a molecule of its molecular mass: having no free carboxylic acid groups, oxeatamide A dimethyl ester (218) could not form a hydrogen-bonded, oligomeric network.

The relative configuration of $\mathbf{2 1 8}$ and selected key NOE enhancement are depicted in Figure 6.9. NOE enhancements between $\mathrm{H}_{3}-18$ and $\mathrm{H}-2 \mathrm{a}$ established them in a 1,3-diaxial relationship. A further enhancement between $\mathrm{H}-2 \mathrm{a}$ and $\mathrm{H}-11$ indicated that the aromatic ring was also axial. The axial positioning of the benzene ring has literature precedent, and explains the anomalous high-field chemical shift $\left(\delta_{\mathrm{H}} 0.42\right)$ of $\mathrm{H}_{3}-18$, which lies in the anisotropic shielding zone of the aromatic ring. ${ }^{218,221,222}$ This resonance is a distinctive signature of these types of 1-aryl-1,3,3-trimethylcyclohexane moieties.

NOE enhancements from $\mathrm{H}-3 \mathrm{~b}$ to $\mathrm{H}-5 \mathrm{~b}$ and $\mathrm{H}-1 \mathrm{~b}$ placed them axially on the other face, as shown in Figure 6.9. While some weak NOE enhancements (e.g. H-1a to H-3a and H-5a) indicative of the other cyclohexane conformer were observed, four long-range (W-coupling) correlations in the COSY (between H-1a and $\mathrm{H}-5 \mathrm{a} ; \mathrm{H}-3 \mathrm{a}$ and $\mathrm{H}-5 \mathrm{a}, \mathrm{H}-3 \mathrm{~b}$ and $\mathrm{H}_{3}-18$ and $\mathrm{H}-5 \mathrm{~b}$ and $\mathrm{H}_{3}-18$ ) established the predominant conformer. In addition, H-1b (ddd 14.3, 12.2, $2.9 \mathrm{~Hz}$ ) showed both geminal coupling and large axial-axial coupling, as did $\mathrm{H}-2 \mathrm{a}$ (q $11.2 \mathrm{~Hz}$ ) and H-3b (ddd 12.8, 11.6, 4.2 Hz), supporting their axial positioning. Therefore the relative configuration of $\mathrm{C}-10$ is assigned as $S^{*}$.

The configuration of $\mathrm{CH}-7$ was assigned as $R^{*}$, based on observed NOE enhancements from $\mathrm{H}_{3}-18$ to $\mathrm{H}_{3}-17, \mathrm{H}-15$ a to $\mathrm{H}_{3}-17$, and from $\mathrm{H}-7$ to and $\mathrm{H}_{3}-20$. A $10 S^{*}$ and $7 R^{*}$ configuration is consistent with previously reported metabolites with this skeleton, discussed in detail in Section 6.4 and 6.6 below. The final structure of oxeatamide A is therefore assigned as 214, with full NMR data presented in Table 6.1. 


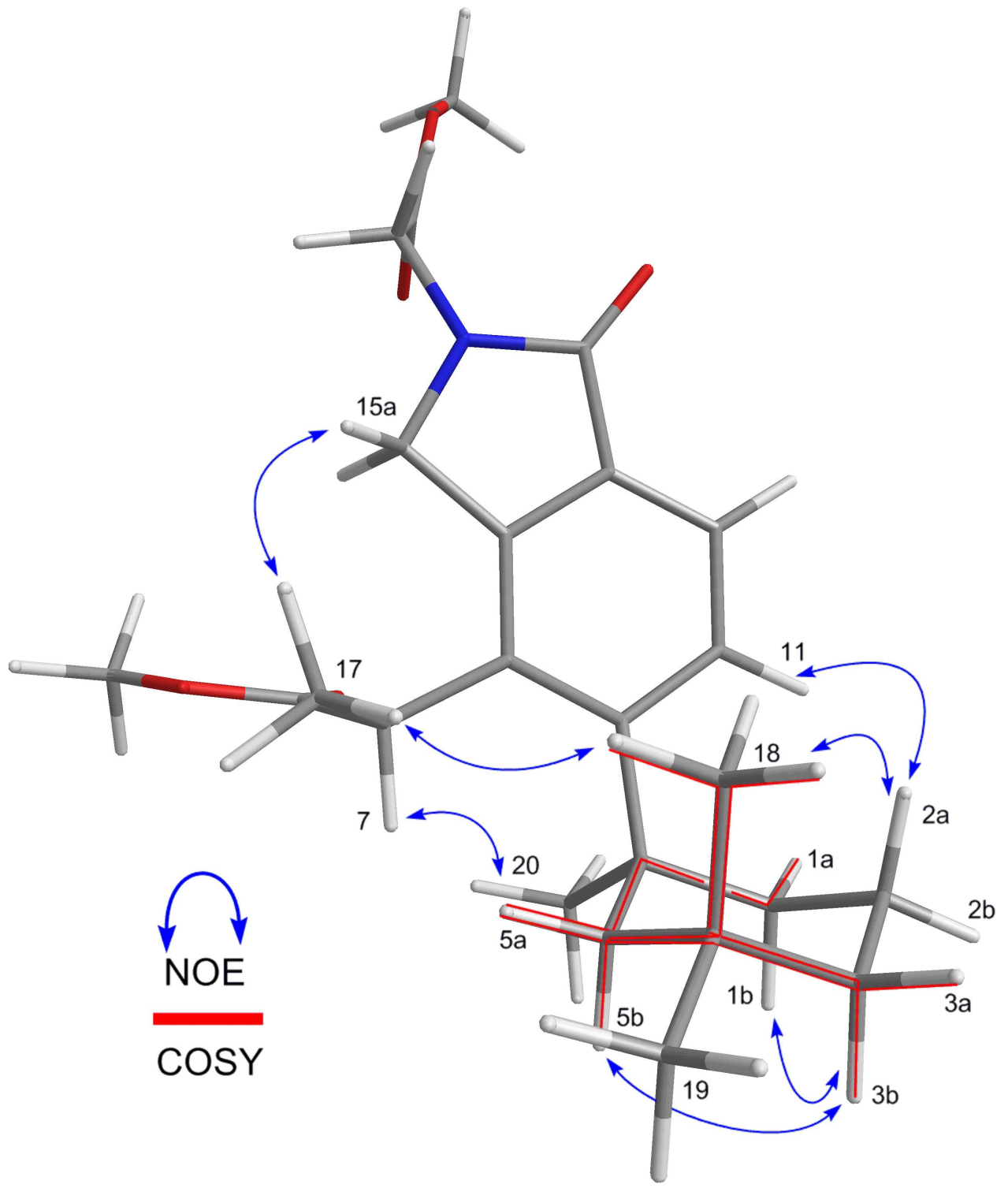

Figure 6.9. Key NOE enhancements of oxeatamide A dimethyl ester (218) establishing the relative configuration. W-coupling is shown in red. 
Table 6.1. NMR data $\left(600 \mathrm{MHz}, \mathrm{CDCl}_{3}\right)$ for oxeatamide A (214).

\begin{tabular}{|c|c|c|c|c|c|c|c|}
\hline pos. & $\begin{array}{l}\delta_{\mathrm{C}} / \delta_{\mathrm{N}} \\
(\mathrm{ppm})\end{array}$ & mult & $J_{\mathrm{CH}}$ & $\begin{array}{c}\delta_{\mathrm{H}} \\
(\mathrm{ppm})\end{array}$ & $\begin{array}{l}\text { mult, } \\
J(\mathrm{~Hz})\end{array}$ & COSY & $\mathrm{HMBC}$ \\
\hline $1 \mathrm{a}$ & 410 & & 127 & 2.31 & $\mathrm{~d}(13.9)$ & $1 \mathrm{~b}, 2 \mathrm{a}, 2 \mathrm{~b}, 5 \mathrm{a}$ & $10(2,5)$ \\
\hline $1 b$ & 41.0 & $\mathrm{H}_{2}$ & 127 & 1.44 & $\mathrm{dd}(14.2,2.7)$ & $1 \mathrm{a}, 2 \mathrm{a}, 2 \mathrm{~b}$ & $2,5,10$ \\
\hline $2 \mathrm{a}$ & & & 124 & 1.80 & $\mathrm{~m}$ & $1 \mathrm{a}, 1 \mathrm{~b}, 2 \mathrm{~b}, 3 \mathrm{a}, 3 \mathrm{~b}$ & $(1,3)$ \\
\hline $2 b$ & 20.1 & $\mathrm{CH}_{2}$ & 122 & 1.65 & $\mathrm{~m}$ & $1 \mathrm{a}, 1 \mathrm{~b}, 2 \mathrm{a}, 3 \mathrm{a}, 3 \mathrm{~b}$ & $1,3,4$ \\
\hline $3 \mathrm{a}$ & & & 125 & 1.32 & $\mathrm{dt}(12.8,3.6)$ & $2 \mathrm{a}, 2 \mathrm{~b}, 3 \mathrm{~b},(5 \mathrm{a})$ & $1,2,4,5,18,19$ \\
\hline $3 b$ & 39.8 & $\mathrm{CH}_{2}$ & 123 & 1.27 & $\operatorname{td}(12.6,3.9)$ & $2 \mathrm{a}, 2 \mathrm{~b}, 3 \mathrm{a}, 17$ & $1,2,4,5,18,19$ \\
\hline 4 & 31.9 & $\mathrm{C}$ & - & - & - & - & - \\
\hline $5 \mathrm{a}$ & & & 124 & 2.04 & d (13.9) & $1 \mathrm{a},(3 \mathrm{a}), 5 \mathrm{~b}$ & 1,10 or $3,10,4,(18)$ \\
\hline $5 b$ & 50.9 & $\mathrm{CH}_{2}$ & 120 & 1.49 & $\mathrm{~d}(14.2)$ & $5 \mathrm{a}, 18$ & $(1), 4,9,10,18,19$ \\
\hline 6 & 179.2 & $\mathrm{C}$ & - & - & - & - & - \\
\hline 7 & 40.9 & $\mathrm{CH}$ & 120 & 4.71 & $\mathrm{q}(7.2)$ & 17 & $6,8,9,(13), 14,17$ \\
\hline 8 & 135.2 & $\mathrm{C}$ & - & - & - & - & - \\
\hline 9 & 151.5 & $\mathrm{C}$ & - & - & - & - & - \\
\hline 10 & 39.8 & $\mathrm{C}$ & - & - & - & - & - \\
\hline 11 & 127.8 & $\mathrm{CH}$ & 159 & 7.58 & $\mathrm{~d}(8.1)$ & $12,(15 \mathrm{a})$ & $8,(9), 10,13,(14), 16$ \\
\hline 12 & 122.7 & $\mathrm{CH}$ & 160 & 7.63 & $\mathrm{~d}(8.1)$ & $11,(15 \mathrm{a})$ & $(8), 9,(11,13), 14,16$ \\
\hline 13 & 130.2 & $\mathrm{C}$ & - & - & - & - & - \\
\hline 14 & 142.0 & $\mathrm{C}$ & - & - & - & - & - \\
\hline $15 \mathrm{a}$ & 502 & & 142 & 4.40 & $\mathrm{~d}(16.5)$ & $(11,12), 15 b$ & $8,(9), 13,14,16,21$ \\
\hline $15 \mathrm{~b}$ & 50.2 & $\mathrm{CH}_{2}$ & 142 & 4.31 & $\mathrm{~d}(16.5)$ & $15 \mathrm{a}$ & $(8,13), 14,(16), 21$ \\
\hline 16 & 169.4 & $\mathrm{C}$ & - & - & - & - & - \\
\hline 17 & 15.5 & $\mathrm{CH}_{3}$ & 128 & 1.58 & $\mathrm{~d}(7.1)$ & 7 & $6,7,8$ \\
\hline 18 & 27.4 & $\mathrm{CH}_{3}$ & 124 & 0.40 & $\mathrm{~s}$ & $5 b, 19,(3 b)$ & $3,4,5,19$ \\
\hline 19 & 33.1 & $\mathrm{CH}_{3}$ & 125 & 0.91 & $\mathrm{~s}$ & 18 & $(2), 3,4,5,18$ \\
\hline 20 & 32.9 & $\mathrm{CH}_{3}$ & 126 & 1.40 & $\mathrm{~s}$ & - & $1,5,9,10$ \\
\hline 21 & -264.5 & $\mathrm{~N}$ & - & - & - & - & - \\
\hline $22 \mathrm{a}$ & 438 & & 140 & 4.77 & $\mathrm{~d}(18.1)$ & $22 \mathrm{~b}$ & $15,(16), 23$ \\
\hline $22 \mathrm{~b}$ & 43.8 & $\mathrm{H}_{2}$ & 140 & 3.97 & $\mathrm{~d}(18.1)$ & $22 \mathrm{a}$ & 16,23 \\
\hline 23 & 173.9 & $\mathrm{C}$ & - & - & - & - & - \\
\hline
\end{tabular}

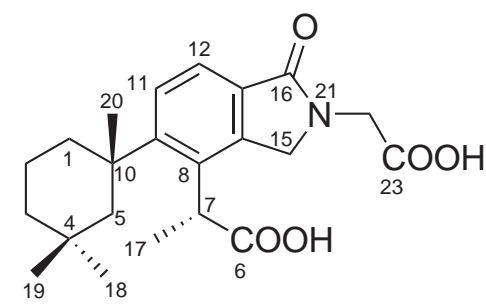

214 
Table 6.2. NMR data (600 MHz, $\mathrm{CDCl}_{3}$ ) for oxeatamide A dimethyl ester (218).

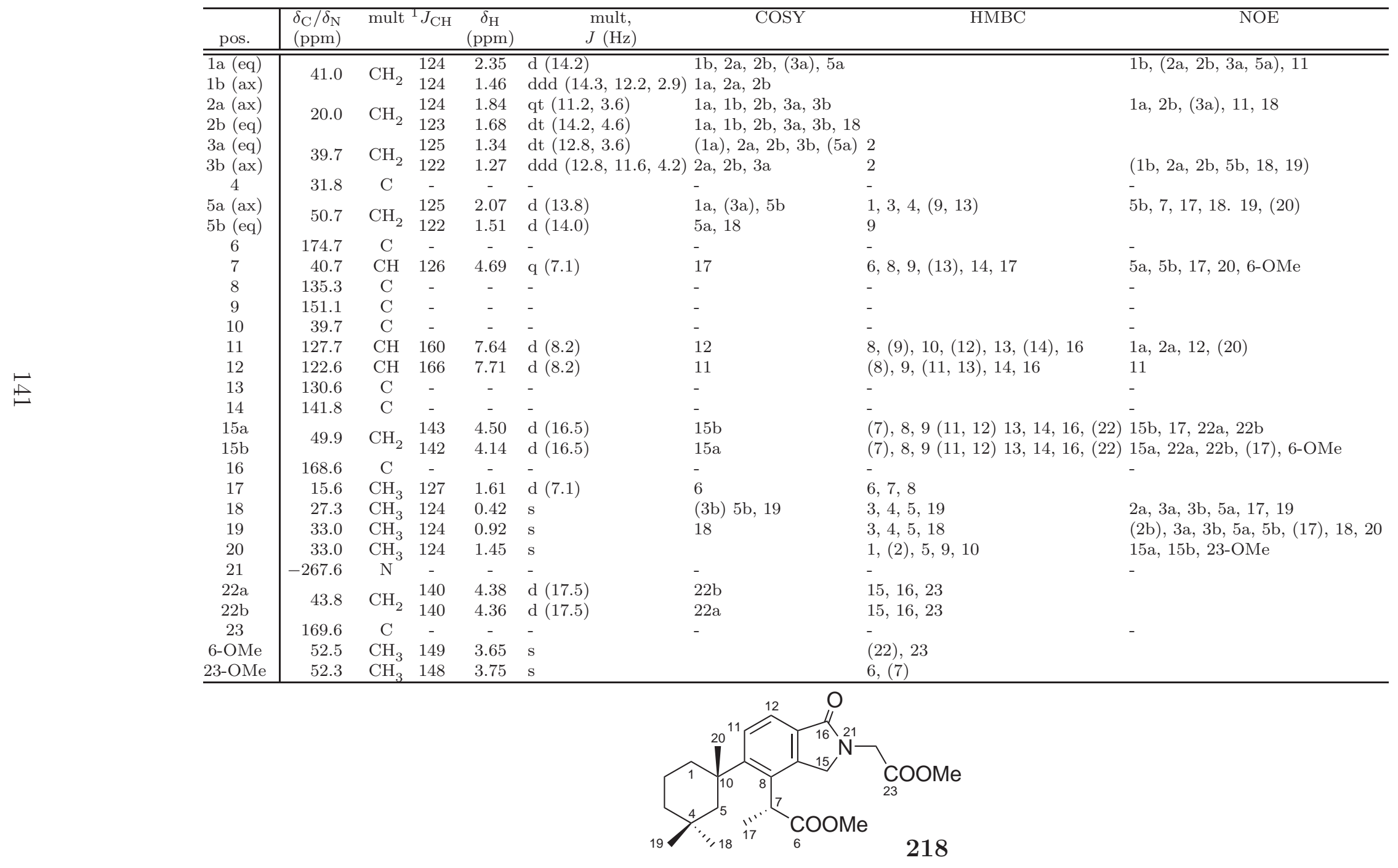




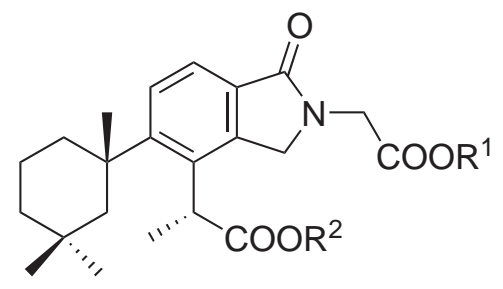

$$
\begin{array}{lll}
\mathbf{2 1 4} & \mathrm{R}^{1}=\mathrm{H} & \mathrm{R}^{2}=\mathrm{H} \\
\mathbf{2 1 8} & \mathrm{R}^{1}=\mathrm{Me} & \mathrm{R}^{2}=\mathrm{Me} \\
\mathbf{2 1 9} & \mathrm{R}^{1}=\mathrm{CH}_{2} \text { TMS } & \mathrm{R}^{2}=\mathrm{Me} \\
\mathbf{2 2 0} & \mathrm{R}^{1}=\mathrm{Me} & \mathrm{R}^{2}=\mathrm{CH}_{2} \text { TMS } \\
\mathbf{2 2 1} & \mathrm{R}^{1}=\mathrm{CH}_{2} \mathrm{TMS} & \mathrm{R}^{2}=\mathrm{CH}_{2} \text { TMS }
\end{array}
$$

\section{Methylation with trimethylsilydiazomethane}

Interestingly, examination of the NMR spectrum of the methylation reaction revealed the presence of three minor by-products in addition to the expected dimethyl ester derivative of oxeatamide A (218). After HPLC separation, the three compounds were analyzed by NMR spectroscopy.

The ${ }^{1} \mathrm{H}$ NMR spectrum of the first compound (Figure 6.10) had a new singlet at $0.05 \mathrm{ppm}$, a new OMe signal at $3.64 \mathrm{ppm}$ and two new AB doublets at 3.84 and $3.79 \mathrm{ppm}$. The ${ }^{1} \mathrm{H}$ spectrum of the second compound (Figure 6.11) was very similar, with a singlet at $-0.18 \mathrm{ppm}$, an OMe signal at $3.75 \mathrm{ppm}$, and two $\mathrm{AB}$ doublets at 3.71 and $3.75 \mathrm{ppm}$. The ${ }^{1} \mathrm{H}$ spectrum of the third compound (Figure 6.12) had both singlets at around $0 \mathrm{ppm}$, both $\mathrm{AB}$ doublet pairs and neither of the OMe signals. The upfield resonances integrated for nine protonsclearly they were TMS groups. The two AB doublets coupled to each other with a coupling constant of $14 \mathrm{~Hz}$, indicating they were a pair of methylene protons with unequal chemical shifts. Their chemical shift indicated they were attached to an oxygen. The OMe signals corresponded to one or the other of the $\mathrm{OMe}$ resonances of $\mathbf{2 1 8}$. These data suggested the three compounds were the 6 -methyl ester, 23-trimethylsilylmethyl ester derivative (219), the 6-trimethylsilymethyl ester, 23-methyl ester derivative (220), and 6,23-ditrimethylsilylmethyl ester derivative (221).

Methylation by diazomethane is independent of solvent, proceeding via the deprotonation of an acidic hydrogen by the diazomethane, and then $\mathrm{S}_{\mathrm{N}} 2$ attack by the carboxylate oxygen (see Scheme 6.1). ${ }^{149}$ This is not the case for $\mathrm{TMSCHN}_{2} \cdot{ }^{223}$ As can be seen in Scheme 6.2, the protic solvent participates in the reaction through attack on the silyl group, generating the resonance stabi- 


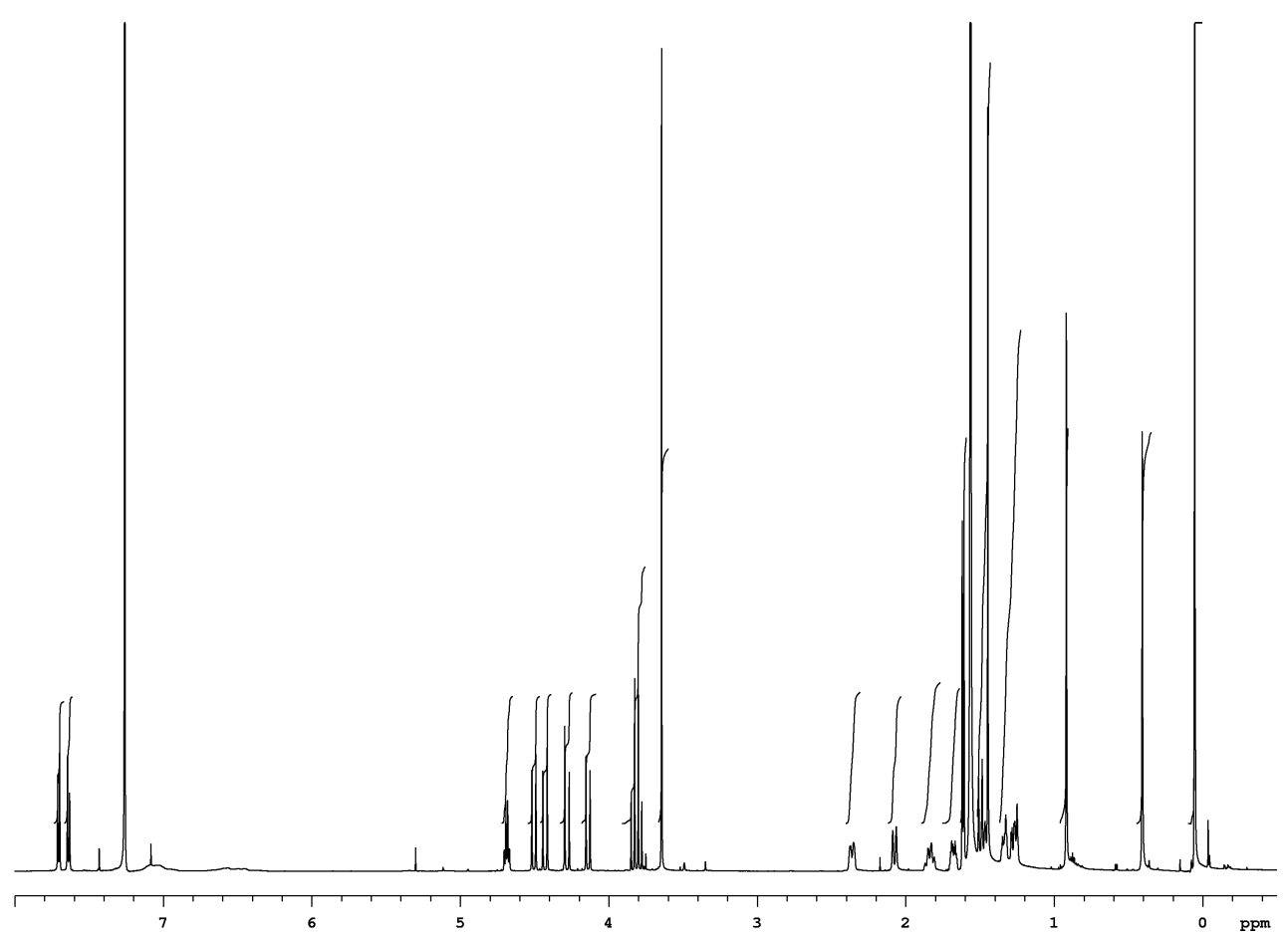

Figure 6.10. ${ }^{1} \mathrm{H}$ NMR spectrum $\left(600 \mathrm{MHz}, \mathrm{CDCl}_{3}\right)$ of oxeatamide A 6-methyl ester, 23-TMSmethyl ester (219).

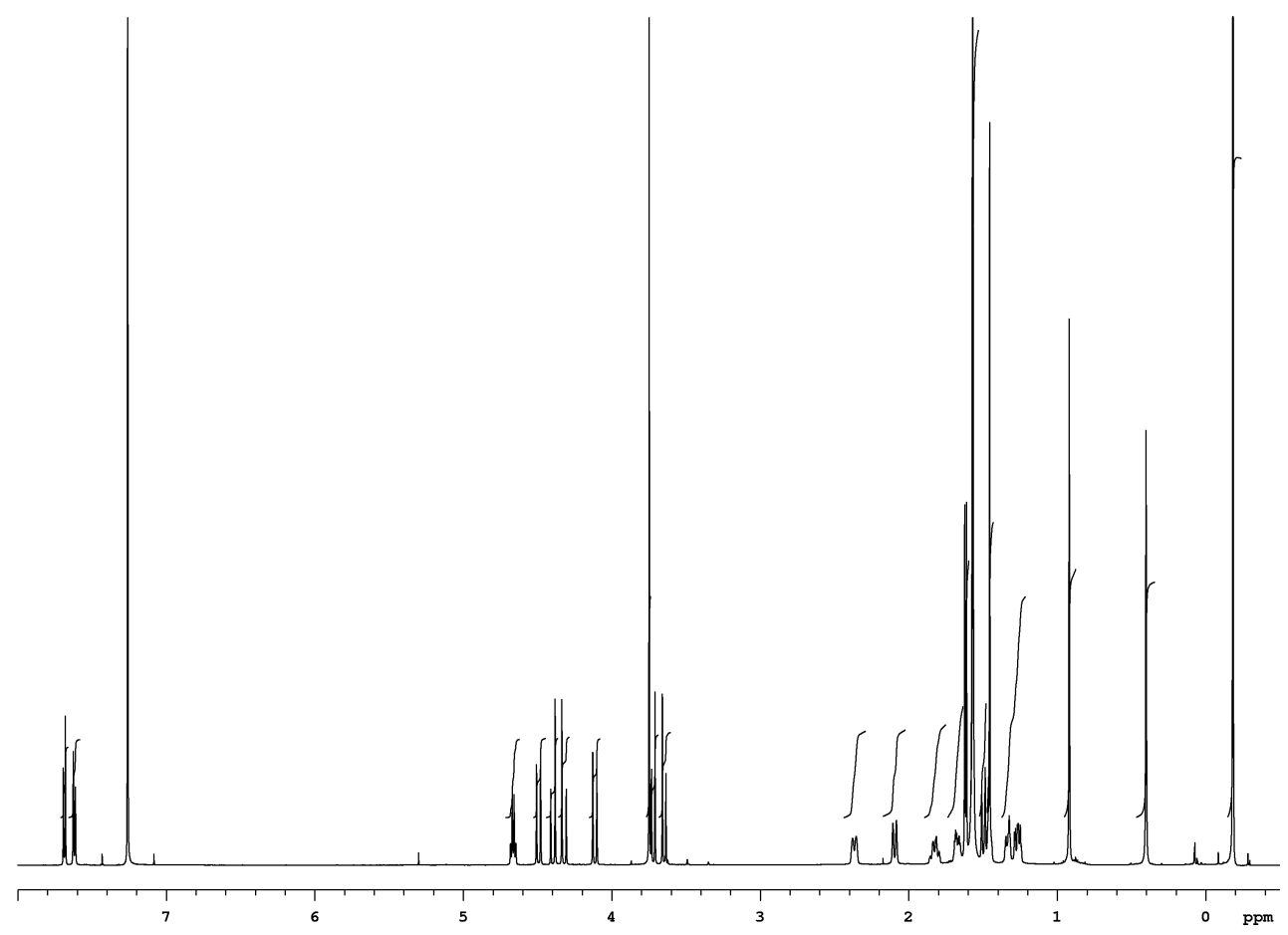

Figure 6.11. ${ }^{1} \mathrm{H}$ NMR spectrum $\left(600 \mathrm{MHz}, \mathrm{CDCl}_{3}\right)$ of oxeatamide A 6TMSmethyl, 23-methyl ester (220). 


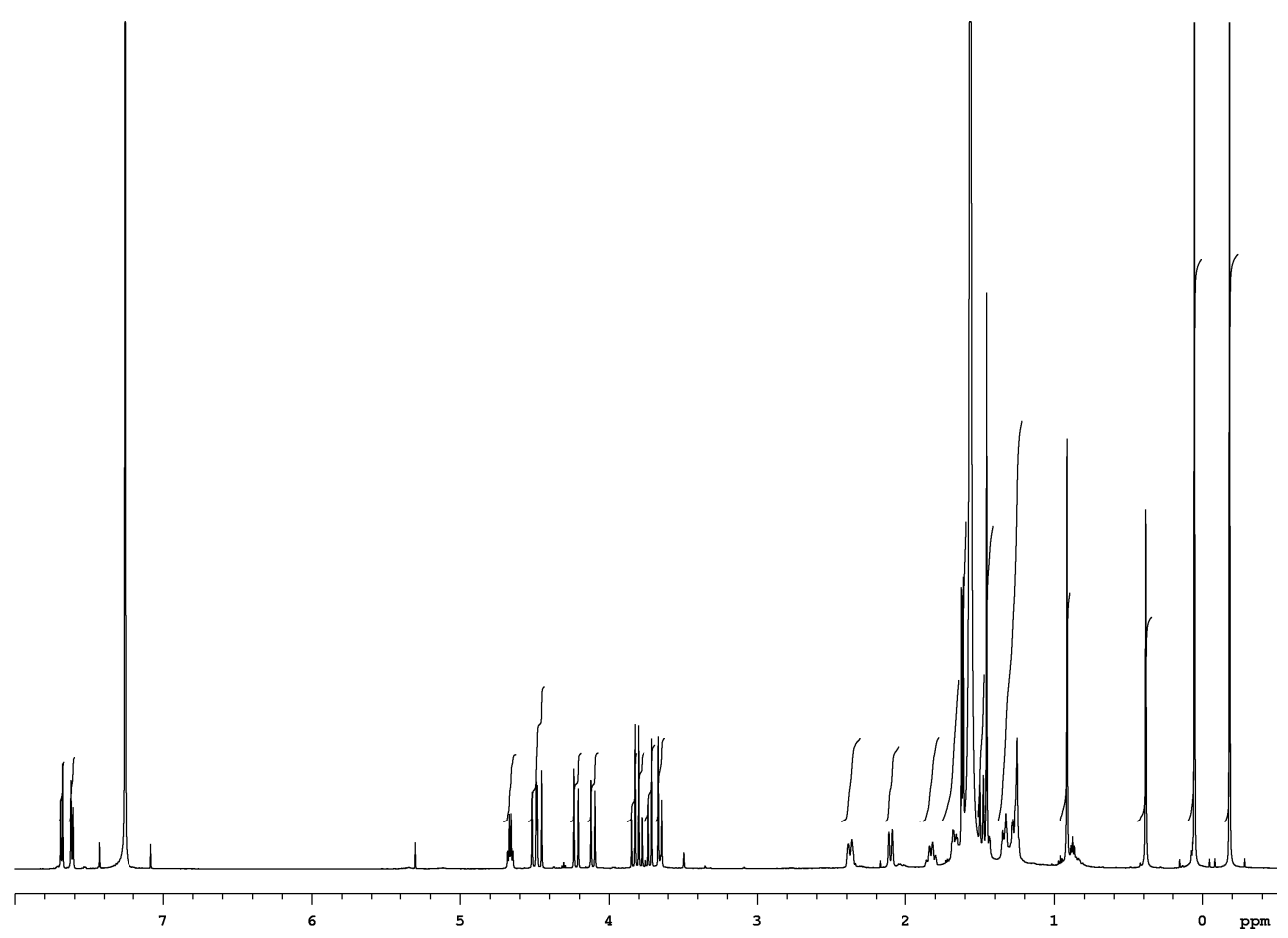

Figure 6.12. ${ }^{1} \mathrm{H}$ NMR spectrum $\left(600 \mathrm{MHz}, \mathrm{CDCl}_{3}\right)$ of oxeatmide $\mathrm{A}$ 6,23diTMSmethyl ester (221).

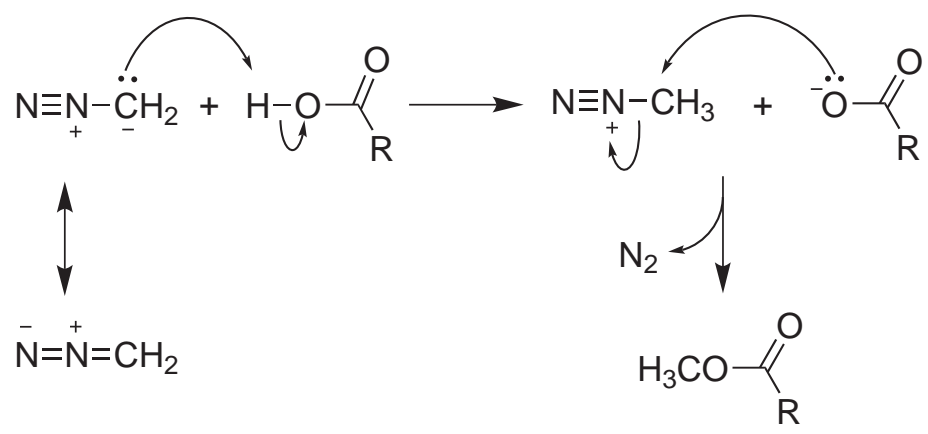

Scheme 6.1. Mechanism of carboxylic acid methylation with diazomethane.

lized diazomethane species in situ. The diazomethane then undergoes an $\mathrm{S}_{\mathrm{N}} 2$ attack by the carboxylate oxygen. The formation of 219-221 during the methylation reaction of oxeatamide $\mathrm{A}$ (which was done in dry $\mathrm{CH}_{2} \mathrm{Cl}_{2}$ ) confirms that methanol or a similar protic solvent is in fact essential to successfully displace the TMS group and to deliver the second proton equivalent. Without it, the TMS group remains, the $\mathrm{S}_{\mathrm{N}} 2$ attack by the carboxylate oxygen happens regardless, and the result is a TMSmethyl ester derivative instead of the expected methyl ester. 


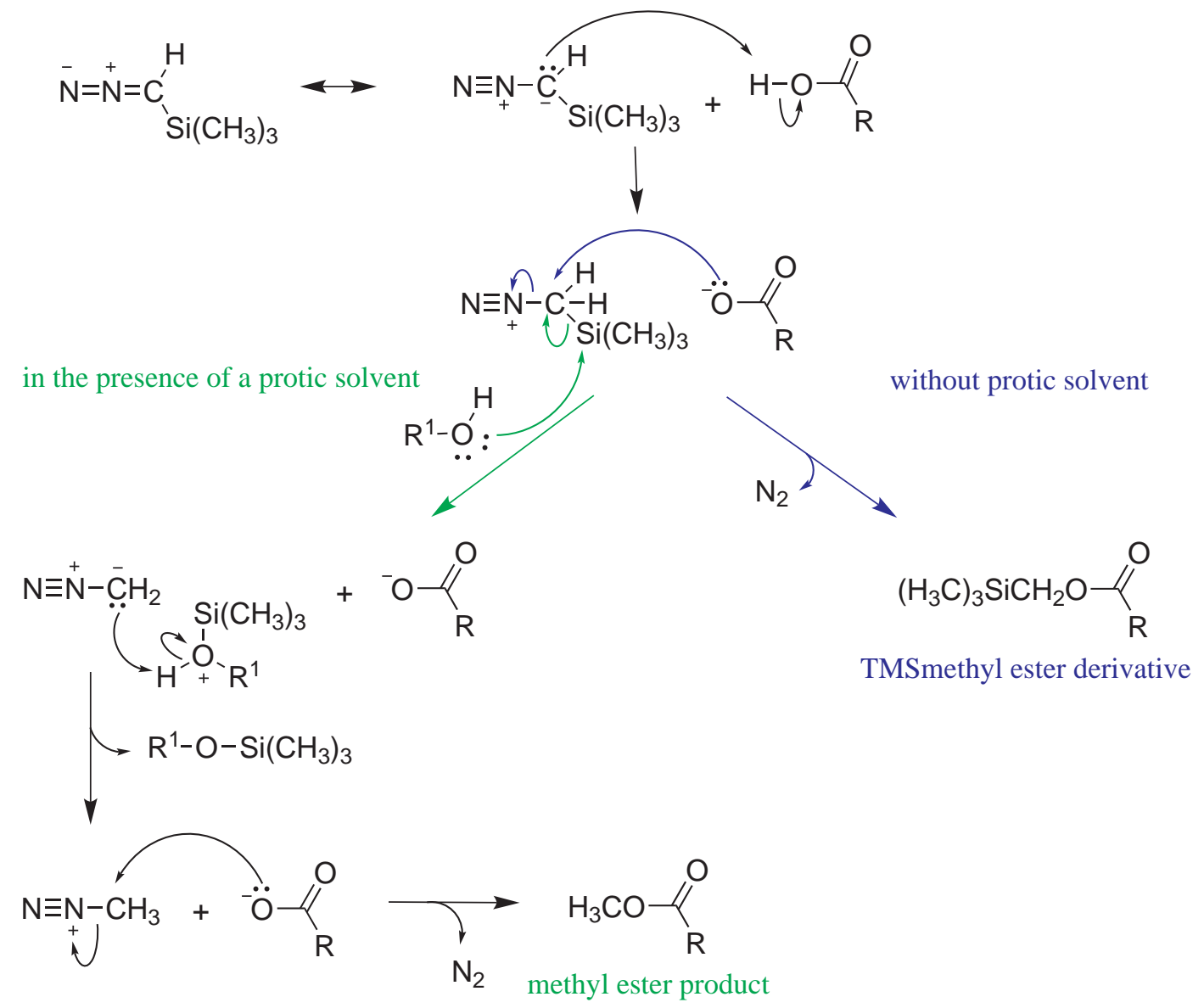

Scheme 6.2. Mechanism of carboxylic acid methylation with $\mathrm{TMSCHN}_{2}$, with or without a protic solvent present. 


\section{Structure elucidation of iso-oxeatamide A}

Two pseudomolecular ions observed by positive ion mode HRESIMS (388.2131 $\left.[\mathrm{M}+\mathrm{H}]^{+}, \Delta 1.8 \mathrm{ppm} ; 410.1949[\mathrm{M}+\mathrm{Na}]^{+}, \Delta 1.5 \mathrm{ppm}\right)$ indicated a molecular formula of $\mathrm{C}_{22} \mathrm{H}_{29} \mathrm{NO}_{5}$ for iso-oxeatamide $\mathrm{A}$ (215), suggesting it was a structural isomer of oxeatamide A (214). The NMR features of $\mathbf{2 1 5}$ were almost identical to that of 214, with three methyl singlets, six aromatic carbons, three carbonyls, and six methylenes apparent as before. The only significant differences were chemical shift changes of certain signals, for example the two aromatic protons (H-11 and H-12) now resonated at $\delta_{\mathrm{H}} 7.61$ and 7.23 (compared to $\delta_{\mathrm{H}} 7.58$ and 7.63 for 214 ), the methyl doublet $\left(\mathrm{H}_{3}-17\right)$ at $\delta_{\mathrm{H}} 1.77$ (compared to $\left.\delta_{\mathrm{H}} 1.58\right)$ and the methine quartet $(\mathrm{H}-7)$ at $\delta_{\mathrm{H}} 4.53$ (compared to $\delta_{\mathrm{H}} 4.71$ ).

A cyclohexane ring was established in a similar manner to that of oxeatamide A. COSY correlations between $\mathrm{H}_{2}-1\left(\delta_{\mathrm{C}} 41.1, \delta_{\mathrm{Ha}} 2.27, \delta_{\mathrm{Hb}} 1.42\right), \mathrm{H}_{2}-2$ $\left(\delta_{\mathrm{C}} 20.2, \delta_{\mathrm{Ha}} 1.80, \delta_{\mathrm{Hb}} 1.66\right)$, and $\mathrm{H}_{2}-3\left(\delta_{\mathrm{C}} 39.9, \delta_{\mathrm{Ha}} 1.31, \delta_{\mathrm{Hb}} 1.26\right)$ established the three contiguous methylenes. HMBC correlations from $\mathrm{H}_{3}-18\left(\delta_{\mathrm{C}} 27.3, \delta_{\mathrm{H}} 0.43\right)$ and $\mathrm{H}_{3}-19\left(\delta_{\mathrm{C}} 33.1, \delta_{\mathrm{H}} 0.91\right)$ to each other as well as to $\mathrm{C}-3, \mathrm{C}-4\left(\delta_{\mathrm{C}} 31.9\right), \mathrm{C}-5$ $\left(\delta_{\mathrm{C}} 51.0, \delta_{\mathrm{Ha}} 2.10, \delta_{\mathrm{Hb}} 1.49\right)$ established the gem-dimethyl moiety. The rest of the cyclohexane ring was put together through further HMBC correlations from $\mathrm{H}_{3}-20\left(\delta_{\mathrm{C}} 33.1, \delta_{\mathrm{H}} 1.32\right)$ to $\mathrm{C}-1, \mathrm{C}-10\left(\delta_{\mathrm{C}} 39.4\right)$ and $\mathrm{C}-5$.

Once again, the two aromatic methines $\left(\mathrm{CH}-11: \delta_{\mathrm{C}} 130.4, \delta_{\mathrm{H}} 7.61 ; \mathrm{CH}-12\right.$ : $\left.\delta_{\mathrm{C}} 121.4, \delta_{\mathrm{H}} 7.23\right)$ displayed a large ortho coupling $(8.3 \mathrm{~Hz})$, placing them next to each other. An HMBC correlation from $\mathrm{H}_{3}-20$ to the aromatic carbon C$9\left(\delta_{\mathrm{C}} 146.8\right)$ and from $\mathrm{H}-11$ to the quaternary alkyl carbon $\mathrm{C}-10$ placed the cyclohexane ring ortho to $\mathrm{CH}-11$, as before. The methyl doublet $\mathrm{H}_{3}-17\left(\delta_{\mathrm{C}} 18.3\right.$, $\left.\delta_{\mathrm{H}} 1.77\right)$ showed a COSY correlation to $\mathrm{H}-7\left(\delta_{\mathrm{C}} 40.6, \delta_{\mathrm{H}} 4.53\right)$, and HMBC correlations to $\mathrm{C}-6\left(\delta_{\mathrm{C}} 181.0\right), \mathrm{C}-7$, and the aromatic carbon $\delta_{\mathrm{C}} 139.4$ (assigned as C-8) suggesting the carboxylic acid functionality was also conserved.

All aromatic positions showed chemical shift differences from those of oxeatamide A (214), suggesting the structural difference was located nearby. The aromatic carbons were assigned on the basis of HMBC correlations from H-11 and H-12. Strong (three bond) correlations from H-11 were observed to C-8 and C-13. H-12 showed weak (two bond) correlations to C-8 and C-13, and a strong correlation to C-9, supporting their assignment. Position C-14 $\left(\delta_{\mathrm{C}} 130.4\right)$ was assigned based on a strong HMBC correlation from H-12.

So far, the connectivity of iso-oxeatamide A (215) was identical to that of oxeatamide A (214). Instead of $\mathrm{H}-11$ and $\mathrm{H}-12$ showing correlations to a carbonyl resonance (the amide carbonyl carbon of oxeatamide A), however, they corre- 


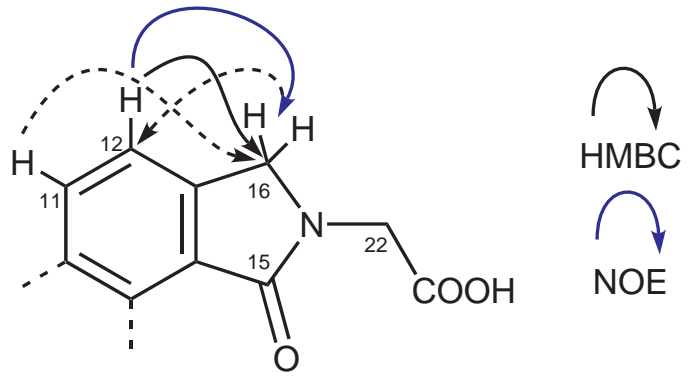

Figure 6.13. Key HMBC correlations and NOE enhancements establishing the lactam orientation of iso-oxeatamide A (215).

lated to the methylene carbon which was therefore assigned as $\mathrm{CH}_{2}-16\left(\delta_{\mathrm{C}} 49.8\right.$, $\left.\delta_{\mathrm{Ha}} 4.37, \delta_{\mathrm{Hb}} 4.28\right)$. Both proton resonances of $\mathrm{CH}_{2}-16$ showed weak HMBC correlations to C-12 (whereas before they had correlated to C-8), supporting this assignment.

The remainder of the molecule remained the same: the ${ }^{1} J_{\mathrm{CH}}$ of $\mathrm{CH}_{2}-16$ was once again large, (142 and $144 \mathrm{~Hz}$ ), suggesting attachment to the nitrogen, and both $\mathrm{H}-16 \mathrm{a}$ and $\mathrm{H}-16 \mathrm{~b}$ showed correlations to $\delta_{\mathrm{C}} 170.0$, now assigned as C-15, implying the amide linkage was still there. HMBC correlations from the other methylene $\mathrm{CH}_{2}-22\left(\delta_{\mathrm{C}} 44.5, \delta_{\mathrm{Ha}} 4.78, \delta_{\mathrm{Hb}} 3.75\right)$, to C-15, C-16 (weakly) and the last carbonyl C-23 $\left(\delta_{\mathrm{C}} 175.3\right)$ established the presence of the $N$-linked glycine residue, as before.

Iso-oxeatamide A (215) is an isomer of oxeatamide A, with the amide functionality in opposite orientation causing perceptable chemical shift differences for CH-12, CH-7 and $\mathrm{CH}_{3}-17$. Final confirmation of this assignment was obtained from a weak but clearly perceptable NOE enhancement from H-12 to H-16a and H-16b (see Figure 6.13).

As with oxeatamide A, coupling constants and long-range W-couplings observed in the COSY spectrum indicated the cyclohexane ring was again in the same chair conformation with the aromatic ring axial. Although the NOEs observed for $\mathbf{2 1 5}$ were once again negative, no inter-molecular enhancements were apparent (perhaps due to a dilution effect). The NOE enhancements were consistent with the relative configuration of $7 R^{*}, 10 S^{*}$ and so iso-oxeatamide A can be assigned with some assurity as $\mathbf{2 1 5}$. Full NMR data for $\mathbf{2 1 5}$ are presented in Table 6.3. 
Table 6.3. NMR data (600 MHz, $\left.\mathrm{CDCl}_{3}\right)$ for iso-oxeatamide $\mathrm{A}(\mathbf{2 1 5})$.

\begin{tabular}{|c|c|c|c|c|c|c|c|c|}
\hline pos. & $\begin{array}{l}\delta_{\mathrm{C}} / \delta_{\mathrm{N}} \\
(\mathrm{ppm}) \\
\end{array}$ & mult & $J_{\mathrm{CH}}$ & $\begin{array}{c}\delta_{\mathrm{H}} \\
(\mathrm{ppm}) \\
\end{array}$ & $\begin{array}{l}\text { mult, } \\
J(\mathrm{~Hz})\end{array}$ & COSY & $\overline{\mathrm{HMBC}}$ & $\mathrm{NOE}$ \\
\hline $1 \mathrm{a}$ & 411 & & 126 & 2.27 & $\mathrm{~d}(14.8)$ & $1 \mathrm{~b}, 2 \mathrm{~b},(5 \mathrm{a})$ & $(10)$ & $\overline{1 \mathrm{~b}, 11}$ \\
\hline $1 b$ & 41.1 & $\mathrm{H}_{2}$ & 122 & 1.42 & $\mathrm{~m}$ & $1 \mathrm{a}, 2 \mathrm{a},(2 \mathrm{~b})$ & $(2,3,5,10)$ & $1 \mathrm{a}$ \\
\hline $2 \mathrm{a}$ & & & 124 & 1.80 & $\mathrm{~m}$ & $1 \mathrm{~b}, 2 \mathrm{~b}, 3 \mathrm{a}, 3 \mathrm{~b}$ & & 11 \\
\hline $2 \mathrm{~b}$ & 20.2 & $\mathrm{CH}_{2}$ & 124 & 1.66 & $\mathrm{dd}(10.0,7.3)$ & $1 \mathrm{a},(1 \mathrm{~b}), 2 \mathrm{a}$ & $1,3,4,(10)$ & \\
\hline $3 a$ & & & 126 & 1.31 & $\mathrm{~m}$ & $2 b, 3 b$ & $2,4,18,(19)$ & \\
\hline $3 b$ & 39.9 & $\mathrm{CH}_{2}$ & 124 & 1.26 & $\operatorname{td}(11.3,3.8)$ & $2 \mathrm{a}, 3 \mathrm{a},(18)$ & $1,2,4,18,(19)$ & \\
\hline 4 & 31.9 & $\mathrm{C}$ & - & - & - & - & - & - \\
\hline $5 \mathrm{a}$ & & & 124 & 2.10 & $\mathrm{~d}(13.9)$ & $(1 \mathrm{a}), 5 \mathrm{~b}$ & $1,3,10,20$ & $5 \mathrm{~b}, 718$ \\
\hline $5 b$ & 51.0 & $\mathrm{CH}_{2}$ & 122 & 1.49 & $\mathrm{~d}(14.2)$ & $5 \mathrm{a},(18)$ & $1,4,9,10,18,19$ & $5 \mathrm{a}, 7$ \\
\hline 6 & 181.0 & $\mathrm{C}$ & - & - & - & - & - & - \\
\hline 7 & 40.6 & $\mathrm{CH}$ & 115 & 4.53 & $\mathrm{q}(6.8)$ & 17 & $6,8,9,14,17$ & $5 \mathrm{a}, 5 \mathrm{~b}, 17,20$ \\
\hline 8 & 139.4 & $\mathrm{C}$ & - & - & - & - & - & - \\
\hline 9 & 146.8 & $\mathrm{C}$ & - & - & - & - & - & - \\
\hline 10 & 39.4 & $\mathrm{C}$ & - & - & - & - & - & - \\
\hline 11 & 130.4 & $\mathrm{CH}$ & 158 & 7.61 & $\mathrm{~d}(8.3)$ & 12 & $(1), 8,10,14,(16)$ & $1 \mathrm{a}, 2 \mathrm{~b}, 12$ \\
\hline 12 & 121.4 & $\mathrm{CH}$ & 166 & 7.23 & $\mathrm{~d}(8.2)$ & 11 & 16 & 12 \\
\hline 13 & 140.9 & $\mathrm{C}$ & - & - & - & - & - & - \\
\hline 14 & 130.4 & $\mathrm{C}$ & - & - & - & - & - & - \\
\hline 15 & 170.0 & $\mathrm{C}$ & - & - & - & - & - & - \\
\hline $16 \mathrm{a}$ & 498 & & 144 & 4.37 & $\mathrm{~d}(16.0)$ & $16 \mathrm{~b}$ & $(12), 13,14,(15)$ & $16 \mathrm{~b}$ \\
\hline $16 b$ & 49.8 & $\mathrm{CH}_{2}$ & 142 & 4.28 & $\mathrm{~d}(16.0)$ & $16 a$ & $(9,12), 13,14,15$ & $16 \mathrm{a}$ \\
\hline 17 & 18.3 & $\mathrm{CH}_{3}$ & 127 & 1.77 & $\mathrm{~d}(6.8)$ & 7 & 7,8 & 7,18 \\
\hline 18 & 27.3 & $\mathrm{CH}_{3}$ & 123 & 0.43 & $\mathrm{~s}$ & $(3 \mathrm{~b}, 5 \mathrm{a})$ & $3,4,5,19$ & $5 \mathrm{a}, 17,19$ \\
\hline 19 & 33.1 & $\mathrm{CH}_{3}$ & 124 & 0.91 & $\mathrm{~s}$ & $(5 \mathrm{a})$ & $3,4,5,18$ & $3 \mathrm{~b}, 5 \mathrm{~b}, 18$ \\
\hline 20 & 33.1 & $\mathrm{CH}_{3}$ & 127 & 1.32 & $\mathrm{~s}$ & & $1,5,9,10$ & 7 \\
\hline 21 & $a$ & $\mathrm{~N}^{\mathrm{J}}$ & - & - & - & - & - & - \\
\hline $22 \mathrm{a}$ & 445 & & 140 & 4.78 & $\mathrm{~d}(17.5)$ & $22 \mathrm{~b}$ & & $22 \mathrm{~b}$ \\
\hline $22 b$ & 44.5 & $\mathrm{CH}_{2}$ & 139 & 3.75 & $\mathrm{~d}(18.3)$ & $22 \mathrm{a}$ & 15,23 & $22 \mathrm{a}$ \\
\hline 23 & 175.3 & $\mathrm{C}$ & - & - & - & - & - & - \\
\hline
\end{tabular}

${ }^{a}$ not observed

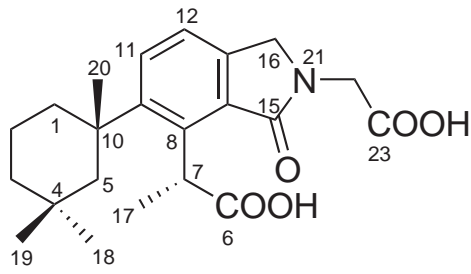

215 


\section{Structure elucidation of oxeatamide A 23-methyl ester}

Positive-ion mode HRESIMS analysis of oxeatamide A 23 methyl ester (216) gave rise to pseudomolecular ions indicative of a molecular formula of $\mathrm{C}_{23} \mathrm{H}_{31} \mathrm{NO}_{5}$ $\left(402.2289[\mathrm{M}+\mathrm{H}]^{+}, \Delta 2.2 \mathrm{ppm} ; 424.2112[\mathrm{M}+\mathrm{Na}]^{+}, \Delta 2.8 \mathrm{ppm}\right)$. Once again, the NMR spectra of $\mathbf{2 1 6}$ were very similar to oxeatamide A (214); the immediately obvious difference was the presence of a new OMe resonance at $\delta_{\mathrm{C}} 53.5, \delta_{\mathrm{H}} 3.73$. The proposed molecular formula differs by $14 \mathrm{Da}$ from that of $\mathbf{2 1 4}$, and can be accounted for by the additional oxymethyl.

In addition, the ${ }^{1} \mathrm{H}$ chemical shifts of the $\mathrm{H}_{2}-22$ methylene pair had converged. In oxeatamide $\mathrm{A}$, the $\mathrm{H}_{2}-22$ pair is 0.80 ppm apart; in $\mathbf{2 1 6}$ they are an $\mathrm{AB}$ pair of doublets separated by only $0.04 \mathrm{ppm}$. This sort of behaviour was seen previously in oxeatamide A dimethyl ester (218), where $\mathrm{H}-22 \mathrm{a}$ is only $0.02 \mathrm{ppm}$ away from $\mathrm{H}-22 \mathrm{~b}$.

A very small (or no) chemical shift difference between the methylene protons is to be expected if there is free rotation around the N-21/C-22 bond. The very large difference observed for $\mathbf{2 1 4}$ is therefore highly unusual. It can be explained by the dimerization of the C-23 carboxylic acid which would effectively stop free rotation, placing $\mathrm{H}-22 \mathrm{a}$ and $\mathrm{H}-22 \mathrm{~b}$ in very different environments. Methylation of the acid disrupts this effect, as was seen for 218. These data suggested that 216 is the 23-methyl ester of oxeatamide A.

The majority of the molecule was identical to oxeatamide A, and was established through a series of COSY and HMBC correlations, detailed in Table 6.4. HMBC correlations from H-11 and H-12 to C-16, from H-15a to C-8, and the almost identical chemical shifts of the molecule suggested the orientation of the amide was as for 214, shown in Figure 6.14.

$\mathrm{CH}_{2}-22$ showed HMBC correlations to the amide carbonyl C-16, the methylene $\mathrm{C}-15$ carbon, and a third carbonyl, C-23 ( $\left.\delta_{\mathrm{C}} 169.8\right)$. C-23 was further upfield than in oxeatamide $\mathrm{A}\left(\delta_{\mathrm{C}} 173.9\right)$, consistent with esterification. The new $\mathrm{OMe}$ resonance showed a strong HMBC correlation to C-23, confirming the structure as oxeatamide A 23-methyl ester (216).

Compound 216 has nearly identical ${ }^{1} \mathrm{H}$ and ${ }^{13} \mathrm{C}$ chemical shifts to oxeatamide A (214) as well as similar (positive) NOE enhancements to oxeatamide A dimethyl ester (218), consistent once again with the relative configuration of $7 R^{*}, 10 S^{*}$, as was established above. The final structure, therefore, is assigned as oxeatamide A 23-methyl ester (216), with full NMR data presented in Table 6.4 . 

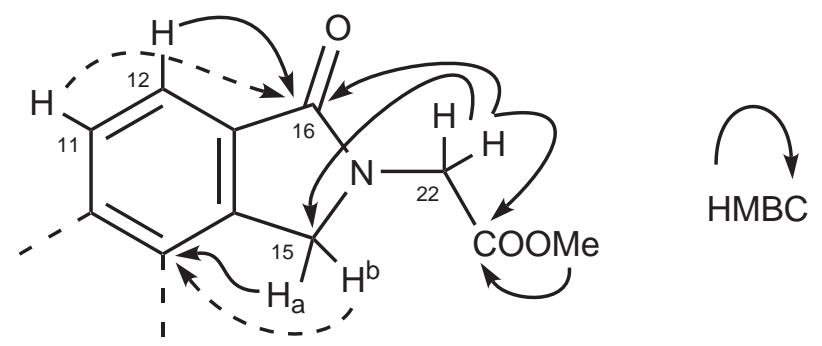

Figure 6.14. Key HMBC correlations establishing the orientation of the lactam moiety and the methyl ester of oxeatamide A 23-methyl ester (216).

Table 6.4. NMR data $\left(600 \mathrm{MHz}, \mathrm{CDCl}_{3}\right)$ for oxeatamide A 23-methyl ester (216).

\begin{tabular}{|c|c|c|c|c|c|c|c|c|}
\hline pos. & $\begin{array}{l}\delta_{\mathrm{C}} / \delta_{\mathrm{N}} \\
(\mathrm{ppm})\end{array}$ & mult & ${ }^{1} J_{\mathrm{CH}}$ & $\begin{array}{c}\delta_{\mathrm{H}} \\
(\mathrm{ppm}) \\
\end{array}$ & $\begin{array}{l}\text { mult, } \\
J(\mathrm{~Hz})\end{array}$ & COSY & HMBC & $\mathrm{NOE}$ \\
\hline $1 \mathrm{a}$ & \multirow{2}{*}{41.1} & \multirow{2}{*}{$\mathrm{CH} 2$} & 126 & 2.36 & $\mathrm{~d}(13.7)$ & \multicolumn{2}{|l|}{$1 \mathrm{~b},(2 \mathrm{a}), 2 \mathrm{~b},(5 \mathrm{a})$} & $1 \mathrm{~b}, 11$ \\
\hline $1 b$ & & & 123 & 1.47 & $\mathrm{~m}$ & \multicolumn{2}{|l|}{$1 \mathrm{a}, 2 \mathrm{a}, 2 \mathrm{~b}$} & $1 \mathrm{a},(11)$ \\
\hline $2 \mathrm{a}$ & \multirow{2}{*}{20.1} & \multirow{2}{*}{$\mathrm{CH}_{2}$} & 125 & 1.83 & $\mathrm{~m}$ & \multicolumn{2}{|l|}{$1 a, 1 b, 2 b, 3 a, 3 b$} & 11,18 \\
\hline $2 \mathrm{~b}$ & & & 123 & 1.68 & $\mathrm{~m}$ & \multicolumn{2}{|l|}{$1 \mathrm{a}, 1 \mathrm{~b}, 2 \mathrm{a}, 3 \mathrm{a}, 3 \mathrm{~b}$} & \\
\hline $3 a$ & \multirow{2}{*}{39.9} & \multirow{2}{*}{$\mathrm{CH}_{2}$} & 126 & 1.34 & $\mathrm{dt}(12.8,4.1)$ & $2 \mathrm{a}, 2 \mathrm{~b}, 3 \mathrm{~b},(5 \mathrm{a})$ & $4,(5)$ & 18 \\
\hline $3 \mathrm{~b}$ & & & 123 & 1.28 & $\operatorname{td}(12.3,3.9)$ & $2 \mathrm{a}, 2 \mathrm{~b}, 3 \mathrm{a}$ & $1,2,4,18$ & 19 \\
\hline 4 & 31.9 & $\mathrm{C}$ & - & - & - & - & - & - \\
\hline $5 \mathrm{a}$ & \multirow{2}{*}{50.9} & \multirow{2}{*}{$\mathrm{CH}_{2}$} & 124 & 2.07 & d (13.8) & $(1 \mathrm{a}, 3 \mathrm{a}), 5 \mathrm{~b}$ & $1,4,10$ & $5 \mathrm{~b}, 7,18,19$ \\
\hline $5 \mathrm{~b}$ & & & 123 & 1.51 & $\mathrm{~d}(14.2)$ & $5 \mathrm{a},(18)$ & $(1), 4,9,10,18$ & $5 \mathrm{a}, 19$ \\
\hline 6 & 175.4 & $\mathrm{C}$ & - & - & - & - & - & - \\
\hline 7 & 40.6 & $\mathrm{CH}$ & 120 & 4.74 & $\mathrm{q}(7.5)$ & 17 & $6,8,9,14,17$ & $5 \mathrm{a}, 17,10$ \\
\hline 8 & 134.7 & $\mathrm{C}$ & - & - & - & - & - & - \\
\hline 9 & 151.1 & $\mathrm{C}$ & - & - & - & - & - & - \\
\hline 10 & 39.8 & $\mathrm{C}$ & - & - & - & - & - & - \\
\hline 11 & 127.8 & $\mathrm{CH}$ & 161 & 7.64 & $\mathrm{~d}(8.3)$ & 12 & $8,(9), 10,13,(14,16)$ & $1 \mathrm{a},(1 \mathrm{~b}), 2 \mathrm{a}, 12$ \\
\hline 12 & 122.8 & $\mathrm{CH}$ & 164 & 7.71 & $\mathrm{~d}(8.3)$ & 11 & $(8), 9,14,16$ & 11 \\
\hline 13 & 130.7 & $\mathrm{C}$ & - & - & - & - & - & - \\
\hline 14 & 142.0 & $\mathrm{C}$ & - & - & - & - & - & - \\
\hline $15 \mathrm{a}$ & \multirow{2}{*}{50.1} & \multirow{2}{*}{$\mathrm{CH}_{2}$} & 142 & 4.53 & $\mathrm{~d}(16.3)$ & $15 b$ & $(8,13), 14,16$ & $15 \mathrm{~b}, 17$ \\
\hline $15 \mathrm{~b}$ & & & 141 & 4.33 & $\mathrm{~d}(16.3)$ & $15 \mathrm{a}$ & $8,13), 14,16$ & $15 \mathrm{a}$ \\
\hline 16 & 168.6 & $\mathrm{C}$ & - & - & - & - & - & - \\
\hline 17 & 15.6 & $\mathrm{CH}_{3}$ & 129 & 1.62 & $\mathrm{~d}(7.0)$ & 7 & $6,7,8$ & $7,15 \mathrm{a}, 18$ \\
\hline 18 & 27.4 & $\mathrm{CH}_{3}$ & 123 & 0.41 & $\mathrm{~s}$ & $(5 b), 19$ & $(1), 4,5,10,19$ & $2 \mathrm{a}, 3 \mathrm{a}, 5 \mathrm{a}, 17,19$ \\
\hline 19 & 33.1 & $\mathrm{CH}_{3}$ & 122 & 0.92 & $\mathrm{~s}$ & 18 & $(1), 4,5,10,18$ & $3 \mathrm{~b}, 5 \mathrm{a}, 5 \mathrm{~b}, 18$ \\
\hline 20 & 33.0 & $\mathrm{CH}_{3}$ & 128 & 1.46 & $\mathrm{~s}$ & & $1,5,9,10$ & 7 \\
\hline 21 & $a$ & $\mathrm{~N}$ & - & - & - & - & - & - \\
\hline $22 \mathrm{a}$ & \multirow{2}{*}{43.6} & \multirow{2}{*}{$\mathrm{CH}_{2}$} & 140 & 4.39 & $\mathrm{~d}(17.7)$ & $22 \mathrm{~b}$ & $15,16,23$ & \\
\hline $22 \mathrm{~b}$ & & & 140 & 4.35 & d (17.6) & $22 \mathrm{a}$ & $15,16,23$ & \\
\hline 23 & 169.8 & $\mathrm{C}$ & - & - & - & - & - & - \\
\hline 23-OMe & 52.5 & $\mathrm{CH}_{3}$ & 148 & 3.73 & $\mathrm{~s}$ & & 23 & \\
\hline
\end{tabular}

${ }^{a}$ not observed<smiles>CC(=O)CN1Cc2c(ccc3c2[C@H](C(=O)O)[C@H](C)C3(C)C)C1=O</smiles> 

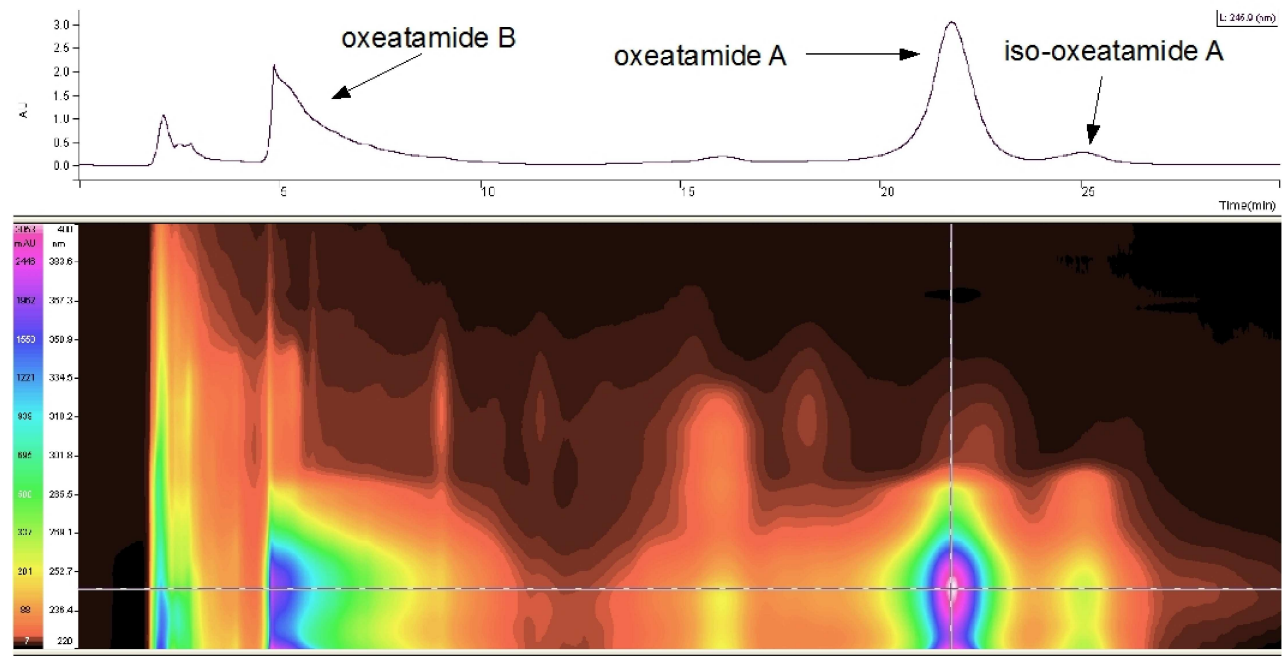

Figure 6.15. Diode array trace from the HPLC separation of the oxeatamides.

\section{Structure elucidation of oxeatamide B}

Oxeatamide B (217) eluted quite early off the reversed-phase HPLC column, streaking over several minutes (as can be seen in Figure 6.15). This immediately indicated a significant difference somewhere in its structure, perhaps a basic group that was charged under the acidic conditions of the HPLC. Compound 217 was sparingly soluble in $\mathrm{CDCl}_{3}$, showing several new, broadened resonances (Figure 6.16).

A pseudomolecular ion was observed by positive ion mode HRESIMS indicating a molecular formula of $\mathrm{C}_{25} \mathrm{H}_{34} \mathrm{~N}_{3} \mathrm{O}_{3}$ for oxeatamide $\mathrm{B}$ (217) (424.2585 $\left.[\mathrm{M}+\mathrm{H}]^{+}, \Delta 1.7 \mathrm{ppm}\right)$, requiring 11 double bond equivalents. Inspection of the ${ }^{13} \mathrm{C}$ spectrum revealed the presence of only 24 carbons, two of them (in the aromatic region) highly broadened. Suspecting some sort of solubility issue, the solvent was changed to DMSO- $\mathrm{d}_{6}$, resulting in a significant sharpening of the ${ }^{1} \mathrm{H}$ resonances, as can be seen in Figure 6.17. The ${ }^{13} \mathrm{C}$ NMR spectrum still showed two broadened resonances, but all 25 carbons were now visible.

Analysis of the NMR spectra revealed that most signals were consistent with the diterpene portion of oxeatamide A (214) as detailed in Table 6.5. The majority of the molecule was constructed similarly to oxeatamide A. COSY correlations established three contiguous methylenes, while HMBC correlations from the methyls established the gem-dimethyl moiety and allowed the construction of the cyclohexane ring as before. Large ortho coupling of the aromatic methines once again implied a 1,2,3,4-tetrasubstituted benzene ring moiety; HMBC correlations allowed the placement of the aromatic carbons.

Figure 6.18 shows selected COSY and HMBC correlations that were used to 


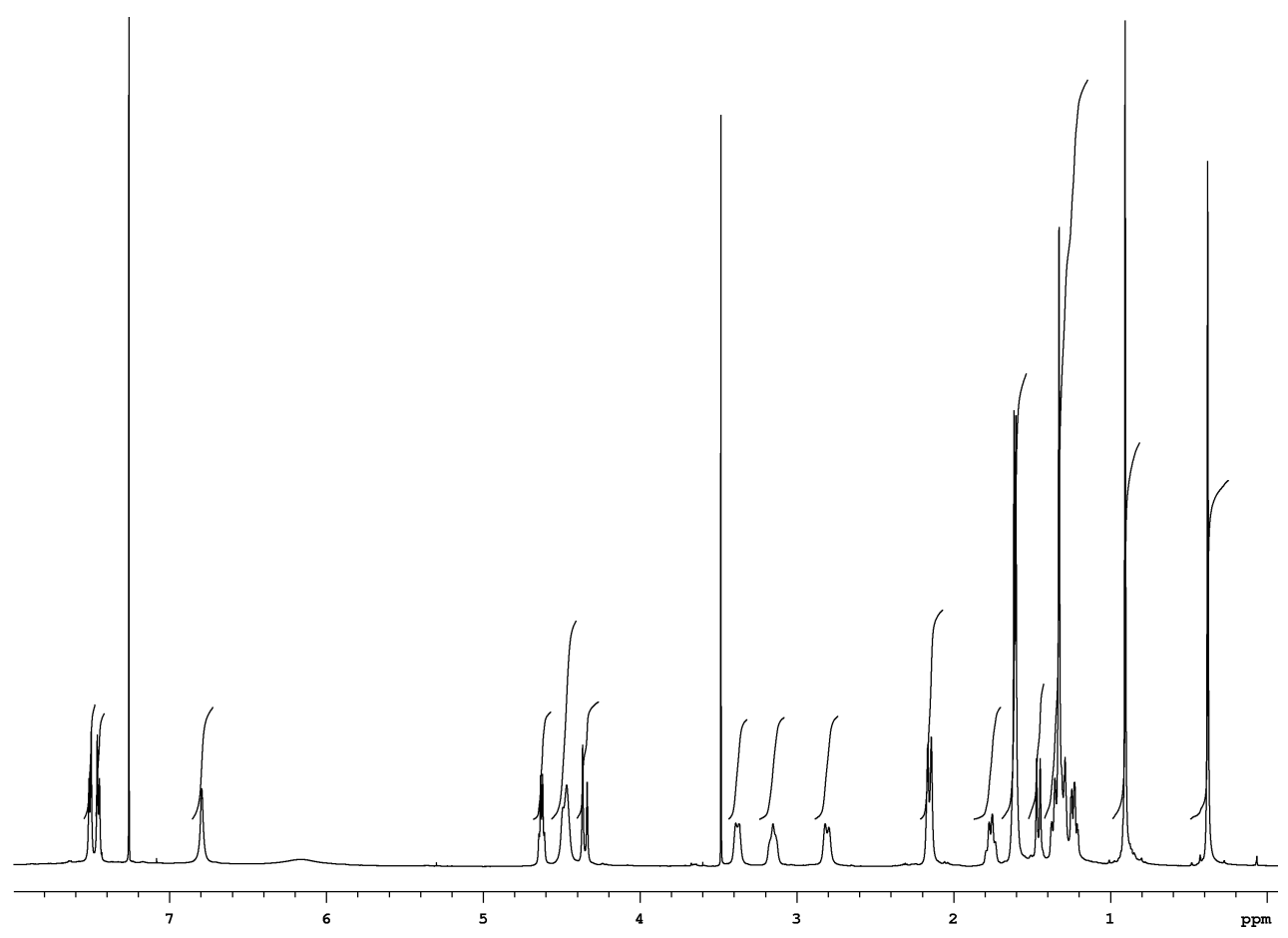

Figure 6.16. ${ }^{1} \mathrm{H}$ NMR spectrum $(600 \mathrm{MHz})$ of oxeatamide $\mathrm{B}(\mathbf{2 1 7})$ in $\mathrm{CDCl}_{3}$.

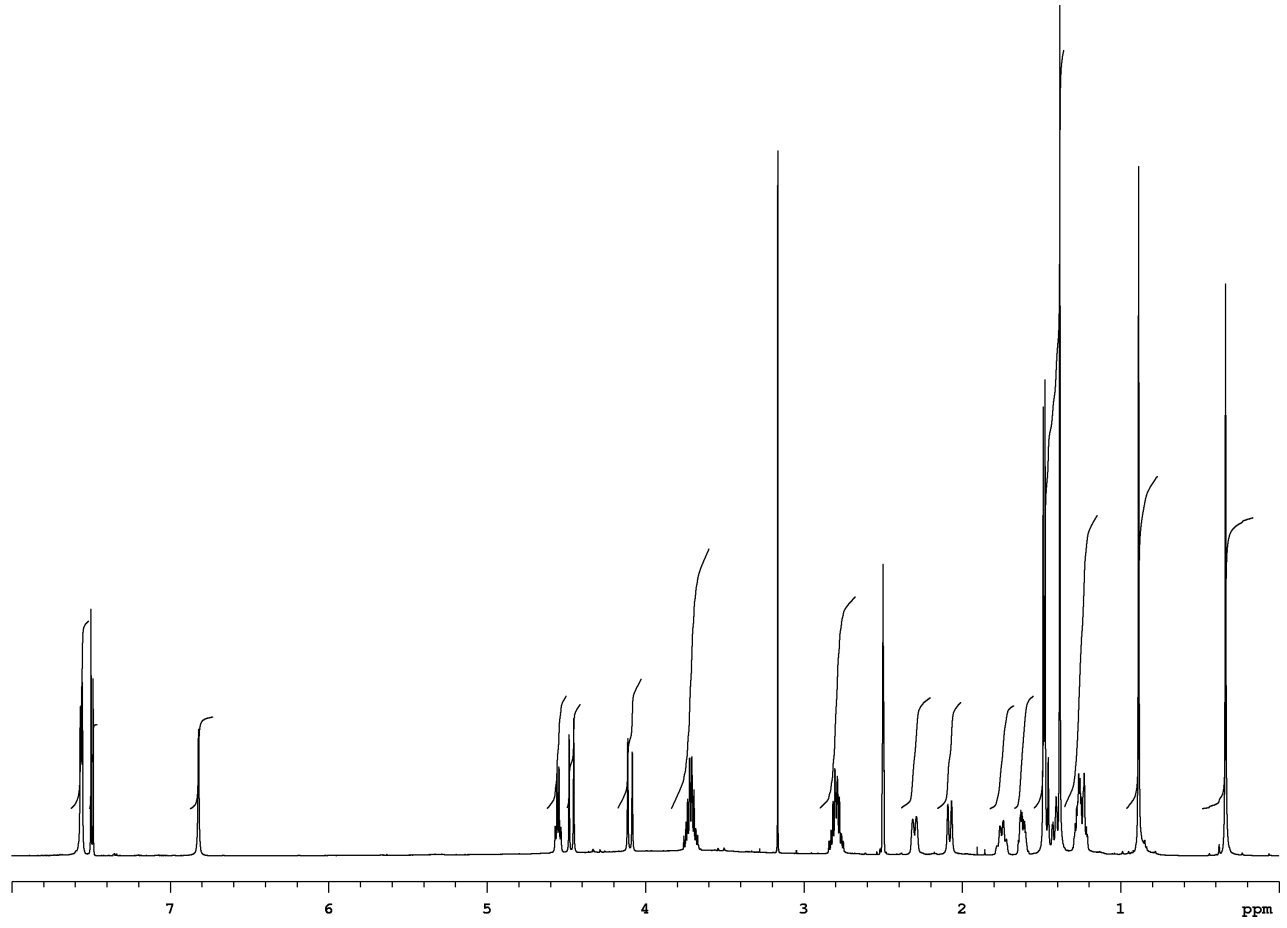

Figure 6.17. ${ }^{1} \mathrm{H}$ NMR spectrum $(600 \mathrm{MHz})$ of oxeatamide $\mathrm{B}(\mathbf{2 1 7})$ in DMSO-d . $_{\text {. }}$ 
construct the majority of oxeatamide B (217), the diterpene portion conserved in all the oxeatamides. Once again, the presence of a lactam was confirmed through observation of an HMBC correlation from $\mathrm{H}_{2}-15$ to N-21. The lactam was placed in the same orientation as for oxeatamide A (214), based on observed HMBC correlations from H-11 and H-12 to the amide carbonyl carbon C-16.

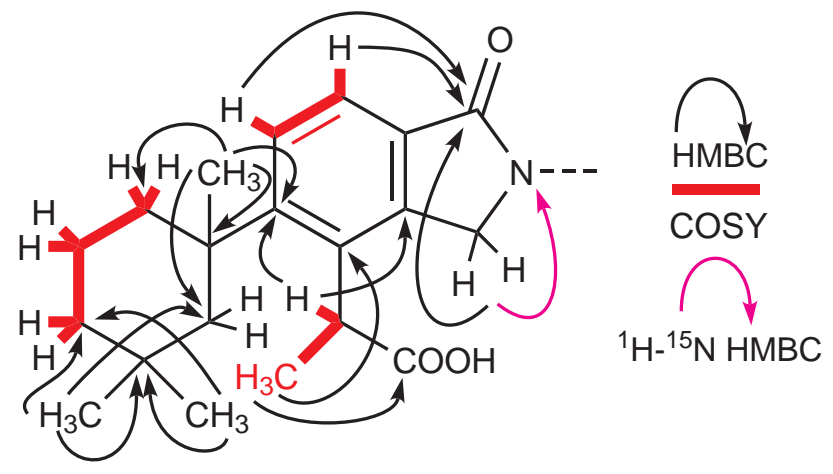

Figure 6.18. Selected COSY and HMBC correlations establishing the diterpene fragment of oxeatamide B (217).

The diterpene lactam accounted for 20 of the carbons, 26 of the protons, the three oxygens, one of the nitrogens and eight degrees of unsaturation. The remaining carbons and protons consisted of two methylenes $\left(\mathrm{CH}_{2}-22: \delta_{\mathrm{C}} 41.8\right.$, $\left.\delta_{\mathrm{Ha}} 3.73, \delta_{\mathrm{Hb}} 3.69 ; \mathrm{CH}_{2}-23: \delta_{\mathrm{C}} 26.0, \delta_{\mathrm{Ha}} 2.82, \delta_{\mathrm{Hb}} 2.78\right)$, two aromatic methines $\left(\mathrm{CH}-26: \delta_{\mathrm{C}} 116.8, \delta_{\mathrm{H}} 6.82 ; \mathrm{CH}-28: \delta_{\mathrm{C}} 134.9, \delta_{\mathrm{H}} 7.56\right)$, whose carbons were broadened, and the aromatic carbon C-24 $\left(\delta_{\mathrm{C}} 134.4\right)$. The two methylenes showed COSY and HMBC correlations to each other, placing them adjacent to one another. A correlation from $\mathrm{H}_{2}-22$ in the ${ }^{1} \mathrm{H}-{ }^{15} \mathrm{~N}$ HMBC to $\mathrm{N}-21$, as well as HMBC correlations to $\mathrm{C}-15$ and $\mathrm{C}-16$ and large ${ }^{1} J_{\mathrm{CH}}$ coupling constants $(138 \mathrm{~Hz})$ indicated $\mathrm{CH}_{2}-22$ was attached to the nitrogen of the lactam. Both methylenes also showed HMBC correlations to the non-protonated aromatic carbon C-24. The remaining two aromatic methines were singlets in the ${ }^{1} \mathrm{H}$ spectrum, and showed HMBC correlations to each other as well as C-24. The three aromatic carbons, as well as the two nitrogens and three degrees of unsaturation that remained unaccounted for suggested an imidazole moiety linked to the methylenes.

NMR data were in accordance with this proposal. H-26 and H-28 showed COSY correlations to each other and HMBC correlations to C-28 and C-26 respectively (see Figure 6.19). The chemical shifts were consistent with average shifts reported for histidine residues in proteins, ${ }^{224}$ and ${ }^{1} J_{\mathrm{CH}}$ coupling constants (188 and $210 \mathrm{~Hz}$ ) were consistent with calculated and observed coupling constants of imidazole rings. ${ }^{225,226}$ 


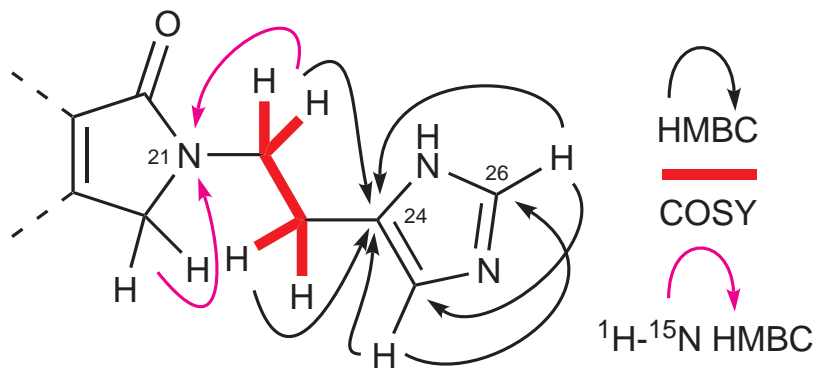

Figure 6.19. Key COSY and HMBC correlations establishing the histamine moiety of oxeatamide B (217).

The imidazole moiety can exist in several ionic and tautomeric forms, depicted in Scheme 6.3. This phenomenon may explain the distinct broadening of the imidazole carbons seen in the ${ }^{13} \mathrm{C}$ NMR spectrum of oxeatamide B (217), and why N-25 and N-27 were not observed in the ${ }^{1} \mathrm{H}-{ }^{15} \mathrm{~N}$ HMBC. This is not unusual: of over 5000 histadine residues in the Biological Magnetic Resonance Data Bank, only about 3\% of the imidazole nitrogens' chemical shifts were observed. ${ }^{224}$

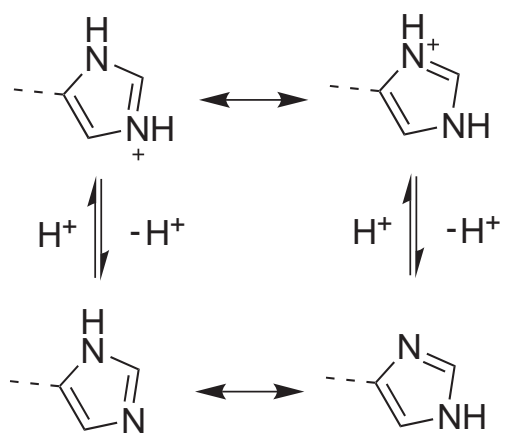

Scheme 6.3. Ionic and tautomeric forms of the imidazole moiety.

A basic group like the imidazole is consistent with the behaviour observed during HPLC, with the charged form of $\mathbf{2 1 7}$ eluting rapidly off reversed-phase packing material under acidic conditions. Oxeatamide B is therefore assigned as 217, with a $N$-linked histamine group instead of a glycine.

Chemical shift considerations, proton coupling constants, W-coupling observed in the COSY as well as NOE enhancements* were once again consistent with a $7 R^{*}, 10 S^{*}$ configuration. The structure is therefore given as $\mathbf{2 1 7}$ with NMR data presented in Table 6.5.

*The NOE enhancements were again negative, most likely due to the viscous solvent (DMSO- $\mathrm{d}_{6}$ ) reducing tumbling rates. 
Table 6.5. NMR data (600 MHz, $\mathrm{d}_{6}$-DMSO) for oxeatamide B (217).

\begin{tabular}{|c|c|c|c|c|c|c|c|c|}
\hline pos. & $\begin{array}{l}\delta_{\mathrm{C}} / \delta_{\mathrm{N}} \\
(\mathrm{ppm})\end{array}$ & mult & ${ }^{1} J_{\mathrm{CH}}$ & $\begin{array}{c}\delta_{\mathrm{H}} \\
(\mathrm{ppm})\end{array}$ & $\begin{array}{l}\text { mult, } \\
J(\mathrm{~Hz})\end{array}$ & COSY & HMBC & NOE \\
\hline $1 \mathrm{a}$ & & & $\overline{126}$ & 2.30 & $\overline{\mathrm{d}(13.5)}$ & $\overline{1 \mathrm{~b}, 2 \mathrm{a}, 2 \mathrm{~b}, 5 \mathrm{a}}$ & $\overline{(2,5), 10}$ & $\overline{1 b}, 2 \mathrm{a}, 2 \mathrm{~b}$ \\
\hline $1 b$ & 40.8 & $\mathrm{CH}_{2}$ & 124 & 1.38 & $\mathrm{~m}$ & $1 \mathrm{a}, 2 \mathrm{a}, 2 \mathrm{~b}$ & $2,10,(20)$ & $1 \mathrm{a}, 2 \mathrm{a}, 2 \mathrm{~b}, 5 \mathrm{~b}$ \\
\hline $2 \mathrm{a}$ & & & 124 & 1.75 & $\mathrm{~m}$ & $1 \mathrm{a}, 1 \mathrm{~b}, 2 \mathrm{~b}, 3$ & $(1,3,4)$ & $1 \mathrm{a}, 1 \mathrm{~b}, 2 \mathrm{~b}, 3$ \\
\hline $2 \mathrm{~b}$ & 19.7 & $\mathrm{CH}_{2}$ & 124 & 1.61 & $\mathrm{~m}$ & $1 \mathrm{a}, 1 \mathrm{~b}, 2 \mathrm{a}, 3$ & $1,3,10$ & $1 \mathrm{a}, 1 \mathrm{~b}, 2 \mathrm{a}, 5 \mathrm{~b}$ \\
\hline 3 & 39.7 & $\mathrm{CH}_{2}$ & 124 & 1.24 & $\mathrm{~m}$ & $2 \mathrm{a}, 2 \mathrm{~b},(5 \mathrm{a})$ & $1,2,4,5,18,19$ & $2 \mathrm{a}, 2 \mathrm{~b}, 5 \mathrm{~b}, 19$ \\
\hline 4 & 31.4 & $\mathrm{C}^{2}$ & - & - & - & - & - & - \\
\hline $5 \mathrm{a}$ & & & 123 & 2.08 & $\mathrm{~d}(14.0)$ & $1 \mathrm{a}, 5 \mathrm{~b},(3)$ & $1,4,(9), 10,(18), 19$ & $5 \mathrm{~b}, 7$ \\
\hline $5 \mathrm{~b}$ & 50.0 & $\mathrm{CH}_{2}$ & 119 & 1.45 & $\mathrm{~m}$ & $5 \mathrm{a}$ & $1,4,9,10,18,19$ & $1 \mathrm{~b}, 3,5 \mathrm{a}$ \\
\hline 6 & 174.7 & $\mathrm{C}$ & - & - & - & - & - & - \\
\hline 7 & 40.8 & $\mathrm{CH}$ & 123 & 4.55 & $\mathrm{q}(7.1)$ & 17 & $6,8,9,(13), 14,17$ & $5 \mathrm{a}, 17,20$ \\
\hline 8 & 136.3 & $\mathrm{C}$ & - & - & - & - & - & - \\
\hline 9 & 149.6 & $\mathrm{C}$ & - & - & - & - & - & - \\
\hline 10 & 39.2 & $\mathrm{C}$ & - & - & - & - & - & - \\
\hline 11 & 126.9 & $\mathrm{CH}$ & 159 & 7.56 & $\mathrm{~d}(8.3)$ & 12 & $(1), 8,9,10,(12,14), 16,22$ & $1 \mathrm{a}, 1 \mathrm{~b}, 2 \mathrm{a}, 12$ \\
\hline 12 & 120.9 & $\mathrm{CH}$ & 165 & 7.49 & $\mathrm{~d}(8.1)$ & 11 & $6,8,9,(10,11,13), 14,22$ & 11 \\
\hline 13 & 131.0 & $\mathrm{C}$ & - & - & - & - & - & - \\
\hline 14 & 141.8 & $\mathrm{C}$ & - & - & - & - & - & - \\
\hline $15 \mathrm{a}$ & 401 & & 143 & 4.47 & $\mathrm{~d}(17.1)$ & $15 \mathrm{~b}$ & $8,(9,11,12), 13,14,16,21$ & $15 \mathrm{~b}, 17,22 \mathrm{a}, 22 \mathrm{~b}$ \\
\hline $15 b$ & 49.1 & $\mathrm{CH}_{2}$ & 142 & 4.10 & $\mathrm{~d}(17.2$ & $15 \mathrm{a}$ & $8,(9,11,12), 13,14,16,21$ & $15 \mathrm{a}, 17,22 \mathrm{a}, 22 \mathrm{~b}$ \\
\hline 16 & 166.8 & $\mathrm{C}$ & - & - & - & - & - & - \\
\hline 17 & 15.5 & $\mathrm{CH}_{3}$ & 127 & 1.48 & $\mathrm{~d}(7.2)$ & 7 & $6,7,8$ & $7,15 \mathrm{a}, 15 \mathrm{~b}, 20$ \\
\hline 18 & 26.7 & $\mathrm{CH}_{3}$ & 123 & 0.34 & $\mathrm{~s}$ & - & $3,4,5,19$ & 19,20 \\
\hline 19 & 32.9 & $\mathrm{CH}_{3}$ & 124 & 0.89 & $\mathrm{~s}$ & - & $3,4,5,18$ & 3,18 \\
\hline 20 & 32.7 & $\mathrm{CH}_{3}$ & 128 & 1.38 & $\mathrm{~s}$ & - & $1,(2,4), 5,9,10$ & 1,18 \\
\hline 21 & -257.7 & $\mathrm{~N}$ & - & - & - & - & - & - \\
\hline $22 \mathrm{a}$ & 418 & & 138 & 3.73 & $\mathrm{dt}(13.7,7.8)$ & $22 \mathrm{~b}, 23 \mathrm{a}, 23 \mathrm{~b}$ & $15,16,21,23,24$ & $15 \mathrm{a}, 15 \mathrm{~b}, 22 \mathrm{~b}, 28$ \\
\hline $22 \mathrm{~b}$ & 41.8 & $\mathrm{CH}_{2}$ & 138 & 3.69 & $\mathrm{dt}(13.5,7.6)$ & $22 \mathrm{a}, 23 \mathrm{a}, 23 \mathrm{~b}$ & $15,16,21,23,24$ & $15 \mathrm{a}, 15 \mathrm{~b}, 22 \mathrm{a}, 28$ \\
\hline $23 \mathrm{a}$ & & & 127 & 2.82 & $\mathrm{dt}(14.7,7.7)$ & $22,23 \mathrm{~b}$ & $21,24,(26), 28$ & 18 \\
\hline $23 \mathrm{~b}$ & 26.0 & $\mathrm{CH}_{2}$ & 127 & 2.78 & $\mathrm{dt}(14.5,7.4)$ & $22,23 \mathrm{a}$ & $21,22,24,(28)$ & 28 \\
\hline 24 & 134.4 & $\mathrm{C}$ & - & - & - & - & - & - \\
\hline 25 & $a$ & $\mathrm{~N}$ & - & - & - & - & - & - \\
\hline 26 & 134.9 & $\mathrm{CH}$ & 210 & 7.56 & br s & 26 & 24,26 & \\
\hline 27 & $a$ & $\mathrm{~N}$ & - & - & - & - & - & - \\
\hline 28 & 116.3 & $\mathrm{CH}$ & 188 & 6.82 & br s & 28 & 24,28 & $22 \mathrm{a}, 22 \mathrm{~b}$ \\
\hline
\end{tabular}

${ }^{a}$ not observed

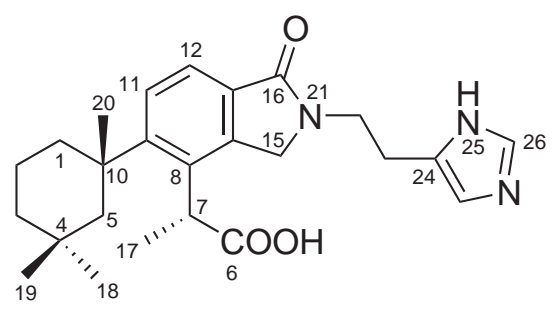

217

\subsection{Biological activity}

The oxeatamides were submitted for cytotoxicity and antimicrobial testing at the School of Biological Sciences, VUW. They were tested in a 48 hour MTT assay against HL-60 (leukemia) cells, but were inactive up to $10 \mu \mathrm{M} .{ }^{227}$ Results suggest they may be active above the $10 \mu \mathrm{M}$ threshold tested, but an $\mathrm{IC}_{50}$ was not determined. 
Oxeatamide A (214), iso-oxeatamide A (215) and oxeatamide B (217) were also tested for antimicrobial activity against Mycobacterium smegmatis MC2155. They showed good activity with $\mathrm{IC}_{50}$ values of $15.1 \mu \mathrm{M}, 61.2 \mu \mathrm{M}$, and $11.8 \mu \mathrm{M}$ respectively. ${ }^{228}$

\subsection{The aplysulphuranes}

Spongian metabolites (compounds possessing the basic spongian skeleton) are common and often biologically active metabolites of sponges of the orders Dictyoceratida and Dendroceratida. ${ }^{229}$ A plethora of related metabolites has been isolated, possessing varying levels and patterns of oxygenation. Dictyoceratid and Dendroceratid sponges are two orders that do not produce any silicaceous spicules, which often makes their taxonomic identification problematic. The two orders do show certain trends in the type of spongian diterpenes they produce, making chemotaxonomy a valuable tool in the taxonomic assignment of these sponges. $^{229}$

The largest group of spongian diterpenes are ones that have undergone some kind of skeletal rearrangement. For example, a Nametkin shift* of the angular C-17 methyl, followed by oxidative cleavage of the C-5/C-6 bond, leads to the aplysulphurane skeleton, as depicted in Scheme 6.4. ${ }^{229}$ Aplysulphurane metabolites have only been found from sponges of the order Dendroceratida. ${ }^{229,231}$
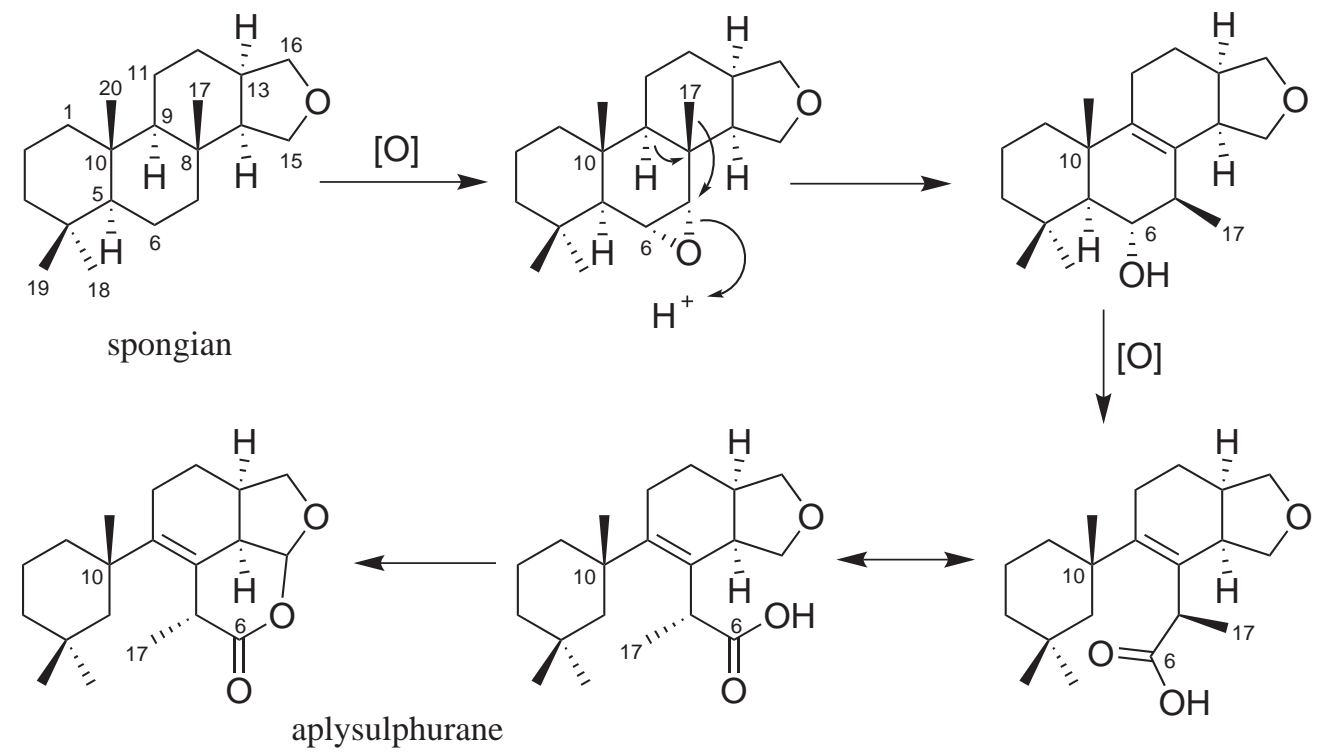

Scheme 6.4. Proposed biogenesis of the aplysulphurane skeleton, adapted from Karuso et al. ${ }^{221}$

${ }^{*}$ the specific 1,2-Wagner-Meerwein shift of a methyl group 230 
The first aplysulphurane to be isolated was aplysulphurin (222) by Karuso et al. from a Dendroceratid sponge identified as Aplysilla sulphurea collected in eastern Australian waters. ${ }^{221}$ Its structure was determined by NMR spectroscopy and confirmed by X-ray crystallography. Compound 222 contains an aromatic ring, an unusual feature in terpenoids, seen again in macfarladins A and B (223, 224), the first aromatic norditerpenes described from marine sources. ${ }^{232}$

In a subsequent publication ${ }^{233}$ Karuso et al. report the isolation of 222 as well as three tetrahydroaplysulphurin isomers (225-227) from the same sponge species (collected in New Zealand), now identified as Darwinella oxeata. Compounds 225-227 do not possess an aromatic ring, but a single olefin in various positions. The proposed biogenesis shown in Scheme 6.4 suggests the "default" location for the double bond is between positions 8 and 9 , and indeed, that motif appears multiple times as in the cadlinolides A-D (228-231). ${ }^{234,235}$

Cadlinolide A and B $(\mathbf{2 2 8}, \mathbf{2 2 9})$ were isolated from the marine sponge Aplysilla glacialis collected off the coast of British Columbia, Canada. Compounds 228, 229 as well as 222 were also isolated from specimens of the nudibranch Cadlina luteomarginata found grazing on the sponge. ${ }^{234}$ Keyzers et al. examined the New Zealand sponge Chelonaplysilla violacea, isolating cadlinolides $\mathrm{C}$ and D $(\mathbf{2 3 0}, \mathbf{2 3 1})$. Compound $\mathbf{2 3 1}$ is the methyl acetal version of $\mathbf{2 2 9}$, and may be an artifact of isolation (as the sponge was extracted in $\mathrm{MeOH}$ ). ${ }^{235}$

C. violacea also yielded pourewic acid (232), 15-methoxypourewic acid B (233) and the isomeric methyl ester of pourewic acid B (234). ${ }^{235}$ Concurrently with the New Zealand study of $C$. violacea, Díaz-Marrero et al. report the isolation of 230, 232 and compound 235 from the Antarctic sponge Dendrilla membranosa. ${ }^{231}$ NOE data collected by Díaz-Marrero et al. for 232 is consistent with the $15 S$ structure depicted, rather than the $15 R$ configuration proposed by Keyzers et al. ${ }^{231,235}$ The presence of a free $\mathrm{C}-17$ carboxylic acid in pourewic acid (232) and 15-methoxypourewic acid B (233) lends credence to the proposed biogenesis of the aplysulphuranes, which suggests a free carboxylic acid intermediate.

Molinski and Faulkner had previously examined D. membranosa, isolating the mildly antibacterial membranolide (236) whose aromatic ring harks back to aplysulphurin (222). ${ }^{217}$ Subsequently, Ankisetty and co-workers report the isolation of further aromatized aplysulphuranes, the membranolides B-D (237-239) from another collection of D. membranosa. ${ }^{218}$ The acetal functional groups of 237-239 were not prone to hydrolysis, and were not artifacts of isolation. Membranolides $\mathrm{C}$ and D showed modest but broad spectrum antibacterial activity. ${ }^{218}$ 
<smiles>CC(=O)O[C@H]1O[C@H]2OC(=O)[C@H](C)c3c([C@@]4(C)CCCC(C)(C)C4)ccc1c32</smiles>

222

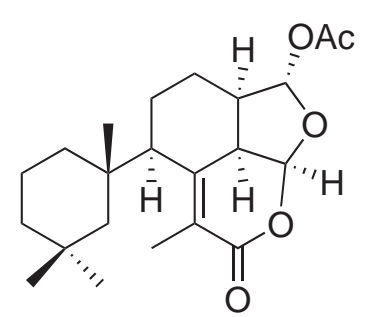

226<smiles>COC(=O)[C@H](C)C1=C([C@]2(C)CCCC(C)(C)C2)CC[C@@H]2COC(C)C12</smiles>

232<smiles>CC(=O)[C@H](C)c1c([C@@]2(C)CCCC(C)(C)C2)ccc2c1C(=O)OC2</smiles>

236

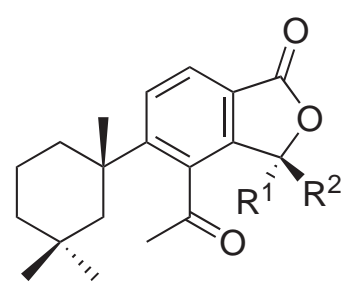

$223 \begin{aligned} & \mathrm{R}^{1}=\mathrm{OAc} \\ & \mathrm{R}^{2}=\mathrm{H}\end{aligned}$

$224 \mathrm{R}^{1}=\mathrm{H}$

$\mathrm{R}^{2}=\mathrm{OAc}$

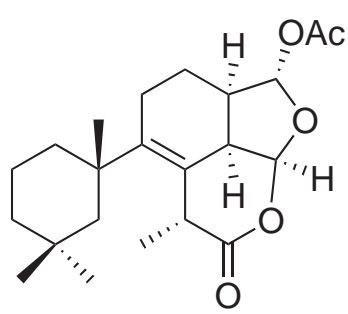

227<smiles>CCCOC1OC(=O)[C@H]2CCC([C@]3(C)CCCC(C)(C)C3)=C([C@H](C)C(=O)O)[C@H]12</smiles>

$233 \begin{aligned} & \mathrm{R}^{1}=\mathrm{Me} \\ & \mathrm{R}^{2}=\mathrm{H}\end{aligned}$

$234 \quad \mathrm{R}^{1}=\mathrm{H}$<smiles>COC1OC(=O)[C@H](C)c2c(C=O)ccc(C)c21</smiles>

237<smiles>CC(=O)O[C@H]1C[C@H]2OC(=O)[C@H](C)C3=C2C1CC[C@H]3C1(C)CCCC(C)(C)C1</smiles>

225<smiles>[R]C1O[C@H]2OC(=O)[C@H](C)C3=C(C4(C)CCCC(C)(C)C4)CC[C@@H]1[C@@H]32</smiles>

$228 \mathrm{R}=\mathrm{O}$

$229 \mathrm{R}=$ epim. H, OH

$230 \mathrm{R}=\mathrm{H}, \mathrm{H}$

$231 \mathrm{R}=$ epim. H, OMe

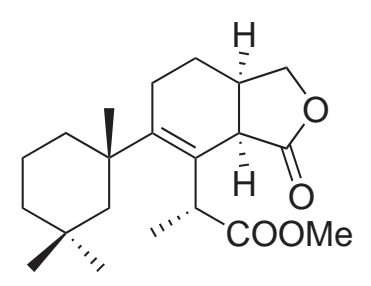

235

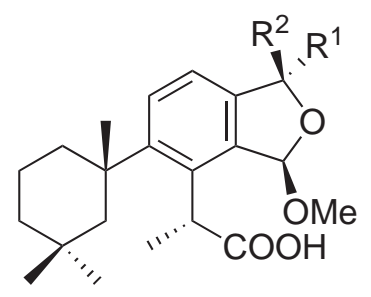

$238 \begin{aligned} & \mathrm{R}^{1}=\mathrm{OMe} \\ & \mathrm{R}^{2}=\mathrm{H}\end{aligned}$

$239 \quad \mathrm{R}^{1}=\mathrm{H}$ 


\subsection{Nitrogenous terpenes}

An abundance of nitrogenous terpenes has been isolated from marine invertebrates and their predators. ${ }^{236}$ The majority of them, however, are isocyanides and the related isothiocyanides, thiocyanates, isocyanates, formamides and the (uniquely marine) dichloroimines. Many of the isocyanide terpenes are isolated together with their corresponding isothiocyanates and formamides. The first examples were axisonitrile-3 (240) and axisothiocyanate-3 (241), isolated from the sponge Axinella cannabina, followed by the formamide axamide-3 (242). ${ }^{237}$ More recently, the isocyanate version 243 has also been reported from the sponge Acanthella cavernosa. ${ }^{238}$ Such frequent co-isolation has led researchers to propose a common biosynthetic pathway for these functional groups, and indeed, incorporation experiments with radio-labelled compounds have established that inorganic cyanide is the common precursor of various isocyano, isothiocyanato, thiocyanato and dichloroimine metabolites. ${ }^{236}$

\section{Amino acid derived nitrogenous terpenoids}

For some terpenes the source of nitrogen is not easy to determine; for many, however, amino acids seem a likely precursor. As the boneratamides A-C (244246)* share the same sesquiterpenoid fragment with axisonitrile-3 (240) and related compounds, ${ }^{239}$ the nitrogen at position 16 most likely comes from inorganic cyanide. The remaining nitrogenous portion is proposed to be of amino acid origin. $^{239}$
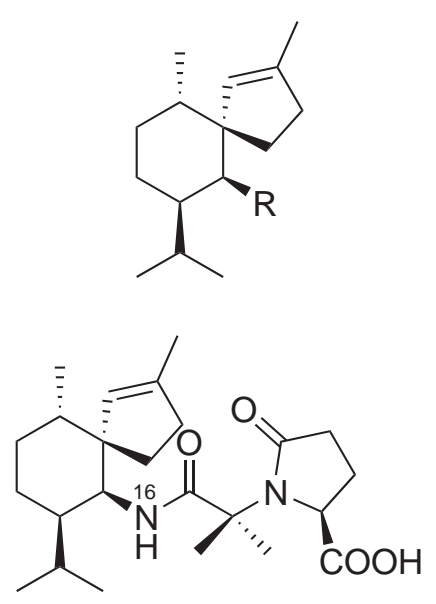

244

$$
\begin{array}{ll}
240 & \mathrm{R}=\text { NC } \\
\mathbf{2 4 1} & \mathrm{R}=\mathrm{NCS} \\
\mathbf{2 4 2} & \mathrm{R}=\mathrm{NHCHO} \\
\mathbf{2 4 3} & \mathrm{R}=\mathrm{NCO}
\end{array}
$$

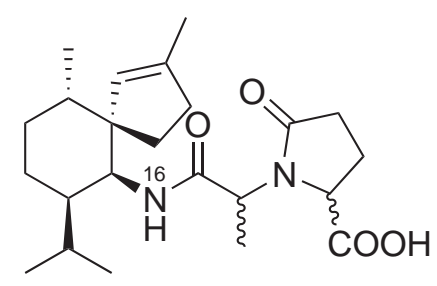

245,246

* Boneratamides $\mathrm{B}$ and $\mathrm{C}$ differ in the relative configuration at one or both of the positions indicated. 


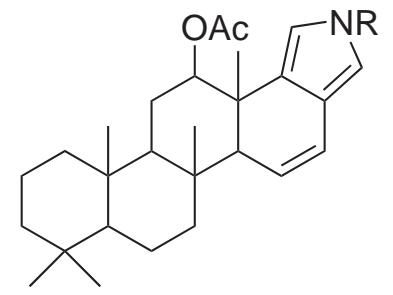

$247 \mathrm{R}=$ dcIle

$249 \mathrm{R}=\mathrm{dcVal}$

$250 \mathrm{R}=\mathrm{dcPhe}$

$251 \mathrm{R}=$ dcGly<smiles>CC(=O)OC1CC2C(C)(CCC3C(C)(C)CCCC32C)C2CC=C(C=O)C(C=O)C12</smiles>

252
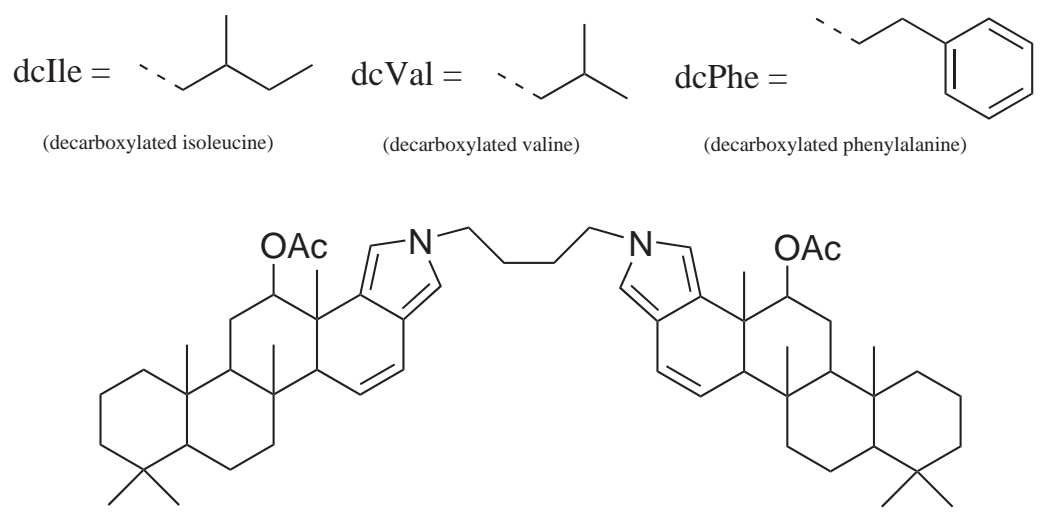

248

Molliorins A-E (247-251) are scalarin-like pyrroloterpenes isolated from the sponge Cacospongia mollior. ${ }^{240-243}$ They are proposed to originate from a sesterterpenoid intermediate (for example scalaradial $(\mathbf{2 5 2})^{244}$ ) and an amino acid precursor: decarboxylated isoleucine, valine, phenylalanine and glycine for $\mathbf{2 4 7}$, 249, 250 and 251 respectively. The central portion of the dimer molliorin B (248) is thought to come from ornithine (2,5-diaminopentanoic acid, a metabolite of the amino acid arginine in the urea cycle). ${ }^{241}$

The sarcotrines, isolated from a marine sponge of the genus Sarcotragus, are another class of nitrogenous sesterterpenes, closely related to such furano compounds as sarcotin A (253) and the variabilin-type compounds previously discussed in Section 5.3 on page 124. In place of the furan the sarcotrines have a lactam moiety, substituted at the nitrogen with a decarboxylated leucine, phenylalanine or isoleucine, as well as the sodium salt form of the amino acid glycine. ${ }^{245,246}$

The tetronic acid moiety of sarcotrines $\mathrm{A}-\mathrm{C}(\mathbf{2 5 4}-\mathbf{2 5 6})$ is quite labile and epimerizes easily at $\mathrm{C}-21$, giving rise to the epi-sarcotrines A-C (257-259). ${ }^{246}$ Quite often, both types of lactam ring ( $\alpha$ - and $\beta$-substituted) are present, as in the pairs sarcotrine A (254) and sarcotrine D (260), sarcotrine E (261) and 
isosarcotrine $\mathrm{E}$ (262), and sarcotrine F (263) and isosarcotrine F (264).

Complete degradation of the tetronic acid could explain sarcotrine F (263) and isosarcotrine $\mathrm{F}$ (264), highly unusual $\mathrm{C}_{24}$ norsesterterpenes. Their presence supports the biogenetic hypothesis that $\mathrm{C}_{21}$ furanoterpenes are derived from sesterterpenes, with $\mathrm{C}_{24}$ norsesterterpenes being the first step in the degradation process. ${ }^{245}$ The trisnorsesterterpenes sarcotragins A and B $(\mathbf{2 6 5}, \mathbf{2 6 6})^{247}$ may be further degradation products.

The sarcotragins and sarcotrins may be biosynthesized from a furan precursor through attack by an amino acid derivative. Such a biocatalytic transformation from furan to amide was performed on the (previously mentioned) linear furanosesterterpene palinurin (192). The fungus Cunninghamella sp. NRLL 5695 was able to bioconvert 192 to palinurine A and B $(\mathbf{2 6 7}, 268)$, whose nitrogenous moiety (2-aminoethanol) can be considered decarboxylated serine. ${ }^{199}$ Both electron-deficient oxymethine carbons of the furan ring are vulnerable to nucleophilic attack, giving rise to two possible products: the $\alpha$ - and $\beta$-substituted lactam rings already seen for the sarcotrines. ${ }^{246}$

This biogenetic mechanism may explain the formation of other nitrogenous terpenes. The sesquiterpene pyrodysinoic acid (269), isolated from a Dysidea sponge, ${ }^{121}$ can conceivably be formed from the common metabolite furodysin $(\mathbf{8 6})$ and the amino acid glycine. Haumanamide (270) and the related spongolactams A-C (271-273) were isolated from a sponge of the genus Spongia, together with a possible precursor: the known spongia-13(16),14-dien-19-oic acid (274). ${ }^{248,249}$ Haumanamide (270) is active against KB cancer cells (MIC $5 \mu / \mathrm{mL}$ ) and LoVO (colon cancer) cells (MIC $10 \mu / \mathrm{mL}),{ }^{248}$ while the spongolactams inhibited the farnesyl transferase enzyme and also show cytotoxicity against a human tumour cell line. ${ }^{249}$ To the best of our knowledge, apart from the oxeatamides compounds 270-273 are the only nitrogenous spongian diterpenes reported.

\subsection{Biogenesis and proposed absolute configu- ration of the oxeatamides}

The oxeatamides are new members of the aplysulphurane family of rearranged spongian diterpenes. Their relative configuration was assigned based on observed NOE enhancements as $7 R^{*}, 10 S^{*}$ consistent with various other aplysulphurane compounds whose relative configurations have been established through a combination of single crystal X-ray diffraction analysis, ${ }^{221,234,250,251}$ conformational studies, ${ }^{231}$ NMR data, ${ }^{217,218,221,235}$ or chemical degradation experiments. ${ }^{217}$ 

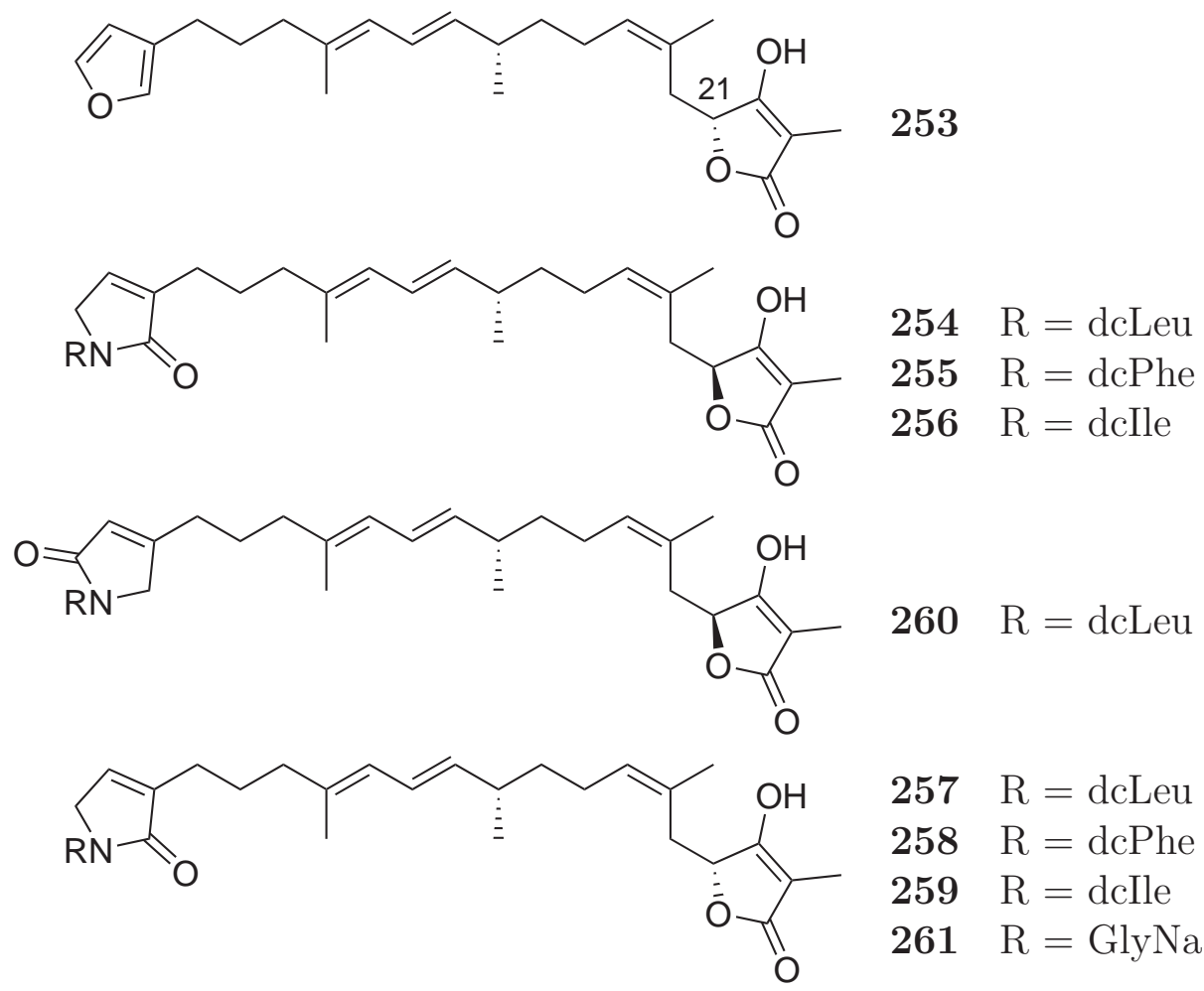<smiles>CC1=C(O)[C@@H](C/C(C)=C\CC[C@@H](C)/C=C/C=C(/C)CCCC2=CC(=O)NC2)OC1=O</smiles><smiles>CC(=O)C(O)C(O)C/C(C)=C\CC[C@H](C)/C=C/C=C(\C)CCCC1=CCNC1=O</smiles><smiles></smiles>

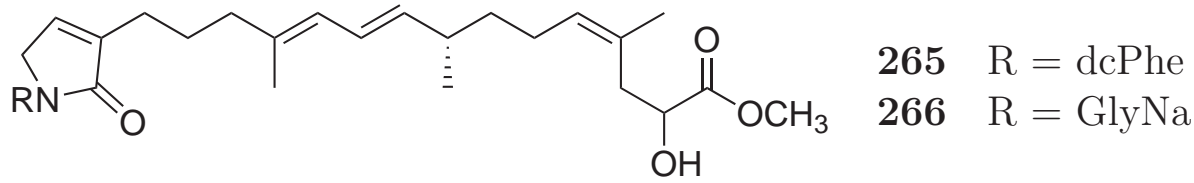
dcLeu $=$

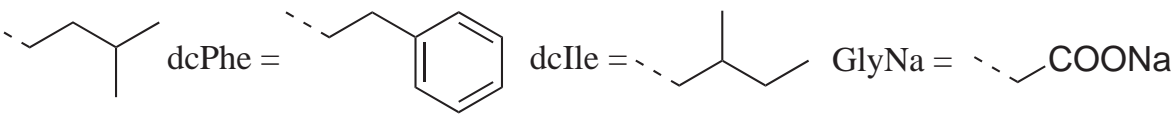


<smiles>CC(=CC=C[C@@H](C)CCC=C(C)CC1OC(=O)C(C)=C1O)CCCc1ccoc1</smiles>

192<smiles>CC(=CC=C[C@@H](C)CCC=C(C)CC1OC(=O)C(C)=C1O)CCCC1=CCN(CCO)C1=O</smiles>

\section{7}<smiles>CC(=CC=C[C@@H](C)CCC=C(C)CC1OC(=O)C(C)=C1O)CCCC1=CC(=O)N(CCO)C1</smiles>

268<smiles>CC1=CC2CC3=CC(=O)N(CC(=O)O)C3C(C)(C)C2CC1</smiles>

269<smiles>CC1=C[C@H]2Cc3ccoc3C(C)(C)[C@@H]2CC1</smiles>

86

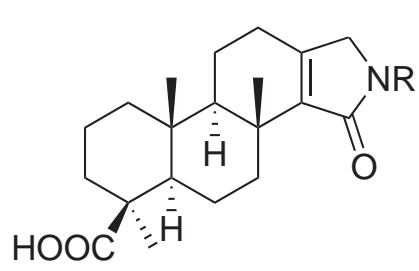

$270 \mathrm{R}=$ dcPhe

$271 \mathrm{R}=$ dcHis

$273 \mathrm{R}=$ Gly<smiles>C[C@]12CCC[C@@H](C(=O)O)[C@@H]1CC[C@@]1(C)C3=C(CCC21)C(=O)NC3</smiles>

$272 \mathrm{R}=\mathrm{dcHis}$<smiles>C[C@]12CCC[C@@H](C(=O)O)[C@@H]1CC[C@@]1(C)c3cocc3CC[C@H]21</smiles>

274

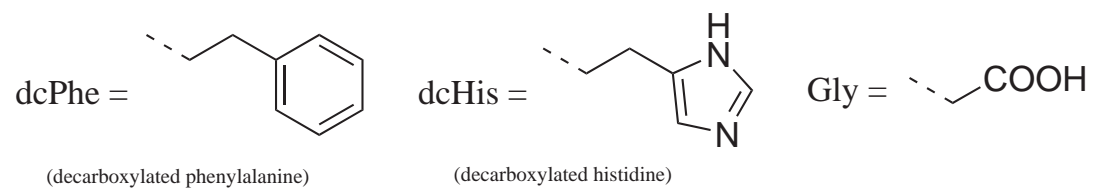



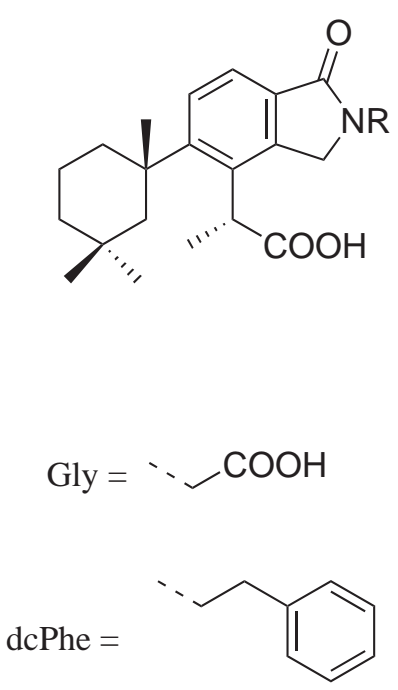

(decarboxylated phenylalanine)

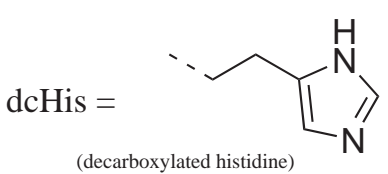

dcIle $=$

(decarboxylated isoleucine)
$214 \mathrm{R}=$ Gly

$217 \mathrm{R}=\mathrm{dcHis}$

$275 \mathrm{R}=\mathrm{CH}_{2} \mathrm{CH}_{2} \mathrm{NH}_{2}$

$276 \mathrm{R}=\mathrm{dcVal}$

$277 \mathrm{R}=$ dcPhe

$278 \mathrm{R}=$ dcIle

$279 \mathrm{R}=\mathrm{dcLeu}$

The conservation of the chirality at those centres in multiple aplysulphuranes lends support to the proposed biogenetic mechanism from the spongian precursor. The proposed mechanism (Scheme 6.4) does not involve the centre at C-10 at all, which should therefore be identical (that is $S$ ) to that of the spongian precursor. ${ }^{231}$ Additionally, the stereospecific Nametkin shift of the $\mathrm{CH}_{3}-17$ methyl and the subsequent oxidative cleavage of the C-5/C-6 bond results in an $R$ configuration at $\mathrm{C}-7$. Therefore the absolute configuration of the oxeatamides is proposed to be $7 R, 10 S$, as has been established for various spongian and related compounds. ${ }^{229}$ Degradation reactions or total synthesis, however, will be necessary for unequivocal proof.

The unusual nitrogenous portion of the oxeatamides is most likely amino acid derived. For oxeatamide A (214) it is from the amino acid glycine, while for oxeatamide B (217) it is decarboxylated histadine (histamine). Recent work by Dowle supports this theory: further investigation of $D$. oxeata has resulted in the isolation of oxeatamide A (214), iso-oxeatamide A (215), oxeatamide B (217), membranolide $\mathrm{C}$ and $\mathrm{D}(\mathbf{2 3 8}, \mathbf{2 3 9})$ as well as the new oxeatamides $\mathrm{C}-\mathrm{G}$ (275-279). ${ }^{252}$ Their nitrogenous moieties are 1,2-diaminoethane, 2-methylpropan-1-amine, 2-phenylethylamine, 2-methylbutan-1-amine and 3-methylbutan1-amine respectively. For 276-279, the nitrogenous portions can be considered decarboxylated valine, phenylalanine, isoleucine or leucine respectively. The origin of the 1,2-diaminoethane moiety of $\mathbf{2 7 5}$ is more difficult to determine.

The existence of iso-oxeatamide A (215), the isomer of oxeatamide A (214) with the lactam in the other orientation, is in concordance with previously isolated, nitrogenous terpenes of mixed biogenesis. Such isomeric pairs have been 
seen with the sarcotragins and sarcotrins, and also with spongolactam A and B $(\mathbf{2 7 1}, \mathbf{2 7 2})$. El Sayed et al. propose they arise through a nucleophilic attack of an amino acid derivative on either of the methine carbons of a furan ring, leading to two possible isomers. ${ }^{229,246}$ As depicted in Scheme 6.5, the nucleophilic attack results in the formation of an aldehyde intermediate, which on subsequent cyclization and oxidation leads to the formation of the lactam.

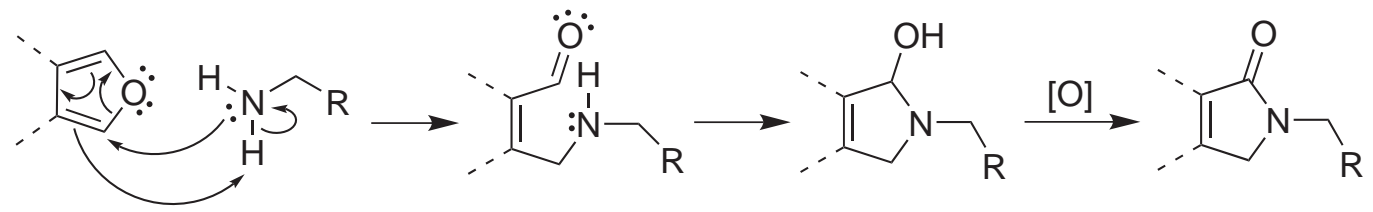

Scheme 6.5. Proposed mechanism for the formation of the lactam moiety, adapted from El Sayed et al. ${ }^{199}$

An alternate biogenetic pathway is depicted in Scheme 6.6 below. The furan precursor may be oxidized by singlet oxygen to $\gamma$-hydroxy butenolide, which contains a masked aldehyde. Imine formation with an appropriate amino acid derivative, followed by reduction and subsequent amide formation leads to the five-membered lactam ring.
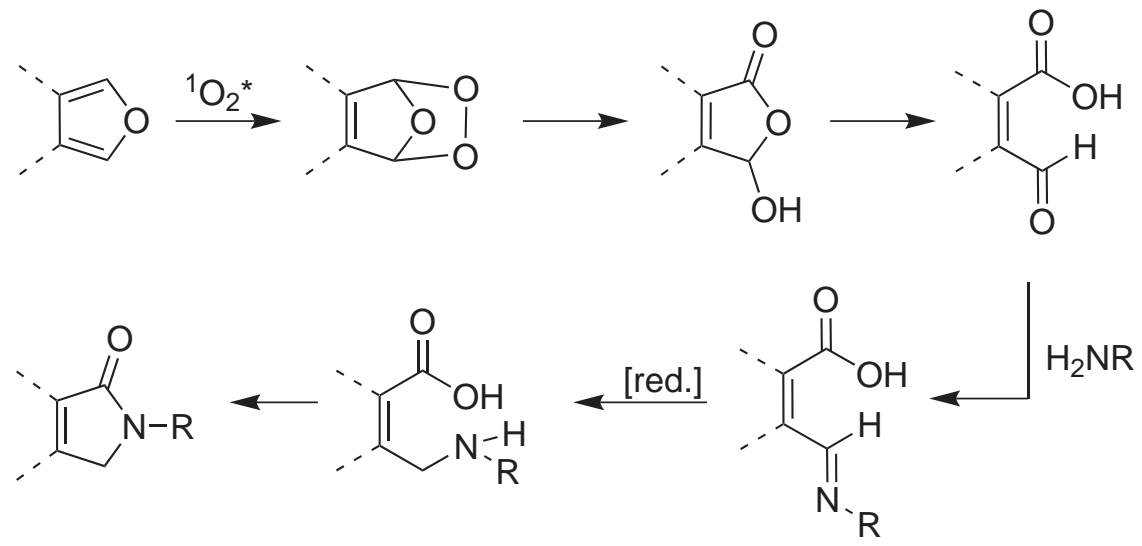

Scheme 6.6. Alternative biogenetic pathway for the formation of the lactam moiety.

Although no furan-containing aplysulphuranes have been found to date, several metabolites of spongian skeleton with a furan D-ring have been isolated. ${ }^{229}$ Such a spongian furan may undergo oxidation, followed by aromatization of the C-ring and skeletal rearrangement to give a putative oxeatamide precursor (the aromatized version of compound 228). This may then follow a similar route (Scheme 6.7) to give the oxeatamides. 
<smiles>Cc1ccc2c3c1[C@H](C)C(=O)O[C@H]3OC2=O</smiles><smiles>Cc1ccc(C(=O)O)c2c1C(CC(C)C)C(=O)OC2O</smiles><smiles>CCCc1ccc(C(=O)O)c(C(=O)O)c1[C@H](C)C(=O)O</smiles><smiles>[R]N1Cc2c(ccc(C)c2[C@H](C)C(=O)O)C1=O</smiles><smiles>[R]NCc1c(C(=O)O)ccc(CC)c1[C@@H](C)C(=O)O</smiles><smiles>[R]N=Cc1c(C(=O)O)ccc(CC(C)C)c1[C@H](C)C(=O)O</smiles>

Scheme 6.7. Proposed biogenetic mechanism for the formation of the lactam of the oxeatamides.

\subsection{Concluding remarks}

Sponges of the orders Dictyoceratida and Dendroceratida often produce spongian diterpenes. The aplysulphurane skeleton is one example of a rearranged spongian backbone, with aplysulphurane metabolites only reported from dendroceratid sponges. Examination of the New Zealand dendroceratid sponge D. oxeata yielded four new aplysulphurane metabolites, which contained two unusual features: an aromatic ring (rarely seen in terpenes) and an $N$-substituted lactam moiety.

The oxeatamides also all possess a carboxylic acid at C-6, and so lend further weight to the proposed biogenetic pathway of the aplysulphurane skeleton, which proceeds through an oxidative cleavage of the C-5/C-6 bond. In solution, these carboxylic acids dimerize; in the case of oxeatamide $\mathrm{A}(\mathbf{2 1 4})$ and iso-oxeatamide A (215) — which possess a second carboxylic acid as part of the nitrogenous moiety - they may even form larger, hydrogen-bonded, oligomeric networks. As a consequence, the compounds 214 and 215 display negative NOE enhancements.

The majority of nitrogenous terpenes reported are isocyanides and related compounds; inorganic cyanide has been shown to be the common precursor of their nitrogen. The oxeatamides are therefore unusual in that the nitrogenous moiety is proposed to arise from nucleophilic attack of an amino acid derivative onto one of the methine carbons of a furan ring. The oxeatamides are therefore one of the few examples of compounds of mixed terpene/amino acid origins. 


\section{Chapter 7}

\section{Conclusion}

Natural products have played a major role in the development of medicine and remain the major source of new pharmaceutical lead compounds. The oceans, still mostly unexplored, have high biological diversity which makes them a lucrative bioprospecting environment.

Nudibranchs are known to sequester defensive metabolties from their prey, and this "preconcentration" by the nudibranch can lead to rapid isolation of the main constituents by the natural product chemist. Indeed, this study resulted in the isolation (often within one or two chromatographic steps) of a range of secondary metabolites. The majority of the compounds have previously been reported in the literature, although this is the first time, to our knowledge, a polymeric 3-alkyl pyridinium salt has been described from a nudibranch. Other, less common New Zealand nudibranch species may also be worthy of chemical investigation.

A method to monitor chromatographic separation of compounds is essential for their efficient isolation and purification. In this study, the use of MS was found to be a useful, alternate monitoring method when separating related glycolipid congeners which did not have a chromophore. It resulted in the isolation of five members of a novel family of glycolipids from the marine sponge Raspailia agminata, the first reported glycolipids from the genus Raspailia.

While the most common strategy for screening organisms and guiding isolation remains bioassay, for a number of years the Marine Natural Products Group at Victoria University has used an NMR based screening method in order to identify promising organisms worthy of further investigation. This method has been extended during the course of this research: a computer program was developed to facilitate the analysis of HSQC spectra of crude sponge extracts and aid in the identification of the presence of interesting secondary metabolites. The use of the 
digital mask program successfully identified several sponges showing interesting and unusual correlations in the HSQC spectrum of their crude extract. Two of those sponges were investigated in detail, resulting in the isolation of some known and a series of new metabolites further validating the utility of NMR in natural product discovery. Scope for further development of the digital mask program includes implementing pattern recognition for early-stage dereplication of known compounds in crude sponge extracts.

The compounds isolated were not particularly active in a general cytotoxicity assay, however cytotoxicity is only one of many possible biological activities. The celluar target of the compounds is yet to be determined; biological activity testing is ongoing.

The real future of biological activity testing lies in genome-wide screening systems such as the yeast single deletion set assay and similar cell-based assays which are currently gaining popularity over single-target bioassays. These high content screening systems are now maturing and libraries of pure natural products, regardless of reported bioactivity, are sought after. The metabolites isolated in this research therefore contribute to the feedstock for these new techniques. Several of the compounds are currently awaiting chemical genetics screening at the School of Biological Sciences, VUW. 


\section{Chapter 8}

\section{Experimental}

\subsection{General experimental}

NMR spectra were obtained using either a Varian Unity Inova $300(300 \mathrm{MHz}$ for ${ }^{1} \mathrm{H}$ and $75 \mathrm{MHz}$ for ${ }^{13} \mathrm{C}$ ), or a Varian DirectDrive $600\left(600 \mathrm{MHz}\right.$ for ${ }^{1} \mathrm{H}$ and $150 \mathrm{MHz}$ for ${ }^{13} \mathrm{C}$ ) equipped with a Varian inverse-detected triple resonance $\mathrm{HCN}$ probe operating at $25 \mathrm{~K} .{ }^{1} \mathrm{H}$ and ${ }^{13} \mathrm{C}$ chemical shifts $(\delta)$ were internally referenced to the residual solvent peak, ${ }^{253}{ }^{15} \mathrm{~N}$ chemical shifts were externally referenced to nitromethane $\left(\mathrm{CH}_{3} \mathrm{NO}_{2}\right)$ as 0 ppm. HRESIMS were run on either a PE Biosystem Mariner 5158 TOF or a Micromass Q-TOF Premier mass spectrometer. MALDI-TOF analysis was performed using an Applied Biosystems DePro MALDI-TOF mass spectrometer. Optical rotations were performed on a Perkin-Elmer 241 polarimeter. UV spectra were recorded on a Varian Carey 100 Scan UV-visible spectrophotometer.

All solvent mixtures for chromatography are reported as \% v/v. HPLC and MPLC was performed on a Rainin Dynamax SD-200 HPLC system with $25 \mathrm{~mL}$ pump heads, equipped with a Varian ProStar 335 Diode Array detector. All organic solvents used were HPLC grade and $\mathrm{H}_{2} \mathrm{O}$ was glass-distilled and deionised using a MilliQ system. Normal phase HPLC was performed using a Rainin Instrument Microsorb-MV analytical $(4.6 \times 250 \mathrm{~mm}, 5 \mu)$ or a Dynamax semi-preparative $(10 \times 250 \mathrm{~mm}, 8 \mu)$ silica column, or a custom-packed Phenomenex analytical DIOL column $(5.0 \times 250 \mathrm{~mm}, 5 \mu)$. Reversed-phase HPLC was performed using Phenomenex Prodigy $\mathrm{C}_{18}$ analytical $(4.6 \times 250 \mathrm{~mm}, 5 \mu)$ or semi-preparative $(10 \times 250 \mathrm{~mm}, 10 \mu)$ columns.

Normal phase flash chromatography was carried out using Kieselgel 60 (230400 mesh ASTM) silica gel or YMC Co. Ltd. DIOL chromatographic resin. Reversed-phase chromatography was carried out using Supelco Diaion HP20 
and HP20SS PSDVB chromatographic resin. Size exclusion chromatography was performed using Sephadex LH-20. All solvents used for benchtop chromatography were glass distilled. All other reagents were purchased commercially (at least reagent grade) and distilled prior to use when necessary.

TLC analyses were performed using Machery-Nagel Alugram Sil G/UV 254 plates. The plates were analysed by (1) fluorescence quenching under UV light $(\lambda=254 \mathrm{~nm})$, (2) dipping in $5 \% \mathrm{H}_{2} \mathrm{SO}_{4}$ in $\mathrm{MeOH}$ then heating, (3) dipping in $5 \% \mathrm{H}_{2} \mathrm{SO}_{4}$ in $\mathrm{MeOH}$, dipping in $0.1 \%$ vanillin in EtOH and heating, or a combination of the above.

\subsection{Isolation of cembranoid diterpenes from the nudibranch $T$. incerta and the soft coral $A$. aurantiacum}

Nineteen T. incerta individuals were collected by hand using SCUBA from Rauhomaumau Island, Tutukaka, New Zealand (353 $37.5^{\prime} \mathrm{S}, 174^{\circ} 32.9^{\prime} \mathrm{E}$ ) in December 2003. The specimens were frozen immediately and stored at $-18{ }^{\circ} \mathrm{C}$ until extraction.

The nudibranchs (41 g wet weight) were extracted whole twice overnight with $\mathrm{MeOH}(100 \mathrm{~mL})$. The extracts were cyclic loaded* onto a $40 \mathrm{~mL}$ HP20 column $(2 \times 12 \mathrm{~cm})$. The column was then washed with $\mathrm{H}_{2} \mathrm{O}(120 \mathrm{~mL})$ and eluted with $120 \mathrm{~mL}$ fractions as follows: (1) $30 \% \mathrm{Me}_{2} \mathrm{CO} / \mathrm{H}_{2} \mathrm{O}$, (2) $75 \% \mathrm{Me}_{2} \mathrm{CO} / \mathrm{H}_{2} \mathrm{O}$, and (3) $\mathrm{Me}_{2} \mathrm{CO}$.

Fraction 2 was backloaded* onto a $20 \mathrm{~mL}$ HP20 column $(2 \times 6 \mathrm{~cm})$, and eluted with $60 \mathrm{~mL} \mathrm{Me}_{2} \mathrm{CO}$. The eluent was concentrated under reduced pressure. The resulting material (90 mg) was separated chromatographically in two portions by adsorbing onto $2 \mathrm{~mL}$ of DIOL and dry-loading onto a $20 \mathrm{~mL}$ DIOL column $(1.3 \times 17 \mathrm{~cm})$. The column was eluted with $80 \mathrm{~mL}$ volumes of: pet. ether, $10 \%, 20 \%, 30 \%, 40 \%, 50 \% \mathrm{CH}_{2} \mathrm{Cl}_{2}$ in pet. ether, $\mathrm{CH}_{2} \mathrm{Cl}_{2}$ and finally with $50 \%$ $\mathrm{MeOH} / \mathrm{CH}_{2} \mathrm{Cl}_{2}$. Fractions eluted with pet. ether were combined based on TLC to afford $2.5 \mathrm{mg}$ of (-)-epi-thunbergol (25).

Fractions eluting with $30 \% \mathrm{CH}_{2} \mathrm{Cl}_{2}$ were combined and loaded onto a silica gel column $(20 \mathrm{~mL}, 1.3 \mathrm{~cm} \times 17 \mathrm{~cm})$. The column was eluted with $80 \mathrm{~mL}$ volumes of: $\mathrm{CH}_{2} \mathrm{Cl}_{2}, 2 \%, 4 \%, 6 \%, 8 \%, 10 \%$ EtOAc in $\mathrm{CH}_{2} \mathrm{Cl}_{2}$ and $10 \% \mathrm{MeOH}$

\footnotetext{
*Please see Appendix A on page 186 for a detailed discussion of cyclic loading and backloading.
} 
in $\mathrm{CH}_{2} \mathrm{Cl}_{2}$. Fractions (approx. $6 \mathrm{~mL}$ ) of the 2-10\% EtOAc solvent mixtures were collected. The fractions were combined on the basis of TLC and as only partial separation was achieved, the column was repeated multiple times on the mixture to eventually afford $13 \alpha$-acetoxypukalide (26) (17.4 mg) and lopholide (27) (3.8 $\mathrm{mg})$ in about $90-95 \%$ purity.

The less polar fractions of the DIOL column (eluting with $20 \% \mathrm{CH}_{2} \mathrm{Cl}_{2}$ ) were combined and further purified on a DIOL column $(5 \mathrm{~mL}, 1.3 \times 4 \mathrm{~cm})$. The column was eluted with $20 \mathrm{~mL}$ of pet. ether, $10 \%, 20 \%, 30 \% \mathrm{CH}_{2} \mathrm{Cl}_{2}$ in pet. ether and finally with $50 \% \mathrm{MeOH} / \mathrm{CH}_{2} \mathrm{Cl}_{2}$. Fractions eluting with $20 \%$ and $30 \%$ $\mathrm{CH}_{2} \mathrm{Cl}_{2}$ were combined on the basis of TLC to afford pukalide (28) (0.5 mg) and $11 \beta, 12 \beta$-epoxypukalide (29) (0.9 mg).

The $10 \% \mathrm{MeOH} / \mathrm{CH}_{2} \mathrm{Cl}_{2}$ elutions from the multiple silica columns were a mix of two compounds and were separated on an analytical DIOL HPLC column which was eluted with $20 \%$ IPA in hexane at a flow rate of $1 \mathrm{~mL} / \mathrm{min}$. Two fractions were collected (retention times 11.5 and 13.6 minutes) to give $13 \alpha$ acetoxypukalide diol (30) (1.2 mg) and lopholide diol (31) (1.4 mg) respectively.

Fraction 3 from the cyclic loading was concentrated under reduced pressure and the material $(62.7 \mathrm{mg})$ was purified on a silica gel column $(50 \mathrm{~mL}, 2.1 \times$ $15 \mathrm{~cm}$ ). The column was eluted with $200 \mathrm{~mL}$ volumes of $50 \%, 75 \% \mathrm{CH}_{2} \mathrm{Cl}_{2}$ in pet. ether, $\mathrm{CH}_{2} \mathrm{Cl}_{2}$ and $50 \% \mathrm{MeOH}$ in $\mathrm{CH}_{2} \mathrm{Cl}_{2}$. Fractions of $10 \mathrm{~mL}$ were collected, and those eluted with the $75 \% \mathrm{CH}_{2} \mathrm{Cl}_{2}$ were combined on the basis of TLC to yield a further $3.4 \mathrm{mg}$ of (-)-epi-thunbergol (25).

\section{Isolation of (-)-epi-thunbergol from A. aurantiacum}

Samples of the soft coral A. Aurantiacum were collected by hand using SCUBA from Elizabeth Reef and Rimariki Island, Tutukaka, New Zealand in April 2003. They were frozen immediately and kept at $-18{ }^{\circ} \mathrm{C}$ until extraction. Voucher specimens (PTN2_45F, PTN2_54J, PTN2_55A) have been deposited at the School of Chemical and Physical Sciences, Victoria University of Wellington, New Zealand.

The soft coral (400 g wet weight) was cut up and extracted overnight with $\mathrm{MeOH}(800 \mathrm{~mL})$. The coral was filtered, then blended with a further $800 \mathrm{~mL}$ $\mathrm{MeOH}$ in a Warring blender and left to extract overnight. The extracts were cyclic loaded onto a column of HP20 $(130 \mathrm{~mL}, 2.5 \times 27 \mathrm{~cm})$. The column was then washed with $\mathrm{H}_{2} \mathrm{O}(400 \mathrm{~mL})$ and then eluted with $400 \mathrm{~mL}$ fractions of: (1) $20 \% \mathrm{Me}_{2} \mathrm{CO} / \mathrm{H}_{2} \mathrm{O}$, (2) $40 \% \mathrm{Me}_{2} \mathrm{CO} / \mathrm{H}_{2} \mathrm{O}$, (3) $60 \% \mathrm{Me}_{2} \mathrm{CO} / \mathrm{H}_{2} \mathrm{O}$, (4) $80 \%$ $\mathrm{Me}_{2} \mathrm{CO} / \mathrm{H}_{2} \mathrm{O}$ and (5) $\mathrm{Me}_{2} \mathrm{CO}$. 
Fraction 4 was backloaded onto a $40 \mathrm{~mL}$ HP20 column $(2 \times 12 \mathrm{~cm})$, which was eluted with $120 \mathrm{~mL} \mathrm{Me}_{2} \mathrm{CO}$ and concentrated under reduced pressure to afford $265.3 \mathrm{mg}$ of material. This was further purified in portions on a DIOL column: the material was adsorbed onto $2 \mathrm{~mL}$ DIOL and dry loaded onto a column of $20 \mathrm{~mL}(3 \times 17 \mathrm{~cm})$. The column was eluted with $80 \mathrm{~mL}$ volumes of pet. ether, $20 \%, 40 \%, 60 \% \mathrm{CH}_{2} \mathrm{Cl}_{2}$ in pet. ether, $\mathrm{CH}_{2} \mathrm{Cl}_{2}$ and $50 \% \mathrm{MeOH}$ in $\mathrm{CH}_{2} \mathrm{Cl}_{2}$. Late eluting pet. ether fractions were combined on the basis of TLC to afford $10.4 \mathrm{mg}$ of (-)-epi-thunbergol (25).

(-)-epi-Thunbergol (25): Clear oil; $[\alpha]_{\mathrm{D}}^{20}-7.2$ ( c 1.0, MeOH); all spectroscopic data were in agreement with those reported. ${ }^{76}$

13 $\alpha$-Acetoxypukalide (26): Clear glass; all spectroscopic data were in agreement with those reported. ${ }^{73}$

Lopholide (27): White solid; all spectroscopic data were in agreement with those reported. ${ }^{73}$

Pukalide (28): White solid; all spectroscopic data were in agreement with those reported. ${ }^{74}$

11 $\beta, 12 \beta$-Epoxypukalide (29): White solid; all spectroscopic data were in agreement with those reported. ${ }^{75}$

13 $\alpha$-Acetoxypukalide diol (30): White solid; UV (MeOH) $\lambda_{\max }, \mathrm{nm}(\varepsilon): 202$ (19,900), 219 (sh, 9,340), 250 (3,900); $[\alpha]_{\mathrm{D}}^{20}+8.3$ ( c 0.1, MeOH); NMR data see Table 2.1; HRESIMS $m / z$ 471.1623 [M $+\mathrm{Na}]^{+}, \mathrm{C}_{23} \mathrm{H}_{28} \mathrm{O}_{9} \mathrm{Na}$ requires 471.1631, $\Delta 1.7 \mathrm{ppm}$.

Lopholide diol (31): White solid; UV (MeOH) $\lambda_{\max }, \mathrm{nm}(\varepsilon)$ : $202(8,130)$, $222(3,210), 250(2,170) ;[\alpha]_{\mathrm{D}}^{20}-9.3$ ( $\left.c 0.1, \mathrm{MeOH}\right)$; NMR data see Table 2.2; HRESIMS $m / z 487.1579[\mathrm{M}+\mathrm{Na}]^{+}, \mathrm{C}_{23} \mathrm{H}_{28} \mathrm{O}_{10}$ Na requires 487.1580, $\Delta 0.2 \mathrm{ppm}$.

\subsection{Isolation of two drimane sesquiterpenes from the nudibranch $D$. denisoni}

Two D. denisoni individuals were collected by hand using SCUBA from Rauho-

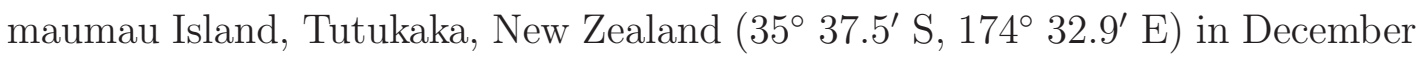
2003. The specimens were frozen immediately and stored at $-18{ }^{\circ} \mathrm{C}$ until extraction. 
The nudibranchs (40 $\mathrm{g}$ wet weight) were extracted twice overnight with $\mathrm{MeOH}(80 \mathrm{~mL})$ and the extracts were cyclic loaded onto a $40 \mathrm{~mL}$ HP20 column $(2 \times 12 \mathrm{~cm})$. The column was then washed with $\mathrm{H}_{2} \mathrm{O}(120 \mathrm{~mL})$ and eluted with $120 \mathrm{~mL}$ fractions as follows: (1) $30 \% \mathrm{Me}_{2} \mathrm{CO} / \mathrm{H}_{2} \mathrm{O}$, (2) $70 \% \mathrm{Me}_{2} \mathrm{CO} / \mathrm{H}_{2} \mathrm{O}$, and (3) $\mathrm{Me}_{2} \mathrm{CO}$.

Fraction 2 was backloaded onto a $20 \mathrm{~mL} \mathrm{HP20} \mathrm{column}(2 \times 6 \mathrm{~cm})$ and eluted with $60 \mathrm{~mL} \mathrm{Me}_{2} \mathrm{CO}$. The sample was concentrated under reduced pressure, and the resulting material $(73.1 \mathrm{mg})$ was separated in portions on DIOL $(20 \mathrm{~mL}$, $1.3 \times 17 \mathrm{~cm})$. The column was eluted successively with $80 \mathrm{~mL}$ volumes of pet. ether, $10 \%, 20 \%, 50 \% \mathrm{CH}_{2} \mathrm{Cl}_{2}$ in pet. ether, $\mathrm{CH}_{2} \mathrm{Cl}_{2}$ and $50 \% \mathrm{MeOH}$ in $\mathrm{CH}_{2} \mathrm{Cl}_{2}$. Several fractions eluted with $10 \% \mathrm{CH}_{2} \mathrm{Cl}_{2}$ in pet. ether were combined on the basis of TLC char and UV absorbance to give $11.5 \mathrm{mg}$ of cinnamolide (35).

Other fractions eluted with $50 \% \mathrm{CH}_{2} \mathrm{Cl}_{2}$ in pet. ether were also combined and further purified on a silica gel column $(15 \mathrm{~mL}, 1.3 \times 12 \mathrm{~cm})$. The column was eluted with $30 \mathrm{~mL}$ pet. ether, $60 \mathrm{~mL} \mathrm{25 \% ,40 \%} \mathrm{Et}_{2} \mathrm{O}$ in pet. ether, $80 \mathrm{~mL}$ $50 \% \mathrm{Et}_{2} \mathrm{O}$ in pet. ether, $60 \mathrm{~mL} 75 \% \mathrm{Et}_{2} \mathrm{O}$ in pet. ether and $\mathrm{Et}_{2} \mathrm{O} .100$ fractions ( $5 \mathrm{~mL}$ each) were collected. Fractions $46-55$ were combined based on TLC to afford $1.3 \mathrm{mg}$ of dendocarbin $\mathrm{A}(\mathbf{3 6})$.

Cinnamolide (35): White solid; all spectroscopic data were in agreement with those reported. ${ }^{88,89}$

Dendocarbin A (36): White solid; all spectroscopic data were in agreement with those reported. ${ }^{90}$

\subsection{Isolation of a polymeric alkyl-pyridinium salt from the nudibranch $A$. luctuosa}

Eleven A. luctuosa individuals were collected by hand using SCUBA from various locations off the coast of Northland, New Zealand (between Cape Brett and Cape Karikari, $\left.35^{\circ} 11.5^{\prime}-34^{\circ} 48.8 \mathrm{~S}, 174^{\circ} 20.3^{\prime}-173^{\circ} 25.8 \mathrm{E}\right)$ in December 2003. The specimens were frozen immediately and stored at $-18{ }^{\circ} \mathrm{C}$ until extraction.

The nudibranchs were extracted whole in two portions (44 and $53 \mathrm{~g}$ wet weight) twice overnight with $\mathrm{MeOH}(100 \mathrm{~mL}$ each) and the extracts were cyclic loaded onto $40 \mathrm{~mL}$ HP20 columns $(2 \times 12 \mathrm{~cm})$. The columns were then washed with $\mathrm{H}_{2} \mathrm{O}(120 \mathrm{~mL})$ and eluted with $120 \mathrm{~mL}$ fractions as follows: (1) $30 \%$ $\mathrm{Me}_{2} \mathrm{CO} / \mathrm{H}_{2} \mathrm{O}$, (2) $75 \% \mathrm{Me}_{2} \mathrm{CO} / \mathrm{H}_{2} \mathrm{O}$, and (3) $\mathrm{Me}_{2} \mathrm{CO}$.

Fraction 1 from one of the columns was backloaded onto a $20 \mathrm{~mL}$ HP20 
column $(2 \times 6 \mathrm{~cm})$ and eluted with $60 \mathrm{~mL} \mathrm{MeOH}$. It was concentrated under reduced pressure to afford $217 \mathrm{mg}$ of a brown oil. This was dissolved in approx. $2 \mathrm{~mL}$ of $10 \% \mathrm{H}_{2} \mathrm{O} / \mathrm{MeOH}$, and insoluble particulates were filtered through cotton wool. The filtrate was loaded onto a $220 \mathrm{~mL}$ LH-20 size exclusion column $(2 \times$ $70 \mathrm{~cm}$ ), and eluted with $10 \% \mathrm{H}_{2} \mathrm{O} / \mathrm{MeOH}$. Early eluting fractions yielded the polymeric alkyl-pyridinium salt (53).

Polymeric APS (53): Yellow-orange glass; NMR data see Table 8.1.

Table 8.1. NMR data (600 MHz, $\mathrm{CD}_{3} \mathrm{OD}$ ) for the polymeric 3-alkyl pyridinium salt (53).

\begin{tabular}{c|rccclll}
\hline pos. & $\begin{array}{c}\delta_{\mathrm{C}} / \delta_{\mathrm{N}} \\
(\mathrm{ppm})\end{array}$ & mult & ${ }^{1} J_{\mathrm{XH}}$ & $\begin{array}{c}\delta_{\mathrm{H}} \\
(\mathrm{ppm})\end{array}$ & $\begin{array}{c}\text { mult, } \\
J(\mathrm{~Hz})\end{array}$ & COSY & HMBC \\
\hline \hline 1 & -67.4 & $\mathrm{~N}$ & - & - & - & - & \\
2 & 145.3 & $\mathrm{CH}$ & 194 & 8.96 & $\mathrm{br} \mathrm{s}$ & $4,5,6,7,14$ & $1,4,6,7,14$ \\
3 & 145.7 & $\mathrm{C}$ & - & - & - & - & - \\
4 & 146.6 & $\mathrm{CH}$ & 174 & 8.46 & $\mathrm{~d}(8.2)$ & $2,5,6,7,14$ & $2,6,14$ \\
5 & 129.0 & $\mathrm{CH}$ & 180 & 8.03 & $\mathrm{t}(6.5)$ & $2,4,6$ & $1,3,6,7$ \\
6 & 143.4 & $\mathrm{CH}$ & 197 & 8.87 & $\mathrm{~d}(5.4)$ & $2,4,5,7,14$ & $1,2,4,5$ \\
7 & 62.9 & $\mathrm{CH}_{2}$ & 143 & 4.63 & $\mathrm{t}(7.3)$ & $2,4,5,8$ & $1,2,6,8,9$ \\
8 & 32.6 & $\mathrm{CH}_{2}$ & 129 & 2.03 & $\mathrm{~m}$ & 7,9 & 7,9 \\
9 & 27.1 & $\mathrm{CH}_{2}$ & 125 & 1.40 & $\mathrm{~m}$ & & 7,8 \\
$10-12$ & 30.0 & $\mathrm{CH}_{2}$ & 123 & 1.40 & $\mathrm{~m}$ & & 12,14 \\
13 & 31.5 & $\mathrm{CH}_{2}$ & 125 & 1.74 & $\mathrm{~m}$ & 12,14 & $3,12,13$ \\
14 & 33.5 & $\mathrm{CH}_{2}$ & 132 & 2.88 & $\mathrm{t}(7.5)$ & $2,4,6,13$ & \\
\hline
\end{tabular}<smiles>[X]CCCCCCCCCCCCCC</smiles>

53

\subsection{Isolation of a pyrrole alkaloid from the nu- dibranch T. morosa}

Three T. morosa specimens were collected by hand using SCUBA from Rauhomaumau Island, Tutukaka ( $\left.35^{\circ} 37.5^{\prime} \mathrm{S}, 174^{\circ} 32.9^{\prime} \mathrm{E}\right)$ and West Chicken Island, Hen and Chickens (35 53.79' S, $174^{\circ} 42.17^{\prime} \mathrm{E}$ ), New Zealand in December 2003. The specimens were frozen immediately and stored at $-18{ }^{\circ} \mathrm{C}$ until extraction.

The three nudibranchs (14 g wet weight) were extracted whole twice overnight with $\mathrm{MeOH}(50 \mathrm{~mL})$ and the extracts were cyclic loaded onto a $40 \mathrm{~mL} \mathrm{HP} 20$ column $(2 \times 12 \mathrm{~cm})$. The column was then washed with $\mathrm{H}_{2} \mathrm{O}(120 \mathrm{~mL})$ and eluted with $120 \mathrm{~mL}$ fractions as follows: (1) $30 \% \mathrm{Me}_{2} \mathrm{CO} / \mathrm{H}_{2} \mathrm{O}$, (2) $75 \% \mathrm{Me}_{2} \mathrm{CO} / \mathrm{H}_{2} \mathrm{O}$, and (3) $\mathrm{Me}_{2} \mathrm{CO}$. 
Fraction 1 was backloaded onto a $20 \mathrm{~mL}$ HP20 column $(2 \times 12 \mathrm{~cm})$, eluted with $60 \mathrm{~mL} \mathrm{MeOH}$, and concentrated under reduced pressure to give $39.6 \mathrm{mg}$ of material. The sample was dissolved in a minimum amount of $\mathrm{MeOH}$, and cyclic loaded onto $2 \mathrm{~mL}$ HP20SS. The coloured cyclic loading eluent was concentrated under reduced pressure to afford tambjamine A (67a) (12.2 mg).

Tambjamine A (67a): Dark green solid; NMR data see Table 2.3.

\subsection{Isolation of three terpenes from the nudi- branch $C$. amoenum}

Twenty eight individuals identified as $C$. amoenum were collected by hand using SCUBA from various locations off the coast of Northland, New Zealand (between Tutukaka and Cape Karikari, $35^{\circ} 37.5^{\prime}-34^{\circ} 48.8^{\prime}$ S, $174^{\circ} 32.9^{\prime}-173^{\circ} 25.8^{\prime}$ E) in December 2003. The specimens were frozen immediately and stored at $-18^{\circ} \mathrm{C}$ until extraction.

The nudibranchs ( $26 \mathrm{~g}$ wet weight) were extracted whole twice overnight with $\mathrm{MeOH}(50 \mathrm{~mL})$ and the extracts were cyclic loaded onto a $20 \mathrm{~mL}$ HP20 column $(2 \times 6 \mathrm{~cm})$. The column was then washed with $\mathrm{H}_{2} \mathrm{O}(60 \mathrm{~mL})$ and eluted with $60 \mathrm{~mL}$ fractions as follows: (1) $30 \% \mathrm{Me}_{2} \mathrm{CO} / \mathrm{H}_{2} \mathrm{O}$, (2) $75 \% \mathrm{Me}_{2} \mathrm{CO} / \mathrm{H}_{2} \mathrm{O}$, and (3) $\mathrm{Me}_{2} \mathrm{CO}$.

The $100 \% \mathrm{Me}_{2} \mathrm{CO}$ fraction was concentrated under reduced pressure to give $122.7 \mathrm{mg}$ of material. This was adsorbed onto $3 \mathrm{~mL}$ silica gel, and dry-loaded onto a silica gel column $(50 \mathrm{ml}, 2.1 \times 18 \mathrm{~cm})$. The column was eluted with $200 \mathrm{~mL}$ volumes of pet. ether, $10 \%, 25 \%, 50 \% \mathrm{CH}_{2} \mathrm{Cl}_{3}$ in pet. ether, $\mathrm{CH}_{2} \mathrm{Cl}_{2}$ and $50 \% \mathrm{MeOH}$ in $\mathrm{CH}_{2} \mathrm{Cl}_{2}$, collecting $10 \mathrm{~mL}$ fractions. Fractions eluting with pet. ether were combined on the basis of TLC to afford $25.2 \mathrm{mg}$ of furodysinin (83).

The $75 \% \mathrm{Me}_{2} \mathrm{CO} / \mathrm{H}_{2} \mathrm{O}$ fraction from the cyclic loading was backloaded onto $20 \mathrm{~mL}$ HP20 column $(2 \times 6 \mathrm{~cm})$ and eluted with $60 \mathrm{~mL}$ of $\mathrm{Me}_{2} \mathrm{CO}$. The sample was concentrated under reduced pressure to give $111.1 \mathrm{mg}$ of material that was adsorbed onto $2 \mathrm{~mL}$ DIOL, and dry-loaded onto a $20 \mathrm{~mL}$ DIOL column $(1.4 \times$ $18 \mathrm{~cm}$ ). The column was eluted with $60 \mathrm{~mL}$ volumes of pet. ether, $50 \% \mathrm{CH}_{2} \mathrm{Cl}_{2}$ in pet. ether, $\mathrm{CH}_{2} \mathrm{Cl}_{2}, 50 \%$ EtOAc in $\mathrm{CH}_{2} \mathrm{Cl}_{2}$, EtOAc and $50 \% \mathrm{MeOH}$ in $\mathrm{CH}_{2} \mathrm{Cl}_{2}$. Fractions of $15 \mathrm{~mL}$ were collected. When concentrated under reduced pressure, fraction 2 contained $7.1 \mathrm{mg}$ of $\mathbf{8 3}$, and fraction 4 contained $2.4 \mathrm{mg}$ of (semi-pure) $O$-methyl-furodysinin lactone (84).

Fraction $6(29.3 \mathrm{mg})$ was further purified on a $15 \mathrm{~mL}$ silica gel column $(1.5 \times$ 
$12 \mathrm{~cm}$ ) eluted with $60 \mathrm{~mL}$ volumes of pet. ether, $25 \%, 50 \%, 75 \% \mathrm{CH}_{2} \mathrm{Cl}_{2}$ in pet. ether, $\mathrm{CH}_{2} \mathrm{Cl}_{2}$ and $50 \% \mathrm{MeOH}$ in $\mathrm{CH}_{2} \mathrm{Cl}_{2}$. The $\mathrm{CH}_{2} \mathrm{Cl}_{2}$ fraction (6.6 mg) was purified on another $20 \mathrm{~mL}$ silica gel column $(1.4 \times 17 \mathrm{~cm})$ eluted with $50 \%, 70 \%$, $80 \%, 90 \% \mathrm{CH}_{2} \mathrm{Cl}_{2}$ in pet. ether, and $\mathrm{CH}_{2} \mathrm{Cl}_{2}$, collecting $5 \mathrm{~mL}$ fractions. Fractions were combined based on TLC to give $8.7 \mathrm{mg}$ (-)-tetradehydrofurospongin-1 $(85)$.

Furodysinin (83): Pale yellow glass; all spectroscopic data were in agreement with those reported. ${ }^{114,117}$

O-methyl-furodysinin lactone (84): Clear glass; all spectroscopic data were in agreement with those reported. ${ }^{114,122}$

(-)-Tetradehydrofurospongin-1 (85): Pale yellow solid; $[\alpha]_{\mathrm{D}}^{20}-63.1(c 0.35$, $\mathrm{CH}_{2} \mathrm{Cl}_{2}$ ); all spectroscopic data were in agreement with those reported. ${ }^{115}$

\subsection{Isolation of five glycolipids from the sponge R. agminata}

The sponge $R$. agminata was collected by hand using SCUBA from Taheke Reef, Cavalli Islands, New Zealand ( $34^{\circ} 57.8^{\prime} \mathrm{S}, 173^{\circ} 59.0^{\prime} \mathrm{E}$ at a depth of $10-15 \mathrm{~m}$ ) in December 2003. The sample was frozen immediately and kept at $-18{ }^{\circ} \mathrm{C}$ until extraction. A voucher specimen (PTN2_79D) has been deposited at the School of Chemical and Physical Sciences, Victoria University of Wellington, New Zealand.

\section{Isolation of agminosides A-E (145-149)}

The sponge (251 g wet weight) was cut up and extracted twice overnight with $\mathrm{MeOH}(900 \mathrm{~mL})$. The extracts were cyclic loaded onto a $200 \mathrm{~mL}$ column of HP20 $(5.5 \times 8.5 \mathrm{~cm})$. The column was then washed with $\mathrm{H}_{2} \mathrm{O}(600 \mathrm{~mL})$ and eluted with $600 \mathrm{~mL}$ fractions of (1) $20 \% \mathrm{Me}_{2} \mathrm{CO} / \mathrm{H}_{2} \mathrm{O}$, (2) $40 \% \mathrm{Me}_{2} \mathrm{CO} / \mathrm{H}_{2} \mathrm{O}$, (3) $60 \%$ $\mathrm{Me}_{2} \mathrm{CO} / \mathrm{H}_{2} \mathrm{O}$, (4) $80 \% \mathrm{Me}_{2} \mathrm{CO} / \mathrm{H}_{2} \mathrm{O}$ and (5) $\mathrm{Me}_{2} \mathrm{CO}$. Fraction 3 was backloaded onto a $80 \mathrm{~mL}$ column of HP20 $(2.5 \times 18 \mathrm{~cm})$ and eluted with $250 \mathrm{~mL} \mathrm{MeOH}$. Upon concentration under reduced pressure, this fraction yielded $450 \mathrm{mg}$ of material that was purified in three portions on LH-20 $(200 \mathrm{~mL}, 2 \times 67 \mathrm{~cm})$ in $\mathrm{MeOH}$. Early eluting fractions were combined (on the basis of TLC char) to afford a mixture of glycolipids (344 mg). Portions of this were repeatedly chromatographed on benchtop and HPLC silica columns using $\mathrm{CH}_{2} \mathrm{Cl}_{2} / \mathrm{MeOH} / \mathrm{H}_{2} \mathrm{O}$ 
mixtures to yield: $11.0 \mathrm{mg}$ agminoside A (145), $2.5 \mathrm{mg}$ agminoside B (146), $1.3 \mathrm{mg}$ agminoside C (147), $3.1 \mathrm{mg}$ agminoside D (148), and $0.5 \mathrm{mg}$ agminoside E (149).

Agminoside A (145): Clear glass; $[\alpha]_{\mathrm{D}}^{20}-3.0$ ( $c$ 1.0, $\left.\mathrm{MeOH}\right) ; \mathrm{NMR}$ data see Table 3.9; HRMALDI-TOF-MS m/z $1943.7707[\mathrm{M}+\mathrm{Na}]^{+}, \mathrm{C}_{85} \mathrm{H}_{132} \mathrm{O}_{48} \mathrm{Na}$ requires $1943.7780, \Delta 3.8 \mathrm{ppm}$.

Agminoside B (146): Clear glass; NMR data see Table 3.12; HRESIMS m/z $1877.7734[\mathrm{M}-\mathrm{H}]^{-}, \mathrm{C}_{83} \mathrm{H}_{130} \mathrm{O}_{47}$ requires 1877.7704, $\Delta 1.6 \mathrm{ppm}$.

Agminoside C (147): Clear glass; NMR data see Table 3.13; HRESIMS m/z $1877.7721[\mathrm{M}-\mathrm{H}]^{-}, \mathrm{C}_{83} \mathrm{H}_{130} \mathrm{O}_{47}$ requires 1877.7704, $\Delta 0.9 \mathrm{ppm}$.

Agminoside D (148): Clear glass; NMR data see Table 3.14; HRESIMS m/z $1835.7599[\mathrm{M}-\mathrm{H}]^{-}, \mathrm{C}_{81} \mathrm{H}_{128} \mathrm{O}_{46}$ requires 1835.7599, $\Delta 0.4 \mathrm{ppm}$.

Agminoside E (149): Clear glass; NMR data see Table 3.15; HRESIMS m/z $1715.7176[\mathrm{M}-\mathrm{H}]^{-}, \mathrm{C}_{77} \mathrm{H}_{119} \mathrm{O}_{42}$ requires $1715.7176, \Delta 1.2 \mathrm{ppm}$.

\section{Methanolysis of a crude mixture of glycolipids}

A portion of the crude mixture of glycolipids $(60 \mathrm{mg})$ was heated in $\mathrm{MeOH}(1 \mathrm{~mL})$ with 3 drops of conc. $\mathrm{HCl}$ in a screw-cap vial at $80-90{ }^{\circ} \mathrm{C}$ for 48 hours. The sample was diluted with $\mathrm{H}_{2} \mathrm{O}(1 \mathrm{~mL})$ and cyclic loaded onto a column of HP20SS $(1 \times 2 \mathrm{~cm})$. The column was then eluted with $6 \mathrm{~mL}$ fractions of $(1) \mathrm{H}_{2} \mathrm{O}$ and (2) $\mathrm{MeOH}$. The MeOH fraction was evaporated to dryness to yield $12.0 \mathrm{mg}$ of aglycon methyl ester (151). The $\mathrm{H}_{2} \mathrm{O}$ fraction was concentrated under reduced pressure to yield $50.8 \mathrm{mg}$ of 1 - $O$-methyl- $\alpha$-D-glucose and 1 - $O$-methyl- $\beta$-D-glucose $(49: 1)$.

The methyl glucoside $(5.0 \mathrm{mg})$ was treated with $2 \mathrm{~mL} \mathrm{1:1}$ pyridine $/ \mathrm{Ac}_{2} \mathrm{O}$ under argon with stirring. After $18 \mathrm{~h}$, the reaction was quenched with $2 \mathrm{~mL}$ $\mathrm{H}_{2} \mathrm{O}$ and the sample was cyclic loaded onto $2 \mathrm{~mL}$ HP20SS. The column was then washed with $\mathrm{H}_{2} \mathrm{O}$, and eluted with $6 \mathrm{~mL} \mathrm{MeOH}$, giving 2,3,4,6-tetra- $O$ acetyl-1- $O$-methyl- $\alpha$-D-glucose $(5.0 \mathrm{mg})$.

Aglycon methyl ester (151): White solid; $[\alpha]_{\mathrm{D}}^{20}-19.5$ ( $\left.c 0.99, \mathrm{MeOH}\right) ; \mathrm{NMR}$ data see Table 3.8; HRESIMS $m / z 439.3381[\mathrm{M}+\mathrm{Na}]^{+}, \mathrm{C}_{24} \mathrm{H}_{48} \mathrm{O}_{5} \mathrm{Na}$ requires 439.3394, $\Delta 3.0 \mathrm{ppm}$.

1- $\boldsymbol{O}$-Methyl-D-glucose: White solid; $[\alpha]_{\mathrm{D}}^{20}+209\left(c 0.65, \mathrm{H}_{2} \mathrm{O}\right)$. 
2,3,4,6-Tetra- $\boldsymbol{O}$-acetyl-1- $\boldsymbol{O}$-methyl- $\alpha$-D-glucose: White solid; NMR data $\left(\mathrm{CDCl}_{3}, 600 \mathrm{MHz}\right) \delta 5.48(1 \mathrm{H}, \mathrm{t}, 10.0 \mathrm{~Hz}, \mathrm{H}-3), 5.07$ (1H, t, $\left.10.3 \mathrm{~Hz}, \mathrm{H}-4\right), 4.95$ (1H, d, 3.9 Hz, H-1), 4.90 (1H, dd, 10.3, 3.9 Hz, H-2), 4.26 (1H, dd, 12.3, $5.0 \mathrm{~Hz}$, H-6a), 4.11 (1H, dd, 12.3, 2.5 Hz, H-6b), 3.98 (1H, ddd, 10.3, 4.5, 2.3 Hz, H-5), $3.41(3 \mathrm{H}, \mathrm{s}, 1-\mathrm{OMe}), 2.10(3 \mathrm{H}, \mathrm{s}, \mathrm{OAc}), 2.08$ (3H, s, OAc), 2.03 (3H, s, OAc), $2.01(3 \mathrm{H}, \mathrm{s}, \mathrm{OAc})$.

\section{Methylation of a crude mixture of glycolipids}

$\mathrm{TMSCHN}_{2}(50 \mu \mathrm{L}, 2 \mathrm{M}$ in hexanes) was added to $8.8 \mathrm{mg}$ of a crude mixture of glycolipids dissolved in dry $\mathrm{MeOH}(1 \mathrm{~mL})$ under argon at $0{ }^{\circ} \mathrm{C}$. After 1 hour, the reaction was quenched with $2 \%(\mathrm{v} / \mathrm{v})$ acetic acid in $\mathrm{H}_{2} \mathrm{O}(1 \mathrm{~mL})$, and was allowed to warm up to room temperature. After the disappearance of all yellow colour from the solution (30 min), the sample was cyclic loaded onto a column of HP20SS $(1 \times 2 \mathrm{~cm})$. The column was then eluted with $6 \mathrm{~mL}$ fractions of (1) $\mathrm{H}_{2} \mathrm{O}$, (2) $50 \% \mathrm{Me}_{2} \mathrm{CO} / \mathrm{H}_{2} \mathrm{O}$, (3) $80 \% \mathrm{Me}_{2} \mathrm{CO} / \mathrm{H}_{2} \mathrm{O}$ and (4) $\mathrm{Me}_{2} \mathrm{CO}$. Fraction 3 was evaporated to dryness to yield $7.4 \mathrm{mg}$ of methylated glycolipids.

\section{Preparation of Mosher's esters of 151}

To a solution of 151 ( $2 \mathrm{mg}, 4.8 \mu \mathrm{mol})$ in $2 \mathrm{~mL} \mathrm{CH}_{2} \mathrm{Cl}_{2}$ was added DMAP (4.5 mg, $36.8 \mu \mathrm{mol})$ and either $(R)$ - or $(S)$-MTPACl $(3 \mu \mathrm{L}, 16.1 \mu \mathrm{mol})$ under argon, and the mixture was stirred overnight. The reaction was quenched with $1 \mathrm{~mL} \mathrm{H}_{2} \mathrm{O}$ and the solution was washed with $4 \mathrm{~mL}$ of $1 \mathrm{M} \mathrm{HCl}, 1 \mathrm{M} \mathrm{NaOH}$, and finally brine. The organic layer was concentrated to yield the $R$-Mosher's ester (5.0 mg) and $S$-Mosher's ester $(4.7 \mathrm{mg})$ derivative.

Mosher's ester derivatives of the aglycon methyl ester: White solids; NMR data see Table 3.7 .

\section{Peracetylation reactions}

To either $145(0.5 \mathrm{mg})$ or a mixture of glycolipids $(0.6 \mathrm{mg})$ was added $500 \mu \mathrm{L}$ pyridine and $500 \mu \mathrm{L}$ acetic anhydride under argon. The mixtures were stirred at room temperature overnight. The reactions were quenched by the addition of $1 \mathrm{~mL} \mathrm{H} \mathrm{H}_{2} \mathrm{O}$, and were cyclic loaded onto $2 \mathrm{~mL}$ HP20SS. The columns were washed with $\mathrm{H}_{2} \mathrm{O}$, and eluted with $6 \mathrm{~mL} \mathrm{Me}_{2} \mathrm{CO}$. Concentration of the $\mathrm{Me}_{2} \mathrm{CO}$ under reduced pressure afforded peracetylated agminoside A $(0.8 \mathrm{mg})$ and peracetylated glycolipid mixture (0.7 mg). 
Peracetylated agminoside A: Clear glass; ESIMS m/z 2172.8, 2214.8.

Peracetylated glycolipid mixture: Clear glass; ESIMS m/z 1349.6, 1595.7, 1637.7, 1884.8, 1926.8, 2172.8, 2214.8.

\section{Acid hydrolysis and chiral derivatization of sugars}

A portion of the crude mixture of glycolipids $(7.3 \mathrm{mg})$ was heated in $2 \mathrm{M}$ TFA $(2 \mathrm{~mL})$ in a screw-cap vial at $100{ }^{\circ} \mathrm{C}$ overnight. The aglycon was extracted with $\mathrm{CH}_{2} \mathrm{Cl}_{2}$ and the aqueous residue was evaporated to dryness under reduced pressure. A $1.7 \mathrm{mg}$ portion of these hydrolysed sugars was subjected to reductive amination with $(S)$-1-amino-2-propanol, as previously described. ${ }^{157}$ The following reagents were added: $40 \mu \mathrm{L}$ of 1:8 $(S)$-1-amino-2-propanol in $\mathrm{MeOH}, 34 \mu \mathrm{L}$ of $1: 4$ glacial acetic acid in $\mathrm{MeOH}$ and $26 \mu \mathrm{L}$ of $3 \% \mathrm{NaBH}_{3} \mathrm{CN}$ in $\mathrm{MeOH}$. The capped vial was allowed to react for 1 hour at $65{ }^{\circ} \mathrm{C}$. TFA $(2 \mathrm{M})$ was added dropwise until the $\mathrm{pH}$ dropped to $1-2$. The mixture was evaporated and coevaporated with $\mathrm{H}_{2} \mathrm{O}(3 \times 0.5 \mathrm{~mL})$ and $\mathrm{MeOH}(5 \times 0.5 \mathrm{~mL})$. The sample was dried under high vacuum, then treated with $2 \mathrm{~mL} \mathrm{1:1}$ pyridine/ $\mathrm{Ac}_{2} \mathrm{O}$ (2 hours, $90{ }^{\circ} \mathrm{C}$ ). The reaction was quenched with $2 \mathrm{~mL} \mathrm{H}_{2} \mathrm{O}$ and cyclic loaded onto a column of HP20SS $(1 \times 2 \mathrm{~cm})$. The column was then eluted with $6 \mathrm{~mL}$ fractions of (1) $\mathrm{H}_{2} \mathrm{O}$ and (2) $\mathrm{MeOH}$. Fraction 2 was evaporated to dryness to yield the 1-deoxy-1-(2-hydroxypropylamino) alditol acetate derivative.

GC was carried out on a Hewlett Packard 5890 Series II gas chromatograph, with a flame ionization detector, operating in split mode (15:1). The column used was HP5 $(30 \mathrm{~m} \times 0.32 \mathrm{~nm}, 0.25 \mu \mathrm{m}$ film thickness $)$ with $\mathrm{N}_{2}$ as the gas carrier $(1 \mathrm{~mL} / \mathrm{min})$, and a head pressure of $12 \mathrm{psi}$. The program started at $180{ }^{\circ} \mathrm{C}(1 \mathrm{~min}), 2{ }^{\circ} \mathrm{C} / \mathrm{min}$ to $220{ }^{\circ} \mathrm{C}(2 \mathrm{~min})$, then $4{ }^{\circ} \mathrm{C}$ to $250{ }^{\circ} \mathrm{C}(5 \mathrm{~min})$. The retention time of the sugar derivative and the D-glucose standard (prepared under the same derivatization conditions) was $16.5 \mathrm{~min}$.

\subsection{Screening protocol}

\section{Preparation of screen sample}

A voucher sample (ca. $10 \mathrm{~g}$ ) of the sponge is preserved in $75 \%$ IPA in $\mathrm{H}_{2} \mathrm{O}$. Approximately $100 \mathrm{~g}$ (wet weight) of sponge is diced and extracted twice with $400 \mathrm{~mL} \mathrm{MeOH}$ overnight. The extracts are cyclic loaded onto a column of HP20 $(80 \mathrm{~mL}, 2.5 \times 18 \mathrm{~cm})$. The column is washed with $250 \mathrm{~mL} \mathrm{H}_{2} \mathrm{O}$ and then eluted 
with $250 \mathrm{~mL}$ volumes of: (1) $30 \% \mathrm{Me}_{2} \mathrm{CO} / \mathrm{H}_{2} \mathrm{O}$, (2) $75 \% \mathrm{Me}_{2} \mathrm{CO} / \mathrm{H}_{2} \mathrm{O}$, and (3) $\mathrm{Me}_{2} \mathrm{CO}$. Fractions 1 and 2 are backloaded onto a column of $40 \mathrm{~mL}$ HP20 (2 $\times 12 \mathrm{~cm}$ ), washed with water, and eluted with $\mathrm{MeOH}$ (fraction 1) or $\mathrm{Me}_{2} \mathrm{CO}$ (fraction 2). All fractions are concentrated under reduced pressure, and approx. $30 \mathrm{mg}$ portions are subjected to NMR analysis.

\subsection{Bulk extraction of sponge MNP998}

The sponge MNP998 was obtained from the National Institute of Water and Atmospheric Research (NIWA). It had been frozen immediately after collection and kept at $-18{ }^{\circ} \mathrm{C}$ until extraction. A voucher sample (MNP998) has been deposited at the School of Chemical and Physical Sciences, Victoria University of Wellington, New Zealand.

The sponge (505 g wet weight) was diced and extracted twice overnight with $\mathrm{MeOH}(2.5 \mathrm{~L})$. The extracts were cyclic loaded onto a $400 \mathrm{~mL}$ column of HP20 beads $(8 \times 8 \mathrm{~cm})$. The column was then washed with $1.2 \mathrm{~L} \mathrm{H}_{2} \mathrm{O}$ and eluted with $1.2 \mathrm{~L}$ fractions of: (1) $20 \% \mathrm{Me}_{2} \mathrm{CO} / \mathrm{H}_{2} \mathrm{O}$, (2) $40 \% \mathrm{Me}_{2} \mathrm{CO} / \mathrm{H}_{2} \mathrm{O}$, (3) $60 \%$ $\mathrm{Me}_{2} \mathrm{CO} / \mathrm{H}_{2} \mathrm{O}$, (4) $80 \% \mathrm{Me}_{2} \mathrm{CO} / \mathrm{H}_{2} \mathrm{O}$ and (5) $\mathrm{Me}_{2} \mathrm{CO}$.

Fractions 1-4 were backloaded onto $150 \mathrm{~mL}$ HP20, and eluted with $450 \mathrm{~mL}$ of $\mathrm{MeOH}$ (fractions 1 and 2) or $\mathrm{Me}_{2} \mathrm{CO}$ (fractions 3 and 4). Concentration of fraction 3 under reduced pressure and subsequent lyophilization yielded $2.56 \mathrm{~g}$ of a beige powder.

\subsection{Isolation of terpenes from a dictyoceratid sponge}

The sponge (order Dictyoceratida) was collected by hand using SCUBA from Dowd Rock, Tutukaka, New Zealand in December 2003. The sample was frozen immediately and kept at $-18^{\circ} \mathrm{C}$ until extraction. Voucher samples (PTN2_47E and PTN2_48C) have been deposited at the School of Chemical and Physical Sciences, Victoria University of Wellington, New Zealand.

The sponge (250 g wet weight) was cut up and extracted twice overnight with $\mathrm{MeOH}(1.25 \mathrm{~L})$. The extracts were cyclic loaded onto a column of HP20 $(200 \mathrm{~mL}, 8 \times 4 \mathrm{~cm})$. The column was then washed with $600 \mathrm{~mL} \mathrm{H}_{2} \mathrm{O}$ and eluted with $600 \mathrm{~mL}$ fractions of (1) $20 \% \mathrm{Me}_{2} \mathrm{CO} / \mathrm{H}_{2} \mathrm{O}$, (2) $40 \% \mathrm{Me}_{2} \mathrm{CO} / \mathrm{H}_{2} \mathrm{O}$, (3) $60 \%$ $\mathrm{Me}_{2} \mathrm{CO} / \mathrm{H}_{2} \mathrm{O}$, (4) $80 \% \mathrm{Me}_{2} \mathrm{CO} / \mathrm{H}_{2} \mathrm{O}$ and (5) $\mathrm{Me}_{2} \mathrm{CO}$. 
Fraction 3 was backloaded onto $80 \mathrm{~mL}$ HP20 $(2.5 \times 18 \mathrm{~cm})$, eluted with $240 \mathrm{~mL} \mathrm{MeOH}$ and concentrated under reduced pressure to yield $199.5 \mathrm{mg}$ of material. Approximately half of this was loaded onto a silica gel column $(40 \mathrm{~mL}$, $1.3 \times 30 \mathrm{~cm})$. The column was eluted sequentially with $160 \mathrm{~mL}$ volumes of $\mathrm{CH}_{2} \mathrm{Cl}_{2}, 1 \%, 2.5 \%, 5 \%$ and $50 \% \mathrm{MeOH}$ in $\mathrm{CH}_{2} \mathrm{Cl}_{2}$. Fractions eluting with $2.5 \%$ $\mathrm{MeOH}$ were combined on the basis of TLC to give $\Delta_{18,20}$-isovariabilin (186) (33.1 mg).

Fraction 5 from the cyclic loading was concentrated under reduced pressure to give $1.28 \mathrm{~g}$ of material. Approximately $400 \mathrm{mg}$ of this was loaded onto a silica gel column $(75 \mathrm{~mL}, 2.5 \times 21 \mathrm{~cm})$. The column was eluted with $300 \mathrm{~mL}$ fractions of (1) pet. ether, (2) $\mathrm{CH}_{2} \mathrm{Cl}_{2}$ and (3) $50 \% \mathrm{MeOH} / \mathrm{CH}_{2} \mathrm{Cl}_{2}$. The pet. ether fraction was concentrated under reduced pressure to yield furospinosulin-1 (187) (107.4 mg).

The $\mathrm{CH}_{2} \mathrm{Cl}_{2}$ fraction was concentrated under reduced pressure, and the resulting material $(111 \mathrm{mg})$ was loaded onto a silica gel column $(40 \mathrm{~mL}, 1.3 \times$ $30 \mathrm{~cm}$ ). The column was eluted with $160 \mathrm{~mL}$ volumes of $50 \%$ and $75 \% \mathrm{CH}_{2} \mathrm{Cl}_{2}$ in pet. ether, $\mathrm{CH}_{2} \mathrm{Cl}_{2}$ and $50 \% \mathrm{MeOH} / \mathrm{CH}_{2} \mathrm{Cl}_{2}$. The $50 \% \mathrm{CH}_{2} \mathrm{Cl}_{2}$ in pet. ether fraction was further purified on a silica gel column $(20 \mathrm{~mL}, 1.3 \times 17 \mathrm{~cm})$. This column was eluted with $60 \mathrm{~mL}$ of pet. ether, then $80 \mathrm{~mL}$ volumes of $10 \%$, $20 \%, 30 \%, 40 \%, 50 \%$ and $60 \% \mathrm{CH}_{2} \mathrm{Cl}_{2}$ in pet. ether, $\mathrm{CH}_{2} \mathrm{Cl}_{2}$ and finally $50 \%$ $\mathrm{MeOH} / \mathrm{CH}_{2} \mathrm{Cl}_{2}$. Fractions eluted with $50 \% \mathrm{CH}_{2} \mathrm{Cl}_{2}$ in pet. ether were combined based on TLC. The resulting sample $(9.1 \mathrm{mg})$ was subjected to HPLC on a semipreparative $\mathrm{C}_{18}$ reversed-phase column which was eluted with $85 \% \mathrm{MeCN} / \mathrm{H}_{2} \mathrm{O}$ at a flow rate of $5 \mathrm{~mL} / \mathrm{min}$. Two fractions were collected (retention times 15.9 and $16.7 \mathrm{~min})$ to yield 6-((2Z,6E)-3,7,11-trimethyl-2,6,10-dodecatrienyl)-2methoxy-p-quinone (189) (0.5 mg) and 6-((2E,6E)-3,7,11-trimethyl-2,6,10-dodecatrienyl)-2-methoxy-p-quinone (188) (2.7 mg) respectively.

$\Delta_{18,20}$-Isovariabilin (186): Pale yellow solid; UV (MeOH) $\lambda_{\max }, \mathrm{nm}(\varepsilon): 204$ $(18,900), 227$ (sh, 8,580); $[\alpha]_{\mathrm{D}}^{20}-8.9$ ( $c$ 0.9, MeOH); NMR data see Table 5.1; HRESIMS $m / z 421.2354[\mathrm{M}+\mathrm{Na}]^{+}, \mathrm{C}_{25} \mathrm{H}_{34} \mathrm{O}_{4} \mathrm{Na}$ requires $421.2355, \Delta 0.2 \mathrm{ppm}$.

Furospinosulin-1 (187): Pale yellow oil; all spectroscopic data were in agreement with those reported. ${ }^{191}$

\section{6-((2E,6E)-3,7,11-trimethyl-2,6,10-dodecatrienyl)-2-methoxy- $p$-qui-}

none (188): Orange solid; all spectroscopic data were in agreement with those reported. ${ }^{195}$ 
6-((2E,6Z)-3,7,11-trimethyl-2,6,10-dodecatrienyl)-2-methoxy-p-qui-

none (189): Orange solid; UV (MeOH) $\lambda_{\max }$, nm $(\varepsilon): 204(23,500), 222$ (sh, 11,000), 277 (sh, 4,690); NMR data see Table 5.2; HRESIMS m/z 365.2095 $[\mathrm{M}+\mathrm{Na}]^{+}, \mathrm{C}_{22} \mathrm{H}_{30} \mathrm{O}_{3} \mathrm{Na}$ requires 365.2093, $\Delta 0.5 \mathrm{ppm}, \mathrm{m} / z$ 397.2341 $[\mathrm{M}+$ $\mathrm{MeOH}+\mathrm{Na}]^{+}, \mathrm{C}_{23} \mathrm{H}_{34} \mathrm{O}_{4} \mathrm{Na}$ requires 397.2355, $\Delta 3.5 \mathrm{ppm}$.

\subsection{Isolation of four aplysulphurane diter- penes from the sponge $D$. oxeata}

The sponge identified as D. oxeata was collected by hand using SCUBA from Port Hardy, D’Urville Island, New Zealand (40 $46.2^{\prime} \mathrm{S}, 173^{\circ} 59.7^{\prime} \mathrm{E}$ ) in April 2000. The sample was frozen immediately and kept at $-18{ }^{\circ} \mathrm{C}$ until extraction. A voucher specimen (MNP1002) has been deposited at the School of Chemical and Physical Sciences, Victoria University of Wellington, New Zealand.

The sponge (505 g wet weight) was cut up and extracted twice overnight with $\mathrm{MeOH}(2.5 \mathrm{~L})$. The extracts were cyclic loaded onto a column of HP20 (400 mL, $8 \times 8 \mathrm{~cm})$. The column was then washed with $1.2 \mathrm{~L} \mathrm{H}_{2} \mathrm{O}$ and eluted with $1.2 \mathrm{~L}$ fractions of (1) $20 \% \mathrm{Me}_{2} \mathrm{CO} / \mathrm{H}_{2} \mathrm{O}$, (2) $40 \% \mathrm{Me}_{2} \mathrm{CO} / \mathrm{H}_{2} \mathrm{O}$, (3) $60 \% \mathrm{Me}_{2} \mathrm{CO} / \mathrm{H}_{2} \mathrm{O}$, (4) $80 \% \mathrm{Me}_{2} \mathrm{CO} / \mathrm{H}_{2} \mathrm{O}$ and (5) $\mathrm{Me}_{2} \mathrm{CO}$.

Fraction 1 was backloaded onto $150 \mathrm{~mL}$ HP20, eluted with $450 \mathrm{~mL} \mathrm{MeOH}$ and concentrated under reduced pressure to yield $125.7 \mathrm{mg}$ of an amorphous solid. Approximately half of this material was adsorbed onto DIOL, and was dry-loaded onto a $20 \mathrm{~mL}$ DIOL column $(1.3 \times 17 \mathrm{~cm})$. The column was eluted with fractions of: (1) $60 \mathrm{~mL}$ of $\mathrm{CH}_{2} \mathrm{Cl}_{2}, 80 \mathrm{~mL}$ of (2) $10 \% \mathrm{MeOH} / \mathrm{CH}_{2} \mathrm{Cl}_{2}$, (3) $20 \% \mathrm{MeOH} / \mathrm{CH}_{2} \mathrm{Cl}_{2}$, (4) $50 \% \mathrm{MeOH} / \mathrm{CH}_{2} \mathrm{Cl}_{2}$ and (5) $\mathrm{MeOH}$.

The $10 \% \mathrm{MeOH}$ fraction was further purified on a semi-preparative $\mathrm{C}_{18}$ reversed-phase HPLC column which was eluted with 70\% MeOH/0.1 M HCOOH at a flow rate of $5 \mathrm{~mL} / \mathrm{min}$. A major compound with a retention time of $21 \mathrm{~min}$ utes was collected. This fraction was backloaded onto $2 \mathrm{~mL}$ HP20SS to de-salt, and eluted with $10 \mathrm{~mL} \mathrm{MeOH}$. The sample was concentrated under reduced pressure to afford oxeatamide A (214) (17.2 mg).

Fraction 2 from the cyclic loading was backloaded onto $150 \mathrm{~mL}$ HP20, eluted with $450 \mathrm{~mL} \mathrm{MeOH}$ and concentrated under reduced pressure to afford $234.1 \mathrm{mg}$ of a red gum. A portion of this material (approx. $80 \mathrm{mg}$ ) was adsorbed onto DIOL and was dry-loaded onto a $20 \mathrm{~mL}$ DIOL column $(1.3 \times 17 \mathrm{~cm})$. The column was eluted with $80 \mathrm{~mL}$ fractions of: (1) $\mathrm{CH}_{2} \mathrm{Cl}_{2}$, (2) $1 \% \mathrm{MeOH} / \mathrm{CH}_{2} \mathrm{Cl}_{2}$, (3) $5 \% \mathrm{MeOH} / \mathrm{CH}_{2} \mathrm{Cl}_{2}$, (4) $10 \% \mathrm{MeOH} / \mathrm{CH}_{2} \mathrm{Cl}_{2}$ and (5) $20 \% \mathrm{MeOH} / \mathrm{CH}_{2} \mathrm{Cl}_{2}$, 
(6) $30 \% \mathrm{MeOH} / \mathrm{CH}_{2} \mathrm{Cl}_{2}$ and (7) $50 \% \mathrm{MeOH} / \mathrm{CH}_{2} \mathrm{Cl}_{2}$.

The $10 \% \mathrm{MeOH}$ in $\mathrm{CH}_{2} \mathrm{Cl}_{2}$ fraction from this column was further purified on reversed-phase HPLC using identical conditions as above. Three fractions were collected (retention times 5-8, 21.0 and 25.1 minutes) to afford (after de-salting) oxeatamide B (217) (6.2 mg) oxeatamide A (214) (7.8 $\mathrm{mg}$ ) and iso-oxeatamide A (215) (0.9 $\mathrm{mg})$ respectively.

Fractions eluting from the HPLC after oxeatamide A (214) were combined, backloaded onto $2 \mathrm{~mL}$ HP20SS to de-salt, eluted with $10 \mathrm{~mL} \mathrm{MeOH}$, and concentrated under reduced pressure. The resulting sample $(2.8 \mathrm{mg})$ was re-injected onto the $\mathrm{C}_{18}$ reversed-phase HPLC and eluted under the same conditions, yielding oxeatamide A 23 -methyl ester $(0.5 \mathrm{mg})$ with a retention time of $27.4 \mathrm{~min}$.

Oxeatamide A (214): White solid; UV (MeOH) $\lambda_{\max }, \operatorname{nm}(\varepsilon): 206(45,100)$ $250(18,800) ;[\alpha]_{\mathrm{D}}^{20}-60.3(c$ 1.0, MeOH); NMR data see Table 6.1; HRESIMS $m / z 388.2115[\mathrm{M}+\mathrm{H}]^{+}, \mathrm{C}_{22} \mathrm{H}_{30} \mathrm{O}_{5}$ requires 388.2124, $\Delta 2.3 \mathrm{ppm}, \mathrm{m} / z 410.1940$ $[\mathrm{M}+\mathrm{Na}]^{+}, \mathrm{C}_{22} \mathrm{H}_{29} \mathrm{NO}_{5} \mathrm{Na}$ requires 410.1943, $\Delta 0.9 \mathrm{ppm}$.

Iso-oxeatamide A (215): White solid; UV (MeOH) $\lambda_{\max }, \mathrm{nm}(\varepsilon): 209(36,800)$ $248(11,200) ;[\alpha]_{\mathrm{D}}^{20}-59.6$ ( c 0.22, MeOH); NMR data see Table 6.3; HRESIMS $m / z 388.2131[\mathrm{M}+\mathrm{H}]^{+}, \mathrm{C}_{22} \mathrm{H}_{30} \mathrm{NO}_{5}$ requires 388.2124, $\Delta 1.8 \mathrm{ppm}, \mathrm{m} / z 410.1949$ $[\mathrm{M}+\mathrm{Na}]^{+}, \mathrm{C}_{22} \mathrm{H}_{29} \mathrm{NO}_{5} \mathrm{Na}$ requires 410.1943, $\Delta 1.5 \mathrm{ppm}$.

Oxeatamide A 23-methyl ester (216): White solid; UV (MeOH) $\lambda_{\max }$, $\mathrm{nm}(\varepsilon)$ : $203(43,500) 239(18,100) ;[\alpha]_{\mathrm{D}}^{20}-62.0$ (c 0.05, MeOH); NMR data see Table 6.4; HRESIMS $m / z 424.2112[\mathrm{M}+\mathrm{Na}]^{+}, \mathrm{C}_{23} \mathrm{H}_{31} \mathrm{NO}_{5} \mathrm{Na}$ requires 424.2100, $\Delta 2.8 \mathrm{ppm}$.

Oxeatamide B (217): White solid; UV (MeOH) $\lambda_{\max }, \operatorname{nm}(\varepsilon): 207(24,300)$ $243(9,030) ;[\alpha]_{\mathrm{D}}^{20}-60.2(c 0.5, \mathrm{MeOH}) ; \mathrm{NMR}$ data see Table 6.5; HRESIMS $m / z 424.2592[\mathrm{M}+\mathrm{H}]^{+}, \mathrm{C}_{25} \mathrm{H}_{34} \mathrm{~N}_{3} \mathrm{O}_{3}$ requires 424.2600, $\Delta 1.7$ ppm.

\section{Methylation of 214}

$\mathrm{TMSCHN}_{2}(50 \mu \mathrm{L}, 2 \mathrm{M}$ in hexanes) was added to $5 \mathrm{mg}$ of $\mathbf{2 1 4}$ dissolved in dry $\mathrm{CH}_{2} \mathrm{Cl}_{2}(1 \mathrm{~mL})$ under argon. After 1 hour, the reaction was opened and left overnight. To the dry residue, $1 \mathrm{~mL}$ of $\mathrm{MeOH}$ was added, followed by $1 \mathrm{~mL}$ of $2 \%(\mathrm{v} / \mathrm{v})$ aqueous acetic acid $(1 \mathrm{~mL})$. The sample was backloaded onto a column of HP20SS $(1 \times 2 \mathrm{~cm})$. The column was then washed with $\mathrm{H}_{2} \mathrm{O}(1 \mathrm{~mL})$ and eluted with $6 \mathrm{~mL}$ fractions of (1) $20 \% \mathrm{Me}_{2} \mathrm{CO} / \mathrm{H}_{2} \mathrm{O}$, (2) $40 \% \mathrm{Me}_{2} \mathrm{CO} / \mathrm{H}_{2} \mathrm{O}$, (3) $60 \% \mathrm{Me}_{2} \mathrm{CO} / \mathrm{H}_{2} \mathrm{O}$, (4) $80 \% \mathrm{Me}_{2} \mathrm{CO} / \mathrm{H}_{2} \mathrm{O}$ and (5) $\mathrm{Me}_{2} \mathrm{CO}$. Fraction 5 was 
concetrated under reduced pressure and further purified on a semi-preparative $\mathrm{C}_{18}$ reversed-phase HPLC column which was eluted with $90 \% \mathrm{MeOH}$ in $\mathrm{H}_{2} \mathrm{O}$ at a flow rate of $5 \mathrm{~mL} / \mathrm{min}$. Four compounds, with retention times of 5.8, 8.5, 9.8 and 18.6 minutes, were collected to afford oxeatamide A dimethyl ester (218) (1.1 mg), oxeatamide A 6-methyl ester, 23-TMSmethyl ester (219) (1.3 mg), oxeatamide A 6-TMSmethyl, 23-methyl ester (220) (1.2 mg), and oxeatamide A 6,23-diTMSmethyl ester (221) (1.0 mg).

Oxeatamide A dimethyl ester (218): White solid; UV (MeOH) $\lambda_{\max }, \mathrm{nm}$ $(\varepsilon): 207(42,100) 241(17,700) ;[\alpha]_{\mathrm{D}}^{20}-118$ (c 0.1, MeOH); NMR data see Table 6.2; HRESIMS $m / z$ 416.2434 $[\mathrm{M}+\mathrm{H}]^{+}, \mathrm{C}_{24} \mathrm{H}_{34} \mathrm{NO}_{5}$ requires 416.2431 $\Delta 0.7 \mathrm{ppm}, \mathrm{m} / z 438.2254[\mathrm{M}+\mathrm{Na}]^{+}, \mathrm{C}_{24} \mathrm{H}_{33} \mathrm{NO}_{5} \mathrm{Na}$ requires 438.2251, $\Delta 0.6$ ppm.

Oxeatamide A 6-methyl ester, 23-TMSmethyl ester (219): White solid; ${ }^{1} \mathrm{H}$ NMR data $\left(\mathrm{CDCl}_{3}, 600 \mathrm{MHz}\right) \delta 7.70(1 \mathrm{H}, \mathrm{d}, 8.3 \mathrm{~Hz}, \mathrm{H}-12), 7.64$ (1H, d, $8.3 \mathrm{~Hz}, \mathrm{H}-11), 4.69$ (1H, q, $7.3 \mathrm{~Hz}, \mathrm{H}-7), 4.50$ (1H, d, 16.0 Hz, H-15a), 4.43 (1H, d, $17.6 \mathrm{~Hz}, \mathrm{H}-22 \mathrm{a}), 4.28$ (1H, d, $17.5 \mathrm{~Hz}, \mathrm{H}-22 \mathrm{~b}), 4.14$ (1H, d, $16.2 \mathrm{~Hz}$, H-15b), $3.84\left(1 \mathrm{H}, \mathrm{d}, 13.9 \mathrm{~Hz}, 23-\mathrm{CH}_{2}[\mathrm{a}] \mathrm{Si}\left(\mathrm{CH}_{3}\right)_{3}\right), 3.79(1 \mathrm{H}, \mathrm{d}, 13.9 \mathrm{~Hz}, 23-$ $\left.\mathrm{CH}_{2}[\mathrm{~b}] \mathrm{Si}\left(\mathrm{CH}_{3}\right)_{3}\right), 3.75$ (3H, s, 6-methyl ester) 2.36 (1H, d, $\left.13.9 \mathrm{~Hz}, \mathrm{H}-1 \mathrm{a}\right), 2.08$ (1H, d, $13.9 \mathrm{~Hz}, \mathrm{H}-5 \mathrm{a}), 1.84$ (1H, qt, 11.5, $3.0 \mathrm{~Hz}, \mathrm{H}-2 \mathrm{a}), 1.68$ (1H, dt, 14.2, $4.2 \mathrm{~Hz}, \mathrm{H}-2 \mathrm{~b}), 1.61$ (3H, d, $\left.7.2 \mathrm{~Hz}, \mathrm{H}_{3}-17\right), 1.50$ (1H, d, $\left.14.1 \mathrm{~Hz}, \mathrm{H}-5 \mathrm{~b}\right), 1.47$ $\left(3 \mathrm{H}, \mathrm{s}, \mathrm{H}_{3}-20\right), 1.45$ (1H, m H-1b), 1.34 (1H, dt, 13.0, $\left.4.2 \mathrm{~Hz}, \mathrm{H}-3 \mathrm{a}\right), 1.27(1 \mathrm{H}$, ddd, 15.2, 11.3, 4.1 Hz, H-3b), 0.92 (3H, s, H $\left.{ }_{3}-19\right), 0.41$ (3H, s, $\left.\mathrm{H}_{3}-18\right), 0.05$ (9H, s, $\left.23-\mathrm{CH}_{2} \mathrm{Si}\left(\mathrm{CH}_{3}\right)_{3}\right)$.

Oxeatamide A 6-TMSmethyl, 23-methyl ester (220): White solid; ${ }^{1} \mathrm{H}$ NMR data $\left(\mathrm{CDCl}_{3}, 600 \mathrm{MHz}\right) \delta 7.69(1 \mathrm{H}, \mathrm{d}, 8.2 \mathrm{~Hz}, \mathrm{H}-12), 7.62(1 \mathrm{H}, \mathrm{d}, 8.2 \mathrm{~Hz}$, H-11), 4.66 (1H, q, 7.2 Hz, H-7), 4.49 (1H, d, 16.8 Hz, H-15a), 4.40 (1H, d, $17.5 \mathrm{~Hz}, \mathrm{H}-22 \mathrm{a}), 4.32$ (1H, d, 17.5 Hz, H-22b), 4.11 (1H, d, 16.5 Hz, H-15b), 3.75 (3H, s, 23-methyl ester), $3.72\left(1 \mathrm{H}, \mathrm{d}, 14.3 \mathrm{~Hz}, 6-\mathrm{CH}_{2}[\mathrm{a}] \mathrm{Si}\left(\mathrm{CH}_{3}\right)_{3}\right), 3.65(1 \mathrm{H}, \mathrm{d}$, $\left.14.3 \mathrm{~Hz}, 6-\mathrm{CH}_{2}[\mathrm{~b}] \mathrm{Si}\left(\mathrm{CH}_{3}\right)_{3}\right), 2.37(1 \mathrm{H}, \mathrm{d}, 14.7 \mathrm{~Hz}, \mathrm{H}-1 \mathrm{a}), 2.09$ (1H, d, $14.2 \mathrm{~Hz}$, H-5a), 1.83 (1H, qt, 11.5, 3.1 Hz, H-2a), 1.67 (1H, dt, 14.1, 4.5 Hz, H-2b), 1.62 $\left(3 \mathrm{H}, \mathrm{d}, 7.4 \mathrm{~Hz}, \mathrm{H}_{3}-17\right), 1.50$ (1H, d, $\left.14.4 \mathrm{~Hz}, \mathrm{H}-5 \mathrm{~b}\right), 1.45$ (3H, s, $\left.\mathrm{H}_{3}-20\right), 1.45(1 \mathrm{H}$, m, H-1b), 1.34 (1H, dt, 13.8, 4.2 Hz, H-3a), 1.26 (1H, ddd, 15.2, 11.5, 3.8 Hz, H-3b), 0.92 (3H, s, $\left.\mathrm{H}_{3}-19\right), 0.40$ (3H, s, $\left.\mathrm{H}_{3}-18\right)$, -0.18 (9H, s, 6- $\left.\mathrm{CH}_{2} \mathrm{Si}\left(\mathrm{CH}_{3}\right)_{3}\right)$.

Oxeatamide A 6,23-diTMSmethyl ester (221): White solid; ${ }^{1} \mathrm{H}$ NMR data $\left(\mathrm{CDCl}_{3}, 600 \mathrm{MHz}\right) \delta 7.69(1 \mathrm{H}, \mathrm{d}, 8.4 \mathrm{~Hz}, \mathrm{H}-12), 7.62$ (1H, d, $\left.8.4 \mathrm{~Hz}, \mathrm{H}-11\right), 4.66$ 
$(1 \mathrm{H}, \mathrm{q}, 7.5 \mathrm{~Hz}, \mathrm{H}-7), 4.50(1 \mathrm{H}, \mathrm{d}, 16.3 \mathrm{~Hz}, \mathrm{H}-15 \mathrm{a}), 4.47(1 \mathrm{H}, \mathrm{d}, 17.8 \mathrm{~Hz}, \mathrm{H}-$ 22a), $4.22(1 \mathrm{H}, \mathrm{d}, 17.8 \mathrm{~Hz}, \mathrm{H}-22 \mathrm{~b}), 4.11(1 \mathrm{H}, \mathrm{d}, 16.2 \mathrm{~Hz}, \mathrm{H}-15 \mathrm{~b}), 3.84(1 \mathrm{H}, \mathrm{d}$, $\left.14.0 \mathrm{~Hz}, 23-\mathrm{CH}_{2}[\mathrm{a}] \mathrm{Si}\left(\mathrm{CH}_{3}\right)_{3}\right), 3.79\left(1 \mathrm{H}, \mathrm{d}, 14.0 \mathrm{~Hz}, 23-\mathrm{CH}_{2}[\mathrm{~b}] \mathrm{Si}\left(\mathrm{CH}_{3}\right)_{3}\right), 3.72$ $\left(1 \mathrm{H}, \mathrm{d}, 14.2 \mathrm{~Hz}, 6-\mathrm{CH}_{2}[\mathrm{a}] \mathrm{Si}\left(\mathrm{CH}_{3}\right)_{3}\right), 3.65\left(1 \mathrm{H}, \mathrm{d}, 14.2 \mathrm{~Hz}, 6-\mathrm{CH}_{2}[\mathrm{~b}] \mathrm{Si}\left(\mathrm{CH}_{3}\right)_{3}\right)$, $2.38(1 \mathrm{H}, \mathrm{d}, 13.4 \mathrm{~Hz}, \mathrm{H}-1 \mathrm{a}), 2.11$ (1H, d, $14.0 \mathrm{~Hz}, \mathrm{H}-5 \mathrm{a}), 1.83$ (1H, qt, 13.0, $3.5 \mathrm{~Hz}, \mathrm{H}-2 \mathrm{a}), 1.67$ (1H, dt, 13.9, $4.4 \mathrm{~Hz}, \mathrm{H}-2 \mathrm{~b}), 1.62\left(3 \mathrm{H}, \mathrm{d}, 7.3 \mathrm{~Hz}, \mathrm{H}_{3}-17\right)$, $1.49(1 \mathrm{H}, \mathrm{d}, 13.9 \mathrm{~Hz}, \mathrm{H}-5 \mathrm{~b}), 1.45$ (3H, s, $\left.\mathrm{H}_{3}-20\right), 1.44(1 \mathrm{H}, \mathrm{m} \mathrm{H}-1 \mathrm{~b}), 1.34(1 \mathrm{H}, \mathrm{dt}$, 13.0, $3.9 \mathrm{~Hz}, \mathrm{H}-3 \mathrm{a}), 1.26$ (1H, m H-3b), 0.91 (3H, s, $\left.\mathrm{H}_{3}-19\right), 0.39$ (3H, s, $\left.\mathrm{H}_{3}-18\right)$, $0.06\left(9 \mathrm{H}, \mathrm{s}, 23-\mathrm{CH}_{2} \mathrm{Si}\left(\mathrm{CH}_{3}\right)_{3}\right),-0.18\left(9 \mathrm{H}, \mathrm{s}, 6-\mathrm{CH}_{2} \mathrm{Si}\left(\mathrm{CH}_{3}\right)_{3}\right)$. 


\section{Appendix A}

\section{Cyclic Loading and Backloading}

Cyclic loading is a technique developed by Northcote and West ${ }^{127}$ and commonly used during this research. It was first used to fractionate crude extracts of organisms being examined by separating the undesirable highly polar salts and non-polar fats from the intermediate polarity compounds of interest. ${ }^{127,190}$ More recently, cyclic loading has found utility as an alternative workup to liquid-liquid partitioning for some synthetic reactions. ${ }^{254}$

Cyclic loading can conceptually be thought of as opposite to chromatography. Instead of increasing amounts of non-polar modifier used to elute compounds off reversed-phase, polar modifier is used to make compounds adsorb onto the column. In the same way, this technique can be extended to normal phase, with increasing amounts of non-polar modifier used to dilute a sample and so cyclic loading it onto normal phase packing material.

While any stationary phase can be used for cyclic loading, our group utilizes PSDVB (poly(styrene-divinylbenzene)) beads, an inexpensive, polymeric, crosslinked, styrenic adsorbent resin as the stationary phase. The resin is highly porous and fully reusable. In addition, it is stable over a large range of $\mathrm{pH}$ values, and does not irreversibly bind polar solutes.

A crude extract contains a wide variety of compounds of very different polarities. To use column chromatography, traditional techniques require the evaporation of solvent from the crude extract (a task often made difficult by "bumping" of the sample) and then redissolving it in a small volume of running solvent - often unachievable due to the large range of component polarities. The advantage of cyclic loading lies in that such a crude extract can easily be loaded onto a column for fractionation.

An organic extract of an organism is passed through the PSDVB column, and the most non-polar constituents will adsorb to the column. The eluent is diluted 


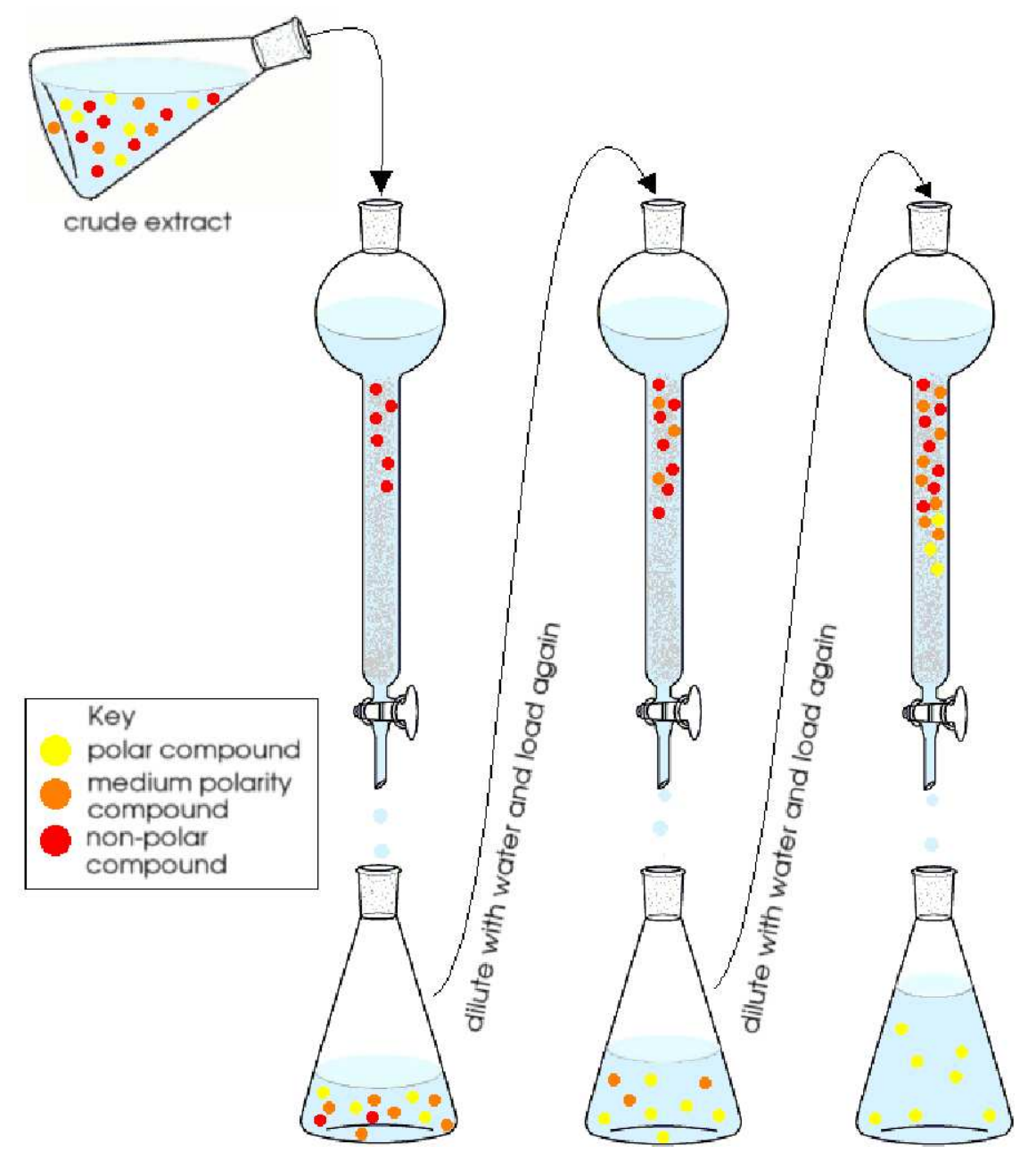

Figure A.1. Cyclic loading diagram.

by half with water and passed through the column again. Usually addition of water to a crude extract would result in the precipitation of the non-polar compounds. This does not happen with cyclic loading, as the most non-polar fats and triglycerides have adsorbed to the column during the first pass.

The dilution and loading cycle is repeated until the organic concentration is $25 \%$ or even $12.5 \%(\mathrm{v} / \mathrm{v})$. As the polarity of the mobile phase increases with each dilution, increasing amounts of the extract constituents lose affinity for the mobile phase and adsorb to the column - see Figure A.1 for a pictorial representation. The column is then washed with water to remove any remaining salts, and can be eluted with water/organic solvent mixtures (step-wise or as a gradient).

Backloading is an extension of the cylic loading technique. Reversed-phase chromatography often generates many samples with high water content, which are time-consuming and sometimes difficult to evaporate under reduced pressure. 
By cyclic loading such samples onto a smaller column (backloading), they can then be eluted with a smaller amount of pure organic solvent which is much easier to evaporate. This technique can also be used to de-salt samples: after backloading, the column is washed with water to remove any salts, and the sample eluted with organic solvent as described.

Synthetic reaction mixtures also frequently contain many compounds with widely differing polarities, and as long as the reaction solvent is water-miscible, can be cyclic loaded in a similar fashion. Any salts or other highly polar molecules will not adsorb to the column, and rather than obtaining a single organic layer from a liquid-liquid partitioning workup, the other compounds can be further fractionated by sequential elution with water/organic solvent mixtures.

The major drawback of the cyclic loading technique is the large volumes of eluent generated, requiring large glassware and increasing periods of time to load onto the column. With each dilution step, the volume of the eluent is doubled - a $1 \mathrm{~L}$ extract, for example, would have to be diluted to $2 \mathrm{~L}$ in the first cycle, then to $4 \mathrm{~L}$, and perhaps even to $8 \mathrm{~L}$ in the end, requiring a total volume of $15 \mathrm{~L}$ to be passed through the column. Nevertheless, the advantage of reversed-phase cyclic loading is that it uses solvents (water, methanol and acetone) that are cheap and better for the environment than most others, and means it is more easily adaptable to industrial scale. 


\section{Appendix B}

\section{NMR Spectra}

B.1 ${ }^{1} \mathrm{H}$ NMR spectrum $\left(300 \mathrm{MHz}, \mathrm{CDCl}_{3}\right)$ of (-)-epi-thunbergol. . . . 192

B.2 ${ }^{1} \mathrm{H}$ NMR spectrum $\left(300 \mathrm{MHz}, \mathrm{CDCl}_{3}\right)$ of $13 \alpha$-acetoxypukalide. . . 193

B.3 ${ }^{1} \mathrm{H}$ NMR spectrum $\left(300 \mathrm{MHz}, \mathrm{CDCl}_{3}\right)$ of lopholide. . . . . . . . . 194

B.4 ${ }^{1} \mathrm{H}$ NMR spectrum $\left(300 \mathrm{MHz}, \mathrm{CDCl}_{3}\right)$ of pukalide. . . . . . . . 195

B.5 ${ }^{1} \mathrm{H}$ NMR spectrum $\left(300 \mathrm{MHz}, \mathrm{CDCl}_{3}\right)$ of $11 \beta, 12 \beta$-epoxypukalide. 196

B.6 ${ }^{1} \mathrm{H}$ NMR spectrum (600 MHz, $\mathrm{CDCl}_{3}$ ) of $13 \alpha$-acetoxypukalide diol.197

B.7 ${ }^{13} \mathrm{C}$ NMR spectrum $\left(150 \mathrm{MHz}, \mathrm{CDCl}_{3}\right)$ of $13 \alpha$-acetoxypukalide diol.198

B.8 COSY spectrum (600 MHz, $\mathrm{CDCl}_{3}$ ) of $13 \alpha$-acetoxypukalide diol. . 199

B.9 HSQC spectrum (600 MHz, $\mathrm{CDCl}_{3}$ ) of $13 \alpha$-acetoxypukalide diol. . 200

B.10 HMBC spectrum (600 MHz, $\mathrm{CDCl}_{3}$ ) of $13 \alpha$-acetoxypukalide diol. 201

B.11 ${ }^{1} \mathrm{H}$ NMR spectrum $\left(600 \mathrm{MHz}, \mathrm{CDCl}_{3}\right)$ of lopholide diol. . . . . . . 202

B.12 ${ }^{13} \mathrm{C}$ NMR spectrum $\left(150 \mathrm{MHz}, \mathrm{CDCl}_{3}\right)$ of lopholide diol. . . . . . 203

B.13 COSY spectrum (600 $\left.\mathrm{MHz}, \mathrm{CDCl}_{3}\right)$ of lopholide diol. . . . . . . . 204

B.14 HSQC spectrum (600 $\mathrm{MHz}, \mathrm{CDCl}_{3}$ ) of lopholide diol. . . . . . . . 205

B.15 HMBC spectrum $\left(600 \mathrm{MHz}, \mathrm{CDCl}_{3}\right)$ of lopholide diol. . . . . . . 206

B.16 ${ }^{1} \mathrm{H}$ NMR spectrum $\left(300 \mathrm{MHz}, \mathrm{CDCl}_{3}\right)$ of cinnamolide. . . . . . . 207

B. $17{ }^{1} \mathrm{H}$ NMR spectrum $\left(300 \mathrm{MHz}, \mathrm{CDCl}_{3}\right)$ of dendocarbin A. . . . . . 208

B. $18{ }^{1} \mathrm{H}$ NMR spectrum $\left(300 \mathrm{MHz}, \mathrm{CD}_{3} \mathrm{OD}\right)$ of the polymeric alkylpyridinium salt. . . . . . . . . . . . . . . . . . 209

B.19 ${ }^{1} \mathrm{H}$ NMR spectrum (300 MHz, DMSO-d $\left.{ }_{6}\right)$ of tambjamine A. . . . 210

B.20 ${ }^{1} \mathrm{H}$ NMR spectrum $\left(300 \mathrm{MHz}, \mathrm{CDCl}_{3}\right)$ of furodysinin. . . . . . . . 211 
B.21 ${ }^{1} \mathrm{H}$ NMR spectrum $\left(300 \mathrm{MHz}, \mathrm{CDCl}_{3}\right)$ of $O$-methyl-furodysinin lactone. . . . . . . . . . . . . . . . . . . . . . 212

B.22 ${ }^{1} \mathrm{H}$ NMR spectrum $\left(300 \mathrm{MHz}, \mathrm{CDCl}_{3}\right)$ of (-)-tetradehydrofurospongin-1. . . . . . . . . . . . . . . . . 213

B.23 ${ }^{1} \mathrm{H}$ NMR spectrum (600 MHz, $\left.\mathrm{CD}_{3} \mathrm{OD}\right)$ of agminoside A. . . . . . 214

B. $24{ }^{13} \mathrm{C}$ NMR spectrum $\left(150 \mathrm{MHz}, \mathrm{CD}_{3} \mathrm{OD}\right)$ of agminoside A. . . . . . 215

B.25 COSY spectrum (600 MHz, $\left.\mathrm{CD}_{3} \mathrm{OD}\right)$ of agminoside A. . . . . . . 216

B.26 HSQC spectrum (600 MHz, $\left.\mathrm{CD}_{3} \mathrm{OD}\right)$ of agminoside A. . . . . . . 217

B.27 HSQC-TOCSY spectrum (600 MHz, $\left.\mathrm{CD}_{3} \mathrm{OD}\right)$ of agminoside A. . 218

B.28 HMBC spectrum (600 MHz, $\left.\mathrm{CD}_{3} \mathrm{OD}\right)$ of agminoside A. . . . . . . 219

B.29 ROESY spectrum (600 MHz, $\left.\mathrm{CD}_{3} \mathrm{OD}\right)$ of agminoside A. . . . . . 220

B.30 ${ }^{1} \mathrm{H}$ NMR spectrum (600 MHz, $\left.\mathrm{CD}_{3} \mathrm{OD}\right)$ of agminoside B. . . . . . 221

B.31 COSY spectrum (600 MHz, $\left.\mathrm{CD}_{3} \mathrm{OD}\right)$ of agminoside B. . . . . . . 222

B.32 HMBC spectrum (600 MHz, $\left.\mathrm{CD}_{3} \mathrm{OD}\right)$ of agminoside B. . . . . . . 223

B.33 ${ }^{1} \mathrm{H}$ NMR spectrum (600 MHz, $\left.\mathrm{CD}_{3} \mathrm{OD}\right)$ of agminoside C. . . . . . 224

B.34 COSY spectrum (600 MHz, $\left.\mathrm{CD}_{3} \mathrm{OD}\right)$ of agminoside C. . . . . . . 225

B.35 HMBC spectrum $\left(600 \mathrm{MHz}, \mathrm{CD}_{3} \mathrm{OD}\right)$ of agminoside C. . . . . . 226

B.36 ${ }^{1} \mathrm{H}$ NMR spectrum (600 MHz, $\left.\mathrm{CD}_{3} \mathrm{OD}\right)$ of agminoside D. . . . . . 227

B.37 COSY spectrum (600 MHz, $\left.\mathrm{CD}_{3} \mathrm{OD}\right)$ of agminoside D. . . . . . . 228

B.38 HMBC spectrum (600 MHz, $\mathrm{CD}_{3} \mathrm{OD}$ ) of agminoside D. . . . . . . 229

B.39 ${ }^{1} \mathrm{H}$ NMR spectrum $\left(600 \mathrm{MHz}, \mathrm{CD}_{3} \mathrm{OD}\right)$ of agminoside E. . . . . . 230

B.40 COSY spectrum (600 MHz, $\left.\mathrm{CD}_{3} \mathrm{OD}\right)$ of agminoside E. . . . . . . 231

B.41 HMBC spectrum $\left(600 \mathrm{MHz}, \mathrm{CD}_{3} \mathrm{OD}\right)$ of agminoside E. . . . . . . 232

B.42 ${ }^{1} \mathrm{H}$ NMR spectrum $\left(600 \mathrm{MHz}, \mathrm{CDCl}_{3}\right)$ of aglycon methyl ester. . . 233

B.43 ${ }^{1} \mathrm{H}$ NMR spectrum $\left(600 \mathrm{MHz}, \mathrm{CDCl}_{3}\right)$ of $\Delta_{18,20}$-isovariabilin. . . . 234

B. $44{ }^{13} \mathrm{C}$ NMR spectrum $\left(150 \mathrm{MHz}, \mathrm{CDCl}_{3}\right)$ of $\Delta_{18,20}$-isovariabilin. . . 235

B.45 COSY spectrum (600 $\left.\mathrm{MHz}, \mathrm{CDCl}_{3}\right)$ of $\Delta_{18,20}$-isovariabilin. . . . . 236

B.46 HSQC spectrum (600 $\left.\mathrm{MHz}, \mathrm{CDCl}_{3}\right)$ of $\Delta_{18,20}$-isovariabilin. . . . . 237

B.47 HMBC spectrum $\left(600 \mathrm{MHz}, \mathrm{CDCl}_{3}\right)$ of $\Delta_{18,20}$-isovariabilin. . . . . 238

B.48 ${ }^{1} \mathrm{H}$ NMR spectrum $\left(600 \mathrm{MHz}, \mathrm{CDCl}_{3}\right)$ of furospinosulin-1. . . . . 239

B.49 ${ }^{1} \mathrm{H}$ NMR spectrum $\left(600 \mathrm{MHz}, \mathrm{CDCl}_{3}\right)$ of $6-((2 E, 6 E)-3,7,11$-trimethyl-2,6,10-dodecatrienyl)-2-methoxy-p-quinone. . . . . . . . 240 
B.50 ${ }^{1} \mathrm{H}$ NMR spectrum $\left(600 \mathrm{MHz}, \mathrm{CDCl}_{3}\right)$ of 6 -((2E,6Z)-3,7,11-trimethyl-2,6,10-dodecatrienyl)-2-methoxy-p-quinone. . . . . . . . 241

B.51 COSY spectrum (600 MHz, $\left.\mathrm{CDCl}_{3}\right)$ of 6-((2E,6Z)-3,7,11-trimethyl-2,6,10-dodecatrienyl)-2-methoxy-p-quinone. . . . . . . . . . 242

B.52 HSQC spectrum $\left(600 \mathrm{MHz}, \mathrm{CDCl}_{3}\right)$ of 6-((2E,6Z)-3,7,11-trimethyl-2,6,10-dodecatrienyl)-2-methoxy-p-quinone. . . . . . . . . . 243

B.53 HMBC spectrum $\left(600 \mathrm{MHz}, \mathrm{CDCl}_{3}\right)$ of $6-((2 E, 6 Z)-3,7,11$-trimethyl-2,6,10-dodecatrienyl)-2-methoxy-p-quinone. . . . . . . . . . 244

B. $54{ }^{1} \mathrm{H}$ NMR spectrum $\left(600 \mathrm{MHz}, \mathrm{CDCl}_{3}\right)$ of oxeatamide A. . . . . . 245

B. $55{ }^{13} \mathrm{C}$ NMR spectrum $\left(150 \mathrm{MHz}, \mathrm{CDCl}_{3}\right)$ of oxeatamide A. . . . . . 246

B.56 COSY spectrum $\left(600 \mathrm{MHz}, \mathrm{CDCl}_{3}\right)$ of oxeatamide A. . . . . . . . 247

B.57 HSQC spectrum $\left(600 \mathrm{MHz}, \mathrm{CDCl}_{3}\right)$ of oxeatamide A. . . . . . . . 248

B.58 HMBC spectrum $\left(600 \mathrm{MHz}, \mathrm{CDCl}_{3}\right)$ of oxeatamide A. . . . . . . 249

B.59 ${ }^{1} \mathrm{H}$ NMR spectrum $\left(600 \mathrm{MHz}, \mathrm{CDCl}_{3}\right.$ ) of iso-oxeatamide A. . . . . 250

B.60 ${ }^{13} \mathrm{C}$ NMR spectrum $\left(150 \mathrm{MHz}, \mathrm{CDCl}_{3}\right)$ of iso-oxeatamide A. . . . 251

B.61 COSY spectrum (600 $\left.\mathrm{MHz}, \mathrm{CDCl}_{3}\right)$ of iso-oxeatamide A. . . . . . 252

B.62 HSQC spectrum (600 $\mathrm{MHz}, \mathrm{CDCl}_{3}$ ) of iso-oxeatamide A. . . . . . 253

B.63 HMBC spectrum (600 MHz, $\mathrm{CDCl}_{3}$ ) of iso-oxeatamide A. . . . . . 254

B.64 ${ }^{1} \mathrm{H}$ NMR spectrum $\left(600 \mathrm{MHz}, \mathrm{CDCl}_{3}\right)$ of oxeatamide A 23-methyl ester. . . . . . . . . . . . . . . . . . 255

B.65 COSY spectrum (600 $\left.\mathrm{MHz}, \mathrm{CDCl}_{3}\right)$ of oxeatamide A 23-methyl ester. . . . . . . . . . . . . . . . . . . 256

B.66 HSQC spectrum $\left(600 \mathrm{MHz}^{\mathrm{CDCl}} \mathrm{CDC}_{3}\right)$ of oxeatamide A 23-methyl ester. . . . . . . . . . . . . . . . . . . 257

B.67 HMBC spectrum (600 MHz, $\mathrm{CDCl}_{3}$ ) of oxeatamide A 23-methyl ester. . . . . . . . . . . . . . . . . . . . 258

B.68 ${ }^{1} \mathrm{H}$ NMR spectrum $\left(600 \mathrm{MHz}, \mathrm{DMSO}-\mathrm{d}_{6}\right)$ of oxeatamide B. . . . . 259

B.69 ${ }^{13} \mathrm{C}$ NMR spectrum $\left(150 \mathrm{MHz}, \mathrm{DMSO}_{-} \mathrm{d}_{6}\right.$ ) of oxeatamide B. . . . 260

B.70 COSY spectrum (600 MHz, DMSO- $\mathrm{d}_{6}$ ) of oxeatamide B. . . . . . 261

B.71 HSQC spectrum (600 MHz, DMSO- $\left.\mathrm{d}_{6}\right)$ of oxeatamide B. . . . . . 262

B.72 HMBC spectrum (600 MHz, DMSO- $\mathrm{d}_{6}$ ) of oxeatamide B. . . . . . 263 


\section{(-)-epi-Thunbergol}

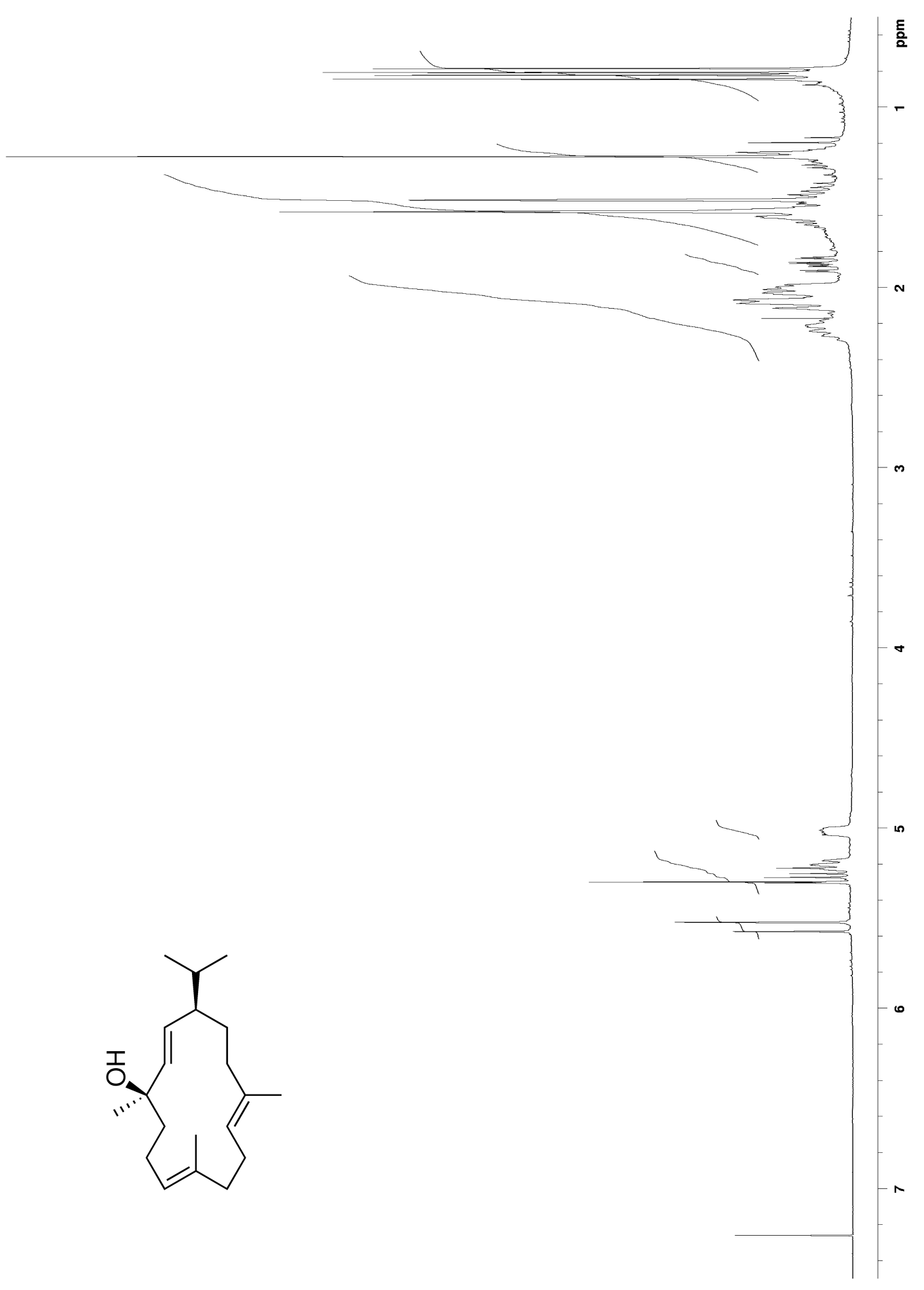

Figure B.1. ${ }^{1} \mathrm{H}$ NMR spectrum $\left(300 \mathrm{MHz}, \mathrm{CDCl}_{3}\right)$ of (-)-epi-thunbergol (25). 


\section{3 $\alpha$-Acetoxypukalide}

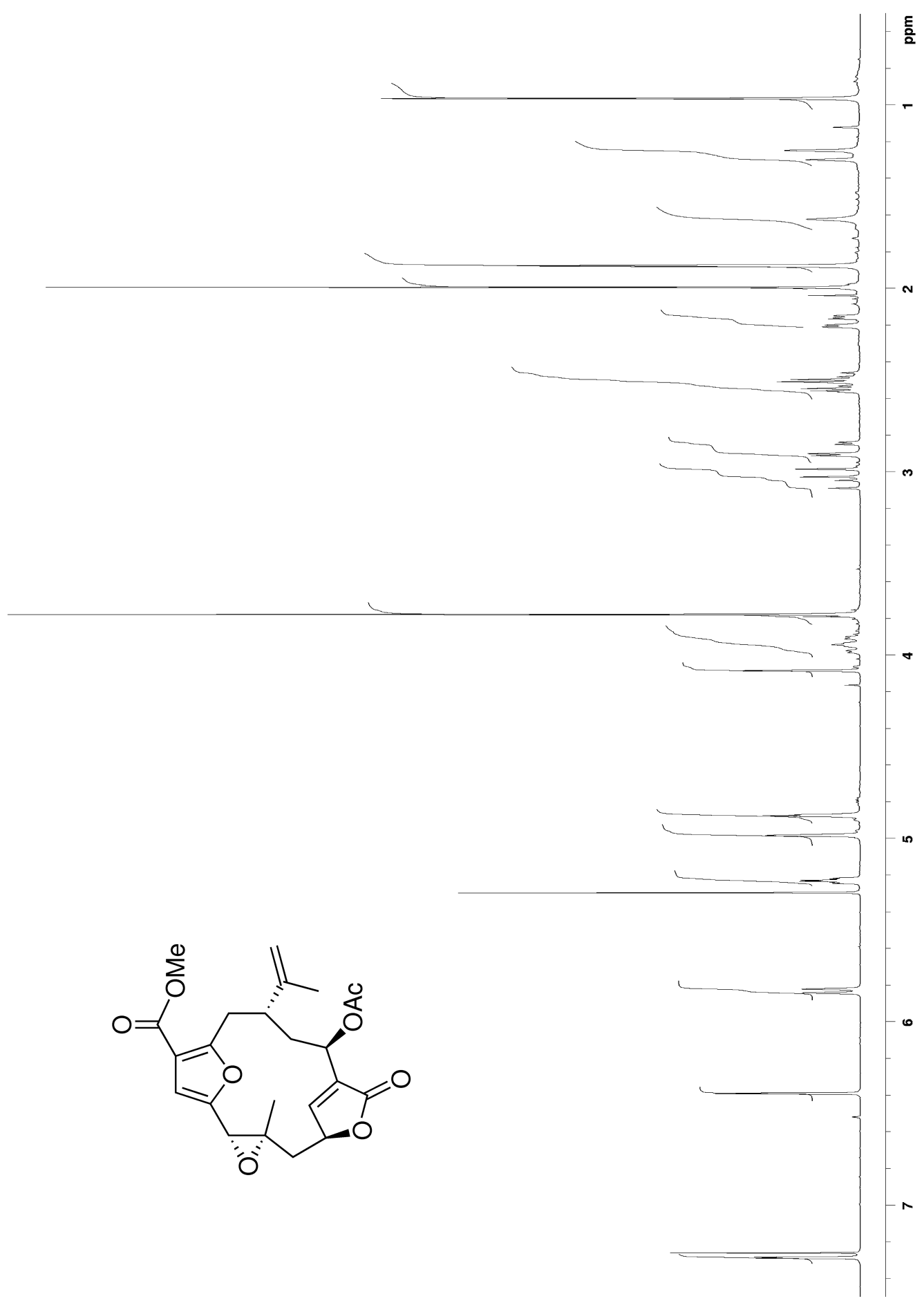

Figure B.2. ${ }^{1} \mathrm{H}$ NMR spectrum $\left(300 \mathrm{MHz}, \mathrm{CDCl}_{3}\right)$ of $13 \alpha$-acetoxypukalide (26). 


\section{Lopholide}

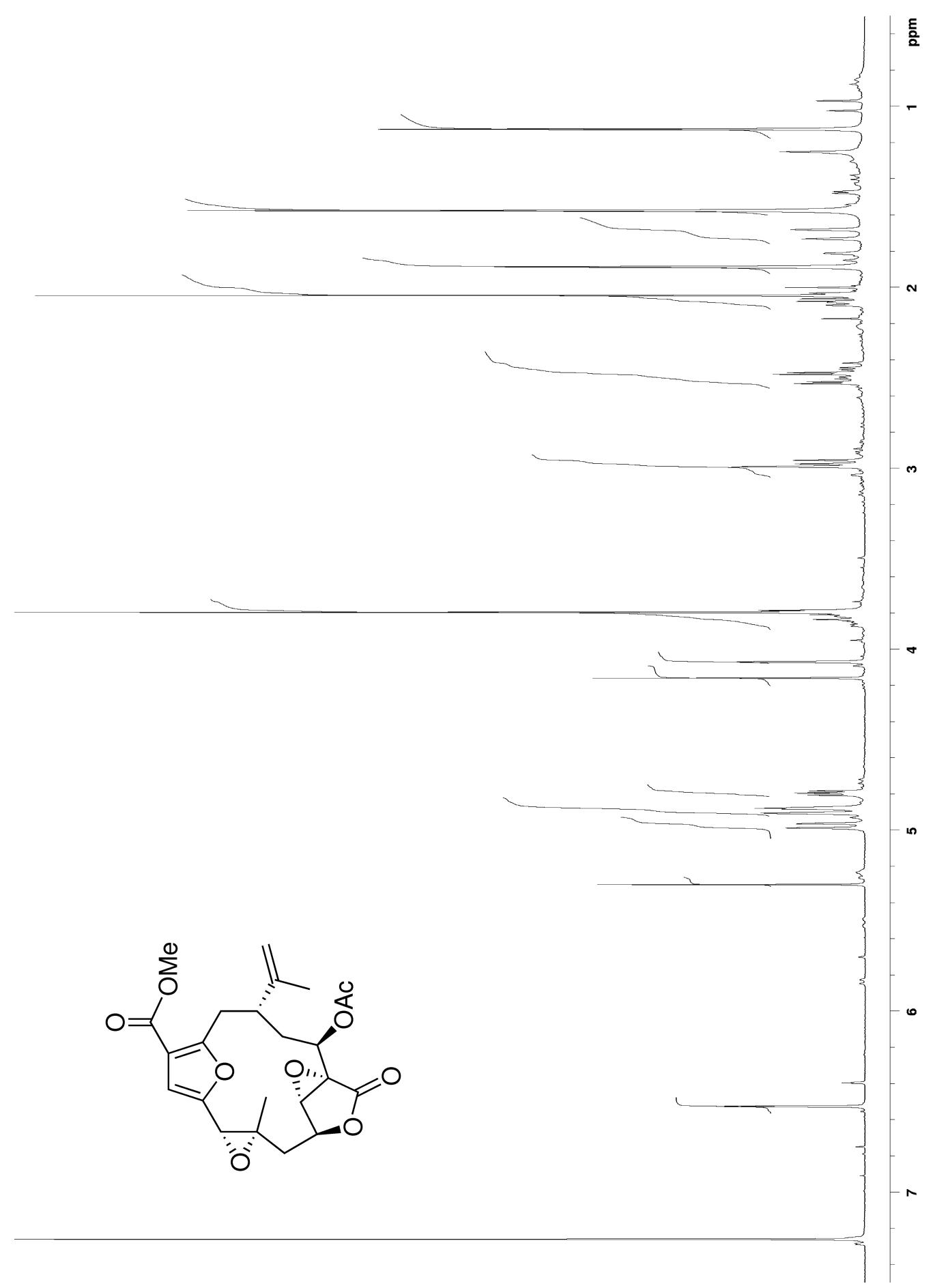

Figure B.3. ${ }^{1} \mathrm{H}$ NMR spectrum $\left(300 \mathrm{MHz}, \mathrm{CDCl}_{3}\right)$ of lopholide (27). 


\section{Pukalide}

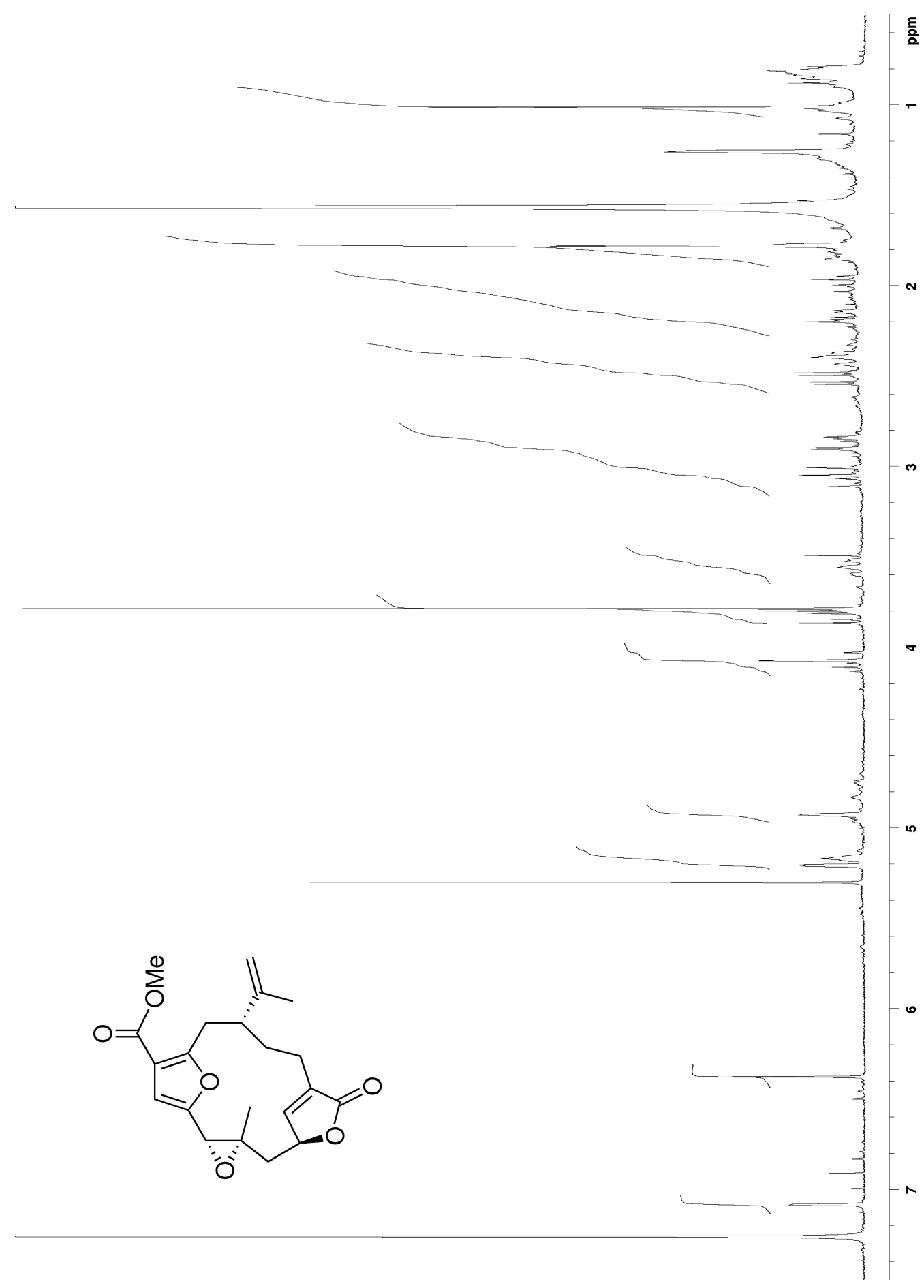

Figure B.4. ${ }^{1} \mathrm{H}$ NMR spectrum $\left(300 \mathrm{MHz}, \mathrm{CDCl}_{3}\right)$ of pukalide (28). 


\section{$11 \beta, 12 \beta$-Epoxypukalide}

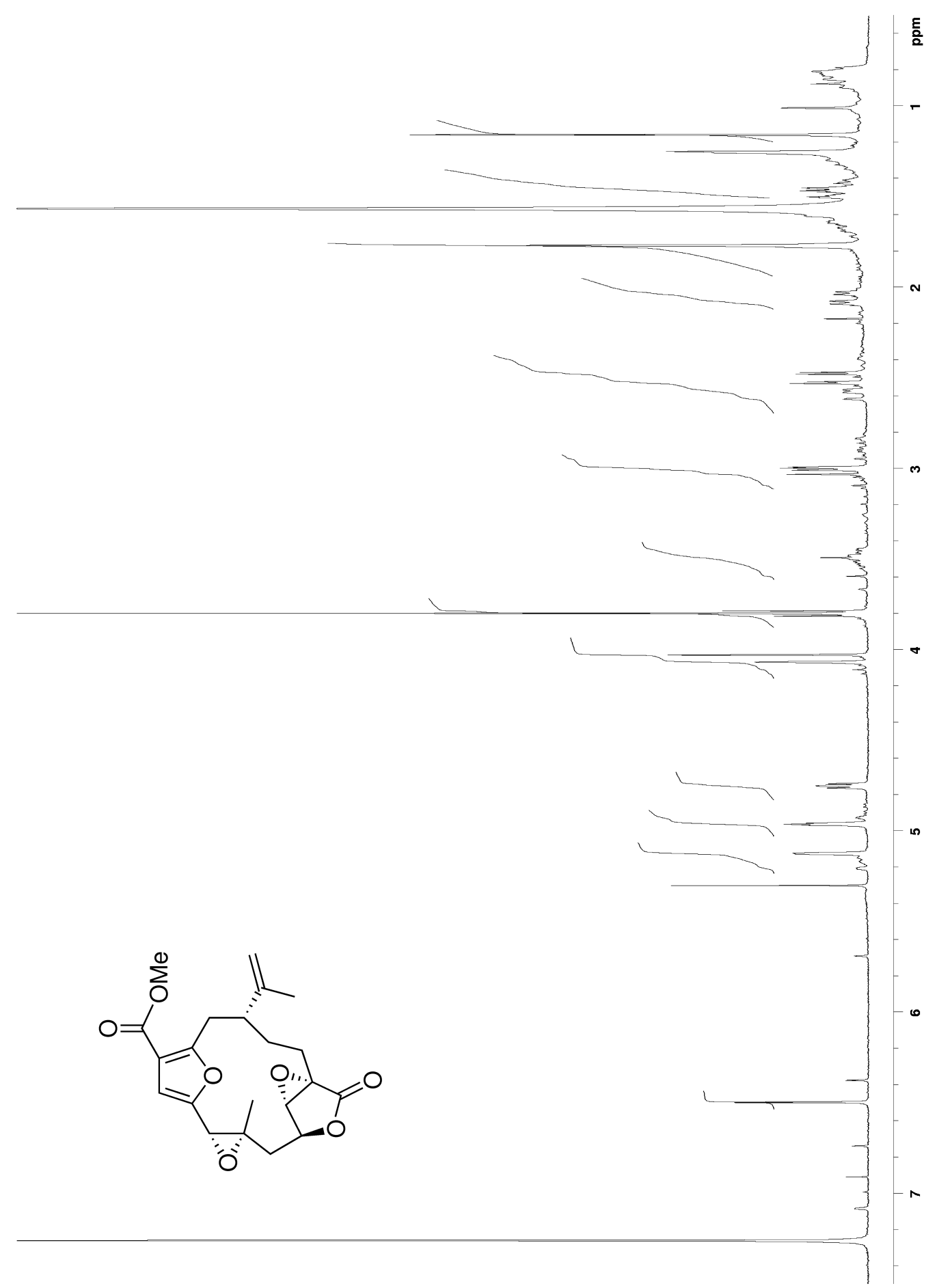

Figure B.5. ${ }^{1} \mathrm{H}$ NMR spectrum $\left(300 \mathrm{MHz}, \mathrm{CDCl}_{3}\right)$ of $11 \beta, 12 \beta$-epoxypukalide (29). 


\section{$13 \alpha$-Acetoxypukalide diol}

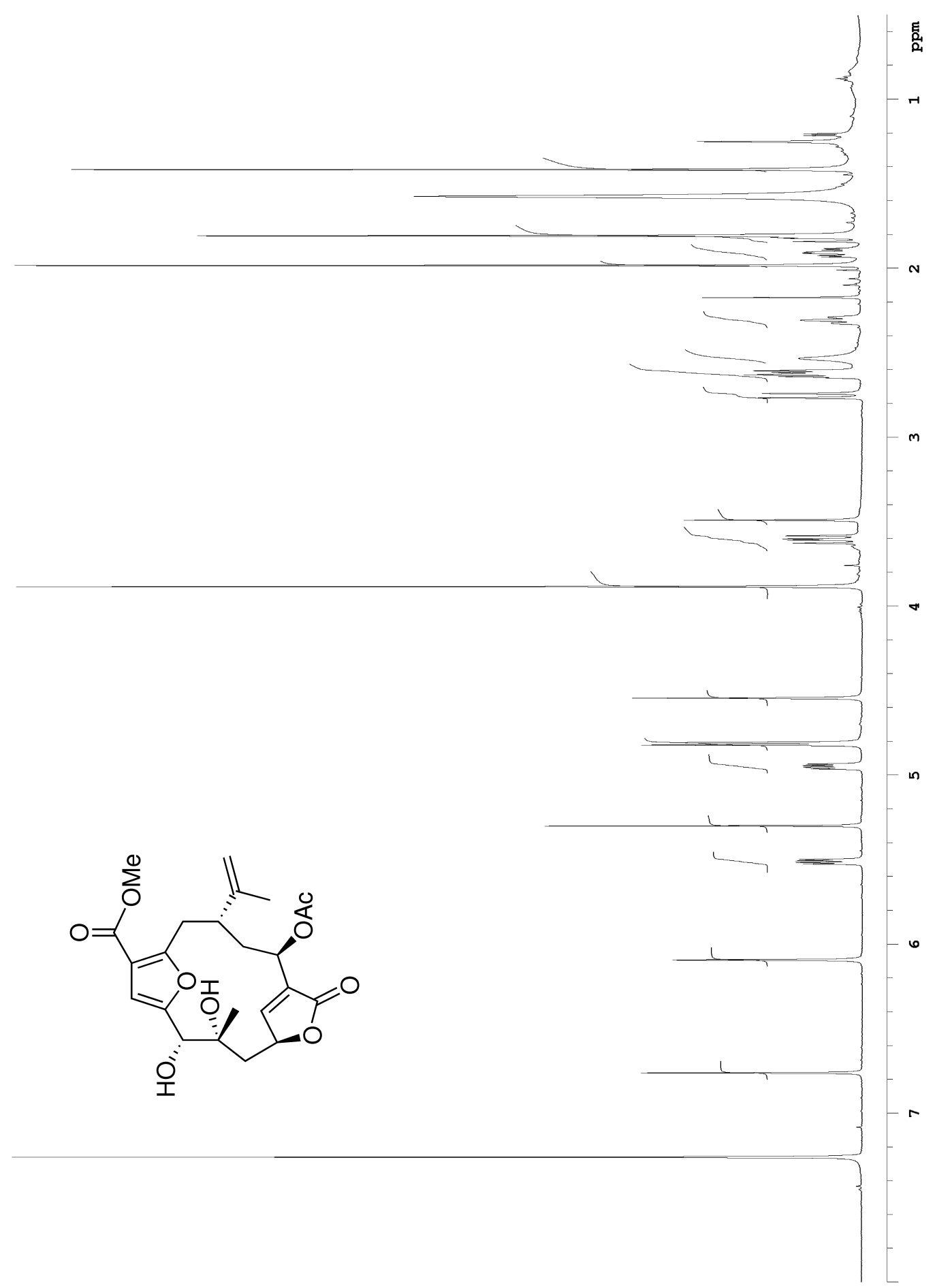

Figure B.6. ${ }^{1} \mathrm{H}$ NMR spectrum $\left(600 \mathrm{MHz}, \mathrm{CDCl}_{3}\right)$ of $13 \alpha$-acetoxypukalide diol (30). 


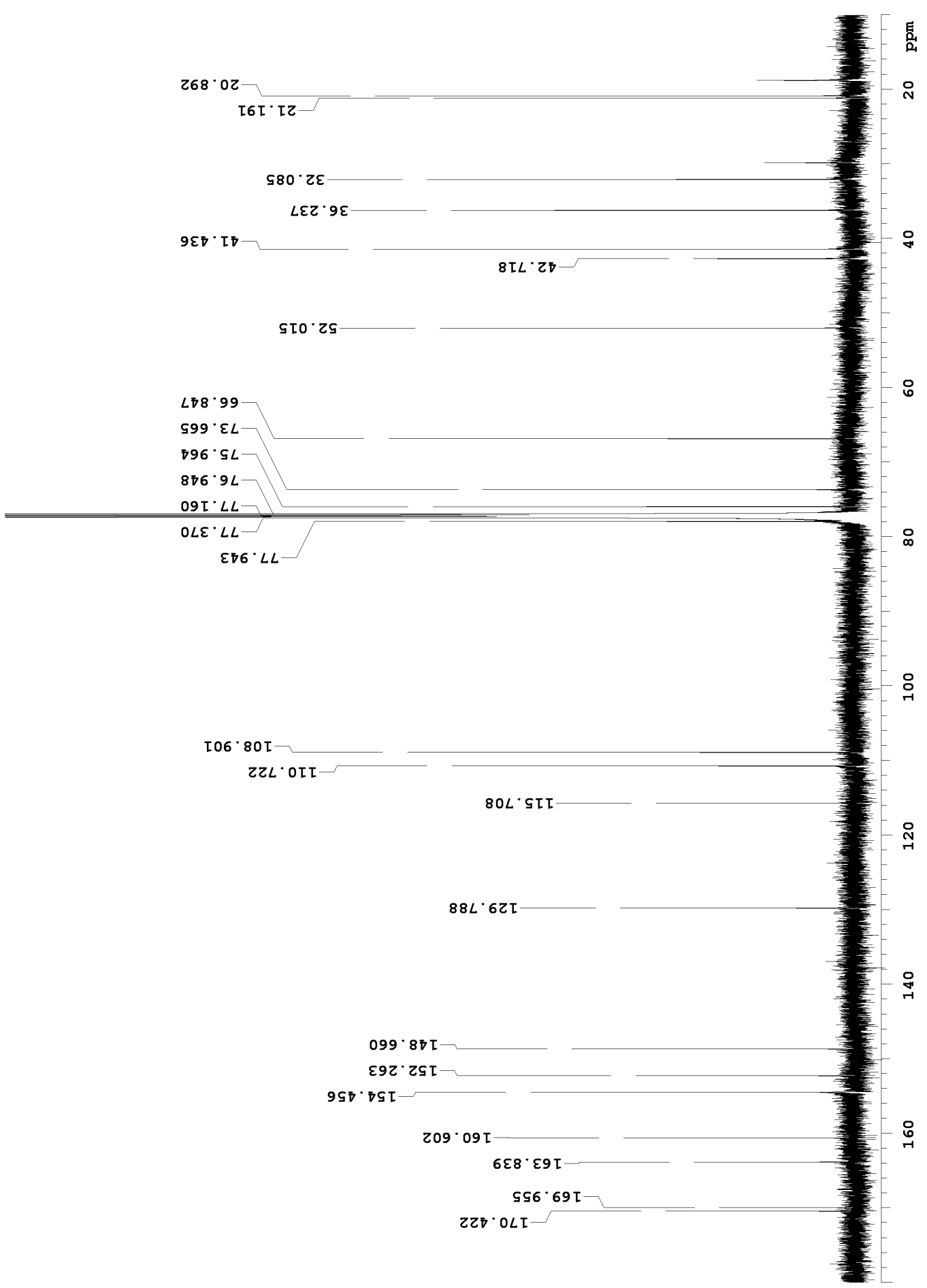

Figure B.7. ${ }^{13} \mathrm{C}$ NMR spectrum $\left(150 \mathrm{MHz}, \mathrm{CDCl}_{3}\right)$ of $13 \alpha$-acetoxypukalide diol (31). 


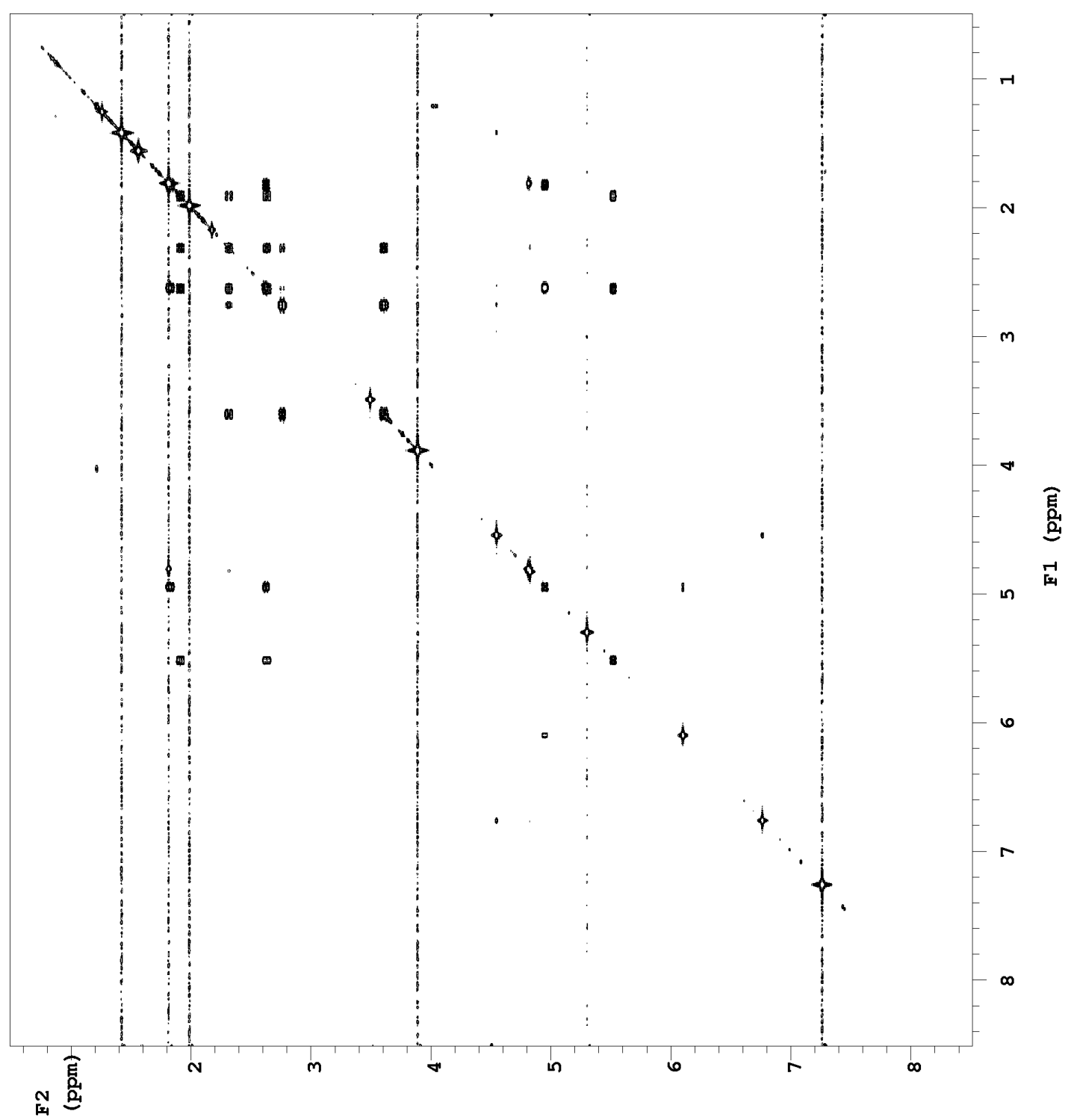

Figure B.8. COSY spectrum (600 $\left.\mathrm{MHz}, \mathrm{CDCl}_{3}\right)$ of $13 \alpha$-acetoxypukalide diol (30). 


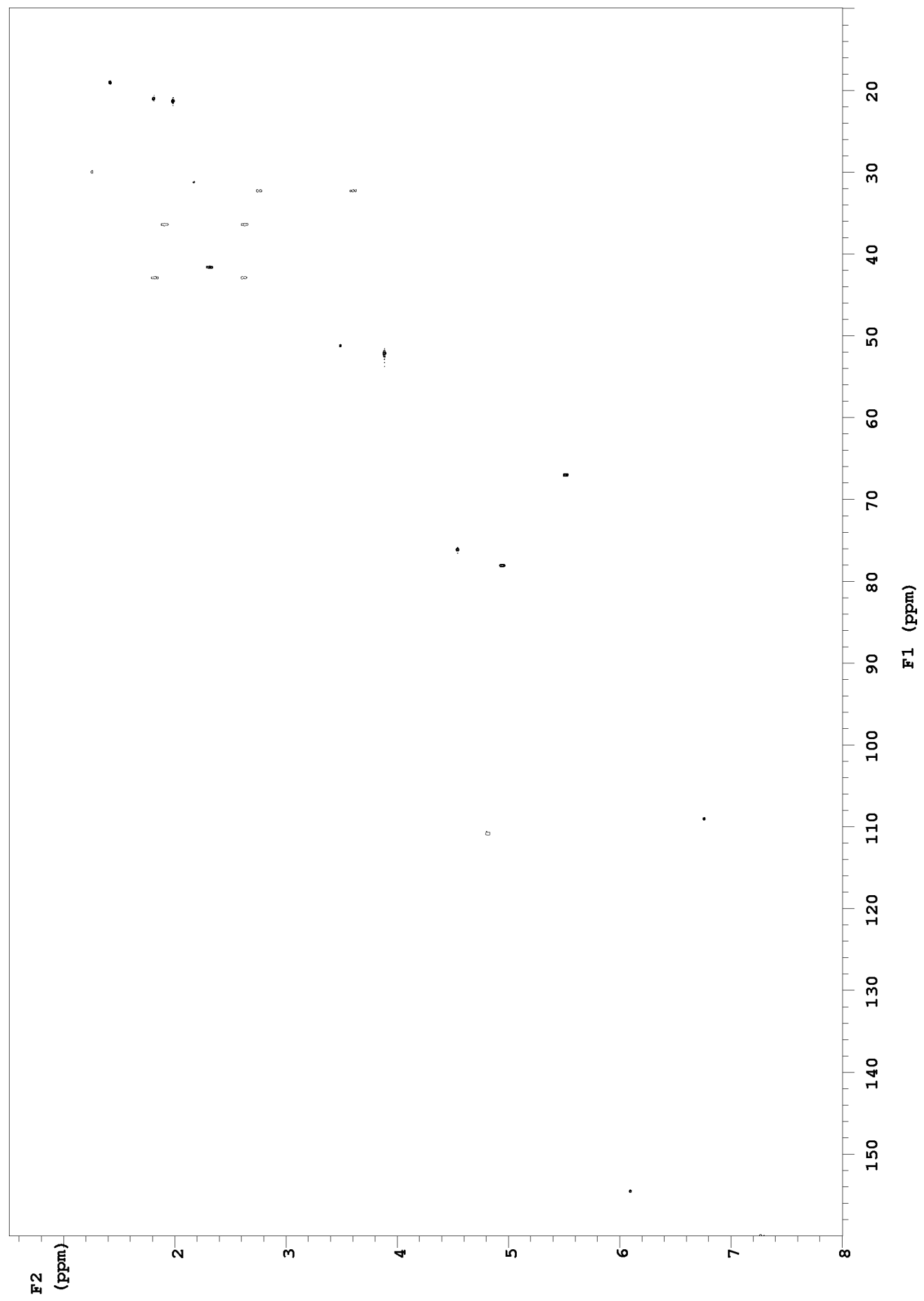

Figure B.9. HSQC spectrum $\left(600 \mathrm{MHz}, \mathrm{CDCl}_{3}\right)$ of $13 \alpha$-acetoxypukalide diol (30). 


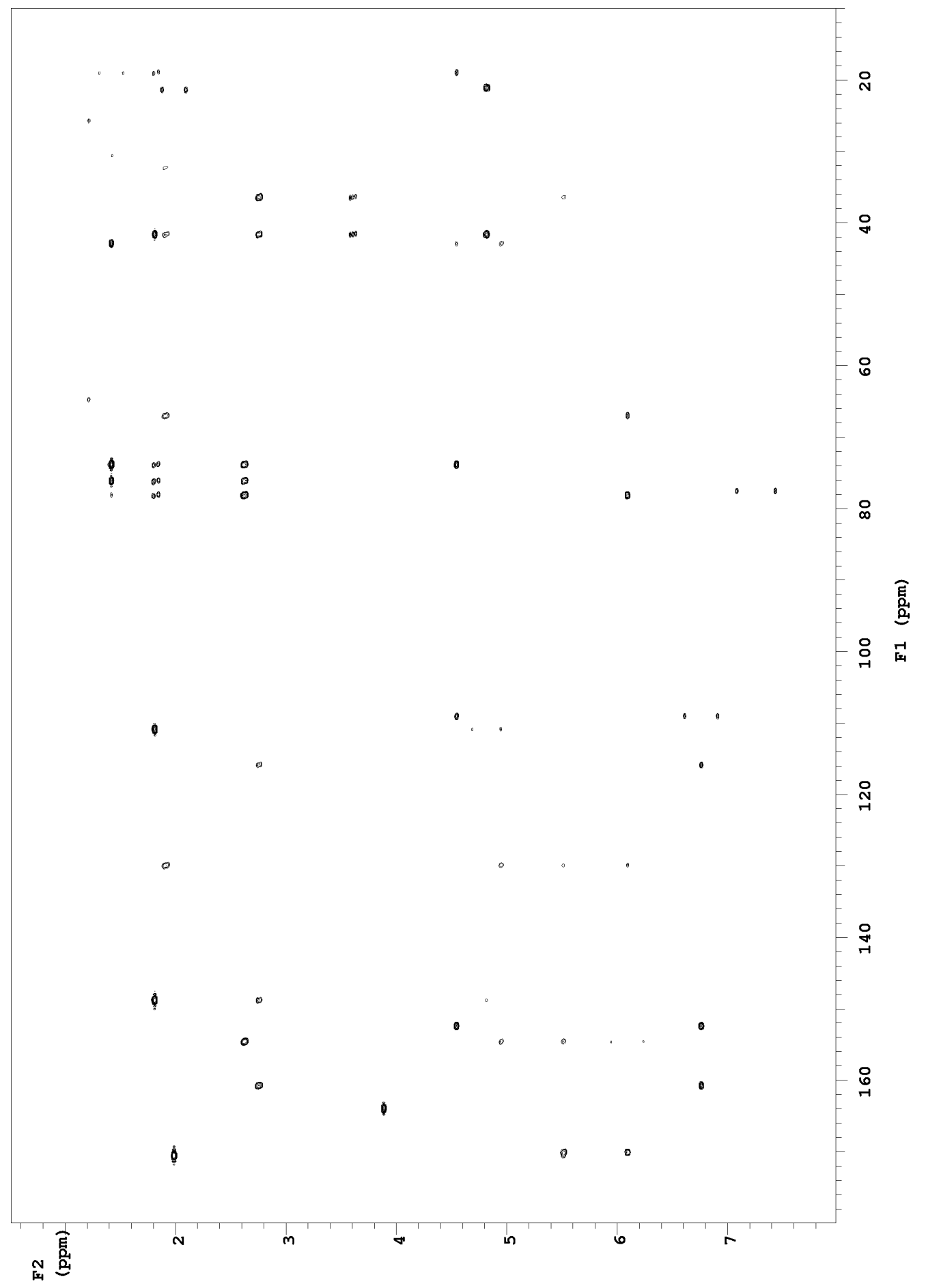

Figure B.10. HMBC spectrum $\left(600 \mathrm{MHz}^{\mathrm{CDCl}} \mathrm{CDC}_{3}\right)$ of $13 \alpha$-acetoxypukalide diol (30). 


\section{Lopholide diol}

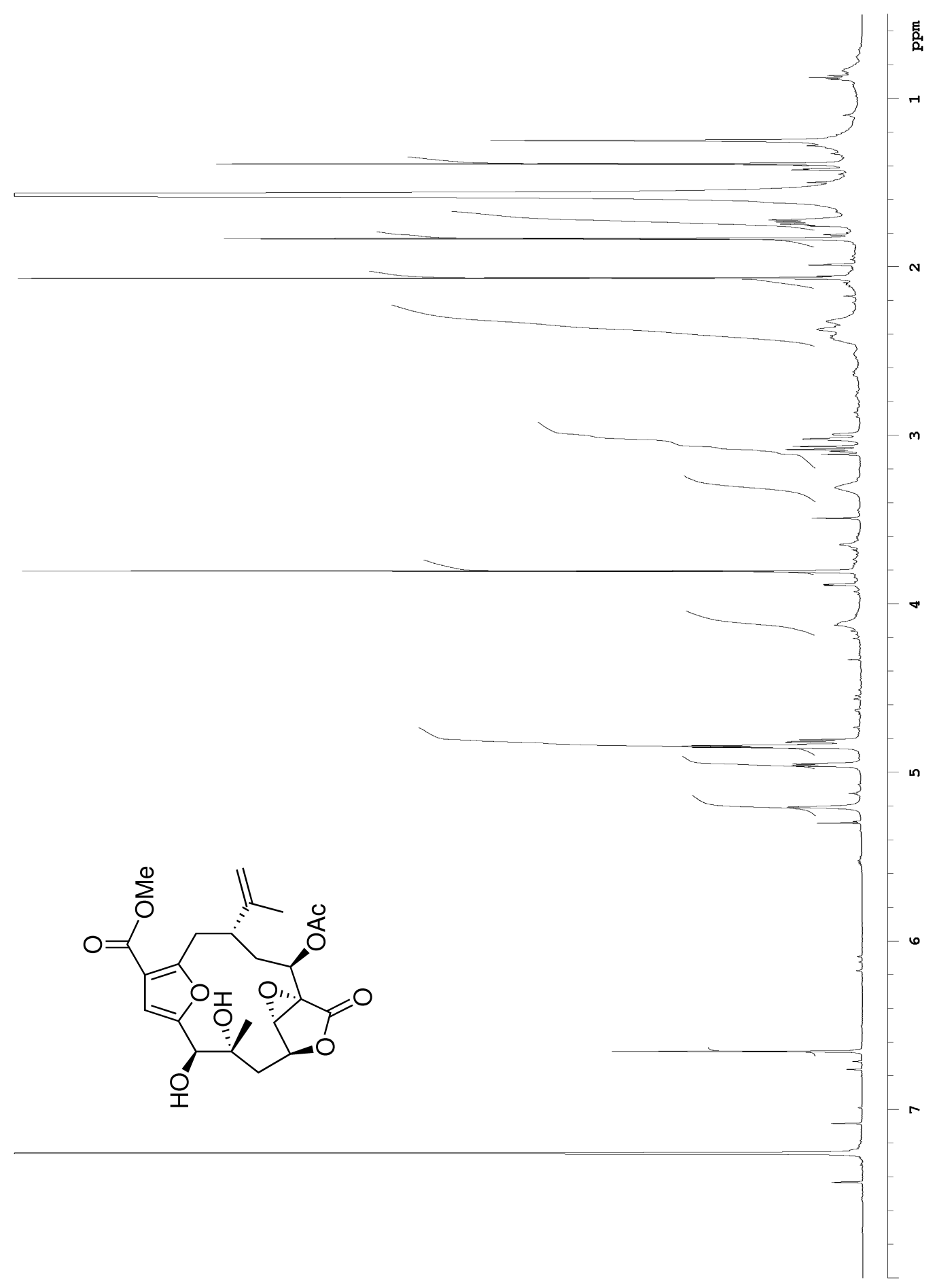

Figure B.11. ${ }^{1} \mathrm{H}$ NMR spectrum $\left(600 \mathrm{MHz}, \mathrm{CDCl}_{3}\right)$ of lopholide diol (31). 


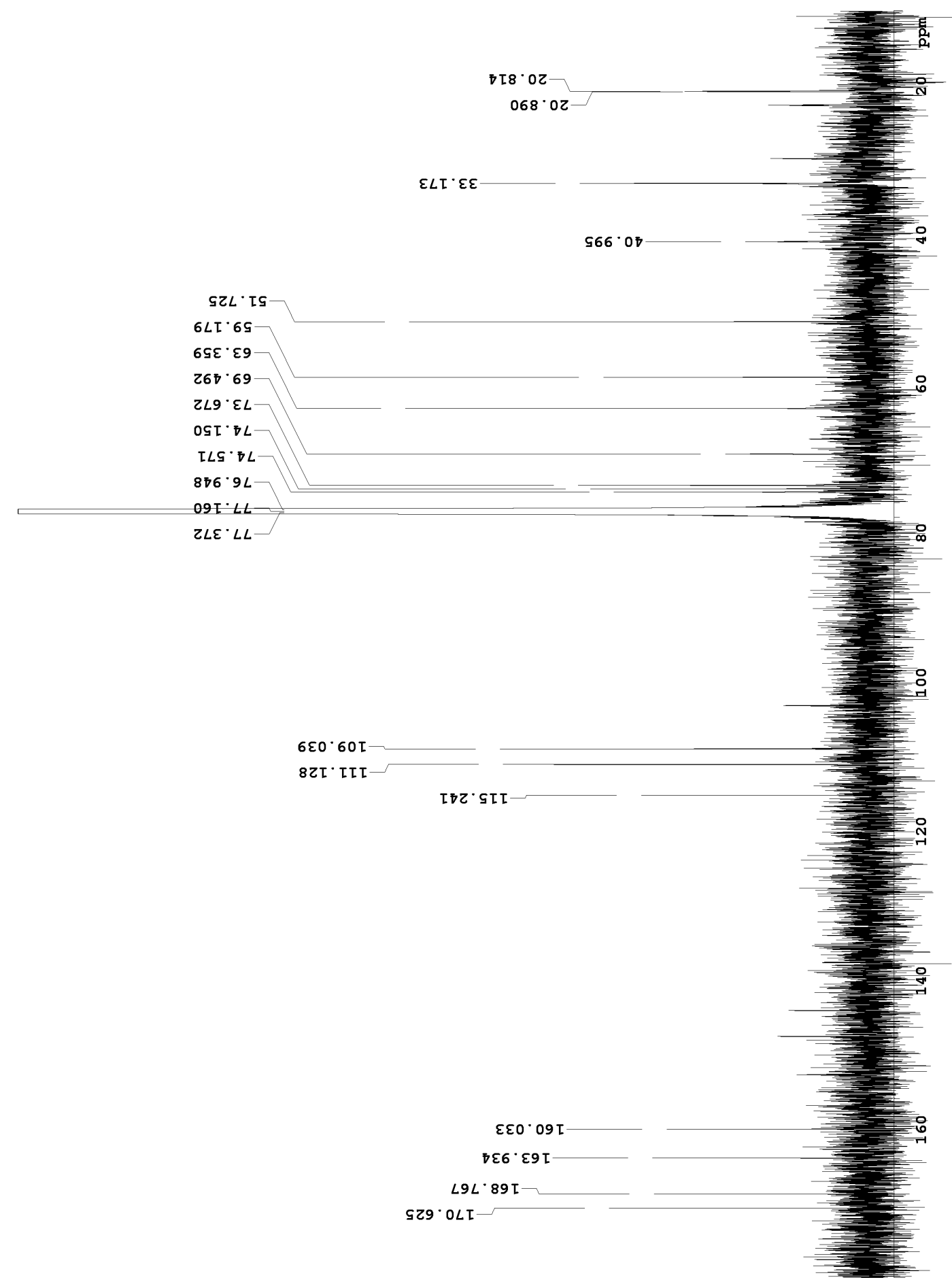

Figure B.12. ${ }^{13} \mathrm{C}$ NMR spectrum $\left(150 \mathrm{MHz}, \mathrm{CDCl}_{3}\right)$ of lopholide diol (31). 


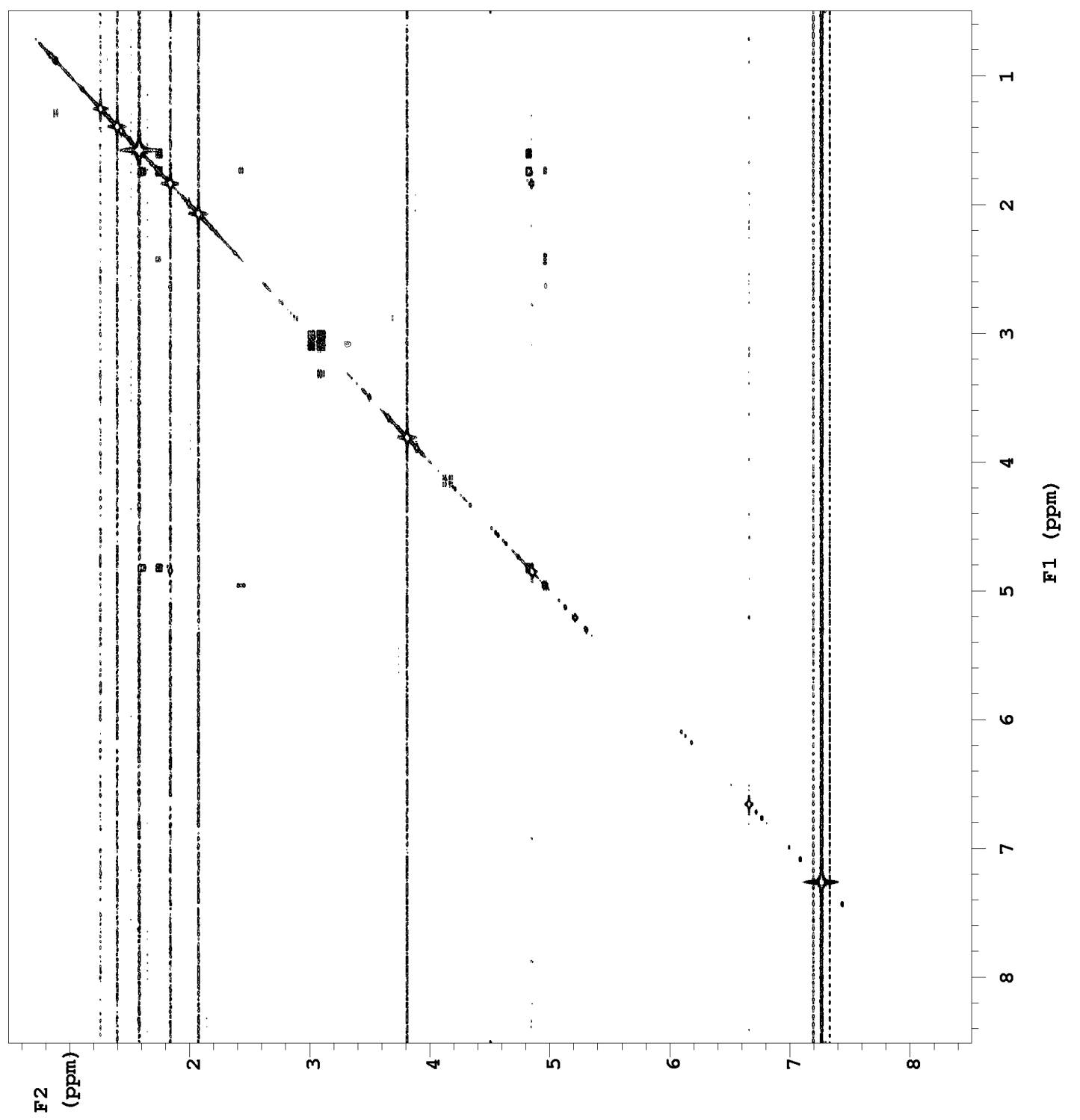

Figure B.13. COSY spectrum (600 $\left.\mathrm{MHz}, \mathrm{CDCl}_{3}\right)$ of lopholide diol (31). 


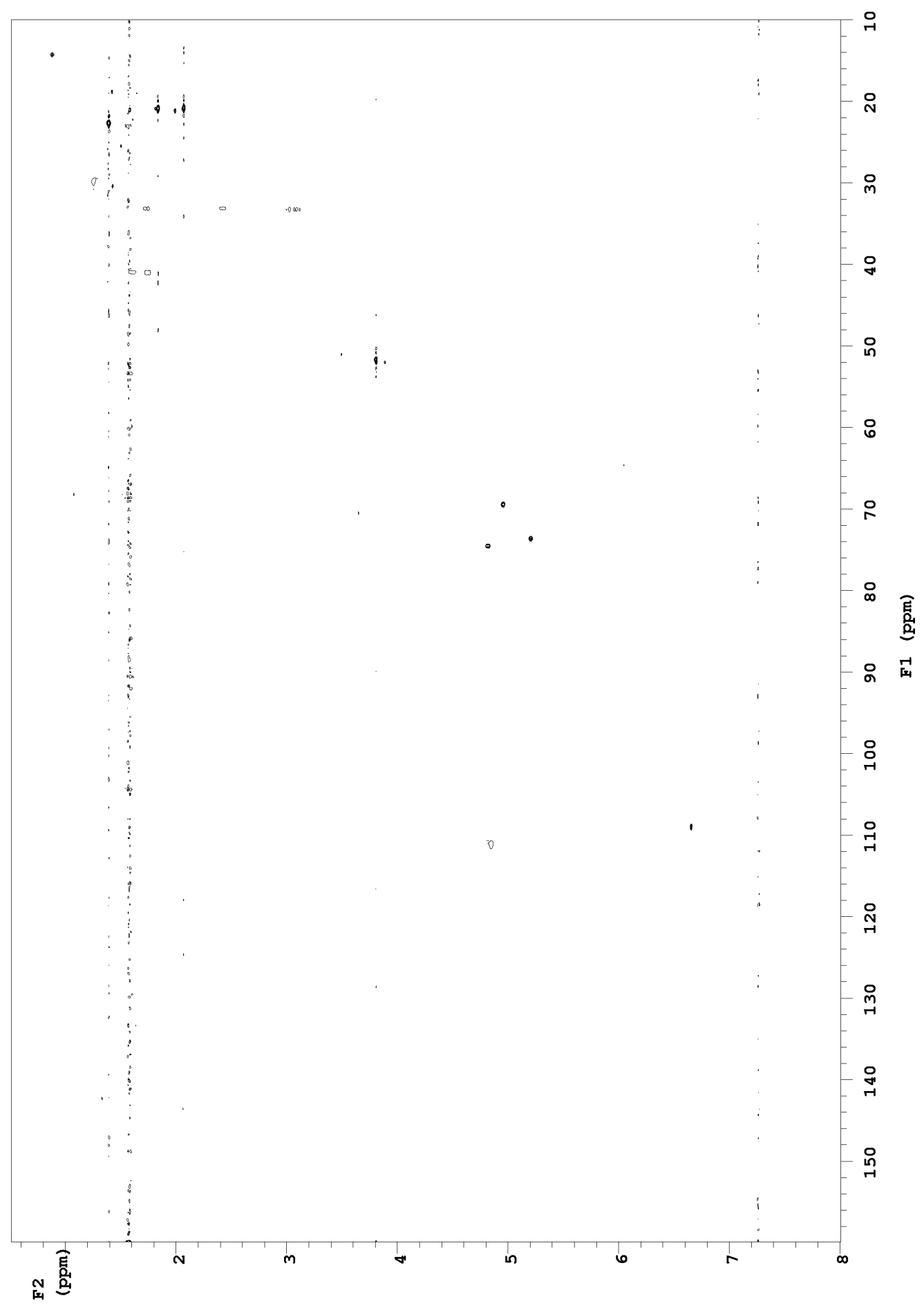

Figure B.14. HSQC spectrum (600 $\mathrm{MHz}, \mathrm{CDCl}_{3}$ ) of lopholide diol (31). 


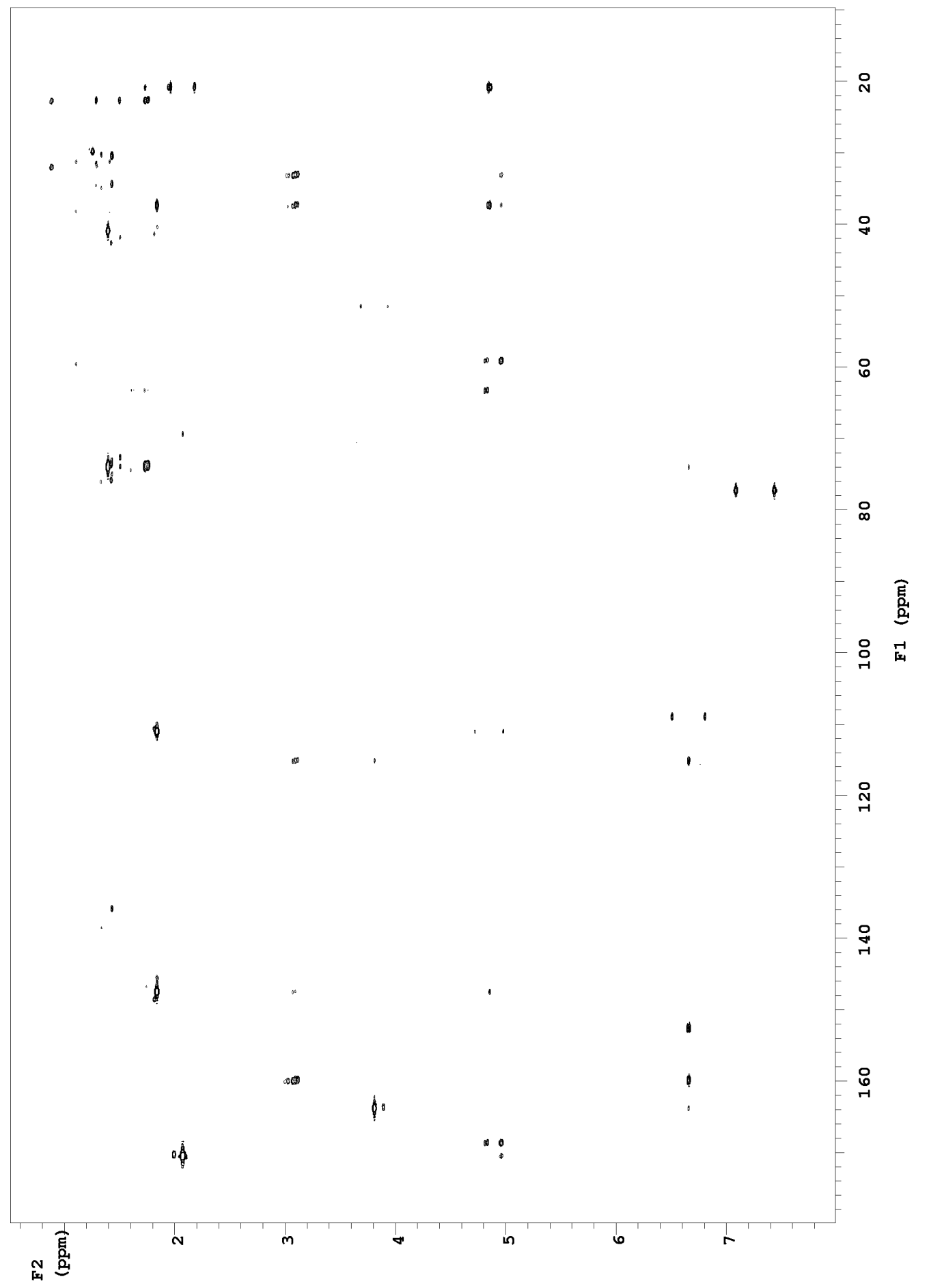

Figure B.15. HMBC spectrum (600 $\left.\mathrm{MHz} \mathrm{CDCl}_{3}\right)$ of lopholide diol (31). 


\section{Cinnamolide}

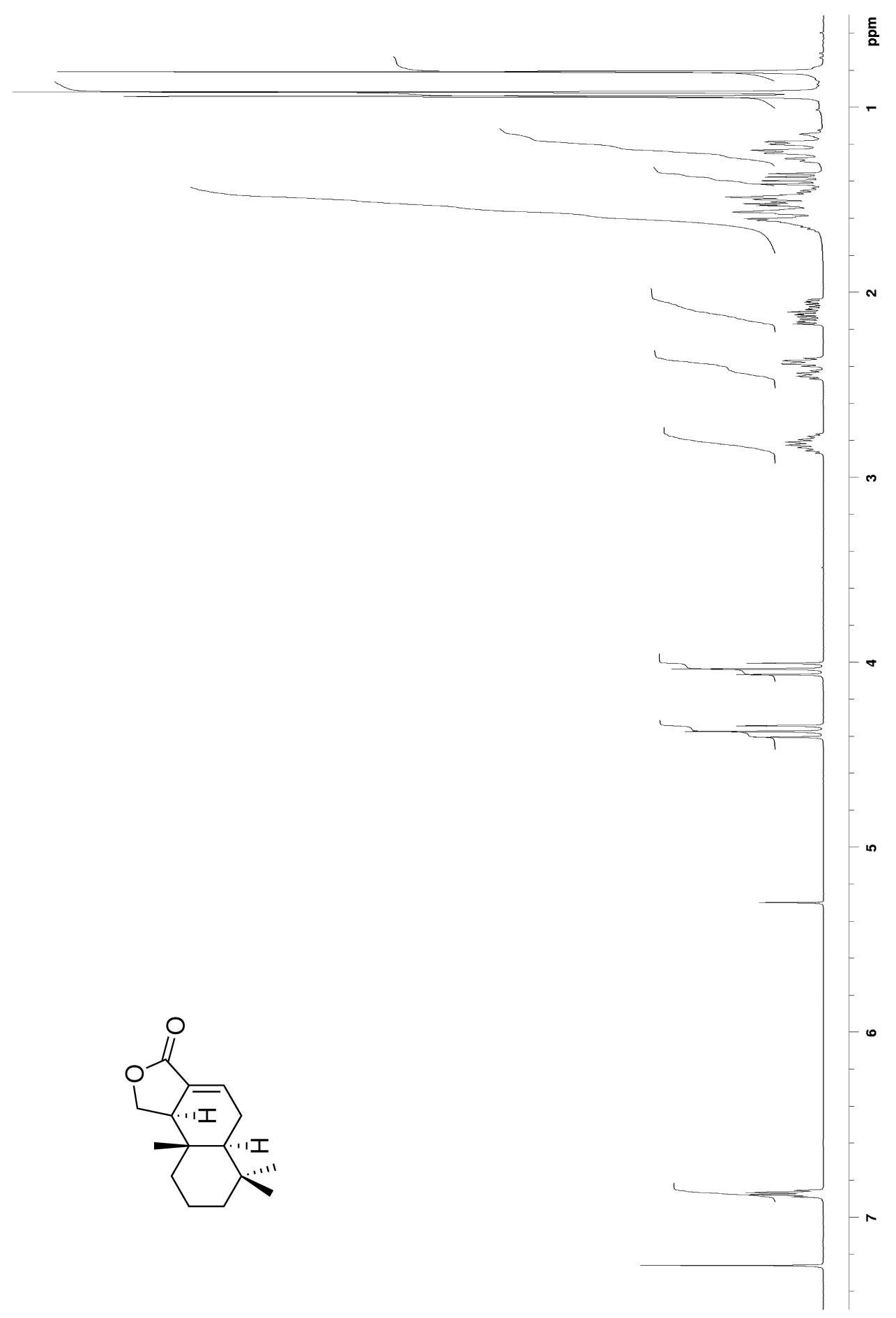

Figure B.16. ${ }^{1} \mathrm{H}$ NMR spectrum $\left(300 \mathrm{MHz}, \mathrm{CDCl}_{3}\right)$ of cinnamolide (35). 


\section{Dendocarbin A}

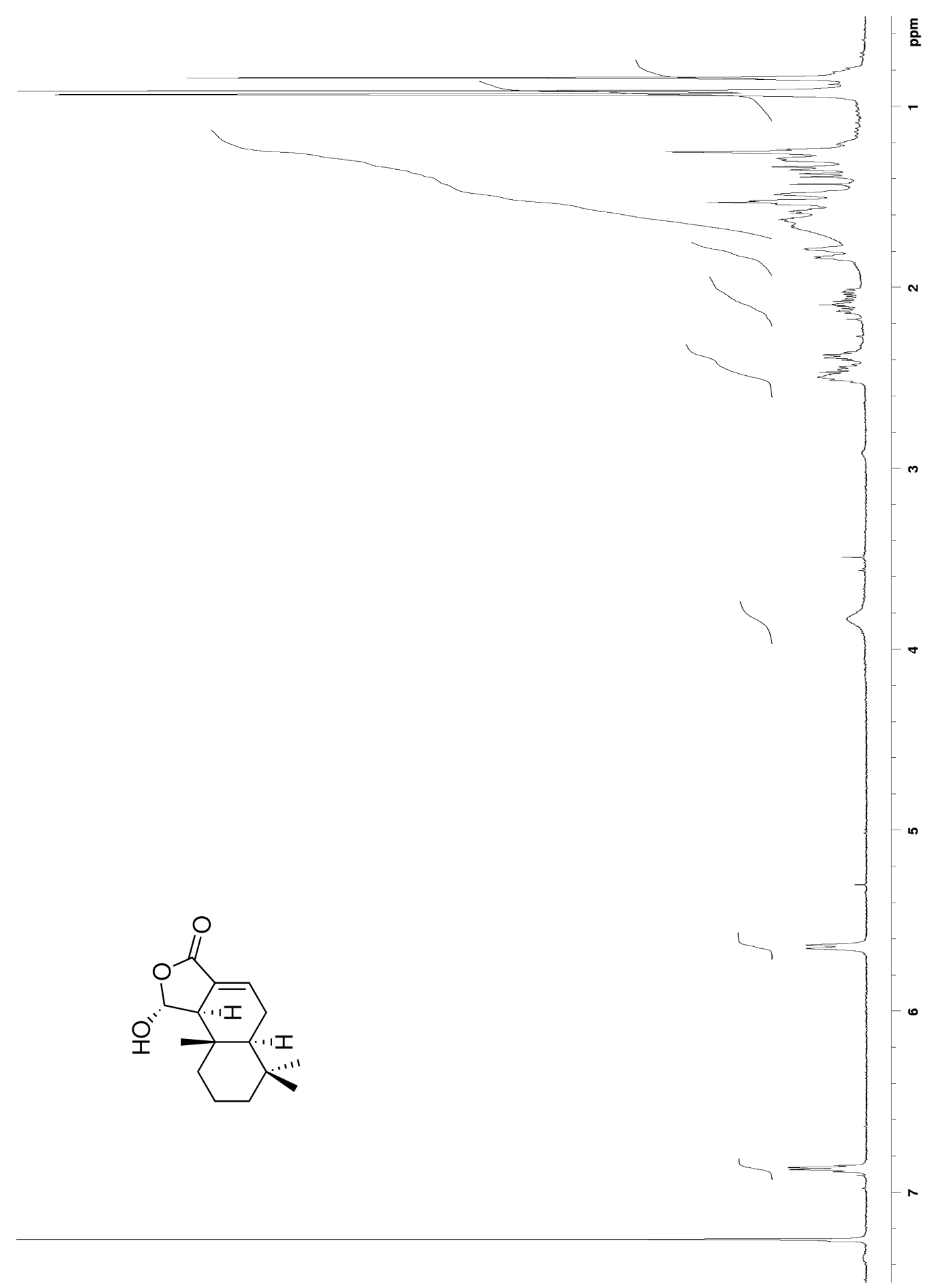

Figure B.17. ${ }^{1} \mathrm{H}$ NMR spectrum $\left(300 \mathrm{MHz}, \mathrm{CDCl}_{3}\right)$ of dendocarbin $\mathrm{A}(\mathbf{3 6})$. 


\section{Polymeric alkyl-pyridinium salt}

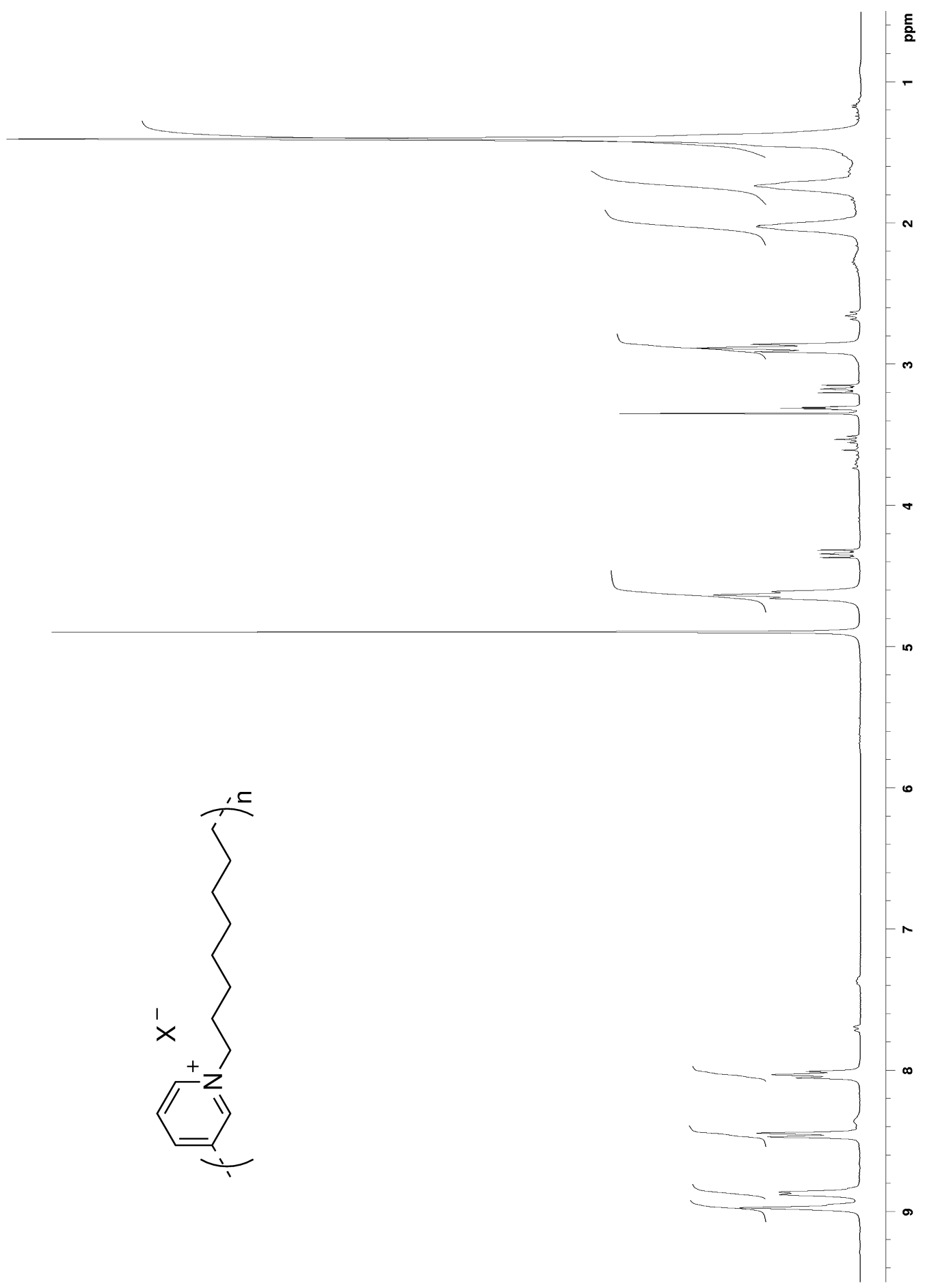

Figure B.18. ${ }^{1} \mathrm{H}$ NMR spectrum $\left(300 \mathrm{MHz}, \mathrm{CD}_{3} \mathrm{OD}\right)$ of the polymeric alkylpyridinium salt (53). 


\section{Tambjamine A}

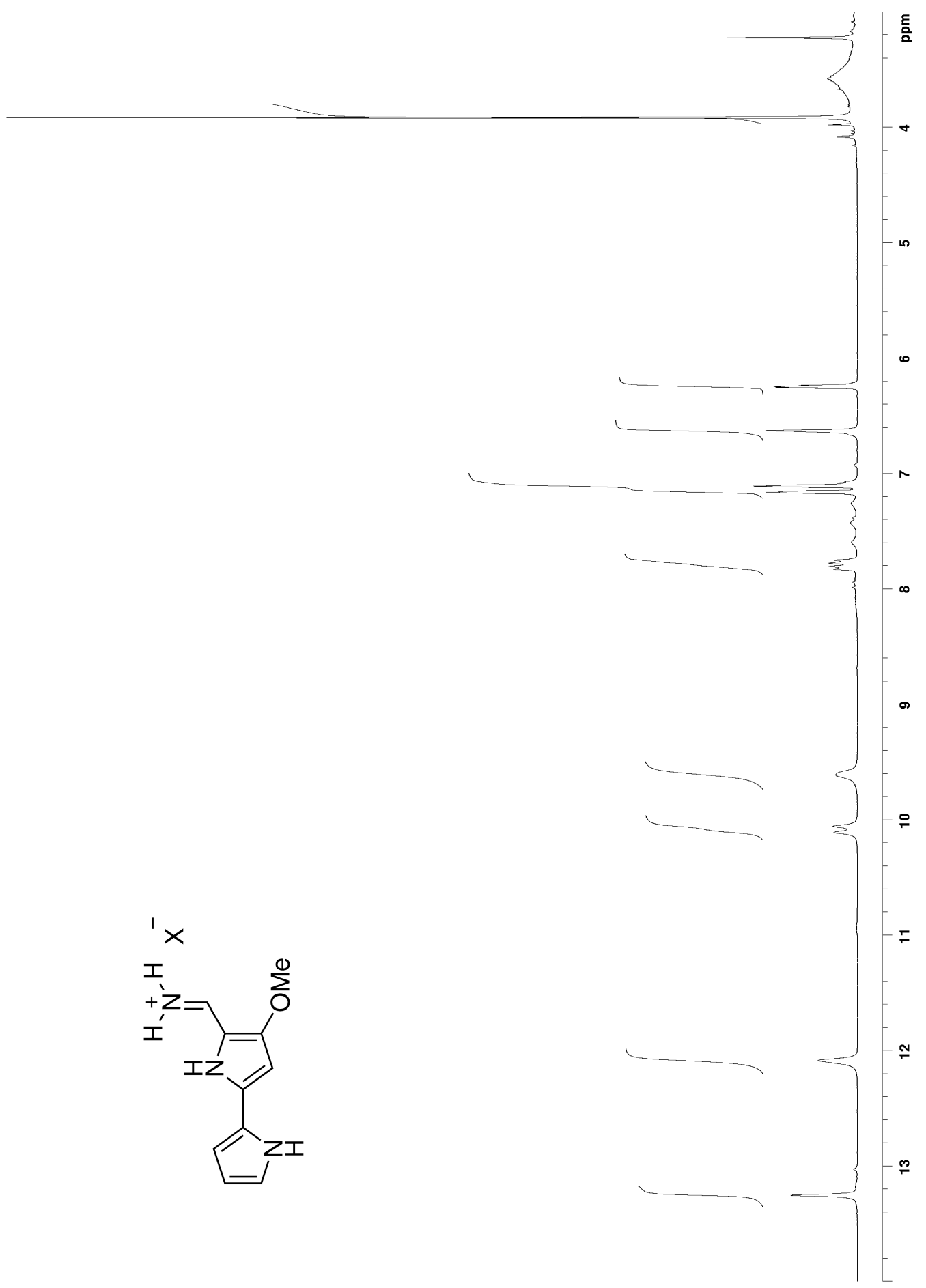

Figure B.19. ${ }^{1} \mathrm{H}$ NMR spectrum $\left(300 \mathrm{MHz}\right.$, DMSO- $\left.\mathrm{d}_{6}\right)$ of tambjamine A (67a). 


\section{Furodysinin}

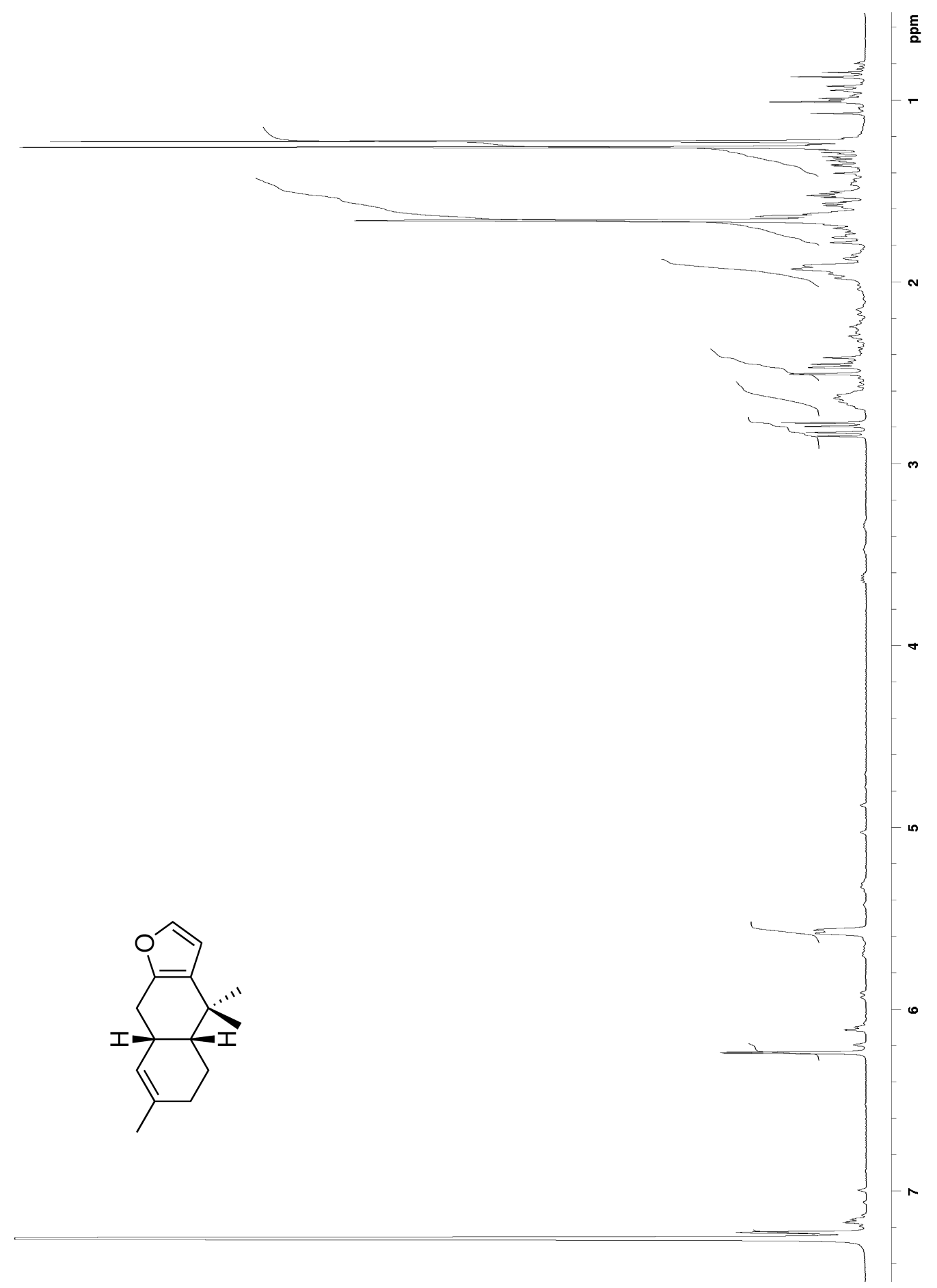

Figure B.20. ${ }^{1} \mathrm{H}$ NMR spectrum $\left(300 \mathrm{MHz}, \mathrm{CDCl}_{3}\right)$ of furodysinin (83). 


\section{$O$-methyl-furodysinin lactone}

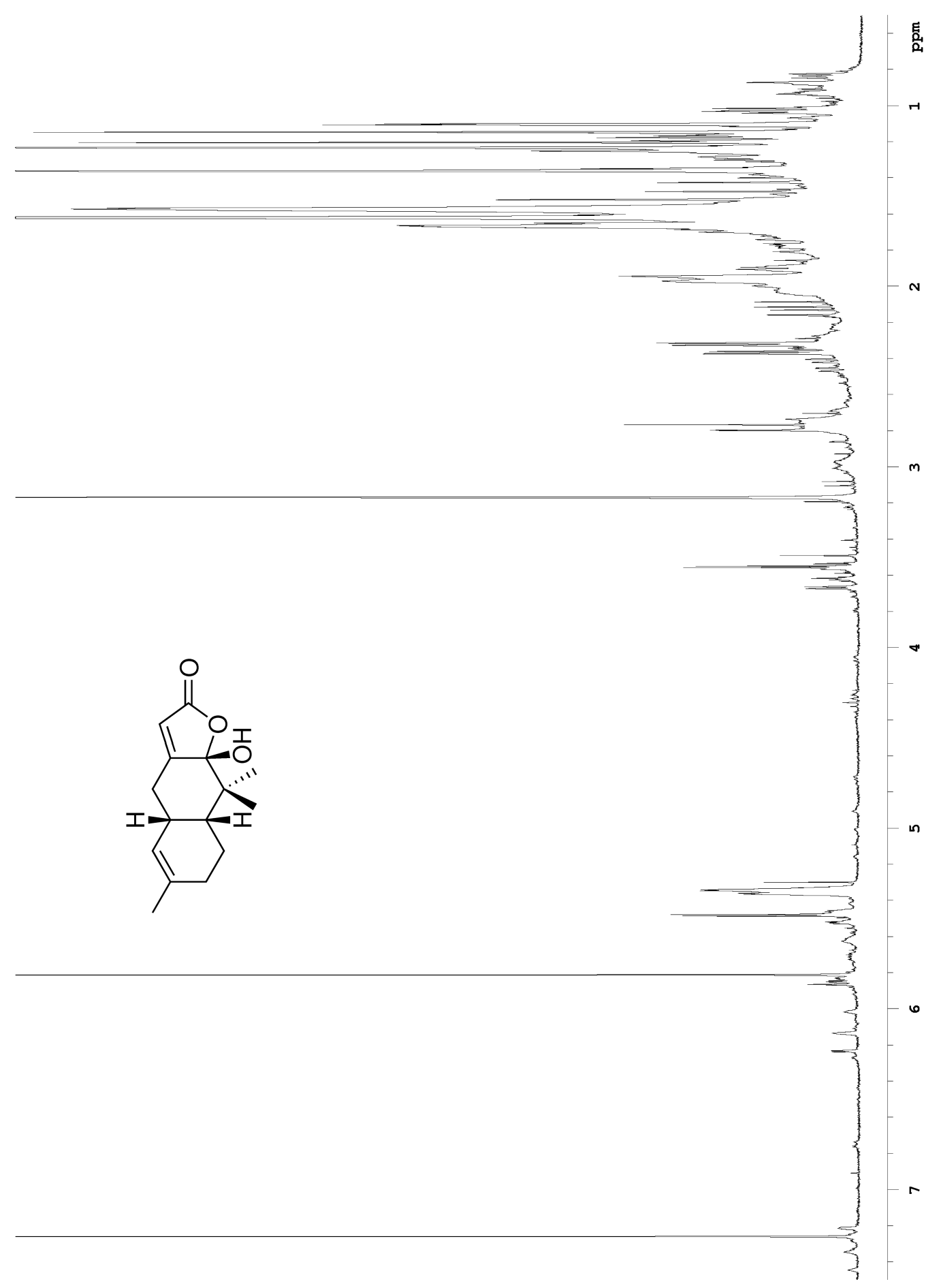

Figure B.21. ${ }^{1} \mathrm{H}$ NMR spectrum $\left(300 \mathrm{MHz}, \mathrm{CDCl}_{3}\right)$ of $O$-methyl-furodysinin lactone (84). 


\section{(-)-Tetradehydrofurospongin-1}

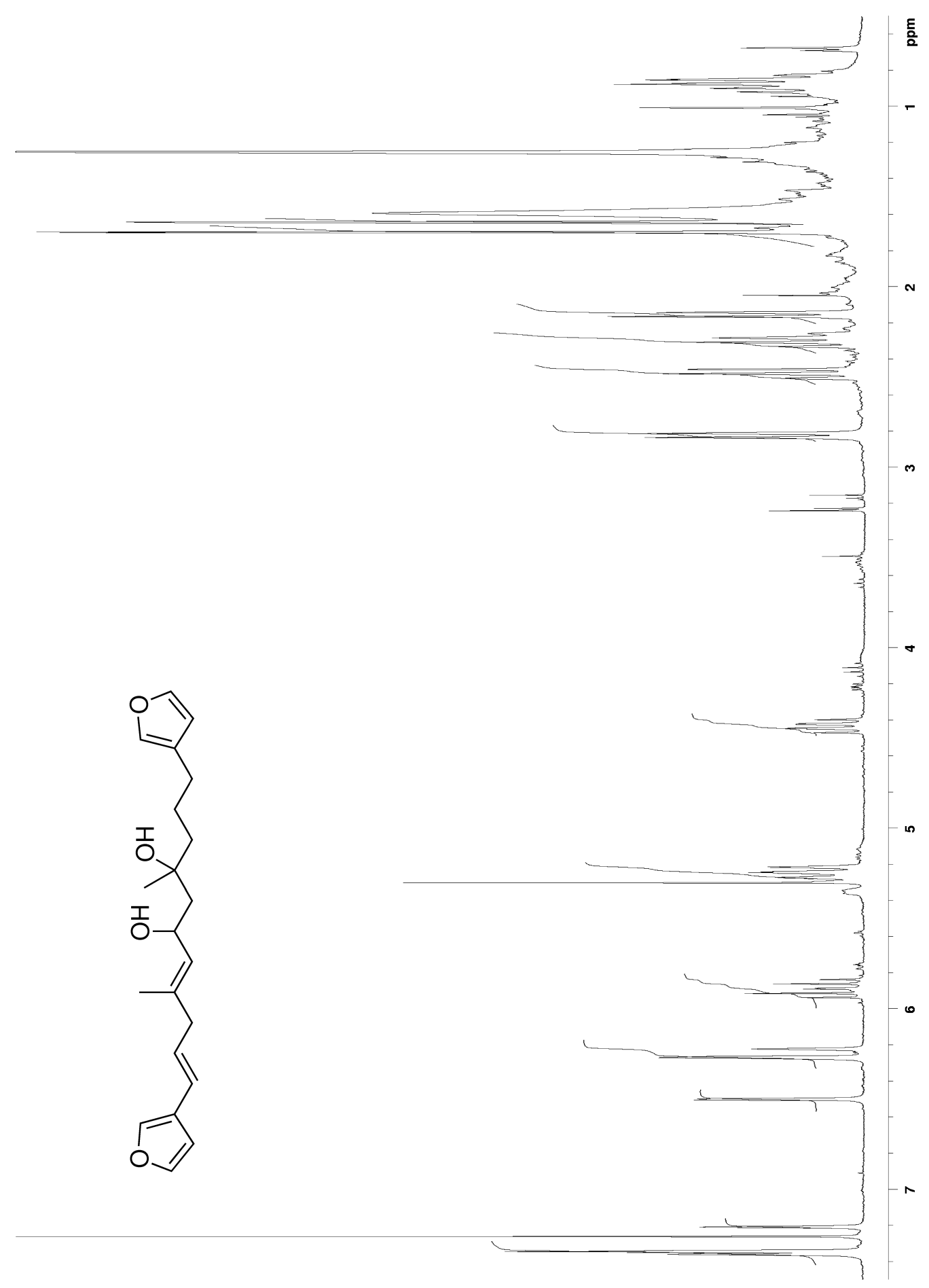

Figure B.22. ${ }^{1} \mathrm{H}$ NMR spectrum $\left(300 \mathrm{MHz}, \mathrm{CDCl}_{3}\right)$ of (-)-tetradehydrofurospongin-1 (85). 


\section{Agminoside A}

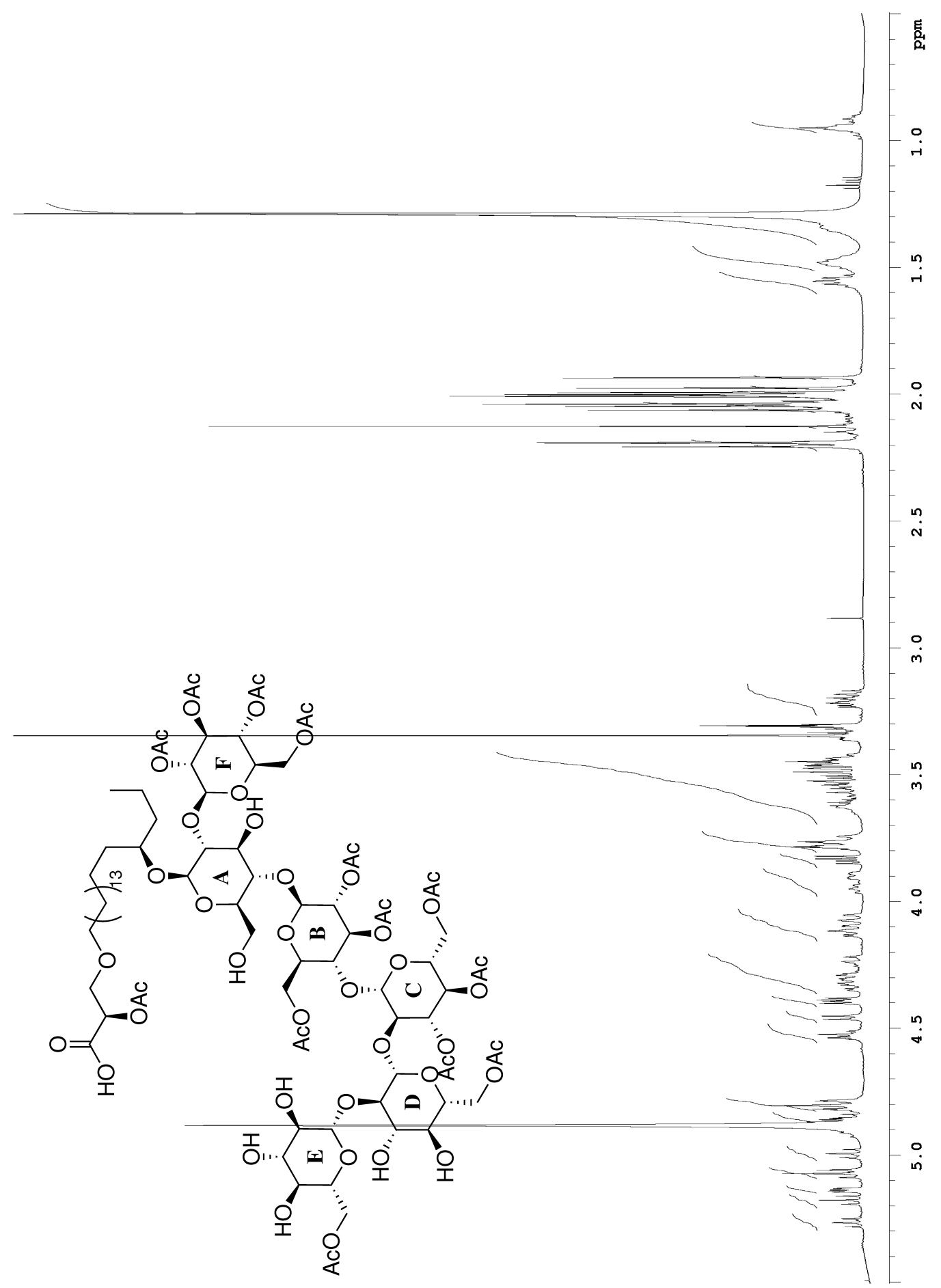

Figure B.23. ${ }^{1} \mathrm{H}$ NMR spectrum $\left(600 \mathrm{MHz}, \mathrm{CD}_{3} \mathrm{OD}\right)$ of agminoside $\mathrm{A}$ (145). 


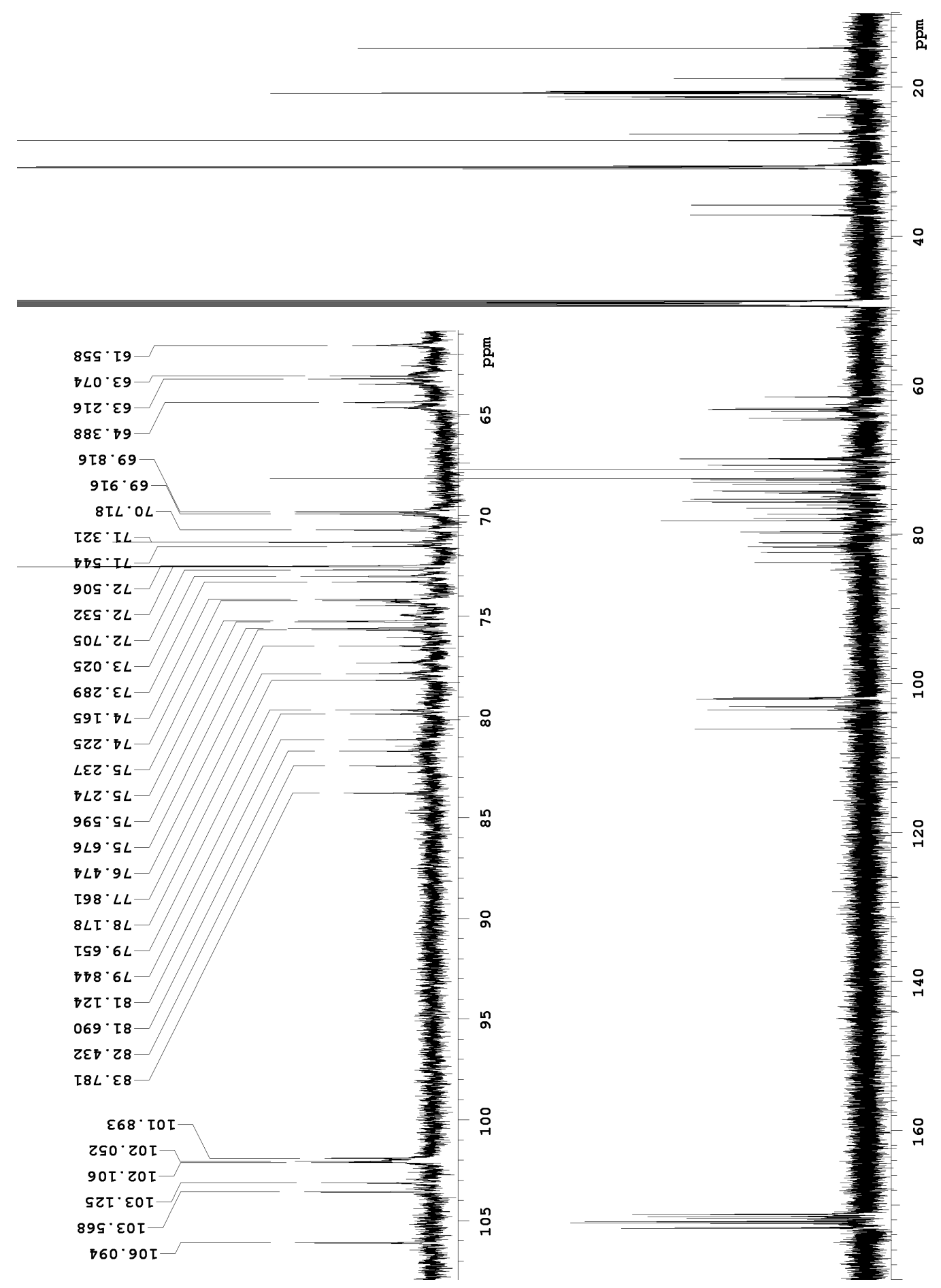

Figure B.24. ${ }^{13} \mathrm{C}$ NMR spectrum $\left(150 \mathrm{MHz}, \mathrm{CD}_{3} \mathrm{OD}\right)$ of agminoside A (145). 


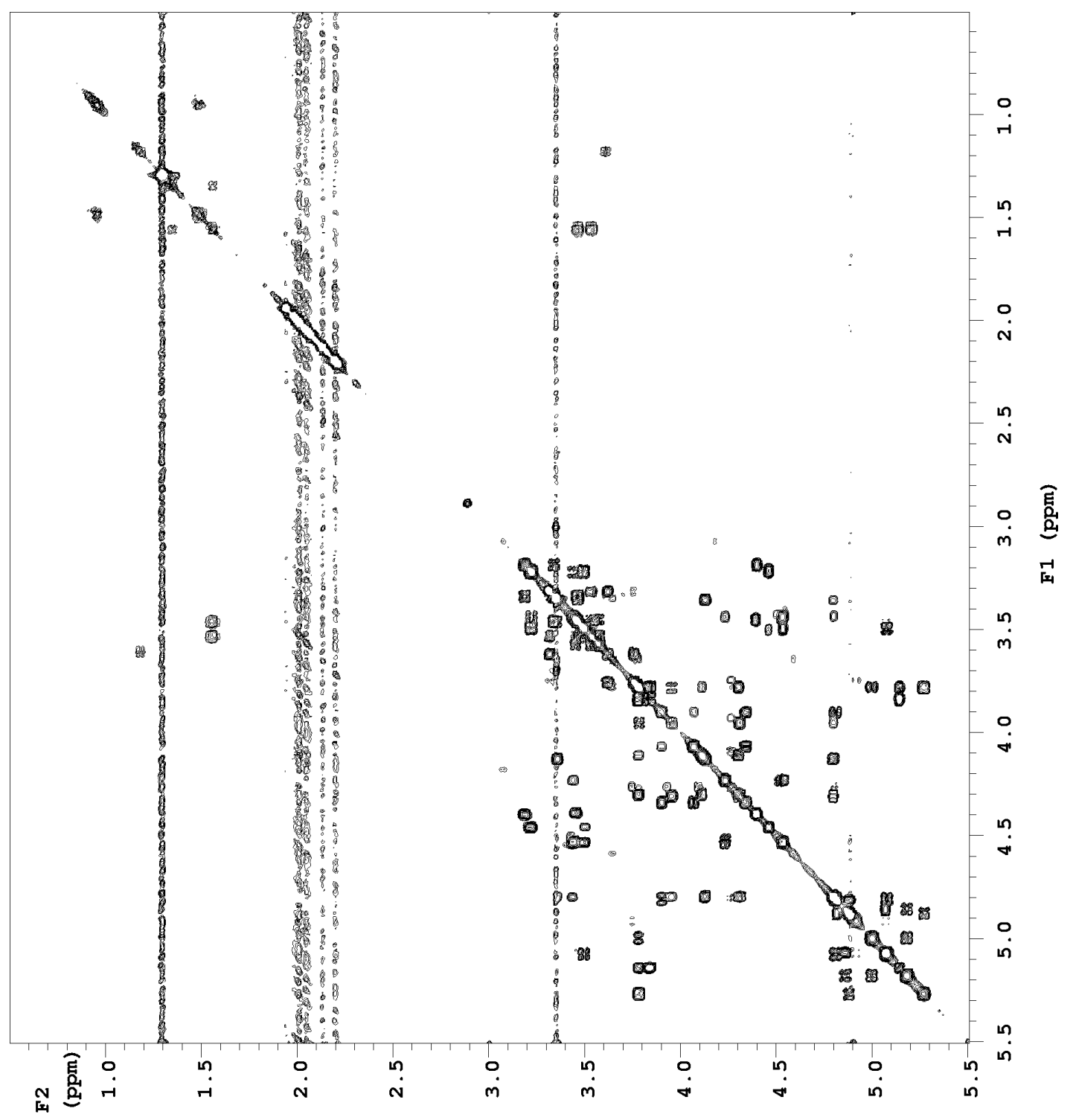

Figure B.25. COSY spectrum (600 MHz, $\left.\mathrm{CD}_{3} \mathrm{OD}\right)$ of agminoside A (145). 


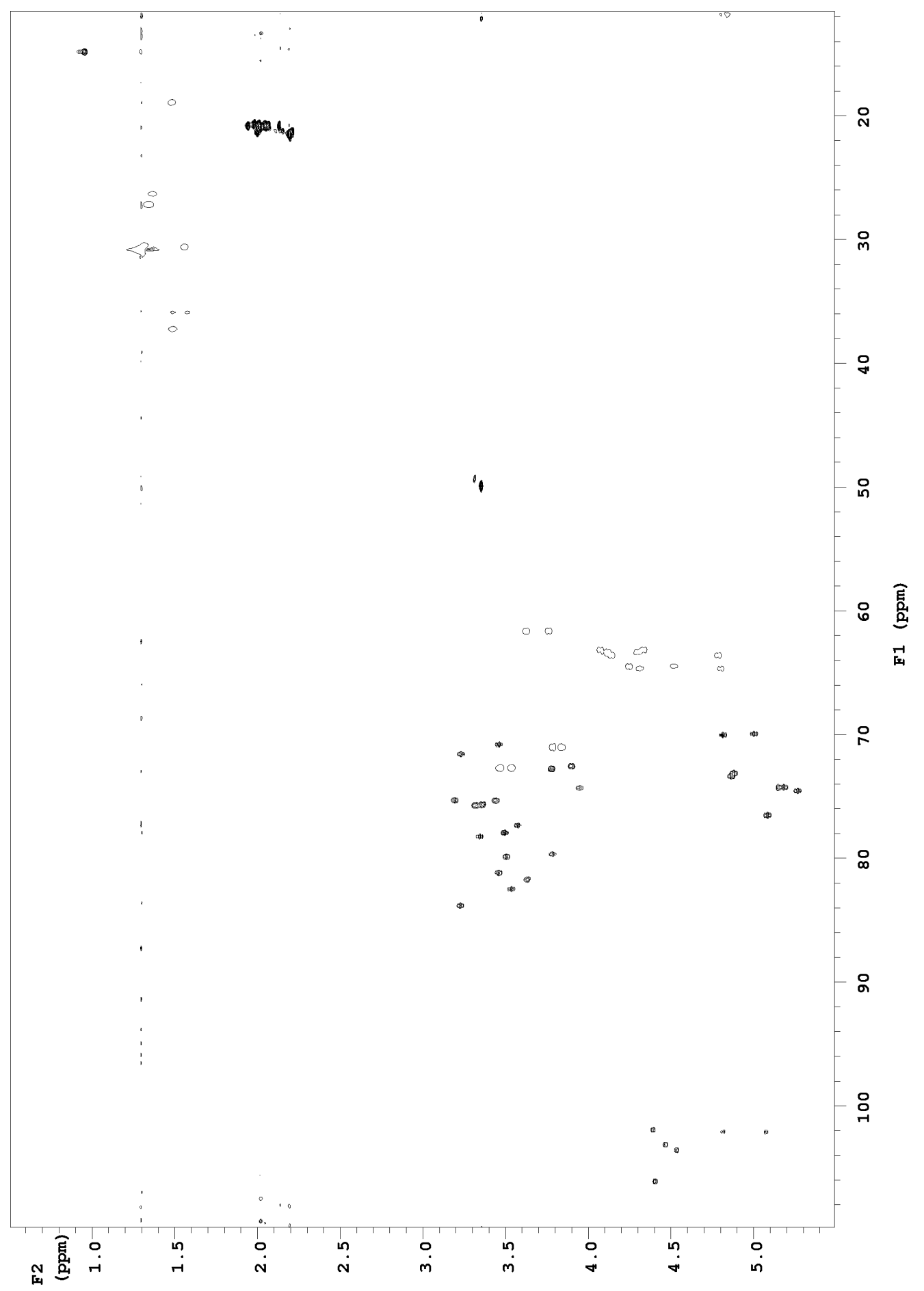

Figure B.26. HSQC spectrum $\left(600 \mathrm{MHz}, \mathrm{CD}_{3} \mathrm{OD}\right)$ of agminoside A (145). 


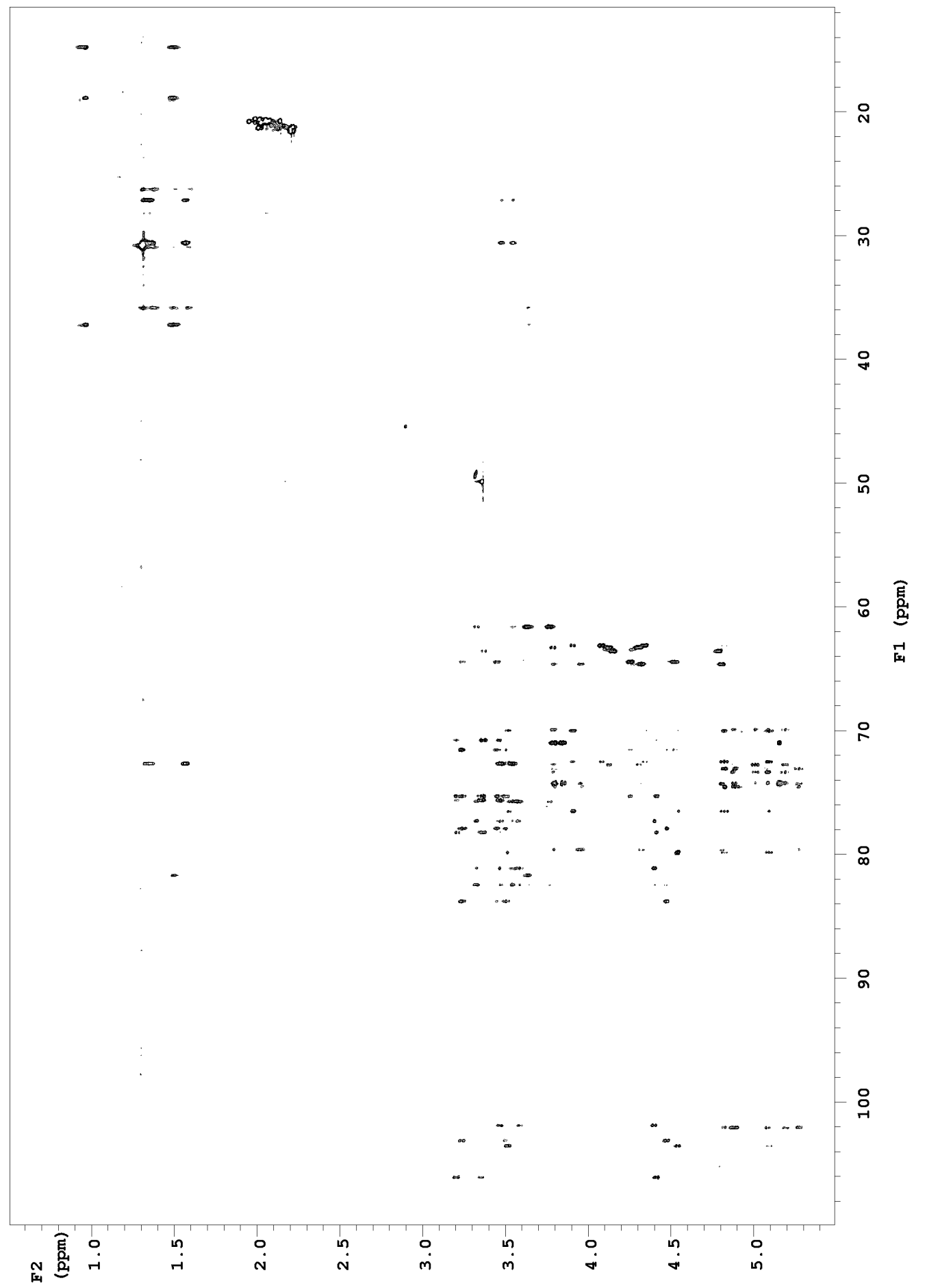

Figure B.27. HSQC-TOCSY spectrum (600 MHz, $\left.\mathrm{CD}_{3} \mathrm{OD}\right)$ of agminoside A (145). 


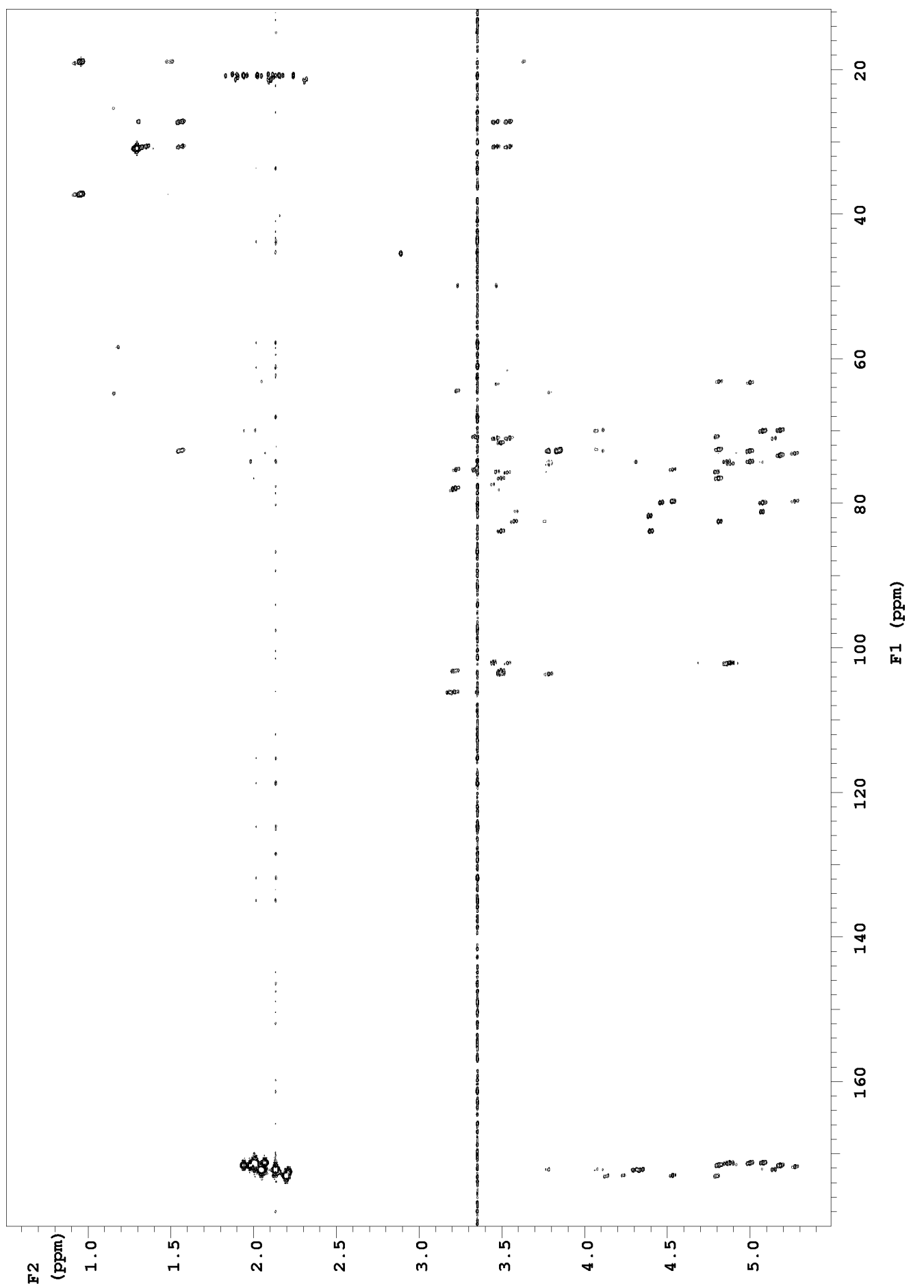

Figure B.28. HMBC spectrum (600 MHz, $\mathrm{CD}_{3} \mathrm{OD}$ ) of agminoside A (145). 


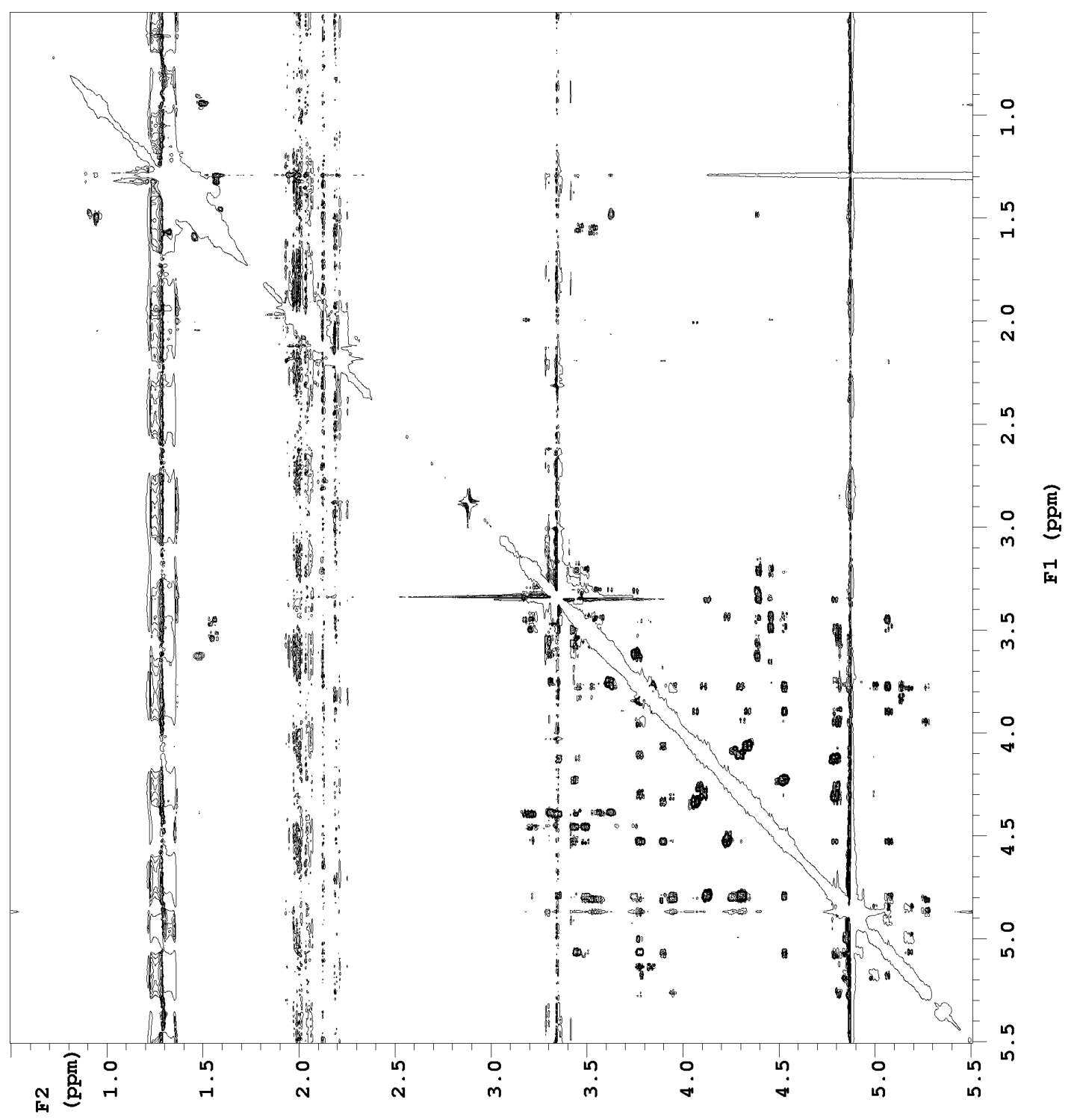

Figure B.29. ROESY spectrum (600 MHz, CD $\left.\mathrm{CD}_{3} \mathrm{OD}\right)$ of agminoside A (145). 


\section{Agminoside B}

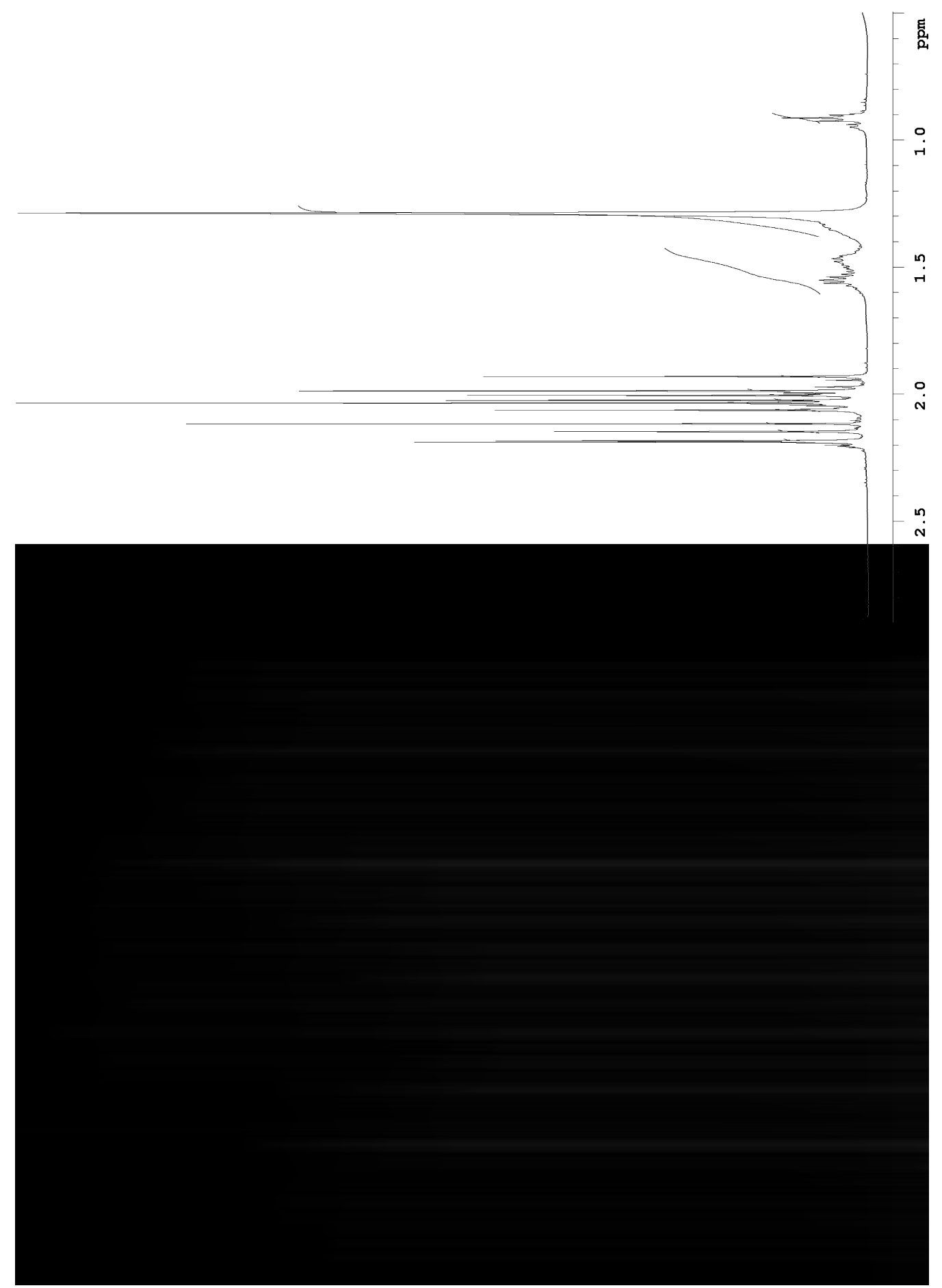

Figure B.30. ${ }^{1} \mathrm{H}$ NMR spectrum $\left(600 \mathrm{MHz}, \mathrm{CD}_{3} \mathrm{OD}\right)$ of agminoside $\mathrm{B}$ (146). 


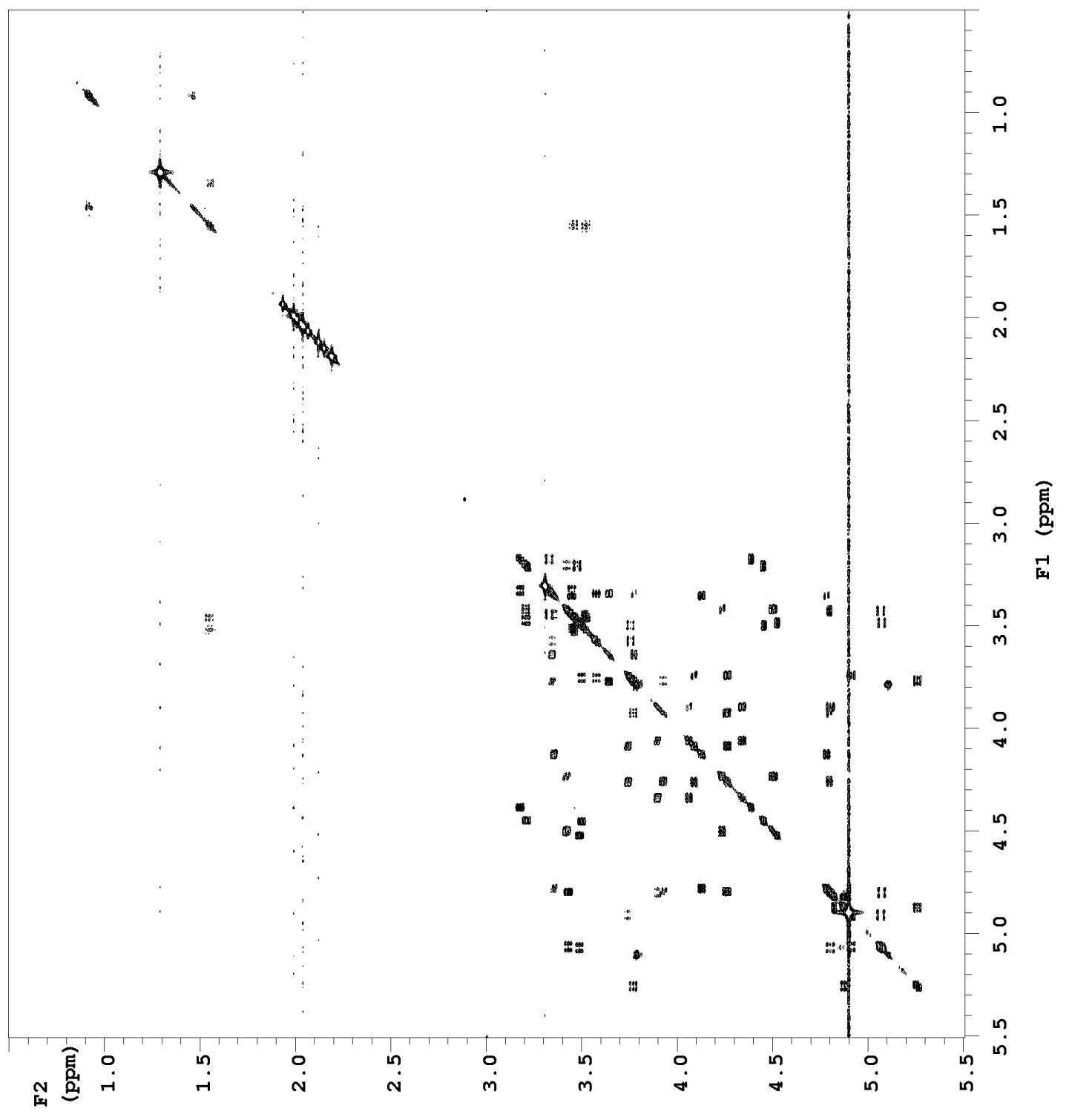

Figure B.31. COSY spectrum (600 MHz, $\left.\mathrm{CD}_{3} \mathrm{OD}\right)$ of agminoside $\mathrm{B}$ (146). 


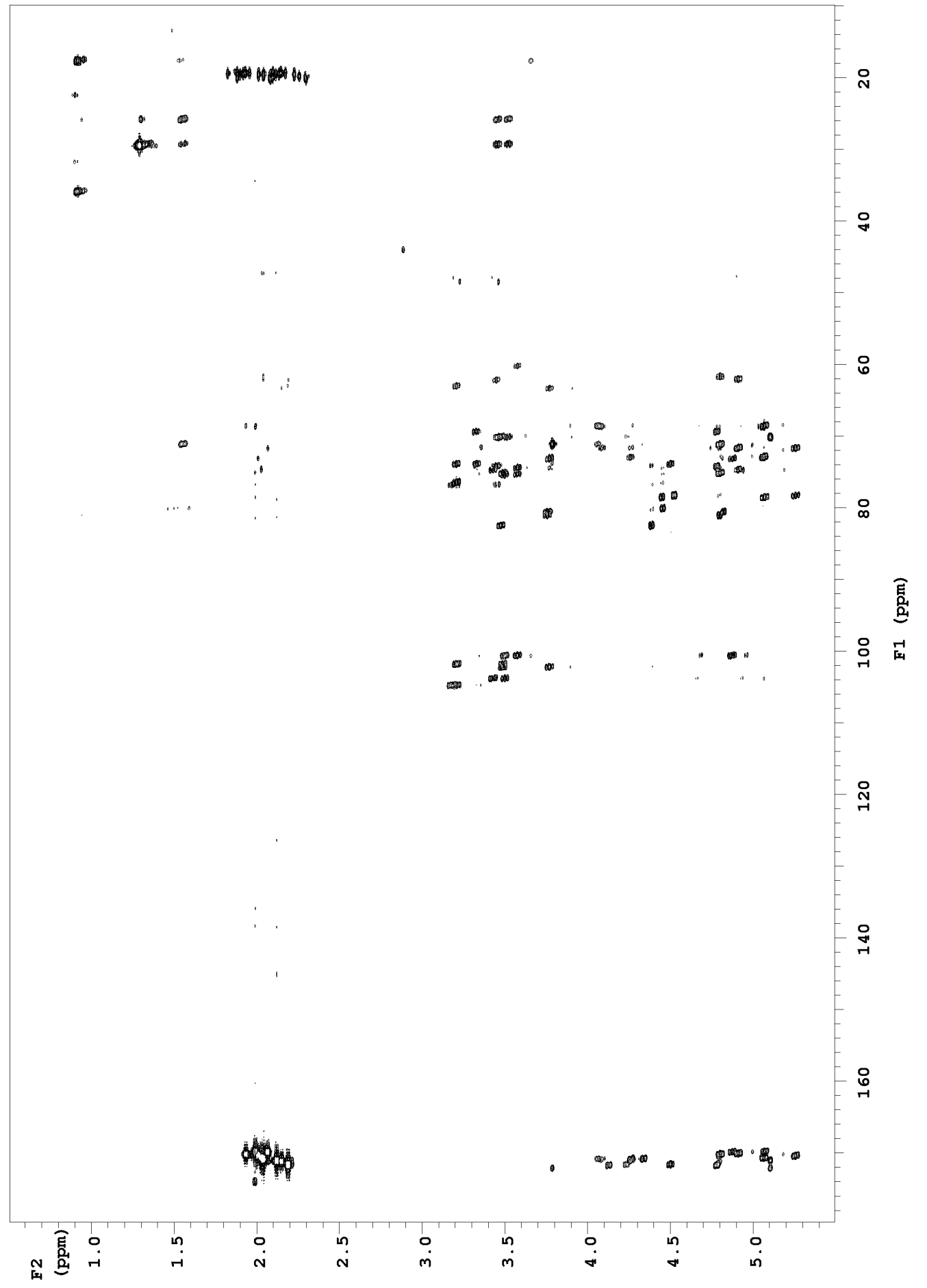

Figure B.32. HMBC spectrum (600 MHz, $\mathrm{CD}_{3} \mathrm{OD}$ ) of agminoside $\mathrm{B}$ (146). 


\section{Agminoside C}

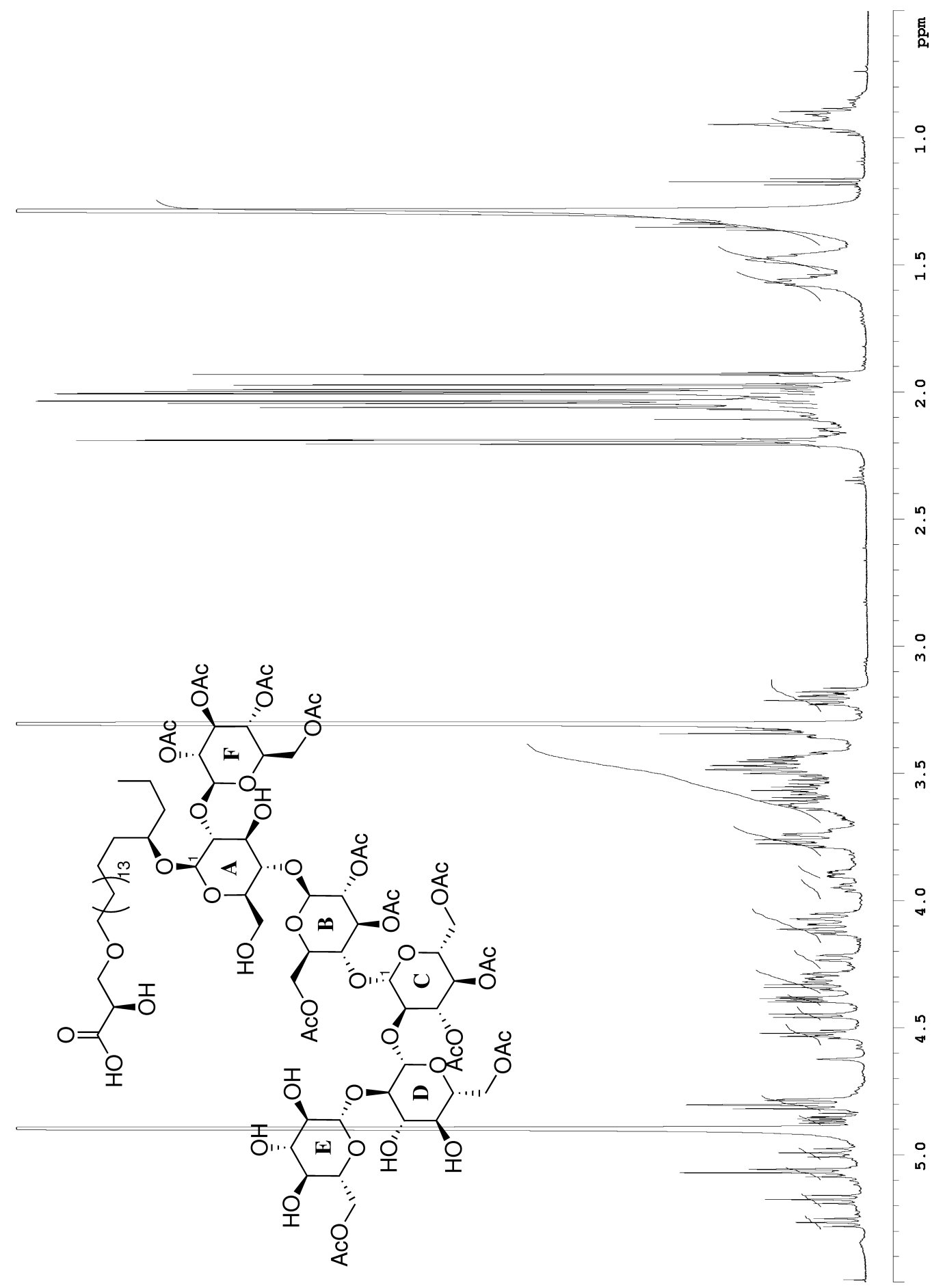

Figure B.33. ${ }^{1} \mathrm{H}$ NMR spectrum $\left(600 \mathrm{MHz}, \mathrm{CD}_{3} \mathrm{OD}\right)$ of agminoside $\mathrm{C}(\mathbf{1 4 7})$. 


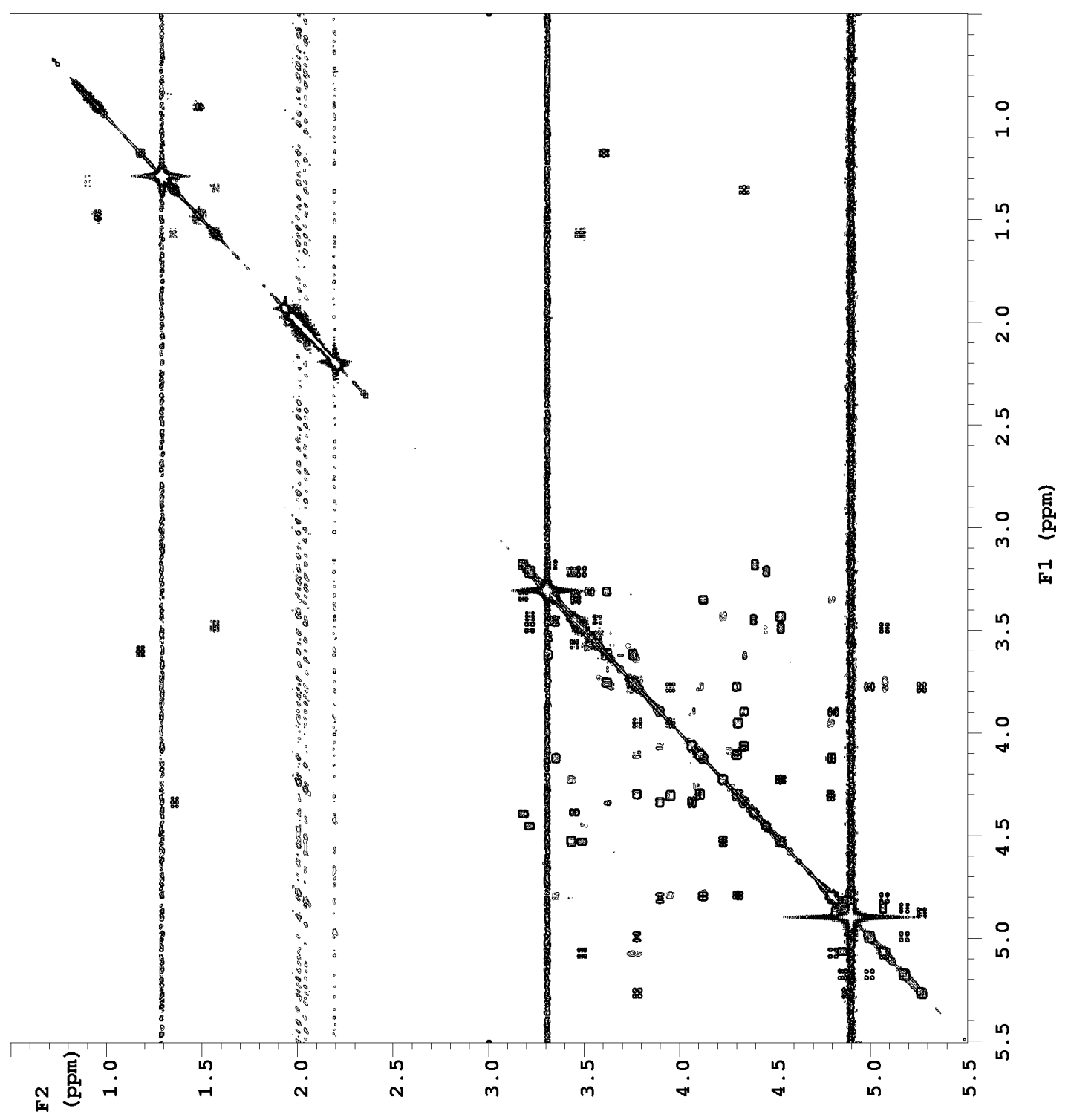

Figure B.34. COSY spectrum (600 MHz, $\left.\mathrm{CD}_{3} \mathrm{OD}\right)$ of agminoside $\mathrm{C}(\mathbf{1 4 7})$. 


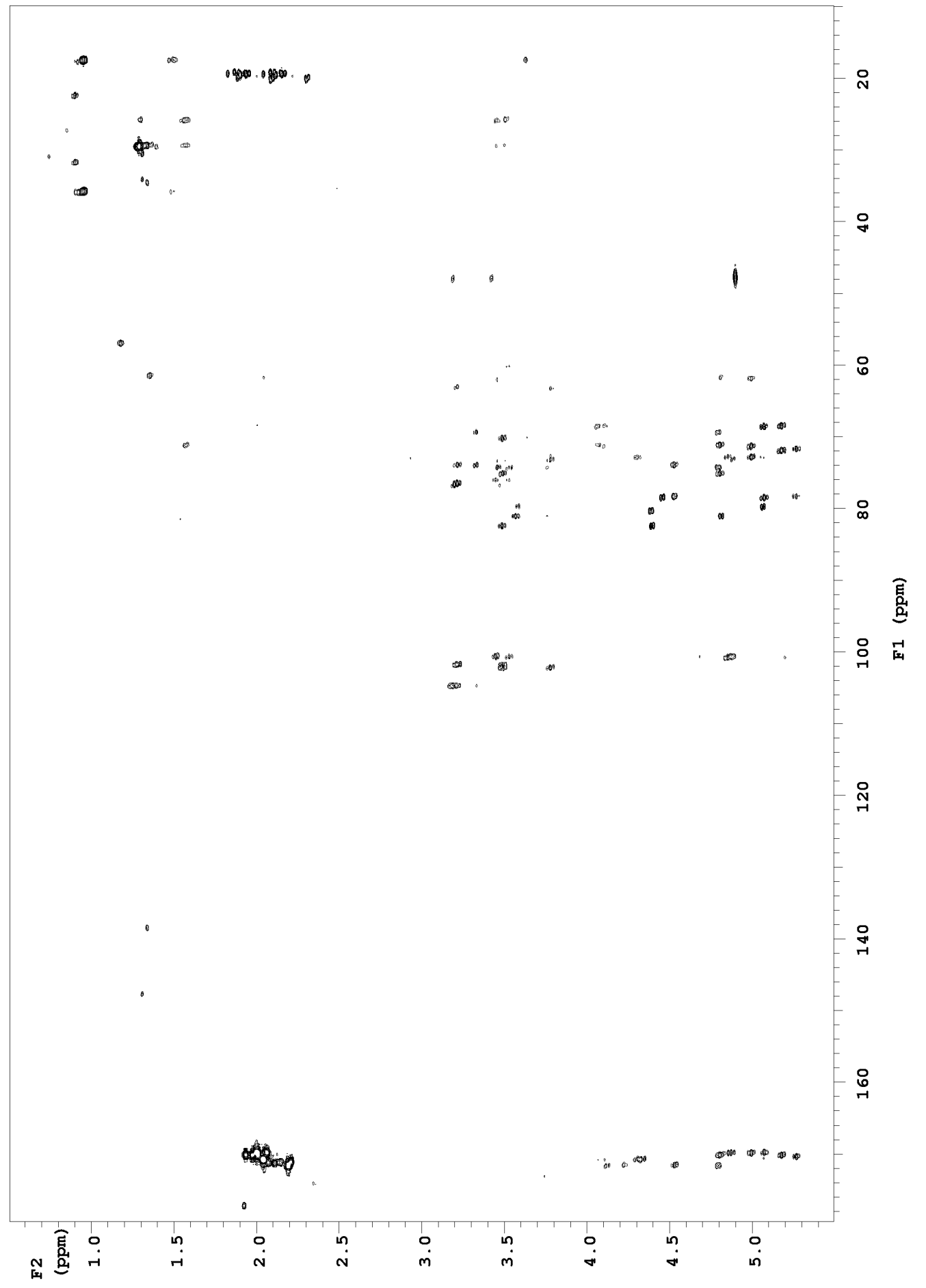

Figure B.35. HMBC spectrum (600 MHz, $\mathrm{CD}_{3} \mathrm{OD}$ ) of agminoside $\mathrm{C}$ (147). 


\section{Agminoside D}

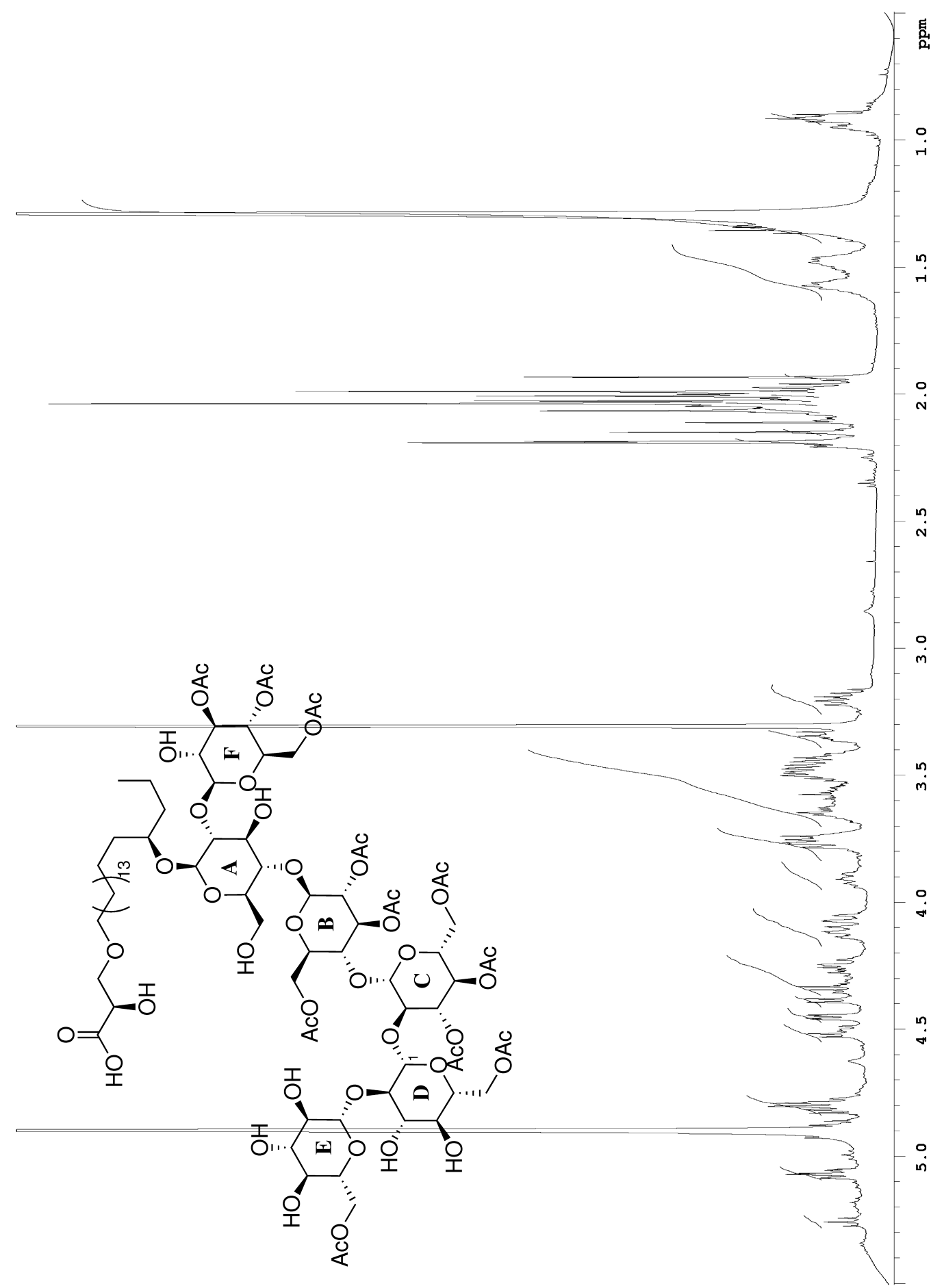

Figure B.36. ${ }^{1} \mathrm{H}$ NMR spectrum $\left(600 \mathrm{MHz}, \mathrm{CD}_{3} \mathrm{OD}\right)$ of agminoside D (148). 


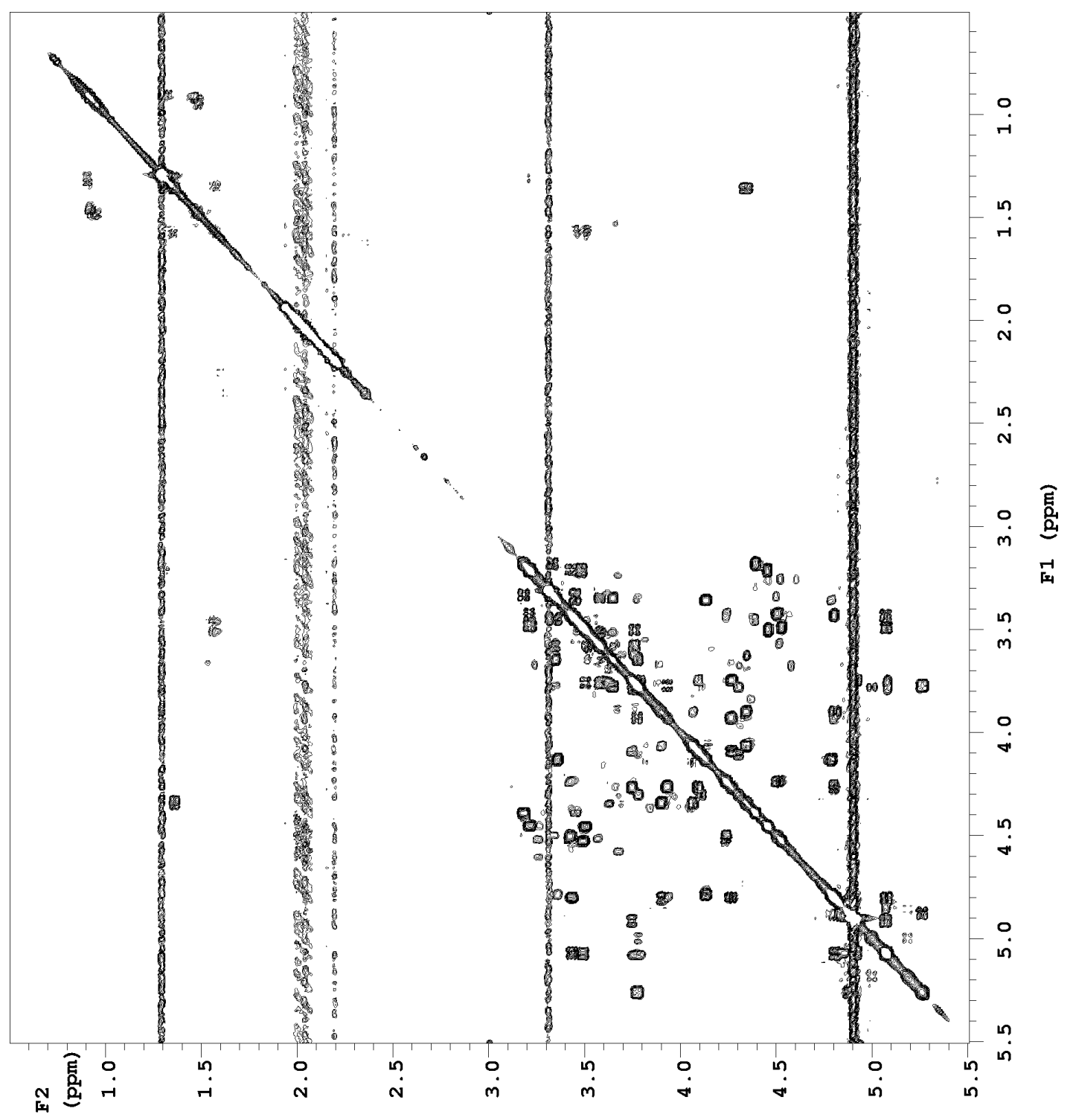

Figure B.37. COSY spectrum (600 MHz, $\left.\mathrm{CD}_{3} \mathrm{OD}\right)$ of agminoside D (148). 


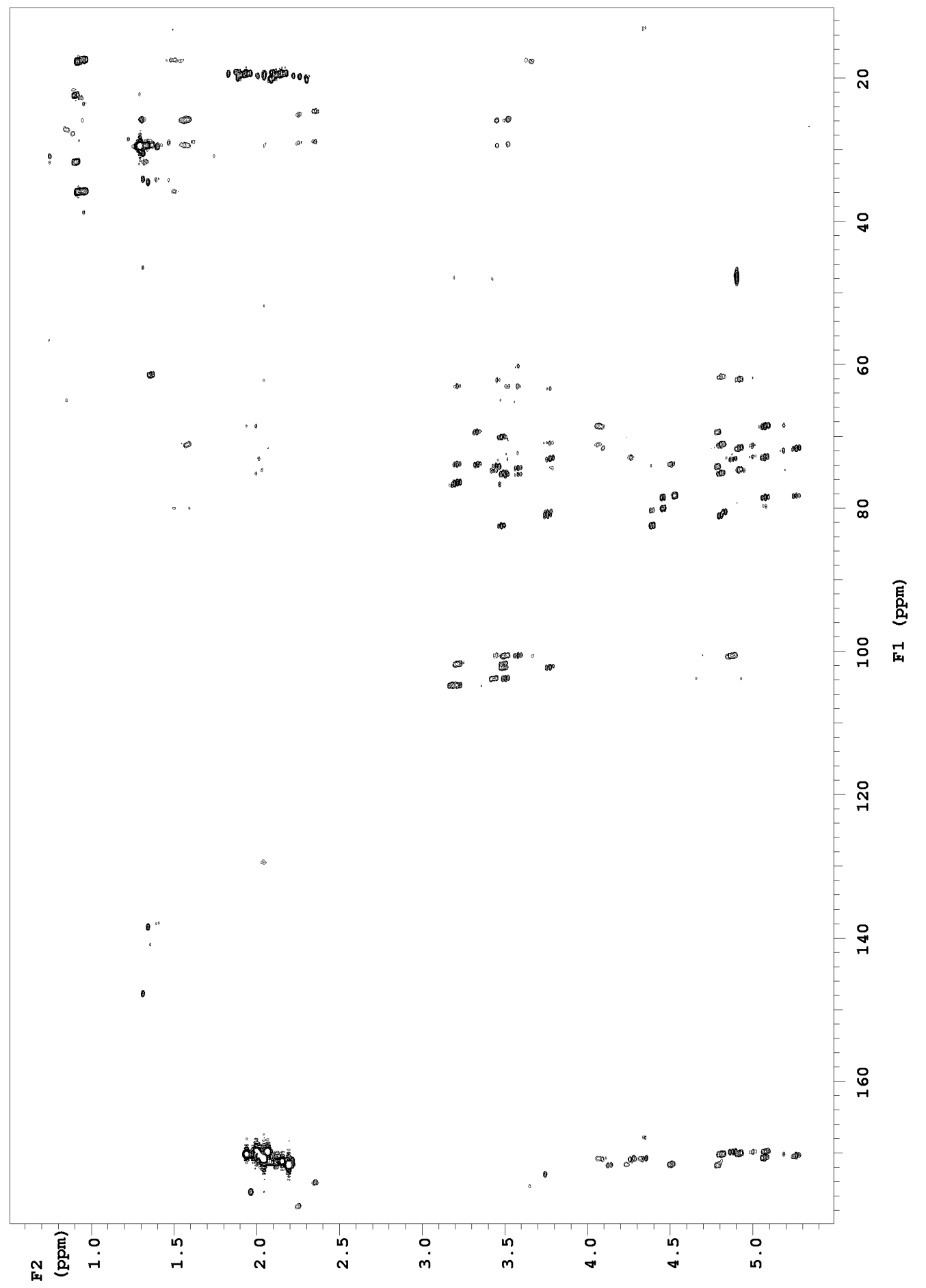

Figure B.38. HMBC spectrum (600 MHz, $\mathrm{CD}_{3} \mathrm{OD}$ ) of agminoside D (148). 


\section{Agminoside E}

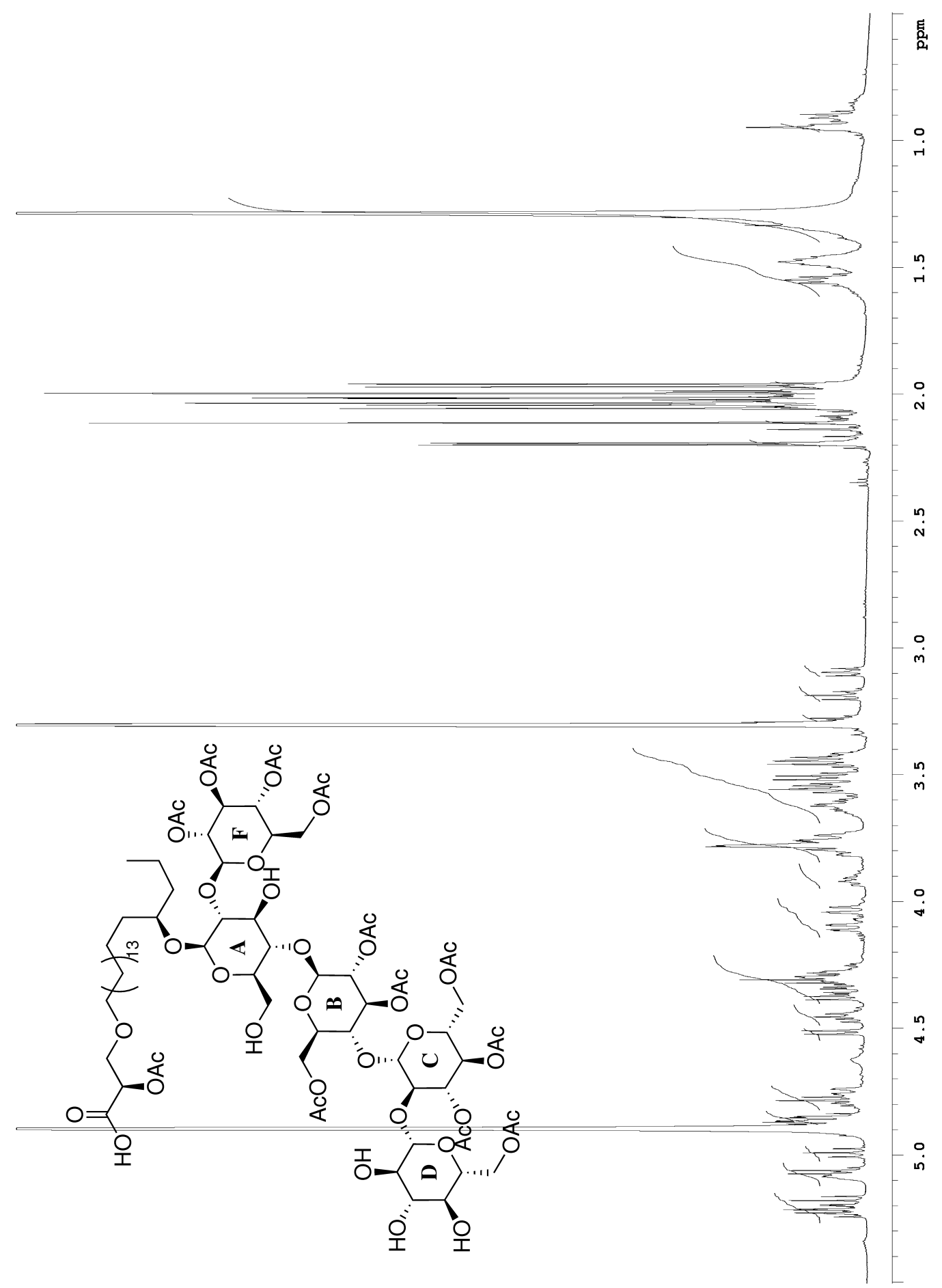

Figure B.39. ${ }^{1} \mathrm{H}$ NMR spectrum $\left(600 \mathrm{MHz}, \mathrm{CD}_{3} \mathrm{OD}\right)$ of agminoside $\mathrm{E}(\mathbf{1 4 9})$. 


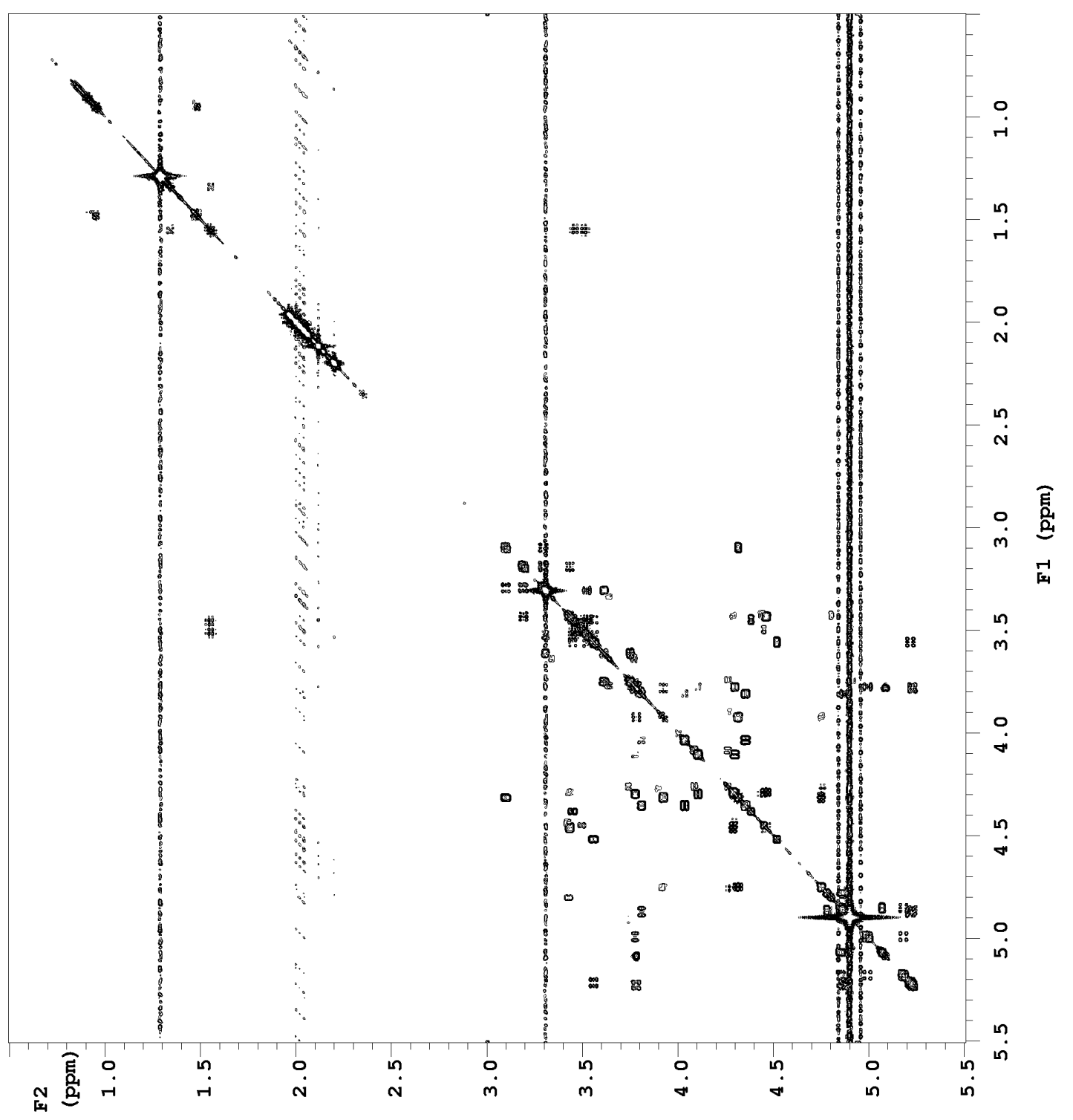

Figure B.40. COSY spectrum (600 MHz, $\left.\mathrm{CD}_{3} \mathrm{OD}\right)$ of agminoside E (149). 


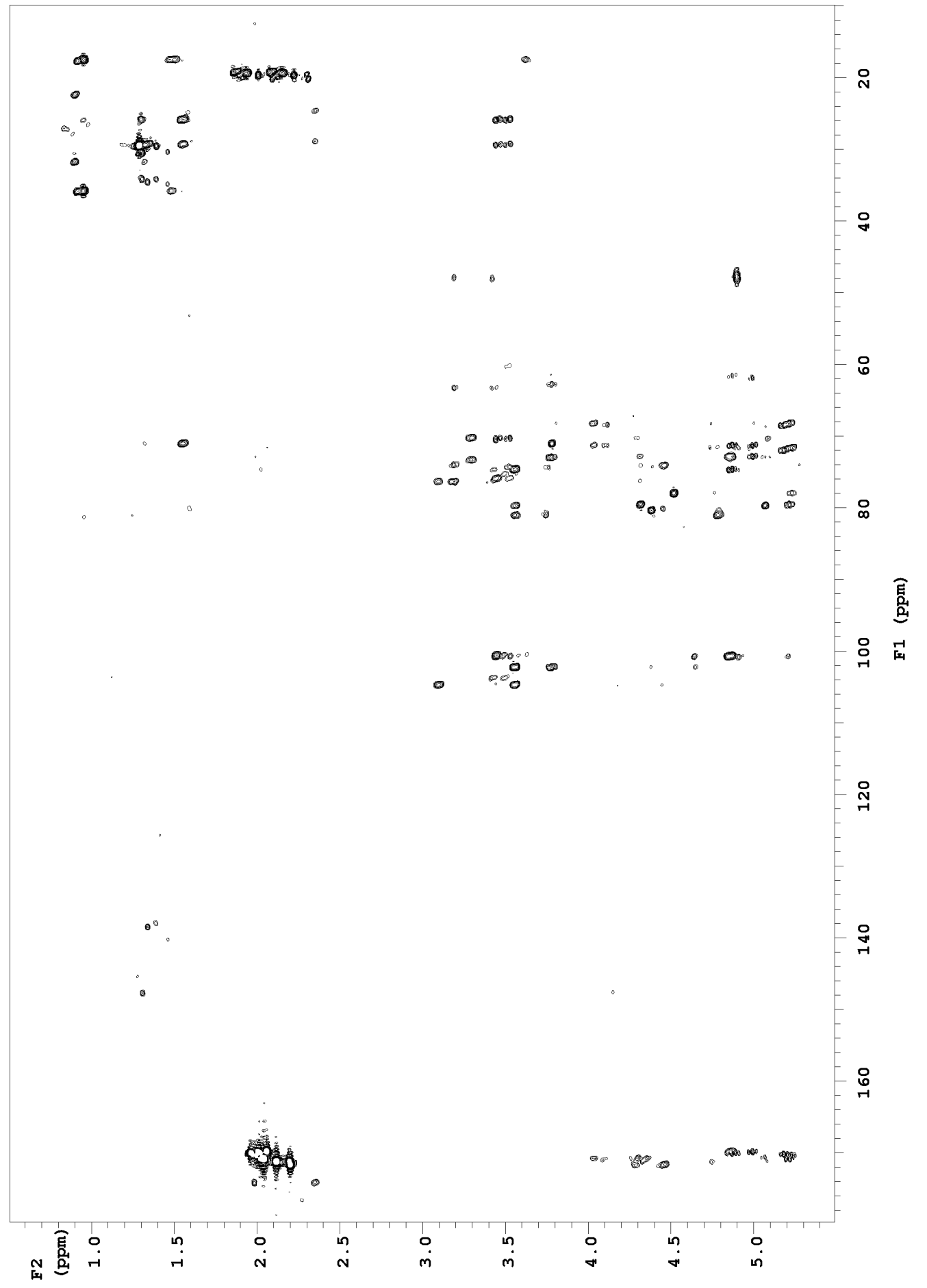

Figure B.41. HMBC spectrum (600 MHz, $\left.\mathrm{CD}_{3} \mathrm{OD}\right)$ of agminoside E (149). 


\section{Aglycon methyl ester}

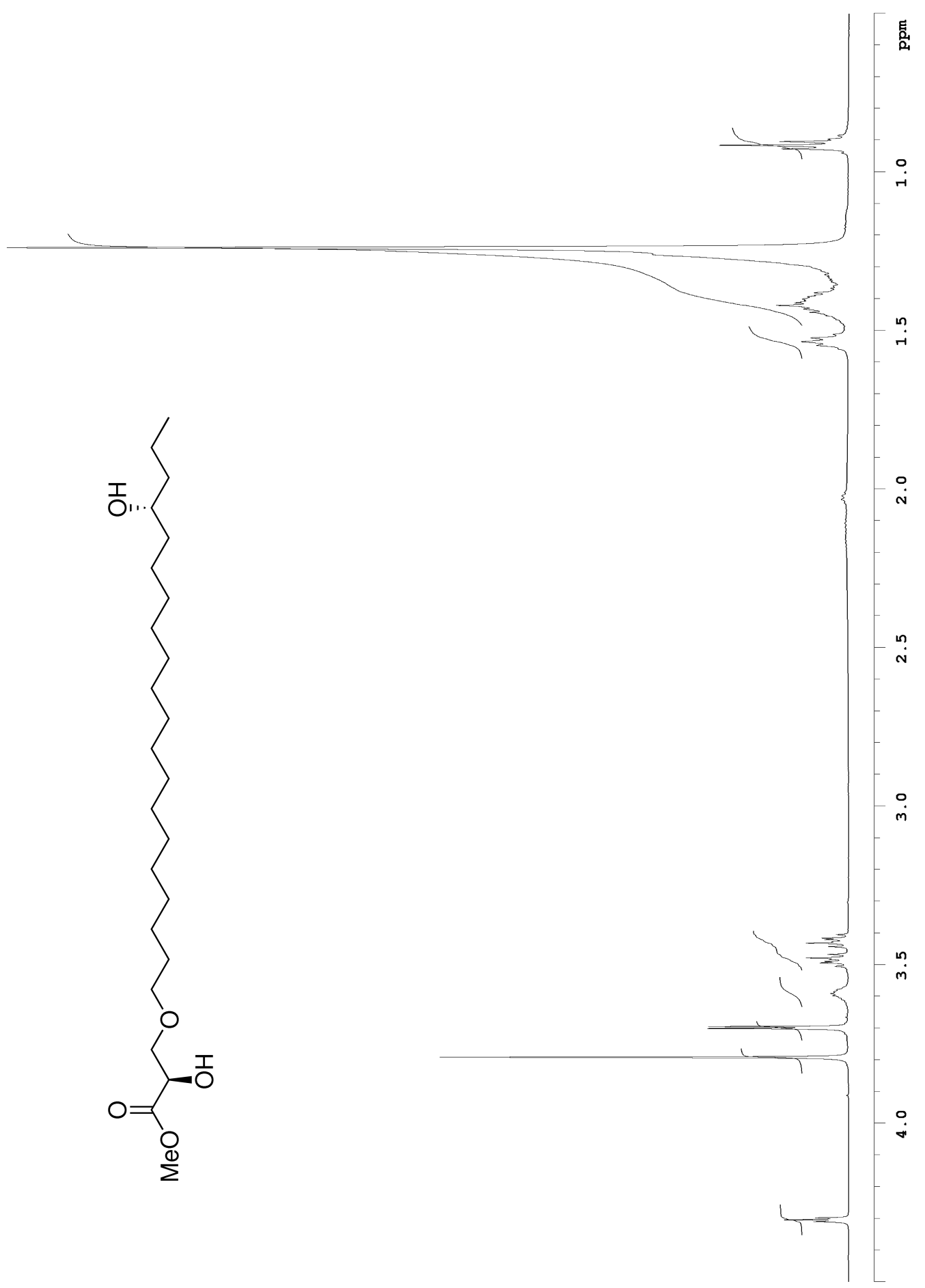

Figure B.42. ${ }^{1} \mathrm{H}$ NMR spectrum $\left(600 \mathrm{MHz}, \mathrm{CDCl}_{3}\right)$ of aglycon methyl ester (151). 


\section{$\Delta_{18,20}$-Isovariabilin}

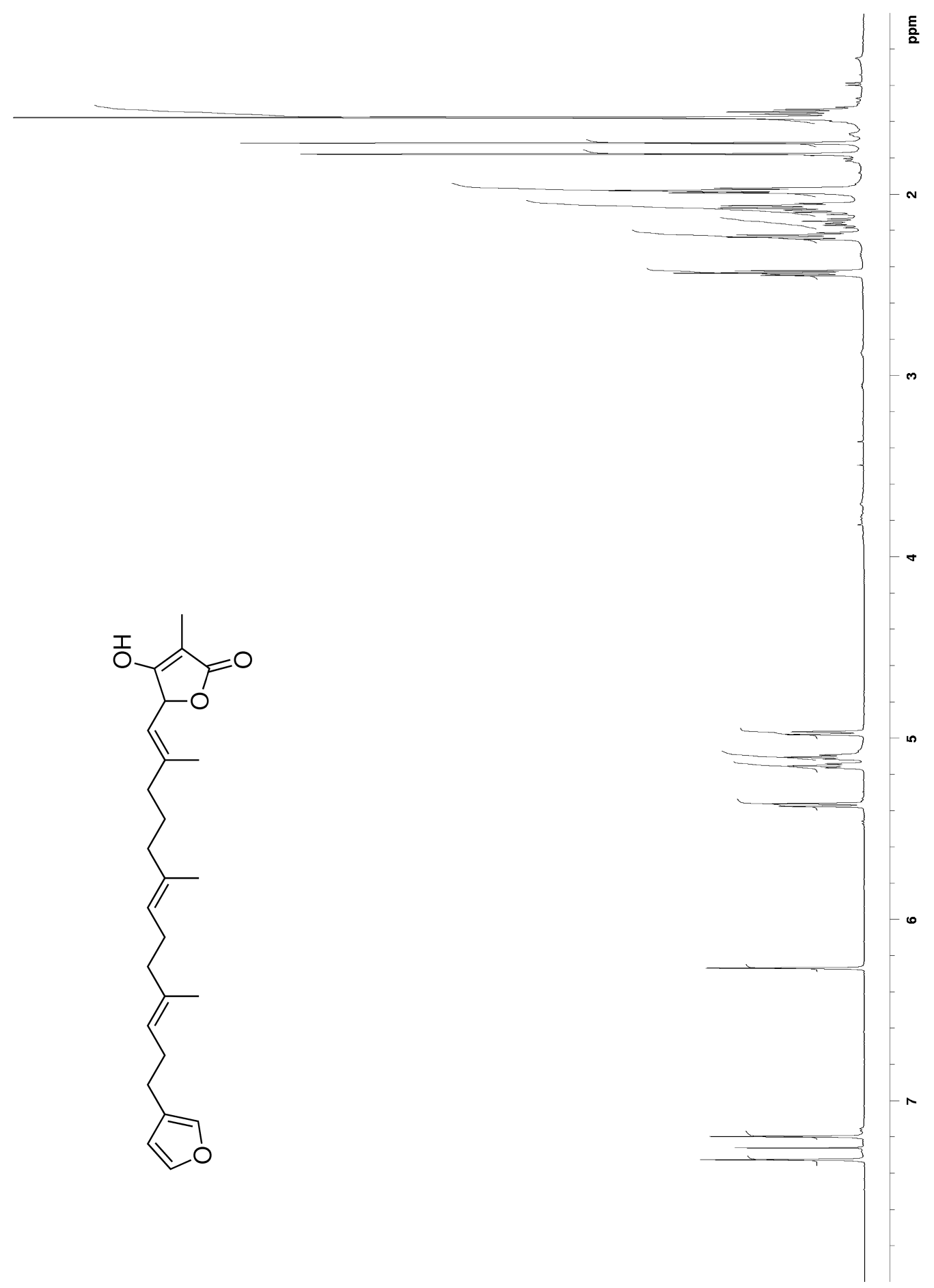

Figure B.43. ${ }^{1} \mathrm{H}$ NMR spectrum $\left(600 \mathrm{MHz}, \mathrm{CDCl}_{3}\right)$ of $\Delta_{18,20}$-isovariabilin (186). 


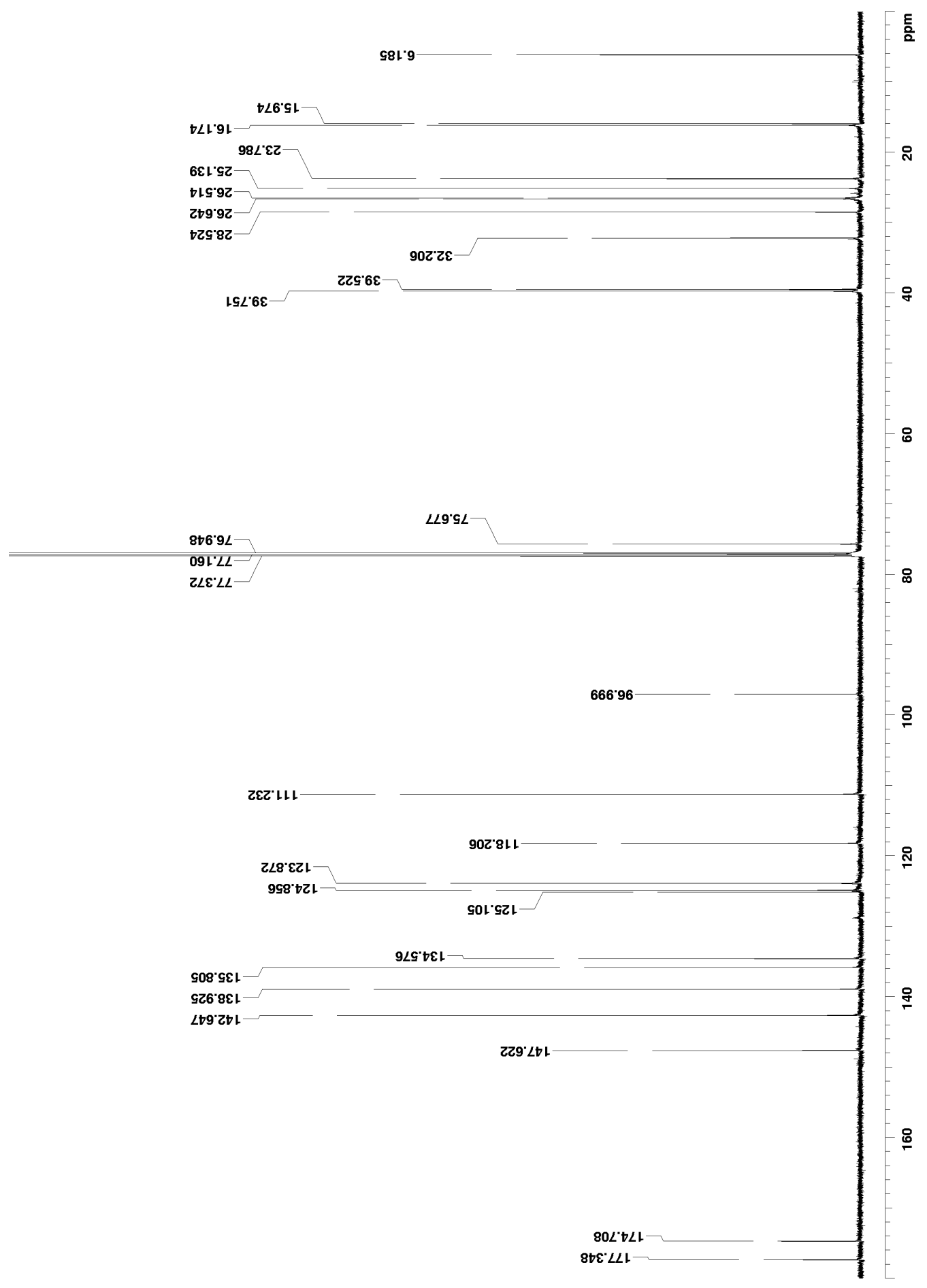

Figure B.44. ${ }^{13} \mathrm{C}$ NMR spectrum $\left(150 \mathrm{MHz}, \mathrm{CDCl}_{3}\right)$ of $\Delta_{18,20}$-isovariabilin (186). 


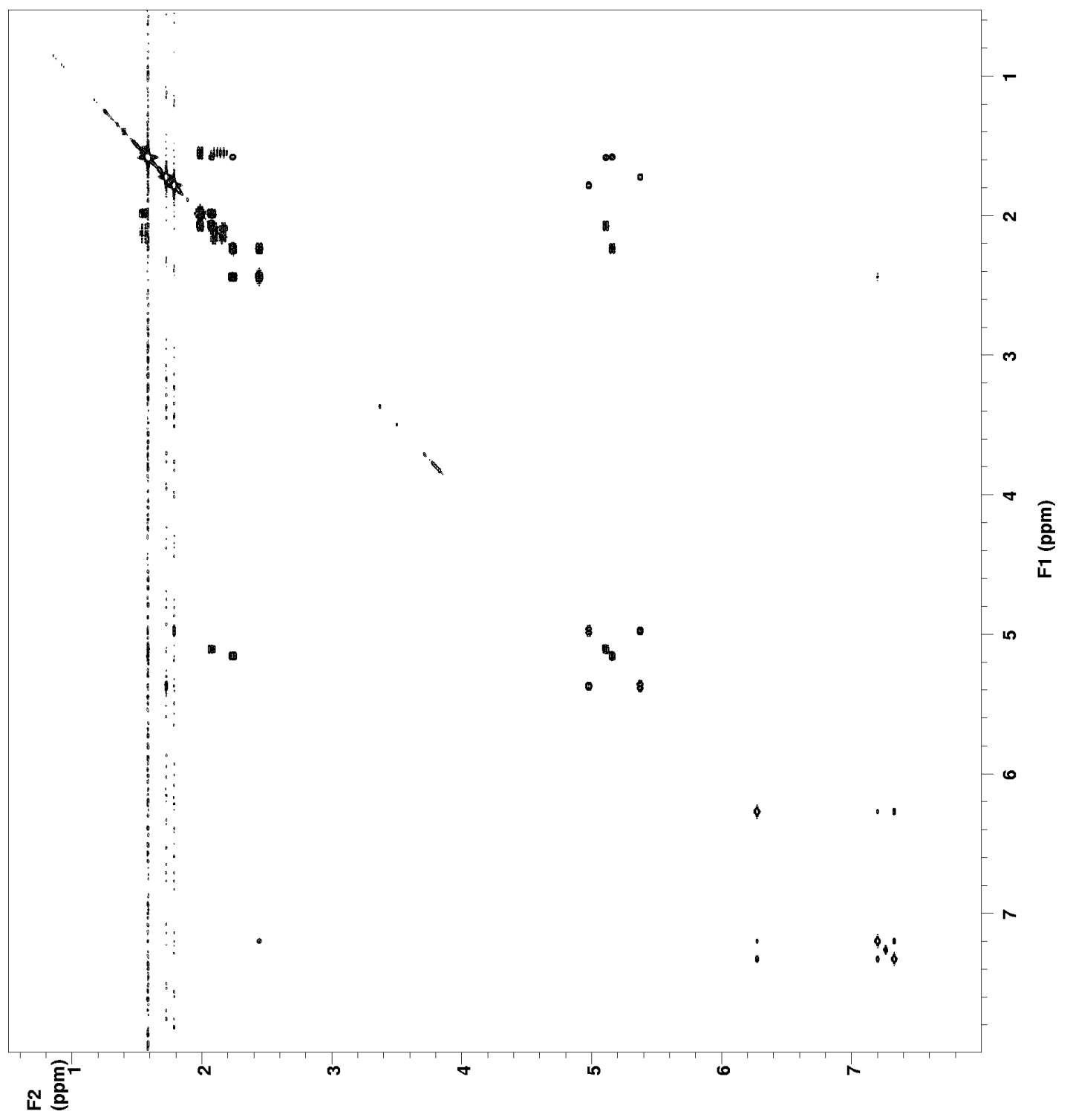

Figure B.45. COSY spectrum (600 $\left.\mathrm{MHz}, \mathrm{CDCl}_{3}\right)$ of $\Delta_{18,20}$-isovariabilin (186). 


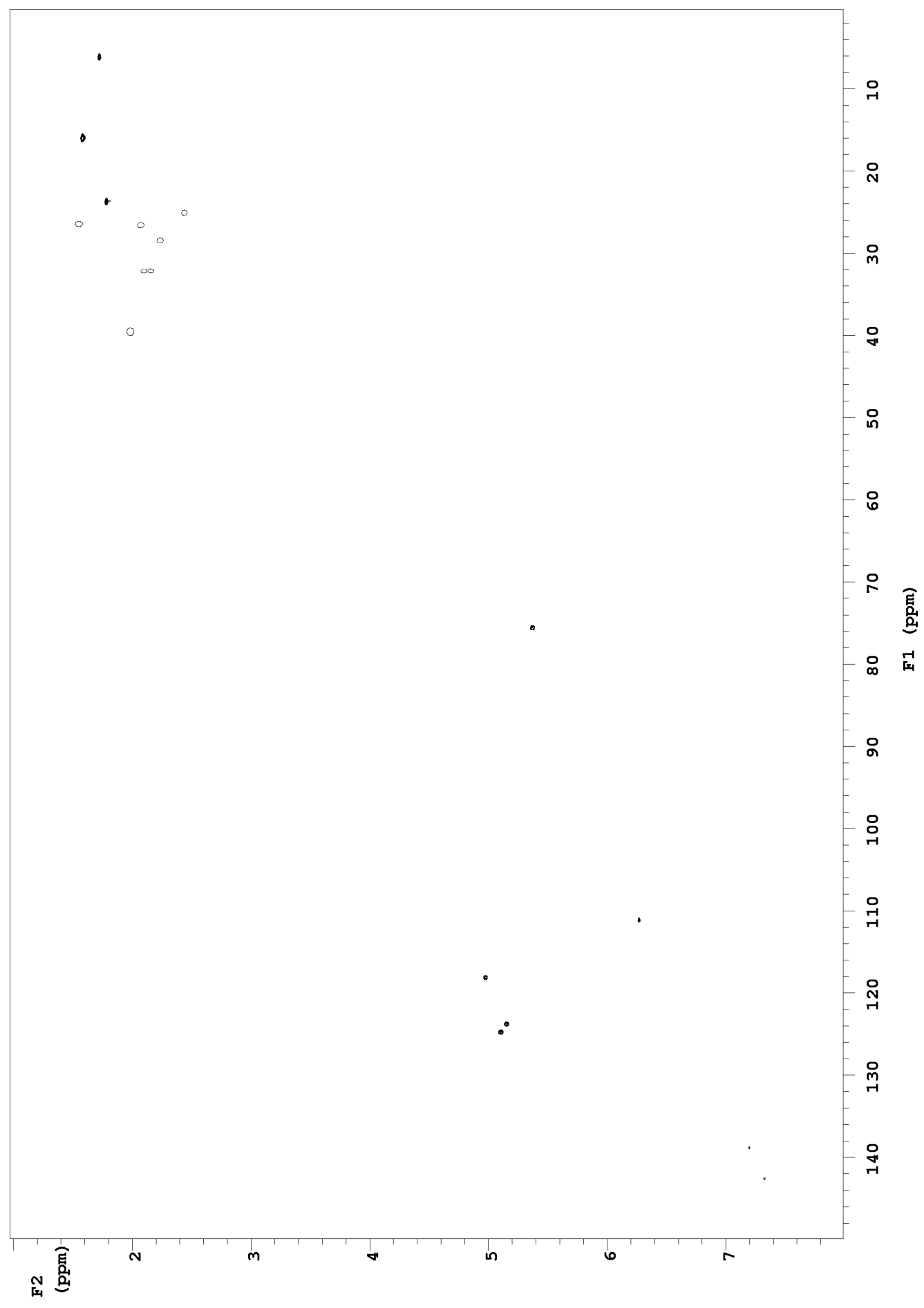

Figure B.46. HSQC spectrum (600 MHz, $\left.\mathrm{CDCl}_{3}\right)$ of $\Delta_{18,20}$-isovariabilin (186). 


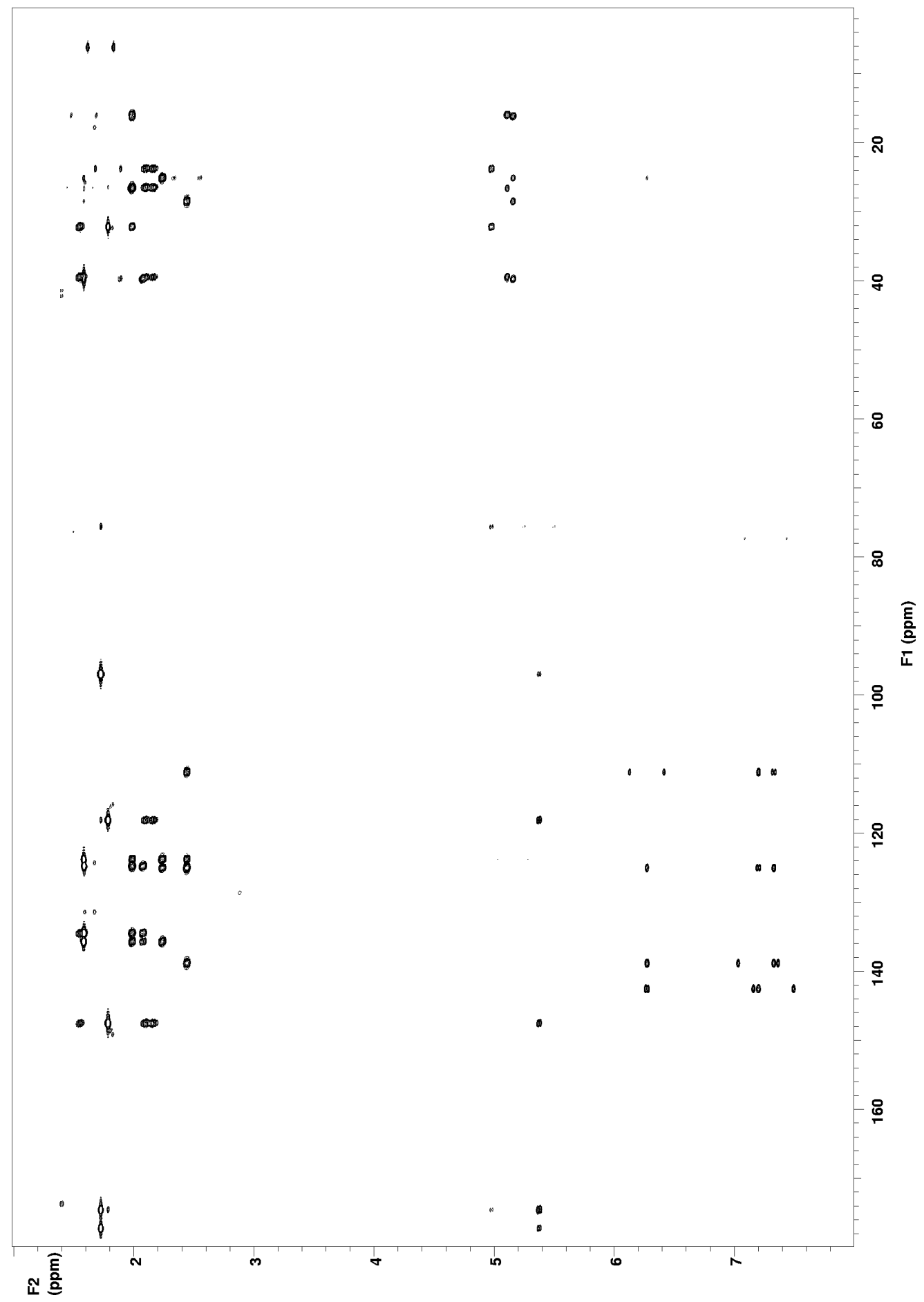

Figure B.47. HMBC spectrum (600 MHz, $\mathrm{CDCl}_{3}$ ) of $\Delta_{18,20}$-isovariabilin (186). 


\section{Furospinosulin-1}

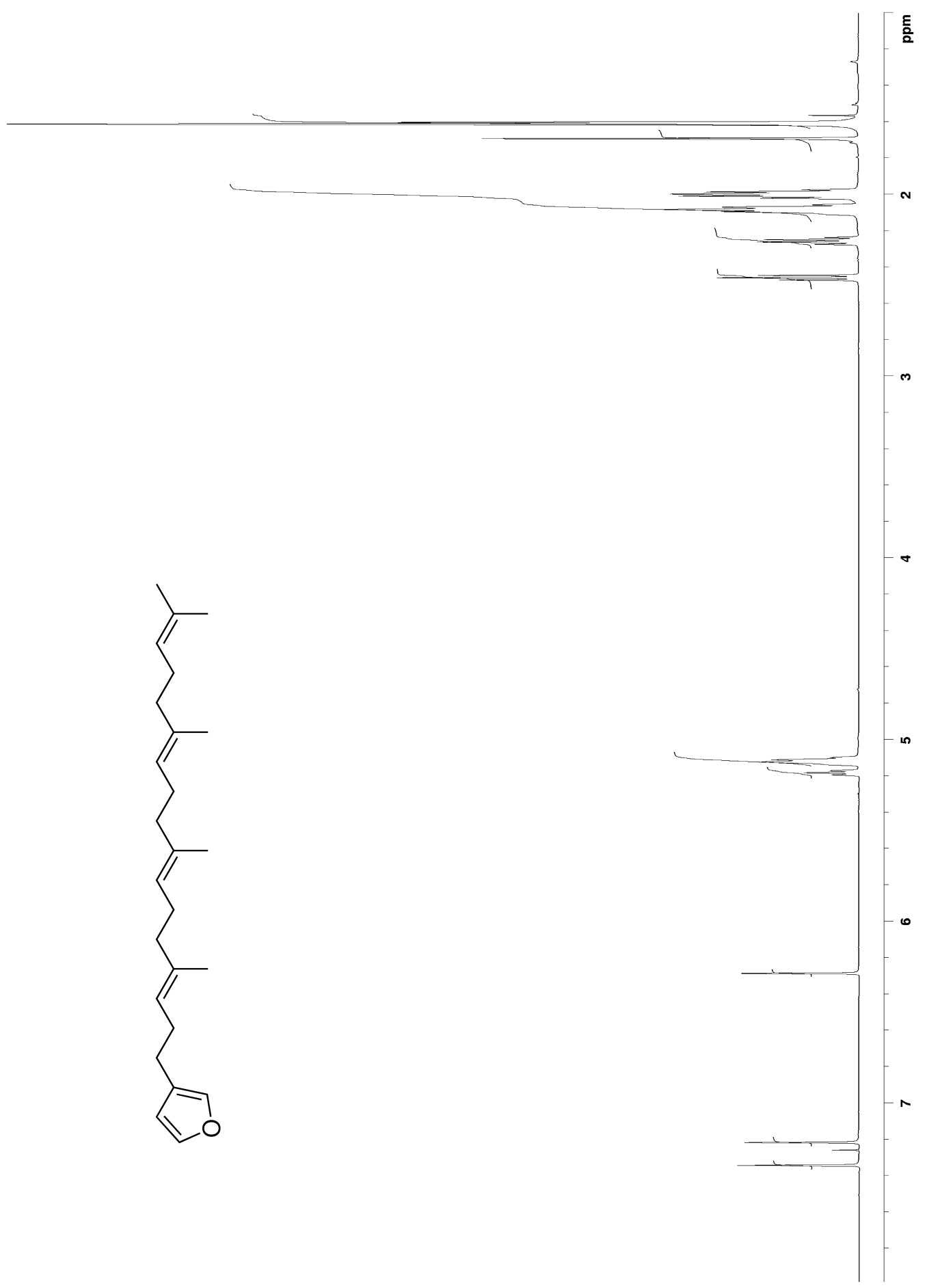

Figure B.48. ${ }^{1} \mathrm{H}$ NMR spectrum $\left(600 \mathrm{MHz}, \mathrm{CDCl}_{3}\right)$ of furospinosulin-1 (187). 
6-((2E,6E)-3,7,11-trimethyl-2,6,10-dodecatrienyl)-2-methoxy- $p$-quinone

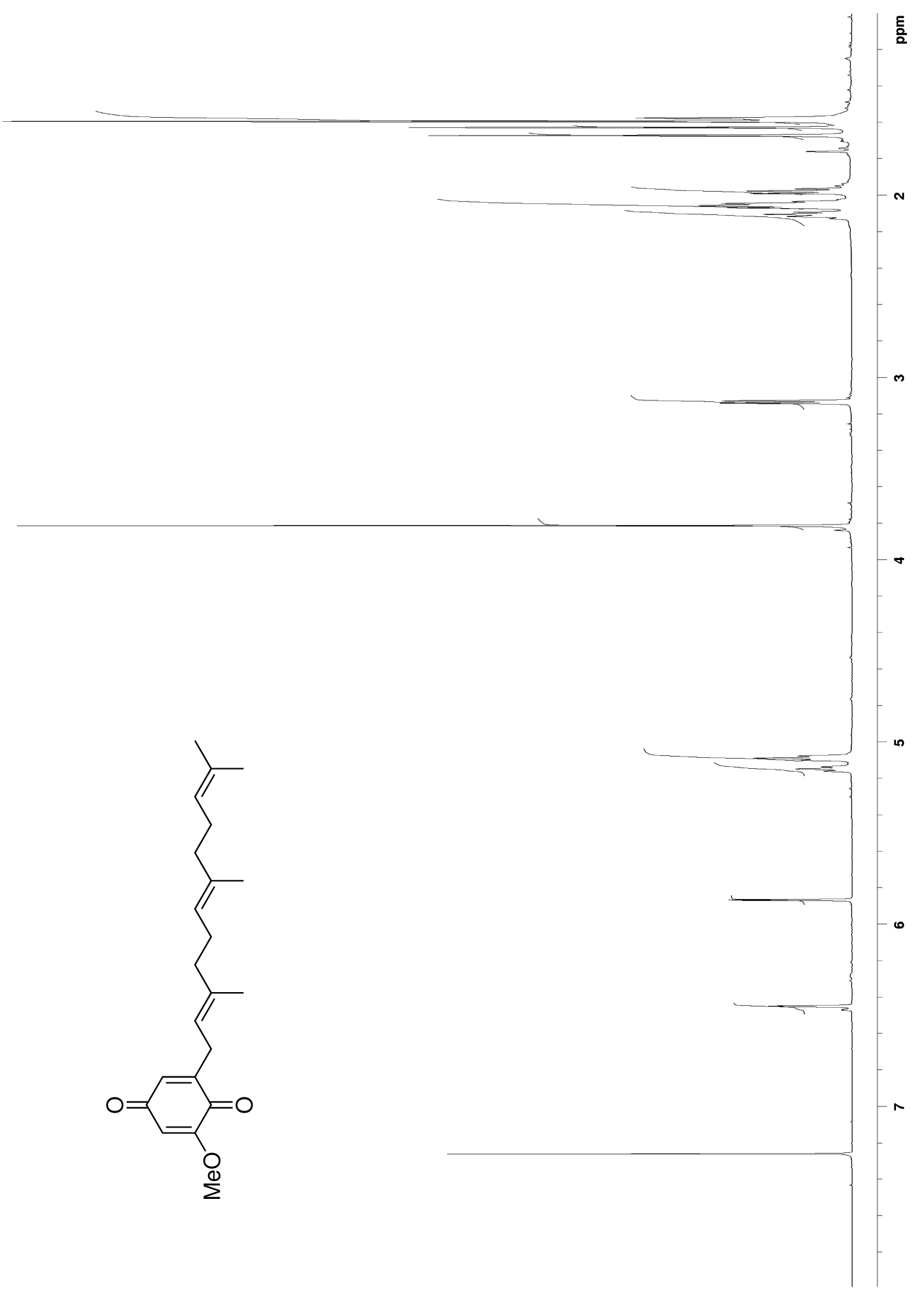

Figure B.49. ${ }^{1} \mathrm{H}$ NMR spectrum $\left(600 \mathrm{MHz}, \mathrm{CDCl}_{3}\right)$ of $6-((2 E, 6 E)-3,7,11-$ trimethyl-2,6,10-dodecatrienyl)-2-methoxy-p-quinone (188). 
6-((2E,6Z)-3,7,11-trimethyl-2,6,10-dodecatrienyl)-2-methoxy-p-quinone

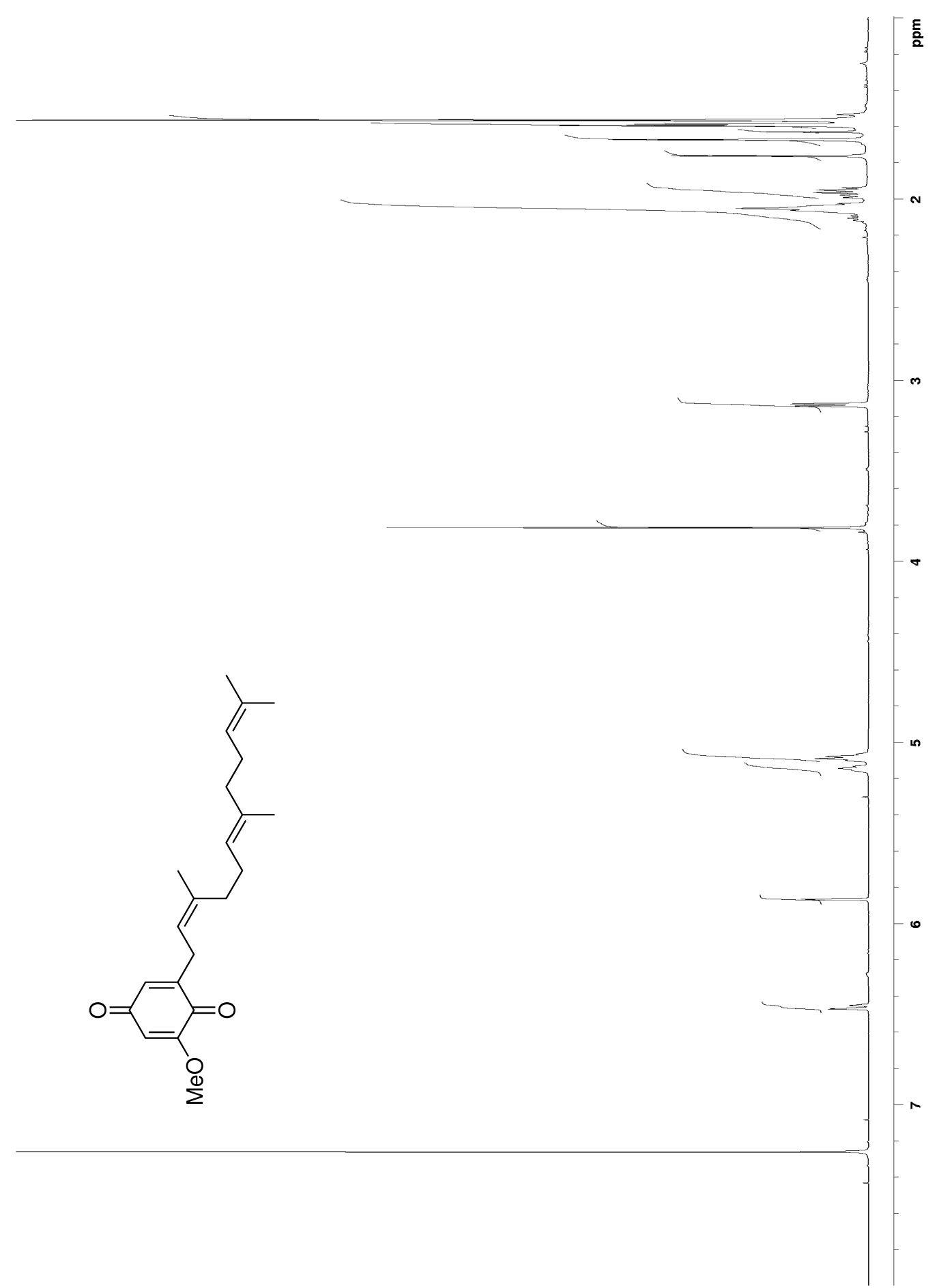

Figure B.50. ${ }^{1} \mathrm{H}$ NMR spectrum $\left(600 \mathrm{MHz}, \mathrm{CDCl}_{3}\right)$ of $6-((2 E, 6 Z)-3,7,11-$ trimethyl-2,6,10-dodecatrienyl)-2-methoxy- $p$-quinone (189). 


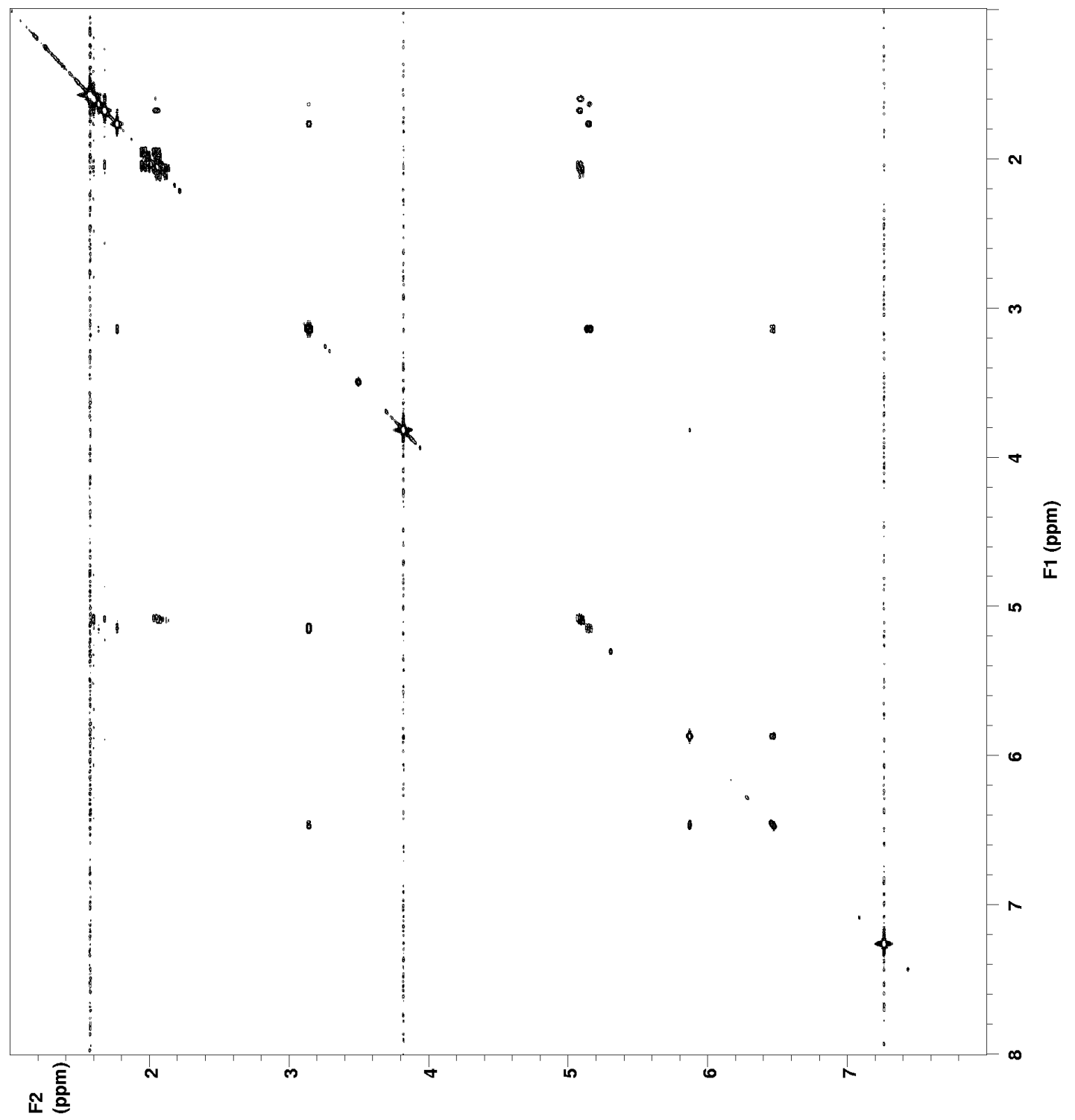

Figure B.51. COSY spectrum $\left(600 \mathrm{MHz}, \mathrm{CDCl}_{3}\right)$ of $6-((2 E, 6 Z)-3,7,11-$ trimethyl-2,6,10-dodecatrienyl)-2-methoxy- $p$-quinone (189). 


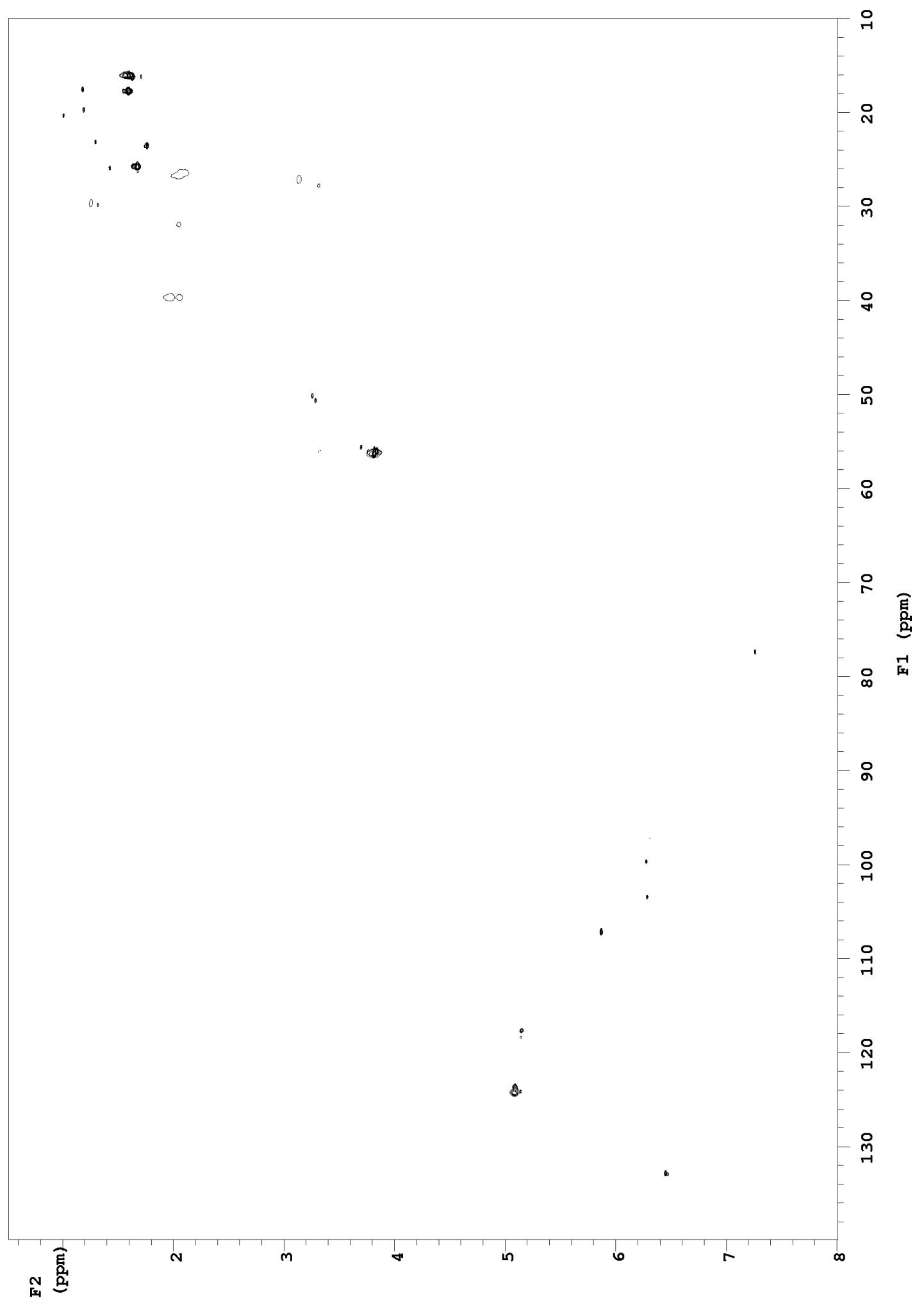

Figure B.52. HSQC spectrum (600 $\left.\mathrm{MHz}, \mathrm{CDCl}_{3}\right)$ of $6-((2 E, 6 Z)-3,7,11$ trimethyl-2,6,10-dodecatrienyl)-2-methoxy- $p$-quinone (189). 


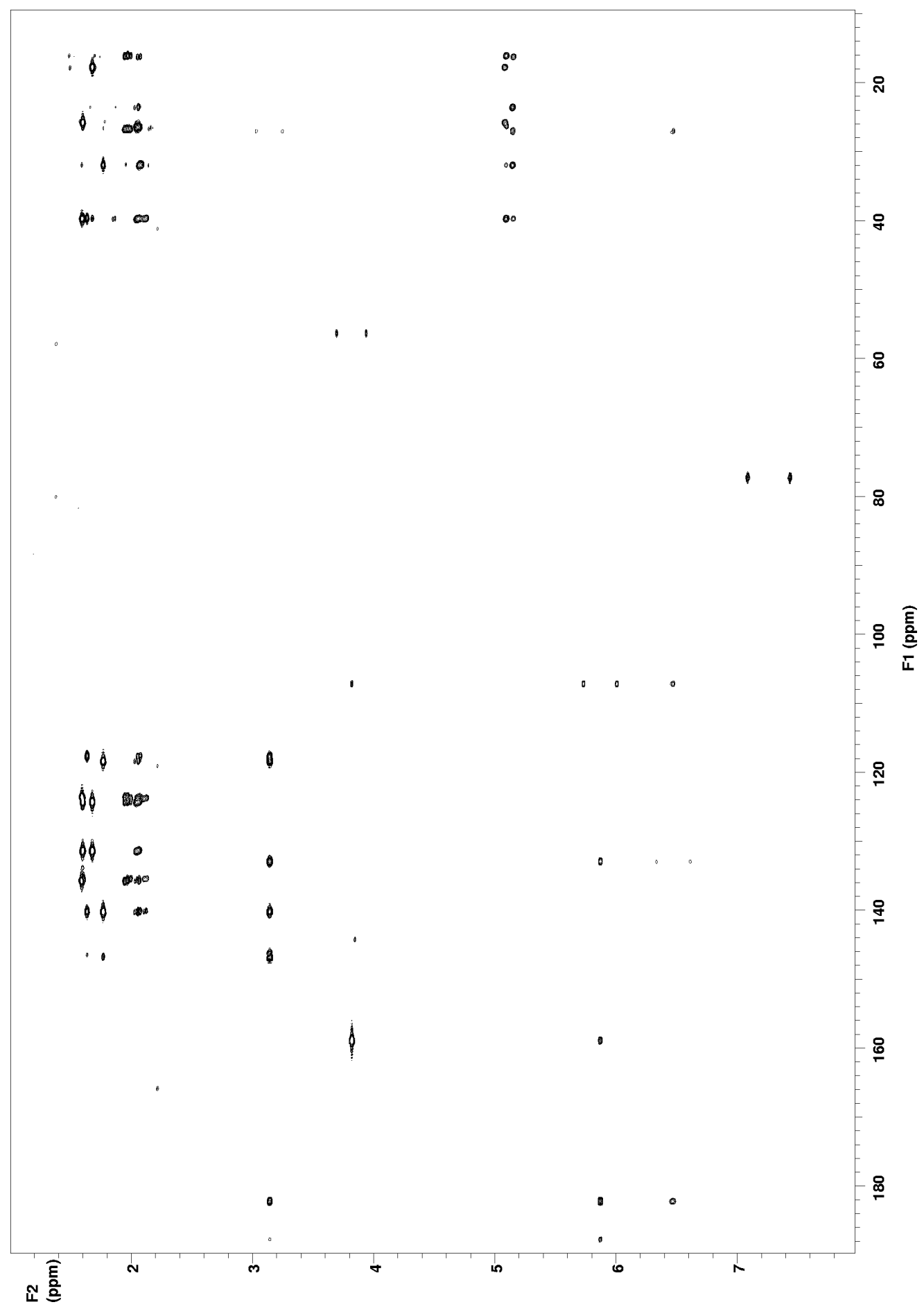

Figure B.53. HMBC spectrum $\left(600 \mathrm{MHz}, \mathrm{CDCl}_{3}\right)$ of $6-((2 E, 6 Z)-3,7,11$ trimethyl-2,6,10-dodecatrienyl)-2-methoxy-p-quinone (189). 
Oxeatamide A

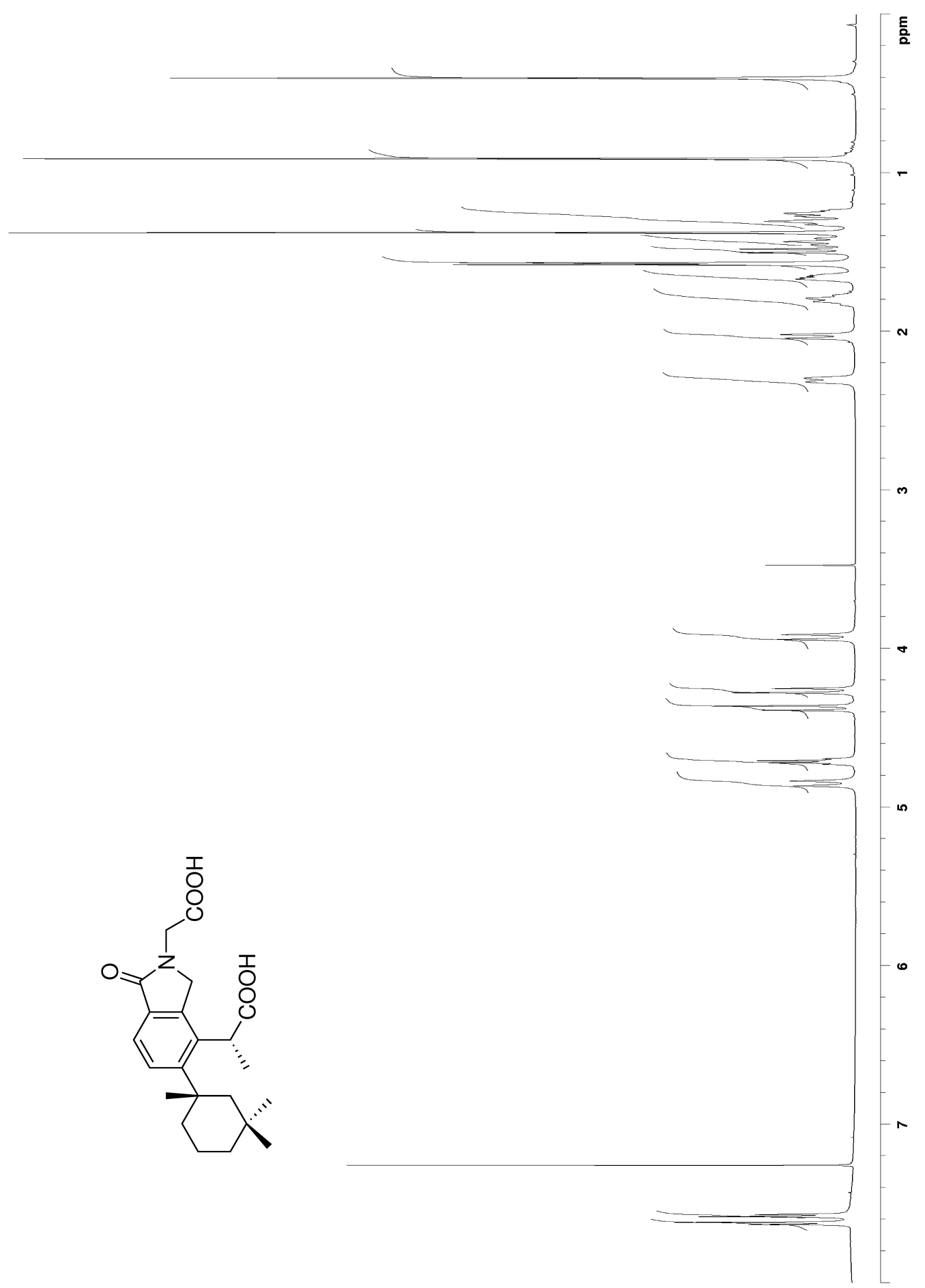

Figure B.54. ${ }^{1} \mathrm{H}$ NMR spectrum $\left(600 \mathrm{MHz}, \mathrm{CDCl}_{3}\right)$ of oxeatamide $\mathrm{A}(\mathbf{2 1 4})$. 


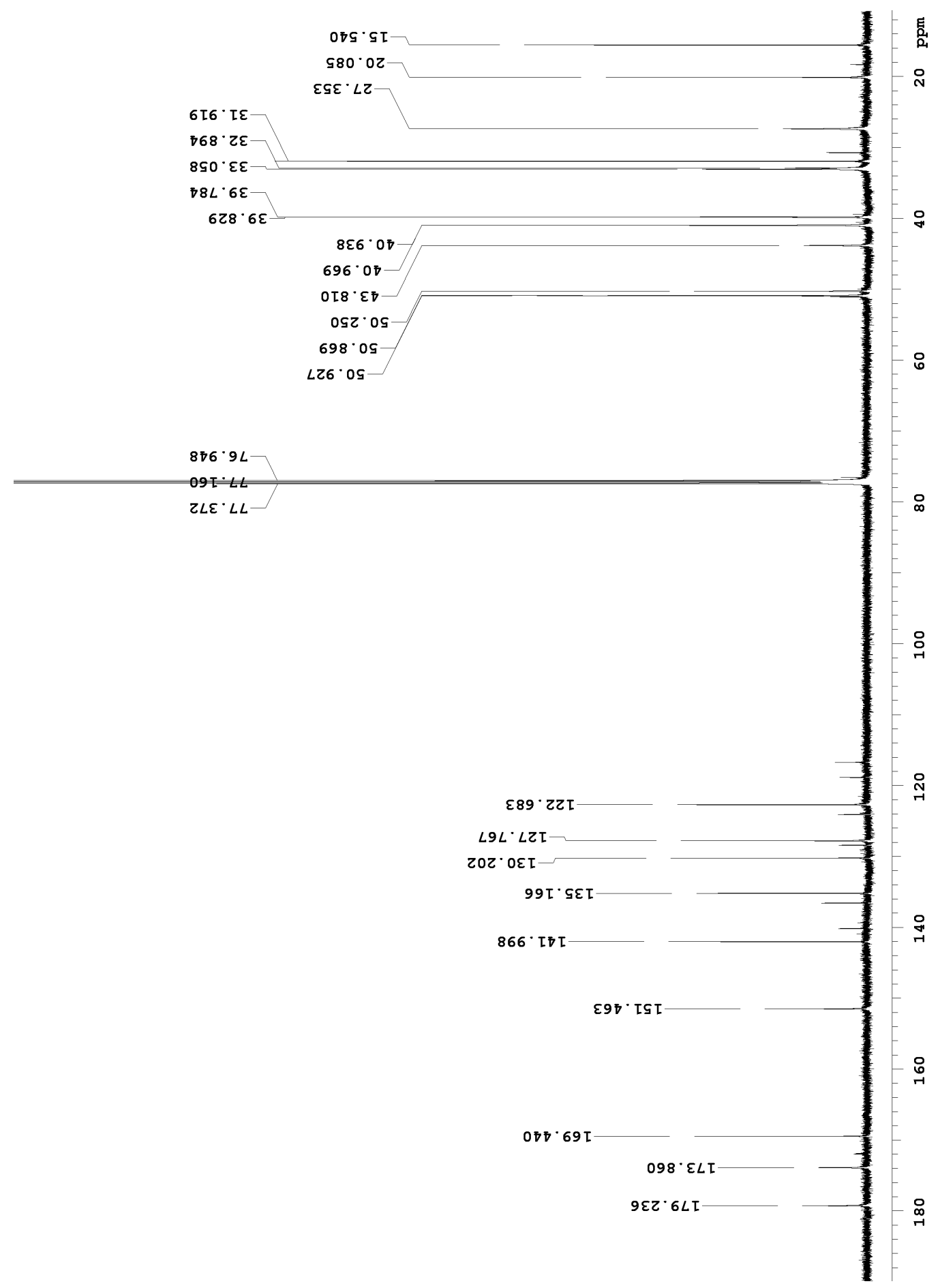

Figure B.55. ${ }^{13} \mathrm{C}$ NMR spectrum $\left(150 \mathrm{MHz}, \mathrm{CDCl}_{3}\right)$ of oxeatamide A (214). 


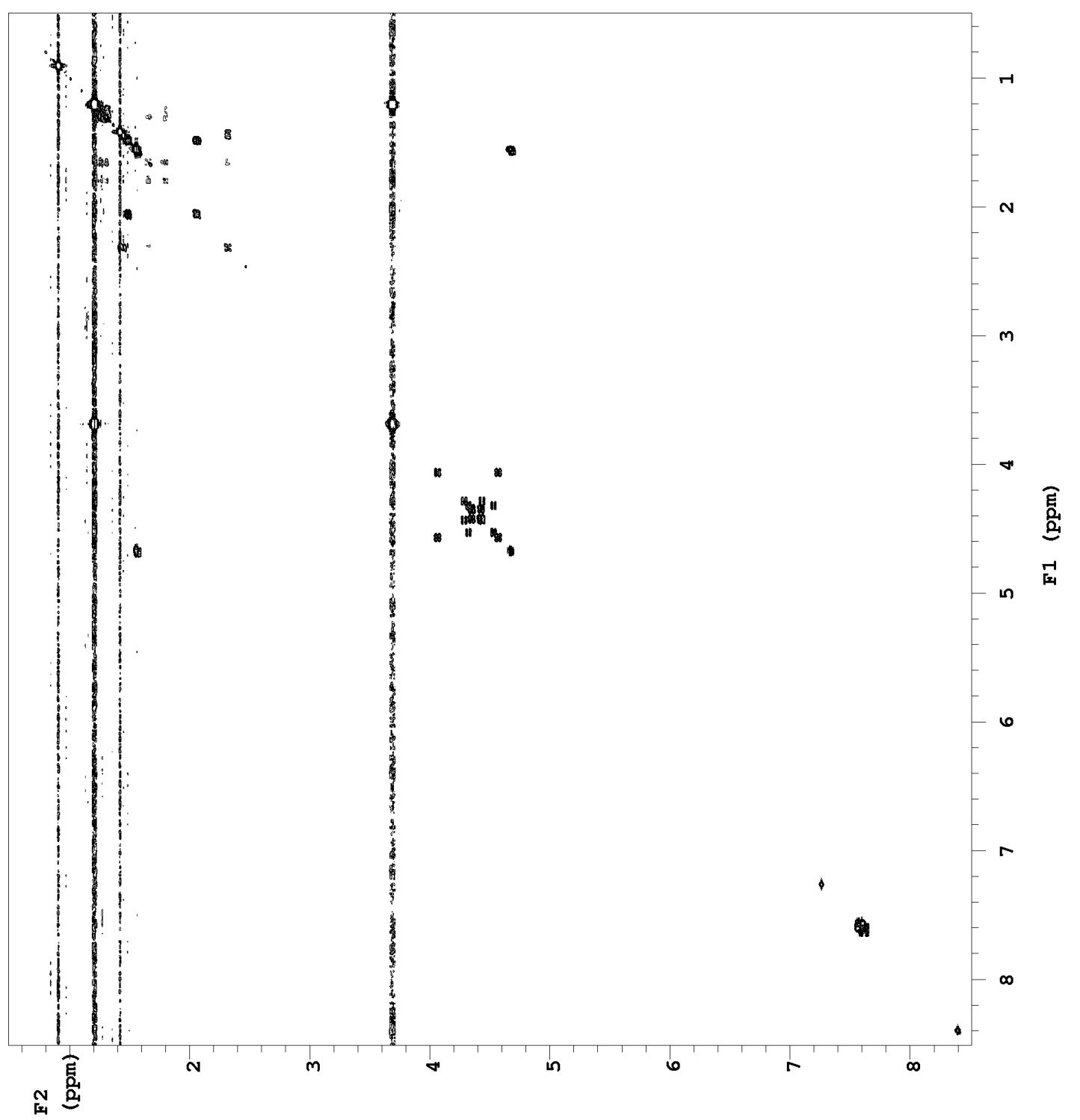

Figure B.56. COSY spectrum $\left(600 \mathrm{MHz}, \mathrm{CDCl}_{3}\right)$ of oxeatamide A (214). 


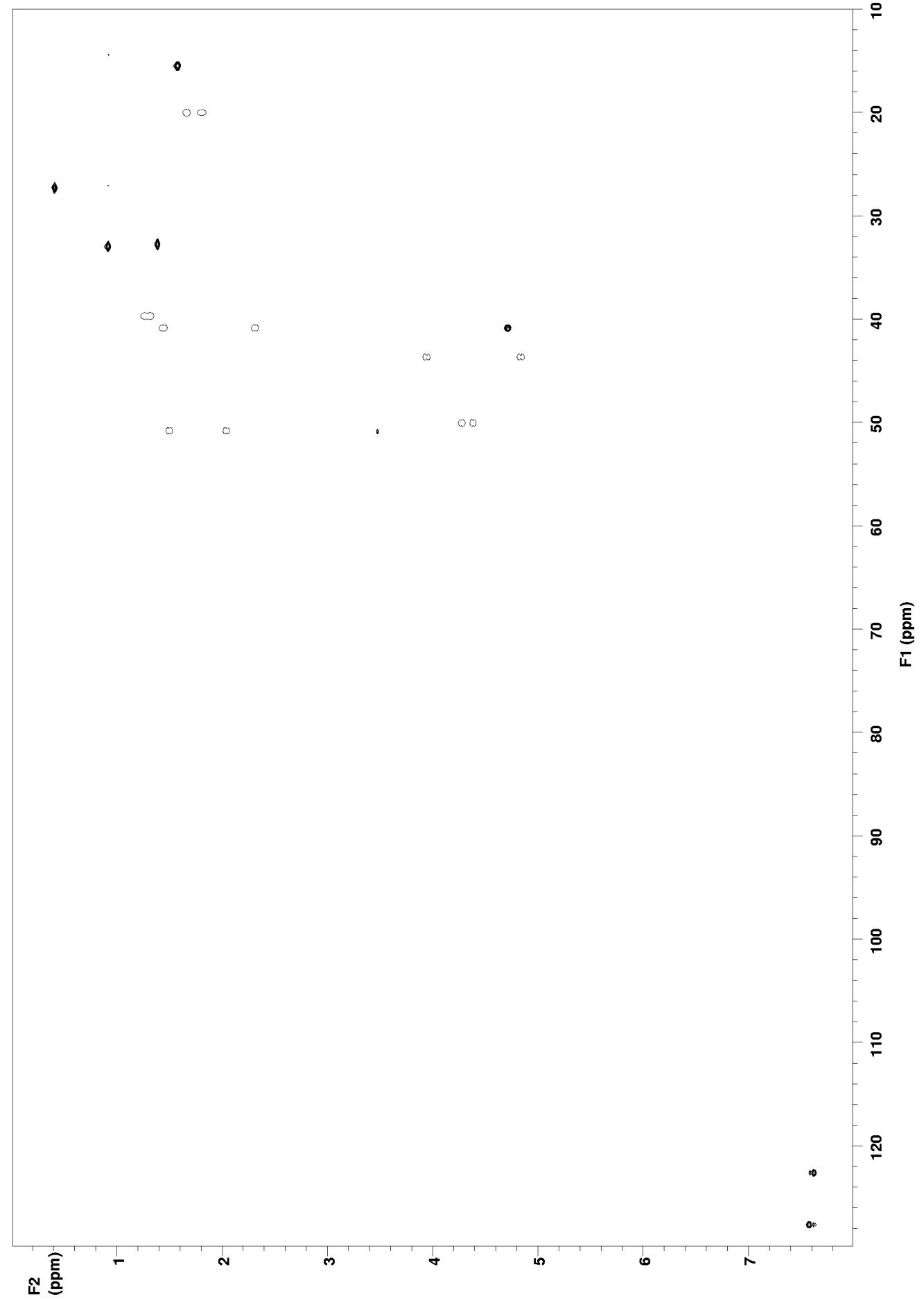

Figure B.57. HSQC spectrum (600 $\left.\mathrm{MHz}, \mathrm{CDCl}_{3}\right)$ of oxeatamide A (214). 


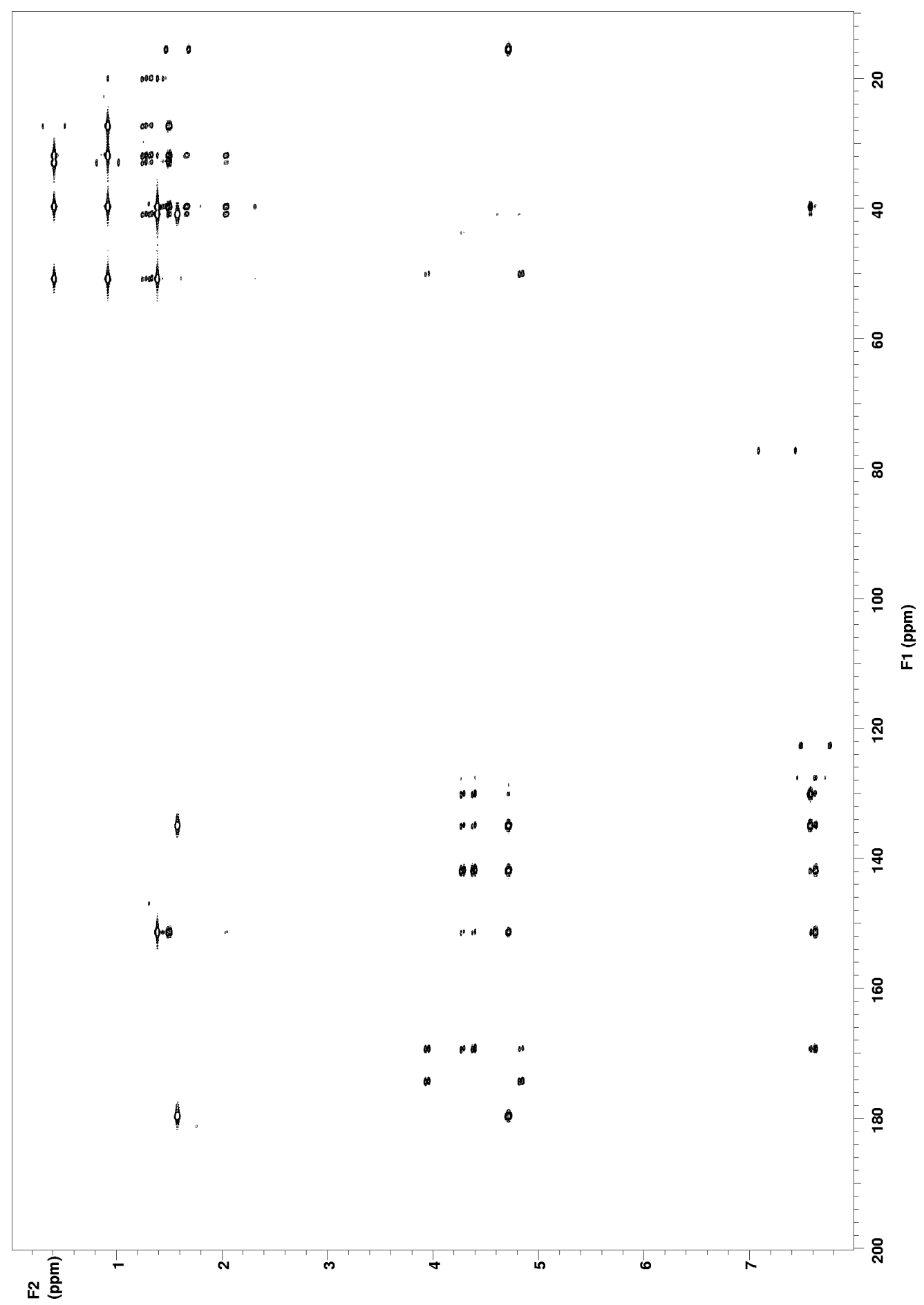

Figure B.58. HMBC spectrum (600 $\left.\mathrm{MHz}, \mathrm{CDCl}_{3}\right)$ of oxeatamide $\mathrm{A}(\mathbf{2 1 4})$. 


\section{Iso-oxeatamide A}

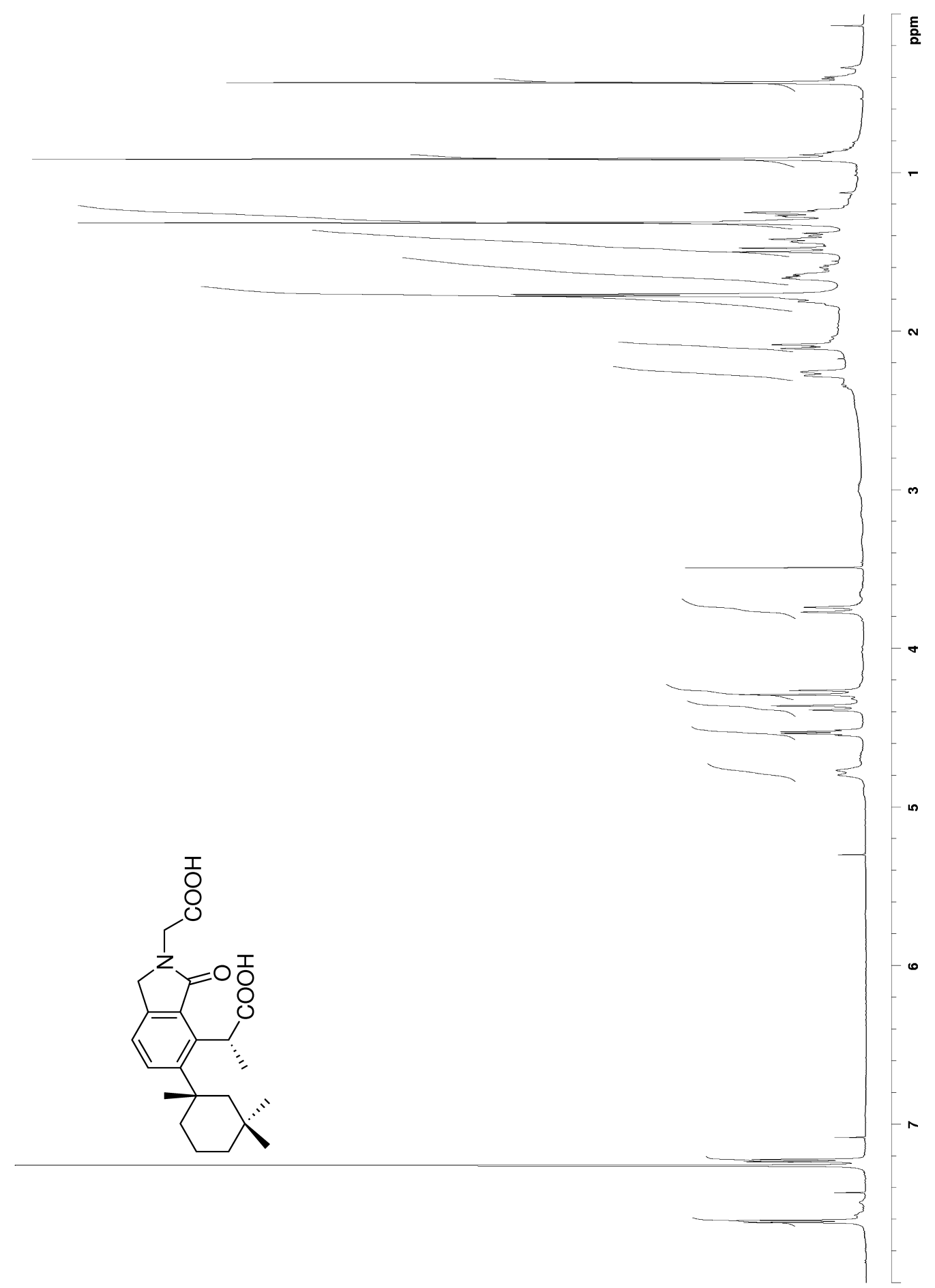

Figure B.59. ${ }^{1} \mathrm{H}$ NMR spectrum $\left(600 \mathrm{MHz}, \mathrm{CDCl}_{3}\right)$ of iso-oxeatamide $\mathrm{A}(\mathbf{2 1 5})$. 


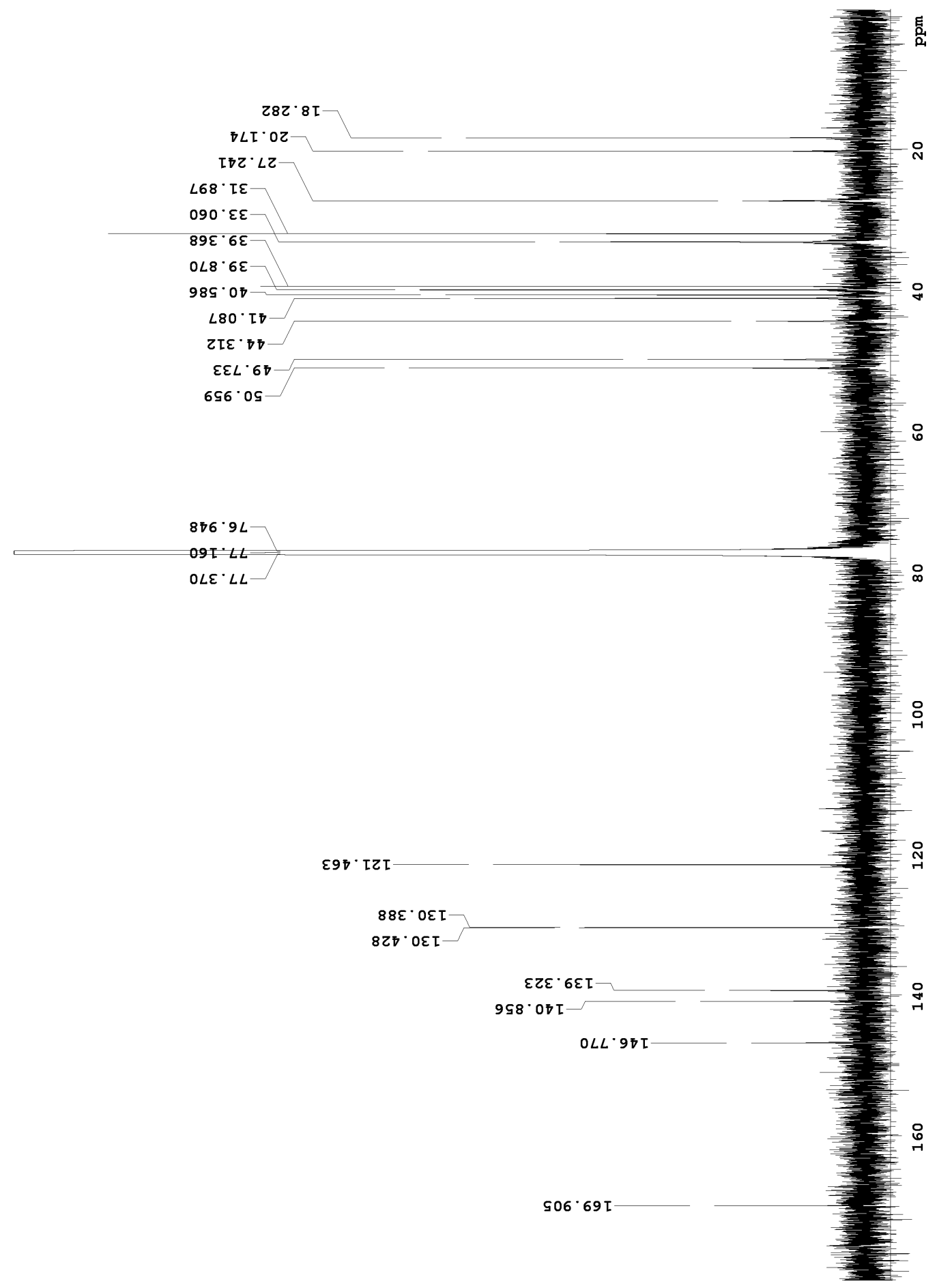

Figure B.60. ${ }^{13} \mathrm{C}$ NMR spectrum $\left(150 \mathrm{MHz}, \mathrm{CDCl}_{3}\right)$ of iso-oxeatamide A (215). 


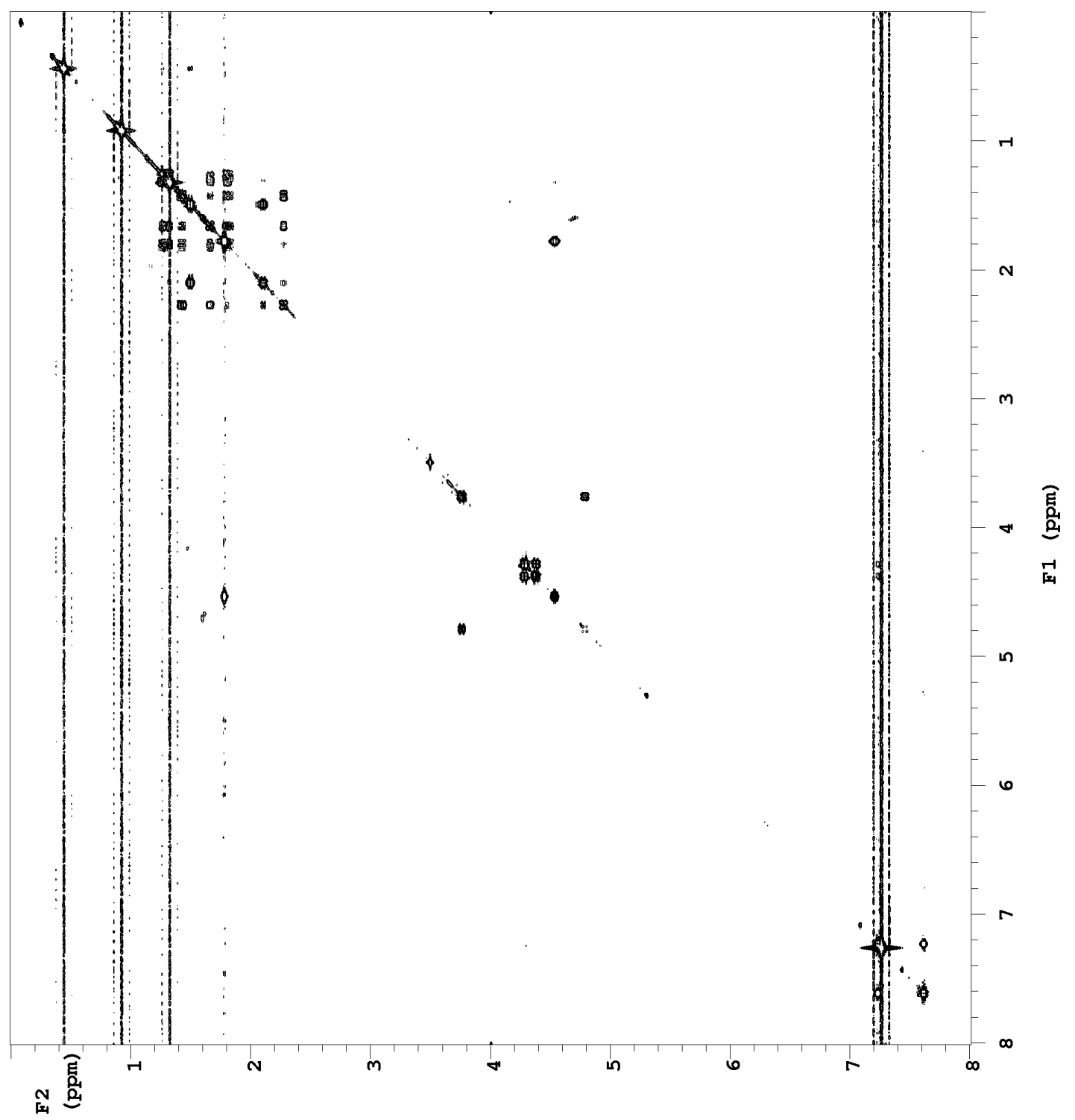

Figure B.61. COSY spectrum $\left(600 \mathrm{MHz}, \mathrm{CDCl}_{3}\right)$ of iso-oxeatamide $\mathrm{A}(\mathbf{2 1 5})$. 


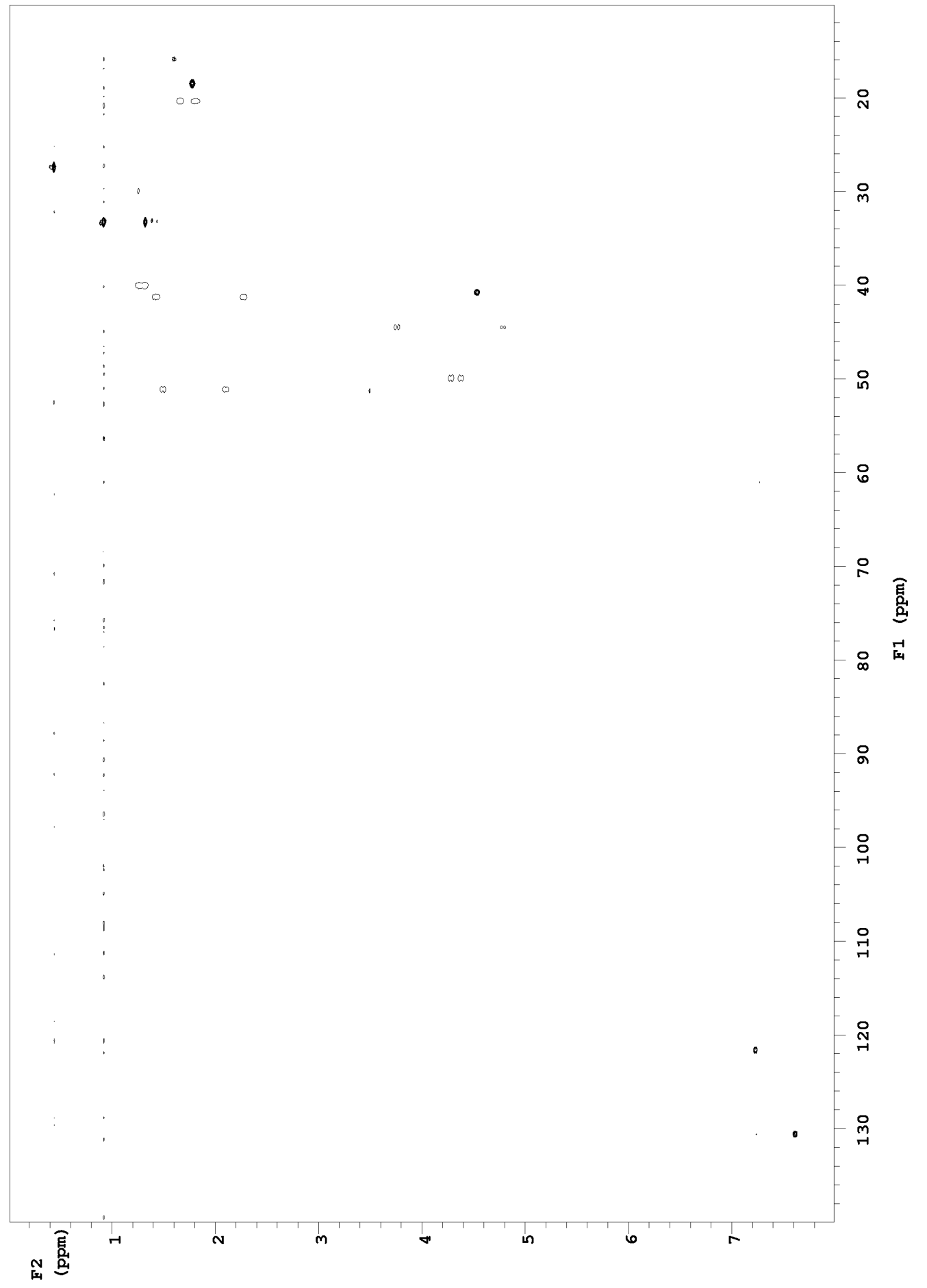

Figure B.62. HSQC spectrum $\left(600 \mathrm{MHz}^{\mathrm{CDCl}} \mathrm{CDC}_{3}\right)$ of iso-oxeatamide $\mathrm{A}(\mathbf{2 1 5})$. 


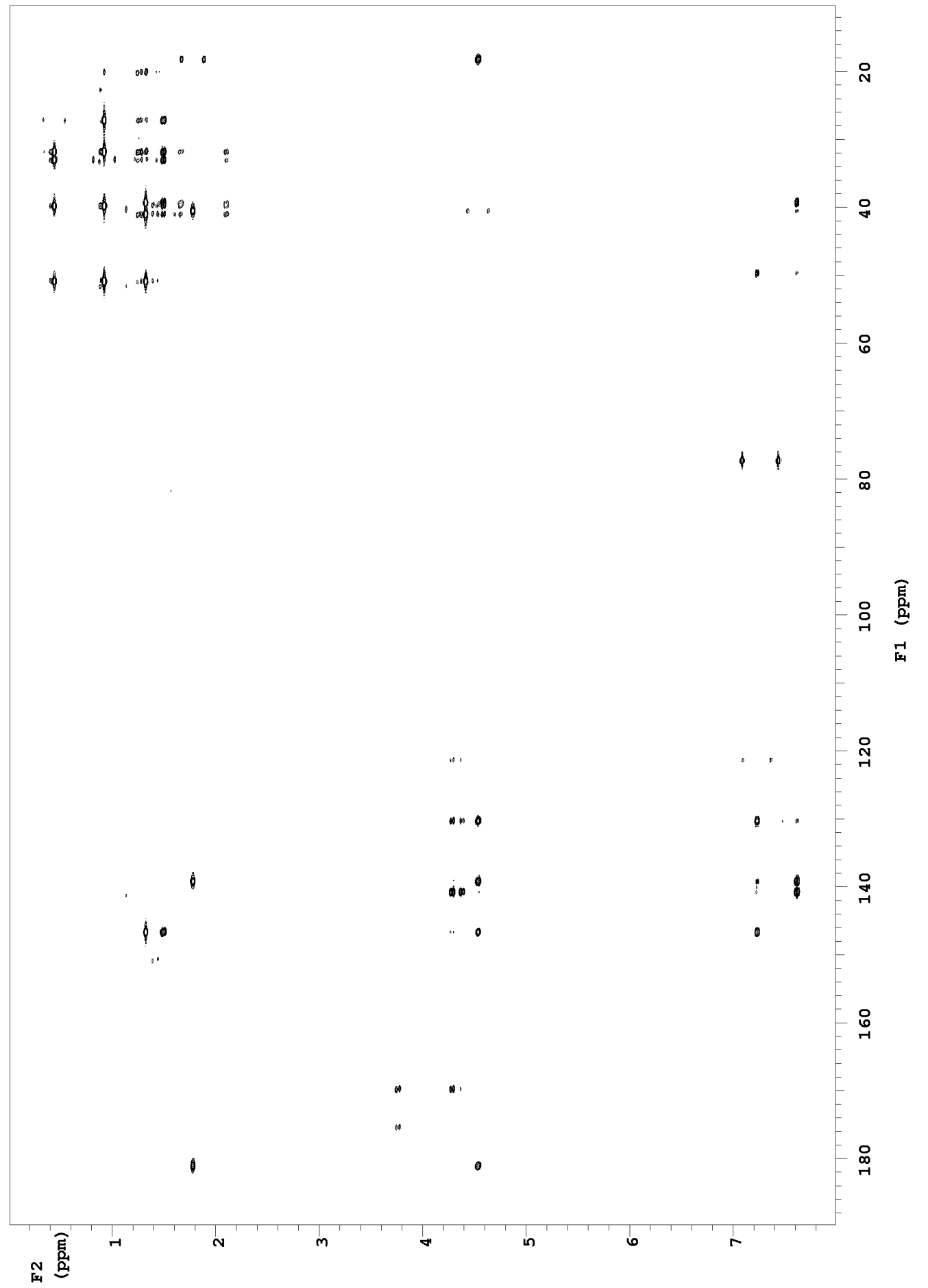

Figure B.63. HMBC spectrum $\left(600 \mathrm{MHz}, \mathrm{CDCl}_{3}\right)$ of iso-oxeatamide A (215). 
Oxeatamide A 23-methyl ester

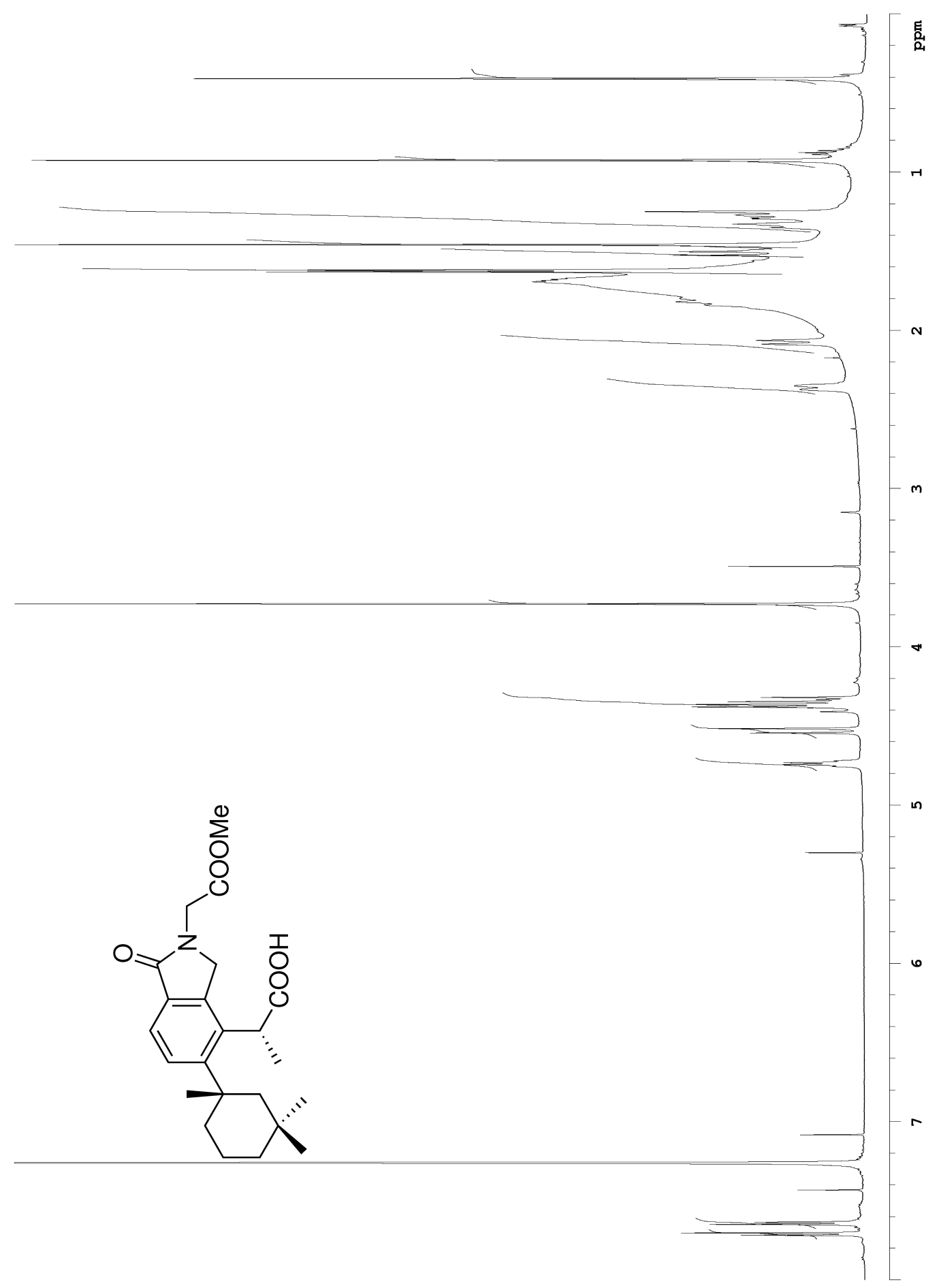

Figure B.64. ${ }^{1} \mathrm{H}$ NMR spectrum $\left(600 \mathrm{MHz}, \mathrm{CDCl}_{3}\right)$ of oxeatamide A 23-methyl ester (216). 


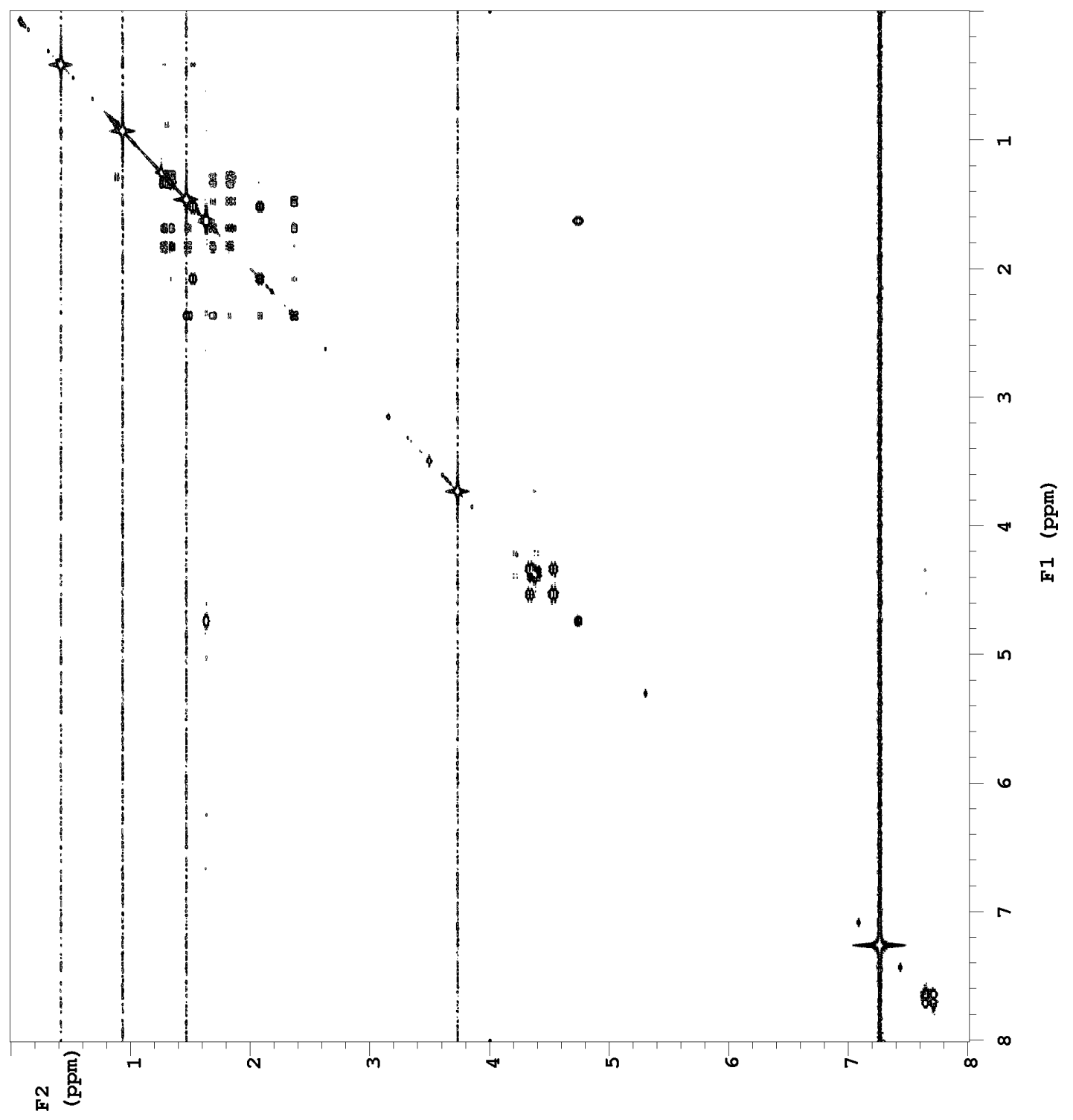

Figure B.65. COSY spectrum $\left(600 \mathrm{MHz}, \mathrm{CDCl}_{3}\right)$ of oxeatamide A 23-methyl ester (216). 


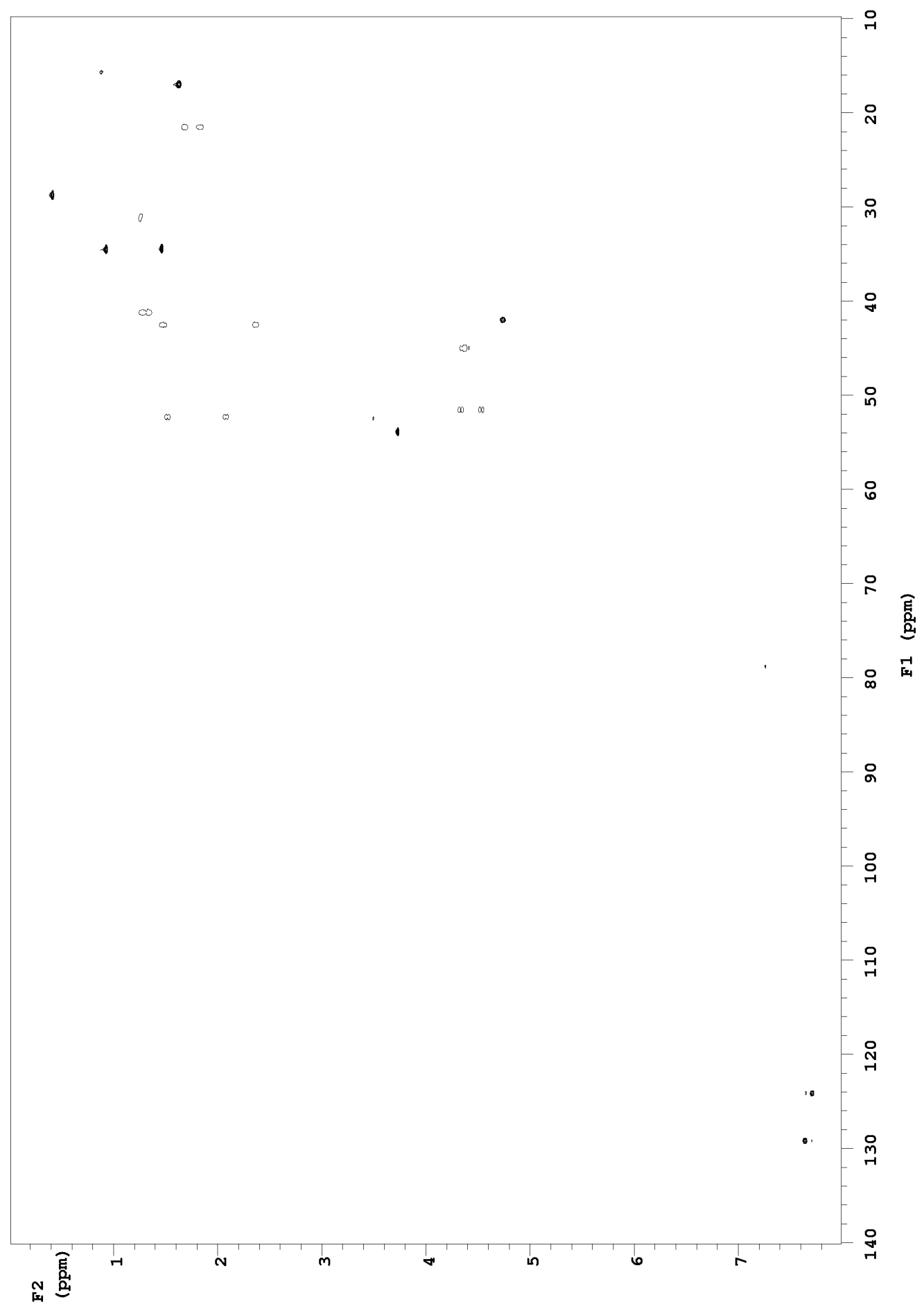

Figure B.66. HSQC spectrum (600 $\mathrm{MHz}, \mathrm{CDCl}_{3}$ ) of oxeatamide A 23-methyl ester (216). 


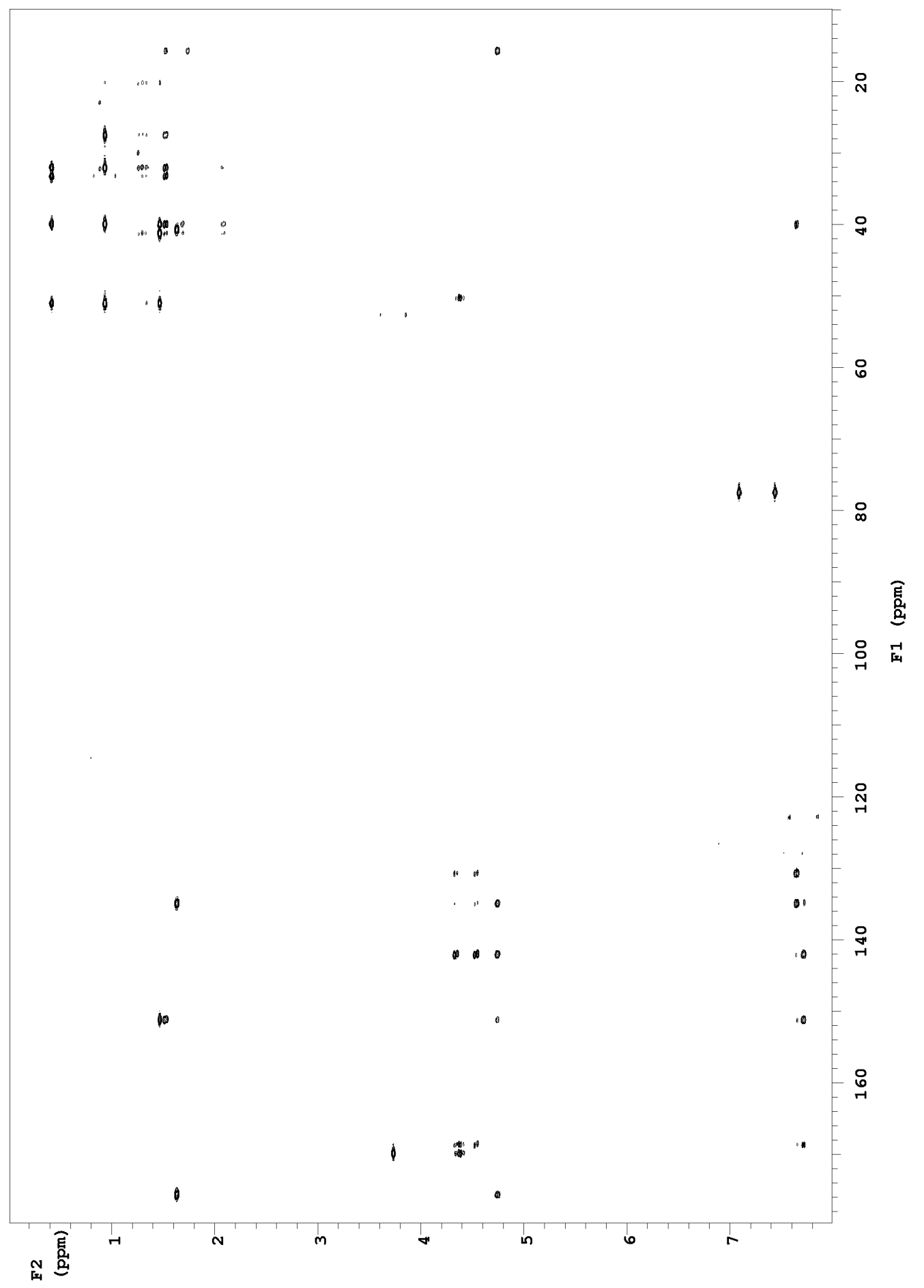

Figure B.67. HMBC spectrum (600 $\left.\mathrm{MHz}, \mathrm{CDCl}_{3}\right)$ of oxeatamide A 23-methyl ester (216). 


\section{Oxeatamide B}

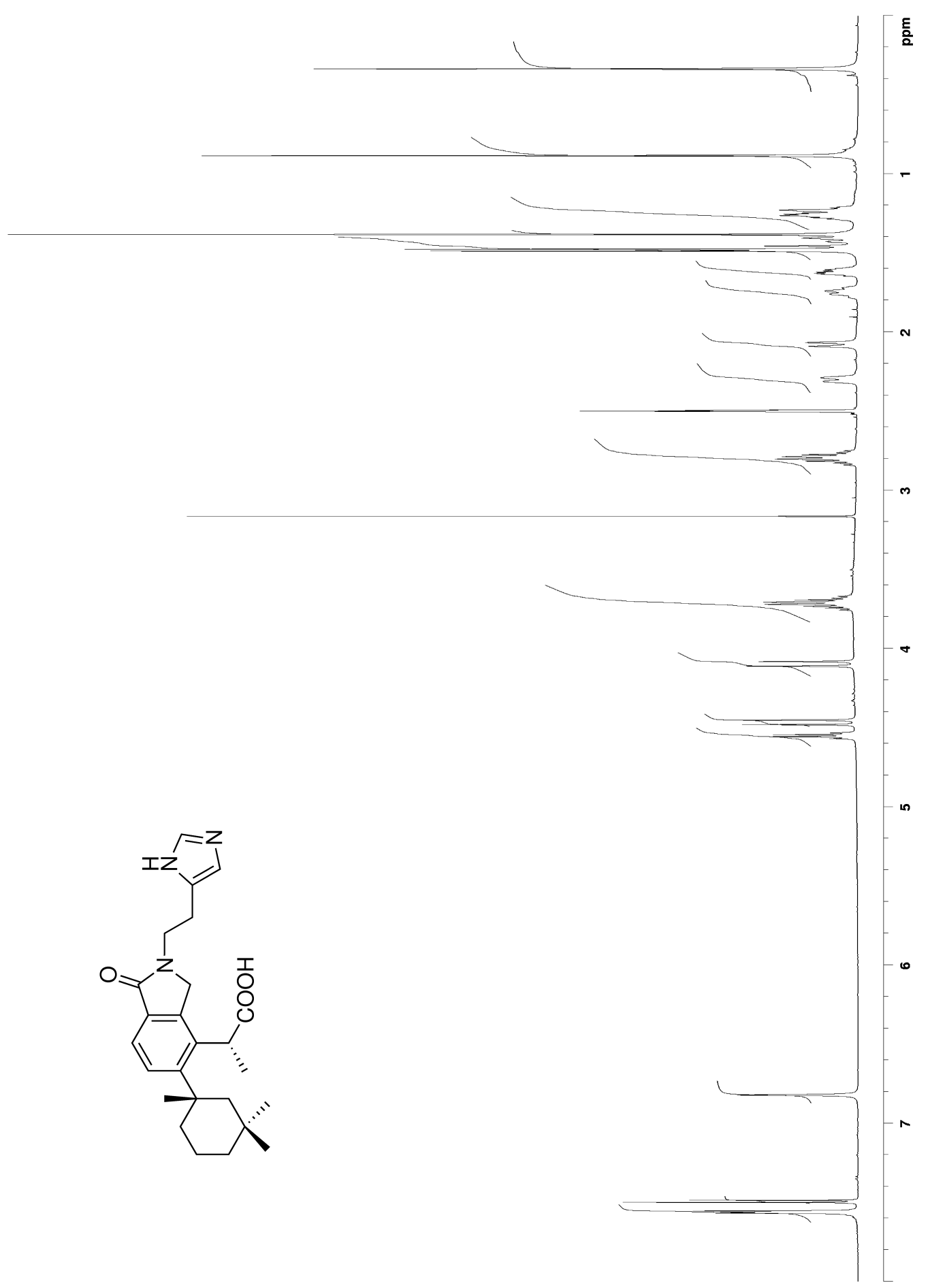

Figure B.68. ${ }^{1} \mathrm{H}$ NMR spectrum $\left(600 \mathrm{MHz}, \mathrm{DMSO}-\mathrm{d}_{6}\right)$ of oxeatamide B (217). 


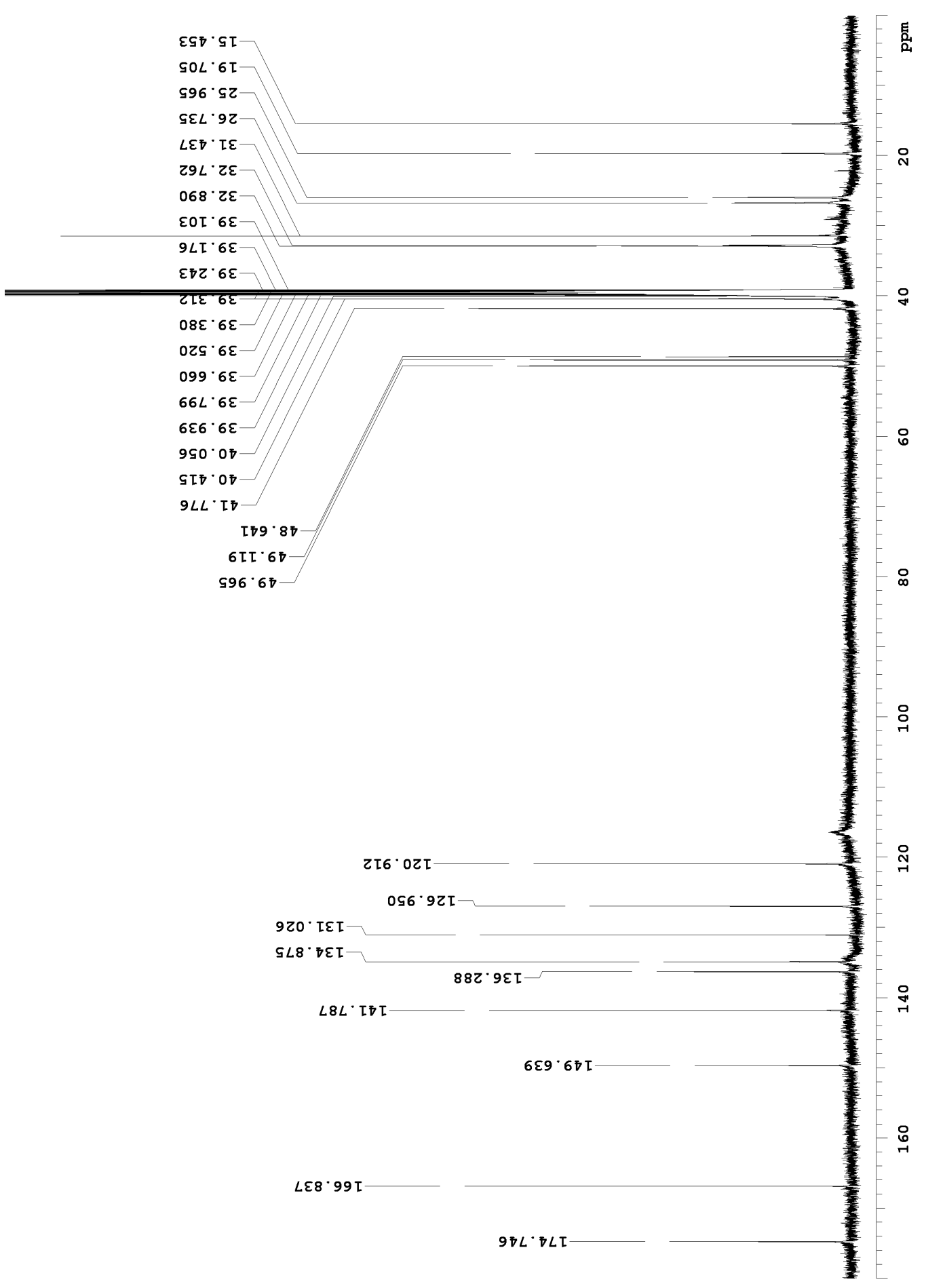

Figure B.69. ${ }^{13} \mathrm{C}$ NMR spectrum $\left(150 \mathrm{MHz}, \mathrm{DMSO}-\mathrm{d}_{6}\right)$ of oxeatamide B (217). 


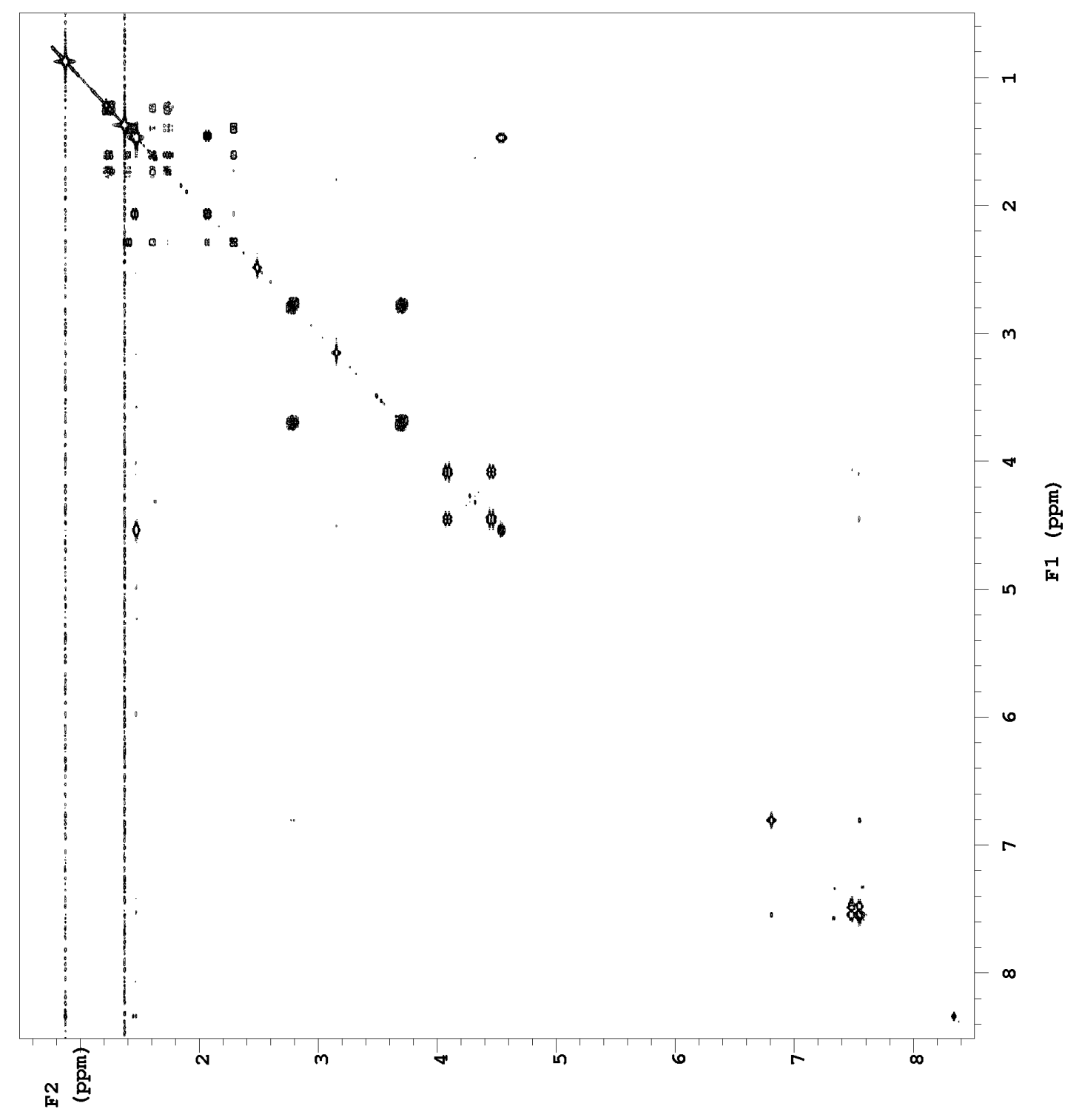

Figure B.70. COSY spectrum $\left(600 \mathrm{MHz}, \mathrm{DMSO}_{-} \mathrm{d}_{6}\right)$ of oxeatamide B (217). 


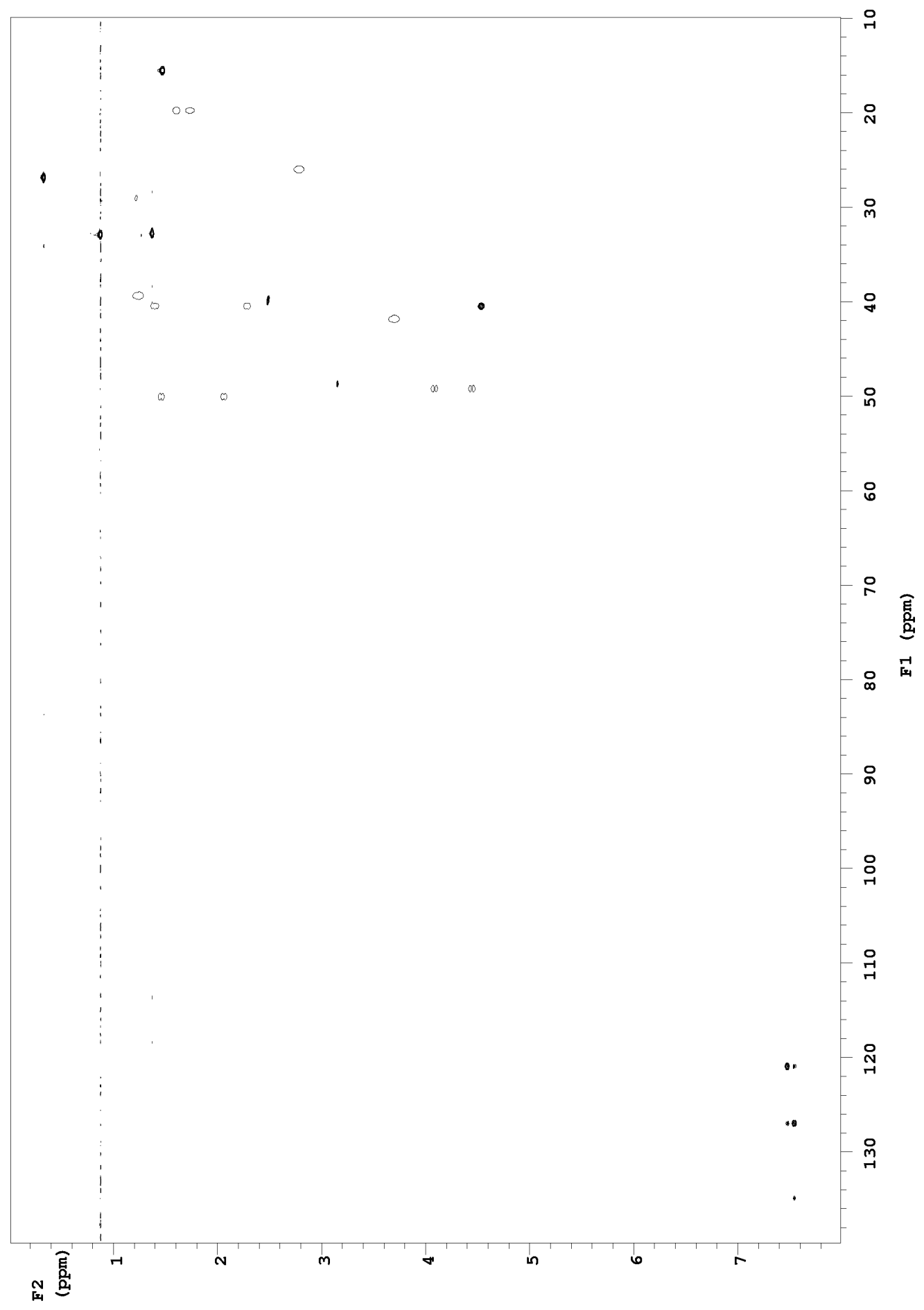

Figure B.71. HSQC spectrum of oxeatamide B (217). 


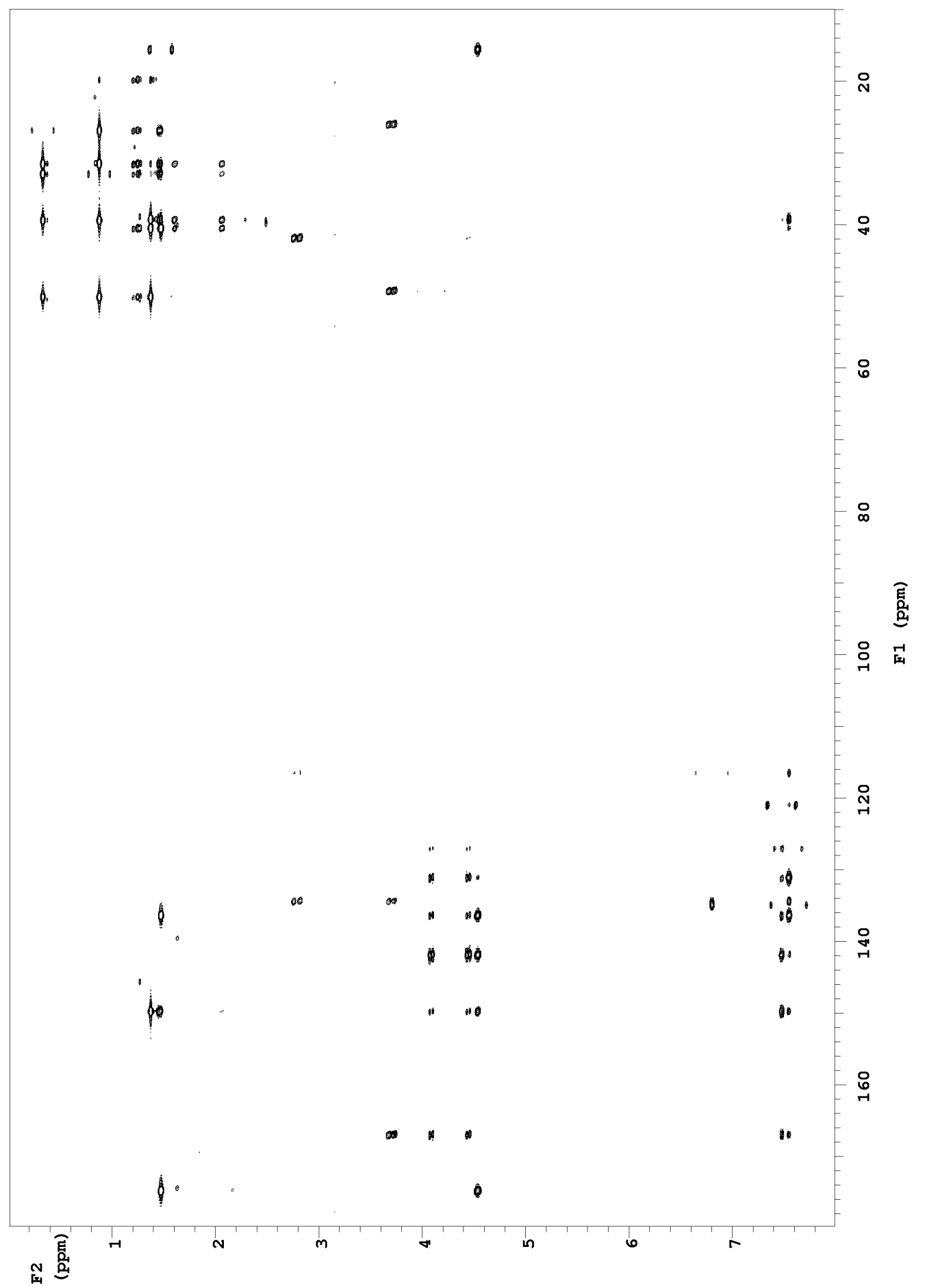

Figure B.72. HMBC spectrum (600 MHz, DMSO-d ${ }_{6}$ ) of oxeatamide B (217). 


\title{
Glossary
}

\author{
() Weak correlations indicated by brackets in NMR data \\ tables \\ br Broad \\ ${ }^{13}$ C NMR Carbon-13 nuclear magnetic resonance \\ $\mathrm{C}_{18}$ Octadecyl derivatized silica gel \\ $\mathrm{CDCl}_{3} \quad$ Deuterated chloroform \\ $\mathrm{CD}_{3} \mathrm{OD}$ Deuterated methanol \\ $\mathrm{CH}_{2} \mathrm{Cl}_{2}$ Dichloromethane \\ COSY Correlation spectroscopy $\left({ }^{1} \mathrm{H}\right.$ to ${ }^{1} \mathrm{H}$ correlations depicted \\ by 2 ) \\ d Doublet \\ $\boldsymbol{\delta}$ Chemical shift (ppm) \\ Da Daltons \\ DAD Diode array detector \\ $\mathbf{d}_{6}$-DMSO Deuterated DMSO \\ DEPT Distortionless enhancement by polarisation transfer \\ DIOL 2,3-Dihydroxy-1-propoxypropyl-derivatized silica gel \\ DMSO Dimethyl sulfoxide \\ DOSY Diffusion-ordered spectroscopy \\ DQF-COSY Double quantum filtered correlation spectroscopy \\ $\mathbf{E D}_{50}$ Dose that is effective in $50 \%$ of test subjects \\ ESIMS Electrospray ionization mass spectroscopy \\ EtOAc Ethyl acetate \\ EU European Union \\ FAB-MS Fast atom bombardment mass spectrometry \\ FDA United States Food and Drug Administration \\ GC Gas chromatography \\ ${ }^{1} \mathbf{H}$ NMR Proton nuclear magnetic resonance
}


HMBC Heteronuclear multiple-bond correlation $\left({ }^{1} \mathrm{H}\right.$ to ${ }^{13} \mathrm{C}$ correlations depicted by $\longrightarrow$ )

$\mathrm{H}_{2} \mathrm{O}$ Water

HPLC High pressure (performance) liquid chromatography

HP20/HP20SS PSDVB stationary support

HRESIMS High resolution electrospray ionization mass spectrum

IC $_{50}$ Concentration that is inhibitory in $50 \%$ of test subjects

IPA Isopropyl alcohol (2-propanol)

FABMS Fast atom bombardment mass spectrum

HSQC Gradient heteronuclear single-quantum correlation

$\boldsymbol{J}$ Scalar coupling constant

LC-NMR HPLC coupled with NMR detection

$\mathbf{L D}_{50}$ Dose that is lethal to $50 \%$ of test subjects

LH-20 Crosslinked dextran-based size exclusion resin

m Multiplet

$\boldsymbol{m} / \boldsymbol{z}$ Mass to charge ratio

MALDI-TOF Matrix-assisted laser desorption/ionization time of flight

$\mathrm{Me}_{2} \mathrm{CO}$ Acetone

MIC Minimum inhibitory concentration

MPLC Medium pressure (performance) liquid chromatography

mult. Multiplicity

MS Mass spectrometry

Colourmetric cytotoxicity assay using 3-(4,5-dimethylthiazol-2-yl)-2,5-diphenyltetrazolium bromide

NOE Nuclear Overhauser effect $\left({ }^{1} \mathrm{H}\right.$ to ${ }^{1} \mathrm{H}$ enhancements depicted by $\longrightarrow$ )

NOESY Nuclear Overhauser enhancement spectroscopy

pet. ether Petroleum ether (hexanes)

pos. Position

ppm Parts per million

PSDVB Poly(styrene-divinylbenzene)

q Quartet

quin Quintet

ROESY Rotating frame Overhauser enhancement spectroscopy

s Singlet

SEM Scanning electron microscope 
SCUBA Self contained underwater breathing apparatus

SPE Solid phase extraction

t Triplet

TLC Thin layer chromatography

TMS Trimethylsilyl

$\mathrm{TMSCHN}_{2}$ Trimethylsilyldiazomethane

TOCSY Total correlation spectroscopy $\left({ }^{1} \mathrm{H}\right.$ to ${ }^{1} \mathrm{H}$ correlations depicted by - )

VUW Victoria University of Wellington 


\section{References}

1. Verdine, G. L. Nature (London) 1996, 384, 11-13.

2. Newman, D. J.; Cragg, G. M.; Snader, K. M. Nat. Prod. Rep. 2000, 17, 215-234.

3. Newman, D. J.; Cragg, G. M. J. Nat. Prod. 2007, 70, 461-477.

4. Stone, M. J.; Williams, D. H. Mol. Microbiol. 1992, 6, 29-34.

5. Piggott, A. M.; Karuso, P. Mar. Drugs 2005, 3, 36-63.

6. Paterson, I.; Anderson, E. A. Science (Washington, D.C.) 2005, 310, 451453.

7. Breinbauer, R.; Vetter, I. R.; Waldmann, H. Angew. Chem. Int. Ed. 2002, 41, 2878-2890.

8. Koehn, F. E.; Carter, G. T. Nat. Rev. Drug Discov. 2005, 4, 206-220.

9. Thomas, G. Medicinal Chemistry, an Introduction; John Wiley \& Sons, Ltd: Brisbane, 2000.

10. Feher, M.; Schmidt, J. M. J. Chem. Inf. Comput. Sci. 2003, 43, 218-227.

11. Newman, D. J.; Cragg, G. M.; Snader, K. M. J. Nat. Prod. 2003, 66, $1022-1037$.

12. Vuorela, P.; Leinonen, M.; Saikku, P.; Tammela, P.; Rauha, J.-P.; Wennberg, T.; Vuorela, H. Curr. Med. Chem. 2004, 11, 1375-1389.

13. Baker, D. D.; Chu, M.; Oza, U.; Rajgarhia, V. Nat. Prod. Rep. 2007, 24, $1225-1244$.

14. Lam, K. S. Trends Microbiol. 2007, 15, 279-289.

15. Gullo, V. P.; Hughes, D. E. Drug Discov. Today Tech. 2005, 2, 281-286.

16. Rollinger, J. M.; Langer, T.; Stuppner, H. Curr. Med. Chem. 2006, 13, 1491-1507.

17. Bindseil, K. U.; Jakupovic, J.; Wolf, D.; Lavayre, J.; Leboul, J.; van der Pyl, D. Drug Discov. Today 2001, 6, 840-847. 
18. Leibnitz Institute for Natural Product Research and Infection BiologyHans-Knöll-Institut, http://www.hki-jena.de/index.php/, (accessed Dec 15, 2007).

19. Grabley, S.; Thiericke, R.; Zeeck, A. The Chemical Screening Approach., In Drug Discovery from Nature; Grabley, S., Thiericke, R., Eds.; SpringerVerlag: Berlin, 1999; pp 124-148.

20. Butler, M. S. J. Nat. Prod. 2004, 67, 2141-2153.

21. Fenical, W.; Jensen, P. R. Marine Microorganisms: a New Biomedical Resource., In Marine Biotechnology; Attaway, D. H., Zaborsky, O. R., Eds.; Plenum Press: New York, 1993; Vol. 1, pp 419-457.

22. Haefner, B. Drug Discov. Today 2003, 8, 536-544 and suppl.

23. Simmons, T. L.; Andrianasolo, E.; McPhail, K.; Flatt, P.; Gerwick, W. H. Mol. Cancer Ther. 2005, 4, 333-342.

24. Shining a spotlight on the biodiversity of New Zealand's marine ecoregion: experts workshop on marine biodiversity, 27-28 May 2003, Wellington, New Zealand; Arnold, A., Ed.; WWF-New Zealand: Wellington, 2003; p 5.

25. Newman, D. J.; Cragg, G. M. J. Nat. Prod. 2004, 67, 1216-1238.

26. Ireland, C. M.; Copp, B. R.; Foster, M. P.; McDonald, L. A.; Radisky, D. C.; Swersey, J. C. Biomedical Potential of Marine Natural Products., In Marine Biotechnology; Attaway, D. H., Zaborsky, O. R., Eds.; Plenum Press: New York, 1993; Vol. 1, pp 1-43.

27. Faulkner, D. J. Nat. Prod. Rep. 2000, 17, 1-6.

28. Braekman, J.-C.; Daloze, D. Phytochem. Rev. 2004, 3, 275-283.

29. Belarbi, E. H.; Gómez, A. C.; Chisti, Y.; Camacho, F. G.; Grima, E. M. Biotechnol. Adv. 2003, 21, 585-598.

30. Sipkema, D.; Franssen, M. C. R.; Osinga, R.; Tramper, J.; Wijffels, R. H. Mar. Biotechnol. 2005, \%, 142-162.

31. Blunt, J. W.; Copp, B. R.; Hu, W.-P.; Munro, M. H. G.; Northcote, P. T.; Prinsep, M. R. Nat. Prod. Rep. 2007, 24, 31-86.

32. Daly, J. W. J. Nat. Prod. 2004, 67, 1211-1215.

33. Costantino, V.; Fattorusso, E.; Menna, M.; Taglialatela-Scafati, O. Curr. Med. Chem. 2004, 11, 1671-1692.

34. Bergmann, W.; Feeney, R. J. J. Am. Chem. Soc. 1950, 72, 2809-2810.

35. Bergmann, W.; Feeney, R. J. J. Org. Chem. 1951, 16, 981-987. 
36. Mayer, A. M. S.; Gustafson, K. R. Eur. J. Cancer 2006, 42, 2241-2270.

37. Mayer, A. M. S.; Rodríguez, A. D.; Berlinck, R. G. S.; Hamann, M. T. Comp. Biochem. Phys. C 2007, 145, 553-581.

38. Olivera, B. M.; Gray, W. R.; Zeikus, R.; McIntosh, J. M.; Varga, J.; Rivier, J.; de Santos, V.; Cruz, L. J. Science (Washington, D.C.) 1985, 230, $1338-1343$.

39. Miljanich, G. P. Curr. Med. Chem. 2004, 11, 3029-3040.

40. Elan Pharmaceuticals, http://www.elan.com/News/2004/20041228.asp, (accessed July 2006).

41. Marine Sponges. Forty-six Sponges of Northern New Zealand; Pritchard, K., Ed.; University of Auckland Marine Laboratory: Wellington, 1984 .

42. Bergquist, P. R. Sponges; Hutchison \& Co.: London, 1978; pp 9-12.

43. Systema Porifera. A Guide to the Classification of Sponges; Hooper, J. N. A., van Soest, R. W. M., Eds.; Kluwer Academic/Plenum Publishers: New York, 2002; Vol. 1.

44. MarinLit: Marine Literature Database, vpc14.3; University of Canterbury: Christchurch, 2007.

45. König, G. M.; Kehraus, S.; Seibert, S. F.; Abdel-Lateff, A.; Müller, D. ChemBioChem 2006, 7, 229-238.

46. Piel, J. Nat. Prod. Rep. 2004, 21, 519-538.

47. Lee, Y. K.; Lee, J.-H.; Lee, H. K. J. Microbiol. 2001, 39, 254-264.

48. Willan, R.; Coleman, N. Nudibranchs of Australasia; Australasian Marine Photographic Index: Sydney, 1984.

49. Rudman, W. B. The Sea Slug Forum, http://www.seaslugforum.net/, (accessed Sep 26, 2007).

50. Faulkner, D. J.; Ghiselin, M. T. Mar. Ecol. Prog. Ser. 1983, 13, 295-301.

51. Cimino, G.; Ghiselin, M. T. Chemoecology 1999, 9, 187-207.

52. Cimino, G.; de Rosa, S.; de Stefano, S.; Sodano, G.; Villani, G. Science (Washington, D.C.) 1983, 219, 1237-1238.

53. Cimino, G.; Fontana, A.; Cutignano, A.; Gavagnin, M. Phytochem. Rev. 2004, 3, 285-307.

54. Burreson, B. J.; Scheuer, P. J.; Finer, J.; Clardy, J. J. Am. Chem. Soc. 1975, 97, 4763-4764. 
55. Biju, P. J.; Kaliappan, K.; Laxmisha, M. S.; Rao, G. S. R. S. J. Chem. Soc., Perkin Trans. 1 2000, 3714-3718.

56. Hochlowski, J. E.; Faulkner, D. J.; Matsumoto, G. K.; Clardy, J. J. Org. Chem. 1983, 48, 1141-1142.

57. Guizzunti, G.; Brady, T. P.; Malhotra, V.; Theodorakis, E. A. J. Am. Chem. Soc. 2006, 128, 4190-4191.

58. Miyamoto, T.; Sakamoto, K.; Amano, H.; Higuchi, R.; Komori, T.; Sasaki, T. Tetrahedron Lett. 1992, 33, 5811-5814.

59. Graziani, E. I.; Allen, T. M.; Andersen, R. J. Tetrahedron Lett. 1995, 36, 1763-1766.

60. Roesener, J. A.; Scheuer, P. J. J. Am. Chem. Soc. 1986, 108, 846-847.

61. Matsunaga, S.; Fusetani, N.; Hashimoto, K.; Koseki, K.; Noma, M. J. Am. Chem. Soc. 1986, 108, 847-849.

62. Matsunaga, S. Trisoxazole Macrolides from Hexabranchus Nudibranchs and Other Marine Invertebrates., In Molluscs; Cimino, G., Gavagnin, M., Eds.; Springer-Verlag: Berlin, 2006; Vol. 43, pp 241-260.

63. Kernan, M. R.; Molinski, T. F.; Faulkner, D. J. J. Org. Chem. 1988, 53, 5014-5020.

64. Fusetani, N.; Yasamuro, K.; Matsunaga, S.; Hashimoto, K. Tetrahedron Lett. 1989, 30, 2809-2812.

65. Kobayashi, J.; Murata, O.; Shigemori, H. J. Nat. Prod. 1993, 56, 787-791.

66. Matsunaga, S.; Liu, P.; Celatka, C. A.; Panek, J. S.; Fusetani, N. J. Am. Chem. Soc. 1999, 121, 5605-5606.

67. Allingham, J. S.; Tanaka, J.; Marriott, G.; Rayment, I. Org. Lett. 2004, 6, $597-599$.

68. Pettit, G. R.; Kamano, Y.; Herald, C. L.; Tuinman, A. A.; Boettner, F. E.; Kizu, H.; Schmidt, J. M.; Baczynkyj, L.; Tomer, K. B.; Bontems, R. J. J. Am. Chem. Soc. 1987, 109, 6883-6885.

69. Willan, R.; Morton, J. Marine Molluscs. Part 2: Opistobranchia; University of Auckland: Auckland, 1984.

70. Garson, M. J. Marine Molluscs from Australian and New Zealand: Chemical and Ecological Studies, In Molluscs; Cimino, G., Gavagnin, M., Eds.; Springer Verlag: Berlin, 2006; Vol. 43, pp 159-174.

71. Grkovic, T.; Appleton, D. R.; Copp, B. R. Chem. in NZ 2005, 69, 12-15.

72. Mackey, S. L. Personal communication, 2004. 
73. Bowden, B. F.; Coll, J. C.; Wright, A. D. Aust. J. Chem. 1989, 42, 757-763.

74. Missakian, M. G.; Burreson, B. J.; Scheuer, P. J. Tetrahedron 1975, 31, 2513-2515.

75. Ksebati, M. B.; Ciereszko, L. S.; Schmitz, F. J. J. Nat. Prod. 1984, 4 †, 1009-1012.

76. Bowden, B. F.; Coll, J. C.; Mitchell, S. J.; Kazlauskas, R. Aust. J. Chem. 1981, 34, 1551-1556.

77. McKillop, A.; Young, D. W. Synthesis 1979, 401-422, 481-500.

78. Chakraborti, A. K.; Rudrawar, S.; Kondaskar, A. Org. Biomol. Chem. 2004, 2, 1277-1280.

79. Kotsuki, H.; Shimanouchi, T.; Ohshima, R.; Fujiwara, S. Tetrahedron 1998, 54, 2709-2722.

80. Coll, J. C.; Bowden, B. F.; Tapiolas, D. M.; Willis, R. H.; Djura, P.; Streamer, M.; Trott, L. Tetrahedron 1985, 41, 1085-1092.

81. Roethle, P. A.; Trauner, D. Nat. Prod. Rep. [Online early access]. 2008, DOI: 10.1039/b705660p. Published online: Feb 25, 2008. http://www.rsc. org/Publishing/Journals/NP/article.asp?doi=b705660p (accessed March 13, 2008).

82. Wahlberg, I.; Wallin, I.; Narbonne, C.; Nishida, T.; Enzell, C. R. Acta Chem. Scand. B 1981, 35, 65-68.

83. Coll, J. C.; Leone, P. A.; Bowden, B. F.; Carroll, A. R.; König, G. M.; Heaton, A.; de Nys, R.; Maida, M.; Aliño, P. M.; Willis, R. H.; Babcock, R. C.; Florian, Z.; Clayton, M. N.; Miller, R. L.; Alderslade, P. N. Mar. Biol. 1995, 123, 137-143.

84. Coll, J. C.; Bowden, B. F.; Heaton, A.; Scheuer, P. J.; Li, M. K. W.; Clardy, J.; Schulte, G. K.; Finer-Moore, J. J. Chem. Ecol. 1989, 15, 11771191.

85. Gerhart, D. J.; Coll, J. C. J. Chem. Ecol. 1993, 19, 2697-2704.

86. Abramson, S. N.; Trischman, J. A.; Tapiolas, D. M.; Harold, E. E.; Fenical, W.; Taylor, P. J. Med. Chem. 1991, 34, 1798-1804.

87. Fenical, W.; Okuda, R. K.; Bandurraga, M. M.; Culver, P.; Jacobs, R. S. Science (Washington D.C.) 1981, 212, 1512-1514.

88. Canonica, L.; Corbella, A.; Jommi, G.; Křepinský, J.; Ferrari, G.; Casagrande, C. Tetrahedron Lett. 1967, 23, 2137-2141.

89. Canonica, L.; Corbella, A.; Gariboldi, P.; Jommi, G.; Křepinský, J. Tetrahedron 1969, 25, 3895-3902. 
90. Sakio, Y.; Hirano, Y.; Hayashi, M.; Komiyama, K.; Ishibashi, M. J. Nat. Prod. 2001, 64, 726-731.

91. Jansen, B. J. M.; de Groot, A. Nat. Prod. Rep. 1991, 309-318.

92. Jansen, B. J. M.; de Groot, A. Nat. Prod. Rep. 2004, 21, 449-477.

93. Faulkner, D. J.; Molinski, T. F.; Andersen, R. J.; Dumdei, E. J.; de Silva, E. D. Comp. Biochem. Physiol. 1990, 97C, 233-240.

94. Talpir, R.; Rudi, A.; Ilan, M.; Kashman, Y. Tetrahedron Lett. 1992, 33, 3033-3034.

95. Fusetani, N.; Asai, N.; Matsunaga, S.; Honda, K.; Yasumuro, K. Tetrahedron Lett. 1994, 35, 3967-3970.

96. Berlinck, R. G. S.; Ogawa, C. A.; Almeida, A. M. P.; Sanchez, M. A. A.; Malpezzi, E. L. A.; Costa, L. V.; Hajdu, E.; de Freitas, J. C. Comp. Biochem. Physiol. 1996, 115C, 155-163.

97. Volk, C. A.; Köck, M. Org. Lett. 2003, 5, 3567-3569.

98. Volk, C. A.; Köck, M. Org. Biomol. Chem. 2004, 2, 1827-1830.

99. Schmitz, F. J.; Hollenbeak, K. H.; Campbell, D. C. J. Org. Chem. 1978, 43, 3916-3922.

100. Albrizio, S.; Ciminiello, P.; Fattorusso, E.; Magno, S.; Pawlik, J. R. J. Nat. Prod. 1995, 58, 647-652.

101. Davies-Coleman, M. T.; Faulkner, D. J. J. Org. Chem. 1993, 58, 59255930 .

102. Sepčić, K.; Guella, G.; Mancini, I.; Pietra, F.; Serra, M. D.; Manestrina, G.; Tubbs, K.; Maček, P.; Turk, T. J. Nat. Prod. 1997, 60, 991-996.

103. Carté, B.; Faulkner, D. J. J. Org. Chem. 1983, 48, 2314-2318.

104. Blackman, A. J.; Li, C. Aust. J. Chem. 1994, 47, 1625-1629.

105. Lindquist, N.; Fenical, W. Experientia 1991, 47, 504-506.

106. Fürstner, A. Angew. Chem. Int. Ed. 2003, 42, 3582-3603.

107. Kazlauskas, R.; Marwood, J. F.; Murphy, P. T.; Wells, R. J. Aust. J. Chem. 1982, 35, 215-217.

108. Matsunaga, S.; Fusetani, N.; Hashimoto, K. Experientia 1986, 42, 84.

109. Franks, A.; Haywood, P.; Holmström, C.; Egan, S.; Kjelleberg, S.; Kumar, N. Molecules 2005, 10, 1286-1291.

110. Nakajima, S.; Kojiri, K.; Suda, H. J. Antibiot. 1993, 46, 1894-1896. 
111. Carté, B.; Faulkner, D. J. J. Chem. Ecol. 1986, 12, 795-804.

112. Martin, G. E.; Hadden, C. E. J. Nat. Prod. 2000, 63, 543-585.

113. Marek, R.; Lyčka, A. Curr. Org. Chem. 2002, 6, 35-66.

114. Fake, A. D. Sesquiterpenoids from the New Zealand Marine Sponge Dysidea sp. Ph.D. Thesis, Victoria University of Wellington, 1999.

115. Umeyama, A.; Shoji, N.; Arihara, S.; Ohizumi, Y.; Kobayashi, J. Aust. J. Chem. 1989, 42, 459-462.

116. Fontana, A.; Albarella, L.; Scognamiglio, G.; Uriz, M.; Cimino, G. J. Nat. Prod. 1996, 59, 869-872.

117. Kazlauskas, R.; Murphy, P. T.; Wells, R. J.; Daly, J. J.; Schönholzer, P. Tetrahedron Lett. 1978, 49, 4951-4954.

118. Ksebati, M. B.; Schmitz, F. J. J. Nat. Prod. 1988, 51, 857-861.

119. Capon, R. J.; MacLeod, J. K. J. Nat. Prod. 1987, 50, 1136-1137.

120. Grode, S. H.; Cardellina II, J. H. J. Nat. Prod. 1984, 47, 76-83.

121. Goetz, G. H.; Harrigan, G. G.; Likos, J. J. Nat. Prod. 2001, 64, 1486-1488.

122. Carté, B.; Kernan, M. R.; Barrabee, E. B.; Faulkner, D. J. J. Org. Chem. 1986, 51, 3528-3532.

123. Cimino, G.; de Stefano, S.; Minale, L.; Fattorusso, E. Tetrahedron 1972 , 28, 267-273.

124. Gustafson, K.; Andersen, J., Raymond Tetrahedron 1985, 41, 1101-1108.

125. Guella, G.; Mancini, I.; Pietra, F. J. Chem. Soc., Chem. Commun. 1986, $77-78$.

126. Guella, G.; Mancini, I.; Pietra, F. Helv. Chim. Acta 1987, 70, 1050-1062.

127. West, L. M. The Isolation of Secondary Metabolites from New Zealand Marine Sponges. Ph.D. Thesis, Victoria University of Wellington, 2001.

128. Seo, Y.; Cho, K. W.; Lee, H.-S.; Rho, J.-R.; Shin, J. J. Nat. Prod. 1999, 62, $122-126$.

129. Cerda-García-Rojas, C. M.; Faulkner, D. J. Tetrahedron 1995, 51, 1087 1092.

130. Czuba, I. R.; Zammit, S.; Rizzacasa, M. A. Org. Biomol. Chem. 2003, 1, 2044-2056.

131. Yosief, T.; Rudi, A.; Stein, Z.; Goldberg, I.; Gravalos, G. M. D.; Schleyer, M.; Kashman, Y. Tetrahedron Lett. 1998, 39, 3323-3326. 
132. Yosief, T.; Rudi, A.; Kashman, Y. J. Nat. Prod. 2000, 63, 299-304.

133. Rudi, A.; Shalom, H.; Schleyer, M.; Benayahu, Y.; Kashman, Y. J. Nat. Prod. 2004, 67, 106-109.

134. Rudi, A.; Aknin, M.; Gaydou, E.; Kashman, Y. J. Nat. Prod. 2004, 67, 1932-1935.

135. Rudi, A.; Kashman, Y. J. Nat. Prod. 1992, 55, 1408-1414.

136. West, L. M.; Northcote, P. T.; Battershill, C. N. Aust. J. Chem. 1998, 51, $1097-1101$.

137. Moraes, G. The Isolation and Structure Elucidation of Novel, Antiinflammatory Secondary Metabolites from New Zealand Marine Invertebrates. Ph.D. Thesis, Victoria University of Wellington, 2006.

138. Ryan, J. M. Novel Secondary Metabolites from New Zealand Marine Sponges. Ph.D. Thesis, Victoria University of Wellington, 2007.

139. Dowle, K. O. Investigation of New and Known Secondary Metabolites from the New Zealand Marine Sponge Raspailia topsenti. Honours Project, Victoria University of Wellington, 2006.

140. Meritt, A. T.; Ley, S. V. Nat. Prod. Rep. 1992, 9, 243-287.

141. Capon, R. J.; Skene, C.; Liu, E. H.; Lacey, E.; Gill, J. H.; Heiland, K.; Friedel, T. Nat. Prod. Res. 2004, 18, 305-309.

142. Searle, P. A.; Molinski, T. F. J. Am. Chem. Soc. 1995, 117, 8126-8131.

143. Molinski, T. F. Tetrahedron Lett. 1996, 37, 7879-7880.

144. Saludes, J. P.; Lievens, S. C.; Molinski, T. F. J. Nat. Prod. 2007, 70, 436-438.

145. Perry, N. B.; Ellis, G.; Blunt, J. W.; Haystead, T. A. J.; Lake, R. J.; Munro, M. H. G. Nat. Prod. Lett. 1998, 11, 305-312.

146. Bergquist, P. R. The Marine Fauna of New Zealand: Porifera, Demospongiae, Part 2 (Axinellida and Halichondrida); New Zealand Department of Scientific and Industrial Research: Auckland, 1970; Vol. 51, pp 26-27.

147. Duckworth, A. R.; Battershill, C. N. Aquaculture 2003, 217, 139-156.

148. Podlasek, C. A.; Wu, J.; Stripe, W. A.; Bondo, P. B.; Serianni, A. S. J. Am. Chem. Soc. 1995, 117, 8635-8644.

149. Smith, M. B.; March, J. March's Advanced Organic Chemistry, 5th ed.; John Wiley \& Sons: New York, 2001; p 479 and 490.

150. Presser, A.; Hüfner, A. Monatsch. Chem. 2004, 135, 1015-1022. 
151. Seco, J. M.; Quñoá, E.; Riguera, R. Tetrahedron: Asymmetry 2001, 12, $2915-2925$.

152. Gulab, S. A. An Aldol Approach Towards the Synthesis of Peloruside A and Analogues Thereof. Ph.D. Thesis, Victoria University of Wellington, 2007.

153. Dale, J. A.; Mosher, H. S. J. Am. Chem. Soc. 1973, 95, 512-519.

154. Sullivan, G. R.; Dale, J. A.; Mosher, H. S. J. Org. Chem. 1973, 38, 21432147.

155. Ohtani, I.; Kusumi, T.; Kashman, Y.; Kakisawa, H. J. Am. Chem. Soc. 1991, 113, 4092-4096.

156. Dictionary of Organic Compounds; Eyre \& Spottiswoode Publishers Ltd., 1965.

157. Cases, M. R.; Cerezo, A. S.; Stortz, C. A. Carbohyd. Res. 1995, 269, 333341.

158. Matthews, J. Victoria University of Wellington, New Zealand. Personal communication, 2006.

159. Hartwell, L. H.; Szankasi, P.; Roberts, C. J.; Murray, A. W.; Friend, S. H. Science (Washington, D.C.) 1997, 278, 1064-1068.

160. Winzeler, E. A. et al. Science (Washington, D.C.) 1999, 285, 901-906.

161. Bellows, D. Victoria University of Wellington, New Zealand. Personal communication, 2007.

162. Fahy, E.; Subramaniam, S.; Brown, H. A.; Glass, C. K.; Merrill Jr., A. H.; Murphy, R. C.; Raetz, C. R. H.; Russell, D. W.; Seyama, Y.; Shaw, W.; Shimizu, T.; Spener, F.; van Meer, G.; van Nieuwenhze, M. S.; White, S. H.; Witztum, J. L.; Dennis, E. A. J. Lipid Res. 2005, 46, 839-861.

163. Chester, M. A. Eur. J. Biochem. 1998, 257, 293-298.

164. Costantino, V.; Fattorusso, E.; Imperatore, C.; Mangoni, A. J. Nat. Prod. 2006, 69, 73-78.

165. Morales-Serna, J. A.; Boutureira, O.; Díaz, Y.; Matheu, M. I.; Castillón, S. Carbohyd. Res. 2007, 342, 1595-1612.

166. Costantino, V.; Fattorusso, E.; Mangoni, A.; di Rosa, M.; Ianaro, A. Bioorg. Med. Chem. Lett. 1999, 9, 271-276.

167. Costantino, V.; Fattorusso, E.; Imperatore, C.; Mangoni, A. Eur. J. Org. Chem. 2005, 368-373.

168. Costantino, V.; Fattorusso, E.; Mangoni, A.; di Rosa, M.; Ianaro, A. J. Am. Chem. Soc. 1997, 119, 12465-12470. 
169. Costantino, V.; Fattorusso, E.; Mangoni, A. Tetrahedron 2000, 56, 59535957.

170. Natori, T.; Koezuka, Y.; Higa, T. Tetrahedron Lett. 1993, 34, 5591-5592.

171. Natori, T.; Morita, M.; Akimoto, K.; Koezuka, Y. Tetrahedron 1994, 50, 2771-2784.

172. Tan, R. X.; Chen, J. H. Nat. Prod. Rep. 2003, 20, 509-534.

173. Aoki, S.; Higuchi, K.; Kato, A.; Murakami, N.; Kobayashi, M. Tetrahedron 1999, 55, 14865-14870.

174. Afiyatullov, S. S.; Kalinovsky, A. I.; Antonov, A. S.; Ponomarenko, L. P.; Dmitrenok, P. S.; Aminin, D. L.; Krasokhin, V. B.; Nosova, V. M.; Kisin, A. V. J. Nat. Prod. 2007, 10, 1871-1877.

175. Costantino, V.; Fattorusso, E.; Mangoni, A.; di Rosa, M.; Ianaro, A. Tetrahedron 2000, 56, 1393-1395.

176. Costantino, V.; Fattorusso, E.; Imperatore, C.; Mangoni, A. Eur. J. Org. Chem. 2001, 4457-4462.

177. Fusetani, N.; Sata, N.; Asai, N.; Matsunaga, S. Tetrahedron Lett. 1993, 34, 4067-4070.

178. Sata, N.; Asai, N.; Matsunaga, S.; Fusetani, N. Tetrahedron 1994, 50, $1105-1110$.

179. Goobes, R.; Rudi, A.; Kasman, Y.; Ilan, M.; Loya, Y. Tetrahedron 1996, 52, 7921-7928.

180. Warabi, K.; Zimmerman, W. T.; Shen, J.; Gauthier, A.; Robertson, M.; Finlay, B. B.; van Soest, R.; Andersen, R. J. Can. J. Chem. 2004, 82, $102-112$.

181. Linington, R. G.; Robertson, M.; Gauthier, A.; Finlay, B. B.; van Soest, R.; Andersen, R. J. Org. Lett. 2002, 4, 4089-4092.

182. Linington, R. G.; Robertson, M.; Gauthier, A.; Finlay, B. B.; MacMillan, J. B.; Molinski, T. F.; van Soest, R.; Andersen, R. J. J. Nat. Prod. 2006, 69, 173-177.

183. MacMillan, J. B.; Linington, R. G.; Andersen, R. J.; Molinski, T. F. Angew. Chem. 2004, 116, 6072-6077.

184. Warabi, K.; Hamada, T.; Nakao, Y.; Matsunaga, S.; Hirota, H.; van Soest, R. W. M.; Fusetani, N. J. Am. Chem. Soc. 2005, 127, 13262-13270.

185. Schroeder, F. C.; Gibson, D. M.; Churchill, A. C. L.; Sojikul, P.; Wursthorn, E. J.; Krasnoff, S. B.; Clardy, J. Angew. Chem. 2007, 119, 919-922 and suppl. 
186. Taggi, A. E.; Meinwald, J.; Schroeder, F. C. J. Am. Chem. Soc. 2004, 126, 10364-10369.

187. Exarchou, V.; Krucker, M.; van Beek, T. A.; Vervoort, J.; Gerothanassis, I. P.; Albert, K. Magn. Reson. Chem. 2005, 43, 681-687.

188. Tsuda, M.; Yasuda, T.; Fukushi, E.; Kawabata, J.; Sekiguchi, M.; Fromont, J.; Kobayashi, J. Org. Lett. 2006, 8, 4235-4238.

189. Schröder, F. C.; Farmer, J. J.; Attygalle, A. B.; Smedley, S. R.; Eisner, T.; Meinwald, J. Science (Washington, D.C.) 1998, 281, 428-431.

190. Keyzers, R. A. The Isolation of Biologically Active Secondary Metabolites from New Zealand Marine Organisms. Ph.D. Thesis, Victoria University of Wellington, 2003.

191. Cimino, G.; de Stefano, S.; Minale, L. Tetrahedron 1972, 28, 1315-1324.

192. Manes, L. V.; Crews, P.; Ksebati, M. B.; Schmitz, F. J. J. Nat. Prod. 1986, 49, 787-793.

193. Barrow, C. J.; Blunt, J. W.; Munro, H. G., Murray; Perry, N. B. J. Nat. Prod. 1988, 51, 275-281.

194. Höller, U.; König, G. M.; Wright, A. D. J. Nat. Prod. 1997, 60, 832-835.

195. Bonny, M. L.; Capon, R. J. J. Nat. Prod. 1994, 57, 539-540.

196. Guella, G.; Mancini, I.; Pietra, F. Helv. Chim. Acta 1987, 70, 621-626.

197. Faulkner, D. J. Tetrahedron Lett. 1973, 39, 3821-3822.

198. Liu, Y.; Zhang, S.; Abreu, P. J. M. Nat. Prod. Rep. 2006, 23, 630-651.

199. El Sayed, K. A.; Mayer, A. M. S.; Kelly, M.; Hamann, M. T. J. Org. Chem. 1999, 64, 9258-9260.

200. Lumsdon, D.; Capon, R. J.; Thomas, S. G.; Beveridge, A. A. Aust. J. Chem. 1992, 45, 1321-1325.

201. Perry, N. B.; Battershill, C. N.; Blunt, J. W.; Fenwick, G. D.; Munro, M. H. G.; Bergquist, P. R. Biochem. Syst. Ecol. 1987, 15, 373-376.

202. Erpenbeck, D.; van Soest, R. W. M. Mar. Biotechnol. 2007, 9, 2-19.

203. Sladić, D.; Gašić, M. J. Molecules 2006, 11, 1-33.

204. Minale, L.; Riccio, R.; Sodano, G. Tetrahedron Lett. 1974, 38, 3401-3404.

205. Cimino, G.; de Stefano, S.; Minale, L. Experientia 1972, 28, 1401-1402.

206. Cimino, G.; de Luca, P.; de Stefano, S.; Minale, L. Tetrahedron 1975, 31, 271-275. 
207. Bifulco, G.; Bruno, I.; Minale, L.; Riccio, R.; Debitus, C.; Bourdy, G.; Vassas, A.; Lavayre, J. J. Nat. Prod. 1995, 58, 1444-1449.

208. Pouchus, Y. F.; Verbist, J. F.; Biard, J. F.; Boukef, K. J. Nat. Prod. 1988, 51, 188-189.

209. Naruta, Y.; Maruyama, K. Recent Advances in the Synthesis of Quinoid Compounds., In The Chemistry of Quinoid Compounds; Patai, S., Rappoport, Z., Eds.; John Wiley \& Sons: New York, 1988; Vol. 2, part 1, p 260.

210. van Soest, R. W. M.; Braekman, J. C. Memoir. Queensl. Mus. 1999, 44, 569-589.

211. Liu, Y.; Zhang, S.; Jung, J. H.; Xu, T. Z. Naturforsch. 2007, 62C, 473-476.

212. Karuso, P.; Bergquist, P. R.; Buckleton, J. S.; Cambie, R. C.; Clark, G. R.; Rickard, C. E. F. Tetrahedron Lett. 1986, 27, 2177-2178.

213. Makarieva, T. N.; Rho, J.-R.; Lee, H.-S.; Santalova, E. A.; Stonik, V.; Shin, J. J. Nat. Prod. 2003, 66, 1010-1012.

214. Kernan, M. R.; Faulkner, D. J. J. Org. Chem. 1988, 53, 4574-4578.

215. Bergquist, P. R. The Marine Fauna of New Zealand: Porifera, Demospongiae, Part 5 (Dendroceratida and Halisarcida); National Institute of Water and Atmospheric Research: Wellington, 1996; pp 17-19.

216. Silverstein, R. M.; Webster, F. X. Spectrometric Identification of Organic Compounds, 6th ed.; John Wiley \& Sons, Inc.: New York, 1997; p 233.

217. Molinski, T. F.; Faulkner, D. J. J. Org. Chem. 1987, 52, 296-298.

218. Ankisetty, S.; Amsler, C. D.; McClintock, J. B.; Baker, B. J. J. Nat. Prod. 2004, 67, 1172-1174.

219. Claridge, T. D. W. High-Resolution NMR Techniques in Organic Chemistry; Pergamon: New York, 1999; Vol. 19, p 286.

220. Jones Jr., M. Organic Chemistry, 2nd ed.; W. W. Norton \& Company: New York, 2000; p 890.

221. Karuso, P.; Skelton, B. W.; Taylor, W. C.; White, A. H. Aust. J. Chem. 1984, 37, 1081-1093.

222. Shapiro, B. L.; Gattuso, M. J.; Hepfinger, N. F.; Shone, R. L.; White, W. L. Tetrahedron Lett. 1971, 12, 219-222.

223. Hashimoto, N.; Aoyama, T.; Shioiri, T. Chem. Pharm. Bull. 1981, 29, $1478-1480$. 
224. Biological Magnetic Resonance Data Bank. Statistics Calculated for Selected Chemical Shifts from Atoms in the 20 Common Amino Acids, http://bmrb.postgenomicnmr.net/ref_info/statsel.htm\#9, (accessed Jan 11, 2008).

225. Bhattacharyya, A.; Nirmala, R.; Subramanian, S. THEOCHEM 1995, 339, $245-254$.

226. Tori, K.; Nakagawa, T. J. Phys. Chem. 1964, 68, 3163-3169.

227. Chan, A. Victoria University of Wellington, New Zealand. Personal communication, 2008.

228. Miller, C. Victoria University of Wellington, New Zealand. Personal communication, 2008.

229. Keyzers, R. A.; Northcote, P. T.; Davies-Coleman, M. T. Nat. Prod. Rep. 2006, 23, 321-334.

230. Smith, M. B.; March, J. March's Advanced Organic Chemistry, 5th ed.; John Wiley \& Sons: New York, 2001; pp 1393-1396.

231. Díaz-Marrero, A. R.; Dorta, E.; Cueto, M.; San-Martín, A.; Darias, J. Tetrahedron 2004, 60, 1073-1078.

232. Molinski, T. F.; Faulkner, D. J. J. Org. Chem. 1986, 51, 2601-2603.

233. Karuso, P.; Bergquist, P. R.; Cambie, R. C.; Buckleton, J. S.; Clark, G. R.; Rickard, C. E. F. Aust. J. Chem. 1986, 39, 1643-1653.

234. Tischler, M.; Andersen, R. J.; Choudhary, M. I.; Clardy, J. J. Org. Chem. 1991, 56, 42-47.

235. Keyzers, R. A.; Northcote, P. T.; Zubkov, O. A. Eur. J. Org. Chem. 2004, 419-425.

236. Garson, M. J.; Simpson, J. S. Nat. Prod. Rep. 2004, 21, 164-179.

237. di Blasio, B.; Fattorusso, E.; Magno, S.; Mayol, L.; Pedone, C.; Santacroce, C.; Sica, D. Tetrahedron 1976, 32, 473-478.

238. Jumaryatno, P.; Rands-Trevor, K.; Blanchfield, J. T.; Garson, M. J. ARKIVOC 2007, 157-166.

239. Williams, D. E.; Patrick, B. O.; Tahir, A.; van Soest, R.; Roberge, M.; Andersen, R. J. J. Nat. Prod. 2004, 67, 1752-1754.

240. Cafieri, F.; de Napoli, L.; Fattorusso, E.; Santacroce, C.; Sica, D. Tetrahedron Lett. 1977, 18, 477-480.

241. Cafieri, F.; de Napoli, L.; Fattorusso, E.; Santacroce, C. Experientia 1977, 33, 994-995. 
242. Cafieri, F.; de Napoli, L.; Iengo, A.; Santacroce, C. Experientia 1978, 34, 300-301.

243. Cafieri, F.; de Napoli, L.; Iengo, A.; Santacroce, C. Experientia 1979, 35, 157-158.

244. Cimino, G.; de Stefano, S.; Minale, L. Experientia 1974, 30, 846-847.

245. Liu, Y.; Mansoor, T. A.; Hong, J.; Lee, C.-O.; Sim, C. J.; Im, K. S.; Kim, N. D.; Jung, J. H. J. Nat. Prod. 2003, 66, 1451-1456.

246. Liu, Y.; Hong, J.; Lee, C.-O.; Im, K. S.; Kim, N. D.; Choi, J. S.; Jung, J. H. J. Nat. Prod. 2002, 65, 1307-1314.

247. Shin, J.; Rho, J.-R.; Seo, Y.; Lee, H.-S.; Cho, K. W.; Sim, C. J. Tetrahedron Lett. 2001, 42, 3005-3007.

248. Pham, A. T.; Carney, J. R.; Yoshida, W. Y.; Scheuer, P. J. Tetetrahedron Lett. 1992, 33, 1147-1148.

249. Mori, D.; Kimura, Y.; Kitamura, S.; Sakagami, Y.; Yoshioka, Y.; Shintani, T.; Okamoto, T.; Ojika, M. J. Org. Chem. 2007, 72, 7190-7198.

250. Manríquez, V.; San-Martin, A.; Rovirosa, J.; Darias, J.; Peters, K. Acta Cryst. 1990, C46, 2486-2487.

251. Buckelton, J. S.; Bergquist, P. R.; Cambie, R. C.; Clark, G. R.; Karuso, P.; Rickard, C. E. F. Acta Cryst. 1987, C43, 2430-2432.

252. Dowle, K. O. New Nitrogenous Spongian Diterpenes from the New Zealand Marine Sponge Darwinella oxeata. M.Sc. Thesis, Victoria University of Wellington, in preparation.

253. Gottlieb, H. E.; Kotlyar, V.; Nudelman, A. J. Org. Chem. 1997, 62, 75127515 .

254. Razzak, M. Labelling of Mycalamide A, a Toxin from the New Zealand Marine Sponge Mycale hentscheli. Honours Project, Victoria University of Wellington, 2005. 